\title{
In search of the perfect citizen? : the intersection between integration, immigration and nationality in the EU
}

Citation for published version (APA):

Carrera, S. (2008). In search of the perfect citizen? : the intersection between integration, immigration and nationality in the EU. [Doctoral Thesis, Maastricht University]. Wolf Legal Publishers.

https://doi.org/10.26481/dis.20081031sc

Document status and date:

Published: 01/01/2008

DOI:

10.26481/dis.20081031sc

Document Version:

Publisher's PDF, also known as Version of record

Please check the document version of this publication:

- A submitted manuscript is the version of the article upon submission and before peer-review. There can be important differences between the submitted version and the official published version of record.

People interested in the research are advised to contact the author for the final version of the publication, or visit the DOI to the publisher's website.

- The final author version and the galley proof are versions of the publication after peer review.

- The final published version features the final layout of the paper including the volume, issue and page numbers.

Link to publication

\footnotetext{
General rights rights.

- You may freely distribute the URL identifying the publication in the public portal. please follow below link for the End User Agreement:

www.umlib.nl/taverne-license

Take down policy

If you believe that this document breaches copyright please contact us at:

repository@maastrichtuniversity.nl

providing details and we will investigate your claim.
}

Copyright and moral rights for the publications made accessible in the public portal are retained by the authors and/or other copyright owners and it is a condition of accessing publications that users recognise and abide by the legal requirements associated with these

- Users may download and print one copy of any publication from the public portal for the purpose of private study or research.

- You may not further distribute the material or use it for any profit-making activity or commercial gain

If the publication is distributed under the terms of Article $25 \mathrm{fa}$ of the Dutch Copyright Act, indicated by the "Taverne" license above, 


\title{
IN SEARCH OF THE PERFECT CITIZEN?
}

\author{
THE INTERSECTION BETWEEN \\ INTEGRATION, IMMIGRATION AND NATIONALITY \\ IN THE EU
}

Sergio Carrera Nuñez

W 
In search of the perfect citizen?

The intersection between integration, immigration and nationality in the EU

Sergio Carrera Nuñez

ISBN 978-90-5850-391-6

Wolf Legal Publishers

POB 31051

6503 CB Nijmegen

The Netherlands

www.wolflegalpublishers

(C) S. Carrera Nuñez 2008 


\title{
IN SEARCH OF THE PERFECT CITIZEN?
}

\author{
THE INTERSECTION BETWEEN \\ INTEGRATION, IMMIGRATION AND NATIONALITY \\ IN THE EU
}

DISSERTATION

to obtain the degree of Doctor at the Maastricht University, on the authority of the Rector Magnificus, Prof. Dr. G.P.M.F. Mols, in accordance with the decision of the Board of Deans,

to be defended in public

on Friday 31 October 2008, at 12.00 hours

by

Sergio Carrera Nuñez 


\section{Supervisors:}

Prof. Dr. Gerard-René de Groot

Prof. Dr. Hildegard Schneider

\section{Assessment Committee:}

Prof. Dr. E.I.L. Vos (Chair)

Prof. Dr. Joaquin Arango (Universidad Complutense de Madrid)

Prof. Dr. Marie-Claire Foblets (Katholieke Universiteit Leuven)

Dr. Maarten Vink

Prof. Dr. Bruno de Witte 
2. Integration and the Treaty of Lisbon

3. The EU Framework on Integration as an Alternative Form of OMC 82

3.1. Nature, Methods and Tools $\quad 82$

3.2. Key Actors in the EU Framework on Integration 85

3.3. Implications of the Substantive and Institutional Elements of the EU 87 Framework on Integration

4. Benchmarking Integration in the EU

4.1. A State of the Art on Benchmarking Integration in the EU 89

4.1.1. The Study on Benchmarking Immigrant Integration in the EU 89

4.1.2. The European Civic Citizenship and Inclusion Index 90

4.1.3. The Migrant Integration Policy Index 93

4.1.4. Study on Setting up a System of Benchmarking to Measure the 94 Success of Integration Policies in Europe

4.2. Current Deficits of Benchmarking Integration 97

4.2.1. A Common Approach on Integration in EU Law/Policy allowing 97 Benchmarking

4.2.2. Benchmarking as a Neutral Tool 98

4.2.3. The Personal and Territorial Scope 100

4.2.4. The Methodology 101

4.2.4.1. Benchmarking and Interdisciplinarity 101

$\begin{array}{ll}\text { 4.2.4.2. Indicators } & 102\end{array}$

$\begin{array}{ll}\text { 4.2.4.3. Typology and Comparison } & 104\end{array}$

4.2.4.4. Results of Benchmarking 105

5. Conclusions 106

\section{Chapter 4: European Immigration Law and Integration}

Introduction

1. European Law on Regular Immigration:

Processes and Institutional Configurations

2. The Directive on the Right to Family Reunification 115

2.1. The Material and Personal Scope 119

2.2. Rights, Criteria and Integration 122

$\begin{array}{ll}2.2 .1 \text { The Rights } & 122\end{array}$

$\begin{array}{ll}\text { 2.2.2. Conditions and Exceptions } & 123\end{array}$

2.2.2.1. Integration as a Condition: Article 4 124

$\begin{array}{ll}\text { 2.2.2.2. Integration as a Measure: Article 7 } & 127\end{array}$

3. The Directive on Long-Term Residents Status 129

3.1. The Negotiations of the Commission's Proposal and the "Integration 131 Condition Clause"

3.2. The Material and Personal Scope 138

$\begin{array}{ll}\text { 3.3. Rights, Conditions and Integration } & 139\end{array}$

$\begin{array}{ll}3.3 .1 . & 139\end{array}$

$\begin{array}{ll}\text { 3.3.2. Conditions for the Acquisition } & 142\end{array}$

3.3.2.1. Integration as a Condition: Article 5.2 143

3.3.2.2. Integration as a Measure: Article $15.3 \quad 144$

4. New Legislative Proposals on Regular Immigration 148

4.1. An EU Framework on Highly Qualified Employment and the 150 EU Blue Card 


\section{TABLE OF CONTENTS}

Table of Contents

Abbreviations VII

Acknowledgements

\section{SECTION I -}

\section{THE INTERSECTION BETWEEN INTEGRATION, IMMIGRATION AND} NATIONALITY IN THE EU: SETTING THE SCENE

\section{Chapter 1: Introduction}

1. Integration, Immigration and Nationality

2. The Legal Framework of Integration of TCNs in the EU 3

3. Outline of the Book and the Questions at Stake 5

4. Scope, Concepts and Methodology 8

\section{SECTION II - THE NORMATIVITY OF INTEGRATION IN EU LAW AND POLICY}

Chapter 2: The Relationship between Integration and EU Law and Policy Introduction

1. Mapping Integration in EU Law and Policy before Europeanisation 13

1.1. From the 1970s to the 1980s: The Roots of European Cooperation on 14 Integration of TCNs

1.2. The Maastricht Era

2. Amsterdam, Tampere and the Origins of the Dual Legal Framing on 33 Integration in the EU

2.1. The Birth of the Dual Framing over Integration in EU Law and Policy 37

2.1.1. A Conmon Immigration Policy 37

2.1.2. An Open Method of Coordination $\quad 39$

3. Conclusion. 42

\section{Chapter 3: The EU Framework on Integration}

1. The EU Framework on Integration: Origins, Concepts, Tools and Structures 45

1.1. The Emerging European Integration Strategy 45

1.2. A Common European Framework and the Linkage between 47 Immigration, Integration and Employment

1.3. The First Annual Report on Migration and Integration 51

1.4. The First Handbook on Integration 52

1.5. The Hague Programme and the Common Basic Principles for 55 Immigrant Integration Policy

1.6. Putting Principles into Practice? A Common Agenda for Integration 61

1.7. The Second Handbook on Integration 64

1.8. The Second Annual Report on Migration and Integration 66

1.9. The Third Annual Report on Migration and Integration 67

1.10. The European Integration Forum and an Integration Website 68

$\begin{array}{ll}\text { 1.11. The European Integration Fund } & 70\end{array}$

1.12. Potsdam and "Promoting Unity within Diversity" 73

1.13. Latest Developments: Principles, Actions and Tools 76 for a Renewed Agenda 
Chapter 6: The Legal Framework on Nationality, Immigration and "The Republican Integration" in France

Introduction

1. The French Republican Paradigm of Integration: Fundamentals 221 and Implications

2. A Historical Overview of Integration in France

3. The French Legal System on the Acquisition of Nationality: Naturalisation 243 and Assimilation

4. The Nomative and Contractual Framing of Integration in French Immigration Law

4.1. The Sarkozy Law I: The Birth of the Nexus between Integration and Immigration Law

4.2. The Contrat d'Accueil et d'Intégration: Integration as a Contractual Bond

4.3. The Sarkozy Law II: The 2006 Law on Inmigration and Integration

4.3.1. Integration as a Contractual Mandatory Bond and a Tool of Migration Control

4.3.2. The Directives 2003/109 and 2003/86: Transposing Integration Measures and Conditions in French Law?

5. Conclusions

SECTION IV - THE INTERPLAY BETWEEN EU AND NATIONAL IMMIGRATION LAW: THE GENERAL PRINCIPLES OF EU LAW

Chapter 7: Testing Member States' Action against the Principle of Proportionality and Fundamental Rights

Introduction

1. The General Principles of EU Law and the Rule of Law in EU Immigration Law

1.1. The General Principles and Member States' Actions in the Scope of EU Immigration Law

2. The General Principles of Proportionality and Fundamental Rights:

The Review of Member States' Actions within EU Immigration Law

2.1. The Principle of Proportionality: Protecting TCNs' Rights in the EU 276

2.1.1. The Principle of Proportionality and Member States' Action 278 "within the Scope of EU Law"

2.1.2. Legitimising Exceptions by the State: 280 The Free Movement of Persons

2.2. Fundamental Rights as General Principles:

The Case of Family Life of TCNs

2.2.1. Fundamental Rights as General Principles of EU Law 285

2.2.2. Member States' Actions in Relation to the Right of 287 Respect for Family Life

2.2.3. Exceptions to Fundamental Rights by the State 288

2.2.3.1. The Exception as Interpreted by the ECJ 288

2.2.3.2. The Exception as Interpreted by the ECHHR 290

2.2.4. Family Life of TCNs: The Case C-540/03 EP v. Council 293

3. The Tests of Fundamental Rights and Proportionality: 298

The Case of France

3.1. First Level: The CAI as a Condition for EC Long-Term Resident Status 301 
4.1.1. The Material and Personal Scope 150

4.1.2. Rights, Conditions and Integration 151

4.1.1.1. The Rights 151

4.1.1.2. The Conditions 153

4.2. Towards a Common Framework of Rights 155

4.2.1. The Material and Personal Scope 155

$\begin{array}{lr}\text { 4.2.2. Rights, Conditions and Integration } & 157\end{array}$

$\begin{array}{lll}4.2 .2 .1 . & 157\end{array}$

4.2.2.2. The Conditions 158

5. The Treaty of Lisbon and the Renewed Institutional Framework
of EU Immigration Law

$\begin{array}{ll}\text { 6. Conclusions } & 160\end{array}$

Annex Section II: Table: Mapping the Normative Usage of Integration 162 of TCNs in EU law (1974 - 2008)

SECTION III - THE NORMATIVITY OF INTEGRATION IN NATIONAL LAW: THE CASES OF SPAIN AND FRANCE

Chapter 5: The Intersection between Integration and the Legal Framework on Nationality and Immigration in Spain

Introduction

1. The Construction of Immigrant Spain and the Spanish 174 "Non-Model" on Integration

1.1. The Spanish 'Non-National Model' on Integration 176

2. Evolution of the Spanish Legislation on Immigration and its Changing 181 Articulation with Integration

2.1. The First Phase: Democratic Spain and the 1985 Immigration Law 182

2.2. The Second Phase: The Birth of the Intersection between Immigration 183 and Integration

2.3. The Third Phase: Immigration as an Institutional and Structural Issue 187

2.3.1. The Law on the Rights and Liberties of Immigrants and 187 their Social Integration

2.3.2. The 2004 and 2008 National Elections 194

3. Integration in the Legal Framework on Nationality and Regular Immigration 196

3.1. The Law on Nationality: Integration as Condition for Naturalisation 196

3.2. Immigration Law and Policy: The Social Integration of Immigrants 203

3.2.1. The "Ley de Extranjeria" and Integration 203

3.2.2. The Strategic Plan of Citizenship and Integration 205

3.3. The Autonomous Communities and Integration 210

3.3.1. Redistributing the Competences over Immigration? 210

3.3.2. The Integral Plans of Immigration and the Social Integration of 211 Immigrants

4. The Directives 2003/109 and 2003/86: Transposing Integration 216

"Measures" and "Conditions" in Spanish Law?

5. Conclusions 
3.1.1. The Principle of Necessity and the CAI

3.1.2. The Principle of Proportionality "strict sense" and the CAI 304

3.2. Second Level: Republican Integration Abroad, 307

Family Reunification and Family Life

3.2.1 Integrating into the French Republic Abroad? The Suitability Test 307

3.2.2. Reviewing the Necessity of Mandatory Integrating Abroad 308

3.2.3. The Principles of Proportionality "strict sense" and Fundamental 308 Rights: Testing Integration Abroad

3.3. Third Level: The CAIF and the Principles of Proportionality 313 and Fundamental Rights

3.3.1. The Necessity of the CAIF 313

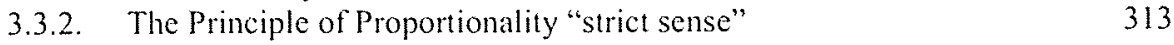

4. Conclusions and Fundamental Rights

\section{SECTION V - CONCLUSIONS}

Chapter 8: The Interplay between the EU and National Levels over Integration: Conclusions and Recommendations 319

1. The Interplay between the EU and the National Levels over Integration 321

1.1. The Normativity of Integration in EU Law and Policy 321

1.2. The Normativity of Integration in National Law 325

1.2.1. Spain:A 'Non-Model' becoming European?. 325

1.2.2. France:The Normativisation, Expansionism and Externalisation 327 of the Republican Integration

1.3. The Interplay between the EU and National Levels:

The EU General Principles and European Immigration Law

2. Reflections on the Normative Framework of Integration in the EU 332

2.1. In Search of the Perfect Citizen? 332

2.1.1. The Perfect National Citizen and Nationality Law 332

2.1.2. The Perfect National Citizen and Immigration Law 335

2.1.3. The Perfect European Citizen 337

3. Recommendations 338

3.1. The Normativity of Integration in EU Law and Policy 339

3.1.1. The EU Framework on Integration $\quad 340$

3.1.2. European Immigration Law 342

3.2. The Normativity of Integration in National Law 342

3.2.1. Spain $\quad 342$

3.2.2. France 343

3.3. The Intersection of EU and National Law: 344 The General Principles of EU Law

$\begin{array}{ll}\text { Resumen/Samenvatting } & 347\end{array}$

References $\quad 355$

Table of Cases $\quad 385$

Legislative and Policy Acts $\quad 391$

Bibliography $\quad 405$

$\begin{array}{ll}\text { Index } & 406\end{array}$ 
AACC

AFSJ

$\mathrm{AG}$

$\mathrm{AMCL}$

ANAEM

CAI

CAIF

CBPS

CESEDA

CFI

CHALLENGE

CiU

$\mathrm{CML}$

COM

COREPER II

DG

DG JFS

DGRN

DILF

EC

ECHR

EC)

ECR

ECIHR

EEA

EESC

EIF

EMMI

EP

EU

FN

FRONTEX

\section{ABBREVIATIONS}

Autonomous Communities

Area of Freedom, Security and Justice

Advocate General

Attestation ministérielle de competences linguistiques

Agence Nationale pour l'Accueil des Etrangers et les Migrations

Contrat d'accueil et d'intégration

Contrat d'accueil et d'intégration pour la famille

Common Basic Principles

Code de l'entrée et du séjour des étrangers et du droit d'asile

Court of First Instance

The Changing Landscape of European Liberly and Security

Convergència i Unió

Centre for Migration Law

European Commission

Committee of Permanent Representatives of the Member States

Directorate General

Directorate General Justice, Freedom and Security

Dirección General de los Registros y del Notariado

Diplôme initial de langue française

European Community

European Convention of Human Rights and Fundamental Freedoms

European Court of Justice

European Court Reports

European Court of Human Rights

European Economic Area

European Economic and Social Committee

European Integration Fund

European Modules for Migrant Integration

European Parliament

European Union

Front National

The European Agency for the Management of Operational

Cooperation at the External Borders of the Member States of the

European Union. 
FSJ

GDRN

GRECO

$\mathrm{HCl}$

HSW

JHA

LODYLE

LOE

LTR

MEP

MPG

NAPS

$\mathrm{NCPI}$

$\mathrm{NGO}$

OJ

$\mathrm{OMC}$

PISI

PP

PSOE

QMV

SCIFA

SEA

TCNs

TEC

TEU

TFU

TS

UK

UMP

WP
Freedom, Security and Justice

General Directorate of the Registries and the Notary

Global Programme of Regulation and Coordination of Foreigners and

Immigration

Haut Conseil à l'Intégration

Highly Skilled Workers

Justice and Home Affairs

Ley Orgánica 4/2000 de Derechos y Libertades de los Extranjeros y su Integración Social

Ley Orgánica 7/1985 sobre Derechos y Libertades de los Extranjeros

en España

Long Term Resident

Member of the European Parliament

Migration Policy Group

National Action Plans

National Contact Points on Integration

Non-Governmental Organisation

Official Journal

Open Method of Coordination

Plan para la Integración Social de los Inmigrantes

Partido Popular

Partido Socialista Obrero Español

Qualified Majority Voting

Strategic Committee on Immigration, Frontiers and Asylum

Single European Act

Third Country Nationals

Treaty establishing the European Community

Treaty on European Union

Treaty on the Functioning of the European Union

Tribunal Supremo

United Kingdom

Union pour un Mouvement Populaire

Working Party 


\section{ACKNOWLEDGEMENTS}

My fascination for issues related to human mobility and diversity, and the various ways through which the State and the EU frame these issues into politics, policies and law, finds its origins in the time I spent at the Faculty of Law of the University of Maastricht from 1998 to 2001. Mastricht was not just an incredibly vibrant and stimulating city in which to live, but also the place where I started to grow both intellectually and personally. I owe my greatest thanks to Hildegard Schneider and René de Groot. They were the first to believe in me and have always left their doors open for sharing their knowledge, support and friendship. Their guidance throughout all these years has been a determining influence in my life and particularly, in my professional career. I am also grateful that they offered me the possibility to conduct my research 'at a distance' while pursuing my work on a professional level in the Justice and Home Affairs Section of the Centre for European Policy Studies (CEPS) in Brussels.

My professional experience during these last six years at CEPS has equally deeply influenced many of the ideas advanced in this book. I would like to start by thanking Joanna Apap for giving me many opportunities and instructing me in the necessary 'survival skills for Brussels'. Her advice and expertise during the preliminary phases of my research helped me enormously to get started on the right track. Working with her was fundamental for making me think in policy terms around issues related to international human mobility, borders and inclusion in the EU. I also owe much gratitude to Elspeth Guild. Her vision and understandings of integration and immigration have been very influential in my own writing. Working with her at CEPS has been also an amazing learning experience. I would also like to thank Daniel Gros, Karel Lannoo, Sally Scott and Anne Harrington for their support in my $\mathrm{PhD}$ adventure during my full-time job at the JHA Section of CEPS, and to all my colleagues at CEPS. Warm thanks go as well to my current and former colleagues in the JHA Section, and in particular to Thierry Balzacq, Anaïs Faure Atger, Florian Geyer, Miriam Mir and Massimo Merlino. I feel privileged to have worked with these talented individuals. Without their enthusiasm and professionalism, I would have not been able to take time off to develop and finalize my research.

This book falls within the context of CHALLENGE (The Changing Landscape of European Liberty and Security), a five-year project funded by DG Research of the European Commission. I have enormously benefited from my function as researcher and member of the coordination team in this project. It has allowed my original legal background to positively evolve towards a more interdisciplinary understanding of the fields at stake in my research. I would like to thank Didier Bigo for his trust in me in the administrative coordination of the project. His ideas, writings and discussions have also influenced several of the arguments and theoretical perspectives underlying this book. I would also like to thank the entire CHALLENGE network for all these years of fruitful cooperation and interaction.

My role as an external expert on immigration for the European Economic and Social Committee and the European Parliament has also been crucial in the development of my ideas in this book. I would like to thank Luis Miguel Pariza Castaños for having offered me the possibility to cooperate with him. I deeply admire his work and contribution to 
the debates surrounding the construction of a common EU immigration and integration policies.

I would like to express my gratitude to Kees Groenendijk, Dora Kostakopoulou, Anastassia Tsoukala and the assessment committee for reading the manuscript and giving me their suggestions as to how to improve it. I would also like to thank Lorenzo Cachón for his warm welcome at the University Complutense of Madrid and for his advice in collecting the relevant sources for Chapter 5 .

The first version of this book was carefully edited by Lee Gillette. I would also like to thank René van der Wolf for taking care of the final touches in the editing. I am solely responsible, however, for any remaining errors.

On a more personal level, I would like to thank my parents and my sister for their unconditional love and for standing behind all my initiatives. I am grateful for their patience during my many absences, while waiting for this moment to arrive. I would like to dedicate this book to Ana, without whose love, support and advice this book would never have come to light. I am profoundly indebted to her for the many sacrifices she has willingly made in the service of making this book and my dreams become a reality.

Brussels, September 2008 


\section{SECTION I - THE INTERSECTION BETWEEN INTEGRATION, IMMIGRATION AND NATIONALITY IN THE EU: SETTING THE SCENE}

\section{Chapter 1: \\ Introduction}

\section{Integration, Immigration and Nationality}

This book studies the normative intersection between integration, immigration and nationality in the European Union (EU). It examines the relationship between integration and the legal frameworks of admission, stay and access to nationality by third country nationals at national and European levels. Integration is being subject to multifaceted processes transforming its traditional policy and legal settings, as well as its classical theoretical premises and approaches. The Europeanisation of immigration policy has provoked the emergence of distinctive European approaches on integration. The legal elements of integration are being developed through two parallel settings: the EU Framework on Integration and European immigration law. These venues constitute two of the main pillars upon which the common EU immigration policy is being constructed, and their nexus raises several elements in need of reflection and study.

The EU Framework on Integration and European immigration law advocate for particular understandings of the integration of third country nationals (TCNs). While the official transfer of immigration to EU competence did not take place until the entry into force of the Amsterdam Treaty in 1999, the public responses covering the domain of legal immigration and the integration of TCNs have been numerous at the European level since the early 1970s. The introduction of Title IV in the Treaty establishing the European Community (TEC) represented a historic transformation in the EU legal system and the European integration processes. The Union has since then managed to start installing a common framework on immigration. The Council Directives on the status of TCNs who are long-term residents 2003/109 and on the right to family reunification 2003/86 constitute two of the most relevant instruments composing the common immigration policy. These acts have inflicted various impacts in the legal systems of the Member States and the status of TCNs in the EU.

The Member States have often shown resistance to the Europeanisation of immigration. They have practiced a series of tactics intending to keep untouched their discretion over the treatment of those falling within the category of non-national. As a result, fields such as that of integration of TCNs have remained closely attached to the domestic realm and mainly driven by the principle of subsidiarity. The European Commission has been encouraged to figure out alternative strategies to the ones formally offered by the Treaties and the Community method of cooperation to move policy convergence forward. The analysis of the ways in which the European institutions are actually managing to foster European cooperation over these areas reveals ongoing attitudes predominating as regards the liberty and security of TCNs in the EU. The establishment of the EU Framework on Integration constitutes an illustrative example of these trends. Its peculiar nature poses a number of questions as regards the effects that its development may inflict over the classical foundations of EU law, its institutional configurations and the status of the TCNs. 
The interplay between EU and national law over the normative intersection between immigration and integration opens at least two major issues: The first one relates to the impact and effects of EU law on national law and the processes of policy formulation in the field of the integration of TCNs - the extent to which national polities, politics and policies are affected by European integration. The second refers to the ways in which that impact relates to the system of checks and institutional/substantive mechanisms reviewing Member States' actions within the scope of EU law.

The first aspect, i.e. the effects of the EU's involvement in integration policy, constitutes a direct expression of the transfer of the field of immigration to EU competence. The Member States have accepted to see their discretion diminished in relation to certain administrative dimensions of immigration law. The processes of Europeanisation involve the instauration of a harmonised legal framework beyond the classical configurations of the nation-state. This supranational legal setting provides common rules, rights and criteria whose scope and reach go beyond the domestic realm. The question might be raised however as regards the actual effects that European noms are having on the classical conceptual understanding or guiding approach(es) of integration, and their normative coverage in the legal traditions of the Member States. The transfer of European immigration law from the transnational level to the Member State arena allows for its potential instrumentalisation by national politics, and the emergence of a transposition potentially driven by their own interests, priorities and politics. On the other hand, other paths of supranational cooperation dealing with the integration of TCNs are also being developed outside the scope of EU law. In particular, the EU Framework on Integration constitutes a parallel venue of Europeanisation falling outside the classical structures provided by the Community method and making use of soft-law/policy mechanisms which, independently of their apparent sof nature, might actually influence the elaboration and formulation of national public policies.

The second element emerges when associating the effects of EU law/policy on integration in national law with the substantive and institutional mechanisms limiting the Member States' discretion in the EU legal order and protecting the individual. The judicial control conducted by EU Courts and the jurisprudential tradition of developing a set of general principles of EU law play a fundamental role in ensuring that the Union remains founded on the principles of democracy, respect for fundamental rights and the rule of law. These mechanisms aim at controlling the EU, European Institutions and the Member States when exercising their executive and normative powers within the scope of EU law. They are also decisive for guaranteeing Europe-wide rights and freedoms conferred to the individual against any illegitimate interference or illiberal exception practiced by public authorities. The potential of these structures and instruments in the ambit of European immigration law, and the role that they might also play in the intersection between immigration and integration of TCNs in EU and national law, are of utmost relevance.

This book examines the processes through which integration becomes a norm in nationality and immigration law and policy at the national and EU levels, and the implications of these processes for the legal status of TCNs and the overall coherency of the common EU immigration policy. Our study intends to facilitate a genealogy of some of the approaches and functions driving the rationale of the term of integration in the EU. We look at the ways in which integration has progressively evolved as an immigration-related norm, and the effects of the changing relationship between the European and national legal settings covering this domain. The assessment will lead to the provision of a set of recommendations as to the ways in which the framing of integration in EU law and national law, and the interplay between these two realms, should take place in the Union. This introductory Chapter starts by setting the scene of 
the legal framework of integration of TCNs in EU law and policy. It then provides a general outline of the book, explaining the structure and the various contents provided through the different Sections and Chapters. The overview is accompanied by a set of research questions addressed in each of the Chapters. Finally, we offer some indications and clarifications as regards key terms and concepts that are used throughout the book.

\section{The Legal Framework of Integration of TCNs in the EU}

Integration has been at the core of the EU. One of the main driving rationales of the European integration process has been the establishment of an internal market.' Within this context integration has played the role of facilitating the mobility of EU national migrant workers across the internal borders of the Member States and ensuring that, while doing so, they enjoy equality, non-discrimination, family reunification and a secure juridical status. ${ }^{2}$ This classical understanding of integration has been subject to deep and dynamic transformations when developing a common legal framework covering the conditions of entry and residence of TCNs in the EU - a common EU immigration policy. Integration has experienced multifaceted nomative processes since the transfer of immigration to EU competence with the entry into force of the Amsterdam Treaty in 1999 and the European Council Conclusions in the city of Tampere on 15 and 16 October 1999. The Conclusions, called the Tampere Programme, presented a roadmap of policy priorities between 1999 and 2004. The Council called for the adoption of the following tenets to guide the EU's policy approach on integration: the principle of fair treatment to legally-residing TCNs; the need to develop a more vigorous integration policy granting to legal TCNs rights and obligations comparable to EU citizens; and the granting of rights which are "as near" as possible" to those of EU citizens to long-term residents.

In light of this, the European Commission put forward a package of legislative proposals to start building an EU immigration law. The Council Directives 2003/109 on the status of long-term residents who are $\mathrm{TCNs}^{4}$ and $2003 / 86$ on the right to family reunification ${ }^{5}$ represent the most relevant EU acts so far adopted in the area of legal immigration (i.e. conditions for a legal admission and stay to TCNs). While these two instruments provide common standards and EUwide rights/guarantees in the domain of immigration, they also constitute a regime of minimums, leaving a wide margin of appreciation to the Member States in times of national implementation. During the Council negotiations of the texts of these measures, their content, and the function that integration plays within them, mutated significantly from the premises advocated at Tampere and toward a more restrictive tone. The original focus on integration that characterised the first versions of both initiatives was substantially transformed. A group of

1 C. Barnard and J. Scott (eds.), The Law of the Single European Market: Unpacking the Premises, Hart: Oxford, 2002. Craig, P. and G. de Büra (2007), EU Law: Text, Cases and Materials, Oxford University Press: Oxford, Sixth Edition.

2 Groenendijk (2006) has argued that "In the first regulation on the free movement of workers...the right to family reunification and the equal access of family members to education and employment... were explicitly recognised, with the aim of assisting the integration of the worker". K. Groenendijk (2006), "Integration Policy and Community Law", in S. Carrera (ed.), The Nexus between Immigration. Integration and Citizenship in the EU, Collective Conference Volume, April 2006, pp. 9-11.

3 Tampere European Council, 15-16 October 1999, Presidency Conclusions, SN 200/99, Brussels.

4 Council Directive concerning the status of third-country nationals who are long-term residents, 2003/109, [2004] OJ L 16/44, 23.1.2004.

5 Council Directive $2003 / 86 / \mathrm{EC}$ of 22 September 2003 on the right to family reunification, OJ L 251/12, 3.10 .2003 . 
Member States pushed for an understanding of integration in line with their respective legislations on immigration control. By doing so, the classical approach(es) of integration in EU law mutated. These transformations, however, also involved the Europeanisation of the domain of integration. By inserting integration as a condition or measure inside the main body of these Directives, the Member States saw their discretion diminished when determining the content and scope of integration of TCNs at EU level. This has been confirmed by the Case C-540/03, European Parliament v. Council of 27 June 2006. As we will argue, this ruling has major implications for the relationship between EU immigration law and the general principles of EU law, as well as the boundaries of Member State sovereignty in this context.

The progressive establishment of a common immigration policy has encountered constant resistance from certain Member States attempting to keep intact their power over these policies. While the domain of integration was considered as a key strategic priority for the Area of Freedom, Security and Justice (AFSJ) by The Hague Programme of 4-5 November $2004,{ }^{6}$ the principle of subsidiarity has so far prevailed. The Member States have conceived integration as one of those areas at the heart of national sovereignty. The tensions emerging when putting in relation the processes of European integration on immigration and the principle of subsidiarity have provoked the development of two separate, yet parallel, normative settings: European immigration law and the EU Framework on Integration.

Since the end of 2002 the EU Framework on Integration has been slowly but progressively developed, and is now composed of a set of Common Basic Principles for Immigration integration policy, ${ }^{7}$ two Handbooks on Integration for policy-makers and practitioners, three Annual Reports on Migration and Integration, the setting up of the National Contact Points on Integration and the upcoming European integration Forum, an Integration Website and a European Integration Fund. The Framework constitutes an innovative multilevel method of governance in the field of integration of TCNs at EU level, involving the interaction of a package of non-binding or soft-law regulatory tools and diversified supranational networks which have given birth to a quasi-Open Method of Coordination, which includes benchmarking and indicators as central tools. The constitutive features characterising the understanding of integration have also evolved in a highly dynamic fashion since the first policy steps taken in the scope of the EU Framework on Integration. This has mainly occurred as a consequence of the increasing exchange of information on national experiences, programmes and policies between the Member States, and particularly due to the active role of the network of National Contact Points on Integration and the adoption of the two editions of the Handbook on Integration.

The Treaty of Lisbon, whose destiny remains currently at stake after the 'no' resulting from the Irish referendum the 12 June 2008, would foster a whole series of innovations of the current configurations applicable to European cooperation on legal immigration and integration policies. In brief, policies related to legal immigration would finally benefit from qualified majority voting in the Council and the co-decision procedure. The new Article 79.4 of the Treaty on the Functioning of the Union (TFU) would provide the basis for developing common legislative measures to encourage and support the work of the Member States in the area of integration of TCNs, and therefore formalising the EU Framework on Integration into a proper Open Method

6 Brussels European Council, Presidency Conclusions, 4 and 5 November 2004, 14292/1/04, Brussels, 8 December 2004, OJ C53/1, 3.3.2005. See T. Balzacq and S. Carrera (2006), "The Hague Programme: The Long Road to Freedom, Security and Justice", in T. Balzacq and S. Carrera (eds.), Security versus Freedom: A Challenge for Europe's Furure, Ashgate Publishing, pp. 1-34.

7 Council of the European Union, Justice and Home Affairs Council Meeting 2618 Basic Principles on Immigrants Integration', 14615/04, 19 November 2004. 
of Coordination through the application of the ordinary legislative procedure (co-decision). ${ }^{8}$ Both policy areas would also gain from the increased involvement of the European Parliament, national parliaments, the committee of regions and the European Court of Justice.

\section{Outline of the Book and the Questions at Stake}

The book is composed of the following five overarching Sections and a total of eight Chapters. Section I outlines the research topics, synthesises the main themes and questions, and clarifies the scope, key terms and methodology. Section II starts the journey by looking at the framing of integration in EU law in Chapters 2, 3 and 4. Chapter 2 first provides a genealogy of the origins and developments of the concepts, approaches and institutional structures covering the integration of TCNs since the first European responses on immigration up to the Treaty of Amsterdam. The objective is to ascertain the existence of any consistent and predominant approaches to the discourse and official rhetoric on integration in EU law and policy from a historical perspective. The first part of the Chapter tracks the term integration in EU law and policy during the stages preceding the Europeanisation of immigration in 1999. We shall sketch any distinctive features of integration explicitly appearing in the various EU acts on legal immigration from the 1970s to the end of the 1990s. The second part of the chapter centres on the consequences of the new procedures and structures introduced by the Treaty of Amsterdam to Title IV TEC, the political agenda agreed to in the Tampere Programme and the birth of the bifurcation of the frameworks covering the legal and policy elements of integration at the EU level. It looks at the ways in which the normative elements surrounding immigration policy after 1999 led to the appearance of a dual legal setting in the field of integration of TCNs: i.e. EU immigration law and the EU Framework on Integration. Chapter 3 examines the origins, tools and structures of the EU Framework on Integration. Particular attention is paid to the evolving understandings of integration within this soft-law pattern of European cooperation. It assesses some of the effects inherent to the methods, factors and tools used by the EU Framework on integration. The similarities and differences between the latter and the Open Method of Coordination (OMC) proposed by the European Commission in 2001 will be addressed, as well as the weaknesses involved in this new multilevel setting of governance. Finally, it studies the technique of benchmarking integration by looking at its main weaknesses.

Chapter 4 examines the relation between integration and EU immigration law. It looks at the features characterising the functions performed by integration in the EU legal system on immigration, and the role that the Member States have played in its origins and latest developments. It commences by offering a concise overview of the current configurations of the regime embracing European immigration law, and the acquis in the area of legal immigration. The analysis will be centred on the Council Directives 2003/109 on the status of third country nationals who are long-term residents and $2003 / 86$ on the right to family reunification. We shall address the main approaches underlying integration in some of the provisions prescribed by these acts, and the role played by integration in relation to their objectives, rights and conditions. A similar exercise will be conducted regarding the two latest legislative proposals published by

Article 79.4 says that "The European Parliament and the Council, acting in accordance with the ordinary legislative procedure, may establish measures to provide incentives and support for the action of Member States with a view to promoting the integration of third-country nationals residing legally in their territories, excluding any harmonisation of the laws and regulations of the Member State". See S. Carrera and F. Geyer (2008), "The Reform Treaty and Justice and Home Affairs: Implications for the Common Area of Freedom, Security and Justice", in E. Guild and F. Geyer (eds), Security versus Justice? Police and Judicial Cooperation in the European Union, Ashgate: Hampshire, pp. 289-307. 
the European Commission in October 2007 on highly qualified employment COM(2007) 637 and an EU framework of rights for third country nationals COM(2007) 638.

The Annex included at the end of Section II provides a table synthesising the main approaches and features that have characterised integration in EU law from 1974 to the present. Section II addresses the following research questions:

1. Are there any visible and/or distinctive Community approaches predominating in the treatment given under EU law and policy to the integration of TCNs? What were, if any, the traditional understandings in EU law of the notion of integration until the entry into force of the Amsterdam Treaty? What were the main effects of the Tampere Programme and the progressive development of a common EU immigration policy over the normative intersection between integration and immigration?

2. What are the roots, tools and structures of the EU Framework on Integration? Has the development of this framework affected in any way the previously identified approaches, meanings and conceptual premises on the integration of TCNs in EU law and policy? What is the institutional landscape of the EU Framework on Integration and how does it work in practice? Who have been the key actors involved? In which way does this path of policy convergence affect the foundations of the EU legal order and the security and liberty of TCNs? What are the vulnerabilities affecting the EU Framework on Integration and the technique of benchmarking integration?

3. How does European immigration law utilise and frame integration? What are the most relevant decision-making and institutional structures attributed by Title IV TEC to the Union for exercising and developing its competences on legal immigration? What are the differences when comparing it to the EU Framework on Integration? What have been the most important measures so far adopted in the scope of the acquis on legal immigration? What are the usages granted to integration with respect to the rights and conditions stipulated by the Council Directives 2003/109 and 2003/86? What is the nature and scope of these EU acts? Does the understanding of integration that they pursue show any innovative features when comparing them with previous European legal and policy responses? And if so, what are the actual origins and reach of these new features? What have been the latest legislative initiatives in the context of EU law on legal immigration? Do they present similar or different aspects as regards integration?

Section III addresses the national arena to study the cases of Spain and France. These countries constitute two paradigmatic examples as regards distinct historical experiences, public philosophies and legal/policy strategies and frameworks on immigration and diversity. They also present different dynamics affecting the evolution of the relationship between the legal categories of immigration/nationality and that of integration. This comparison becomes most relevant when looking at the ways in which the processes of European harmonisation on immigration and integration have influenced, or not, the classical public philosophies and nomative setting on integration in their respective legal systems. In particular, Chapter 5 is dedicated to the integration of TCNs as provided by the policy and legal landscape on nationality and immigration in Spain. After assessing some theoretical issues characterising the current Spanish public strategies in the management of diversity, we aim at ascertaining the origins of the link between integration, immigration and nationality in Spanish law. The Chapter provides a historical overview of the major policy and regulatory responses adopted during the last twenty years in these domains. The goal consists of searching possible origins and facilitating a broad vision of key policy developments and politics in the Spanish legal system over these areas. The Chapter contimues by studying current regulations on nationality and immigration, paying 
particular attention to their express references to integration. We will review the influence of the Europeanisation processes, and especially of the EU Framework on Integration, over national processes of formulating policy dealing with immigration and integration matters. The implications of the distribution of competences inside the Spanish legal system as regards integration of TCNs between the central State and the Autonomous Communities (AACC) will also be at the heart of our analysis. Finally, the last Section of this Chapter will evaluate the extent to which the integration-related provisions presented by the Council Directives on the status of third country nationals who are long-term residents 2003/109 and on the right to family reunification 2003/86 have affected the traditional approaches performed by integration in the Spanish legal immigration system.

Chapter 6 examines the nature and impact of the articulation between integration and the laws on nationality and immigration in France. Similar to the Spanish case, we stan by facilitating a theoretical account of the dominant public techniques of management of immigration and diversity conducted by the French State and the philosophies resting behind the Republican paradigm of integration. This will be followed by an overview of the political and legislative developments influencing the major transformations and reconfigurations of the normative nexus between nationality, inmmigration and integration in French law. This analysis intends to sketch the possible roots of the treatment of integration in French political debate, policy and law. The Chapter continues by considering the ways in which the laws on nationality and immigration make use of integration of TCNs, and the modern processes and trends underlying that framing. Finally, the influence exercised by EU law on French immigration law is also addressed. We shall look at how European immigration law in its implementation in the domestic legal regime has taken shape, and the reactions and strategies advocated by the French authorities in these processes.

This Section will address the following questions:

1. What are the conceptual premises driving the techniques of managing diversity in Spain? Is there any public policy carried out at State level? When does the category of "the social integration of immigrants" appear in Spain? What are the roots and actual configurations of the linkages between integration as a nom in the laws of nationality and immigration? What have been the main dynamics affecting that intersection and how does integration function in each of these legal realms? Can we perceive any example illustrating influences from the EU? And if so, have these impacts transformed the ways in which integration was interpreted and practiced by Spanish law and policy? What is the role and effects of the different levels of governance over the public policies on integration?

2. What are the defining elements of the strategies on the management and control of immigration and diversity in France? What are the theoretical premises, fundamentals and implications of the State's managerial techniques? When does integration appear in the French political debate and legal tradition? What are the roots and actual configurations of the linkages between integration as a norm in the scope of the laws of nationality and immigration? What are the functions of integration in each of them?

3. In which way have the integration-related provisions provided by the Council Directives 2003/109 and 2003/86 been transposed in Spanish and French immigration laws? What have been the political logics and normative tendencies characterising the national transposition processes, and the actual regulatory outputs putting them into practice? Has the implementation of these EU acts involved any transformation in the classical approaches performed by this legal concept in their respective immigration laws? 
Section IV takes a step further by focusing on the interplay between the EU and national immigration laws, and their relationship with the institutional and substantive mechanisms guaranteeing the rule of law and the respect of fundamental rights in the EU legal order. At the heart of our analysis will be the availability of any EU instruments for controlling and reviewing Member States' implementing actions within the scope of European immigration law. The potentials offered by the general principles of EU law when limiting the discretion and margin of appreciation of the Member States are significant. They constitute a key testing ground for the assessment of the legitimacy and lawfulness of any exceptions and restrictions applied by the Member States to European rights granted to TCNs in EU immigration law. Chapter 7 examines the way in which Member States' actions within the scope of EU immigration law, particularly when transposing it in their national legal systems, might be subject to judicial review. After drawing some theoretical lines delineating the general principles and their role inside the Union's legal system, we will assess their applicability to EU law on legal immigration. The conjunction between the principles of proportionality and fundamental rights will be of particular importance as regards the protection of TCNs in the context of Member States' actions when implementing European immigration law. We will apply the tests of proportionality and fundamental rights to the French example, and review their compatibility with the domestic implementation in France of the normative understanding of integration provided by EU immigration law.

In light of this, this Section seeks to address the following issues:

1. What are the general principles of EU law? What are their origins, nature and functions? Are they applicable to Member States' actions? What is the significance of these principles as regards EU immigration law and the ways in which the latter is being transformed into national law and practiced in the domestic arena? Do they offer guarantees to TCNs whose Europeanwide rights might be affected, derogated or potentially infringed by the national authorities at times of implementation?

2. Do the transposition measures adopted in France pass satisfactorily the tests of proportionality and fundamental rights? Is the technique of using integration as a legal conditionality and a contractual tool of immigration control in the areas of family reunification and the status of long-term resident compatible with the EU general principles of proportionality and fundamental rights? And what about the legality of the application of "Republican integration abroad" as a mandatory requirement for benefiting from family reunification in the French legal system?

\section{Scope, Concepts and Methodology}

This book looks at the ways in which the integration of TCNs is framed, understood and used by the laws and policies on nationality and immigration in the EU. It addresses the extent to which integration has become a European issue and how this supranational processes have affected national legislations and policies destined to TCNs. Our primary aim is not to contribute to the already large academic debate by proposing yet another definition of what integration should or not mean, but rather by studying the origins, functions and evolving approaches of the

9 There are as many definitions and conceptualizations of integration as scholars dealing with this and other related themes all across the various disciplines of the social sciences and humanities. Among other the following sources provide definitions meeting almost every taste. Inter alia see D. Schnapper (2007), Qu'est-ce que l'integration?, Folio Actuel 125, Gallimard: Paris; G. R. de Groot (2006), "Reflections on Integration and Access to Nationality/Citizenship through Natulalisation: A Comparative Perspective", 
constructed term of "integration" in law and policy at European and national levels. By looking at the interplay between the EU and national arenas, the book aims at identifying some of the approaches driving these regulatory and policy techniques combining integration with the legal frameworks of immigration and nationality. In the light of this, we use the term "normativity of integration" when alluding to the various concepts, evolving approaches and institutional structures addressing the integration of TCNs in immigration and nationality law/policy. The examination of integration as a norm, and the assessment of the impacts of the relationship between EU law and the Member States' legal systems, aims at understanding the logics and tensions driving this changing intersection in the EU. The normativity of integration remains subject to constant harmonisation processes at the EU level. These Europeanisation processes have multifaceled effects in the Member States' legal traditions. The dynamics characterising the processes of European integration around the policy field of immigration make the Member States subject to an increasing set of institutional and substantial mechanisms transforming their traditional role and discretion within the EU legal regime.

With the prospect of the entry into force of the Treaty of Lisbon of 13 December 2007 during 2009 , and because this Treaty would replace the term Community by Union, ${ }^{10}$ we will instead use the terms European or European Union (EU) immigration law when referring to the legal instruments adopted under the current Title IV of the TEC on "Visas, Asylum, Immigration and other Policies related to Free Movement of Persons". When alluding to the acts adopted on the basis of Articles 63.3.a and 63.4 TEC, we will also use the term of regular immigration instead

in S. Camena (ed.), The Nexus between Immigration. Integration and Cirizenship in the EU, Collective Conference Volume, April 2006, pp. 21-27; Penninx, R. (2005), "Integration of Migrants: Economic, Social, Cultural and Political Dimensions", in M. Macura, A.L. MacDonald and W. Hatig (eds), The New Demographic Regime. Population Challenges and Policy Responses, New York/Geneva: United Nations, pp. 137-152; S. Carrera (2005), "Integration as a process of inclusion for migrants? The case of long-term residents in the EU", in H. Schneider (ed.), Migration, Mmegration and Citizenship: A Challenge for Emope's Fumre, pp. 109-138; M. Pajares (2005), La lmegración Ciudadana: Una Perspectiva para la Immigración, Barcelona: Icaria Antrazyt; K. Groenendijk (2004), 'Legal Concepts of Integration in EU Migration Law', Emopean Jommal of Migration and Law, Vol. 6, No. 2, pp. 111-126; Penninx, R. (2004), Integration of Migrants: Economic, Social, Cultural and Political Dimensions, background paper for the UNECE Conference 12-14 January 2004, Geneva; H. Entzinger and R. Biezeveld (2003), Benclmarking Immigram Integration, European Research Centre on Migration and Ethnic Relations, Erasmus University of Rotterdam, report written for the European Commission; $A$. Favell (1998), Philosophies of Integration: Immigration and the ldea of Citizenship in France and Britain, London: Macmillan; McAndrew, M. and M. Weinfeld (1996), "The Social integration of immigrants and the response of institutions", in M. Lombardi (ed), Metropolis: First Conference, Milan: Fondazione Cariplo, pp. 51-73 (retrieved from http:/www.internationalmetropolis.net); S. Castles and M.J. Miller, The Age of Migration: Intenational Population Movements in the Modern World. Basingstoke: MacMillan, etc.

10 Brussels European Council Presidency Conclusions 21/22 June 2007, Council of the European Union $11177 / 1 / 07$, Brussels, 20 July 2007. Annex I of the Conclusions provided the IGC Mandate for the Reform Treaty and stated that the latter will contain "wo substantive clauses amending respectively the Treaty on the European Union (TEU) and the Treaty establishing the European Community (TEC). The TEU will keep its present name and the TEC will be called Treaty on the Functioning of the Union, the Union having a single legal personality. The word "Community" will throughout be replaced by the word "Union"; it will be stated that the two Treaties constitute the Treaties on which the Union is founded and that the Union replaces and succeeds the Community". See also Treaty of Lisbon amending the Treaty on European Union and the Treaty establishing the European Community, signed at Lisbon, 13 December 2007, O. C306/01, Volume 50, 17 December 2007, in 2.2.a says that "the words 'Community' and 'European Community' shall be replaced by 'Union' and any necessary grammatical changes shall be made, the words 'European Communities' shall be replaced by 'European Union'...", see page 42. 
of that of legal immigration. By challenging the significance of the legal or illegal nature of the residence and stay of TCNs, the actual strategies driving this categorisation become transparent. The framing of the phenomenon of immigration from a pure illegal or legal perspective leads to the emergence of a nexus between human mobility and insecurity. The notions of illegal immigration, or illegal immigrant, have been therefore subject to extensive academic critique. " The use of this terminology ascribes to the person a status implying suspicion and criminality. Authors like Bigo (2002) and Huysmans (2002) have referred to the dilemmas involved when attempting to move from constructed concepts which present critical connotations by actually continuing to use the very same terms. ${ }^{12}$ Because the actual determining factor for attributing this nomative label is the non-compliance by the person involved with a set administrative rules, framing the discussions on regular or irregular terms is more appropriate.

The terms third country national or immigrant are used interchangeably when referring to those not holding the nationality of an EU Member State, and therefore not falling within the status of European citizens as defined in Article 17.1 of the EC Treaty. ${ }^{13}$ The following categories of TCNs fall outside the personal scope of our examination: those who are beneficiaries of rights on derivative grounds (such as family members of European citizens or immigrant workers employed by a company established in one Member State and providing its services in another), or those who may fall within the scope of agreements concluded between the EU and/or Member States and third countries.

Finally two conceptual clarifications: Our concept of Europeanisation is inspired by the one put forward by Radaelli (2001), who defined it as a

process of construction, diffusion, and institutionalization of formal and informal rules, procedures, policy paradigms, styles, "ways of doing things" and shared beliefs and norms, which are first defined and consolidated in the making of EU policy and politics, and then incorporated into the logic of domestic discourses, identities, political structures and public policies. $^{14}$

We will also use the term of governmentality following the notion of M. Foucaull (2001) when referring to system developed under the EU Framework on Integration. ${ }^{15}$ The concept of governmentality includes all the governmental practices that make it possible to constitute, define, organise and instrumentalise the strategies of individuals and their liberties and relations. ${ }^{16}$ The use of this term becomes most relevant at times of studying the EU Framework

"See for instance E. Guild (2004), "Who is an Irregular Immigrant", in B. Bogusz, R. Cholewinski, A. Cygan and E. Szyszczak (eds), Irregular Migration and Human Rights: Theoretical, European and International Perspectives, Leiden: Martinus Nihjoff, pp. 3-28.

12 See D. Bigo (2002), 'Security and Immigration: Toward a Critique of the Governmentality of Unease', Alternatives: Global, Local, Political, Vol. 27, Special Issue, February 2002, pp. 63-92. J. Huysmans (2002), 'Defining Social Constructivism in Security Studies: The Normative Dilemma of Writing Security', Alternatives: Global, Local, Political, Vol. 27, Special Issue, February 2002, pp. 41-62.

13 Article 17.1 TEC stipulates that "Every person holding the nationality of a Member State shall be a cirizen of the Union".

14 C. Radaelli (2001), "The Domestic Impact of the European Union Public Policy: Notes on Concepts, Methods and the Challenge of Empirical Research', Politique emopeene, 5, pp. $107-142$.

is M. Foucault (1997), Sécurité, territoire, population : Coms al Collège de France (1977-1978), Gallimard Seuil: Paris, pp. 111-113.

16 In words of Foucault "j'entends l'ensemble constitué par les institutions, les procedures, analysis et réflexions, les calculs et les tactiques qui permettent d'exercer cette forme bien spécifique, bien que complexe, de pouvoir, qui a pour cible principale la population, pour forme majeure de savoir, l'économie politique, pour instrument technique essentiel les dispositifs de sécurité"..." la tendance, la 
on Integration as the latter is far from following a simple and straight-forward top-dow governance approach. ${ }^{17}$ The way in which it operates and has been structured rather involves a major transformation of, and to some extent a challenge to, the classical foundations of the Community method of cooperation and governance. It diversifies the usual ways through which the EU legal system functions and develops. The Framework can be perceived as a new multilevel setting comprising the interaction of a package of non-coercive regulatory tools and active transnational networks, and characterised by a complex interplay of strategies and politics exercised by the Council, the European Commission, other European institutions, supranational networks and key stakeholders. These strategies are mutually influencing (top-down and bottomup) and reinforcing, yet they are driven by a complex web of heterogeneous premises, interests and goals.

As regards the book's methodology, it is necessary to stress its inter-disciplinary nature and approach. While the driving research focus is law (i.e. a legal analysis of the intersection between integration, immigration and nationality in the EU), the input and influence from academic sources coming from political science and sociology have been considerable. This might well be a challenging endeavour for any "legal mind", such as the one that I am supposed to have. Yet, it is also essential for gaining a global and more comprehensive understanding of the issues and debates at stake when referring to the field of integration of TCNs. I have used information mainly from publicly available sources within the EU and national legislation and case law. This has been combined with an in-depth reading of key academic literature on integration, immigration and nationality provided in the book's reference list. I have also conducted a number of interviews with EU officials in Brussels. I would like to express my gratitude especially to: Joanna Apap (European Parliament, DG Internal Policies of the EU), Stefano Bertozzi, Emanuela Canetta Rossi Palermo, Guilia Henry and Sandra Pratt (DG Justice, Freedom and Security, European Commission), Martino Paolo Cossu (Council of the EU) and Luis Miguel Pariza Castaños (EESC, SOC Section). I completed my research in the beginning of February 2008. I incorporated relevant developments taking place until the end of July 2008.

ligne de force qui, dans tout l'Occident, n 'a pas cessé de conduire, et depuis fort longtemps, vers la prééminence de ce type de pouvoir qu'on peut appeler le 'gouvernement' sur tous les autres: souveraineté, discipline ; ce qui a amené, d'une part, le développement de toute une série d'appareils spécifiques de gouvernement, et, d'autre part, le développement de toute une série de savoirs". $M$. Foucault (1997), Dits et Écrits 1954 - 1988, Il (1976 - 1988), Édition Établie sous la Direction de D. Defert et F. Ewald avec la collaboration de J. Lagrange, Quarto Gallimard: Paris. Immigration: Toward a Critique of the Govemmentality of Unease', Altematives: Global. Local, Political, Vol. 27, Special Issue, February 2002, pp. 63-92. 



\section{SECTION II - THE NORMATIVITY OF INTEGRATION IN EU LAW AND POLICY}

\section{Chapter 2:}

\section{The Relationship between Integration and EU Law and Policy}

\section{Introduction}

European cooperation regarding the mobility of TCNs and their legal status has provided various instruments dealing with, or referring to, integration since the 1970s. This Chapter examines the changing relationship between integration and EU law and policy. It studies the origins and main developments affecting the concepts, approaches and institutional structures covering the category of integration since the first European responses on immigration up to the Treaty of Amsterdam. It maps out the main EU acts where integration has been expressly included, and examines the functions, approaches and characteristics of this term in these nomative responses as well as in the rhetoric used by the European institutions and other key supranational actors. The objective behind this historical account is to ascertain the existence of any consistent and predominant approaches to the nomative usage and rhetoric on integration in EU law and policy. The first part of the Chapter tracks the category of integration during the stages preceding the Europeanisation of the domain of immigration in 1999. We shall sketch any distinctive features of integration explicitly appearing in the various EU acts on regular immigration from the 1970s to the end of the 1990s. The second section centres on the consequences of the new procedures and structures introduced by the Treaty of Amsterdam to Title IV TEC, the political agenda agreed to in the Tampere Programme and the birth of the bifurcation of the regulatory frameworks covering the legal and policy elements of integration at the EU level. It looks at the ways in which the period after 1999 led to the appearance of a dual setting in the field of integration of TCNs: i.e. European immigration law and the EU Framework on Integration.

\section{Mapping Integration in EU Law and Policy before Europeanisation}

This Section examines the ways in which EU law has understood integration of TCNs since the first steps adopted in European cooperation on immigration policy. ${ }^{18}$ It provides an overview of some of the main meanings, functions and distinctive features of integration in the various Community acts on regular immigration from the 1970s to the end of the 1990s. The objective is far from presenting an exhaustive account and detailed analysis of every measure in the European regulatory landscape of immigration during this timeframe, ${ }^{19}$ but instead to pay

18 As explained in Chapter One of the book, the personal scope of the mapping exercise does not include those European laws and policies referring to the integration of the following legal categories of TCNs: those who are beneficiaries of rights on derivative grounds (such as family members of European citizens or immigrant workers employed by a company established in one Member State and providing its services in another), and those covered by agreements concluded between the European Community and/or Member States and third countries.

19 The academic literature offering an account of the origins and developments on European law on immigration has been extensive. Among many others: E. Guild and J. Niessen (1996), The Emerging Immigration and Asylum Law of the European Union, Kluwer Law Intemational: The Hague, The Netherlands; E. Guild (1999), The Legal Framewrork and Social Consequences of Free Movement of 
attention to the official discourse used mainly by the European institutions regarding the most relevant instruments, and ascertain the existence of any identifiable trends in relation to the nomative understanding and treatment of integration in EU law and policy. The genealogy intends to shed some light as regards the existence of any predominant EU approach(es), or of the interaction of determining features facilitating a common direction driving the strategies around the integration of TCNs in the common EU immigration policy.

\subsection{From the 1970s to the 1980s: The Roots of European Cooperation on Integration of TCNs}

One of the first significant manifestations of Community action in relation to the integration of TCNs occurred at the end of 1974, when the Commission presented an Action Programme in favour of Migrant Workers and their Families COM(74) 2250 of 14 December $1974 .^{20}$ The Programme focused on social and educational measures aimed at improving the conditions of migrant workers and their families, and called for an improved coordination of national policies at the Community level. The latter would include a common strategy offering a "Community approach" on "the choice for policies of assimilation or integration of migrant workers and their families". 21 This act presented a number of relevant elements that need to be underlined. The introductory section started by stipulating that

...the social conditions of the migrant do indeed give cause for serious concern - especially in the case of third country migrants, who have no Community protection and rely solely often on restrictive national legislation, for example, in regard to the type of job they can take, where they may live, and the right to be joined by their families.

The Commission concluded that common solutions should be found not only in relation to problems faced by Community migrants, but also those of nationals from third countries. The argument continued by saying that "after more than a decade of benefit from migrant labour","

Persons in the European Union, Kluwer Law International: The Hague; H. Staples (1999), The Legal Status of Third Coummy Nationals Resident in the European Union, European Monographs 22, Kluwer Law International: The Hague; S. Peers (2000), EU Justice and Home Affairs Law, Person Education Limited: Essex, pp. 63-81; K. Hailbronner (2000), Immigration and Asylum Policy of the European Union, Kluwer Law International: The Hague; E. Guild (2001), Immigration Law in the European Communiry, Kluwer Law International: The Hague; E. Guild and C. Harlow (2001), Implementing Amsterdam: Immigration and Asylum Rights in EC Law, Hart Publishing: Oxford; P. de Bruycker (2003), The Emergence of A European Immigration Policy - L'Emergence d'une Politique Européene D'immigration, Bruylant: Brussels; F. Julie-Laferriere, H. Labaye et O. Edstrom (2005), La Politique Europénne D'lmmigration et D'Asile: Bilan Critique Cinq Ans Après le Traité D'Amsterdam, Bruylant: Bruxelles; S. Peers and N. Rogers (eds) (2006), EU Immigration and Asylum Law: Text and Commentay, Martinus Nijhoff Publishers: Leiden.

20 Action Programme in favour of migrant workers and their families, COM(74) 2250, 14 December 1974 , European Commission, European Communities. The Action Programme was transmitted by the Commission to the Council on 18 December 1974. Groenendijk (2006) has argued that "In the first regulation on the free movement of workers... the right to family reunification and the equal access of family members to education and employment... were explicilly recognised, with the aim of assisting the integration of the worker". K. Groenendijk (2006), "Integration Policy and Community Law", in S. Carrera (ed.), The Newis beneen Immigration. Integration and Cirizenship in the EU, Collective Conference Volume, April 2006, pp. 9-11. See page 22 of the Programme, Section titled "Coordination of Migration Policies".

22 The Commission recognized that "The Community now faces a period of insufficient job opportunities. This situation has been reflected in the actions taken by a number of Member States to temporarily 
the Community presented a "large unassimilated group of foreign workers" who while being exposed to the fulfilment of all the obligations linked to life and work in the receiving State, they were far from enjoying an "equal share of its benefits and rights". This, it was argued, was intolerable. Further, it was considered necessary to stop any discrimination and apply "equality of treatment" in relation to living and working conditions to all those TCNs "who had been legally admitted to employment in the Community". One of the main objectives put forward was therefore the goal to achieve equal treatment of legally admitted and residing third country workers. The Commission recommended a number of measures aiming at applying this overarching objective to the following dimensions:

First, one of the concerns was the education of children. The Programme proclaimed that

Migration, for children, gives rise to the particular problems of family disruption and integration into a new language and culture. They are faced with the difficulty of assimilation to the new language and educational system while at the same time preserving their native language and culture.

It was argued that "the language difficulty, which also affects the parents..." constituted one of the main problems at stake, and pointed out the lack of "bicultural programmes" adopted to respond to the migrant's dual need "of integrating into the life and culture of the host country, while preserving the native culture and language". 3

Second, in the field of social security, it was emphasised that TCN workers should benefit from equality of treatment "by progressive stages" with Community workers independently of whether their status would be covered or not by association or bilateral agreements. ${ }^{24}$

Third, in the area of social services it was recommended that they

...should give the fullest information about the new country, and all necessary help in regard to reception, language, training, accommodation and social integration generally.

Among other proposed measures, the Member States could introduce "integrated programmes for migrants" along with schemes for the training of social workers and teachers working with migrants and their families. ${ }^{25}$

Fourth, the Programme highlighted in respect of the dimension of housing that migrants are often forced to take unsatisfactory accommodation, and consequently they live in "shanty towns and unhealthy overcrowded ghettoes", something which was considered to be "one of the main obstacles to integration in the host country and causes social frictions and xenophobia". 26

suspend the admission of migrants from third countries. In this situation it is necessary, not only as indicated above to move towards concertation of immigration policies, but also in the short term to try to ensure that migrants, especially those from Community countries, do not suffer unduly from the recession of jobs".

23 Refer to page 19 of the programme. It was proposed for example the equal treatment for migrant children in the award of study grants and similar assistance, the development at the national level of reception and accelerated training classes to assist children to settle in the new enviromment, etc.

24 It was also recommended the adoption of a series of measures, such as eliminating nationality as a condition for eligibility for benefits, allowing the export of pensions, to apply Community provisions relating to social security to third country migrants and their families while they are living in the Community, to guarantee that all the migrant workers (in regard to family allowances), etc. See page 17.

25 Refer to page 18 of the Programme.

26 Page 18. 
Fifth, in the scope of vocational training, including language teaching, the Commission stressed that "the lack of vocational and linguistic training,..., is a serious handicap for the migrant to qualifying for worthwhile employment or advancement"27.

Finally, health was another issue being dealt with, by highlighting that the problems faced by migrant workers were

...aggravated by linguistic barriers in communication with medical staff. These barriers, indeed, complicate migrants' efforts to obtain information on a whole range of essential topics on entering the new country, and point to the need for adequately equipped reception facilities and social workers. 28

Overall, the focus of the Programme was concentrated not only on the status and security of Community migrant workers (those holding the nationality of a Member State), but also of those categorised as third country workers legally admitted to the EU. Further, particular attention was granted to the dimension of "working and living conditions", 29 and not so much to political and civic rights. ${ }^{30}$ The Action Programme COM(74) 2250 constitutes an illustrative example of the proactive role that has been played by the Commission when dealing with the legal status of TCNs, which becomes more surprising when taking into consideration the early stage of European integration when this instrument was adopted.

The Council took note of the Programme in a Resolution of 9 February $1976,{ }^{31}$ in which it did not fully follow the forward-looking position defended by the Commission, especially as regards the equality of treatment for third country migrant workers with a regular administrative status of residence. In particular, while some promising elements were included in the Preamble, ${ }^{32}$ the main body of the Resolution allocated a prominent position to the objective of improving the protection and equality of a very specific category of persons, i.e. Community nationals or "citizens of the Member States". In contrast with the discursive tone around which the

27 See page 17. Among other measures, it was recommended the introduction in all the Member States of the paid day-release system to allow migrant workers to acquire adequate language and vocational training, pilot schemes for training, etc.

Pages 13 and 19

It was stipulated that "The first practical effects of this coordinated action should be: - the gradual extension to third country migrants of equality of living and working conditions, and particularly the right to be accompanied by their families; and the transfer of wages and savings to the country of origin".

In this regard the Programme stated an interesting objective to be attained "at the latest by 1980" and consisting of "the granting to migrants... of full participation in local elections according to the conditions to be defined relating in particular to the qualifying period of residence".

Council Resolution on an action programme for migrant workers and members of their families, Bulleting of the European Communities, B.E.C. Supplement 3/76, 9 February 1976.

The Council Resolution started by saying that "Whereas it is also necessary to improve the circumstances of workers who are nationals of third countries and members of their families who are allowed into the Member States, by aiming at equality between their living and working conditions, wages and economic rights and those of workers who are nationals of the Member States and members of their families".

This becomes clear when reading for instance the Preamble, which states that "Whereas the prime objective,..., is to enable workers who are nationals of Member States ... to improve the conditions of freedom of movement for such workers and for member of their families and to seek appropriate solutions with a view of eliminating progressively such unwarranted restrictions on their rights as may still exist in the Community Regulations in force". A similar approach had been taken by previous of its texts, such as the Council Resolution on an Action Programme for Migrant Workers and Members of their Families, 9 February 1976, where the Council called mainly in relation to Community migrant workers for the adoption of measures which would be "offering appropriate assistance 10 migrant 
principle of equality had been interpreted by the previous Commission's Action Programme, its nature within the Resolution took a more stringent scope. While both legal acts shared the understanding of the immigrant as a worker, the Council restricted further the economic dimension of equality to Community nationals. ${ }^{34}$ The Resolution made a broad reference to the situation of third country workers in its Point 2.c, which intended to somehow encourage "the achievement of equality for workers who are nationals of third countries and members of their families who are legally resident in the Member States, with regard to living and working conditions, wages and economic rights".35

The next important attempt put forward by the Commission took the form of a Communication on Guidelines for a Community Policy on Migration, which was transmitted to the Council on 7 March $19855^{36}$ This instrument identified the integration of immigrants as one of the sectors within the wider field of migration in need of some kind of European response. Contrary to previous legal Community instruments, it dealt with issues related to TCNs as workers and citizens. The Commission called for the improvement of the legal status of the immigrants in order to ensure a "stable footing" in comparison with the Community nationals. ${ }^{37}$ Policies destined to integrate the immigrant and his/her family should "overcome certain obstacles to putting the foreign population on a stable footing, which are inextricably bound up with the very status of being a migrant". It went even further by stressing that

It is a constant factor of the Commmity approach to these problems that the aim should be equality of treatment in living and working conditions for all migrants, whatever their origin, and workers who are nationals. (Emphasis added.)

In light of this, the Commission referred for the first time to a "Community approach" applying to third country workers. It also identified the paradigm of equality of treatment as a "constant

workers and members of their families to facilitate their integration in the host country, particularly by improving the social infrastructure and making more information available, and by encouraging them to take advantage of the official services available to nationals".

3. The only signal to a wider concept of equality could be found in Para. 5 of the Resolution where it vaguely said that "5. It confirms its desire that, subject to the Community's powers and responsibilities, everyone within it should have an equal opportunity of deriving advantages and making a contribution". Further, paragraph 3 stated that "Considers that with a view to promoting the social and occupational advancement of migrant workers and members of their families, particular importance should be attached to measures concerning vocational training, housing, social services, medical and social care schemes including preventive medicine, schooling of children, information, and the creation of a better understanding among the general public of the host country of the problems of migrant workers and members of their families".

35 See paragraph 2.c of the Council Resolution. The rest of provisions inserted in Article 2 seem to be exclusively related to Community migrant workers.

36 Commission Communication, Guidelines for a Community Policy on Migration, $\operatorname{COM}(85) 48$ fmal, 7 March 1985, Bulleting of the European Communities, Supplement 9/85. It was stipulated in paragraph 2 of the Introduction that "The policies advocated in this Communication are designed to deal with the problems of the migrant as a worker and as a citizen".

37 It was stressed in point 27 titled "Social and Education Integration Measures" that "it is only against the background of an improvement and clarification of the status of migrants that action aimed at the social and educational advancement of migration, particularly the second generation, can have its full effect. This is particularly so as regards the uncertainties which flow from rules for the issue and renewal of residence and work permits, procedures for the reuniting of families, conditions governing naturalization, language and vocational training, education, cultural adaptation, health and housing". 
factor" of that common approach. ${ }^{38}$ An express reference was made to the need to adapt the legal status of immigrants from third countries "with the aim of consolidating foreign communities which have acquired the characteristics of permanence, by reason of their length of stay".

The Commission's Guidelines paid further attention to the general "cultural and educational aspects of integration". The Communication presented the acquisition of "an adequate knowledge" of the language of the receiving country as a "must" for the migrant workers and the adult family members to "play their part in society and working life". ${ }^{39}$ In the same footing, it was argued that this "obligation" does not need to undermine the important role played by the language and culture of origin in the social insertion of immigrants. In fact, it was stressed that a "successful integration depends on the interrelationship between the host culture and the culture of origin". This represented one of the first occasions where a reference to the existence of obligations within the normative context of integration was expressly raised by the Commission. Further, this Communication addressed in an implicit manner the two-way process principle, which has over time confirmed itself as one of the most important conceptual premises substantiating the EU Framework on Integration (See Chapter 3 below). According to this tenet, an effort by both the immigrants as well as by the receiving population would be necessary for integration to succeed. ${ }^{41}$ It would not only be for the immigrant to make everything possible to integrate, it would also need to be accompanied by the willingness and efforts of the receiving society. In this context, the Commission also stated, "preserving and even promoting the language and culture of the country of origin is not at all incompatible with a willingness to accept insertion in a new enviromment".

Among the sectors of intervention identified by the Communication, the Commission called for Community legislation applying to "migrant workers of the Member States" that would aim at removing "obstacles to integration by exploring the forms of participation in the life of the host country". 42 The Communication intended to set up a non-binding consultation procedure between Member States and the Commission on problems faced by immigrants, ${ }^{43}$ which would have offered to the latter the possibility to put forward Community guidelines addressing "common challenges". .4 $^{4}$ aragraph 21 of the Communication called for an improved consultation between the Member States about "measures to promote social and educational integration, together with the maintenance of cultural ties with the country of origin and the intensification of social and vocational promotion schemes directed specifically at the second generation".

38 See introduction that states that " $\mathrm{ht}$ is clear that, from a legal point of view, Community nationals have a special position, in that their rights as regards migration are protected by Community legislation under the Treaty of Rome. However, migrant communities, whether of Community or non-Community origin, face much the same problems in their social and working life". Page 12.

40 Paragraph 30 stipulates that "...bilingualism and biculturalism represent a necessary instrument in the integration process and a source of enrichment for local cultures".

41 Paragraph 11 reads as follows: "Furthermore, the Commission emphasizes that insertion in the society of the host country only succeeds through the double effect of the willingness and effort of the native population, on the one hand, and that of the migrants themselves, on the other".

42 Paragraphl4.e.

43 The areas qualified as 'problematic' were: Labour market policy, social and educational integration and social security measures.

44 In particular, the Commission's proposals were divided in three fields of intervention: Community legislation, consultation and information. See pages 7-15. 
After the presentation of this instrument, and based on the recognition expressed by the Council in its Resolution on Guidelines for a Community Policy on Migration, ${ }^{45}$ about the desirability to promote consultation and cooperation among the Member States in migration-related issues, the European Commission adopted on 8 July 1985 a Decision setting up a Prior Communication and Consultation Procedure on Migration Policies in relation to non-member countries. ${ }^{46}$ The Decision had as its legal basis the old Article 118 TEC, which is currently spread over Articles $137,138,139$ and 140 of its consolidated version. This provision confers to the Commission the task to promote close cooperation and coordination between the Member States in the field of social policy, and particularly in the dimensions of labour and working conditions. ${ }^{47}$ According to Article 1, the system proposed would have required Member States to exchange and make public in advance information about ${ }^{48}$

draft measures which they intend to take with regard to third country workers and members of their families, in the areas of entry, residence and employment, including illegal entry, residence and employment, as well as the realization of equality of treatment in living and working conditions, wages and economic rights, the promotion of integration in the workforce, society and cultural life, and the voluntary return of such persons to their country of origin. ${ }^{49}$ (Emphasis added.)

One of the main logics lying behind this mutual exchange of information would have been the Commission's willingness to identify "problems of common concern" among the Member States, and consequently to facilitate the adoption of common guidelines intending to provide them with appropriate answers. In particular, in addition to the setting up of the administrative system of information exchange, a highly contested element included in the Decision was the wording used by Article 3. This provision would have conferred to the European Commission

45 Council Resolution of 16 July 1985 on guidelines for a Community policy on migration, OJ C 186 , 26.7.1985. However it is also interesting to see how the Council Resolution carefully stated in its paragraph 5 that this would be subject to "the Community's powers and responsibilities". The Council recognized in various occasions the need for establishing appropriate mechanisms for carrying out a "consultation procedure" on migration policies at European level. Sec for instance the Council Resolution of 27 . lune 1980 on Guidelines for a Community Labour Market Policy, OJ C 168, 8.7.1980; Council Conclusions on a Community Medium-Term Social Action Programme, OJ C175, 4.7.1984; See also the Fontainebleau European Council, 25 and 26 June 1984, EC 6-1984, point 1.1.9.

46 Commission Decision of 8 July 1985 setting up a prior communication and consultation procedure on migration policies in relation to non-member countries, OJ L 217, 19.8.1985.

47 Article 140 EC Treaty (ex Article 118c) provides that "With a view to achieving the objectives of Article 136 and without prejudice to other provisions of this Treaty, the Commission shall encourage cooperation between the Member States and facilitate the coordination of their action in all social policy fields under this chapter, particularly in matters relating to: employment, labour law and working conditions, basic and advanced vocational training, social security, prevention of occupational accidents and diseases, occupational hygiene, the right of association and collective bargaining between employers and workers".

48 Article 1.2 specified that "The Member States shall communicate to the Commission and to the other Member States, in the areas mentioned in paragraph 1 the texts of provisions laid down by law, regulation or administrative action already in force, and also the texts of agreements made with third countries".

49 According to Article 1 of the Decision the exchange of information would also need to include: "Draft agreements relating to the abovementioned matters, as well as draft cooperation agreements which they intend to negotiate or renegotiate with third countries, when these agreements involve provisions relating to the abovementioned matters, and draft agreements relating to conditions of residence and employment of their nationals working in third countries and members of their families, which they intend to negotiate or renegotiate with those countries". 
the power to ensure that any draft national measures would be compatible with, and would not jeopardise the result of, European measures covering the very same areas, something which provoked the resurgence of a whole series of nervous reactions from the Member States. ${ }^{50}$ In fact, the Decision constituted a visible expression of the struggles between the Member States and the European Commission regarding the competence, sovereignty and discretion over immigration policy. Two months after the publication of the Decision by the European Commission, a group of six Member States (Germany, France, The Netherlands, Denmark, the UK and Ireland) presented a challenge before the European Court of Justice (ECJ) asking for the Commission's Decision to be declared void. This materialised in the case Germany and others $v$. Commission which became known as "the Migration Policy case". 51 The main basis upon which the action was brought was the lack of competence by the European Commission to adopt a binding decision on migration policy, as this area was considered to fall outside the social field envisaged by Article 118 TEC. The applicants maintained that immigration fell within those areas of exclusive jurisdiction of the Member States. ${ }^{5 ?}$

The ECJ went first into the analysis as to whether the expressions "promoting close cooperation" and "arranging consultations" as referred to in the mentioned TEC provision could include the competence of the Commission to enact legally binding measures in this field. Second, the Court addressed whether the collaboration between Member States in social policy includes policies on immigration. ${ }^{53}$ As to the second question, the ECJ highlighted that Article 118 TEC called on the Commission to assume "the task of promoting close cooperation between member states in the social field". In this regard, the ECJ held that collaboration in the social field did cover immigration to the extent that it concerned the situation of workers from non-member countries as regards their impact on the community employment market and on working conditions. The Court concluded that the employment situation and the improvement of living and working conditions within the Community are affected by migration-related measures. ${ }^{54}$ However, a critical element identified in the material scope of the Commission Decision was the inclusion in Article 1 of the obligation for the Member States to communicate draft measures dealing with "the promotion of integration in the workforce, society and cultural life". The Luxembourg Court held that the link between the promotion of integration in the cultural life and employment

30 Article 3 reads as follows: "to ensure that the agreements and measures referred to in Article 1, including those relating to development aid, are in conformity with, and do not compromise the results of, Community policies and actions in these fields, in particular as regards Community labour market policy".

s1 Joined Cases C- 281, 283, 284, 285 and 287/85, Germany and Others v. Commission [1987] ECR 3245.

52 In addition, according to Paragraph 9 of the judgement, "The French Republic maintains that matters relating to the conditions of entry, residence and employment of nationals of non-member countries affect the member states' security and go substantially beyond the social field referred to in article 118 ".

53 H. Staples (1999), The Legal Status of Third Country Nationals Resident in the European Union, European Monographs 22, Kluwer Law International: The Hague, pp. 85-87.

54 The ECJ also held in para 17 that "As early as 1974 , in its resolution of 21 January 1974 concerning a social action programme..., the council recognized that the migration policies pursued by the member states affect the community's social policy, in particular in view of their influence on the community employment market and on community workers' employment conditions. In that resolution it acknowledged the need, and expressed the political resolve, to promote consultation on immigration policies vis-à-vis non-member countries. It reiterated that view in its resolution of 9 February 1976 on an action programme for migrant workers and members of their families... and in its resolution of 27 June 1980 on guidelines for the community labour-market policy..., which is referred to in the Commission's decision. The decision also refers to the resolution on guidelines for a community policy on migration already approved by the council, which was to be formally adopted on 16 July 1985 ....". 
and working conditions was tenuous, and therefore concluded that the Decision went beyond, and fell partly outside, the social field stipulated in the Article 118 TEC.

Concerning the first of the referred questions, the ECJ was of the opinion that the Commission had the competence to enact a binding decision related to immigration, but that this power should be confined to arranging the procedure for the notification of information and consultation. However, the Court pointed out that Article 3 of the Decision went beyond the pure arrangement of an administrative procedure because it gave to the Commission the power to ensure that the agreements and measures communicated were "in conformity with" Community policies in the fields covered by the decision. In light of this, the ECJ ruled that the Commission would have exceeded its powers by determining the result to be achieved in that consultation and by preventing the Member States from implementing drafts, agreements and measures which it would consider not to be in conformity with community policies and actions. Therefore, the Decision was declared void.

Even though the ECJ annulled the Decision, this ruling presented a series of innovative elements as regards the competence of the Commission in the field of immigration, and the normative usage of integration in EU law. While the Court considered that the "cultural integration of immigrant communities" fell outside the scope of Article 118, it was of the opinion that this issue was anyhow linked with the effects of any migration policy. ${ }^{55}$ Further, the ECJ considered that the promotion of integration "in the workforce and society" fell within the scope of Article 118 TEC (social policy), and therefore also within the competence of the European Commission inasmuch as the measures in question would be connected with "employment and working conditions". 56

It was not until 28 September 1990 that the Commission took further action, with the publication of a Report dealing with Policies on Immigration and the Social Integration of Migrants in the European Community SEC(90) 1813. ${ }^{57}$ The Report, which became known as the Braun Report, ${ }^{58}$ was drafted by a group of experts on behalf of the European Commission based on the request by the Strasbourg European Council of 8-9 December 1989. ${ }^{59}$ This document started from the premise that integration is "inescapable" as a policy in order to diffuse "the tensions inherent to immigration". It presented the following general meaning of integration: "to be one of us socially, economically and, at least in a rudimentary way, politically"; integration is "...a

55 Paragraph 22 of the ruling stated that "as regards the cultural integration of immigrant communities from non-member countries, whilst this may be linked, to an extent, with the effects of migration policy, it is aimed at immigrant communities in general without distinction between migrant workers and other foreigners, and its link with problems relating to employment and working conditions is therefore extremely tenuous".

56 Paragraph 21 of the judgment reads as follows: "the promotion of the integration into the workforce of workers from non-member countries must be held to be within the social field within the meaning of article 118, in so far as it is closely linked to employment. this also applies to their integration into society, having regard to the objectives pursued by the contested decision, inasmuch as the draft measures in question are those connected with problems relating to employment and working conditions, and there is no reason to consider that the decision intended to give a different meaning to that concept".

57 Commission of the European Communities, Policies on Immigration and the Social Integration of Migrants in the European Community, SEC(90) 1813 final, 28 September 1990, Brussels.

58 Among the group of experts that had drafted the report, there was Mr. F. Braun, who was Special Advisor to the President J. Delors, and who was the chairman of the group. See Annex 11 of the Report.

59 The European Council called for the enactment of "an inventory of national positions on immigration...to provide a basis for discussion of the matter within the Council". 
process which prevents or counteracts the social marginalization of immigrants". 60 Among the number of factors that were identified by the Report as having general validity at the European level of integration policy, the following can be pointed out:

First, it alluded to a nexus between control over immigration and integration. The opinion of the experts was that "member states' borders have to be controlled effectively if their integration policies are to succeed".

Second, it emphasised the importance of the security of residence for the immigrant. It argued for the existence of a link between "the desire to integrate" of TCNs with the feeling of security conceming her/his residence status. ${ }^{61}$ Ensuring a status of permanent resident was therefore conceived as a necessary step for any integration policy. ${ }^{62}$ Paragraph 50 went further by stating that "the desirable change from temporary to permanent residence status...must signal the acceptance of the foreigner as a member of the society with unrestricted social and economic rights". In addition to the idea of equal societal membership, granting a security of residence was considered to be a "signal to the immigrant that he can make his home where he is".

Third, the two-way process tenet, according to which integration concerns 'both sides' - the receiving society and the immigrants - was once more affimed. ${ }^{63}$

Fourth, paragraph 39 conceived integration to derive its social legitimation from Western Europe's fundamental value of solidarity with the poor, and its political legitimation from the humanitarian principle of equality of treatment.

Fifth, it stated integration is necessary in order to offer migrants the opportunity to live "normally" in the receiving country. ${ }^{64}$ Further, "it entails providing migrants with sufficient resources...to enable them gradually to attain 'parity' with the national population". The nomality and parity principles should be applicable, as provided in the Conclusions of the Report, not only to migrants legally present in the territory, but also to "fresh inflows", independent of their status according to national law. ${ }^{65}$

60 The Report provided in paragraph 38 that "Understood in this way, integration leaves aside the somewhat heated...debate on assimilation versus multiculturalism. Social integration is necessary even where assimilicionist policies are pursued. Social integration is also necessary under a multicultural, intercultural or ethnic minority perspective", page 14.

It was stated in paragraph 48 that "The desire to integrate depends crucially on whether immigrants feel secure in respect of their residence status. Immigrants who fear that they can be removed from their host society s territory on social or economic grounds or because of some misdemeanour will, at best, be hesitant or half-hearted in their integration efforts. Living in uncertainty is not conducive to investing years of language or vocational training, one s savings, emotions or loyalties in the host society or to looking for a marriage partner there. The duration of the changeover period from temporary to permanent residence status has in Western Europe tended to shorten rather than to lengthen, which is a movement in the right direction".

Other concepts qualified as essential ingredients for integration were: employment, education, housing, as well as civic and political rights and the acquisition of citizenship. Additional aspects related to the role of the law, public statements and public opinion and the Islam were also addressed.

Paragraph 48 started by saying that "Integration concerns both sides, the host society and the immigrants, whether they be workers, family members or refugees".

64 See "Conclusions and Suggestions", paragraph 99.

65 It was expressly said that "the option of Integration is unavoidable for all the Member states. It denotes the need to offer migrants and their descendants the opportunity to live "normally" In the host country. It entails providing migrants with sufficient resources (knowledge of the local language, housing, education, vocational training etc. To enable them gradually to attain "parity" with the national population. This approach seems now to be widely favoured. In the Community countries. It should be 
Further, the Braun Report recommended increased European cooperation in this field. A series of non-binding initiatives for action were proposed. In particular, it was recommended to devise a "set of basic principles on the integration of immigrants" which would clarify the fundamental rights and freedoms of individuals and would also set out "the requirements" applicable to the content of the policies and to the immigrants. ${ }^{66}$ These basic principles would synthesise the broad lines on which there could be an agreement among the Member States, and would ease the achievement of convergence and agreement at the European level. ${ }^{67}$ Among the other recommendations that were put forwar ${ }^{68}$ was the development of exchanges and consultation on the social aspects of integration. ${ }^{69}$ While the majority of these recommendations did not materialise in the short-term, they did have an influence on some of the most important legislative and policy acts that, as we will study in the next Chapter, have been promulgated and developed after the entry into force of the Amsterdam Treaty in 1999 in the context of the EU Framework on Integration.

Another significant measure adopted by the Commission, and which had as one of its main considerations the need to strengthen integration policies for the benefit of 'legal immigrants', was the Communication on Immigration SEC(1991) 1855 of 23 November 1991. ${ }^{70}$ This instrument built upon the principles already developed by previous official Commission documents as regards "integration of third country nationals". In this way, for instance, the Communication referred to "the challenge of integration", and re-emphasised the importance of controlling immigration flows as a prerequisite for any harmonious integration of regularly settled immigrants. It also argued that security of stay and permanent residence are fundamental prerequisites for any successful integration. ${ }^{71}$ In addition, the Commission stated that integration "is a dynamic process based on joining the system of the host society because it permits participation by those belonging to it". It was also acknowledged that national "legislation has progressively granted new economic and social rights to immigrants in view of the increasingly permanent nature of their settlement", 72 and stressed that "The Member States enshrine this fundamental principle of integration in their national legislation by using the parameter of the length of legal and permanent residence". An implicit reference was also made to the two-way

applicable not only to migrants lawfully present and their descendants but also to fresh inflows likely to be limited in number but no less real, stemming mainly from family reunification and applications for refugee status", paragraph 99, page 35 .

See paragraphs 110 and 111 .

67 "This would undoubtedly provide each country with an opportunity 10 gain insight into the reasoning behind the actions of other countries, to discover areas of convergence, to bring differences into the open and perhaps even to reach agreement". Paragraph 111.

68 Other initiatives included the improvement of information on immigration in Europe, building up a clear picture of movement and take the issue of integration into account in common policies such as in the relations with third countries.

69 "...regular exchanges of information between the Member States on policies in these fields and their effects may facilitate integration and avoid the adverse effects which are likely to arise from excessive disparities".

70 Commission Communication on Immigration, SEC(1991)1855 final, 23 October 1991, Brussels. The Commission said that "the Member States' implementation of a restrictive legal/administrative framework has proved insufficient to either control migration flows or to ensure the integration of immigrants legally settled in the country".

7 Paragraph 60.

72 Paragraph 51. 
process tenet as a key ingredient for successful integration. ${ }^{73}$ By the same token, the Communication reiterated that the parity principle consists of "the implementation of a legal/administrative system which allows the immigrant population to achieve 'parity' with the national population". ${ }^{4}$ Further, after making reference to "the split in the social equilibrium of our societies" as a consequence of the "problems raised by integration", the Commission proposed as a solution that

One possibility is that the principle of equality and non-discrimination takes precedence over the recognition of ethnic minorities. In this case, integration problems are dealt with by applying common law. This approach may also be supplemented by the implementation of support mechamisms to give the least favoured groups greater equality of access to the socio-economic system.. The decisive factors here are the length of the immigrant's residence and the govermment institutional approach to the major integratory mechanisms (school, work accommodation, implementation of exchange and dialogue structures). (Emphasis added.) ${ }^{75}$

The Communication identified as a "consistent feature" in the European approach being developed since 1974, the achievement of equality of treatment in living and working conditions between legally resident immigrants, whatever their origin, and the Community nationals. ${ }^{76}$ Here the Commission's position shifted from previous responses and discursive lines of reasoning. The principle of equality of treatment was placed front and centre, and was therefore considered the root of a supposed 'Community approach'. Moreover, the Commission encouraged the debate over rights and obligations in the integration processes of TCNs. ${ }^{77}$ Equality not only in relation to rights but also obligations was identified as an essential premise for the achievement of solidarity in society. Along this line, the Commission was of the opinion that the immigrants had "the obligation" to adapt to the lifestyle of the receiving society to eliminate the inequalities and legal uncertainties inherent to his/her status. ${ }^{78}$

From the 1970s to the 1980s, the following six factors can therefore be identified as constituting some of the most important common denominators of the 'Community approach(es)' delineating integration: First, security of stay and residence of legally residing TCNs are conceived as fundamental in order to ensure that integration succeeds. Second, some of the policy acts make an implicit reference to the two-way process tenet ("integration concerns both sides") as one of the guiding conceptual premises. Third, there is a nexus between immigration control and integration. Fourth, the principles of parity and normality between legally-resident TCNs and the citizenry were placed at the heart of the understanding of integration. The principle of equal treatment between legally resident TCNs and the Community nationals was identified as a "consistent feature of the Community approach". A fifth ingredient is the role of the language, not only to have access to different societal and economic dimensions of the

73 Paragraph 59 reads as follows "Integration into the host society stems firstly from acceptance of the immigrant population as reflected in the removal of inequalities and socio-legal uncertainties surrounding their status and. secondly, from the desire of the migrants themselves to adapt to the lifestyle in the country in which they are living".

74 Paragraph 25.

75 Paragraph 33.

76 Paragraph 42. See also paragraph 59 which states that "equality of treatment for legally residents immigrants is a fundamental objective for the whole society".

7 It stipulated that "integration... stems firstly from the acceptance of the immigrant population as reflected in the removal of inequalities and socio-legal uncertainties surrounding their status, and, secondly, from the desire of the migrants themselves to adapt to the lifestyle in the country in which they are living".

78 Paragraph 59. 
receiving state, but also as an 'obligation' on the side of the TCNs. Another feature, which in 1991 makes one of its first appearances, consists of understanding equality of treatment not only in relation to rights and legal security, but also to 'obligations' of the TCN for him/her to integrate into the "the lifestyle of the receiving society".

\subsection{The Mastricht Era}

The entry into force of the Maastricht Treaty, or Treaty on European Union (TEU), in November 1993 marked a new stage in relation to the institutional configurations and harmonisation processes of immigration. The birth of the European citizenship, ${ }^{79}$ the establishment of the threepillar structure following the image of a Greek temple and the institutionalisation of intergovernmental cooperation in the area of immigration constituted some of the most relevant innovations introduced by this Treaty. Immigration was placed under the umbrella of the Third Pillar provided by Title VI of the TEU entitled "Cooperation in the Fields of Justice and Home Affairs". 80 The TEU did not offer a definition on what Justice and Home Affairs really meant, yet Article K.1 provided a list of areas considered to be within this new rubric, and which were qualified as "matters of common interest". Among others, these included "immigration policy and policies regarding nationals of third countries". The Third Pillar was characterised by the institutionalisation of an intergovernmental method of cooperation destined to maintain the discretion of the Member States over sensitive fields closely attached to the traditional conception of national sovereignty as regards the discretion over the liberty and security of the non-national. The intergovernmentalism guiding its structures and methods was subject to numerous criticisms in the academic literature, which expressed the pronounced democratic deficit and the lack of judicial oversight of the decisions taken in areas where the legal positioning of the individual is so much at stake. ${ }^{81}$

79 For analysis of some of its implications see inter alia G.R. De Groot (1998), "The relationship between the nationality legislation of the Member States of the European Union and European Citizenship", in M. La Torre (ed.), European Citizenship: An Institutional Challenge, The Hague: Kluwer International Law; G.R. De Groot (2004), Towards a European Nationality Law - Vers wn droit ewropéen de nationalité, Inaugural lecture delivered on 13 November 2003 on the occasion of the acceptance of the Pierre Harmel chair of professeur invité at the University of Liège, Unigraphic, University of Maastricht; S. Kadelbach (2003), Union Citizenship, Jean Monnet Working Paper 9/03, Max Planck Institute for Comparative Public Law and International Law, Heidelberg, pp. 24-27. E. Guild (2006), "Citizenship and Fundamental Rights", in J. Carlier and E. Guild (2006) (eds), The Future of Free Movement of Persons in the EU - L 'avenir de la libre circulation des personnes dans IVE, Bruylant: Brussels, pp. 45-63.

so The First Pillar included the TEC and its institutional mechanisms (Arts. K.1 to K.9) and the Second Pillar embraced the Common Foreign and Security Policy (CFSP).

81 See for example, J. Monar (1994), "The Evolving Role of the Union Institutions in the Framework of the Third Pillar", in J. Monar and R. Morgan, The Third Pillar of the European Union: Cooperation in the Fields of Justice and Home Affairs, European University Press: Brussels, pp. 69-83; J. Monar (1995), "Democratic Control of Justice and Home Affairs: The European Parliament and the National Parliaments", in R. Bieber and J. Monar (eds), Justice and Home Affairs in the European Union: The Development of the Third Pillar, European University Press: Brussels, pp. 243-257; E. Guild and S. Peers (2001), "Defence or Defiance? The Court of Justice's Jurisdiction over Immigration and Asylum", in E. Guild and C. Harlow, Implementing Amsterdam: Immigration and Asylum Rights in EC Law, Hart Publishing: Oxford, pp. 267-289; See also S. Peers (2000), 'Who is Judging the Watchmen' The Judicial System of the Area of Freedom, Security and Justice', 18 Yearbook of Emropean Law. 
The entry into force of the TEU also created the bond between the new status of European citizenship and the holding of Member State nationality. ${ }^{82}$ As the European Commission highlighted in its Communication on the follow-up to the recommendations of the High-level Panel on the free movement of persons, ${ }^{83}$ creating Union citizenship made the rights to enter, reside and remain in the territory of another Member State an integral part of the legal heritage of every EU citizen. Member State nationality was established as the sine qua non for acquiring Union citizenship, and for having the capacity to claim the exercise of the rights and freedoms linked to it. ${ }^{84}$ The premise behind the constructed legal status of European citizen is to move beyond the traditional configurations of the nation-state. It confers rights, non-discrimination and security to the individual outside her/his state of nationality. ${ }^{85}$ By doing so, it encourages nationals of the Member States not to be static, but to move (to become migrants) and actively participate in transnational relations and networks. The practice of mobility constitutes the connecting factor by which a subject becomes a beneficiary of the rights and a claimant of freedoms attached to European citizen status. The supranational status of European citizen therefore implied the exclusion of those long-term resident TCNs. ${ }^{86}$ While nationality and EU citizenship were conceived to be inseparable and superimposed, matters of nationality remained within the exclusive competence of the Member States. ${ }^{87}$ Member States have ever since jealously guarded their competence concerning legislation on the acquisition, loss and proof of nationality as an essential part of their national sovereignty. They have kept the discretion to

82 For a study of the concepts of Citizenship of the Union and European identity within the debate concerning the dynamics of exclusion and inclusion affecting immigrants see M. Martiniello (1994), "Citizenship of the European Union. A Critical View", in R. Bauböck (ed), From Aliens to Citizens: Redefining the Status of Immigrants in Europe, Avebury: Aldershot, pp. 29-48.

Communication from the Commission on the follow-up to the recommendations of the High-Level Panel on the Free Movement of Persons, COM(1998) 403 final, Brussels. Resolution on the second report from the Commission on citizenship of the Union, COM(1997) 230 C4-0291/97, OJ C 226, 20 July 1998.

De Groot (2005), "Towards a European Nationality Law", in H. Schneider (ed), Migration, Integration and Citizenship: A Challenge for Europe 's Future, Volume I, pp. 13-53.

Guild, E. (2004), The Legal Elements of European ldentity: EU Citizenship and Migration Law, Kluwer Law International, European Law Library, The Hague.

86 About the exclusionary nature of European citizenship see T. Kostakopoulou (2001), Citizenship, Identity and Immigration in the European Union: Between Past and Fumre, Manchester University Press: Manchester; For its potentials see Kostakopoulou, T. (2007), 'European Citizenship: Writing the Future', European Law Joumal, Special Issue on EU Citizenship, Vol. 13, Issue 5, pp. 623-646; For a 'state of the art' on this issue see R. Bauböck, A. Kraler, M. Martiniello and B. Perchinig (2006), "Migrants' Citizenship: Legal Status, Rights and Political Participation", in R. Penninx, M. Berger and K. Kraal (eds), The Dynamics of Imernational Migration and Settlement in Earope: A State of the Art, IMISCOE Joint Studies, Amsterdam University Press, pp. 65-98.

Declaration on nationality of a member state attached to the final Act of the Treaty on European Union, OJ C 191, 29 July 1992, which states, "The Conference declares that, wherever in the Treaty establishing the European Community reference is made to nationals of the member states, the question whether an individual possesses the nationality of a member state shall be settled solely by reference to the national law of the member state concerned. Member states may declare, for information, who are to be considered their nationals for Community purposes by way of a declaration lodged with the Presidency and may amend any such declaration when necessary." See also European Council, Conclusions of the Presidency, Edinburgh, 11 and 12 December 1992, Annex 1: Decision of the Heads of State and Government concerning certain problems raised by Denmark on the Treaty on European Union, Section A: Citizenship. This was accompanied by a unilateral Declaration by Denmark stating the differences between the meaning of Union citizenship and that of the Danish citizenship. 
decide who can or camnot be an EU citizen. ${ }^{88}$ That notwithstanding, the ECJ has made important interventions and proactive interpretations of the limits of the status of European citizen, and has challenged, and progressively eroded, the exclusive competence of the Member States over nationality-related matters. ${ }^{89}$

Furthermore, the TEU continued the tradition of dealing with topics related to immigration under the umbrella of 'soft-law'. ${ }^{90}$ This somehow legitimised the previously demonstrated will of Member States to keep the national fences around competence over these areas high enough to prevent intrusion. The Third Pillar therefore embraced a legal framework embedded in interstate discretion and a prominent intergovernmental method of cooperation. During the Maastricht-phase, the Commission continued underlining the importance of strengthening cooperation and creating a joint Community response to face the "common challenges posed by immigration" and arrive at "joint solutions". It also highlighted the limited and incomplete nature of the legal responses so far taken at the European level, and re-emphasized the necessity to improve the situation of TCNs legally resident within the Community. Some of these claims were introduced in the Communication on Immigration and Asylum Policies COM(94) 23 of 23 February 1994, ${ }^{91}$ which as regards to the normativity of integration continued with the consistent features identified in its legal ancestors, yet in some respects it modemised them further. The Communication aimed at stimulating the debate about the new competences attributed by the TEU as regards the area of immigration, the possibilities for a coordinated supranational response and the framework that would cover any future cooperation over this domain.

ss The ECJ interpreted the exclusive competence over nationality matters by the member states in the Micheletri case. The ruling put into question the total exclusivity member states have had over nationality and their discretion to exclude some categories of persons. The ECJ emphasised that this competence must be exercised in compliance with EU law. The ruling put into question the total exclusivity member states have had over nationality and their discretion to exclude some categories of persons. The ECJ emphasised that this competence must be exercised in compliance with EC law. Case C-369/90, M. V. Micheletti and others v. Delegacion del Gobieno en Cantabria [1992] ECR 1-4239, paragraph 10.

The Court of Luxembourg has often challenged the classical premise according to which nationalityrelated matters remain under the exclusive competence of the Member States. See for instance Case C184/99, Grzelczyk v Centre Public d'Aide Sociale d'Onignes-Lomain-la-Nenve [2001] ECR I-6193, paragraph 31; Case C-192/99, Manjit Kaur, [2001] ECR 1-1237; Case C-200/2002, Kunqian Catherine Zhu, Man Lavette Chen, v Secretaly of State for the Home Department, [2004], 1-9925; Case C-145/04, Spain v. United Kingdom, [2006], ECR 1-7917, paragraph 94; Case C-300/04, Eman and Sevinger v. Council of the State [2006], ECR 1-8055, paragraph 61; For a study of the latest case law on European citizenship see F. G. Jacobs (2007), 'Citizenship of the European Union - A Legal Analysis', European Law Joumal, Special Issue on EU Citizenship, Vol. 13, Issue 5, pp. 591-622; See also Guild, E. (2007) "Citizens without a Constitution, Borders without a State: EU free Movement of Persons", in A. Baldaccini, E. Guild and H. Toner (eds), Whose Freedom Security and Justice? EU Immigration and Asyltum Law and Policy. Oxford: Hart Publishing, pp 25-55.

90 For a critique see P. Müller-Graff (1994), "The Legal Bases of the Third Pillar and its Position in the Framework of the Union Treaty", in J. Monar and R. Morgan (eds), The Third Pillar of the European Union: Cooperation in the Fields of Justice and Home Affairs, European University Press: Brussels, pp. 21-36.

91 Commission Communication on Immigration and Asylum Policies, COM(1994) 23 final, 23 February 1994, Brussels. See also the Commission Communication on Immigration, SEC(1991)1855 final, 23 October 1991, Brussels. This Communication identified as 'common problems': the manipulation of the right of asylum to enable immigration on economic grounds, the constant need for management of the effects of continued immigrant pressure, control of migration flows, and the integration of legally settled immigrants. 
Strengthening of integration policies for legal TCNs was identified as one of the most important elements for any comprehensive European approach to immigration. ${ }^{92}$ The Commission sustained that integration policies should aim directly to achieve an improvement of "the situation of TCNs legally resident in the Community by taking steps which will go further towards assimilating their rights with those of citizens of the Member States". "The Communication detemined it essential for any integration policy to ensure "the prospect and security of permanent residence status" for all legal residents satisfying certain "stability criteria". Security as regards residence status was also viewed as necessary to encourage the immigrants' willingness to integrate into the receiving society. The Commission advocated for the creation of a jointly agreed permanent residence entillement which could be granted after a qualifying period. ${ }^{94}$ It proposed the harmonisation of the legal status of legally resident TCNs in order to guarantee a permanent residence entitlement for those satisfying stability criteria. This could be coupled with steps towards the realisation of free movement "for the purpose of engaging in an economic activity" for legally resident immigrants and family reunification. ${ }^{95}$ The notion of nomality was reiterated in paragraph 119, which stated "integration...means offering migrants and their descendants the opportunity to live 'normally' in the host country". As regards the TCN's obligations, it was stated that the adaptation to the receiving society needed to take place without losing their cultural identity.

An analysis of the legislative responses and the official discourse around the domain of integration would not be complete without taking into account the active role played by the European Economic and Social Committee (EESC). The Opinion drafted by the EESC about Communication (1994)23 deserves to be highlighted, as this was the first occasion when the two-way process principle was expressly mentioned in an EU official document as follows: ${ }^{96}$

The Economic and Social Committee regards integration as a two-way process. A comprehensive integration policy should therefore be targeted not only at the immigrant population, but should also involve the population of the host country, so that measures which promote integration among young people, in schools and in the workplace can attain their true objective of improving mutual understanding.

92 According to the text of the Communication "The Commission therefore looks to this Communication as a basis to stimulate a new and wide-ranging debate as to how the new possibilities which the Treaty on European Union creates can be used to provide the coordinated response necessary, and the framework, to guide the Union in its future work". See also the Working Programme prepared by the Council offering a framework for the coordination of national immigration legislations. European Union, The Council, "Priority Work Programme for 1994 and Structures to be set up in the field of Justice and Home Affairs", JAI 12, 10684/93, 2.12.1993.

The Communication made reference to 'the Braun Report' in relation to the desirability to apply a wider personal scope that would equally cover new flows of migrant workers independently of their administrative status (regular or irregular, family members and asylum seekers).

See point III.4.1, paragraph 124 of the Communication.

95 In this regard the Communication also stated in paragraph 128 that "The Social Partners represented in the Permanent Committee on Employment requested on 14 May 1992 that obstacles to taking up employment in another Member State for nationals of third countries who have a permanent residence status in one Member State should be eliminated. This idea had already been reflected in the 1991 work programme, which foresaw the "examination, within the appropriate fora, of the possibility of granting third-country nationals who are long-term residents $\ln$ a Member State certain rights or possibilities, for example concerning access to the labour markel".

96 Opinion of the European Economic and Social Committee on the Commission Communication on an Immigration and Asylum Policies, 94/393/13, OJ No. 393/69, 31.12.1994. See in particular point 8 on "integration policy". 
Further, the EP Resolution on the same Communication of 21 September 1995 emphasised the importance of strengthening the legal position of TCNs who are regularly resident in one Member State, and stated that the right of free movement should be granted to all persons living lawfully in the EU. ${ }^{97}$ The EP also called on the European Commission to reinforce the residence status of TCNs because of "the varying practices in the Member States as regards the right of residence which hamper long-term planning for immigrants". Finally, the Resolution represented one of the first times an official recommendation was put forward to the European Commission to

... draw up a Community programme for the integration of immigramts, central to which is the strengthening of the social position of migrants and in which specific attention is paid to the position of immigrants' wives. ${ }^{98}$ (Emphasis added.)

On the other hand, and based on a report elaborated by the Ministers responsible for immigration and asylum of the Member States on 3 December 1991 about the future agenda for immigration and asylum law, ${ }^{99}$ the Council agreed on a package of Resolutions offering rules for different categories of immigrants. ${ }^{100}$ A total of five were adopted, dealing with admission for the purposes of employment, ${ }^{101}$ family reunification, ${ }^{102}$ pursuing activities as self-employed persons ${ }^{103}$ and study, ${ }^{104}$ and another one concerning the status of third country nationals residing on a long-term basis in the territory of the Member States. ${ }^{105}$ These resolutions were subject to

97 European Parliament, Resolution on the Communication from the Commission on immigration and asylum policies COM(94) 0023, C3-0107-94, A4-0169/1995, 21.9.1995.

Paragraph 46. See also paragraph 47 that stated "Calls upon the Commission to prepare an action programme for the integration of immigrants which respects their cultural identities and draws upon the opportumities provided by Socrates and Leonardo programmes for the education and training of migrants, their families, and public servants who acts as 'gate-keepers' to systems of integration, e.g. police, housing, health, education, etc".

99 This report was submitted by to the same European Council that reached an agreement on the Treaty of Maastrich in December 1991. Document SN 4038/91, 3 December 1991. The report was published in E. Guild and J. Niessen (1996), The Emerging Immigration and Asylum Law of the European Union, Kluwer Law Intemational: The Hague, pp. 449-91; For an analysis of the report see K. Hailbronner (1995), "Migration Law and Policy Within the Third Pillar of the Union Treaty", in R. Bieber and J. Monar (eds), Justice and Home Affairs in the European Union: The Developmem of the Third Pillar, European University Press: Brussels, pp. 95-126.

100 For an analysis of each of these Resolutions and their effects in practice see S. Peers (1998), 'Building Fortress Europe: The Development of EU Migration Law', 35 Common Market Law Review' 1235; See also T. Bunyan (1997), Key Texts on Justice and Home Affairs in the European Union, Volume 1 , Statewatch.

101 Council Resolution of 20 June 1994 on limitation on admission of third-country nationals to the territory of the Member States for employment, O. C 274/3, 19.9.1996, p. $0003-0006$.

$102 \mathrm{SN} 2828 / 1 / 93,1$ of June 1993. This Resolution was not published in the OJ. See E. Guild and J. Niessen (1996).

103 Council Resolution of 30 November 1994 relating to the limitations on the admission of third-country nationals to the territory of the Member States for the purpose of pursuing activities as self-employed persons, Official Journal C $274,19.9 .1996$, p. $0007-0009$.

104 Council Resolution of 30 November 1994 on the admission of third-country nationals to the territory of the Member States for study purposes, Official Joumal C 274, 19.9.1996, p. 0010-0012.

105 Council Resolution of $4 \mathrm{March} 1996$ on the status of third-country nationals residing on a long-term basis in the territory of the Member States, Official loumal C $080,18.3 .1996$, p. $0002-0004$. A sixth Resolution was adopted related to marriages of convenience in December 1997, OJ 1997 C $382 / 1$. 
various criticisms on a number of grounds: ${ }^{106}$ First, they did not provide any substantive legal harmonisation whatsoever; second, they constituted legislative acts with a rather ambiguous legal status. ${ }^{107}$ The Resolution concerning the status of third country nationals residing on a long-term basis in the territory of the Member States, ${ }^{108}$ published on 4 March 1996, was based on Article K.1.3.b of the TEU and identified the conditions of residence by immigrants on the territory of Member States as "a matter of common interest". The Resolution started with the premise that "the integration of long term residents contributes to greater security and stability, both in daily life and in work, and to social peace in the various Member States". Based on that, the Council acknowledged in the Preamble the need for the Member States to define a set of common rules dealing with long-term resident immigrants that would bring some sort of inspiration to their respective policies on integration.

The main lines of this Resolution can be briefly summarised as follows: First, TCNs who could provide proof of legal and uninterrupted residence of a maximum period of ten years should be recognised as long-term residents. ${ }^{109}$ In this way, the aim was not to harmonise the exact time frame for qualifying as a long-term resident, but to leave to Member State national laws the determination of the actual period of time under the ten-year ceiling. Second, those persons falling within the category of long-term residents should be granted a residence authorisation lasting for at least ten years. ${ }^{110}$ Third, the conditions for granting the residence authorisation included the exceptions on public policy and/or national security, as well as the consideration of the level and stability of the means of existence (which could include health insurance and the conditions for exercising an occupation). "Finally, long-term residents should benefit from "no less favourable treatment" than nationals in a series of societal dimensions ${ }^{112}$ and should obtain the necessary authorisation to engage in gainful activities. ${ }^{113}$

106 S. Peers, "Raising Minimum Standards or Racing for the Bottom: The Commission's Proposed Migration Convention", in E. Guild (ed) (1999), The Legal Fromenrork and Social Consequences of Free Movement of Persons in the Etwopean Union, Kluwer Law International: The Hague. See also S. Peers (1997), 'Justice and Home Affairs: Undercuting Integration: Developments in Union Policy on ThirdCountry Nationals', European Law Review 22, pp. 76-84.

M. Hedeman-Robinson (1996), 'Third-Country Nationals, European Citizenship and Free Movement of Persons: A Time for Bridges Rather than Divisions', 16 Yearbook of European Law, p. 321.

108 In a Resolution agreed on October 1996, the Council identified as one of the priorities in the field of justice and home affairs until June 1998 in point 4.e the "examination of the legal status of third-country nationals residing legally in the territory of the Member States". Council Resolution of 14 October 1996 laying down the priorities for cooperation in the field of justice and home affairs for the period from 1 July 1996 to 30 June 1998, Official Journal C 319, 26.10.1996, p. 0001 - 0006. See S. Peers (1997), 'Undercutting Integration: Developments in EU Policy on Third-Country Nationals', European Law' Review 22, pp. 76-84.

This would also include "those who, under the legislation of the Member State concerned, are granted the same residence conditions as the category of persons referred to in the first indent".

110 "or for a period corresponding to the longest period of validity under their national law, which should tend to be of equivalent length, or an unlimited residence authorization, to persons recognized as being long-term residents in accordance with paragraph 1 (1)".

i1. Article IV.I and 2.

112 In particular, Article V.2 provided that "A long-term resident and the members of his family legally resident with him should enjoy no less favourable treatment than is enjoyed, in accordance with the legislation of the Member State concerned, by nationals of that Member State with regard to: - working conditions, - membership of trade unions, - public policy in the sector of housing, - social security, in accordance with, in addition to the national legislation of the Member State concerned, the international agreements on the matter, - emergency health care, - compulsory schooling". Further, Article V. 3 stated that "In accordance with the legislation of the Member State concerned, it should be possible for the 
The constant use and reference to national law as the last resort for defining the main elements covered by this instrument show the great care that was taken not to interfere too much in the prerogatives of the Member States. 14 In fact, this Resolution represented a 'gentlemen's agreement' covering a very broad range of principles, along with a narrow list of rights, which would be perfectly compatible with already existing national regulatory frameworks. Some of these principles were so open and flexible in nature that they would also allow Member States to continue applying their traditional immigration norms, conditions and restrictions.

Shortly after political agreement was found on the Treaty of Amsterdam, the Commission presented a proposal for a Convention on rules for the admission of third country nationals to the Member States (97)387 on the 30 July 1997..$^{115}$ This Convention was the practical materialisation of the Commission's willingness to have a legally binding Community act covering these policies within the European ambit. Among other measures, this Third Pillarinstrument provided a set of basic rights for long-term residents, including provisions dealing with the possibility to have access to employment in another Member State. It was argued that "the Union must encourage the integration of legally resident migrants". "Also, the Commission said that

The integration of migrants is an imperative dictated by the democratic and humanitarian tradition of the Member States and constitutes a fundamental aspect of any immigration policy. The integration of immigrants is essential to safeguard equilibrium in our societies.

Chapter VIII, which comprised Articles 32-35, dealt with "Third Country Nationals who are Long Term Residents". The general rule stipulated by the Convention in this regard was that an immigrant should be recognised as a long-term resident after a five-year period of legal residence in the territory of a Member State, and if s/he was in possession of a residence authorisation for a total of ten years. In comparison with the previous Council Resolution of 1996, this Convention offered a wider list of rights attached to long-term resident status. It also contained a provision (Article 35) dealing specifically with the rights of the long-term resident immigrant in another Member State from the one that granted the status. 17 This, the Convention signalled, "represents a source of stability for those concerned and thus serves as an effective integration factor". 118 The length of effective, regular and legal residence was deemed to constitute a positive indication of the person's integration into the state, ${ }^{119}$ and family

\footnotetext{
long-term resident that and the members of his family legally resident with him to be granted noncontributory benefits".

113 Article VIl.

114 In fact, "In accordance with national law" appears to be one of the favourite sentences used constantly by the Resolution.

115 European Commission Proposal for a Council Act establishing the Convention on Rules for the Admission of Third-Country Nationals to the Member States, COM(97)387, Brussels, 30.7, 1997. For an analysis refer to S. Peers (2000), EU Justice and Home Affairs Law, Pearson Education Limited: Essex, pp. 90-92.

116 In this regard, reference was made to the Commission Communication on Immigration of 1991.

117 The article referred to the access to employment and education. Further, Article 35.2 of the Convention stipulated that "A third-country national settled in accordance with paragraph 1 in a Member State others than that which has recognized him as a long-term resident shall be recognized as such likewise in his new Member State of residence, after a period of two years' residence. This shall be shown by the issue of a residence authorization for a period equal to that which enabled him to be recognized as a long-term resident in his previous Member State of residence".
} 
reunification was deemed "an important factor for the success of any coherent and efficient policy of integration". 120

The Convention, however, was never adopted. In fact, the Commission had already provided in its introductory statement the intention to present a new draft in the form of a Directive once the Treaty of Amsterdam would have entered into force. ${ }^{121}$ Independent of the Commission's plans, the Convention proposal, and particularly the provisions on extending free movement rights for long-term residents, was not very well received in the Council, and it did form part of the political agenda and official deliberations. Notwithstanding considerable efforts put forward by the European Commission, ${ }^{122}$ the Maastricht period therefore failed to provide any real legal harmonisation on regular immigration. ${ }^{123}$

After the signature of the Amsterdam Treaty in 1997, the Commission published in 14 July 1998 another Communication entitled Towards an Area of Freedom, Security and Justice COM(1998) $459,{ }^{124}$ in which it identified "the economic and social integration of lawfully established nonUnion nationals" as an essential element of this common European space. In particular, the integration of non-EU nationals was located under the rubric of "An Area of Freedom", 125 and "a wider concept of Freedom". 26 The principle of equal treatment was here restated as a priority

120 Page 4 of the Explanatory Memorandum and Articles 24-31.

21 It stressed that "The Commission has always wanted the immigration rules to be within the Community ambit. It accordingly welcomes the results of the intergovemmental Conference and the prospects opened up by the Amsterdam Treaty. That Treaty has not yet been signed, let alone ratified, but it would be a mistake to postpone consideration of the subject-matter of this proposal until it has entered into force. In the current situation the Commission can make proposals only on the legal bases available in Title VI of the Treaty on European Union. Once the new Treaty has entered into force, however, the Commission will obviously present a new draft in the form of a directive. This will preserve the fruits of the previous deliberations on the substance but in the context of the new legal basis".

For an analysis of the Convention see S. Peers (2000), EU Justice and Home Affairs Law, Pearson Education Limited: Essex, pp. 90-92. Another proposal that was presented by the Commission was a Proposal for a Council Directive on the right of third-comny nationals to travel in the Community, $\operatorname{COM}(95) 346$ final, 95/0199 (CNS), Brussels, 12.7.1995. The legal basis of this last proposal was Article 100 TEC. Nor the Convention neither this proposal for Council Directive were adopted.

123 Among the few legally binding instruments that were successfully adopted during this phase of European integration we may underline the Joint Action of 16 December 1996 adopted by the Council on the basis

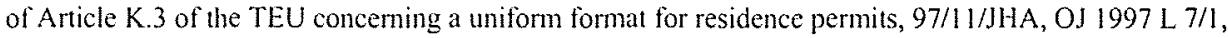
C 193, 19.6.1998.

Commission Communication, Towards an Area of Freedom, Security and Justice, COM(1998) 459 final, 14.7.1998, Brussels. Concerning the concept of "Area of Freedom", the Communication established that "The wider concept of freedom embodied in the Treaty of Amsterdam aims to give freedom" a meaning beyond free movement of people across internal borders. It is also freedom to live in, a law-abiding environment in the knowledge that public authorities are using everything in their individual and collective power (nationally, at the level of the Union and beyond) to combat and contain those who seek to deny or abuse that freedom. Freedom must also be complemented by the full range of fundamental human rights, including protection from any form of discrimination".

i2s It was stated that "The three notions of freedom, security and justice are closely interlinked. Freedom loses much of its meaning if it cannot be enjoyed in a secure environment and with the full backing of a system of justice in which all Union citizens and residents can have confidence. These three inseparable concepts have one common denominator - people - and one cannot be achieved in full without the other two. Maintaining the right balance between them must be the guiding thread for Union action".

126 Not only including the free movement of persons but complementing it by "the full range of fundamental human rights, including protection from any form of discrimination", page 5. Also, "A wider concept of 
by saying that "the European Union needs to develop a common understanding of the extent to which third country nationals and EU citizens should be treated equally". The Commission pointed out two weaknesses of the legal instruments that had been adopted so far in relation to immigration: First, they were based on soft-law such as recommendations and resolutions and therefore were not legally binding, and second, these instruments did not have adequate monitoring arrangements. In light of this, the transfer to Community competence of this policy area was expected to offer a unique possibility to circumvent these weaknesses through the use of proper EC legal instruments via the Community method of cooperation. Which, as we will study in the next section and in Chapter 3 , has not really materialised, but it has rather become exacerbated and institutionalised in the policy domain of integration".

In light of the above, the Maastricht era continued with prominent intergovernmental cooperation and the use of soft-law instruments. The integration of TCNs (and in particular that of 'legal residents') was considered to be a fundamental aspect of every immigration policy. The predominant features granted to the category of integration during this phase of European cooperation may be summarised as follows: First, the prospect and security of permanent residence status for those qualifying stability criteria continued to be considered of special importance. It was proposed to grant security of residence to those immigrants fulfilling the criteria of permanent or stable residence. The granting of rights to long-term resident immigrants and family reunification were viewed as a source of stability and security, and as serving toward an "effective integration factor". The length of effective, regular and legal residence was deemed to be an important factor indicating integration. The integration of long-term residents was framed as "a matter of common interest". It was stated that they should receive "no less favourable treatment" than nationals. A second element that was underlined during this phase was an explicit reference to the two-way process principle as a key ingredient for any "comprehensive integration policy". Further, some references to the principle of normality, the principle of equality, also present in the previous phase, and that of obligations of the immigrants to adapt to the receiving society were expressly mentioned in some specific instances. Finally, integration was encapsulated into a "wider concept of Freedom" in an AFSJ.

\section{Amsterdam, Tampere and the Origins of the Dual Legal Framing on Integration in the EU}

The Amsterdam Treaty represented a historical moment as regards the processes of Europeanisation around the phenomenon of the mobility and status of TCNs in the EU. The domain of immigration was then transferred to Community competence. This took place by moving the habitual residence of this policy from the former Third Pillar of the TEU to the current First Pillar present in Title IV TEC, which received the title of "Visas, asylum, immigration and other policies related to free movement of persons", and which currently comprises Articles 61-69. ${ }^{127}$ The development of a common EU immigration policy has ever

freedom can not be exclusively reserved for EU citizens. It must also include the more than ten million third country nationals who live lawfully and permanently in our Member States".

127 It needs to be noted that the legal basis of some of the acts adopted under the heading of irregular immigration are still located between the First Pillar and the Third Pillar. Further, all the Schengen instruments dealing with police and judicial cooperation in criminal matters still remain under Title Vl of the TEU (the Third Pillar). Therefore, any cooperation in these fields continues to be based mainly on an intergovernmental method of cooperation. The former EU Third Pillar remained substantiated by the cooperation on "Provisions on Police and Judicial Cooperation in the Criminal Matters" under the old Title VI TEU, Articles 29-42. 
since been officially positioned as one of the most important strategic policy priorities for the achievement of a European Area of Freedom, Security and Justice (AFSJ). ${ }^{128}$ In particular, Articles 63.3 and 63.4 TEC offered the legal basis for its progressive attainment by requiring the Council to adopt measures on the "conditions of entry and residence $[\ldots]$ including those for the purpose of family reunion" and "defining the rights and conditions under which nationals of third countries who are legally resident in a Member State may reside in other Member States". 129

After the entry into force of the consolidated version of the TEC in May 1999, the European Council held an important meeting in the city of Tampere on 15-16 October 1999 under the auspices of the Finish Presidency. ${ }^{130}$ The conclusions, which were named The Tampere Programme, represented a turning point after the formal shift of immigration towards Community competence. This was the first occasion where a multi-annual programme was agreed by the Council as regards polices related to an AFSJ. ${ }^{131}$ The Programme presented a roadmap of policy priorities and specified concrete deadlines for their achievement. This fiveyear framework covering the period between 1999 and 2004 aimed at crystallising a 'proper balance' between the three dimensions of FSJ. Among the package of overarching objectives that were presented (Tampere milestones), four can be underlined as potentially having a more central role in relation to the common EU immigration policy and its treatment of integration:

1. The principle of fair treatment of legally-residing TCNs; ${ }^{132}$

2. The need to develop a more vigorous integration policy granting to legal TCNs rights and obligations comparable to EU citizens; ${ }^{133}$

3. The granting of rights which are "as near as possible" to those of EU citizens to longterm residents TCNs; ${ }^{134}$ and

128 One interpretation of the meanings behind an 'Area of Freedom, Security and Justice' has been provided by P. Boeles (2001), "Introduction: Freedom, Security and Justice for All", in E. Guild and C. Harlow (eds), Implementing Amsterdam: Immigration and Asylum Rights in EC Law, Hart Publishing: Antwerpen, pp. 1-12. For a critical account of the concept of 'Freedom' see D. Bigo (2006), "Liberty, whose Liberty? The Hague Programme and the Conception of Freedom", in T. Balzacq and S. Carrera (eds), Security versus Freedom? A Challenge for Europe's Future, Ashgate Publishing: Hampshire, pp. $35-44$.

129 In particular, Article 63.3 EC Treaty establishes that "The Council, acting in accordance with the procedure referred to in Article 67, shall within a period of tive years after the entry into force of the Treaty of Amsterdam adopt: 3. measures on immigration policy within the following areas: (a) conditions of entry and residence, and standards on procedures for the issue by Member States of long term visas and residence permits, including those for the purpose of family reunion, (b) illegal immigration and illegal residence, including repatriation of illegal residents".

130 Tampere European Council, 15-16 October 1999, Presidency Conclusions, SN 200/99, Brussels.

131 For an analysis see Apap, J and S. Carrera (2004), "Progress and Obstacles in the Area of Justice and Home Affairs in an Enlarging Europe", in J. Apap (ed), Justice and Home Affairs in the EU; Liberty and Securty lssues after Enlargemen, Cheltenham; Edward Elgar, pp. 1-24.

132 Paragraph 18 of the Presidency Conclusions that: "The European Union must ensure fair treatment of third-country nationals who reside legally on the territory of its member states."

133 Paragraph 18 also provides that "A more vigorous integration policy should aim at granting them rights and obligations comparable to those of EU citizens. It should also enhance non-discrimination in economic, social and cultural life and develop measures against racism and xenophobia".

134 Paragraph 21 reads as follows "The legal status of third country nationals should be approximated to that of Member States' nationals. A person, who has resided legally in a Member State for a period of time to be determined and who holds a long-term residence permit, should be granted in that Member State a set 
The objective to approximate national legislations on the conditions for admission and residence. ${ }^{135}$

The nexus between the first three principles represents what we may call the EU fair and nearequality paradigm. As it has been evidenced from the previous stages of European cooperation dealing with the integration, the principle of near-equality and that of security of residence had been among those playing a more significant role in the 'Community approach(es)' part of the main legal acts and official discourses since the early 1970s. The Tampere Programme consolidated some of these parameters, and paved the way for the development of transnational legal responses developing some of these approaches even further. It provided the political foundation for the launch of a common immigration policy and a "vigorous integration policy". 136 The milestones proclaimed by the Programme, however, have experienced many challenges towards their materialisation into proper EU law. The European Commission has encountered many barriers to transforming them into proper laws through the ordinary procedural configurations and institutional mechanisms envisaged in Tille IV TEC. Among others, the following two might be especially highlighted:

On the one hand, the Amsterdam Treaty provided in Article 67 that for a period of five years after its entry into force the decision-making processes applicable to these areas would remain outside the scope of qualified majority voting in the Council and the co-decision procedure as provided by Article 251 TEC. ${ }^{137}$ Unanimity and consultation with the European Parliament were therefore the general rule. By a Council Decision adopted on 22 December 2004, all the fields, with the exception of regular immigration, contained in Title IV TEC were transferred to the Community method and its improved procedural configurations. ${ }^{138}$

On the other hand, the fact that Article 63.3 TEC does not expressly refer to the integration of TCNs, but mentions only the conditions of residence, has left room for debate as regards the extent to which the TEC contained a proper legal base for the adoption of European legislation on integration. By and large, even after Amsterdam and the Tampere Programme, the predominant official position of the Member States has been that the field of integration of

of uniform rights which are as near as possible to those enjoyed by EU citizens; e.g. the right to reside, receive education, and work as an employee or self-employed person, as well as the principle of nondiscrimination vis-a-vis the citizens of the State of residence."

135 Paragraph 20 it stated that "The European Council acknowledges the need for approximation of national legislations on the conditions for admission and residence of third country nationals, based on a shared assessment of the economic and demographic developments within the Union, as well as the situation in the countries of origin".

136 Paragraph 10 stipulates that "The separate but closely related issues of asylum and migration call for the development of a common EU policy".

137 Article 67 TEC provides that the Council shall act unanimously on a proposal from the Commission or on the initiative of a member state, after consulting the European Parliament. On 22 December 2004, the Council adopted a decision applying as of 1 January 2005 the co-decision procedure (Article 25I TEC) and qualified majority voting to all Title IV-related legal instruments, except those dealing with regular immigration.

138 Council Decision 2004/927/EC of 22 December 2004 providing for certain areas covered by Title IV of Part Three of the Treaty establishing the European Community to be govemed by the procedure set out in Article 251 of that Treaty, OJ L 396/45. The Presidency Conclusions of the Brussels European Council, 4-5 November 2004 stated that "The European Council asks the Council to adopt a decision based on Article 67.2 TEC immediately after formal consultation of the European Parliament and no later than 1 April 2005 to apply the procedure provided for in Article 25I TEC to all Title IV measures to strengthen freedom, subject to the Nice Treaty, except for legal migration". 
TCNs is closely intertwined with the principle of subsidiarity, ${ }^{139}$ and that this is an area where their competence prevails over the Union's. The doubts around the existence of a proper legal basis to enact European legislation on integration were to a large extent resolved with the formal compromise surrounding the adoption of the European Integration Fund, and would be substantially clarified with the entry into force of the Treaty of Lisbon (Chapter 3, Sections 2.2.11 and 2.2.13). In any case, and as we will see in Chapter 4, it is worth emphasising that the European Commission decided not to include any express reference to integration in the main body of the two first versions of the Proposals for Directive on the status of third country nationals who are long-term residents and on the right to family reunification. It was the Member States themselves who advocated for the introduction of provisions in these two acts with express reference to integration measures and/or conditions. It could therefore be argued that the deliberate inclusion by the Member States of integration as a norm in EU immigration law provided an answer to any open question related to the scope of Article 63.3 TEC and the reach of the term conditions of residence.

Indeed, this debate exemplifies the anachronistic relationship between the official political commitments to develop a common legal framework on these topics, and the actual legally binding juridical instruments agreed to by the Member States in the policy domains of regular immigration and integration. ${ }^{140}$ Independent of the innovations provided by the TEC and the political agreement in the Tampere Programme, Member States have continued practising a strategy of resistance towards Europeanisation in these fields. This has been coupled with a certain degree of competition among themselves in times of negotiation, adoption and implementation of substantial and institutional developments related to an AFSJ, and particularly on issues as sensitive as policies on regular and labour immigration in their national arenas. They still see themselves as rivals and competitors in relation to the struggles over the degree of sovereignty which is at stake toward the development of transnational policies.

These logics of intergovernmentalism and competition emerging among Member States, and becoming most sharply evident inside the rooms of the Council, have not only led to tensions affecting the changing relationship between the Community and intergovernmental methods of

139 For a detailed study of the relationship between EU law and national law, and the principle of supremacy of the former see for example P. Craig and G. de Búrca (2007), EU Law: Text, Cases and Materials, Oxford University Press: Oxford, Sixth Edition, Chapter 10, pp. 344-378; See also S. Prechal (2007), 'Direct Effect, Indirect Effect, Supremacy and the Evolving Constitution of the European Union', in C. Banard (ed.), The Fundamentals of EU Law Revisited: Assessing the Impact of the Constitutional Debate, Oxford University Press: Oxford, pp. 109-152; J. Steiner, L. Woods and C. Twigg-Flesner (2006), EU Law, $9^{\text {th }}$ Edition, Oxford University Press: Oxford, Chaper 4, pp. 69-88; G. Davies (2006), 'Subsidiarity: The Wrong Idea, in the wrong place, at the wrong time', Common Market Law Review, Vol. 43, No. 1, pp. 63-84; K. Alter (2001), Establishing the Supremacy of European Law: The Making of an International Rule of Law in Europe, Oxford University Press: Oxford; De Witte, B. (1999), 'Direct Effect, Supremacy and the Nature of the Legal Order', in P. Craig and G. de Butrca (eds), The Evolution of EU Law, Oxford University Press: Oxford, pp. 177-213.

For various analysis about the lack of policy convergence experienced by the field of regular immigration and some potential reasons laying behind see among others J. Apap and S. Carrera (2003), Towards a Proactive Immigration Policy for the EU?, CEPS Working Document No. 198, CEPS, Brussels, December 2003; T. Balzacq and S. Carrera (2006), 'The Hague Programme: The Long Road to Freedom, Security and Justice', in T. Balzacq and S. Carrera (eds.), Security versus Freedom: A Challenge for Europe's Future, Ashgate Publishing, pp. 1-34; T. Balzacq and S. Carrera (2005), Migration. Borders and Asylum: Trends and Vulnerabilities in EU Policy, CEPS, Brussels, July 2005; M. Anderson and $J$. Apap (2002), Striking a Balance between Freedom, Security and Justice in an Enlarged European Union, CEPS, Brussels. 
cooperation over these domains, but have also provoked the rise of an altemative supranational framework covering the normative usage of integration in addition to the one already presented by EU immigration law. Differing from the EU legal system developed under the Title IV TEC and the European immigration law (EU hard-law approach), the EU Framework for the Integration (EU soft-law/policy approach) constitutes a peculiar ingredient of the common immigration policy, and presents a number of characteristics that avoid the classic configurations of the EU legal system and the Community method of cooperation.

\subsection{The Birth of the Dual Framing on Integration in EU Law and Policy}

\subsubsection{A Common Immigration Policy}

The first indication by the European Commission on how it intended to translate the Tampere milestones into concrete actions took the form of the Communication on a Community Immigration Policy COM(2000)757 of 22 November 2000. ${ }^{141}$ Even though the main focus of this act was immigration, ${ }^{142}$ the Commission also justified dealing with the integration of TCNS by stating that the two dimensions are intrinsically intertwined. In this way it paid attention to integration policy within the context of the "fair treatment of third country nationals and the promotion of diversity". The Commission also assumed an ambitious position by stating the need to improve coordination between Member States in this and other related fields. While recognising that "integration is primarily the role of the Member States", it emphasised the importance of civil society's role, especially at the local level "where integration measures must be implemented". ${ }^{43}$ In this regard, the Commission proposed the establishment of micro-level actions based on partmerships between the different actors involved, and comprising, for example, local and regional authorities, police, media, social partners, NGOs, migrants themselves and their associations, etc., which, the argument continued, "each has a part to say in the design and implementation of integration programmes". It was argued that

Such a horizontal approach requires co-ordination at national and local level and the EU could contribute by developing a pedagogical strategy, promoting the exchange of information and good practice, especially at local level and the development of guidelines or common standards for integration measures.

It thus called for a "Community Action Programme" in order to promote the integration which could aim

at improving the understanding of the issues concerned through the evaluation of practices, developing benchmarks and orher indicators promoting dialogue between the actors concemed and supporting European networks and the promotion of awareness activities. (Emphasis added. $)^{1 \text { ta }}$

141 Commission Communication, on a Community Immigration Policy COM (2000) 757, 22.11.2000.

142 For instance the European Commission stated that in order to meet the Tampere Scoreboard it was going to present a number of legislative proposals intending to "establish a coherent legal framework which will take into accoun concepts which have already been successfully applied in the Member States. The framework would determine the basic conditions and procedures to be applied whilst leaving it ip to each Member State to adopt national measures on the admission of third commy nationals based on the criteria set out in the Directives", see point 3.4.2.

143 See also page 20 of the Communication.

144 Page 20 of the Communication. 
The way in which integration was treated followed the milestones and principles put forward by the Tampere Programme. The Commission identified as a priority "to ensure fair treatment of third country nationals legally on the territory of the Member States through an integration policy aimed at granting them rights and obligations comparable to those of EU citizens". ${ }^{45}$ It was also pointed out that "successful integration policies" should start "as soon as possible after admission" and that "settlement packages" could be offered to all new TCNs tailored to their needs and comprising for instance language training, information on political and social structures, accessing services, etc. ${ }^{146}$ Further, the Communication also expressly confirmed that "integration is a two-way process involving adaptation on the part of both the immigrant and the host society", and was conceived as an essential element to create "a welcoming society". Point 3.5 of the Communication, entitled "Integration of Third Country Nationals", emphasised that

The European Union is by its very nature a pluralistic society enriched by a variety of cultural and social taditions, which will in the future become even more diverse. There must therefore be respect for cultural and social differences but also of our fundamental shared principles and values: respect for human rights and human dignity, appreciation of the value of pluralism and the recognition that membership of society is based on a series of rights but brings with it a mumber of responsibilities for all of its members be they nationals or migrants. The provision of equality with respect to conditions of work and access to services, together with the granting of civic and political rights to longer-term migrant residents brings with it such responsibilities and promotes integration. (Emphasis added.)

In many respects the understanding of integration articulated by the European Commission in this measure conformed to its previous legal instruments. An interesting new development in comparison to past responses, however, was that of the conception of immigrant obligations, which was somehow widened by referring not only to her/his need to fulfil them in relation to "the lifestyle" of the receiving society, but also to the necessity to adapt to "our fundamental shared principles and values". 177 The Communication confirmed in this manner another consistent feature in the European approach(es) on integration, which is a lack of recognition of the huge asymmetry in the status of the parties involved as regards who has the greater onus concerning the duties, responsibilities and obligations. This onus becomes greater when referring to principles and values whose understanding and content is far from being unanimous in a diverse and enlarged EU.

Finally, another innovative aspect presented by the Communication COM(2000)757 was the introduction of the concept of civic citizenship, inspired by Article 45.2 of the Charter of Fundamental Rights of the European Union. ${ }^{188}$ This legal status would comprise "a common set of rights and obligations" which TCNs would acquire gradually over a period of legal residence

145 It was stated that "an EU immigration policy must, therefore, incorporate steps to ensure that migrants benefit from comparable living and working conditions to those of nationals".

146 See page 20.

147 In point 3.5. ("Integration of Third Country Nationals") the Communication stated that "There must therefore be respect for culural and social differences but also of our fundamental shared principles and values: respect for human rights and human dignity, appreciation of the value of pluralism and the recognition that membership of society is based on a series of rights but brings with it a number of responsibilities for all of its members be they nationals or migrants", page 19.

148 Article 45.2 of the Charter says "Freedom of movement and residence may be granted, in accordance with the Treaty establishing the European Community, to nationals of third countries legally residents in the territory of a Member State". Chanter of Fundamental Rights of the European Union, Of $2000 / C$ $364 / 1,18.12 .2000$. 
without the need to be naturalised. ${ }^{149}$ In fact, the proposal to foster integration via the recognition of civic citizenship was later supported by the EESC in its Opinion on Immigration, Integration and the Role of Civil Society Organizations of 21 March 2002. ${ }^{150}$ Here, the EESC argued for the development of a concept of integration conceived as civic integration that would be based on 'bringing immigrants' rights and duties, as well as access to goods, services and means of civic participation progressively into line with those of the rest of the population, under conditions of equal opportunities and treatment". It considered that the main factor for integration should be the concept of citizenship, and not so much culturally related aspects. ${ }^{151}$ The EESC also signalled that those immigrants living on a stable basis in the EU should be treated "in the same way" and be recognised as having "the same rights and duties" at EU level as Member State nationals. In this light, it was argued, civic citizenship could represent a possible way of conferring European citizenship upon long-term residents. ${ }^{152}$

\subsubsection{An Open Method of Coordination}

The Communication COM(2000)757 was accompanied by another one, bearing the title Open Method of Coordination for the Community Immigration Policy COM(2001) 387 of July 2001. ${ }^{153}$ Here, the European Commission recognised that the development of a common immigration policy required the adoption of a coordinating method following the one already applied in the context of the European Employment Strategy, ${ }^{154}$ and which received the name of

149 B. Perchinig (2006), "EU Citizenship and the Status of Third Country Nationals", in R. Bauböck (ed.), Migration and Cinizenship: Legal Stans. Rights and Political Participation, IMISCOE Reports, Amsterdam: Amsterdam University Press, pp. 67-82.

While the role of the EESC is merely consultative, it has been one of the more active actors at EU level in the field of immigration and integration of immigrants. See EESC, Opinion on Immigration, Integration and the Role of Civil Society Organisations, SOC/075, Brussels, 21 March 2002, rapporteur: Mr. Pariza Castaños.

Paragraph 1.5 reads as follows: "Cultural diversity will be approached in a different way in each country, in accordance with the model in use, but this must not impact upon the principle of equality of rights and duties. In other words, whatever immigrants' cultural patterns may be, they do not detract from their status as persons who must have the same rights and duties as everyone else".

See point 5.6 of the Opinion when it says that "'Civic citizenship', based on the Charter of fundamental rights, as proposed by the Commission in its communication of November 2000 on a Community immigration policy, is one possible means of bringing European citizenship closer to long-term residents, but cannot become effective because the Treaty does not provide an adequate legal basis".

Commission Communication, on a Open Method of Coordination for the Community Immigration Policy, COM(2001)387, Brussels, 11.7.2001.

This method of cooperation was first initiated by the Luxembourg jobs summit in November 1997 , which created the so-called "Luxembourg Process". See European Commission, Joint Employment Report 2000, COM(2000)551, Brussels, September 2000. It is worth recalling however that while a version of this method was already applied since the mid-1990s in the scope of the European Monetary Union (EMU), the actual label of OMC made only its first appearance at the Lisbon Presidency Conclusions of 23 and 24 March 2000. The Lisbon Strategy identified as a new strategic goal for the Union to reach "a greater social cohesion." This strategy would specifically aim at modernizing "the European social model, investing in people and combating social exclusion", and its implementation would be facilitated by the application of a new open method of coordination "as the means of spreading best practice and achieving greater convergence towards the main EU goals". For an analysis of the origins of the $\mathrm{OMC}$, and a comparison between its implementation in the fields of employment and social inclusion areas see C. de la Porte (2002), "Is the Open Method of Coordination Appropriate for 
an Open Method of Coordination (OMC). ${ }^{155}$ In the Commission's view, "while the Member States remain responsible for a number of significant issues with respect to the admission of economic migrants and for developing and implementing integration policy", "56 the OMC would be complementary to the enactment of the ordinary legislative framework, and its implementation would be the most appropriate way to stimulate the gradual development of common responses through coordination and experimentation of national policies. ${ }^{157}$ Further, the Commission would support the OMC by proposing initiatives for "European guidelines, ensuring coordination of national policies, exchange of best practice and evaluation of the impact of the Community policy". 158 The OMC would foster discussion on migration-related issues with the aim of promoting the progressive convergence of national policies and practices, and in the long-term lead to the establishment of common standards and harmonised objectives.

How would the OMC work in practice? The proposed system would be based on the production by the Council of "Multi-annual Guidelines for the Union" that would be accompanied by specific timetables for the achievement of a set of common goals. These guidelines would be implemented by the Member States in National Action Plans (NAPs). The NAPs would include two sections: ${ }^{150} \mathrm{~A}$ first section offering statistics on TCNs, information on cooperation between different authorities, social partners, NGOs and migrants' organisations, information on the interaction of parallel legislative measures on migration, resources used and "interesting experiences and good practices", problems encountered as well as information on the implementation of EU Directives. The second section of the Plans would provide the actions that they would like to take at national, local and regional levels for the implementation of the guidelines for the next phase. The NAPs would then be subject to an evaluation (peer review) and adaptation on an annual basis. The European Commission would come into the picture by preparing synthesis reports on common problems and concerns, and would also identify those fields where common "European solutions" would be needed. This would then facilitate the presentation of EU legislation following an identified line of action.

Organising Activities at European Level in Sensitive Policy Areas?', European Law Joumal, Vol. 8, No. 1, March 2002, pp. 38-58.

The literature on the origins of the OMC and its current application to different EU policies has been extensive. For a 'state of the art' see V. Hatzopoulos (2007), 'Why the Open Method of Coordination is Bad for You: A Letter to the EU', European Law Journal, Vol. 13, No. 3, May 2007, pp. 309-342; Refer also to J. Niessen (2002), 'Consultations on Immigration Policies', European Journal of Migration and Law, Vol. 4, No. 1, pp. 79-83; and J. Niessen (2000), The Management and Managers of Immigration, Migration Policy Group, Brussels, where a clear proposal was made about the applicability of the cooperation under 'the Luxembourg Process' 10 immigration policy, which included the annual adoption of guidelines for the member states' employment policies, recommendations for their implementation in the national arena, the elaboration of national Action Plans for Employment by the Member States and the production of a joint employment report.

See page 5 of the Communication.

157 For a critical analysis of the OMC in the context of immigration see S. Velluti (2007), 'What European Strategy for Integrating Migrants? The Role of the OMC Soft Mechanisms in the Development of an EU Immigration Policy', European Journal of Migration and Lan', Vol. 9, No. 1, pp. 53-82; A. Caviedes (2004), 'The Open Method of Coordination in Immigration Policy: A Tool for Prying Open Fortress Europe', Journal of European Public Policy, 11:2, April 2004, pp. 289-310; B. Bogusz (2004), "Modes of Govemance for an EU Immigration Policy - What Role for the Open Method of Coordination", in B. Bogusz, R. Cholewinski, A. Cygan and E. Szyszczak (eds), Imegular Migration and Human Rights: Theoretical, European and International Perspectives, Martinus Nihjoff: Leiden.

159 Refer to Point 4.1 of the Communication, page 12. 
According to the Communication, the Commission would play a central role in the actual workability of the $\mathrm{OMC}$ on immigration. Therefore, in addition to putting forward legislative proposals on the bases of the Amsterdam Treaty and the Tampere Programme, and monitoring their practical implementation to ensure 'consistency', it would also prepare initiatives for European guidelines and the promotion of cooperation, exchange of information and best practices, and evaluation and monitoring. ${ }^{160}$ This would be accompanied by wide consultation, and even the establishment of "committees and working groups", with senior officials, experts, social partners, local and regional authorities, etc. While it was stated that the role of other European institutions in the OMC, such as the European Parliament, EESC and the Committee of Regions, would be very important and that they should be "closely involved", the Communication did not specify which functions they would perform in practice. ${ }^{161}$ 'The Commission would also establish measures to commence a dialogue with civil society at the European level. ${ }^{162}$ Finally, the Communication identified as "Supporting Measures" that

... a broader programme is necessary to facilitate the exchange of information and best practice among the wide range of authorities and organisations involved, in particular with respect to the integration of third county nationals, and to provide support for actions designed to test and develop European objectives with respect to immigration policy. It intends, therefore...to put forward proposals for a specific Commmity Action Programme...The objective will be to support legislation and policy development within a European framework through the improving of knowledge, the strengthening of the capacity of all the actors involved and the raising of awareness with respect to integration strategies. (Emphasis added.)

Indeed, one of the most important fields identified by the European Commission for the OMC to apply was the integration of TCNs. The Guideline no. 6, entitled "Ensuring the development of integration policies for third country nationals residing legally on the territories of the Member States", 163 referred to the development of "common and comprehensive" policies by;

1. Setting up a framework ensuring the involvement of local and regional actors, social partners, civil society and migrants themselves in the development and implementation of national strategies;

160 Point 4.2 on "Developing and Evaluating the Community Immigration Policy", pages 13-14.

161 Point 4.3 of the Communication stated that "In view of the multi-dimensional aspects of migration policy, the European Parliament, the Economic and Social Committee and the Committee of the Regions should be closely involved with the development and implementation of the Community immigration policy. The Commission will also present to the institutions the ammual migration report including the European immigration guidelines. Further consideration should be given, in consultation with the institutions themselves, to the most effective ways in which they can be associated in the coordination mechanism at the European level so that they can make their full contribution".

162 Point 4.4 says that "The active involvement of politicians, the social partners, of regional and local actors and other relevant organisations, such as non-governmental organisations and associations of migrants as stakeholders and of the media, at both national and European levels, is essemial to the success of the policy and to the achievement of the goals set out in the guidelines".

163 In particular the Communication presented the following six: Guideline 1: Developing a comprehensive and coordinated approach to migration management at national level; Guideline 2: Improving information available on legal possibilities for admission to the EU and on the consequences of using illegal channels; Guideline 3: Reinforcing the fight against illegal immigration, smuggling and trafficking by supporting the following measures; Guideline 4: Establishing a coherent and transparent policy and procedures for opening the labour market to third country nationals within the framework of the European employment strategy; Guideline 5: Integrating migration issues into relations with third countries, and in particular with countries of origin; and Guideline 6: Ensuring the development of integration policies for third country nationals residing legally on the territories of the Member States. 
2. Promoting integration through information and awareness campaigns;

3. Developing instruments targeting women and second generation migrants;

4. Developing "settlement programmes" for 'new migrants' and their families, which would include language training, information on the cultural, political and social characteristics of the country, "including the nature of citizenship and of the fundamental European values";

5. Developing measures supporting victims of human trafficking and smuggling; and

6. Exploring the validity of the concept of "civic citizenship". 164

This Communication provides yet another illustrative example of the difficulties encountered by the European Commission when trying to develop the objectives enshrined in the Tampere Programme. Member States were still not ready to embark on such a European journey toward the coordination of policies as sensitive as "the management of migration flows" and "admission of economic migrants". In fact, the Communication was never formally discussed inside the Council. Notwithstanding that in the area of immigration the OMC has therefore been absent, it has been implemented in other related fields such as for instance that of social protection and inclusion. ${ }^{165}$ Furthermore, as we will examine in the next Chapter, an 'alternative' version of the OMC proposed in 2001 by the Commission does currently apply to the European policy on the integration, and has materialised in the EU Framework on Integration.

\section{Conclusion}

This Chapter has provided a genealogy of the changing dynamics affecting the normativity of integration in EU law and policy since the 1970s until the phase posterior to the entry into force of the Amsterdam Treaty. We have identified a series of constant factors and distinctive features constituting some of the most relevant classical denominators of the 'European approach(es)' embracing the category of integration. Further, European cooperation on integration has been characterized by a prominent intergovernmental method cooperation and the use of soft-law instruments. While the transfer to Community competence of the field of immigration was expected to provide a response to the weaknessess inherent to these procedural and substantive legal techniques through the use of EU law and the Community method of cooperation, this transformation has proved to be difficult to materialize. In fact, the aftermath of the Communications (2000)757 and (2001)387 might be identified as the official point of departure of the dual legal and policy contextualisation of the domain of integration. Since then the Commission, with the support of the Council and other European institutions and supranational actors, started developing the European law on regular immigration and the EU Framework on Integration through different tools, structures and patterns of cooperation. These two dimensions differ in status and location within the common immigration policy and the EU legal system.

164 In this respect it was stated that "Exploring the validity of the concept of civic citizenship by identifying the rights and responsibilities, which would ensure the fair treatment of third country nationals legally residen in the Member State concemed".

165 E. Szysczak (2006), 'Experimental Governance: The Open Method of Coordination', European Law Joumal, Vol. 12, No. 4, pp. 486-94. Szyszczak (2006) has argued that there are at present 13 OMCs in place, which are structured in four different categories: First, developed areas (including a legal basis in the Treaty, such as the EES and the Broad Economic Policy Guidelines); Second, adjunct areas (social protection and social inclusion, pensions, health care); Third, nascent areas (innovation and research, education, immigration, environment, etc); and Fourth unacknowledged ones (tax). 
The mechanisms, players and institutional structures surrounding the normativity of integration in each of them vary greatly. We will leave the analysis of the relationship between integration and EU immigration law to Chapter 4. The next Chapter studies the origins, scope and implications of the EU Framework on Integration. 



\section{Chapter 3:}

\section{The EU Framework on Integration}

The integration of TCNs has been subject to multifaceted policy processes since the transfer of immigration to EU competence in 1999. While the domain of integration has been considered a strategic priority for the AFSJ and the establishment of a common EU immigration policy, the principle of subsidiarity has so far prevailed. The Member States have conceived it as one of those areas falling at the heart of national sovereignty and their exclusive competence. This intergovernmental logic has led to the emergence of an altemative policy framework aiming at fostering policy convergence through means different from those already provided by the traditional Community method of cooperation. The EU Framework on Integration makes now use of a set of non-legislative modes of policy-making and soft-law governance techniques based on knowledge sharing, policy coordination and the exchange of information, and which include benchmarking and indicators as central tools.

Since the end of 2002 the EU Framework on Integration has been slowly but progressively developed, and is now composed by a considerable number of substantive and institutional mechanisms including a set of Common Basic Principles for Immigration Integration Policy (CBPs), two Handbooks on Integration for policy-makers and practitioners, three Annual Reports on Migration and Integration, the setting up of the National Contact Points on Integration and the upcoming European Integration Forum, an Integration Website as well as a European Integration Fund. The common Framework constitutes an innovative multilevel setting of governmentality in the field of integration of TCNs at EU level comprising the interaction of a package of non-coercive regulatory tools and diversified supranational networks which have given birth to a quasi-Open Method of Coordination (OMC). In this context, benchmarking has been presented as a policy priority.

This Chapter starts by assessing the origins, scope and implications of the EU Framework on Integration. It addresses the ways in which the tools, networks and structures composing it have been constructed until the consolidation of this sui generis legal and policy transnational infrastructure. While doing so it continues mapping the references to integration of TCNs in EU policy, and assessing the evolution of the meanings and approaches attributed to this category. Indeed, the features characterizing the nomative understandings of integration have been particularly dynamic and prolific in the context of the EU Framework on Integration. The Second part of the Chapter examines the conceptual premises and practical methodologies through which attempts of benchmarking integration of TCNs at EU level are being conducted, and assesses the current deficits from which this technique currently suffers.

\section{The EU Framework on Integration: Origins, Concepts, Tools and Structures}

\subsection{The Emerging European Integration Strategy}

The meeting of the Justice and Home Affairs Council of 14 and 15 October 2002 addressed the topic of integration of TCNs with a legal stay in the Member States and represented the first occasion where the Council decided to boost the establishment of an EU Framework on Integration. ${ }^{166}$ The Council attached great importance to the promotion of the exchange of

166 Council of the EU, Justice and Home Affairs and Civil Protection, Council meeting 2455, 12894/02, Luxembourg, 14-15 October 2002. 
information of national experiences and policies, which could lead to the establishment of "best practices" regarding the integration of TCNs. Therefore, it called for the establishment of national contact points in the Member States to foster cooperation between the national authorities in charge of the integration dossier in the national arena. The Council considered integration as an "important element in the establishment of a European asylum and immigration policy, which could include integration requirements". In light of this, the term "integration requirements" was for the first time brought into the European policy discourse. Further, it was emphasised that "newly arrived' TCNs should have access to information "on their host society" and language courses in accordance with national law. ${ }^{167}$ The implications of the general conclusions agreed to in this JHA Council meeting had major implications for the future of the European strategy on integration. They can be seen as the official green light coming from the Council for the European Commission to start building a common framework of cooperation.

One of the first outcomes of these Conclusions was the establishment of the European network of National Contact Points on Integration (NCPI). Following the Council's appeal, the European Commission created this transnational forum comprised of experts from national administrations responsible for the integration of TCNs and which includes, depending on each Member State, representatives from Ministries of Interior, ${ }^{168}$ Ministries of Labour and Social Affairs, ${ }^{169}$ Ministries of Integration, ${ }^{170}$ etc. In March 2003 the first meeting of the NCPI took place in Brussels, and since then the tasks of the network have become more consolidated as regards the exchange of information and experiences, monitoring progress across related policies, as well as towards the strengthening of coordination in relation to relevant policies at the national and EU levels and ensuring that efforts at both levels are mutually reinforcing. They have been actively involved in the elaboration of the most relevant policy tools of the EU Framework on Integration. For instance, the exchange of information has materialised in the publication of two Handbooks on Integration. They have also contributed to the elaboration of the three editions of the European Commission's Annual Reports on Migration and Integration, all of which are analysed in detail below. The network, chaired by DG JFS of the European Commission, now includes the participation of all Member States, including the UK, Ireland and Denmark, and plays a decisive role in the developments and future prospects of the Framework on integration.

167 Paragraph 8 stipulated that "The Council stresses that newly atrived immigrants should have quick and appropriate access to information on their host society and language courses should be established in accordance with national law". In paragraph 9 it was stated that "The Council also finds it important that national systems encourage an active participation of third country nationals in community life and on the labour market in accordance with national law. Integration policies of Member States imply concented action by governments, regional and local authorities, migrant and non-govermmental organisations, the social partmers and civil society".

Among others, Austria, Cypnis, Germany, Italy, Slovakia, Slovenia, United Kingdom (Home Office), Romania (Ministry of Administration and Interior).

Such as, Finland, Poland, Spain, Lithuania and Bulgaria.

170 For instance, Denmark, Belgium (Cabinet for Minister for Public Office, Social Integration, Big Cities' Policy and Equal Opportunities), France, Latvia, Estonia, Luxembourg, the Netherlands (Ministry of Justice), Sweden (Ministry of Justice), Ireland (Reception and Integration Agency), and Hungary (Ministry of Justice and Law Enforcement). 


\subsection{A Common European Framework and the Linkage between Immigration, Integration and Employment}

On 9-10 September 2002 the EESC hosted a conference, in cooperation with the European Commission, on "Immigration: Civil society's role in the promotion of integration". The aim of this event was to place integration at the centre of European immigration policy and to strengthen the role of civil society and social partners in that process. One of the main general conclusions of the conference was a proposal for "a European programme for the integration of immigrants and refugees". 171 This was reiterated in an EESC Opinion on Immigration, Integration and the Role of Civil Society Organisations of March 2002, ${ }^{172}$ which called for

A Community framework programme to promote the social integration of immigrants and refugees. The programme should spur the other institutions to step up their integration policies at all levels. The framework programme must be actively backed by civil society organisations and the European Economic and Social Committee can play an important role here. ${ }^{173}$

On the basis of the Tampere milestones, the Council Conclusions of October 2002, ${ }^{174}$ and following discussions facilitated by the EESC in this event, the Commission presented a Communication on Immigration, Integration and Employment, COM(2003)336 on 3 June 2003, jointly drafted by DG Employment, Social Affairs and Equal Opportunities and DG JFS. ${ }^{175}$ The Commission called for a "more coherent European framework for integration" which would reinforce "policy coordination". 176 As regards to the meanings and functions that integration played inside this Communication, after emphasising the relationship between the EU principle of fair and near-equality and "a more vigorous integration policy", the following understanding of integration was provided:

171 Conference "Immigration: The Role of Civil Society in Promoting Integration", Brussels, 9 and 10 September 2002. The Conclusions of the Conference were attached in an Appendix of the EESC Opinion on the Commission Communication on Immigration, Integration and Employment, 1613/2003, SOC/138, 10 December 2003. It was stated that "The European Union and its Member States should foster the integration of immigrants, minorities and refugees, particularly at regional and local level. A European programme to advance integration is needed. The social partners and civil society organisations have a key role to play in integration [...] The conference has brought together civil society and the European institutions, and the EESC has acted as a form for this encounter. The EESC will continue to promote ties with the social partners and civil society organisations, the aim being for the future common immigtation and asylum policy to meet in full the undertakings made at the Tampere Council, and to reflect the conclusions of this conference".

172 EESC, Opinion on Immigration, Integration and the Role of Civil Society Organisations, SOC1075, Brussels, 21 March 2002, rapporteur: Mr. Pariza Castanos.

173 Point 3.6.1

174 Paragraph 13 of the JHA Council Conclusions of October 2002 had said that "The Council notes with interest that the Commission is intending to issue a communication on the integration of third country nationals legally staying in Member States. Such a communication could form the basis of further Council deliberations on this topic".

175 Communication from the Commission to the Council and the European Parliament, on immigration, integration and employment, COM(2003) 336, 3 June 2003, Brussels. See also European Commission, Commission Staff Working Paper, Extended Impact Assessment on the Communication on Immigration, Integration and Employment, SEC(2003) 694, Brussels, 3.6.2003.

176 In point 4.2 the Commission called for two concrete policy proposals: 1 . The elaboration of an annual report on the development of a common immigration policy, and 2. the strengthening of the coordination of integration policies via exchange of information and cooperation under the umbrella of the group of mational contacts points on integration. 
Integration should be understood as a wo-way process based on mutual rights and corresponding obligations of legally resident third country nationals and the host society which provides for full participation of the immigrant. This implies on the one hand that it is the responsibility of the host society to ensure that the formal rights of immigrants are in place in such a way that the individual has the possibility of participating in economic, social, cultural and civic life and on the other, that immigrams respect the fundamental norms and values of the host society and participate actively in the integration process, withoul having 10 relinquish their own identity. (Emphasis added.)

The definition hereby provided intended to compile some of the principles and approaches that, as shown in the previous Chapter, traditionally rooted the European approach(es) on integration. This understanding, however, presented other features that further developed the two-way process tenet and the meanings of "responsibilities". It was considered that the responsibility of the receiving society was to guarantee a secure legal status composed of a formal set of rights providing access to all societal dimensions. The Communication then once again added to the immigrant's obligations by referring to the duty of the latter to respect "the norms and values of the host society, and participate actively" towards that endeavour. Further, the Commission advocated for an incremental approach which would involve the development of 'the balance' of rights and obligations over time, and therefore the longer the legal residence the more rights would be conferred upon TCNs. The Communication identified the need for a "holistic approach" which would take into consideration "not only the economic and social aspects of integration, but also issues related to cultural and religious diversity, citizenship, participation and political rights". ${ }^{177}$ A last element was the link instituted between integration and the dimension of employment. Immigration and integration were understood as part of the solution for dealing with the economic and demographic challenges that Europe was considered to be facing. 178

Taking political momentum into account, the Greek presidency of the Council officially recognised the need to develop a common policy framework on the integration of legally resident TCNs. ${ }^{179}$ The European Council at Thessaloniki of June 2003 called for the development of a comprehensive and multidimensional policy on integration that would focus

177 The key elements identified by the Communication for "holistic integration policies" were: integration in the labour market, education and language skills, housing and urban issues, health and social services, the social and cultural enviromment, nationality, civic citizenship and respect for diversity.

178 W. Kok (2004), Facing the Challenge: The Lisbon Strategy for Growh and Employment, Office for Official Publications of the EC: Luxembourg,

179 It needs to be stressed the influence played by the so-called 'Athens Migration Policy Initiative' (AMPI), a group of leading experts and academics who advised the Greek Government on migration matters during its 2003 Presidency of the EU. AMPI was originally launched as a joint initiative between the Migration Policy Institute in Washington and the Greek Ministry of Foreign Affairs. It gave priority to the development of an EU harmonized approach on integrating legal immigrants. An international conference was organized in Athens on the 15 and 16 May 2003 which received the titled of "Managing Migration for the Benefit of Europe" and that was sponsored by the Greek Presidency of the EU. See the Summary Report of the Athens Capstone Conference and the package of Policy Briefs which were prepared for the occasion at www.migrationpolicy.org/AMPI; See in particular R. Penninx (2003), Immigration without Integration: A Recipe for-Disaster, Policy Brief, Summary Report of the Athens Capstone Conference, pp.60-64, retrievable from www migrationpolicy.org/AMPI; Ray, B. (2003), The Policy Challenges of Imervention in Local and Private Imegration Processes, Policy Brief, Summary Report of the Athens Capstone Conference, pp. 64-68, retrievable from www migrationpolicy.org/AMPI; and S. Spencer (2003), The Challenges of Integration for the European Union, Policy Brief, Summary Report of the Athens Capstone Conference, pp. 68-72, retrievable from www.migrationpolicy.org/AMPI 
on granting to TCNs rights and obligations 'comparable' to EU citizens. ${ }^{180}$ The Council followed some of the directions already established by the Commission Communication $\operatorname{COM}(2003) 336$, such as the importance to develop an EU integration policy in order to efficiently deal with "the new economic and demographic challenges that the EU is now facing". It recognised the two-way process tenet as an important feature of integration, and confirmed that, while primary responsibility rests with the Member States, integration policies should be developed within a coherent EU framework. In light of this and in order to facilitate that framework, it proposed the development of a set of "common basic principles for integration of immigrants". "These Conclusions constituted irrefutable evidence that integration had reached the EU's official agenda, ${ }^{182}$ and involved a strong political message from the Council to advance European cooperation on integration of TCNs.

In 2003 the EP issued two Reports dealing with the domain of integration of TCNs: A first Report was adopted on 16 June 2003 conceming the Commission Communication on an open method of coordination for the common immigration policy, where the EP called on the Council to take an official position on the OMC "at the earliest opportunity". 183 The EP welcomed the Commission's proposal, ${ }^{184}$ and called on the Commission to ensure that detailed and practical action is taken on integration policy by "determining which Community programmes may be used to develop the integration policy and guaranteeing the exchange of information and good practices between Member States". "It was equally stressed that the EP should be involved in the definition of the constitutive elements of the OMC in connection with the guidelines put forward by the Commission in 2001. It continued by saying that an OMC of national policies could not

...under any circumstances take the place of the legislative initiatives called for, and that the method could prove difficult to introduce if it were to be misused for the purpose of further delaying the legislative process or concealing the fact that deadlock has been reached.

It is also important to highlight Paragraph 32 of the Report which stated that

180 Thessaloniki European Council, 19-20 June 2003, Presidency Conclusions, 11638/03, Brussels. See specifically paragraphs 28-35, "The development of a policy at European Union level on the integration of third-country nationals legally residing in the territory of the European Union".

181 Paragraph 31 of the Council Conclusions stated that "Integration policies should be understood as a continuous, two-way process based on mutual rights and corresponding obligations of legally residing third-country nationals and the host societies. While primary responsibility for their elaboration and implementation remains with the Member States, such policies should be developed within a coherent European Union framework, taking into account the legal, political, economic, social and cultural diversity of Member States. In order to intensify the development of such a framework, the definition of common basic principles should be envisaged".

H. Urth (2005), 'Building a Momentum for the Integration of Third-Country Nationals in the European Union', European Journal of Migration and Law, Vol. 7, No. 2, pp. 163-180.

183 European Parliament, Report on the Commission Communication on an open method of coordination for the Community immigration policy, COM(2001)387 - C5-0337/2002 - 2002/2181(COS), A5. 0224/2003, 16 June 2003, Rapporteur: Anna Terrón i Cusi.

184 See Paragraph 4 of the Report which stipulates that "Welcomes the Commission's proposal to put in place: - national action plans providing statistics on the numbers and situation of third country nationals admitted, by category; - information on periodic guidelines, objectives and timetable; - information on the impact of the measures adopted and their interaction with legal and illegal flows; - information on the hidden labour market, its impact on national economic activity and the presence of immigrants on this market; - projections of demand for immigrant labour, as set out in the action plans for employment; cooperation experiments set up in conjunction with regional and local authorities and civil society". 
...Member States should not misuse integration policy as a way of rendering immigration impossible in practice; calls on Member States not to impose integration tests and language requirements which immigrants are required to comply with before they enter a Member State (Emphasis added.)

The EP identified five features as the ones that should constitute any "active policy on integration": First, establishing clear rules governing the legal status of TCNs residents and their right to good administration; second, allowing for proper integration in the labour market; third, guaranteeing tuition for learning the national language or languages and access to education; fourth, guaranteeing access to social and health services; fifth, working to ensure dignified living conditions in cities and neighbourhoods. Finally, the report endorsed the idea advocated by the European Commission and the EESC of creating a status of civic citizenship "enabling third country nationals legally resident in the European Union to enjoy a status conferring on them economic, social and political rights and duties, including the right to vote in local and European elections". 186

The second Report by the EP focused on the Communication on immigration, integration and employment and was adopted on 1 December 2003. ${ }^{187}$ Here the EP stressed that "the integration of new migrants, established third country nationals and EU citizens of ethnic minority origin is becoming a key factor for social cohesion", and "is one element of achieving social inclusion, for the benefit of the individuals concerned as well as local communities and wider society". It also argued that while labour market issues were highly relevant,

...integration also depends on a range of other factors including the social contexl, education and language skills, civic participation, the involvement of civil society and the social partners, effective implementation of EU funding programmes to tackle labour market disadvantage... as well as the legal framework... ${ }^{188}$

The Report identified a wide personal scope as regards those who "require different policies on integration", and expressed that this should be taken into account in policy-making. In particular, it stated that integration would not only cover newly arrived migrants, but also TCNs who are long-term residents and 'third generation migrants'. ${ }^{189}$ Further, language skills were considered to be one of the key factors promoting integration, "since such skills facilitate the structuring of thoughts, the ability to be autonomous, a better understanding of society and the way in which it is organized and the development and improvement of the interpersonal abilities that foster social cohesion". 190 Along with a version of the two-way process principle, ${ }^{191}$ the Report restated the same five features highlighted by the previous EP Repont of June 2003 as the ones constituting any "active policy on integration". Yet, it added another constitutive element consisting of the need to ensure that immigrants can participate in social, cultural and political life, and reformulated the one dealing with language in the following manner:

\footnotetext{
186 Paragraph 29 of the Report.

187 European Parliament, Report on the Communication from the Commission on Immigration, Integration and Employment, 2003/2147(INI), A5-0445/2003, I December 2003, Rapporteur: Claude Moraes.

188 Paragraph K.2 of the Report.

189 Paragraph K.3.

190 Paragraph K.4.

191 It was said in Paragraph 17 that "...integration is a matter for society as a whole, and that efforts are needed both from migrants and from indigenous populations in order to achieve genuine social cohesion".
} 
- The duty of the resident to follow courses in the national language or languages provided by the host country and the right of access to education... (Emphasis added.) ${ }^{192}$

The Report recommended the setting up of "integration programmes" that would cover all the constitutive elements for the initial reception of persons arriving in an EU Member State and "that provisions related to these areas in the field of integration policy for second and third generation immigrants should be reviewed in order to align them with the objectives set out in this resolution".

Before continuing in our process of offering a genealogy of the constructed category integration in the context of the EU Framework on Integration, it is worth underlying here that it was during the last phase of 2003 that the two Council Directives on the right to family reunification $2003 / 86$ and on the status of third country nationals who are long-term residents 2003/109 (EU law on regular immigration) were adopted by the Council. We refer in this regard to Chapter 4 of this book, which offers a detailed study of these Directives as well as the perspectives and approaches underlying integration in their respective provisions. As we will argue, the adoption of these two measures introduced a new functionality of integration in EU law and policy, i.e. that of integration as a 'condition' or a 'measure'.

\subsection{The First Annual Report on Migration and Integration}

The Thessaloniki Conclusions invited the European Commission to present an "Annual Report on Immigration and Integration in Europe". 193 The Commission presented the First Annual Report on Migration and Integration in the form of Communication COM(2004)508 on I6 July $2004{ }^{194}$ It aimed at providing a review of the development of a common immigration policy in the EU and "to ensure that the needs of immigrants are properly streamlined in all EU policies affecting them and to inform the Council on progress made". The Report offered a broad overview of migration trends in Europe, and described policies on the admission and integration of TCNs both at the national and European levels. As regards the identification of any trends in national policies on integration, it was stated that

Overall, it is difficult to assess whether there has been progress in developing comprehensive integration strategies at national level. However, a number of Member States are in the process of developing specific integration courses or programmes targeted at immigrants and refugees and there is a growing understanding of the need to mainstream immigration aspects into all policies and to mobilise stakeholders through greater co-operation among national, regional and local authorities, as well as with civil society. (Emphasis added.)

It concluded that Member States were increasingly concerned as regards the integration of "the newly arrived", and in trying to ensure that TCNs "understand and respect the fundamental norms and values of the host society and with respect to language abilities", which, in view of the Annual Report, were major barriers to integration. Section 3 ("Overview and Broad Trends in National Policies in Integration") of the Annex attached to the Annual Report stated that

\section{Paragraph 24.}

193 Paragraph 33 provided that "In that respect the European Council invites the Commission to present an Annual Report on Migration and Integration in Europe, in order to map EU-wide migration data, immigration and integration policies and practices. This Report, which should contain an accurate and objective analysis of the above issues, will help develop and promote policy initiatives for more effective management of migration in Europe".

194 Commission Communication, First Amual Report on Migration and Integration, COM(2004)508, Brussels, 16.7.2004. 
"language tuition for newly arrived immigrants is gaining in importance", 195 and the provision of "civic education to new immigrants" was growing. The Commission also made reference to the difficulties raised by some Member States

...the increasing need for providing civic education or orientation to new immigrants, such as information about findamental rights and obligations, including equality of men and women, basic norms and the core values of the host society. Such efforts could be seen as an increased recognition of the need for developing and implementing a holistic approach to integration, which should include meastres to facilitate civic, cultural and political participation. (Emphasis added.)

The Commission stated the need for developing common policy instruments addressing integration in close connection with shared policies on admission. Furthermore, the concept of "mainstreaming" was highlighted by stating that comprehensive integration policies need to combine mainstreaming (defined as actively and openly taking into account immigrant issues in all relevant policies and measures at the EU and national levels) and "specific programmes". Finally, a call for more action was made in relation to: First, a more systematic and comparable collection of information at EU level; second, the further development of the exchange of information between the NCPI to ensure mainstreaming, the development of "good practices", that "efforts at national and EU level are mutually reinforcing", as well as to identify a number of priority areas and propose policy recommendations for European cooperation; ${ }^{196}$ third, the establishment of a common European framework within which national policies should be developed; and fourth, the definition of common basic principles.

\subsection{The First Handbook on Integration}

The Handbook on Integration for Policy Makers and Practitioners was elaborated by the Migration Policy Group (MPG) ${ }^{197}$ on behalf of the European Commission (DG JFS), and it was published in November 2004. ${ }^{198}$ The main objective of the Handbook was "to act as a driver for the exchange of information and best practices between the Member States". It was carried out in close cooperation with the NCPI and was based on the outcomes of three seminars in Copenhagen, Lisbon and London, respectively, which were organised by the Ministries in charge of the integration of TCNs in each of these three countries. The events included the participation of governmental and non-governmental policy-makers as well as practitioners, who exchanged information concerning three key issues: "introduction programmes", participation in

195 It stated that "Germany for instance is proposing 600 hours of language training in their anticipated national integration programme. At the same time the focus has increased in some countries on the responsibility of the immigrant to integrate and learn the language of the host society. In the Netherlands an increased responsibility on the newcomers for his or her integration is envisaged by placing the cost of the introduction programme on the newcomer and requiring an integration exam".

196 It was also stated that "The Commission will pay particular attention to monitoring the progress achieved by the Member States in the next National Action Plans for employment and those for social inclusion".

For information about the mission and activities of the MPG see htp://wurw.migpolgroup.com

J. Niessen and Y. Schibel (2004), Handbook on Integration for Policy-makers and Practitioners, DG Justice, Freedom and Security, European Commission, November. The Handbook on Integration for Policy-Makers and Practitioners was based on the conclusions of a number of seminars that were held in Copenhagen, Lisbon and London during 2004; See for example the concluding document from the first technical seminar on the introduction of newly arrived immigrants and refugees held in Copenhagen on 5-6 February 2004, Immigration and Asylum Committee, National Contact Points on Integration, March 2004, MIGRAPOL-Integration, 22 final. Retrievable from http://ec.europa.eu/justice_home/fsj/immigration/integration/fsj_immigration_integration_en.htm 
civic and political life and the development of indicators. The Handbook was therefore structured in three different Chapters dealing with each of these three domains. In addition to the outcomes of the seminars, the document explains the way in which the MPG (which issued discussion papers and drafted the conclusions of the seminars) and the NCPI (which offered examples of "best practices" and "promising initiatives of integration" from their own countries) also provided substantial input in the form and content of the final text.

The two kinds of integration programmes from which the Handbook draws, "best practices" and "lessons leamed", are the following: 1. the introduction of courses for newly arrived immigrants (Chapter one "Introduction of Newly Arrived Immigrants and Recognized Refugees"), and 2. civic participation (Chapter two). ${ }^{199}$ Further, Chapter three explored the use of indicators and benchmarks. It identified priority areas and best practices at the national level and presented a set of policy recommendations ${ }^{200}$ and general lines ("catalogue of inspiring ideas") on integration policies intended for policy-makers and practitioners.

The Handbook did not provide any concise definition of what integration means, but it did point out a number of key dimensions providing a working definition. ${ }^{201}$ It stated that the overall goal of integration is "self-sufficiency". The Handbook stated that "governments seek to enable immigrants to lead an independent life concerning housing, job, education, social networks and participation in society". Terms such as self-sufficiency and independence had not appeared in any previous EU-related official document dealing with this field. The influences exercised by some Member States' NCPI during the elaboration of this report were decisive in introducing this and other domestic elements among the meanings attributed by the Handbook to integration at the EU level. This supposition becomes evident when studying the content of the positions taken by some Member States during the negotiations of the Council Directives 2003/109 on the status of third country nationals who are long-term residents and 2003/86 on the right to family reunification in the Council, and the express reference that was made by some Member States to "self-sufficiency" of the TCNs as a desirable function of integration (Refer to Chapter 4 of this book). It also needs to be highlighted that the interpretation of the notions of independence or self-sufficiency can be subject to diverse considerations and connotations, some of which might position TCNs in an even more vulnerable status. One possible interpretation would justify a hands-off approach by the State and public authorities in terms of (not) offering a secure legal status guaranteeing equality of treatment at times of having access to for instance social benefits, or making TCNs financially responsible of her/his own integration programmes and courses.

In addition, reference was made to the conception of integration as a two-way process paradigm calling also for action as regards "the attitudes of the recipient societies, and their citizens". The Handbook also links the achievement of positive outcomes for TCNs when acceding to, or being included in, different societal domains (such as employment, housing, education, health, etc.) toward the development of "certain skills" such as language proficiency and knowledge of the host society. In light of this, it points out how Member States are increasingly granting

199 Chapter 2 of the Handbook dealt with this topic in the following way "This Chapter addresses the wide field of civic participation from two angles: first, it looks at organizations delivering services and illustrates how they can become more accessible to immigrants, thus enhancing a sense of belonging. Second, it looks at engaging people in active participation in society. Immigrants and non-immigrants can be mobilised around religious dialogue or around the different facets of active citizenship".

As to the policy recommendations presented by the Handbook, it is said that they "should be taken as... suggestions to policy makers and practitioners and a catalogue of inspiring ideas".

201 In words of the handbook "While a single exact definition of integration may prove to be too narrow, the identification of core integration dimensions can serve as a useful "working definition"." 
importance not only to the socio-economic dimensions of integration, but also to the sociocultural spheres, and continues by arguing that "this approach stipulates the need for integrating immigrants in all aspects of society, including the civic, cultural and political fields". In this regard, it is stated that integration programmes

... are an investment for the future which both the immigrant and the society should be willing to make. They give immigrants a start enabling them to acquire vital skills to become self-sufficient and are therefore well worth the effort. The return on investment for society is that immigrants become better-equipped citizens capable of contributing to society (Emphasis added.) ${ }^{202}$

These understandings put forward by the Handbook of integration intended to provide some inspiring grounds for promoting among the Member States the use of introduction programmes for the "newcomers" 203 to acquire the necessary "skills" in order to be allowed to fully participate in the socio-economic dimensions of the receiving society, and to meld into its civic and cultural spheres. ${ }^{204}$ As stated by the Handbook

An inroduction to values is best framed as a common endeavour in which both newcomers and the receiving society strive to meet the standards set by the country's noms and rules. (Emphasis added.)

The personal scope of the Handbook paid special attention not only to those TCNs falling within the category of "resident immigrants", but also to those labelled as "newcomers or newly arrived immigrants", as potential participants of integration programmes. These and other features of the Handbook constitute clear expressions of a bottom-up approach by which Member State practices and legislation move beyond the configurations of the nation-state and are subject to some sort of Europeanisation through their framing as "best practices" or "lessons learned" at EU level. Best practice is defined by the Handbook as "approaches that have been shown, through research and evaluation, to be effective and sustainable and produce outstanding results, and that can be applicable in and adapted 10 a different situation". 205

Chapter 3 of the Handbook deals with "integration indicators". It is said that they would aim at measuring "the real situation of immigrants and identifying the extent to which integration is progressing". 206 "A successful use of indicators builds on appropriate data collection and on the careful selection of indicators in line with the overall targets of integration". While a full discussion about the implications of the use of benchmarking and indicators is developed in detail in Section 4 below, it is enough here to point out that it remains open to discussion, taking into account the malleability of soft-law techniques such as best practices, indicators, indexing

\section{Page 14.}

203 The Handbook emphasis that "introduction programmes help newcomers acquire the skills to fully participate in society... Demand for skills must be matched with strong mechanisms for the acquisition of these skills and possibilities for using them... It is not only up to the immigrant to achieve skills, but also to governments and societal actors to ensure that ample opportunity is available for the participation on the basis of equality and non-discrimination. Getting the balance of responsibility right is crucial for devising fair and effective integration policies". See page 9.

h is also stated that "Besides language, introduction course often also stress the impontance of "social orientation' and of giving immigrants knowledge of the functioning and the values of society. Courses can cover the fundamental elements of the constitution, such as respect of human rights and democracy, and the functioning of the political system including opportunities for political and civil society participation. Orientation about gender equality and children's rights are important components of many programmes". Page 17. 
and benchmarking, the extent to which their use may end up being a dangerous instrument in an area where fundamental rights and security of TCNs are a central issue of concern. Finally, the Annex of the Handbook presents seven steps for the design and implementation of integration programmes based on the examples given in its three chapters, and aims at facilitating the translation of overall policy goals into integration programmes. ${ }^{207}$ Also, it argues, that the seven steps could serve as the basis for the exchange of "good or best practices" at the national and European levels.

The seven steps are:

1. Providing the rationale for action. It is said that

The rationale [of language training programmes or civic participation] demonstrates that there is a problem, illustrates what the programme will bring about, describes the targets, and connects a specific programme with overall integration goals.

Examples of rationales provided by the Handbook include, for instance, demonstrating that "groups of persons - be they immigrants or not" lack a sufficient knowledge of the language and "principal values and customs" to a degree that hampers their participation in society, or illustrates how such knowledge fosters their independence or "self-sufficiency", defines "targets" (who) and "focus" (which skills to be developed);

2. Formulating the programme. This phase could comprise a mapping exercise, scientific research, expert advice, etc.;

3. Stakeholders consultations at an early phase;

4. Defining the problem. The Handbook refers to the need to identify the "problems" that they want to address in order "to be able to set priorities"; 208

5. Defining objectives "in terms of means and ends";

6. Deciding on strategies;

7. Implementing the programme. ${ }^{209}$

\subsection{The Hague Programme and the Common Basic Principles for Immigrant Integration Policy}

The Hague Programme, the second multi-annual programme on policies related to policies related to an AFSJ agreed to by the European Council on $4-5$ November 2004, provides, by replacing its predecessor adopted at Tampere, the new legislative timetable and policy roadmap for the period 2004-2009. ${ }^{210}$ The Programme placed the integration of TCNs as one of the most relevant policy areas to be developed during that five-year timeframe. ${ }^{211}$ The Council

It is argued that "A problem analysis demonstrates for example what the language deficiencies are among which groups, or it demonstrates which barriers to participation exist for which groups".

This would include, for instance, "A plan for evaluation and impact assessment establishing whether the programme has achieved its objectives and has addressed the problems identified...".

210 H. Schneider (2005), "Towards a European Migration Policy: From Maastricht to Amsterdam, from Tampere to the Hague", in H. Schneider (ed.), Migration. Integration and Citizenship: A Challenge for Europe's Future, Volume II, Forum Maastricht: Maastricht, pp. 7-33.
}

21 Brussels European Council, Presidency Conclusions, 4 and 5 November 2004, 14292/1/04, Brussels, 8 December 2004, Annex I, "The Hague Programme: Strengthening Freedom, Security and Justice in the 
reconfimed the need for greater coordination of national integration policies and EU initiatives in this field. ${ }^{212}$ It restated the appeal at Thessaloniki in 2003 for the establishment of "common basic principles underlying a coherent framework on integration". The JHA Council Conclusions of 19 November 2004 adopted by unanimity the "Common Basic Principles for Immigrant Integration Policy" (CBPs), which provided a first decisive move toward the progressive establishment of the EU Framework on Integration by specifying what integration is supposed to comprise at EU level. ${ }^{213}$ If we look closely at the Council Conclusions, however, it is surprising to see how prior to explaining the CBPs, the Council emphasised the predominance of national competence over the development and implementation of integration policy, and stated that the policies over these areas would need to continue to differ from one Member State to another without any need for change in this regard. ${ }^{214}$ However, it considered "essential" the development of CBPs without providing a convincing justification for doing so. ${ }^{215}$ The only justification put forward was that "it is clearly in the common interest of all Member States of the Union that each individual Member State pursues effective integration strategies". It is worth underlying that according to López Pich (2007), ${ }^{216}$ Spain was the only Member State presenting

European Union", point 1.5. European Council, The Hague Programme: Strengthening Freedom, Security and Justice in the European Union, 2005/C53/01, OJ C53/1, 3.3.2005. The European Commission then published on May 2005 an Action Plan implementing the Hague Programme where integration was reconfirmed as one of the top ten strategic priorities for the creation of an AFSJ in the EU. Commission of the European Communities, Communication from the Commission to the Council and the European Parliament: The Hague Programme: Ten priorities for the next five years, $\operatorname{COM}(2005)$ 184, Brussels, 10 May 2005. See also EESC Opinion on the Communication from the Commission to the Council and the European Parliament: The Hague Programme: Ten priorities for the next five years The Partnership for European renewal in the field of Freedom, Security and Justice COM(2005) 184 final, SOC 209, Brussels, 15 December 2005.

212 The Dutch presidency of the EU held an important conference on integration policy. See in this regard the compendium of Policy Briefs being presented at "The Ministerial Integration Conference on 'Turning Principles into Actions", Groningen, 9-11 November 2004, organized by the Netherlands Ministry of Justice and the Migration Policy Institute of Washington.

213 Council of the European Union, Justice and Home Affairs Council Meeting 2618", "Common Basic Principles on lmmigrants Integration", 14615/04, 19 November 2004, Brussels.

214 It was stated that "The development and implementation of integration policy is therefore the primary responsibility of individual Member States rather than of the Union as a whole". "These policies will differ significantly from Member State to Member State. They must be geared to the individual needs of the receiving society, reflecting each individual Member State's history and legal framework".

Bertozzi (2007) has referred to this "ambivalent attitude" as a "Cartesian dualism" and has argued that the CBPs "are a good compromise between legitimate and natural national concerns and the need to develop a European framework for this thorny issue". S. Bertozzi (2007), Integration: An Ever CloserChallenge, CEPS Working Document No. 258, February 2007, Centre for European Policy Studies, CEPS: Brussels; For a policy-oriented analysis of the CBPs see H. Ceri Jones, C. Pineda, F. Pissart and T. Timmermans (2005), Beyond the Common Basic Principles on Integration: The Next Steps, European Policy Centre: Brussels, which acknowledged that the fact that the CBPs were developed by governments alone in the Council, with little participation of other European institutions and stakeholders, made necessary to have a sort of inter-institutional declaration supporting it. It also referred to the fundamental role that the European Parliament could have in this respect; See also M. Illamola Dausà (2005), 'Égalité et intégration', F. Julie-Laferriere, H. Labaye et örjan Edstrom (dir.), La Politique Européenne D'Immigration et D'Asile: Bilan Critique Cinq Ans Après le Traité D'Amsterdam, Bruylant: Bruxelles, pp. 175-202.

216 In his view "This proposal was destined to recognize the cultural identity of TCNs". See P. López Pich (2007), 'La Politica der Integración de la Unión Europea', Revista Migraciones, Vol. 22, Diciembre 2007, pp. 221-256. 
an amendment inside the Council to the finally agreed list of principles. The Spanish proposal, which aimed at including an express reference to the support for the maintenance of the languages and cultures of origin of TCNs, was not very well received by the other Member States. The eleven CBP principles, whose actual content was developed in the Annex of the Council Conclusions, ${ }^{217}$ can be summarised as follows:

1. Integration is a dynamic, two-way process of mutual accommodation ("mutual rights and responsibilities") by all immigrants and residents of Member States. This principle was explained as follows:

It demands the participation not only of immigrants and their descendants but of every resident. The integration process involves adaptation by immigrants, both men and women, who all have rights and responsibilities in relation to their new country of residence. It also involves the receiving society, which should create the opportunities for the immigrants' full economic, social, cultural, and political participation. Accordingly, Member States are encouraged to consider and involve both immigrants and national citizens in integration policy, and to communicate clearly their mutual rights and responsibilities.

2. Integration implies respect for "the basic values of the EU". The Council understood that this principle involves the obligation by "every resident in the EU" to adapt and adhere closely to "the basic values of the Union" and the laws of the Member States, and by the Member States to ensure that all residents "understand, respect, benefit from, and are protected on an equal basis by the full scope of values, rights, responsibilities, and privileges established by the EU and Member State laws". The following "values" were mentioned as coming from the Treaties and being common to all the Member States: principles of liberty, democracy, respect for human rights and fundamental freedoms, the rule of law, and the respect of the Charter of Fundamental Rights of the Union.

3. Employment is a key part of the integration process and is central to the participation of immigrants.

4. 1. Basic knowledge of the host society's language, history and institutions is indispensable for integration; 2. enabling immigrants to acquire this basic knowledge is essential to successful integration. Here, the Council referred to the increasing importance allocated by some Member States to the introduction of integration programmes covering these aspects. These programmes, it was argued, "will allow immigrants...to start the longer-term process of normative adaptation to the new society".

5. Efforts in education are critical to preparing immigrants, and particularly their descendants, to be more successful and more active participants in society. ${ }^{218}$

6. Access for immigrants to institutions, as well as to public and private goods and services, on a basis equal to national citizens and in a non-discriminatory way is a critical foundation for better integration. This principle was understood in the following manner:

217 The Annex was titled "Common Basic Principles for Immigrant Integration Policy in the European Union", and stated that "The explanations provided are intended to give direction to the common basic principle. The description is indicative, by no means exhaustive and will be further developed in the future", page 19.

218 The explanations of this principle included the following affirmation "Transferring knowledge about the role and working of societal institutions and regulations and transmitting the norms and values that form the binding element in the functioning of society are also a crucial goal of the educational system. Education prepares people to participate better in all areas of daily life and to interact with others". 
If immigrants are to be allowed to participate fully within the host society, they must be treated equally and fairly and be protected from discrimination. EU law prohibits discrimination on the grounds of racial or ethnic origin in employment, education, social security, healthcare, access to goods and services, and housing. Consequently, transparent rules, clearly articulated expectations and prediciable benefits for lav-abiding immigrants are prerequisites to better immigration and integration policies. Any legal exceptions to this accessibility must be legitimate and ransparent. (Emphasis added.)

7. Frequent interaction between immigrants and Member State citizens is a fundamental mechanism for integration. Shared forums, inter-cultural dialogue, education about immigrants and immigrant culture, and stimulating living conditions in urban environments enhance the interactions between immigrants and Member States citizens. Good cooperation among the different actors involved is highly necessary.

8. 1. The practice of diverse cultures and religions is guaranteed under the Charter of Fundamental Rights and must be safeguarded, 2. unless practices conflict with other inviolable European rights or national law. ${ }^{219}$

9. The participation of immigrants in the democratic process and in the formulation of integration policies and measures, especially at the local level, support their integration. ${ }^{220}$

10. Mainstreaming integration policies and measures in all relevant policy portfolios and levels of government and public services is an important consideration in public policy formulation and implementation, while at the same time specifically targeted policies for integrating immigrants are being developed; and

11. Developing clear goals, indicators and evaluation mechanisms are necessary to adjust policy, evaluate progress on integration and to make the exchange of information more effective. The Annex of the Conclusions clarified in this regard that

The purpose of such evaluation is to lean from experience, a way to avoid possible failures of the past, adjust policy accordingly and showing interest for each others efforts. When Member States share information about their evaluative tools at European level and, where appropriate, develop European criteria (indicators, benchmarks) and gauges for the purposes of comparative learning, the process of knowledge-sharing will be made more effective...Exchanging information provides for taking into account the different phases in which Member States find themselves in the development of their own integration policies and strategies. (Emphasis added.)

The stated objectives of the CBPs are: ${ }^{221}$

219 It was said that "However, Member States also have a responsibility to ensure that cultural and religious practices do not prevent individual migrants from exercising other fundamental rights or from participating in the host society. This is particularly important as it pertains to the rights and equality of women, the rights and interests of children, and the freedom to practice or not to practice a particular religion. Constructive social, inter-cultural and interreligious dialogue, education, thoughtful public discourse, support for cultural and religious expressions that respect national and European values, rights and law's (as opposed to expressions that violate both the letter and spirit of such values and rights), and other non-coercive measures are the preferred way of addressing issues relating to unacceptable cultural and religious practices that clash with fundamental rights. However if necessary according to the law legal coercive measures can also be needed". The Council timidly expressed that "Wherever possible, immigrants could even be involved in elections, the right to vote and joining political parties".

221 Council of the European Union, Justice and Home Affairs Council Meeting $2618^{\text {th }}$, Brussels. "Common Basic Principles on Immigrants Integration', 14615/04, 19 November 2004, paragraph 8; See S. Carrera (2006), "Integration of Immigrants Versus Social Inclusion: A Typology of Integration Programmes in 
First, to assist Member States in formulating integration policies for TCNs by offering them a simple non-binding but thoughtful guide of basic principles against which they can judge and assess their own policies, and to serve as a basis for the EU to explore how existing EUinstruments on integration can be developed further.

Second, to serve as a basis for the Member States to explore how EU, national, regional, and local authorities can interact in the development and implementation of integration policies.

Third, to assist the Council to reflect upon and, over time, agree on EU-level mechanisms and policies needed to support national and local-level integration policy efforts, particularly through EU-wide learning and knowledge-sharing.

The JHA Council Conclusions of November 2004 also included an important statement according to which the principles are supposed to be "complementary and in full synergy with existing legislative frameworks, including international instruments on human rights, Community instruments containing integration provisions, EU objectives on gender equality and non-discrimination, and other EU policies". Further, while the main target group (personal scope) addressed by the EU Framework on Integration would be mostly 'newcomers' and those legally residing TCNs before crossing the bridge toward long-term residence, the Conclusions stated that

They may also target diverse audiences, the mix of which varies between the Member States for example, from temporary workers to permanent residents and to the children of immigrants; from individuals who await to be admitted to those who are already residing; from immigrants who have acquired citizenship to long-established third-country nationals; and from highly skilled refugees to individuals who have yet to acquire the most elementary skills.

The principles intend to offer a first definition of what integration means in the EU. ${ }^{222}$ However it is our view that they rather encapsulate in one harmonised list a certain number of the perceived shared features that had been already achieved in previous European legal responses dealing with this topic. They offer a synthesis and compilation of "the European point(s) of view" about the conceptualisations and broad features that the term integration has played in a number of European responses especially since the mid-1980s. Yet, there are other principles which were also included in the list and whose origins were not as rooted in the classical Community approach(es) as the Council might argue, ${ }^{223}$ yet by being in "full" compliance with existing Community instruments on regular immigration they consolidate the use of some innovative, and rather critical, functionalities of integration (See Chapter 4).

In terms of offering an understanding about how integration was thereby framed, the two-way process tenet represents the $\mathrm{CBPI}$ and covers all remaining principles. This tenet, which has been present in EU discourse since the mid-1980s, appears to be conceived as a process of mutual accommodation whereby the responsibilities and efforts lie not only with TCNs, but also with 'the receiving society'. Based on this official reasoning, the CBPs 2, 4.1, 5 and 8.2 belong to the package of TCNs responsibilities. On the other hand, CBP 4.2 corresponds to efforts

the EU", in T. Balzacq and S. Carrera (2006) (eds.), Security versus Freedom: A Challenge for Europe's Future, Ashgate Publishing: Aldershot, pp. 87-112.

222 S. Pratt (2006), "Immigration, Integration and Citizenship: Latest Developments and the EU's Role", in S. Carrera (ed.), The Nexus between Immigration. Imegration and Citizenship in the EU, Collective Conference Volume, April 2006, Centre for European Policy Studies: CEPS, Brussels, pp. 12-15.

223 For a critique of the CBPs and some of the problems raised by some of them see M. Martiniello, (2008) Towards a Coherent Approach to Immigrant Integration Policy(ies) in the Etropean Union, retrievable from www.oecd.org on January 2008. 
allocated to 'the receiving society'. CBPS 3,6 and 8.1 represent the main principles embracing the rights and freedoms being conferred to TCNs. In general terms, and taking into account past experiences, the CBP 6 brings into the set of principles the EU fair and near-equality paradigm, which perhaps could have been placed higher in the list. Finally, CBP10 is focused on mainstreaming integration policies and CBPl 1 on the development of indicators and evaluation mechanisms.

Table 1: The Common Basic Principles underlying the EU Framework on Integration

\begin{tabular}{|c|c|c|}
\hline \multicolumn{3}{|c|}{ Two-way Process Tenet - CBP 1} \\
\hline \multicolumn{2}{|c|}{ OBLIGATIONS } & RIGHTS \\
\hline Immigrants & Receiving Society & Immigrants \\
\hline $\begin{array}{c}\text { CBP 2: Respect for the basic } \\
\text { values of the EU }\end{array}$ & $\begin{array}{c}\text { CBP 4.2: Enabling immigrants } \\
\text { to acquire this basic knowledge } \\
\text { about the receiving society's } \\
\text { language, history and } \\
\text { institutions }\end{array}$ & CBP 3: Employment \\
\hline $\begin{array}{c}\text { CBP 4.1: Basic knowledge of } \\
\text { the receiving sociely's } \\
\text { language, history and } \\
\text { institutions }\end{array}$ & & CBP 5: Access to education \\
\hline CBP 5: Efforts in education & & $\begin{array}{c}\text { CBP 6: Equal treatment and } \\
\text { non-discrimination }\end{array}$ \\
\hline $\begin{array}{c}\text { CBP 8.2: Practice of diverse } \\
\text { cultures and religions unless } \\
\text { practices conflict with national } \\
\text { law }\end{array}$ & & $\begin{array}{l}\text { CBP 8.1: Practice of diverse } \\
\text { cultures and religions }\end{array}$ \\
\hline
\end{tabular}

On 3 May 2005 the EP adopted a Report on "the links between legal and illegal migration and integration of migrants", 224 in which it presented its opinion on the First Annual Report on Migration and Integration and, to a certain extent, the CBPs. The Report stressed that while the responsibility for integration resides with individual Member States, they should coordinate their policies "by means of the open method of coordination pursuant the common basic principles recently adopted by the Council". ${ }^{225}$ It also stated that the coordination of national policies should not prevent the instauration of a European integration policy, and called on Member States to define minimum common criteria. ${ }^{226}$ As regards the main features underlying the concept of integration, Paragraph 50 of the Report recognised the importance of

...encouraging efforts to learn the language of the host society and encouraging the organisation of civics courses and reaching programmes on topics including male/female equality, and of

224 European Parliament, Report on the Links between Legal and Illegal Migration and Integration of Migrants, 2004/2137(INI), A6/0136/2005, 3 May 2005, Rapporteur: Patrick Gaubert. This Report was additionally focused on the Commission Communication, Study on the Links between Legal and Illegal Migration, $\operatorname{COM}(2004) 412,4.6 .2004$, Brusseis.

225 Paragraph 48 of the Report.

226 Paragraph 49. 
furthering integration by means of work, of taking action to combat ghettoisation, and of political participation in local elections; supports the introduction programmes run by certain Member Siates which involve mutual commitment on the part of the host countries and (in particular) the first wave of immigants; wishes to encourage immigrants to respect the fimdamental values of the Union by' a symbolic act of commitment. (Emphasis added.)

Similarly to the previous EP Reports of 2003, the EP confirmed the two-way process paradigm ${ }^{227}$ and its vision according to which an "active integration policy" should comprise the following six elements: First, clear rules on the legal status of TCN residents and their right to good administration; second, integration in the labour market; third, requirements to follow courses in the national language(s), of access to education and recognition of qualifications; fourth, access to social and health services; fifth, decent living conditions in urban and other localities; and sixth, participation in social, cultural and political life. ${ }^{228}$

\subsection{Putting Principles into Practice? A Common Agenda for Integration}

The Commission published on 1 September 2005 a Communication entitled "A Common Agenda for Integration - Framework for the Integration of Third Country Nationals in the European Union", COM(2005) 389. ${ }^{229}$ The Communication constituted a concrete step by the Commission to establish a European Framework for Integration ${ }^{230}$ by putting forward concrete measures to strengthen the practical applicability of the CBPs. It also identified as comerstones of this framework a series of "suggested actions or a road map" intended to provide some guidance to implement the CBPs at the national and European levels. ${ }^{231}$ The Commission clarified that the package of actions thereby presented was only "indicative and not exhaustive", and it left it to Member States "to set priorities and select the actions", though the latter should be considered as "main elements of all national and EU integration policies". Furthermore, in the Commission's words, these actions were built upon the Handbook on Integration and the financial Community instruments focused on the integration of TCN. Here, we may perceive how the 'policy softness' inherent to the Handbook exercise did not prevent it from having direct repercussions in concrete soft-law responses such as this important Communication. This peculiar form of policy-making may be harder than one might be at first inclined to think! It is also interesting to see the way in which the European Commission justifies having a common EU Framework on Integration by stating that

227 Paragraph 48 stipulates that integration "implies rights and obligations both for the host society and the immigrant".

228 Paragraph 51 of the Report.

229 Commission Communication, A Common Agenda for Integration - Framework for the Integration of Third Country Nationals in the European Union, COM(2005) 389, Brussels, I September 2005.

230 In words of the Commission, this Communication represents 'the Commission's first response to the invitation of the European Council to establish a coherent European framework for integration. The comerstones of such a framework are proposals for concrete measures to put the CBPs into practice, together with a series of supportive EU mechanisms. Taking into account existing EU policy frameworks, the Communication provides new suggestions for action both at EU and national level.' According to Collet, "by proposing so many scattered, though useful, initiatives under each principle, the Commission risks compromising the coherence of its framework". E. Collet (2006), One Size fits All? Tailored Integration Policies for Migrants in the European Union, EPC Working Paper No. 24, European Policy Centre: Brussels.

231 Annex of the Communication. 
argument continued, would stem from the consolidation of a common legal framework on the conditions of admission and stay of TCNs (EU law on regular immigration), and the development of the following soft components: "cooperation activities, exchange of information, mainstreaming and evaluation" through the implementation of CBPs 10 and 11 . In view of the Commission, "legal migration and integration are inseparable and should mutually reinforce one another". ${ }^{236}$ In light of this, the Communication put forward a number of actions at the national and EU levels for the implementation of these two principles, and included in relation to CBP10, for instance, mainstreaming integration in all relevant national policies and EU programmes, supporting further cooperation and coordination among relevant institutions and stakeholders involved in integration, ensuring that NCPS constitute a national focal point for sharing information and coordination between the different levels of government, etc. ${ }^{237}$ Concerning CBPII, it was proposed to increase the monitoring and evaluation of national policies, enhance the use of statistics, develop evaluation schemes and an improved knowledge of the impact of compulsory integration programmes, etc.

The Council Conclusions on a Common Agenda for Integration of 1-2 December 2005 supported the general orientations advocated by the Commission in this Communication. ${ }^{238}$ Moreover, the Communication COM(2005) 389 served as grounds for the European Parliament to become once more involved in the construction processes of the EU Framework on Integration. The EP Report on "Strategies and Means for the Integration of Immigrants in the European Union" was published on 17 May 2006. ${ }^{239}$ It called for strengthening the EU's commitment on integration, ${ }^{240}$ and urged the Council to reconsider the 2001 European Commission's proposal to apply the OMC in this policy area, where it would be necessary to involve the EP in the whole procedure. ${ }^{241}$ Integration was defined in paragraph I as

236 See Point 4 on "Conclusions".

237 See Point 3.1 on "Mainstreaming and Evaluation: Common Basis Principles 10 and 11 ", page 11.

238 The Council acknowledged the importance "of defining a framework at European level for the integration of legally residing third-country nationals in all aspects of society and, in particular, concrete measures for implementing the Common Basic Principles" and pointed out "the need to further enhance a coherent approach to integration policies and measures, based on common goals, through the continuous strengthening and development of instruments for cooperation and exchange of information". Further, the Conclusions gave special importance to the role of the NCPI by saying that their "activities and their impact, and its improved analysis of issues common to Member States, should be regularly brought to the attention of the relevant bodies of the Council, so that the Network's role in providing expertise to the decision-making bodies of the EU is enhanced".

239 European Parliament Report on Strategies and Means for the Integration of Immigrants in the European Union, 2006/2056/INI, A6-0190/2006, 17.5.2006, Committee on Civil Liberties, Justice and Home Affairs, Rapporteur: Stavros Lambrinidis. See also, European Parlianent Resolution on Strategies and Means for the Integration of Immigrants in the European Union, 2006/2056(INI), 6 July 2006.

240 Point E of the Resolution stated that "whereas the European Union's commitment to integration has long been curbed by the commonly-held idea that 'integration is local'; whereas, in fact, integration is just as global in its implications, especially when it fails, since the failure by a single Member State to implement successful integration policies can have adverse consequences for the Union as a whole,...".

241 Point L. 17 of the Resolution. It was even recommended in point 14 that "the Council to use the bridging clause of Article 67.2, second indent, of the Treaty to give Parliament co-decision powers on integration and legal migration and qualified majority voting in the Council; considers that it is important for Members to have the power of co-decision on integration policy, given that they represent the political voice of the EU, and considers, therefore, that they should represent the opinions of both immigrants and citizens and should share responsibility for making integration policy in the EU legislative process". 
a "two-way process" that presupposes both the immigrants' willingness to, and responsibility in, integrating into their host society and EU citizens' willingness to accept and include migrants, and consists in integrated actions for influencing the behaviours of both immigrants and receiving societies on all relevant levels and for mobilising resources on both sides in order to implement policies; whereas this two-way process involves a mutual commitment, with both rights and obligations, for the host society and immigrants.

Further, as regards the understanding and functions attributed to a "successful EU integration policy" by the EP, the following priorities need to be highlighted: First, it called on the Commission and Member States to make use of the potential of Commission delegation and consular authorities all over the world, "to assist in integrating potential immigrants through familiarising them with EU and Member State culture, history, language and civic rights and responsibilities". ${ }^{42}$ Second, the Resolution stated that the EP

Is in favour of integration programmes applied by certain Member States involving a mutual commitment by the host country and immigrants; hopes that immigrants can in this way be made more aware of the Emopean Union's fundamental values and be enabled at the same time to acquire basic knowledge on the functioning of the host society; stresses the importance of encouraging the learning of the host society's language and organising civic education courses. (Emphasis added.)

\subsection{The Second Handbook on Integration}

The Second Edition of the Handbook on Integration for Policy-Makers and Practitioners was released in May 2007. ${ }^{243}$ It aims at providing "good practices" and "lessons learned" drawn from the experience of policy-makers and practitioners across Europe. The introduction starts by making reference to the important role played by the Handbook to exercise "a larger policy process in the field of integration in the European Union, notably the development of the European Framework on integration". The drafting of the second edition took place according to a rather similar methodology as that of the 2004 edition. Here also, the MPG, in close cooperation with the NCPI, prepared the document on the basis of the outcomes of technical seminars that took place in Tallinn, Rome, Dublin, Berlin and Madrid during 2005 and 2006, and which dealt with the following themes: mainstreaming integration (Chapter 1), housing in urban environment (Chapter 2), economic integration (Chapter 3) and integration governance (Chapter 4). Finally, Annex I makes suggestions for the translation of policies into integration programmes. It is interesting to see the way in which the Handbook addressed the authorship of the text by stating that

National Contact Points on Integration and MPG are seen as the 'editors', preparing a conceptual framework for the seminars, laking stock of the information gathered at each seminar, selecting practices, and supplementing them with additional research. (Emphasis added.)

The exercise of taking stock, selecting practices and supplementing them with additional research can be considered as very proactive editing, indeed. Further, we need not to forget who the NCPI really are, and consequently question the extent to which their 'independence' is truly ensured during these 'editing' processes.

\section{Point 12}

243 J. Niessen and Y. Schibel (2007), Handbook on Inregration for Policy-Makers and Practitioners, Second Edition, DG Justice, Freedom and Security, European Commission, May, Brussels. The Second edition has been also translated into all the official languages of the EU.

See http:/ec.europa.eu/justice_home/fsj/immigration/integration/fsj_immigration_integration_en.htm 
The introductory section of the Second Handbook offers its conceptual framing as regards integration, and in doing so goes further than the one used in its furst edition. It starts by saying that "Integration is not easy to plan: it is a long-term process, and it is non-linear. An international political event or a criminal act can set back integration processes significantly. Integration is also multi-faceted, demanding a capacity for adaptation...including immigrants themselves". The question then is posed as to what does integration mean. In this regard it advocates for actually setting aside any conceptual debates, ${ }^{244}$ and rather focusing on a more "pragmatic approach" by looking at "outcomes in terms of social and economic mobility, education, health, housing, social services, and societal participation". This option is somehow surprising if we take into account the importance that a theoretical framework, and its related political and ideological goals, has for the identification of what could be considered as "best" or "worst" in terms of practices and programmes, as well as for conducting any evaluation and assessment of the success of the latter. Furthermore, the Handbook argues,

What is loosely called 'integration' thus encompasses. Justice and Home Affairs aspects linked to the legal framework of admission and residence, naturalisation and antidiscrimination, as well as aspects that are more closely related to the policy fields of social affairs, labour market. edication or culture. This variety is reproduced at each level of govemment, with different Commission Directorates-General, ministries, and municipal departments all involved in integration activities. It also extends to non-governmental actors of different kinds. It requires coordination between ministries and various levels of govemance as well as between govemmental and non-governmental actors. (Emphasis added.)

Handbook authors therefore preferred to leave conceptual discussions aside, and instead evaluate practical measures and some approaches that could be considered critical for the improvement of what it called "immigrant's outcomes": (1) The elimination of inequalities through a revival of the concept of civic citizenship in light of security of residence; and (2) the acquisition of competences ('learning to learn') through language proficiency and training/education ('empowerment also reinforces knowledge').

Chapter 4 of the Handbook, entitled "Integration Governance", deserves special interest, as it considers the structures, mechanisms, processes and forms of collaboration comprising the framework for integration policies and practices. It argues that the materialisation of general policy goals into integration programmes can only occur through careful planning ('objectives should be SMART ${ }^{245}$ ) and evaluation of the appropriateness and quality of integration policies themselves through "good governance indicators" rather than "attempting to measure the "degree of integration' of individuals or immigrant groups, which remains a challenge". 246 Finally, Annex 1, entitled "Praxis-based Policies - the Translation of Practices into Policies", presents a number of policy recommendations that can be framed with two: ${ }^{247}$ First, measuring the quality of integration projects and programmes by studying their relevance, efficiency, effectiveness, sustainability and impact; and, second, appraising projects and programmes by

${ }^{244}$ The Handbook argues that "The question might be expected to trigger familiar debates about assimilation or multiculturalism, but participants at the technical seminars preparing the handbook hardly used these terms".

245 The term SMART comes from the features that the Handbook calls for the objectives to be: 'Specific, Measurable, Accepted, Realistic and Time-dependent'. Here a direct reference is made to the European Commission, Impact Assessment Guidelines, SEC (2005) 791, 15 June 2005, pages 20-22.

In summary, it says, "... a well-balanced mix of quantitative and qualitative methods, and of internal and external evaluations, is most likely to contribute to a comprehensive understanding. At the same time, limitations will remain because of the multifaceted and complex nature of integration". Page 79.

See pages $89-91$. 
comparing them to each other, identifying actors, formulating policy options and assessing their impact. We insist on the fact that neither policy strand considers it necessary to study and assess the very theoretical premises and political/policy goals upon which the projects and programmes on "integration" would be built and developed, and which, in our view, should be amongst the most important factors when determining not only their efficiency, effectiveness, sustainability, etc., but also their compliance with the rule of law and fundamental rights reigning the EU legal system (see Chapter 7 of this book). ${ }^{248}$ A third edition of the Handbook has been planned for 2009.

\subsection{The Second Annual Report on Migration and Integration}

The Second Annual Report on Migration and Integration SEC(2006)892 was published by the European Commission on 30 June $2006 .{ }^{249} \mathrm{It}$ is striking to see how on this occasion the Annual Report did not take the shape of a Communication, but rather a Commission Staff Working Document, which might be considered to be a lower-ranking soft-law mechanism whose actual legal status is even more uncertain than that enjoyed by a Communication. The Second Report continues with the objective of reporting annually on the development of a common immigration policy and the mapping of EU-wide migration data. It offers a broad overview of perceived migration trends in the EU with respect to current legislations and policy changes related to integration of TCNs at the national and EU levels. ${ }^{250}$ Its Annex provides a summary report of integration policies in the EU-25, which was developed in conjunction with the NCPI.

The Report points out in this regard how some Member States are requiring "new immigrants" to fulfil certain "integration obligations", 251 and that there is a tendency towards an emphasis on obligatory integration measures. ${ }^{252}$ The case of the Netherlands was mentioned as constituting a

248 A recent publication by the MPG intended to provide the means for incorporating the "lessons learned" in the first and second editions of the Handbook to put into practice the 11 CBPs on integration. As regards the CBP1, the Report states that "compulsory programmes and the use of incentives should be evaluated after some time so as to establish whether this enhances the quality of the courses and increases attendance". See J. Niessen and M. A. Kate (2007), From Principles to Practice: The Common Basic Principles on Integration and the Handbook Conchisions, Migration Policy Group: Brussels, June 2007. Retrievable from http://www.migpolgroup.com

249 Commission Staff Working Document, Second Annual Report on Migration and Integration, SEC(2006) 892, Brussels, 30.6.2006.

250 The most substantial part of the Second Annual Report is composed by a summary report on integration policies at the national level in the EU-25. See Amex of the Repont titled "Summary Report on Integration Policies and Recent Developments in the EU-25", pp. 7-21.

251 Point 3.3 of the Annex mentioned the following Member States: Austria, Germany, Luxembourg, Belgium (Flemish Community), Finland, The Netherlands and France.

252 See for instance International Centre for Migration Policy Development (ICMPD) (2005), Integration Agreements and Voluntary Measures: Compulsory or Volumany Nature - Comparison of Compulson Integration Courses, Programmes and Agreements and Volumary Integration Programmes and Measures in Austria, France, Germany, the Netherlands and Swizerland, ICMPD, Vienna, May; I. Michalowski (2004), An Overview on Introduction Programmes for Immigrants in Seven European Member States, Adviescommissie voor Vreemdelingenzaken, The Hague; A. Fermin (2001), The Justification of Mandatory Integration Programmes for New Immigrants: Summary of the Dutch report "Verplichte inburgering van nienwkomers", European Research Centre on Migration and Ethnic Relations, University of Utrecht; S. Carrera (2006), A Typology of Different Integration Programmes in the EU, Briefing Paper, DG Internal Policies, European Parliament, January 2006; S. Carrera (2006), $A$ Comparison of Integration Programmes in the EU: Trends and Weaknesses, CHALLENGE Research Paper No. 1, Centre for European Policy Studies (CEPS), Brussels; C. Joppke (2007), 'Beyond National 
paradigmatic example because of its objective to implement "pre-departure standards" before granting family reunification. ${ }^{253}$ In this regard, the Commission stressed that

...care must be taken to ensure that national integration measures and integration conditions fully comply with Community legislation. The integration measures, as well as integration conditions authorised under Directive 2003/86 on family reunification and Directive 2003/109 on the status of third-country nationals who are long-term residents, should be applied without any discrimination (see in particular recital 5 of the two Directives). The definition of integration conditions and integration measures should not undermine the efficiency of the Directives (Emphasis added.)

Moreover, the Commission reiterated a rights-based approach, according to which the best way for TCNs to integrate is having their "basic rights" to education, housing, healthcare and social services recognised. In this context, reference was made to the Council Directive 2003/109, and that those TCNs qualifying for EC long-term resident status should be guaranteed equal treatment subject to the conditions prescribed by the Directive. It was stated that "Careful examination of national transposition measures and concrete practice will be necessary".

\subsection{The Third Annual Report on Migration and Integration}

The Third annual Report on Migration and Integration COM(2007) 512 was published by the European Commission on 11 September $2007,{ }^{254}$ and continued with the same objectives pursued by its two predecessors. The Annex offers a summary report of integration policies in EU-27 in cooperation with the NCPs. The Report puts forward some conceptual aspects related to integration when stating that

Integration of third-country nationals is a process of mutual accommodation by both the host societies and the immigrants and an essential factor in realising the full benefits of immigration...the link between legal migration policies and integration strategies needs to be continually reinforced (Emphasis added.)

In addition, the Commission started by making reference to the comerstones of the EU Framework on Integration, and sustained that "the Common Agenda provides supportive EU mechanisms to facilitate this process developing a distinctive European approach to integration

Models: Civic Integration Policies for Immigrants in Western Europe', West European Politics, Vol. 30 , No. 1, January 2007, pp. 1-22.

For a study of the case of the Netherlands see among others; Human Rights Watch (2008), The Netherlands: Discrimination in the Name of Integration - Migrant's Rights under the Integration Act Abroad, May 2008; L. Besselink (2006), "Unequal Citizenship: Integration Measures and Equality", in S. Carrera (ed.), The Nexus benween Immigration. Imtegration and Cinizenship in the EU, Collective Conference Volume, Centre for European Policy Studies, CEPS: Brussels pp. 14-19; K. Groenendijk, K. (2006d), "Integration Policy and Community Law", in S. Carrera (ed.), The Nexus between Immigration. Integration and Citizenship in the EU, Collective Conference Volume, Centre for European Policy Studies, CEPS: Brussels, pp. 9-11; L.F.M. Besselink (2005), Inburgering, gelijke behandeling en verbliffsrecht van veemdelingen in Nedevland, Staats-en Bestuursrech, Faculteit Rechtsgeleerdheid, University of Utrecht (retrieved from www.libertysecurity.org); V. Marinelli (2005), "The Netherlands", in J. Niessen, Y. Schibel and C. Thompson (eds), Current Immigration Debates in Europe: A Publication of the Emopean Migration Dialogue, Migration Policy Group, Brussels; I. Michalowski (2004), "Integration Programmes for Newcomers - A Dutch model for Europe?", in A. Böcker, B. de Hart and I. Michalowski, Migration and the Regulation of Social Integration, IMIS-Beiträge Special issue, No. 24, IMIS, Universität Osnabrück.

Commission Communication, Third Annual Report on Migration and Integration, COM(2007)512, 11 September 2007, Brussels. 
through cooperation and exchange of good practice". Among the trends identified as regards national integration policies, the Report put them in relation to the CBPs on integration and stated, "Most concepts present in Member States' integration policies are codified by the Common Basic Principles and they are, to different extents, reflected in their integration strategies". It is striking to see how the summary report on integration policies at the EU-27 level included in the Annex identified the impact that the CBPs are already having in some Member States. ${ }^{255}$ For instance, the Commission explains, the CBPs have been expressly mentioned in official declarations and political statements in countries like Austria, Czech Republic, Denmark and Spain. They have also been explicitly incorporated in some Member State programmes such as the Spanish Strategic Plan on Citizenship and Integration. ${ }^{256}$ It also confirmed the national trend pointed out in the Second Annual Report, which is consistent with the spread of mandatory integration programmes. ${ }^{257}$ Moreover, and in order to develop further the Common Agenda, the European Commission highlighted the following initiatives for the near-future:

First, study concepts of participation and citizenship and their relevance to integration processes.

Second, explore the added value of common European Modules for Migrant Integration (EMMI). They would be "based on existing good practice to develop guidelines on various aspects of the integration process (introductory courses, promoting participation of immigrants and other citizens in local life, etc)".

Third, raise awareness and disseminate widely "the opportunities that immigrants bring for societal development, economic growth and cultural diversity".

Fourth, assess the ways in which integration processes could contribute more actively "to preventing social alienation and discrimination against immigrants focusing especially on youth".

Fifth, promote the development of "common indicators and indexes" to evaluate integration programmes and "to provide benchmarks for comparative analysis".

Finally, the Report concluded by referring to the way in which the European Commission is currently exploring ways to improve and redesign the format and context of the Annual Reports on Migration and Integration to transform them into up-to-date instruments for the comparative analysis of immigration and integration policies, and that "it will present a new concept [for the Annual Report] to provide a more comprehensive information and monitoring tool".

\subsection{The European Integration Forum and an Integration Website}

The involvement of stakeholders in the construction of the EU Framework on Integration has been placed by the European Commission as a clear priority. In light of this, the above-

255 The Summary Report was drafted on the basis of a questionnaire completed by the National Contact Points on Integration (except those of Cyprus and Malta). The questionnaire refers to third-country nationals who are legally residing in the Member States, both newly-arrived and long-established immigrants and refugees.

256 See page 11 and ss of the Third Anmual Report.

257 Page 13 states that "Introduction programmes are established in most Member States and they are compulsory in some countries, i.e. Austria, Belgium, Denmark, France, Germany, Greece and The Netherlands". 
mentioned Communication on "A Common Agenda for Integration" COM(2005) $389^{258}$ mentioned the establishment of a European Integration Forum. The Forum would bring together the main stakeholders active in the area of integration at the EU level. The EESC was formally requested by the European Commission to elaborate an Opinion concerning the establishment of the Forum, which was adopted on 9 July 2008. ${ }^{259}$ The fact that the Commission entrusted the EESC to deliver this task is not surprising when taking into account that the latter, through several of its Opinions, ${ }^{260}$ has constituted one of the main European actors aiming at stimulating a political and social debate at the EU level about the need to establish a European Framework on Integration and strengthen the role played by civil society and social partners toward that goal. $^{261^{\circ}}$

Concerning the nature of the Forum, its actual membership will total a maximum of 100 members, and it will meet twice a year. One third of the Forum's members will include EU umbrella organizations working in the area of integration and including the social partners. The remaining participants will come from consultative bodies of the Member States (with each Member State sending between one and four representatives) ${ }^{262}$ As regards its functions, the EESC has proposed that the Forum would have the competence to elaborate Opinions, Recommendations and Reports concerning integration policies at the EU level, which would include proposals and recommendations. It has been also proposed that the Forum could also contribute to the Conferences preceding the drafting of the Handbooks on Integration and meetings of the NCPI. The CBPS will constitute the roadmap of the Forum's activities and agenda. It will also have the capacity to "assess the objectives and programmes of the European Integration Fund, as well as the other instruments provided for under European integration policy". The Opinion also stipulates that

258 Commission Communication, A Common Agenda for Integration - Framework for the Integration of Third Country Nationals in the European Union, COM(2005) 389, (Brussels, 1 September 2005).

EESC, Elements for the Structure, Organization and Functioning of a Platform for the Greater involvement of Civil Society in the EU-level promotion of policies for the integration of third country nationals, Opinion, SOC/281, Brussels, 9 July 2008.

See EESC Opinion, Immigration, Integration and the Role of Civil Society Organisations, SOC/075, Brussels, 21 March 2002, rapporteur: Mr. Pariza Castanos; the Opinion of the EESC on the Commission Communication on an Immigration and Asylum Policies, 94/393/13, OJ No. 393/69, 31.12.1994; EESC Opinion on the Commission Communication on immigration, integration and employment, $\mathrm{SOC} / 138$, Brussels, 10 December 2003, rapporteur: Mr. Pariza Castanos; See also EESC (2007), Immigration: The Role of Civil Society in Integration, Foreword by Franco Frattini, Office for the Official Publications of the European Communities: Luxembourg. For more information see the website of the SOC Section of the EESC at http://www eesc.europa.eu/sections/soc/index_en.asp?id=1001 socen

26) In the EESC Opinion on Immigration in the EU and integration policies: cooperation between regional and local governments and civil society organizations, SOC/219, Brussels, 13 September 2006, rapporteur: Mr. Pariza Castaños, it was stated that "The EESC believes it is of great inportance that civil society organisations play a part in drawing up policies and implementing actions. If an integration plan is to succeed, it is important for civil society to be involved", point 7.2.2 of the Opinion.

Paragraph 3.6 .5 of the Opinion clarifies that "In this way, the forums, platforms, councils and similar institutions that exist in the Member States - especially those involving immigrant organisations - will also be represented in the European Forum. In those Member States where no such organisations exist, the economic and social councils (or similar institutions) could have a place in the Forum". It continues by saying in paragraph 3.6 .6 that "immigrants' organisations, most of which are organised on national lines and do not have European networks, must be encouraged to become involved in the European Integration Forum; the Member State forums, platforms, councils or ESCs should, therefore, nominate delegates from the most representative immigrants' organisations". 
Exchanging technical know-how and good practice should be one of the Forum's main tasks, to be carried out in cooperation with the network of National Contact Points (Emphasis added.)

The European Commission is expected to approve the Forum's rules of procedure and appoint the members at the proposal of the EESC in the beginning of 2009. At a parallel level, the Communication COM(2005)389 had referred to the objective of establishing a private-public partnership to set up a website dealing with integration. The website would contain an inventory of 'good practices', to promote structural exchange of experiences and information on integration. It aims at offering a scarchable database on 'best practices' and information on EU initiatives. The recommendations and other documents put forward by the Forum would be published on the integration website. The website on integration is being developed by the MPG together with three other organisations, ${ }^{263}$ and is expected to be operational before the end of $2008^{264}$

\subsection{The European Integration Fund}

The European Commission presented on April 2005 a Communication presenting the first framework programme on Solidarity and Management of Migration Flows for the Period 2007 to $2013 .^{265}$ This proposal advocated for an ambitious allocation of funds for the integration of immigrants of 1.7 billion euros for the period 2007-2013. ${ }^{266}$ After receiving the amendments of the Council and the EP opinion, the European Fund for the Integration of Third Country Nationals (EIF) was formally adopted on June 2007 by the Council Decision 2007/435/EC. The financial coverage finally adopted was 825 million euros: $:^{267} 768$ million euros for National Programmes distributed among the Member States on the basis of a distribution key expressing solidarity on the basis of the number of legally staying third country nationals and 57 million euros for Community Actions. ${ }^{268}$ The UK and Ireland expressed their wish to take part in the adoption of the decision. The formal adoption of the EIF strengthened the arguments of the validity of Article 63.3.a TEC to adopt European legislation in the field of integration of $\mathrm{TCNs}^{269}$

263 These include UNISYS, Social Change Online and Eurocities.

26 See the announcement at htp://www.migpolgroup.com/news/3586.html and which says that "The content of the website will rely on MPG's experience and knowledge in the integration field, which includes the production of the Handbook on Integration for Policy Makers and Practitioners. MPG will also be working closely with EUROCITIES to mobilise and develop key stakeholder networks".

265 European Commission's Proposal for a Decision establishing the European Integration Fund for the period 2007-2013 as a part of the General Programme 'Solidarity and Management of Migration Flows', Brussels, COM(2005) 123 final, Brussels, 6 April 2005.

Article 4 of the Communication, $\operatorname{COM}(2005) 123$ final (ibid.), reads as follows: "The general objective of the Fund is to support the efforts of Member States in enabling third-country nationals of different cultural, religious, linguistic and ethnic backgrounds to settle and take actively part in all aspects of European societies as regards admission procedures, basic introduction programmes and activities, participation in civic and political life and respect for diversity and civic citizenship".

267 Council Decision establishing the European Fund for the Integration of Thirci-Country Nationals for the Period 2007 to 2013 as part of the General Programme "Solidarity and Management of Migration Flows", 2007/435/EC, 27 June 2007, OI L 168/18, 28.6.2007.

268 For more information about the Community actions of the Integration Fund see the following website http://ec.europa.ew/justice_home/funding/integration/funding_integration_en.htm

269 The Council Decision on the EFI starts by making reference to this provision of the TEC as its founding legal bases. 
Among the main features characterising the EIF, the following might be highlighted: ${ }^{270}$ Recital 10 of the Preamble and Article 2.1 clarify that the objective of the Fund is to contribute to national efforts by Member States to develop and implement integration policies enabling TCNs "to fulfil the conditions of residence and to facilitate their integration into European societies, in accordance with the CBPs". ${ }^{271}$ Article 2.2 emphasises that it should promote the development of "national integration strategies for third country nationals" taking into account the two-way process principle (CBPI). The specific objectives of the Fund are provided in Article 3, which stipulates the following four of them: First, to facilitate the development and implementation of "admission procedures" relevant to and supportive of integration; Second, to develop the integration of "newly-arrived third country nationals" in the Member States; Third, increasing the Member States' capacity to develop, implement, monitor and evaluate policies on integration; and Fourth, exchange of information, best practices and cooperation among the Member States.

The EIF primarily targets the co-financing of concrete actions supporting the integration of "newly-arrived third country nationals". ${ }^{272}$ According to Article 1.2, non-nationals who are in a third country and who are complying with "pre-departure measures and/or conditions set out in national law, including those relating to the ability to integrate in the society of this Member State fall under the scope of this Decision". Recital 6 of the Preamble of the Council Decision states that the CBPs are "complementary to and in full synergy with" EU immigration law. 273 Further, Recital 19 states that the criteria for allocating financial amual resources to the Member States should take into consideration the total number of TCNs legally staying in their territory and the total number of immigrants newly admitted over a given period. Therefore, it appears that the EIF actually benefits the richest Member States, which attract most third country nationals. Article 12 states that there will be an annual Fund allocation of 500,000 euros each year. ${ }^{274}$ The remainder of the available annual resources will be broken down between the Member States as follows: On the one hand, $40 \%$ in relation to the average of the total number of legally residing third country nationals over the previous three years; and on the other hand, $60 \%$ in proportion to the number of third country nationals who have obtained an authorisation to reside on its territory over the previous three years. ${ }^{275}$ The way in which it works in practice is as follows:

270 For as study of all the financial programmes offered by the European Commission supporting integration, and which include the EIF, see M. A. Kate and J. Niessen (2007), Locating Immigrant Integration Policy Meastre in the Machineny of the Europeon Commission, Migration Policy Group: Brussels.

271 For the specific objectives see Article 3 of the Decision, and the eligible actions in Article 4

272 The Council Decision states in recital 13 of the Preamble that "Reference, could be made in this context to Council Directive 2003/109/EC of 25 November 2003 concerning the status of third-country nationals who are longuterm residents which refers to the period of five years of legal residence as a requirement with which third-country nationals have to comply in order to qualify for long-term residence status".

273 The recital reads as follows "The Common Basic Principles are complementary to and in full synergy with the Community legislative instruments on the admission and stay of legally residing third-country nationals concerning family reunion and long term residents, and other relevant existing legislative frameworks, including those relating to gender equality, non-discrimination and social inclusion".

274 Of the 825 million Euros, a total of 768 Euros is distributed among the Member States. The remaining $7 \%$ ( 57 million Euros) remains to finance European-level actions.

275 The following categories of TCNs are excluded for the purpose of the calculation related to the last $60 \%$ : seasonal workers, TCNs admitted for the purposes of studies, pupil exchange, unremunerated training or voluntary service, and those admitted for scientific research, as well as TCNs who have received a 
The European Commission adopts strategic guidelines establishing a framework for intervention which shall give priority to the promotion of the CBPS and to develop "a common approach to the integration of third country nationals in the EU". 276 Another key strategic guideline identified by the Commission's Decision establishing specific priorities that will be covered by EIF between 2007-2013 has been "the development of indicators and evaluation methodologies to assess progress, adjust policies and measures and to facilitate co-ordination of comparative leaning", as well as "of common models and standards at EU level" ${ }^{277}$ Possible actions that the Member States could include within this strategic guideline are for instance: supporting research on indicators and benchmarking for measuring the progress of immigration and integration, and developing monitoring tools and evaluation schemes, or developing indicators and evaluation methodologies to assess introductory programmes. On the basis of the strategic guidelines, Member States present a draft multiannual programme, which will be implemented in annual programmes $^{278}$ and require approval by the Commission. When preparing their draft multiannual programmes, Member States are requested to target from throughout the available Community resources under the EIF at least three of the priorities identified by the Commission. Among the various priorities, those dealing with the implementation of actions designed to put the CBPS into practice (Priority 1) and those of indicators and evaluation mechanisms (Priority 2) are mandatory. ${ }^{27 \%}$

The EIF will make possible 'matching ambitions' (corresponding with the CBPs) to actual 'results' (projects and programmes) at the national and EU levels. The allocation of this funding scheme to the EU soft-law framework will facilitate a greater impact of the latter at various levels of governance. The first launch of project proposals was published by the European Commission in December 2007. ${ }^{280}$ Under this call for proposals, "transnational actions

renewal of an authorisation issued by a Member State or a change of status, including TCNs who acquire long-term resident status in accordance with Council Directive 2003/109/EC.

276 European Commission, Decision Implementing Council Decision 2007/435/EC as regards the adoption of strategic guidelines for 2007/2013,21/VI11/2007.

277 The Decision elaborates frames this strategic guideline as Priority 2, which is elaborated as follows: "The integration of third-country nationals is a dynamic area of expertise and practice. Its evolving character is a crucial element which can enhance success in this area. One of the main success factors is constant measuring and monitoring of policies and activities so that they bring the results which are intended. Development of clearly-defined objectives and assessment instruments is of the utmost importance in order to be more effective. Such instruments should be encouraged at all levels of integration governance, i.e. national, regional, local and European. They are also important for the development of common models and standards at EU level".

27s Article 19 states that "2. The Commission shall provide the Member States, by 1 July of each year, with an estimate of the amounts to be allocated to them for the following year from the total appropriations allocated under the annual budgetary procedure, calculated as provided by Article 12. 3. Member States shall submit to the Commission, by I November of each year, a draft annual programme for the following year,...". Article 20 provides the Mid-Term Review of the Multiannual Programme, and in its paragraph 1 provides that "The Commission shall review the strategic guidelines and where necessary, adopt, by 31 March 2010, revised strategic guidelines for the period 2011 to 2013".

Other priorities include: Priority 3: "Policy capacity building, co-ordination and intercultural competence building in the Member States across the different levels and departments of government"; Priority 4: "Exchange of experience, good practice and information on integration between the Member States". See pages 4-5 of the Annex of the Decision implementing the Decision 2007/435/EC.

European Commission, Press Release, Integrating Third Country Nationals: The Commission launches the 2007 Call for Proposals under the New Community Actions of the European Fund for the Integration of Third Country Nationals, IP/07/1882, Brussels, 10 December 2007. A total of 4,503 million euros have been allocated for the Community actions during 2007. 
promoting the integration of third-country nationals in the EU Member States have been funded". In particular, these actions needed to pursue one the following three principles: First, enhance interaction between third country nationals and Member State citizens and promote integration measures and best practices targeted at society as a whole; second, promote integration strategies and measures targeted at different immigrant groups; and third, reinforce the link between migration and integration policies.

\subsection{Potsdam and "Promoting Unity within Diversity"}

The German Presidency of the EU that took place during the first half of $2007^{281}$ organised an Informal Meeting of EU Ministers Responsible for Integration on 10-11 May 2007 in Potsdam (Germany), ${ }^{282}$ which aimed at renewing and fostering a political consensus among Member States on "integration efforts" at the EU and national levels, and a "frank exchange of views on how migration and integration interact". ${ }^{283}$ On that occasion, the former Vice President of the European Commission and responsible of the DG JFS, Frattini, presented the Second Edition of the Handbook on Integration and delivered a speech entitled "A Common Approach for European Policy on the Integration of Immigrants" on 10 May 2007, which emphasised the following elements: ${ }^{284}$ It was first highlighted that through the development of the Common Agenda on Integration a distinctive "European Approach to Integration" was now clearly recognisable. He then stated that "the link between migration and integration cannot be overemphasized" and put forward the following initiatives to consolidate the EU approach to integration, directly inspired by the Third Annual Report on Migration and Integration:

281 See the Programme of the German Presidency of the Council of the EU where it was emphasized that "Migrant integration is a prerequisite for the peaceful co-existence of people with different national, linguistic and religious backgrounds [...] Germany will take advantage of a meeting of the ministers responsible for integration issues to move forward work to develop a coherent approach to integration policy and intensify the exchange of experiences in this area. One focal topic will be dialogue with Islam. The Presidency also intends to strive to counteract intolerance, racism, anti-Semitism and xenophobia in all their manifestations. Intercultural dialogue can also play a key role in this area"; See The Federal Govermment of Germany, Europe - succeeding together, Presidency Programme, I January to 30 June 2007, page 18; See also the background paper for the Informal Mecting of Justice and Home Affairs Ministers, "Initiative concerning the European migration policy", held in Dresden on 14-16 January 2007 (both documents are retrievable from http://www.eu2007, de/en on January 2007).

In fact, the call for organising informal meetings of EU Ministers in charge of integration was first included in the Commission Communication 2005/389, and was later on confirmed by the Council Conclusions on a Common Agenda for Integration of December 2005 which stated in paragraph 3 of the Conclusions that "The Council and the Representatives of the Governments of the Member States believe that in order to pursue effectively a Common agenda for integration, the Presidency Troika, in cooperation with the Commission, should agree arrangements on the organisation and timing of Ministerial discussions and/or Conferences. These should be held regularly, ideally on an annual basis and, with a view to continuing the political debate initiated at the Conference of Groningen on 9-11 November 2004, should consider pertinent and thematic issues on the integration of third-country nationals in the EU and assess the need for further action. The Ammual Report on Migration and Integration, enhanced as necessary to aid analysis and comparative learning, could provide a useful basis for such discussions", page 38 .

Refer also to The Federal Govermment of Germany, German Presidency of the Council of the EU, Informal Meeting EU Integration Ministers, Postdam, 10/11 May 2007', Information from the Presidency, retrievable from http://www.eu2007.de/en on January 2007. 
First, European Modules for Migrant Integration (EMMI). Based on the identified interests of some Member States in integration programmes, he proposed to study the possibility of developing European-wide programmes, "using the experience gathered in the drafting of the Handbook on Integration". The modules could in this way deal with various dimensions such as introductory courses, and would provide guidelines and common standards. ${ }^{285}$

Second, the development of a common European system of evaluation and monitoring of integration policies through "benchmarks and indicators". Frattini stated

To that end, the Annual Report on Immigration and Integration should be improved and become a more comprehensive information and monitoring tool, covering Member States activities in more detail, including policies at local level and the contribution of civil society. To help steer the EU agenda, it should also identify new areas for action and make recommendations for funtre policy. (Emphasis Added.)

In this respect the former Commissioner alluded to the work already developed by the British Council, which together with the Migration Policy Group (MPG) and other experts had developed the so-called "Migrant Integration Policy Index", MIPEX (for a detailed study see Section 4.1. below).

Third, investigating a new approach in relation to the concept of "active participation and citizenship" as a way for ensuring immigrants' participation in society. Frattini moved beyond the former concept of "civic citizenship" and proposed a new approach called "active participation", according to which the rights and obligations of the immigrants are not seen in the context of the length of residence, but rather on the basis of their 'economic life' and membership in the labour market through a work contract. ${ }^{286}$

The meeting at Potsdam was followed by the JHA Council Conclusions on "Strengthening of Integration Policies in the European Union by promoting Unity in Diversity" of 12-13 June $2007,{ }^{287}$ which started by expressing

... the need to promote a global and coherent approach to integration policies, migrant flow management, development and cooperation with the countries of origin. They recognise the complementary linkage between immigration and integration.

After confirming the global fashion of the common EU immigration policy, the Council entered into some elements related to the conceptual understanding of integration by first referring to the dynamic two-way process principle "which should be underpinned by an agreed value system". Also, it was said that those TCNs aiming at staying permanently "should make a deliberate effort to integrate, in particular leaming the language of their host society, and understanding the values of the European Union". The reference to a deliberate effort to integrate and understand the values of the EU raise a number of questions: Who really understands these national and/or European values? Which values are they talking about? The word value becomes increasingly prominent in the nomativity of integration and of the responsibilities on the side of the TCNs to

285 The modules would be developed by 'experts', under the guidance of the NCPs, for implementation at national level.

286 He expressly said that "Fundamental rights of immigrants will not be linked to their length of stay, whereas obligations can vary on the basis of the duration of the work contract. For instance, if an immigrant has a two-year contract, he/she will be required to learn the local language and the institutional framework of a given country. Those who stay longer, on the other hand, would have to pass an additional set of requirements prior to receiving permanent residence in the host countries".

287 Council of the European Union, Justice and Home Affairs Council Meeting 2807, Press Release, 10267/07, Luxembourg, 12-13 June 2007. 
integrate. ${ }^{288}$ Furthermore, the Council invited the NCPI and the European Commission to explore and study the possibilities of expanding the "European approach" of integration in relation to the following themes and ideas, most of which were very much related to those underlined by the previous Frattini's speech at Potsdam:

First, conceptions and approaches of participation and citizenship, taking into account, for instance, an exchange of views and experiences as regards the naturalisation systems being applied in Member States.

Second, the added value of common EMMI. ${ }^{289}$

Third, improve the public image of immigration by enhancing the capacity of public institutions and the media "to reflect in balanced way and manage migration-related diversity in society".

Fourth, the ways in which integration programmes and policies can contribute to the prevention of social alienation and radicalisation. "The lack of integration" was perceived as a cause of radicalisation and acts of political violence qualified as terrorism. ${ }^{290}$ In this respect reference can be made to the Commission Communication concerning Terrorist recruitment: Addressing the Factors contributing to Violent Radicalization, COM(2005) 313 of 21 September $2005,{ }^{291}$ states that

In the majority of cases, third-country nationals have integrated well within the Member States of the EU. However, if integration fails it can provide fertile ground for violent radicalization to develop... alienation from both the country of origin and the host country can make it more likely for a person to look for a sense of identity and belonging elsewhere such as in a powerful extremist ideology. (Emphasis added. $)^{292}$

288 Paragraph 3 of the Conclusions provided that "The Council and the Representatives of the Governments of the Member States emphasise the need to continue to strengthen the integration policies of Member States with a view to managing diverse societies, counteracting all forms of discrimination and intolerance, maintaining social cohesion and ensuring that immigrants are able to reach their full potential and are able to participate to the fullest extent possible in the social, economic, cultural and civic life of the relevant Member State".

The exact wording is "examine the added value of developing common European modules for migrant integration as a full project in the light of experience at national levels with introduction and language courses, the involvement of the host society, promoting the participation of immigrants in local life and various other aspects of the integration process".

S. Carrera (2006), "Integration of Immigrants versus Social Inclusion? A Typology of Integration Programmes in the EU", in T. Balzacq and S. Carrera (2006), Security versus Freedom? A Challenge for Europe's Future, Ashgate: Hampshire, pp. 87-112; See also S. Carrera and F. Geyer (2007), Terorism, Borders and Migration: The Commission's 2008 Policy Strategy in the Area of Freedom, Security and Justice, CEPS Policy Brief No. 131, June 2007, Centre for European Policy Studies: Brussels; T. Balzacq and S. Carrera (2005), The EU's Fight against International Tenorism: Security Problems, Insecure Solutions, CEPS Policy Brief, No. 80, Centre for European Policy Studies: Brussels; See also D. Bigo and S. Carrera (2004), From New York to Madrid: Technology as the ultra-solmion to the permanem state of fear and emergency in the EU, CEPS Commentay. Centre for European Policy Studies, CEPS: Brussels.

291 Commission Communication concening Terrorist recruitment: Addressing the Factors contributing to Violent Radicalization, COM(2005) 313 final, (Brussels, 21 September 2005); Commission decision of 19 April 2006 setting up a group of experts to provide policy advice to the Commission on fighting violent radicalisation, OJ L I11, 24.4.2006, pp. 9-11.

292 Point 2.4.1 of the Communication. Preventing 'people' turning into terrorists constitutes one of the four pillars of the European counter-terrorism strategy. Council of the European Union, The European Union counter-terrorism strategy: Prevent, protect, pursue, respond - The European Union's strategic 
Fifth, promote the development of common indicators and indexes to be used by the Member States "on voluntary basis" to assess their own policies.

Finally, the Council considered that "intercultural dialogue has become an important instrument in fostering the successful integration of citizens of different origin, culture and religion in Europe and in counteracting racism and extremism". The Council called the Member States to start exchanging information in this regard within the framework of the 2008 Year of Intercultural Dialogue. ${ }^{293}$

\subsection{Latest Developments: Principles, Actions and Tools for a Renewed Agenda}

The publication of the Communication on "Towards a Common Immigration Policy" COM(2007)780 of 5 December $2007^{294}$ represented the formal expression of a renewed commitment by the European Commission to progressively establish a common immigration policy in the EU. The driving approach inspiring the Communication appears to be based on justifying further progress towards a harmonised policy because of the multifaceted logics of economic opportunities, economic growth, competitiveness and prosperity that it would bring to Member States and the Union as a whole ('The European interest'). ${ }^{295}$ The "integration of legal migrants" entails, in the words of the Commission, social and economic costs and calls for an "integration policy based on non-discrimination, equal treatment,... allows immigrants to contribute more to society, and improves their potential in education and employment". ${ }^{296}$ After reiterating the nexus between immigration and integration policy, the Communication stipulated that integration needs to be understood as a "continuum' "running from entry, through settlement and to social and economic inclusion". Special reference was made to "the strong political demand", shown by the adoption by the Council of the CBPS on Integration and the EIF, and "the pragmatic approach" characterising the EU Framework on Integration. ${ }^{297}$ When dealing with what the Commission calls the "integration challenge", special importance was attributed, among other dimensions, ${ }^{298}$ to the role of language skills. ${ }^{299}$ Further, anti-discrimination and

commitment to combat terrorism globally while respecting human rights, and make Europe safer, allowing its citizens to live in an AFSJ, Council Document 14469/4/05, 30.11.2005, pp. 7-9.

It also stated that "The Council and the Representatives of the Governments of the Member States further welcome the initiative of Germany to convene the first two expert meetings for this purpose and with a view to the preparation, in consultation with the NCPI, of a report for the Ministerial Conference in 2008, which should include proposals for the establishment of a flexible procedure capable of reacting to intercultural problems or conflicts with a potential cross-border dimension".

Commission Communication, Towards a Common Immigration Policy, COM(2607)780 final, SEC(2007) 1632, Brussels, 5.12.2007.

295 These logics become clear when looking at the language used (e.g. economic opportunities, economic needs, targeted financial instruments, budgetary implications, labour force and shortages, economic development, public finances, contribution to the prosperity of the EU, etc), and some of its phrases such as the one saying that "The EU lags behind other main immigration destinations in terms of integration. The potential for significant overall gains from immigration can only be realised if integration is successful".

Page 2 of the Introduction.

297 See page 4 of the Communication.

298 Other sectors included, for instance, public finances, access to the labour market, education, housing and health.

299 In page 9 it is provided that "Language skills are crucial for integration. Migrants may be trapped in a vicious circle in which access to the labour market is restricted because of inadequate language skills, 
equal rights were mentioned on several occasions as two fundamental aspects to be addressed in order to face the challenges posed by integration. ${ }^{300}$ Finally, the Lisbon Strategy of 2000 comes once again into the picture in the following manner:

Effective integration of new immigrants and those already present in the labour market is an essential condition for achieving the Lisbon goals of growth and jobs.

In the beginning of 2008, Barroso, President of the European Commission, launched an internal brainstorming exercise about the future key policy priorities for the development of an AFSJ. ${ }^{301}$ Migration was placed as one of the central political objectives. ${ }^{302}$ Barroso's increased interest to foster 'more results' on migration was accompanied by the French government's enthusiasm over this domain during its Presidency of the EU (July-December 2008). The French Presidency collaborated informally with the Commission in the adoption of a strategy to adopt a set of general policy guidelines upon which the near-future EU policy on immigration would be further developed in the context of the next multi-annual programme on an AFSJ (the successor of the Hague Programme), which is expected to be agreed under the auspices of the Swedish Presidency sometime during the second half of 2009 . This strategy materialized in the presentation of two policy measures: First, a Commission Communication on a common immigration policy, and second the presentation by the French government of the so-called "European Pact on Immigration and Asylum".

The Communication on "A Common Immigration Policy in Europe: Principles, Actions and Tools" COM(2008)359 of 17 June 2008 provided the new political vision of the European Commission for the further development of a common EU immigration policy. ${ }^{303}$ This common policy, the text argues, should aim at a "coordinated and integration approach to immigration" at

while language skills are developed through employment and training. Acquiring the language of the host country can be particularly important for migrant women who may otherwise be cut off from their new society and have difficulties in helping their children integrate at school".

This is the case for example in page 2 of the Introduction that reads as follows "An integration policy based on non-discrimination, equal treatment, rights and duties allows immigrants to contribute more to society, and improves their potential in education and employmen", or in page 8 that states that "antidiscrimination and equal rights policies are important for addressing some of the obstacles faced by immigrants and their descendents". Similarly, page 11 of the conclusion points out that "In parallel, fostering integration can help avoid prejudices and promote a tolerant and inclusive society. Antidiscrimination and equal rights policies are important for addressing some of the obstacles faced by immigrants and their descendents".

301 See Commission Communication, The European Interest: Succeeding in the Age of Globalisation, $\operatorname{COM}(2007) 581$ final, Brussels 3.10.2007, which states: "The EU is already working on many of the policy elements needed to equip it to take on the challenge of globalization with confidence...in the coming months, the Commission will be putting new ideas on the table to address these key challenges... Review of internal policies is already under way, aiming to reshape Europe to face gloablisation and give it the right platform to look beyond its borders." Further the Communication identifies "Migration in a Globalized World" as one of the key political objectives and states: "In a Europe with no internal borders, the changing demands of an ageing society and a labour market in constant evolution have challenged established assumptions about immigration... a new global approach is needed so that migration strikes the right balance between the risk of labour market shortages, economic impacts, negative social consequences, integration policies and extemal policy objectives".

D. Bigo, S. Carrera and E. Guild (2008), What Future for the Area of Freedom, Security and Instice? Recommendations on EU Migration and Borders Policies in a Globalising World, CEPS Policy Brief No. 156, March 2008, Centre for European Policy Studies, CEPS: Brussels.

303 Commission Communication, A Common Immigration Policy for Europe: Principles, Actions and Tools, $\operatorname{COM}(2008) 359$ final, 17.6.2008, Brussels. 
EU, national and regional/local levels. ${ }^{304}$ As regards the express references related to integration, it is first stated that "Apart from the economic potential, immigration can also enrich European societies in terms of cultural diversity. However, the positive potential of immigration can only be realised if integration into host societies is successful. This requires an approach which does not only look at the benefit for the host society but takes also account of the interests of the immigrants" 305 The Communication identified ten common principles upon which the common immigration policy is expected to be articulated, and grouped them under three main headings: Prosperity, Security and Solidarity. Integration has been placed under the heading of "Prosperity: The Contribution of Legal Migration to the Socio-Economic Development of the EU", and more particularly in subsection 3 entilled "Prosperity and Immigration: Integration is the Key to Successful Immigration". One of the ten common principles (number 3) reads as follows:

The integration of legal immigrants should be improved by strengthened efforts from host Member States and contribution from immigrants themselves ("two-way process"), in accordance with the Common Basic Principles on Integration adopted in 2004. Immigrants should be provided with opportunities to participate and develop their full potential. European societies should enhance their capacity to manage immigration-related diversity and enhance social cohesion. (Emphasis added.)

Among the set of concrete actions that the text proposes to be pursued at EU and/or Member State level in the field of integration the following might be highlighted:

First, to strengthen the "mainstreaming approach" of the EU Framework on Integration, mainly inside the European Commission itself, in order to cover 'globally' elements related to "civic participation", social inclusion, anti-discrimination, equal opportunities, access to employment, education, "intercultural dialogue", etc.

Second, to develop "mutual learning and exchange of best practices to strengthen the ability of host countries to manage their increasing diversity" and of "common indicators and adequate statistical capacity...to evaluate integration policy outcomes".

Third, "to support integration programmes for newly arrived immigrants" and

emphasizing practical intercultural skills needed for effective adaptation as well as the commitmen to findamental European values; this could be further explored by identifying the basic rights and obligations for newly arrived immigrants, in the framework of specific national procedures (e.g. integration curvicula, explicit imtegration commitments, welcoming programmes, natonal plans for citizenship and integration, civic introduction or orientation courses). (Emphasis added.)

Finally, the measure called the European Council to adopt the set of common principles which would constitute the basis upon which the common immigration policy will be taken forward. The Commission proposed that this process would occur through "coordinated and coherent action" by the EU and its Member States and by setting up a "common methodology" consisting of the translation of the common principles into common objectives and indicators that would

304 Further, the Communication emphasizes that "A common policy vision is needed which builds on past achievements and aims at providing a more coherent and forthcoming framework for future action by the Member States and the EU itself. The added value of the EU will be in providing European instruments where they are needed and providing the right framework for achieving coherence where Member States act on the basis of their competences. Transparency and mutual trust are now more than necessary for this common vision to be effective and deliver results".

See page 3 of the Communication. 
ensure their implementation. The European Commission would elaborate an annual report on the basis of the implementation of the common objectives and Member States' "national immigration profiles". 306 The implementation of the "concrete actions" would be monitored, on the basis of a Commission's repont, on an annual basis by the Spring European Council, which would be carrying out a "political assessment of the situation at European and national levels" and put forward recommendations.

One of the key priorities of the French Presidency of the Council of the EU's work programme has been the European Pact on Immigration and Asylum. ${ }^{307}$ The work programme expressly states that the Pact will aim at laying down 'the foundations' of a reinforced common policy and a number of strong political commitments on "common principles" to be monitored by the European Council. ${ }^{308}$ A first draft of the Pact was presented at the informal JHA Council meeting in Cannes on 7-8 July 2008, and the JHA Council meeting of 24-25 July in Brussels, ${ }^{309}$ where it was stated that

The Presidency proposes that the Member States adopt the Pact at the European Council in October, in order to express at the highest political level the common principles that are to guide migration policies at national and at EU level, as well as strategic guidelines to be pursued to flesh them out.

The Pact presents general principles structured around "five basic political commitments".310 One of these commitments has been entitled "organize legal immigration to take account of the priorities, needs and reception capacities determined by each Member State, and encourage integration". "Within this heading the Pact provides three concrete actions where integration is mentioned. Two of them aim at fostering, and developing further, some of the constitutive elements of the EU Framework on Integration, and another relates to the domain of family reunification.

306 According to page 15 of the Communication "The agreed common objectives and indicators will be factored into national immigration profiles... These profiles will ascertain the national labour market situation and immigration patterns and help to strengthen the evidence base for immigration policies that effectively address the priority needs of the Member States. They will bring together all relevant information needed and their scope will cover both immigrants already in their territory and potential immigrants. These profiles will look at the skills composition of the immigration population and identify future labour needs".

307 French Presidency of the Council of the EU, Work Programme, Europe Taking Action to meet Today's Challenges, (1 July - 31 December), page 17 on 'Towards a Renewed Political Commitment on Asylum and Immigration', retrievable from www.ue2008.fr

The Programme states that "Thus, within the framework of the Pact, the French Presidency will call for legal immigration to be organised, taking into account the Member States' needs and their abilities to take in immigrants; for integration to be promoted; for illegal immigration to be combated, in particular by ensuring that illegal immigrants are actually removed; for Europe to be better protected by more effective border controls; for a Europe that provides asylum to be developed; and for a partnership to be built with the migrants' countries of origin and transit countries, to contribute to their development", page 17.

309 Council of the EU, Justice and Home Affairs $2887^{\text {th }}$ Council meeting, Brussels, 24 and 25 July 2008 , $11653 / 08$.

310 French Presidency of the Council of the EU, European Pact on Immigration and Asylum, Unofficial version dated 4 July 2008. Available at www.libertysecurity.org

311 The other 'commitments' are: control irregular immigration by ensuring the return of irregular aliens to their country of origin or a country of transit; make border controls more effective; construct a Europe of asylum, and create a comprehensive partnership with the countries of origin and transit to encourage the synergy between migration and development. 
As regards the actions dealing with the EU Framework, the current version of the Pact alludes to the CBPs and invites the Member States to develop ambitious policies "of immigrants who are likely to settle permanently". The two-way process paradigm is now presented in different fashion following a 'balance metaphor' according to which integration policies would be based on "a balance between migrants" rights (to education, work, security and public and social services) and duties (compliance with the host country laws, etc)". Reference is made to the need to promote the exchange of information on "best practices" in terms of reception and integration. It develops further the concept of 'duties' by stressing that

They will include specific measures to promote language-leaming and access to employment, an essential factor in integration; they will stress respect both for national identities of Member States and the European Union and their fundamental values such as human rights, freedom of expression, tolerance, equality between men and women, and compulsory school attendance (Emphasis added.)

Moreover, another action concerns the policy area of family reunification and calls for the latter to be "better regulated" by

Inviting each Member State, in compliance with the European Convention for the Protection of Human Rights and Fundamental Freedoms, to take account in its national legislation of its own reception capacities and families' integration capacities as evaluated by their resources and accommodation in the host country and, for example, their knowledge of that country's language (Emphasis added.)

\section{Integration and the Treaty of Lisbon}

The Treaty of Lisbon ${ }^{312}$ signed on 13 December 2007 would emerge from the combination of the amendments included in the Mandate for the work of the Intergovernmental Conference (IGC) as agreed to in the German Presidency Conclusions of 21-22 June 2007, ${ }^{313}$ as well as from those included in the text adopted by the Intergovernmental Conference of Heads of State and Govemment in Lisbon on 18 October 2007, which was actually based on the work of the Working Party of Legal Experts published on 5 October 2007. ${ }^{314}$ The Treaty would generate two separate bodies of law: an amended version of the Treaty on European Union (TEU) and the Treaty on the Functioning of the Union (TFU). The TFU, which would be the new denomination of the current Treaty establishing the European Community (TEC), contains a new Title V "Area of Freedom, Security and Justice", comprising five chapters and bringing together the currently dispersed FSJ policies (Articles 67-89). While the future of the Treaty is at present at stake after the 'no-vote' resulting from the Irish referendum on the Lisbon Treaty of 12 June 2008 , it is deemed necessary to assess the major innovations that would be introduced by the

$3 ! 2$ Treaty of Lisbon amending the Treaty on European Union and the Treaty establishing the European Community, signed at Lisbon, 13 December 2007, 2007/C306/01, OJ C306/01, 17.12.2007. See House of Lords (2008), The Treaty of Lisbon: An Impact Assessment, European Union Committee, $10^{\text {th }}$ Report of Session 2007-2008, Volume I: Report, House of Lords: London; S. Carrera and F. Geyer (2008), "The Reform Treaty and Justice and Home Affairs: Implications for the Common Area of Freedom, Security and Justice", in E. Guild and F. Geyer (eds), Security versus Justice? Police and Judicial Cooperation in the European Union, Ashgate: Hampshire, pp. 289-307.

313 Council of the European Union, Brussels European Council, Presidency Conclusions, 21 \& 22 June 2007, Brussels 20 July 2007, $11177 / 1 / 07$.

314 Conference of the Representatives of the Governments of the Member States, Intergovernmental Conference (IGC) 2007, Draft Treaty amending the Treaty on European Union and the Treaty establishing the European Community, Brussels, 5 October 2007. 
new institutional configuration as regards the area of integration of TCNs. ${ }^{315}$ The Treaty would contain an express legal basis in the TFU to promote the integration of legally resident TCNs. The new Article 79.4 provides that

The European Parliament and the Council, acting in accordance with the ordinary legislative procedure, may establish measures to provide incentives and support for the action of Member States with a view to promoting the integration of third-country nationals residing legally in their territories, excluding any harmonisation of the laws and regulations of the Member States. (Emphasis added.)

In light of the above, while it appears that integration policy would not be subject to proper harmonisation processes at the EU level, the current soft-law multilevel setting would be granted a clear Treaty legal basis. It would therefore offer the possibility for the latter to become institutionalised. European cooperation in the field of integration would also benefit from the ordinary legislative procedure, which corresponds to the current co-decision procedure envisaged in Article 251 TEC (European Commission right of initiative and qualified majority voting - QMV - in the Council). This would ensure a higher degree of efficiency, legal certainty, accountability and democratic control of the laws and policies being developed. The role of the EP and national Parliaments would also be strengthened in comparison to the present state of affairs. The EP is still not sufficiently involved in the decision-making processes covering the area of integration. This innovation would provide a response to claims about a democratic deficit ${ }^{316}$ consisting of a lack of proper democratic accountability affecting areas developed through soft-law mechanisms such as the EU Framework on Integration.

The role of the national Parliaments would be particularly relevant as regards the principle of subsidiarity. According to the Protocol on the Application of the Principles of Subsidiarity and Proportionality, national Parliaments would benefit from a reinforced control mechanism. Article 6 of that Protocol states that any national Parliament or any chamber of a national Parliament may within eight weeks from the date of transmission of a draft legislative act send to the Presidents of the EP, the Council and the Commission a reasoned opinion stating why it considers that the draft in question does not comply with the principle of subsidiarity. ${ }^{317}$ The Committee of Regions would be also recognized an enhanced role in the subsidiarity test as

315 For a study of the main innovations that will be introduced by the new institutional configuration presented by the Treaty as regards an AFSI refer to S. Carrera and F. Geyer (2007), The Reform Treaty: and Justice and Home Affairs: Implications for the common Area of Freedom. Security and Justice, CEPS Policy Brief No. 141, August 2007, Centre for European Policy Studies: Brussels.

316 M. den Boer, "The European Convention and its Implications for Justice and Home Affairs Cooperation", in J. Apap (ed.), Justice and Home Affairs in the EU: Liberty and Security Issues after Enlargement, Edward Elgar Publishing: Cheltenham, pp. 121-133; M. Anderson and J. Apap (2002), Striking a Balance between Freedom, Security and Justice in an Enlarged European Union, Centre for European Policy Studies, CEPS: Brussels, pp. 25-28; J. Apap and S. Carrera, "Progress and Obstacles in the Area of Justice and Home Affairs in an Enlarging Europe", in J. Apap (ed.), Justice and Home Affairs in the EU: Liberty and Sectrity Issues after Enlargement, Edward Elgar Publishing: Cheltenham, pp. I24.

317 Moreover, Article 7.3 reads as follows "Where reasoned opinions represent at least a simple majority of the votes allocated to the national Parliaments in accordance with the second subparagraph of paragraph 1, the proposal must be reviewed. After such review, the Commission may decide to maintain, amend or withdraw the proposal. If it chooses to maintain the proposal, the Commission will have, in a reasoned opinion, to justify why it considers that the proposal complies with the principle of subsidiarity. ... if by a majority of $55 \%$ of the members of the Council or a majority of the votes cast in the European Parliament, the legislator is of the opinion that the proposal is not compatible with the principle of subsidiarity, the legislative proposal shall not be given further consideration". 
regards those European policies where the local and regional dimensions will have a prominent role, such as integration policy. Article 8 of the same Protocol grants the Committee the possibility to present an action before the ECJ on grounds of infringement of the principle of subsidiarity and against legislative acts for the adoption of which the TFU provides its consultation before proposing legislative acts. ${ }^{318}$

The ECJ, which would be denominated the Court of Justice of the European Union, would also have full jurisdiction to review and interpret legislative measures related to an AFSJ. At present the jurisdiction of the Court over the EU Framework on Integration is limited, if not completely absent. ${ }^{319}$ It is, however, uncertain the extent to which the jurisdiction of the Luxembourg Court would cover the review of legal measures falling outside proper legal harmonisation. Finally, and as we will study in detail in Chapter 7, the Charter of Fundamental Rights would become a legally binding and justiciable bill of rights at the EU level. ${ }^{320}$ The new Article 6 TEU would contain a cross-reference to the Charter, granting it "the same legal value" as the Treaties. This would render the Charter directly legally binding for the European institutions, Union bodies, offices and agencies as well as Member States when they implement Union law. The mandatory nature of the Charter would put EU actors and Member States under a clear legal obligation to ensure that in all legal acts related to an AFS fundamental rights are also duly respected. ${ }^{321}$

\section{The EU Framework on Integration as an Alternative Form of OMC}

\subsection{Nature, Methods and Tools}

The nature, methods and some of the tools composing the EU Framework on Integration fall within the category of soft-law, and their implementation can be seen as a peculiar version of the Open Method of Coordination (OMC) ${ }^{322}$ of the kind proposed by the European Commission in

318 See Article 2 of the Protocol.

31.) E. Guild and S. Peers (2001), "Deference or Defiance? The Court of Justice's Jurisdiction over Immigration and Asylum", in E. Guild and C. Harlow (eds), Implementing Amsterdam: Immigration and Asylum Rights in EC Low, Hart Publishing: Oxford.

320 The Charter of Fundamental Rights of the Union, OJ C-364/1, 7 December 2000. See also Council of the European Union, Charter of Fundamental Rights of the European Union, 15535/07, Brussels, 26 November 2007.

321 The LIBE Committee's Opinion in the EP's Report on the Treaty of Lisbon states that "making legally consistent, binding and transparent, at Treaty level, the relationship between the fundamental rights outlined in the Charter of Fundamental Rights of the European Union and the related EU policies needed to ensure the protection and promotion of those rights. With a binding Charter, the EU legislator will now be able to implement in a more consistent way all policies which could affect the fundamental rights of a person. This will be the case not only as regards the policies expressly comprised in the area of freedom, security and justice, such as the right of asylum, or the right to a fair trial, but also as regards the more general policies linked to the protection of human dignity against any form of discrimination, the protection of minorities, the right to transparency and to sound administration at European level, social rights and the right to data protection". European Parliament, Report on the Treaty of Lisbon, 2007/2286(INI), A6/0013/2008, 29 January 2008. See also European Parliament, Resolution on the Treaty of Lisbon, 2007/2286(INI), 20 February 2008, which in paragraph 3 titled "Affirming Values, Strengthening Rights of Citizens, Improving Clarity" establishes that "the EU Charter of Fundamental Rights... will give the citizens of the Union legal certainty, ensuring that all provisions of EU law, and all action taken by the EU institutions or based on EU law, will have to comply with those standards". 
2001 (See Section 2.1.2. of Chapter 2 above). ${ }^{323}$ The Framework illustrates a way in which a version of the $\mathrm{OMC}$ is actually being implemented at the EU level in an immigration-related area. The similarities with the $\mathrm{OMC}$ put forward by the Commission Communication $\operatorname{COM}(2001) 387$ become transparent when making a comparison between the two configurations:

A first point in common is that the EU Framework on Integration aims at complementing the enactment of the ordinary EU legislative framework on regular immigration. Further, this setting intends to influence Member State national policies and programmes on integration as a result of fostering informal discussions, the exchange of information ('knowledge sharing') and transnational coordination. Further, in the 2001 version of the OMC, the Council was supposed to present "Multi-annual Guidelines for the Union". The conjunction between the CBPs on Integration and the rules according to which the EIF is going to work may potentially have similar effects on Member States. The latter will need to show the implementation of policies in compliance with the CBPS if they want to pass satisfactorily the mechanisms of review and assessment that have been envisaged in the Council Decision establishing the EIF 2007/435/EC, and hence benefit from European funding. Another point demonstrating links is the publication by the Commission of Handbooks and Annual Reports on Migration and Integration, which, in cooperation with the NCPI and 'independent experts' aim at synthesising trends in national and European policies, "to act as a driver for the exchange of information and best practices" and propose policy recommendations. Finally, the role played by evaluation (benchmarking and indexing) also sheds some light as regards the connotations of the EU Framework on Integration as a version of $O M C$.

It is also true that both framings present distinctions. The EU Framework does not formally aim in the long-term at any potential legislative harmonisation. This has been confirmed by the new Article 79.4 TFU (see Section 2 above). Also, the functions and powers enjoyed by the Commission are more limited and blurred when ensuring coordination and Member State compliance with the CBPS. There is also the broad and rather general nature of the actions proposed by the Commission to implement the CBPs in the domestic arenas. Another difference relates to the way in which Member States under the OMC would need to present in a rather formalistic and elaborative manner National Action Plans (NAPS) including a whole range of issues allowing a review to be carried out by the European Commission and the Council, and the identification of problems encountered and lessons learned/best practices.

That notwithstanding, the similarities that the EU Framework on Integration has with the 2001 OMC for a Community Immigration Policy are undeniable, even though some of their features do not perfectly match. It could therefore be argued that the EU Framework actually constitutes a non-formally recognised or quasi-OMC. What are the most significant factors and principles upon which the EU Framework on Integration as a quasi-OMC has been developed? And what are their major implications and effects? The following can be emphasised:

First, ever since 2001 there has been repeated recognition at the EU official level that Member States maintain the main competence and a high degree of discretion when adopting and implementing policies in the area of integration. ${ }^{324}$ This is a field which has been considered to

323 Commission Communication, on a Open Method of Coordination for the Community Immigration Policy, COM(2001)387, Brussels, 11.7.2001.

324 See for instance paragraph 31 of the Thessaloniki European Council Conclusions which stated "While primary responsibility for their elaboration and implementation remains with Member States,...": See also Paragraph 3 of the JHA Council Conclusions of November 2004 that said "The development and 
be closely intertwined with the Member States' realm, and as having its major implications and repercussions at the local and regional levels. There has been a common official understanding at the EU level that the diversity and competences of the national, local and regional levels need therefore to be preserved. The principle of subsidiarity has in this way played a determining role in any attempt at progressively Europeanising these policies.

Second, the Framework constitutes a pragmatic alternative to the Community method. It aims at facilitating the coordination, the exchange of information, the promotion of 'best practices' and 'lessons learned' among Member States through other means. It also makes reference to the use of evaluation and impact assessments of existing policies, programmes and practices trough a patchwork of strategic techniques of management which include, for instance, benchmarking, common indicators and indexing (See Section 4 below). European integration takes place not only through proper laws or norms, but also on the basis of exchange of information, benchmarking and indicators. While these techniques have been conceived to exemplify a soft nature, they may actually prove to be not as soft as one would expect and very effective when applied to policy process frameworks in domestic realms. ${ }^{325}$

As it has been addressed in Section 1 of this Chapter, the EU Framework on Integration (in particular the CBPS, and to some extent the Handbooks) has proved to be a productive source of soft-law/soft-policy instruments whose influence has already been proved in some Member States. This has been the case even if the EU Framework is in such an early phase, given its official birth between 2002 and 2003. That influence has included, for instance, direct references in national policy processes, such as in the case of Spain (Chapter 5 of this book). In other cases the Framework has been part of official declarations and political statements at the national level. The effects that the Framework is having might well be more tangible and observable than when attempting to measure the short-term impact of the $\mathrm{OMC}$ in other European policy areas such as employment and social inclusion. Regarding integration, the quasi-OMC is proving to be an effective tool that is already showing 'some results' in terms of policy impact at various levels of governance in Europe.

Third, the normative outputs are not the classical Regulations, Directives or Decisions, but rather policy tools in the form of Communications, Annual Reports, Commission's Staff Working Documents, Handbooks, Common Agendas, etc., whose nature and effects are far from being commonly agreed to and clearly stipulated. These policy documents could fall within the label of 'soft-law'. It would be questionable the extent to which some of them could be at all considered as law per se. All of them lack any legally binding force, ${ }^{326}$ and in this way their

implementation of integration policy is therefore the primary responsibility of individual Member States rather than of the Union as a whole".

325 M. López Santana (2006), Domestic Implications of European Soft-Law: Framing and Transmitting Change in Employment Policy', Journal of European Public Policy, Vol. 13, No. 4, June 2006, pp. 481499. Lopez Santana argued the OMC has restrained several dimensions in the field of employment and labour market policies by: "(a) defining (and reinforcing) what problems domestic policy-makers should attack to increase member state competitiveness, and to deal with internal and external challenges; (b) pointing out and/or reinforcing the idea that a policy line is good or bad and necessary; (c) restricting and limiting the policy options and courses of action that domestic policy-makers should develop; and (d) providing potential courses of action that allow policy-makers to 'draw lessons' and to 'learn' about ways to solve or diminish the problem in question".

F. Snyder (1994), "Soft Law and Institutional Practice in the European Community", in S. Martin (ed.), The Constriction of Europe, Essays in Honour of Emile Noël, Kluwer: Dordrecht, pp. 197-225; See also L. Senden (2003), Soft Law in European Community Law: Its Relationship to Legislation, Wolf Legal Publishers: Nijmegen. 
effects differ greatly from the ones characterising ordinary EU law. ${ }^{327}$ The EU Framework on Integration has not envisaged any sort of formal enforcement mechanism to guarantee that the national arenas actually comply with the CBPs and 'best practices'. It is up to Member States to take advantage of the fruits of the Common European Agenda on Integration. Therefore, while soft-law might prove to be a useful tool for the achievement of more uniformity in the application of the law while allowing for a high degree of differentiation, ${ }^{328}$ the question remains as to how the use of soft-law and the OMC could really ensure a solid common policy and prevent soft-regulatory instruments from losing all their transnational significance, coherency and consistency when implemented in the national arena. Of course, the importance of the EIF cannot be underestimated. We have argued that the linkage of soft-law and/or soft-policy with a strong financial framework might constitute a very effective mechanism to ensure that only those national policies and programmes in compliance with the settled common objectives established in the CBPs will be funded. The funding scheme would therefore function as 'the incentive' of the trajectory and the controller of the consistency of a particular policy approach.

\subsection{Key Actors in the EU Framework on Integration}

The EU Framework on Integration establishes a multilevel system of governmentality substantially affecting relations among various European institutional actors, as well as their respective status and roles, which differs significantly from the one guaranteed by the Community method and the Treaties. The consequence of this institutional resettlement is that the traditional role of European institutions suffers and is altered, as are the premises of the EU. ${ }^{329}$ As regards the institutional dimension of the quasi-OMC on integration, it could be said that the Council and the European Commission so far appear to preserve the main voices in these transnational processes. The DG JFS of the Commission plays the sensitive role of struggling to promote the development of a blurred and dispersed common regulatory framework while at the same time not making the Council too nervous about the actual reach and potential of the progress being achieved and its effects, if any, on Member State sovereignties.

The involvement of the EP has been until recently rather weak, and almost non-existent when more important decisions have been made. This has been the case, for instance, as regards the CBPs, which were mainly adopted by the Council of the EU and the Representatives of the Governments of the Member States, after being greatly inspired by the Commission. The

327 As to the ways in which the hard-soft law academic debate might be actually resolved by putting both together in the context of a theory of 'hybrid constellations' see D. M. Trubek and L. G. Trubek (2005), "The Open Method of Coordination and the Debate over "Hard' and 'Soft' Law", in J. Zeitlin and P. Pochet (eds), The Open Method of Coordination Action: The European Employmen and Social hnclusion Strategies, P.I.E.-Peter Lang: Brussels, pp. 83-103; See also D. M. Trubek, P. Cottrell and M. Nance (2005), Soft-Law, Hard-Law and Ewopean Integration: Toward a Theory of Hybridity, Jean Monnet Working Paper 02/05, The Jean Monnet Programme, NYU School of Law, New York; For an account of the discussion as to whether we can refer the OMC as sofi-law, hard-law or non-law see V. Hatzopoulos (2007), 'Why the Open Method of Coordination is Bad for You: A Letter to the EU', Erwopean Lan' Joumal, Vol. 13, Issue 3, May 2003, pp. 309-342.

328 L. Senden and S. Prechal (2001), "Differentiation in and Through Community Soft-Law", in B. de Witte, D. Hanf and E. Vos (eds), The Many Faces of Differentiation in EU Law, Intersentia: Antwerpen, pp. 181-199.

329 V. Hatzopoulos (2007), "Why the Open Method of Coordination is Bad for You: A Letter to the EU', European Law Jounal, Vol. 13, Issue 3, May 2003, pp. 309-342. 
building of the EU Framework on Integration has shown a transparent democratic deficit over the dynamic policy outputs and various political compromises being reached and agreed to so far. Until now, the position of the EP, and its opinion as regards the EU Framework on Integration, has remained ad hoc and lacking any enforceable nature on the European Commission and even less with respect to the Council. ${ }^{330}$ Interestingly, other European bodies such as the EESC, the forum for organised civil society and social partners at the EU level, has also been an active player in the progress and developments of some of the conceptual premises, nature and tools of the current EU Framework. ${ }^{331}$

The institutional landscape of the EU Framework on Integration cannot be understood without granting the necessary attention to the networks that have been, or are in the process of being, established in this context. The NCPI, which brings together representatives from Member State Ministries in charge of the dossier of integration, has become a very influential setting conceming the ways in which the Framework is being developed as well as the consideration of future strategies. Their participation has taken place both in the drafting of the three Annual Reports on Migration and Integration published so far by the European Commission, in the renewal of their conception and methodology, and, most important, in the drafting of the two editions of the Handbooks on Integration with the MPG. The linkages between the NCPI and the Council structures are also increasingly considered to be necessary and in need of promotion. ${ }^{332}$ Indeed, the NCPI appears to have at present a certain degree of independence, and to some extent freedom, from those Member State representatives taking part in the Council Working Groups. The NCPI network has conformed itself as a forum with great potential, which is at present at the crossroads between 'the up' (European institutions) and 'the down' (Member States - national, regional and local realms). The nature and operability of this Network means the impacts of soft-law mechanisms and methods of cooperation characterising the EU Framework on Integration do not follow a simplistic and linear pattern of governance (bottomup or top-down), and provides a Forum facilitating the existence of a complex and rapidly evolving web of competing strategies with multilevel effects. That notwithstanding, until present

330 However, it needs to be underlined that the JHA Council Meeting of June 2007 did acknowledged the EP Report on Strategies and Means for the Integration of Immigrants in the European Union, 2006/2056/INI, A6-0190/2006, 17.5.2006, Committee on Civil Liberties, Justice and Home Affairs, Rapporteur: Stavros Lambrinidis. Yet, the Resolution was mentioned in the same degree of importance than others elaborated for instance by the EESC and the Committee of Regions. The Preamble of the Conclusions on "Strengthening Integration Policies in the European Union" stated that "Recalling the Report of the European Parliament on strategies and means for the integration of immigrants in the European Union of May 2006, the Opinion of the EESC on Immigration in the EU and integration policies: cooperation between regional and local governments and civil society organisations of September 2006 and the Opinion of the Committee of the Regions of May 2006 on the Commission on a Common Agenda for Integration, (among other activities developed at Community level on integration by the European Parliament, the Economic and Social Committee and the Committee of the Regions)".

331 EESC (2007), Immigration: The Role of Civil Sociery in Integration, Foreword by Franco Frattini, Office for the Official Publications of the European Communities: Luxembourg. For more information see the website of the SOC Section of the EESC at http://www.eesc.europa.eu/sections/soc/ index_en asp?id=1001 socen

332 See paragraph 11 of the JHA Council Conclusions of 12 and 13 June 2007 which provided that "The Council invites incoming Presidencies and the Commission to proactively develop the Common Agenda for Integration and to promote the principles set out in paragraph 1 . The Commission is further invited to report in particular to the [2008] Ministerial Conference on Integration on the results of the tasks assigned to the NCPI network, as described in point 9 of these Conclusions. This report should be the starting point for discussion on future priorities", see above note 263. 
they have provided a transnational venue prioritising certain policies, programmes and practices at the national level considered to be 'the best' or in need of promotion in the whole EU.

In addition, we cannot forget the role that the European Integration Forum will play in the near future (See Section 1.10 above). The Forum will include members of civil society and social partners constituting EU umbrella organisations and having a membership across a number of Member States, migrants' organizations and forums/platforms at the national level. The functions that will be attributed to this new European network will potentially ensure that the voice, experiences and interests of all these actors will be heard within the EU Framework on Integration. The relationship between the functions of the Forum and those of the NCPI will be of especial interest. Finally, the network of integration-related actors and stakeholders would not be complete without referring to the European networks of local and regional authorities. On the 5 November 2007 the European Commission together with Eurocities, ${ }^{33}$ signed the Milan Declaration. ${ }^{334}$ The Declaration recognized the key role of cities in integration policies and the need to strengthen their voices in the shaping of the EU's agenda on integration. It also opened the so-called "integrating cities process" as a platform for fostering the dialogue between cities on the relationship between the CBPs and the local dimension. ${ }^{335}$

\subsection{Implications of the Substantive and Institutional Elements of the EU Framework on Integration}

The legal outputs and network activities taking place within the scope of the quasi-OMC on Integration fall outside the system of checks comprising the EU legal system. Even though the JHA Council Conclusions of November 2004 stated that the CBPS are "complementary and in full synergy with existing legislative frameworks, including international instruments on human rights, Community instruments containing integration provisions, EU objectives on gender equality and non-discrimination, and other EU policies", there are no mechanisms or procedures for it to be reviewed and controlled outside the configurations of the European Commission and the Council. How does the EU Framework intend to ensure that the CBPs are, and will be, truly compatible with the EU legal system and its substantive foundations? What are the existing guarantees when the CBPs are transferred to the national level and Member States implement them (even by making a direct reference) into their domestic laws and policies? Is the implementation of the CBPs considered to be an action of Member States "within the scope of EU law", and does the ECJ therefore have jurisdiction to review and interpret that sort of "nonbiding implementation'? Would the EU general principles play any role in this regard?

333 Eurocities is the network of major European cities. Founded in 1986, the network brings together the local governments of more than 130 large cities in over 30 European countries. www.eurocities.org

334 See Milan Declaration, "Integrating Cities", was signed by the former Vice-President of the European Commission and Commissioner responsible for Freedom, Security and Justice, Franco Frattini, and Letizia Moratti and lvo Opstelten - the Mayors of Milan and Rotterdam respectively. See also the announcement at the Eurocities Flash (An Information System for Eurocities Members), $N^{\circ} 72$, November 2007, page 3. The first Integrating Cities (European Policies, Local Practices) Conference took place in Rotterdam (The Netherlands), the 8-10 October 2006. http://www.integratingcities.nl /introduction.php Refer to the website of the second Integrating Cities Conference of Milan that took place on the 5 and 6 November 2007 at http://www.integratingcities it/index.html

There are other umbrella organizations of local authorities, such as for example, ERLAI, a Brusselsbased network of regional and local officers on asylum and immigration, are also active players in the debate on benchmarking integration in the EU. 
It appears that most of the answers to these questions might receive a negative, or at least contested, answer. This becomes evident when taking into account that the jurisdiction of the ECJ remains absent from any review of the validity of the provisions included in soft-law measures and tools, and even more so as regards any potential national 'implementation'. ${ }^{336}$ As we will examine in Chapter 7, the general principles of EU law constitute a fundamental mechanism of Community Courts to ensure compliance of EU immigration law, and the national instruments transposing it, with the rule of law and liberty. The general principles of proportionality and fundamental rights centre on the protection of the individual against any illiberal acts and practices by the Union or a Member State when acting within the EU Framework. The principles facilitate a process according to which the practices of the liberal state, and the Union as a whole, are subject to judicial review. When studying the EU Framework on Integration, however, it is uncertain the extent to which these principles might actually display their effects due to the limitations inherent to their justiciability and uncertainties as regards their legal nature.

The security and liberty of the individual in relation to these processes is weak and vulnerable. What are the judicial remedies available to those TCNs whose European rights and freedoms might be affected by the EU Framework on Integration, and what constitutes national implementation by the different levels of Member State government (national, local and regional)? The limits applicable to the exercise of judicial review go hand-in-hand with a lack of effective remedies available to the individual to resist intrusions or derogations by Member States of the rights thereby provided. The relevance that the EU Framework on Integration might have over the rights of the individual, and particularly over those who do not hold Member State nationality, is potentially large, and this is something which will increase over time. The rule of law and fundamental rights could be endangered because of the lack of judicial accountability and review of the measures taken into consideration and being implemented. The degree of justice would remain very much in question regarding the progressive consolidation and development of the EU Framework on Integration.

\section{Benchmarking Integration in the EU}

Benchmarking has been presented as one of the main elements upon which the EU Framework on Integration is supposed to operate and develop in the years to come. ${ }^{337}$ As it has been highlighted above, the Justice and Home Affairs (JHA) Council Meeting of 19 November 2004 identified as one of the eleven CBPs the development of European criteria (indicators, benchmarks) for adjusting policy and to "evaluate progress on integration and to make the exchange of information more effective". In the same vein, the JHA Council Conclusions on Strengthening of Integration Policies in the European Union by promoting Unity in Diversity of 12-13 June 2007 gave the political mandate for the European Commission to promote the development of "common indicators and indexes" to be used by the Member States on a voluntary basis to assess their own policies. This Section examines the conceptual premises and practical methodologies through which attempts at benchmarking integration of TCNs at the EU level are being conducted. It first provides a 'state of the art' on benchmarking integration in the

336 For an in-depth study on the ways in which Community Courts may use soft-law for interpreting EC law, see L. Senden (2003), Soft Lau in European Community Law: Its Relationship to Legislation, Wolf Legal Publishers: Nijmegen, Chapter on "Indirect Legal Effects for the Judiciary", pp. 379-414.

337 S. Carrera (2008), Benchmarking Integration in the EU: Analyzing the Debate on Integration Indicators and moving it Forward, Study Commissioned by the Bertelsmann Stiftung Foundation Berlin, September. 
EU by looking at a selected group of studies and reports conducted by key actors from civil society and academia. The analysis focuses on the rationale, personal and territorial scope, conceptual setting and methodology. The assessment will then provide us with the necessary data to ascertain tensions and dilemmas characterising the benchmarking technique in the field of integration in the EU.

\title{
4.1 A State of the Art on Benchmarking Integration in the EU
}

\subsubsection{The Study on Benchmarking Immigrant Integration ${ }^{338}$}

This study was conducted by the European Research Centre on Migration and Ethnic Relations of the University of Rotterdam and was funded by the European Commission (DG JFS) in 2002. The rationale of the study was

\begin{abstract}
to explore some aspects of the concept of integration and to assess how these aspects can be measured in a way that enables comparisons between the Member States, groups of immigrants and also over time...it can...contribute to a better monitoring of immigration and integration processes and to greater effectiveness of policies in this field. ${ }^{339}$ (Emphasis added.)
\end{abstract}

The study identifies three possible types of comparisons that could take place in benchmarking: between TCNs, between Member States and across time. As regards the conceptual setting, it differentiates between the term 'integration' (relating to the structural dimension/institutional participation, i.e. ways of promoting immigrant participation in the major institutional arrangement of society such as labour market, education, health care system, etc.), and that of 'acculturation' (relating to the cultural dimension/cultural orientation and identification "phenomenon that immigrants gradually take over certain major elements of their surrounding cultural environment"). While a clear distinction is made between these two terms, later on the report advocates "for reasons of efficiency" not to distinguish between these two concepts, and every time that it refers to integration it also includes acculturation. ${ }^{340}$

From a methodological point of view, it is argued that while there is a substantial diversity when comparing Member States' approaches and policies on integration of TCNs, they do present some similarities and points of convergence allowing for comparison, and therefore for benchmarking. ${ }^{341}$ The study also mentions that in a meeting with the NCPI the following core elements of integration were agreed to: "respect for fundamental values in a democratic society, and rights comparable with corresponding obligations". ${ }^{342}$ It then differentiates among three major 'dimensions of integration': socio-economic, legal-political and cultural, and attributes a number of indicators to each of them:

338 H. Entzinger and R. Biezeveld (2003), Benchmarking Immigram Integration, European Research Centre on Migration and Ethnic Relations, Erasmus University of Rotterdam, report written for the European Commission, contract No. DG Jai-A-2/2002/006, retrievable from

http://ec.europa.eu/justice_home/funding/2004_2007/doc/study_indicators_integration.pdf.

See also H. Entzinger and R. Biezeveld (2004), "Benchmarking in Immigrant Integration", in R. Süssmuth and W. Weidenfeld (eds), Managing Integration: The Emropean Union's Responsibilities towards Immigrants, Verlag Bertelsmann Stiftung: Gütersloh, pp. 123-136.

Page 5 .

Page 11 of the report.

For instance, it refers that the following study showed that: J. Niessen (2001), Diversity and Cohesion: new Challenge for the Integration of Immigrants and Minorities, Strasbourg: Council of Europe.

Page 18. 
1. Socio-economic integration would include the following indicators: participation in the labour marketemployment, income level, representation in low-skill jobs, average in finding employment in accordance with education, use of social security, levels of education and training, language skills, quality of housing and residence patterns ('segregation').

2. Legal-political integration would refer to issues such as the EU values "granting equal rights to all citizens and to third country nationals residing in their territory", and the concept of "civic citizenship". Civic citizenship would comprise "a common set of rights and obligations" which the third country national would acquire gradually over a period of legal residence without the need to be naturalised. Indicators within this dimension include the numbers of TCNs naturalised or who obtain a secure residence status, the number of those holding dual citizenship, participation in political decision-making, politics and civil society, family reunification, "and even more so, the right to marry someone from a third country". It is said that

...some consider the choice of a spouse from the migrant's home country as harmful to the integration of both parties. Therefore some EU countries have tried to impose stricter rules to family reunification in recent years. ${ }^{343}$

3. Cultural integration. Indicators forming part of this dimension would comprise, for instance, attitudes towards basic rules and norms of the host country, frequency of social contacts, choice of spouse, language skills and delinquency. In addition to these three integration dimensions, the study ascribes importance to "the attitudes of recipient societies", and refers to the two-way process principle (that has now become CBP1), and indicators such as reported cases of discrimination, perception of immigrants in the receiving society, institutions sufficiently accessible to immigrants, an increased awareness of diversity among police, incidence and effects of diversity policies, the role of media, etc. In this respect, the study raises the following question: What exactly constitutes the core of that society, its basic values and rules? It is argued that "of certain values it can be said that they are shared by virtually everyone in the European Union, such as the rule of law, respect for democracy, equality of men and women, and the separation of church and state". Then it refers to the tensions that exist between "two opposing ideologies" with regard to the culnural integration dimension, and which is "whether migrants are expected to assimilate fully to the host society or whether they may keep their own cultural identity". It is also acknowledged how there are major differences in the approach to be taken among the Member States and about "the desirability of certain degrees of acculturation".

\subsubsection{The European Civic Citizenship and Inchusion Index ${ }^{344}$}

The 2005 European Civic Citizenship and Inclusion Index was compiled thanks to a partnership between the MPG, the British Council and the Foreign Policy Centre. What is the rationale of the Index? According to the Executive Summary of the Report, it was intended

to fill a knowledge gap on civic citizenship policies and inclusion at a European level. It is important for Member States to think about issues of immigrant inclusion in a European perspective, in order to keep up with the reality of EU-level policymaking, and the rapidly emerging EU Common Space of Justice, Freedom and Security. This is the first attempt to present the EU's policies governing civic citizenship and inclusion in a concise and comparable format. (Emphasis added.)

\footnotetext{
343 Pages 22 and 34.

344 A. Geddes and J. Niessen (with A. Balch, C. Bullen and M. J. Peiro) (2005), European Civic Citizenship and Inchusion Lndex, British Council Brussels, Foreign Policy Centre and Migration Policy Group.
} 
The goals of the Index were: First, to present data as of October 2004 in order to facilitate a comparative exercise among the Member States and "EU averages"; second, to enable monitoring and evaluation of how the Member States are implementing the principles of "civic citizenship and inclusion agreed by all of them" in law and policy; third, to pinpoint cases of best practice amongst Member States; and finally to allow for a comparative exercise over time. It advocates for the concept of civic citizenship to constitute "the cornerstone" in the development of "common standards of inclusive citizenship which gradually extends the responsibilities and entitlements of EU citizenship to all legally resident". Moreover, it understands equality and access as two of the key aspects that should guide European immigration and integration policies. Following this understanding, TCNs should progressively become "active and full citizens". 345 The concept of civic citizenship is then linked with that of "immigrant inclusion", which is understood as requiring labour market inclusion, family reunification, security of residence (long-term residence), naturalisation and anti-discrimination. The first edition of the Index only covers those labelled as "legally residing third country nationals", "346 and measures law and policy, not the effectiveness and efficiency of the way in which this rule works in practice. ${ }^{347}$ Furthermore, it does not focus on data related to "cultural integration' and political participation, but instead evaluates policies and legislation dealing with the concepts of civic citizenship and labour market at the EU-15 level.

How to understand and read the Index? Member State policies and regulations ${ }^{348}$ are compared with a common normative framework which argues that the inclusion of TCNs is required in the following strands: 1. Labour market inclusion; 2. family reunification; 3. long-term resident status; 4. naturalisation and 5. anti-discrimination. These five strands or areas are understood as a must for creating favourable conditions for "migrant inclusion". For each of the five, the Index assesses four dimensions "of the statuses and protections that immigrants enjoy": Dimension One: Eligibility/Scope; ${ }^{349}$ Dimension Two: Conditions for acquisition/Remedies; ${ }^{350}$ Dimension

345 The conceptual framing is more developed in J. Niessen, M. J. Peiro and Y. Schibel (2005), Civic Citizenship and Immigrant Inchusion - A Guide for the Implementation of Civic Citizenship Policies, MPG: Brussels.

346 The following groups are not included: asylum seekers and refugees, and "ethnic minorities who hold EU citizenship. For example, immigrants who have naturalised or subsequent generations of migrants who are given EU citizenship at birth are not covered in the Index". See page 9.

347 Page 25 says that "it does not reflect how well immigrants are actually included into Europe's economies and societies". "They are about law and the options are legal options. They are not about practices and how the law is (not applied)".

348 Once the data has been compiled by national experts following the completion of a questionnaire - "In order to be able to compare Member States and to establish whether civic citizenship measures are put in place, a list of almost 100 measures with each three options was sent as a questionnaire to independent experts who determined for all measures which option applies for their country". For a list of the experts that took part in the Index see Amex of J. Niessen, M. J. Peiro and Y. Schibel (2005), Civic Citizenship and Immigrant Inchusion - A Guide for the Implementation of Civic Citizenship Policies, MPG: Brussels.

"What are the eligibility requirement for the status? What is the scope of anti-discrimination legislation? How casy is access to the labour market?".

350 "What are the conditions that immigrants need to fulfil to access the status? What are the remedies available in cases of discrimination? How secure is employment?". 
Three: Security of status/Equality Agencies/Integration measures; ${ }^{351}$ and Dimension Four: Rights Associated/Proactive Policies. ${ }^{352}$

The premise upon which the whole Index exercise is based is a constructed common/practical normative framework offering "the policy conditions which are more favourable to immigrant inclusion", and that the authors consider as "the best direction" with respect to civic citizenship and immigrant inclusion. The common framework is composed of EU legislation, intemational conventions and NGO proposals on immigration and integration. In particular, the following instruments are expressly mentioned as forming the basis of the Index: the Council Directives $2003 / 109$ on the status of third country nationals who are long-term residents and 2003/86 on the right to family reunification, the Council Directives on non-discrimination 2000/78 and $2000 / 43,{ }^{353}$ the Council of Europe Convention on Nationality, the MPG and ILPA's Amsterdam Proposals and the Starting Line. ${ }^{354}$ It is argued that this common setting allows for a twopronged comparison between Member States and "the framework of desirable policy", or between Member State performances.

The benchmarking envisaged by the Index can only work with a set of indicators. Annex 1 of the Index presents its list of indicators that apply per strand and dimension of integration. Overall, it makes use 100 indicators related to a specific policies in each of the strands, "based on the existing commitments of member states to give immigrants rights and obligations comparable to EU citizens" and "whether they are living up to their commitments at EU level", which they term "promises of equality". On the basis of the purported normative framework, "The choice and wording of the indicators are [also] inspired by NGO proposals, EU legislation and international conventions". said the authors of the Index state that the indicators do not tell whether inclusion has been successful, only whether the legal and policy frameworks are favourable. For instance, it is interesting to stress that the Index qualifies as "unfavourable" the use of integration conditions as provided by both Directives 2003/86 and 2003/109 (See Chapter 4 of this book). The Index also values conditions going beyond a language test as "unfavourable".

The use of indicators is intended to measure the favourable or unfavourable nature of a particular policy option for "immigrant inclusion". This measurement is calibrated using three markers: favourable (which equates to 'best practice'), less favourable and least favourable conditions (which equates to "worst practice'). The label favourable applies to the "more liberal provisions

351 "How secure is the status? How strong are the equality agencies which monitor anti-discrimination? What labour market integration measures exist to facilitate migrants' inclusion?".

352 "What are the rights associated with the status? What are the pro-active policies in place to combat discrimination?".

353 Council Directive 2000/78/EC of 27 November 2000 establishing a general framework for equal treatment in employment and occupation, OJ L 303, 2.12.2000. Council Directive 2000/43/EC of 19 June 2000 implementing the principle of equal treatment between persons irrespective of racial or ethmic origin, OJ L 180, 19.7.2000.

354 The Amsterdam Proposals (1990), The ILPA/MPG Proposed Directives on Immigration and Asy/lum, prepared by Steven Peers and co-ordinated by E. Guild, S. Rowlands and J. Niessen, London and Brussels; See for instance 1. Chopin (1999), 'The Starting Line Group: A Harmonized Approach to Fight Racism and to Promote Equal Treatment', European Jommal of Migration and Law 1, pp. 111-129; See also 1 . Chopin and J. Niessen (1998), Proposals for legislative measures to combat racism and to promote equal rights in the European Union, co-published by the Starting Line Group and the British Commission for Racial Equality; and I. Chopin (2000), 'Possible Harmonization of Anti-Discrimination Legislation in the European Union: European and Non-Governmental Proposals', Europecm Joumal of Migration and Law' 2, pp. 413-430. 
and interpretations" in the European normative framework highlighted above. The other two options reflect versions of the more restrictive provisions composing the framework. For each indicator, each country is given a score of 1 for last favourable, 2 for less favourable or 3 for favourable. ${ }^{355}$ In cases where the Member State had no legislation at all, a score of 1 was given. The Index carries out a numerical exercise calculating "averages" and "indices": "A strand average per country is calculated as the average of all the indicators in the strand"; "The dimension average per country per strand is calculated as the mean of all the indicators in the dimension, in the strand"; "For each strand, the EU average is calculated as an arithmetic mean of the 15 scores". The results are presented in two equivalent formats: score values (comparing countries to the European normative framework to see how favourable their policies are regarding "immigrant inclusion") and index values (comparing states). As regards score values, the degrees of variation between countries can take many different forms, as the $1 / 2 / 3$ scoring is applied to 100 indicators. The average is rounded to two decimal places, "which allows for a more nuanced reading". Concerning the index values, the 1-3 range is converted into a standardised base that uses 100 as the equivalent of the EU average for each of the dimensions, strands and results. The Index interprets a score over 100 as exceeding the EU average.

\subsubsection{The Migrant Integration Policy Index ${ }^{356}$}

The second edition of the Index was also carried out by the MPG and the British Council. This time it was co-funded by the European Commission (DG JFS, INTI Programme). ${ }^{357}$ The main objective of the MIPEX is

...to improve migrant integration policies in Europe, by providing objective, accessible and comparable data for scrutiny and debate... it is therefore vital that the integration policies of European governments are scruinized and monitored. MIPEX is intended as a 'mirror' that can be of help to Member States for them to see how they are performing on migram integration policy. (Emphasis added.)

The MIPEX evaluates integration policies in the EU-25, as well as in Canada, Switzerland and Norway as of 1 March 2007. It covers six areas "which shape a migrant's joumey to full citizenship: labour market access, family reunion, long-term residence, political participation, access to nationality and anti-discrimination". 358 "Best practice" in each policy indicator is equivalent to the highest "European standard", which is defined in a similar way as the 2005 Index. The MIPEX nomative framework uses a particular understanding of "European standards" as the best practice against which to test Member State policies. The personal scope still focuses only on TCNs legally residing in an EU Member State. The focus is on government policy and its legal/policy framework. The conceptual setting of the MIPEX understands integration from the perspective of the concept of "equal or mutual opportunities and

35s The report explains that in the anti-discrimination strand the score depended on the number of areas covered by a particular normative measure (a rate of 3 was given when the act included race/ethnicity, religion/belief and nationality; 2 when it covered two areas, and $I$ when it only included one or none discrimination ground. See footnote 10 of the Report).

356 J. Niessen, T. Huddleston and L. Citron (2007) (in cooperation with A. Geddes and D. Jacobs), Migrant Integration Policy Index, British Council and Migration Policy Group. See www.integrationindex.eu See also J. Niessen (2006), "Integration, Citizenship and the Benchmarking of lntegration in the EU", in S. Carrera (ed.), The Nexus between Immigration. Integration and Citizenship in the EU, Collective Conference Volume, April 2006, pp. 33-37.

357 See http://ec.europa.eu/justice_home/funding/2004_2007/inti/funding_inti_en.htm

358 Integration programmes, access to housing, education and healthcare are cross-cutting issues. 
responsibilities for all, both in socio-economic and civic terms". Further, it defines benchmarking as

a tool for policy improvement based on the identification of key areas of improvement, setting standards and indicators, searching for best practices that meet those standards, and adapting policies from lessons learned to meet and exceed these standards. ${ }^{359}$

The MIPEX methodology is also similar to that of the 2005 Index. In each strand or policy area, it measures the best practice up to the constructed "European standards". It is said that

Some of these standards are contained in EC Directives, which EU Member States are obliged to transpose into their national laws. Others come from Council of Europe Conventions that ratifying States have committed to implement. Where Directives and Conventions only provide minimum standards or allow numerous derogations, MIPEX turns to higher standards of best practice: EC Presidency Conclusions, proposals for EC Directives put forward by European-wide stakeholders, or the policy recommendations of comprehensive comparable European research projects. ${ }^{360}$

Each strand is divided into the four usual dimensions. The report says that

A country receives a $1-3$ score on each indicator...the indicator scores in each dimension are averaged together to give a dimension score. Each strand therefore has four dimension scores. The average of the four dimension scores in each strand produces a strand score. Each country therefore has six strand scores. The six strands are then averaged together to give an overall score for each country. Other averages (EU25/15/10) are calculated as a simple mean score of the given countries. The initial $1-3$ scale is converted into a $0-100$ scale for dimensions and strands, where $100 \%$ is best practice. Rankings and comparisons can then be made on the basis of these scores. ${ }^{361}$

MIPEX uses 140 policy indicators, ${ }^{362}$ and follows the same path as the 2005 Index, though its nature is being fine tuned and broaden. According to the Report "The indicators were designed through a series of expert consultations and later scrutinised and approved by MIPEX's Scientific Advisory Committee". Each of the 140 indicators relates to a specific policy area in one of the six strands. It is said that "they have been designed to benchmark laws and policies against these "highest European standards"”.

\subsubsection{Study on Setting up a System of Benchmarking to Measure the Success of Integration Policies in Europe 363}

The study was carried out by the MPG and funded by the DG Internal Policies of the Union (Policy Department $C$ ) of the EP. The objective was to explore the extent to which the technique of benchmarking "can be transferred from the private sector and be used in the public sector", to propose an organised and targeted European system for benchmarking integration policies, and to propose a set of policy recommendations relevant to benchmarking the effectiveness of a future integration framework for the EU. The study starts with an in-depth analysis of

\footnotetext{
359) Page 6.

360 Page 5.

361 Page 6.

362 It is important to highlight that each of the indicators constitute the set of questions sent to the national experts in the form of questionnaire. They are presented in Annex 2 of the MIPEX "List of Indicators".
}

363 J. Niessen and T. Huddleston (2007), (With N. Verbruggen and M. A. Kate), Setting up a System of Benchmarking to Measure the Success of Integration Policies in Europe, Policy Department C, Citizens Rights and Constitutional Affairs, European Parliament, PE 378.288, January 2007. 
benchmarking. After assessing its origins in the private sector, ${ }^{364}$ where this method has been used to ensure a "continuous and systematic search for and implementation of best practices, which lead to superior performance", the following elements are identified as features of the technique: 1. Identifying key areas to be improved; 2. setting standards according to "best/good practice'; 3. examining how actors meet the standards, and 4. adapting and applying "lessons learned" 10 meet or exceed the standards. As regards the conceptual setting, the EP study introduces a working definition of benchmarking based on a "citizens-based approach". It advocates for a shared definition of integration driven by a "European framework concept of integration" which

...should situate integration policies within the broader context of sustainable economic development and social cohesion. Integration policies must encourage immigrants and nationals alike to become active citizens. It must promote solidarity and equality among all members of society. (Emphasis added.) ${ }^{365}$

The understanding of integration as civic citizenship is particularly addressed in Chapter VII of the study. In this definition, and similarly to the 2005 Index and MIPEX, the authors rely mainly on a specific interpretation of the European framework and the Council of Europe on immigration and integration. ${ }^{366}$ In particular, as regards the European framework, they refer to the 1999 Tampere Programme and use European citizenship and equality based on antidiscrimination as "the optimal standard". It is said that "the EU Framework definition of integration is characterized by its gradual 'comparable rights and obligations' approach which aims to be comprehensive, multidimensional, voluntary and as follows collaborative among many levels of govemance". 367 It also raises the following question: What constitutes successful integration and strong integration policies? Following their benchmark definition of integration, a successful integration is considered to include: ${ }^{368}$ The active participation of all residents; the respect and exercise of "comparable rights and responsibilities"; and the acquisition of "intercultural competencies".

The personal scope of the study exclusively covers 'legally resident TCNs' or 'newcomers'. Chapter V "From Integration Impediments to Areas of Improvement" provides the benchmarking system's methodology. It intends to provide "benchmarkers" with the necessary instruments for measuring "immigration integration debates" and to pinpoint "integration impediments and areas of improvement". The study starts by explaining how "the decision to benchmark" is based on preliminary assessments of the situation which "informs the decision to benchmark, focuses the benchmarking and makes it relevant for the ongoing policy debates" ${ }^{369}$ The preliminary assessment consists of identifying a number of "ongoing discussions" or "integration debates" in the EU. ${ }^{370}$ The assessment would aim at identifying a number of "impediments", which are defined as "policies (or lack thereof) and societal realities that hamper

364 For instance they quote and make use of the publication of the European Foundation for Quality Management (EFQM), Excellence Toolbook for Benchmarking, Brussels: EFQM, 2003. See www.efqm.org

365 Page 59.

366 See M. Coussey (2000), Framewrork of Integration Policies, Council of Europe, Directorate General III Social Cohesion, Directorate of Social Affairs and Health, Council of Europe Publishing: Strasbourg.

367 Page 67.

368 Page 146.

369 Page 99.

370 It is interesting to note that among them they mention the issue of 'shared values' and integration as an immigration control mechanism, yet then it decides not to benchmark it. See page 101 . 
the ability of a diverse society to ensure the long-term well-being of all its members". ${ }^{371}$ The search of impediments would offer the scope of benchmarking, and launch the search for standards, targets, best practices, indicators and benchmarks.

Chapter III introduces four dimensions intending to offer a comprehensive picture of well-being in a diverse society - "dimensions of well-being": 1. Non-discrimination; 2. dignity; 3. development; and 4. participation. They are applied to "four areas of life" subject to public policies, and which include: citizenship, economic inclusion, social cohesion (housing and health services ${ }^{372}$ ) and education. Therefore, using "the technique of impediment searching", the natural step would be to point out specific impediments in each area of life by dimension of well-being. The next step in the benchmarking procedure would be to transform the impediments into "areas of improvement" or "action-oriented policy goals". In words of the study:

The idenification of impediments permits benchmarkers to develop policies and services that turn impediments into clear-cut and constructive areas of improvement... benchmarkers may then enter the benchmarking exercise's analysis by undergoing policy assessments on their current policy response, identify standards and search for and study best practice on this specific area of improvement. ${ }^{373}$

The focus of turning impediments into areas of improvement would need to follow the "ideal standard" (standard setting) or normative framework set by the study, ${ }^{374}$ and which consists of eliminating "the specific lived impediment in order to encourage the well-being of all members of society, with a focus on active participation, the acquisition of competences and the granting of comparable rights and responsibilities". According to the model, and for the purpose of "analysis" and "implementation", benchmarkers would develop "quantitative or qualitative" indicators related to the processes of policy formation or the outcomes (efficiency, effectiveness and sustainability). Chapter VI argues that "integration can be measured in terms of successes and failures and integration policies in terms of strengths and weaknesses", and the use of indicators serves as the instrument toward the assessment of success and effectiveness. The following indicators are presented with the option for the benchmarker to choose those more appropriate: 1. Context indicators (including, for instance a situational context, such as the number of immigrants in the receiving population); 2 . governance indicators (the normative situation of the country with respect to international and European laws and policies); 3 . global/outcome indicators (relative to top general policy goals with long-term outcomes and impacts); 4. output indicators (specific short-term policy goals); 5. operational/input indicators (operational objectives in terms of goods and services); 6. process/performance indicators (relevance, efficiency, effectiveness and sustainability). Each of them can be categorised as quantitative or qualitative.

\section{Page 104.}

See also Annex 1 of the Study titled "Migrant-Friendliness Quality Questionnaire" and where a set of questions are presented to measure whether hospitals are "migrant-friendly". See pages 247-252.

373 Page 130.

374 See Annex 4 titled "Normative Framework of European Civic Citizenship and Inclusion Index", pages 264-273, and which states that "Equality and access are cornerstones of European immigration integration policies. Equal treatment of immigrants is often a condition for their admission in terms of working and living conditions and they acquire more rights and assume more responsibilities over time in this way gradually becoming full and active citizens. Policies can set favourable integration conditions and they include securing residence, facilitating family reunion, encouraging naturalisation and combating discrimination. These areas, taken together, promote civic citizenship". 
Finally, the EP Study uses graphs similar to those provided by the MIPEX to represent the integration policy in an area of life. In fact, the second part of the study constitutes a sort of update of the MIPEX, following the same conceptual and methodological patterns. ${ }^{375}$ Finally, we come to the phase of policy intervention, in which "the goals set by the "areas of improvement' are amenable to a combination of public interventions". It is said that the Study aims at combining the Council of Europe's approach on measuring integration by looking at processes ("process approach") 376 with the MIPEX methodology ("normative approach"). In this way, it establishes "four cross-cutting levels of policy intervention" in each "area of life": 1. Existence of law and policy-framing; 2. implementation and service delivery; 3 . beneficiaries (situation of immigrants); and 4 . climate in the receiving society.

\subsection{Current Deficits of Benchmarking Integration}

What are the main vulnerabilities inherent to the technique of benchmarking integration of TCNs in the EU? On the basis of 'the state of the art' on benchmarking integration provided in the previous Section, the main deficits can be grouped under the following overarching themes: lack of common approach, non-neutral nature, personal and territorial scope and methodology.

\subsubsection{A Common Approach on Integration in EU Law/Policy allowing Benchmarking?}

A key premise for enabling any benchmarking exercise to take place is the existence of a common conceptual understanding or guiding approach on integration. The approach will determine the focus and direction given to each of the phases composing the monitoring and evaluation processes of benchmarking. There is, however, a conceptual deficit in relation to the constructed category of integration in the EU both in academia and at the policy level. This deficit is not so much linked to the need for providing a precise definition of integration, ${ }^{377}$ but rather to the difficulty of achieving a shared theoretical understanding which is commonly accepted in a diverse supranational governance setting such as the EU. As a Council of Europe Report (1997) rightly argued

...the evaluation or measurement of integration has to begin with a definition of the basic terms... what exactly is meant by the term "integration" is of great importance. Without

375 In addition, Annex 5 of the Report presents a list of Research Reports by country that were consulted by the national experts at times of answering a questionnaire very similar to the one being already used in the MIPEX. See pages $274-283$.

376 Council of Europe, Community Relations Series, Measurement and Indicators of Integration, Strasbourg, 1997. Council of Europe, Proposed Indicators for Measuring Integration of Immigrants and Minorities with a View to Equal Rights and Opportunities for all, MG-IN, Strasbourg 2003. The Report says that "Whereas the Council of Europe started the discussion on indicators with a view to promote the societal integration of immigrants, the European Union used the development of indicators as a means to measure progress in the achievement of the Lisbon goals. While the Council moved from specific immigrant integration indicators to more general social inclusion indicators, the European Union started with general social, economic and educational indicators and is now beginning to add to those specific immigrant integration indicators".

Berliner Beiträge zur Integration und Mignation (2007), Indikatoren zur Messung von Integrationserfolgen: Ergebnisse des Transnationalen Projekts, Senatsverwaltung für Integration, Arbeit und Soziales, Berlin. It is said that "the concept of integration should be precisely defined for the monitoring of integration in order to make it applicable". See pages 86 and 87. 
common standards as to what is meant by "migrant" and by "integration" all attempts to measure migrants' integration in different countries are likely to be of little meaning... ${ }^{378}$

Is there any identifiable common European approach(es) on integration in EU law/policy? As it has been shown in this and the previous Chapter, and as it will be further evidenced in Chapter 4, the classical features characterising the European approach(es) on integration have greatly evolved in the last years both in the scope of EU immigration law and the EU Framework on Integration. It would therefore be difficult to argue that there is one (or several) predominant and clearly identified approach on integration at the EU level. The interpretation of integration used by some of the studies examined above is not always the one predominating in EU law and policy. This aspect points to one of the main vulnerabilities inherent to benchmarking: The importance of the driving conceptual and ideological focus/approach and/or understanding of integration. Some of the studies often distinguish a series of integration dimensions, such as socio-economic, legal-political and cultural. ${ }^{399}$ However, the actual measurement of each of them will greatly depend on the theoretical framing of integration. Moreover, while the CBPs intend to offer a first hamonised definitional background of the main tenets comprising integration in the EU, they rather encapsulate a certain number of perceived shared features which are too broad to provide any clear specific vision and concise response to this approachrelated deficit. As it has been explained, the CBPs represent a non-binding guide of broad tenets allowing for the implementation and development of any sort of understanding, interpretation and ideology about integration of TCNs. In fact, they show the tensions that currently exist in the evolving EU approach(es) on integration. These frictions become evident when comparing CBPs 2 and 4.1 with the one on the two-way process paradigm (See Section 1.5 above).

\subsubsection{Benchmarking as Neutral Tool?}

Entzinger and Biezeveld (2003) have pointed out the inherent difficulties in benchmarking stemming from "the differences in ideological outlook and political priorities". ${ }^{380}$ They state that

Differences between the Member States in their interpretation of "integration" may lead to different objectives of their integration policies. However, even if every Member State interpreted "integration" in exactly the same way, integration policies would still differ in their objectives, as the ideal society that governments envisage will not be the same everywhere and at all times. (Emphasis added.) ${ }^{381}$

378 Council of Europe (1997), Measurement and Indicators of Integration, Community Relations, Directorate of Social and Economic Affairs, Council of Europe Publishing: Strasbourg, page 5.

37. Other instances include for example B. Schulte (2004), "The Open Method of Coordination as a Political Strategy in the Field of Immigrant Integration Policy", in R. Sussmuth and W. Weidenfeld (eds), Managing Integration: The European Union's Responsibilities towards Immigrants, Verlag Bertelsmann Stifung: Gütersloh, pp. 137-145; and Caritas Europa (2007), Imegration: A Process Involving All, Advocacy Paper on the Integration of Migrants and Refugees, Brussels, August 2007, where after explaining that the definition of integration advocated by Caritas Europa includes the respect for fundamental rights, equality and participation (page 6), it distinguishes between the following dimensions to be relevant at times of developing indicators of integration: 1. legal integration (elimination of legal barriers to integration and the establishment of equal rights for all members of society), socio-economic integration (equal access to the labour market, access to training, and to the housing market), and sociocultural integration ("knowledge of language(s) is a key and a powerful vehicle for integration...language tuition should be an essential part of any integration policy and should be accessible, affordable and available as soon as possible after the migrants' arrival"), page 18. 
There is indeed a strong dependency-factor in benchmarking to a certain ideological setting embracing what integration means and how it should be deemed successful. There is a lack of neutrality underlying the entire exercise and a great degree of discretion by "who is benchmarking" to determine the focus, scope and the way in which results will be presented. The guiding conceptual approach and the standard setting might also shift easily, and include any ideological direction. However, this change in ideology would not however prevent benchmarking from working effectively. Therefore, benchmarking could end up being instrumentalised to justify any sort of ideology and political tendency regarding integration. Furthermore, a substantial degree of subjectivity and value judgements predominate in the identification of "impediments" or "the preliminary assessment of the situation", 382 the categorisation of favourable (best) or not favourable (worst), the use of the indicators and the way in which the results are presented. This has been recognised, for instance, in the 2005 Index which states that

The normative framework is, of course, based on certain value judgements. This is neessary to create a common framework to score policies. The nomative judgements are based on mainstream arguments in the inclusion discourse about equal treatment and inclusion. ${ }^{383}$

Moreover, Entzinger and Biezeveld also highlight that setting a standard for an "ideal integration process of immigrants is simply impossible given the wide variety of factors influencing immigration and integration, the immense diversity of migrants and the huge differences in approach of these matters across the EU". ${ }^{384}$ Questions arise as to the determination of 'ideal', 'best' or 'good'? What do these terms mean when assessing a policy or how it is implemented? 'Best' and 'ideal' are malleable adjectives often attributed according to a certain ideological understanding and approach of 'the common standard' against which to test the norm or practice. What are the highest European common standards for labelling a policy as 'the best' or 'the worst case'? What is the precise content of these common standards? The answer to these questions will equally depend on the reading and interpretation of the alleged standards. As Bruno, Jacquot and Mandin (2006) have argued, ${ }^{385}$ benchmarking is not neutral. It needs to be understood as a strong political action which constitutes a norm of disciplining national politics, policies and, eventually, laws. Europeanisation takes place on the basis of graphs and matrixes

382 For instance in the EP 2007 Study it is said that the sources from where they took their "impediments" were inspired, among other sources, from the technical seminars organized under the auspices of the NCPl and the European Commission, which is in fact the framework under which the Handbook on Integration for Practitioners and Policy Makers is taking place. The influence of the Handbook exercise is also obvious in page 140 of the Report where it says "Participants at one of the EU Handbook on Integration's technical seminars recognised the value of indicators in policy formation, implementation and review. They recommended a cautious use of indicators, with a waming to avoid a simplification of the integration process into targets for a limited period of time - between two elections for example".

What they call "mainstream arguments" include for instance R. Süssmuth and W. Weidenfeld (eds), Managing Integration: The European Union's Responsibilities towards Immigrants, Verlag Bertelsmann Stiftung: Gütersloh; K. Groenendijk, E. Guild and R. Barzilay (2000), Sudy on The Legal Sratus of Third-Commy Nationals who are Long-Term Residents in a Member State of the Ewopean Union, Centre for Migration Law, Radboud University of Nijmegen, Nijmegen: The Netherlands. Page 5 .

I. Bruno, S. Jacquot and L. Mandin (2006), 'Europeanization through its Instrumentation: Benchmarking, Mainstreaming and the Open Method of Coordination... Toolbox or Pandora's Box', Journal of European Public Policy, Vol. 13, No. 4, pp. 519-536; See also I. Bruno (2007), 'Généalogie du Benchmarking. Itinéraire d'une technique de gouvernement', P. Laborier et J. Vogel (dirs.), Les Sciences Camerales. Activités Pratiques et Histoire des Dispositifs Publics, PUF: Paris, pp. 97-107. 
presented as unquestionable and scientifically rigorous. Concerning the labelling of a practice as best or worst, it is interesting to note when the 2007 EP Study says that

A government's lower investment in a particular type of programme may be intentional and therefore would not be judged as a deficiency in need of remedy.

Also, the clear-cut attribution of 'best' or 'worst' will be exceptional in practice. In a majority of cases there will be a wide and blurred range of practices and policies/rules falling in between of the extremes, i.e. the best and the worst cases, and whose qualification as less or more favourable will depend even to a greater extent on values and opinion, and not so much on objective and value-free criteria.

\subsubsection{The Personal and Territorial Scope}

Another deficit associated with benchmarking, and more generally the EU Framework on Integration, is the target group and relates to the question of who is an immigrant. Most of the reports presented in section 4.1 usually look at a much reduced group of non-EU citizens, i.e. those qualified as 'legally resident TCNs' and/or 'newcomers'. Yet, what about all the others who do not necessarily fall within this narrow legal category? It seems that the personal scope presented in some of the reports is being inspired by the one advocated by DG JFS of the European Commission. The personal scope of integration policies at EU level usually does not cover, for instance, the situations of refugees and asylum seekers ${ }^{386}$ or irregular immigrants. Also, by focusing only on legally-residing TCNs there is an underlying assumption that it is possible to know and identify who they are, and that there is a homogeneous group of people clearly identifiable and undoubtedly falling within this constructed legal category. The category of TCNs is far from being homogeneous, hermetic and static. It is heterogeneous, diverse and dispersed. Those individuals labelled as TCNs include nationals from all over the world with widely differing backgrounds, prospects and links with the country of nationality and residence. Furthermore, into what is this group asked to be integrated? There appears to be another presumption about the existence of a "host society" and "nation" which is already wellintegrated, cohesive and homogenous. The perception, or rather ideological and political pretension, which also underlies the two-way process principle, about the existence of two identifiable and distinctive sides, i.e. the immigrant and the receiving nation, is false and it constitutes one of the core weaknesses in the scope of benchmarking integration.

Some of the benchmarking exercises call for the necessity of the Member States to collect as much data as possible about those qualified as 'naturalised immigrants' holding the nationality of the State, but who are still considered as 'non-integrated' ('foreign citizens' - 'nationals with different ethnic origin'). This call might be blinded by the need to have more data to compare, and it fails to duly take into account the ethical impacts of such an exercise. It needs to be emphasised that within the scope of benchmarking the collection of data does not serve only as a necessary element allowing for comparison, but as an instrument for monitoring or managing integration. There exists a clear control-oriented logic behind the collection and storage of ethnic-origin data. In addition to the ethical questions that this exercise might entail in terms of fundamental rights and non-discrimination, the following questions could be raised: When will these individuals no longer be considered as immigrants or foreigners, but as equal citizens? Is

386 For a study suggesting a set of indicators to assess how far refugee integration for both individuals and communities has been achieved see A. Ager and A. Strang (2004), Indicators of Integration: Final Report, Home Office Development and Practice Report, Home Office: London. 
this an issue to be discussed in the scope of TCNs integration? Or is it rather a matter related to social inclusion, social protection and citizenship?

Finally, the question might be posed, who will be 'the benchmarker'? Will it be the EU or the Member States? Who will be the 'Benchmarking Community' as referred to by the EP 2007 Study? There is an implicit danger in the flexibility of the benchmarker's identity. If the benchmarking community is not clearly defined, the State might see in benchmarking more of an opportunity for evaluating the individual's performance on integration in the different Member States, and not so much to compare and monitor its own achievements on social inclusion and social (in)cohesion. Ensuring the active and constant involvement of the civil society and immigrant's organisations in the benchmarking exercise is not only essential for ensuring that their interests and rights are duly protected in the processes of policy-making, but also to avoid its use as a management technique of the State. Moreover, what would it imply if governments operate, or act like, the business community? The transfer of benchmarking from the private to the public sector might facilitate its usage in the management of integration or as a coercive managerial approach disciplining behaviour by means of the norm. A shift in the conceptual and ideological setting of standards makes benchmarking a dangerous tool of governance. By becoming part of a State policy and politics, the benchmarking exercise can become a victim of its own purpose and rationale.

It is also uncertain the extent to which a certain practice or policy can be at all considered "best" across the EU and beyond. Is the technique of benchmarking an adequate method for an EU at 27? When taking into account the lack of a common theoretical and ideological understanding of integration in EU law, and the difficulties raised as regards the personal scope, it would be hard to argue that benchmarking could cope with the diversity and heterogeneity existing across different Member States' histories, public philosophies, legislation and politics regarding immigration and diversity. In fact, what might be considered ideal in Germany or France might well become a 'worst practice' when applied in Hungary, Spain or Latvia. ${ }^{387}$ Few would disagree with the fact that there are issues and policies which are mostly or only relevant to particular Member States. Further, it is worth recalling the incoherency subsumed in the territorial scope characterising the EU immigration policy and the EU Framework on integration. While the UK, Ireland and Denmark benefit from a special status in EU immigration law on the basis of their Protocols attached to the Amsterdam Treaty, and currently both the UK and Ireland have opted out of a majority of the Directives dealing with regular immigration, these three countries participate in the EU Framework on Integration. What does this mean relative to the construction of a comprehensive and coherent common immigration policy in the EU?

\subsubsection{The Methodology}

\subsubsection{Benchmarking and Interdisciplinarity}

Most of the benchmarking exercises only tend to look at the normative dimension of integration. They map the legal and policy setting and compare it with other states. Some of the reports are driven by a predominant regulatory perspective without considering the implementation dimension or informal practices surrounding access and participation. This constitutes a disciplinary weakness of current benchmarking techniques. The law dictates little about how the

387 See for instance J. Tóth (2007), Ethnic Citizenship - can it be obtained and tested? Not yet published. See G.R. de Groot (2007), A Clarification of the Fundamental Rights Implications of Stateless and Erased Persons, Briefing Paper European Parliament, DG Internal Policies, November 2007. 
norms optimally function in terms of social inclusion. What might initially look like favourable, good or 'best' from a pure legal standpoint could prove to be inadequate when analysing the way in which the norm is implemented and its effectiveness in practice. Furthermore, the measurement, monitoring and evaluation of social issues always entail a challenging endeavour.

From a strictly methodological point of view, the use of indicators and benchmarking might be easier to apply to a legal exercise. This is the case, for instance, when checking whether the laws on family reunification and long-term residence are more or less liberally transposed in the Member States. However, a purely legal focus is not exempt from further weaknesses. For example, the use of the same indicators to check the legal framework in the EU-27 will naturally confront situations where the national law of some Member States does not match the questions or indicators, or where the indicator that has been chosen by the benchmarkers is not relevant to the law of a particular state. ${ }^{388}$ Also, as a way of illustration, taking naturalisation as one of the dimensions of integration implies attributing a certain value to having access to the nationality of the nation-state for TCNs to be included, something which might be open to discussion. ${ }^{389}$ Finally, concerning issues related to political participation, if we were to take as an indicator the existence of consultative bodies, matters such as whether and how they really operate, the extent to which they truly guarantee access, etc., should also be addressed.

That notwithstanding, the narrow legal perspective often determines the ranking of those Member States which are considered to be performing best or worst according to the chosen standards. For instance, the MIPEX includes a ranking of Member States which are doing better in migrant integration policy. It seems that Latvia, Cyprus, Austria, Greece and Slovakia are among 'the worst', and Sweden, Portugal, Belgium and the Netherlands are among 'the best'. 390 One would expect this ranking to change when moving beyond a purely legal measurement and considering the impact, implications, effectiveness, efficacy, etc., of these norms and policies. The legal framework might be perfect, but what actually matters is the way in which it is implemented. This is particularly crucial as regards issues of anti-discrimination.

\subsubsection{Indicators}

The OMC cannot live without benchmarking, and the latter cannot survive without a set of homogenous indicators allowing for the identification of a number of sectoral areas to be assessed. Yet, what exactly do indicators indicate? What is their function? The indicators are used as a measuring instrument to mark a specific issue related to a policy or law, and to examine whether the latter is in compliance with the approach set by 'the ideal standard'. In this

388 This point is acknowledged in the 2005 Index, where it is stated in page 15 that "the normative judgements are based on mainstream arguments in the inclusion discourse about equal treatment and inclusion". "In some countries, certain aspects of the normative framework may not fit with the public philosophy of integration".

389 For instance the Council of Europe Report of 1997 stated that "... in reality statements concerning the development of naturalization rates over time or comparisons of naturalization rates in various countries are of limited use when serving as indicators of integration. Can a recent rise in naturalizations really be explained with a growing inclination to integrate? Or is it the result of the host country's decision to tolerate dual citizenship when naturalizing foreigners? in other words: changing naturalization requirements can have an influence on naturalization rates. But does it influence the individual's degree of integration?". Council of Europe (1997), Meastwement and Indicators of Integration, Community Relations, Directorate of Social and Economic Affairs, Council of Europe Publishing: Strasbourg, Page 12.

See page 3 of the MIPEX. 
respect we might refer to the 2007 EP Study, which acknowledges that it is a normative exercise including "the identification of beneficiaries, the choice of what process to measure and a selection and agreement of benchmarking partners". The study goes on to state that

Indicators must be designed to facilitate nuanced and reasoned assessments. This use of indicators becomes even more risky when policy-makers draw general conclusions about the level of integration in society as a whole. They should make explicit the reasons behind a choice of certain indicators in order to give context to their meaning in the political debate. Subordinating indicators to perceptions in public debates causes serious consequences for integration. ${ }^{391}$

The use of indicators is not straight forward from a methodological point of view. As it has been recognised by an NTI research project funded by the Commission, "indicators are not 'aseptic' tools. Indicators also reflect different approaches and integration models; they reflect different elements, areas and priority actions". "39? In light of the reports reviewed in Section 4.1, considerable diversity is likely to be encountered when identifying, classifying, selecting and constructing a list of indicators at the various levels of governance that exist in the EU. The challenging task of agreeing at the EU level on a common set of indicators would become even more complicated when trying to develop a comprehensive and coherent system of indicators at national, local and regional levels across the Member States. Further, assuming that these dilemmas would be successfully overcome, the question then would arise as regards the way in which these indicators would be used to conduct the evaluation or measurement. What would be the unit and sources of measurement? For instance, how would "the attitude towards basic rules, norms and shared values" of the receiving country be measured? Would these indicators be based on 'facts' or "wisdom'? Would they constitute reliable instruments? Concerning the ambiguity involved in the use of indicators, Entzinger and Biezeveld (2003) have said that

More ambiguities can be distinguished in other potential indicators. In fact, such ambiguities reflect differences in policy objectives and contradictions between the course of integration processes in different domains. An integration policy that aims implicilly or even explicilly at assimilation will define its objectives in terms that are quite different from those of a policy that aims at recognizing and facilitating migrant cultures; they may still use the same indicators, but when it comes to interpreting the effects of their efforts, they may draw opposite conclusions. ${ }^{393}$

A similar critical stance was taken by the Council of Europe (1997), which expressed that

Apart from language skills, which are relatively easy to evaluate, it seems almost impossible to find indicators for cultural integration everybody can agree with. The problem starts with the term itself: what exactly is "culture", religion? Music? Cooking? It continues with the difficulties... what exactly is meant by cultural integration? Giving up one's folk songs or being tolerated by the majority culture? ${ }^{394}$

The Council of Europe report of 1997 raised similar concerns about using indicators in areas such as "political participation" or social integration, where, as the report states, "statements

\footnotetext{
391 Pages 142-146.

INT1-Project 13 Indicators on Immigrant Integration (June 2005 - June 2006), Immigrant Integration Indicators: Proposal for Contributions to the Formulation of a System of Common Integration Indicators (2006), Research \& Documentation Centre (WODC), Ministry of Justice, The Netherlands. Retrievable from http:/english.wodc.nl/publicaties

Page 41 .

394 Council of Europe (1997), Measurement and Indicators of Imtegration, Community Relations, Directorate of Social and Economic Affairs, Council of Europe Publishing: Strasbourg.
} 
concerning the migrants' social integration are often limited to speculations", and which continued by stating that

Bearing these problems in mind it becomes rather doubtful whether the identification of indicators and the measurement of integration based on these indicators can be a fruitful undertaking at all. It is questionable whether one can succeed in reliably identifying a set of indicators really pointing at a progress in integration... and covering all dimensions of integration at the same time in order to supply a complete impression of the state of integration in a given country. ${ }^{395}$

In addition, one of the reports analysed in Section 4.1 refers to issues with respect to "shared values' as a possible indicator for cultural integration. While the meaning of what constitutes a value remains a contested issue, addressing the same question as regards 'European values' raises even greater dilemmas and divisions. Who would be in a position to define the meaning of a European citizen's values and way of life? What does it mean to be European? And what would be the features and distinctive ingredients of a supposed European set of values? These questions of definition would be difficult to reconcile with the rich diversity reigning in an enlarged EU.

\subsubsection{Typology and Comparison}

The system of indicators aims at facilitating the comparison between Member States' integration policies and laws. Any typology or comparative exercise tends to fall into the trap of oversimplifying social realities. This occurs through the effort to make the comparison to be understandable and coherent. Benchmarking is based on the premise that a comparative work can in fact be undertaken between Member States, and that the results from this comparison will be comprehensive enough to inform and promote better policy-making at the EU level. One major difficully is finding any comparable data/categories of information on integration which go beyond the mere legal and policy frameworks (and stereotypes) about national integration models. ${ }^{396}$ As Penninx el al. (2008) have expressed

Cross-national comparability of seemingly simple data such as those on migration turns out to be profoundly problematic. The problem is that administrative data are collected within a specific institutional context for specific purposes, using definitions that reflect their particular tasks, assumptions and preoccupations...the basic problem for scientists in using such data for comparative purposes are twofold: do they measure the same phenomenon and are they complete and representative? ? $^{397}$

395 Council of Europe (1997), page 13.

396 INTI-Project 13 Indicators on Immigrant Integration (June 2005 - June 2006), Immigrant Integration Indicators: Proposal for Contributions to the Formulation of a System of Common Integration Indicators (2006), Research \& Documentation Centre (WODC), Ministry of Justice, the Netherlands. Retrievable from http://english.wodc.nl/publicaties The report concluded by saying that "The lack of comparable statistics, different policies and models in Europe in the field of immigration and integration remain obstacles for the successful development of comparative data and indicators across Europe". For a summary of the project see European Commission, DG Justice, Freedom and Security, INTI Report: Integration of Third-Commy Nationals, 2003-2004 Projects (June 2006), Brussels. A similar argument was sustained by the Commissioner for Integration and Migration of the Senate of Berlin (ed.) (2007), Encouraging Diversity - Strengthening Cohesion, Integration Policy in Berlin 2007-2011, Der Beauftragte für Integration und Migration, Berlin.

397 Penninx, R., D. Spencer and N. Van Her (2008), Migration and Imtegration in Europe: the State of Research, ESRC Centre on Migration, Policy and Society (COMPAS), University of Oxford retrievable from www norface.org 
Indeed, gathering reliable and objective data about access and participation in socio-economic dimensions might be a rather daunting endeavour if the main sources are limited to surveys, opinion polls, personal contacts/relationships and research on attitudes. ${ }^{398}$ This issue becomes even more critical concerning access to any information related to what some have denominated as 'cultural integration'. Therefore, the question arises as to whether integration-related figures/data could be sufficiently comparable and trustworthy for a global monitoring exercise to be carried out.

\subsubsection{Results of Benchmarking}

What is the nature of the results? Are they robust and fact-based? Benchmarking uses nontransparent, complex and obscure methods and tools. It becomes a numeric matching exercise most of the time using quantitative indicators, or starting with qualitative ones and then presenting them in a purely quantitative picture. This method allows for non-comprehensive and rather complex analysis which alienates scientific assessment of effectiveness and usefulness. Any attempt to understand the way in which some of the benchmarking reports work, or have been constructed, becomes a mission impossible, and this is so even for experts in the areas of immigration and inclusion. While some of the benchmarking reports of Section 4.1 have involved experts and academics in its preliminary phases, they are at times not involved in the way in which the results are achieved and presented. The very nature of the benchmarking output alienates any comprehensive scientific evaluation. For instance, the methodology pursued by the 2005 Index is far from being easily understandable and transparent. It is characterised by an opaque technique which clouds how it really works and how the results came about. ${ }^{399}$ This setting prevents any possibility to challenge or question its adequacy and the validity of the results. It is presented in terms that are too scientific. The results are strategically presented as a scientific tool. Everything becomes numbers and has to be quantified, or quantifiable. It becomes an instrument based on graphs and statistics, which imbues it with a respectful scientific image that is difficult to challenge. There appears to be a conscious strategy to use

398 For an attempt see D. de Palo, R. Faini and A. Venturini (2006), The Social Assimilation of Immigrants, IZA Discussion Papers Series No. 2439, Institute for the Study of Labour, November 2006, which aims at "studying the extent of social relations of migrants and compare it with that of natives" (page 7) based on the so-called "European Community Household Panel (ECHP) which is a multi-country longitudinal survey based on a standardized questionnaire; For another repon using a similar survey-based methodology see O. Causa and S. Jean (2007), Integration of Immigrants in OECD Countries: Do Policies Matter?, Economic Department Working Papers No. 564, OECD, retrievable from www.oecd.org/eco

399 A good example is foomote 11 of the Index which says that: "The criterion used for this analysis is: two country outcomes are significantly different if the difference is equal to a difference caused by an average score difference of 1 for one of their sets. There is, however, one complication, because the strand means are calculated as the average of all indicator values belonging to the strand and not as the average of the four dimension means per strand, a dimension difference of I score point therefore has a different weight (more indicators means more weight) depending on the table. In defining significant difference the model is used that approximates the strand mean by working with the mean of four dimension values per strand. There are 4 dimensions per strand. Therefore, the criterion effect on a strand mean is 0.25 . There are 20 dimensions per country ( 5 strands of 4 dimensions); therefore the criterion effect on a country mean is 0.05 . In conclusion: two countries have a significant mean difference if two respective strand means differ more than 0.25 . Two countries have a significant country mean difference if the respective means differ more than 0.05 . Two countries have a significant country index difference if their country index differs more than 2.5 points". 
benchmarking to present in an irrefutable and scientific-like manner some results whose basis would be subject to confrontation and contestation.

For example, the 2005 and 2007 versions of the MIPEX use "averages" and "indices" to present the final results. It is extremely difficult to understand the ways in which the different classes of averages have been measured and calculated. It is far from simple and user-friendly to understand the methodology behind the synthesised results. In addition, they present the concluding results in bar graphs and radar graphs, attempting "to provide the clearest statement of a country's performance on policy relative to our normative framework", 400 but which actually manage to hide very effectively the real processes through which the examination and evaluation have been conducted. Some of the reports end up using the kind of tools (graphs and statistics) and methods as those used by public authorities to justify, for instance, the implementation of restrictive immigration and integration policies at the level of the Member States.

\section{Conclusions}

This Chapter has focused on the roots, tools and institutional structures composing the EU Framework on Integration. It has addressed the extent to which the development of this Framework has affected the approaches and functionalities of integration in the EU. The development of the EU Framework on Integration has provoked substantial transformations in the traditional factors and classical features attributed to integration during the previous phases of European integration studied in Chapter 2. The nature of the Framework as a quasi-OMC uses the exchange of information and 'best practices' between the Member States as central elements in the EU's integration policy. These methods of cooperation, along with the Handbook on Integration exercise, have left the door open to certain policy initiatives and public philosophies on integration currently practiced by some Member States. The goal of moving Europeanisation forward has at times given supranational legitimacy to particular domestic approaches and innovative concepts. Terms such as integration requirements, integration programmes for newcomers, integration abroad and pre-departure measures, national plans for citizenship and integration, integration component of admission policies, self-sufficiency, etc, have progressively found a place in the European Institutions official discourse and the main policy tools coming out the EU Framework on Integration.

The meanings attributed to integration in EU law and policy have therefore mutated towards the management of immigration and a predominant acculturation dimension. Integration is being subject to an innovative framing in EU law and policy which instead of following closely the tenets of equality, citizenship, the two-way process, and the EU fair and near-equality paradigm, rather uses it as a requirement or obligation for TCNs to adhere to a certain 'way of life' and 'values' to have access to security of residence, family reunion and social inclusion. The paradigms driving the classical nomative understandings of integration in EU law and policy have substantially shifted from one that advocated the fair and near-equality of TCNs to another which conceives integration as a legal measure or immigration norm "inside or abroad". This shift becomes evident when looking at CBP2 (respect of the 'basic values of the EU') and CBP4.1 ('Basic knowledge' of the host society's language, history and institutions is indispensable for integration). Furthermore, the national predominance has also greatly inspired the European Commission to develop new initiatives until now alien from any of the classical European approach(es) on integration (e.g. the EMMI).

\footnotetext{
4(4) Page 41 of the 2005 Index.
} 
We have also analysed the institutional landscape of the EU Framework on Integration, the ways in which it works in practice and the key actors involved. The Framework constitutes a multilevel system of governmentality allowing for an alternative governance setting between the DG JFS of the European Commission, the NCPI, the MPG and other supranational networks of local and regional authorities falling outside the system of checks provided by the Community method of cooperation. The nature and operability of these actors and networks facilitates the existence of a complex and rapidly evolving web of competing strategies with multilevel effects. They have provided a transnational venue prioritising certain policies, programmes and practices at the national level considered to be "the best" for the entire EU.

This Chapter has also examined the vulnerabilities affecting benchmarking integration. We have argued that one of the key deficits is the lack of a commonly shared approach of integration at EU level. Benchmarking is not a neutral or ideology-free tool, but rather encompasses a heavy political baggage. Best or worst are malleable adjectives often attributed according to a certain ideological understanding and approach over 'the common standard' against which to test the norm, policy or practice at stake. It is not clear who will be in the position of 'benchmarker'. There is also an important difficulty at times of addressing the personal scope of benchmarking. Current benchmarking techniques generally face various methodological deficits which call for critical reflection and plural discussion. There are a series of constraints involved in attempting to apply an interdisciplinary approach, finding a common set of indicators, overcoming the shortcomings inherent to any comparative analysis, and presenting the benchmarking results in a transparent and comprehensive manner. The benchmarking language, terminology and rhetoric appear to take for granted these deficiencies. Improving these weaknesses might well raise ethical implications in respect of non-discrimination and fundamental rights which must not be overcome by blinded objectives of having access to "data to compare" and the official goal of monitoring integration in the EU. 



\section{Chapter 4:}

\section{European Immigration Law and Integration}

\section{Introduction}

This Chapter looks at the relationship between integration and EU immigration law. It studies the various ways in which the integration of TCNs has been understood, framed and regulated by EU law. The functions that integration performs in the EU legal system on immigration present also different connotations when comparing them to the traditional approach(es) that it has received since the original phases of European cooperation on immigration policy (Chapter 2). The negotiations of the Council Directives proposed by the European Commission on regular immigration, and their final configurations, have led to a fundamental transformation of the predominant classical perspectives attributed by EU policy to integration. While some of the consistent features identificd in the 'European approaches' over this area still persist, there is an increasing use of integration by these laws inspired by certain national arenas. This particular usage demands that integration functions as a normative criterion conditioning the access to rights, guarantees and freedoms provided by these Council Directives. It constitutes a derogative clause in hands of the Member States in relation to the common framework offered by EU immigration law. As we will analyse in this Chapter, the role that some particular Member States have performed in the evolving relationship between integration and EU immigration law has been crucial.

The Council Directives 2003/109 on the status of third country nationals who are long-term residents and 2003/86 on the right to family reunification constitute the two legal acts of the common EU immigration policy with major far-reaching impacts. Both instruments have substantial implications for the legal status and security of TCNs at the EU level, and their fundamentals generally follow the patterns set by the Tampere milestones and the EU fair and near-equality paradigm. While they appear to offer a wide margin of appreciation to Member States via the technique of implicit minimum harmonisation and the application of numerous exceptions to the rights that they envisage, their relevance cannot be underestimated. By being framed within the Community method of cooperation provided by Title IV of the TEC (First Pillar), they benefit from the institutional structures and substantive mechanisms of the EU legal system. Both Directives constitute proper EU law. Member States are bound to act in accordance with their provisions and must respect their conditions. Those individuals falling within their personal scope might also rely on them at times of an alleged interference or unlawful discretion by a Member State in relation to the EU-wide rights thereby guaranteed. The level of discretion enjoyed by Member States is therefore constrained to the common standards prescribed by their wording and catalogue of provisions. They stand as a European framework below whose ceiling no Member State will be allowed to pass. It is therefore interesting to look at the actual nature that the normativity of integration displays in a legal framework where the sovereignty of the Member State is restrained in comparison to European cooperation developed under the EU Framework on Integration.

After offering a short overview of the current configurations of the EU legal system on immigration, and the Freedom, Security and Justice acquis in the policy area of regular immigration, Sections 2 and 3 of this Chapter examine the Council Directives on the right to family reunification 2003/86 and on the status of third country nationals who are long-term residents 2003/109. Our approach will follow a similar methodology than the one carried in previous Chapters by addressing the perspectives and approaches underlying the use of the 
category of integration in the provisions of these Directives. Particular attention will be given to the relationship between the functions played by integration and the scope, rights and conditions of the two measures. Finally, a similar exercise will be conducted regarding the two latest legislative proposals put forward by the European Commission in the context of regular immigration, i.e. highly qualified employment and an EU framework of rights for TCNs.

\section{European Law on Regular Immigration: Processes and Institutional Configurations}

The legal elements surrounding the mobility of those not holding the nationality of a Member State are rooted in Title IV of the TEC "Visas, Asylum, Immigration and other Policies related to Free Movement of Persons". This Title proclaims that in order to establish an AFSJ, the Council shall adopt measures in the field of immigration and other measures "safeguarding the rights of nationals of third countries" in accordance with Article 63. Paragraphs 3 and 4 of this provision present the distinction traditionally made in national immigration legislations between the legal or illegal nature of immigration on the bases of its compliance with a given set of administrative rules. Indeed, the legality or illegality of the mobility exercised by TCNs depends on whether the person involved respects a set of rules intended to manage and control the various stages forming part of this multifaceted phenomenon. Such a system distinguishes between the kind of mobility that is conceived as welcomed, desired, independent (wealthy), useful and/or profitable (the 'good' human mobility or 'legal immigration'), and that which is deemed as undesired, unwanted, dependent (poor) and, in some cases, presented as an insecurity issue because of its perceived potentials for posing threats to the stability and safety of the liberal State (the 'bad' human mobility or 'illegal immigration'). The transfer to Community competence of immigration policy has involved the transnational institutionalisation and legitimacy of this understanding by the nation-state of human mobility by the non-nationals.

Articles 63.3.a and 63.4 TEC correspond with the concept of 'legal immigration'. The first one calls for the Europeanisation of measures dealing with the conditions of entry and residence and the standards for issuing long-term visas and residence permits, including those for family reunification. The second demands the adoption of common rules defining the rights and conditions under which TCNs 'legally resident in one Member State' may reside in another. No express reference to integration is made in any of these provisions. Article 63.3.b provides the legal basis for the adoption of measures falling within the rubric of 'illegal immigration and residence' of TCNs. Our analysis focuses on the first of the legal and policy frameworks, as this is the one closely intertwined with the conditions for admission and stay granting security of entry, residence and inclusion to TCNs in the EU. When making reference to the dimension of the common EU immigration policy dealing with this field, we will use the terms irregular/regular immigration instead of those commonly used at the EU official level, namely illegal/legal immigration.

Before embarking on the study of the key legislative instrument composing the EU legal

402 Article 67.2 TEC states that "After this period of five years; - the Council shall act on proposals from the Commission; the Commission shall examine any request made by a Member State that it submit a proposal to the Council; - the Council, acting unanimously after consulting the European Parliament, shall take a decision with a view to providing for all or parts of the areas covered by this Tille to be governed by the procedure referred to in Article 251 and adapting the provisions relating to the powers of the Court of Justice". 
framework on regular immigration, it is worth recalling some of the most important decisionmaking and institutional structures which have been conferred by Title IV TEC for the EU to exercise its competence over immigration. As we have pointed out in the previous Chapter, the Treaty of Amsterdam provided in Article 67 that for a transitional period of five years after its entry into force, the decision-making processes applicable to these areas would remain outside the scope of qualified majority voting in the Council and the co-decision procedure provided by Article 251 TEC. The Council therefore acts on unanimity on a proposal from the European Commission or on the initiative of Member States, and the EP is only consulted. Following the mandate given by Article 67.2 TEC, ${ }^{402}$ the Council adopted a Decision on 22 December 2004 by which all the immigration-related fields contained in Title IV TEC, with the exception of regular immigration, were moved to the Community method. ${ }^{403}$ The exclusion of cooperation over the 'legal' dimensions of immigration from these processes of liberalisation shows existing tensions inherent to logics of intergovernmentalism and strategies of resistance still conducted by some Member States when transferring any drop of national sovereignty to the transnational arena as regards the discretion to apply exceptions over those policies dealing with rights, security and protection of non-nationals. ${ }^{404}$ Moreover, the current institutional arrangements restrict the role of the EP to consultation and at times, as we will see when studying the Directive 2003/86 on the right to family reunification, eliminates it altogether during formal adoption. When reading the limited degree of democratic accountability affecting these decision-making processes together with the partiality of the competence by the ECJ to review and interpret its outputs, the scenario becomes critical. As we will explore in detail in Chapter 7, the ECJ does enjoy full jurisdiction to review and interpret measures of the institutions of the Community having their legal basis in Title IV TEC. However, there is an important limitation contained in Article 68 TEC. This provision restricts the possibility for presenting a preliminary ruling (Article 234 TEC) to the national courts and tribunals of Member States against whose decisions there is no judicial remedy under national law. ${ }^{405}$ It therefore comes as no surprise that the number of cases which actually manage to reach Luxembourg in the field of regular immigration have been until present rather limited. As we will see in Section 5 below, the entry into force of the Treaty of Lisbon would finally advance the full array of methods and institutional structures for the Community method in the area of regular immigration. It would be left to the Member States to exert the political will to establish common policies.

Furthermore, it is worth recalling that the territorial scope of application of the package of legislative measures adopted in the domain of immigration show a very complex picture as

403 Council Decision 2004/927/EC of 22 December 2004 providing for certain areas covered by Title IV of Part Three of the Treaty establishing the European Community to be governed by the procedure set out in Article 251 of that Treaty, OJ L 396/45.

404 E. Guild, "Mechanisms of Exclusion: Labour Migration in the European Union" in J. Apap (ed.), Justice and Home Affais in the EU-Liberty and Security Issues affer Enlargemen, Cheltenham: Edward Elgar, 2004, pp. 211-55; See also E. Guild (2001), "Primary Immigration: The Great Myths", in E. Guild and C. Harlow (eds.), Implementing Amsterdam: Immigration and Asy/lum Rights in EC Law, Han Publishing, pp. 65-94; F. Pastore (2004), "Visas, Borders, Immigration: Formation, Structure and Current Evolution of the EU Entry Control System" in N. Walker (ed.), Europe's Area of Freedom. Secwity and Jistice. Academy of European Law, European University Institute, Oxford: Oxford University Press.

405 Article 68.1 TEC states that "Article 234 shall apply to this Title under the following circumstances and conditions: where a question on the interpretation of this Title or on the validity or interpretation of acts of the institutions of the Community based on this Title is raised in a case pending before a court or tribunal of a Member State against whose decisions there is no judicial remedy under national law, that court or tribunal shall, if it considers that a decision on the question is necessary to enable it to give judgment, request the Court of Justice to give a nuling thereon". 
regards the Member States, to which they actually apply and upon which they are binding. Based on Protocols attached to the TEC by the Treaty of Amsterdam in 1999, the UK, Ireland and Denmark enjoy a special status in relation to their participation in those legal measures adopted within the context of Title IV. The UK and lreland are exempt from all the measures adopted under this Title, yet they benefit from the right to 'opt in' to any act dealing with these domains on a case-by-case basis and within a period of three months after the proposal is presented to the Council. ${ }^{406}$ These countries have often participated in the adoption of most of the proposals dealing with irregular immigration. Conversely, they have remained outside of the scope of application of a substantial majority of the acts related to regular immigration. ${ }^{407}$ In fact, the UK and lrish governments have not 'opted in' to any of the EU laws that have so far been adopted on the bases of Article 63.3 TEC, and are not bound by or subject to its application, nor are they bound by the active interpretation of the ECJ of these instruments. Differing from the UK and Irish opt-out, the Protocol on the Position of Denmark implies that this country takes no part whatsoever in any regular immigration-related measure under Article 63 TEC. $^{408}$

On the basis of the procedures and structures conferred by the Treaty of Amsterdam to Title IV TEC, and the political framing of the Tampere Programme to the policy agenda to put it into practice, the European Commission published two Communications on a Community Immigration Policy COM(2000)757 of 22 November $2000,{ }^{409}$ and on an Open Method of Coordination for the Community Immigration Policy COM(2001) 387 of July 2001, ${ }^{410}$ which we have identified as a decisive moment in the bifurcation of the normativity of integration at the EU level (See Chapter 2). These instruments provided the Commission's strategies to make the legal, policy and institutional arrangements over immigration and integration to start developing in the EU. They configured the official point of departure of the dual framing around the field of integration in EU law and policy: EU immigration law and the EU Framework on Integration. It is time now to look at how the legislative proposals that were envisaged by the Commission in its Communication COM(2000)757 have become, or not, proper EU law.

406 According to Article 3 of the Protocol on the Position of the United Kingdom and Ireland "The United Kingdom or Ireland may notify the President of the Council in writing, within three months after a proposal or initiative has been presented to the Council purstant to Title IIla (current Title IV) of the Treaty establishing the European Community, that it wishes to take part in the adoption and application of any such proposed measure, whereupon that State shall be entitled to do so". Article 4 says that "The United Kingdom or Ireland may at any time after the adoption of a measure by the Council pursuant to Title Illa of the Treaty establishing the European Community notify its intention to the Council and to the Commission that it wishes to accept that measure".

407 For an overview of the most relevant legislative measures where the UK and Ireland have exercised their power to opt-in see T. Balzacq and S. Carrera (2005), Migration. Borders and Asy/um: Trends and Vulnerabilities in EU Policy, CEPS, Brussels, July 2005; See also S. Peers (2005), "The UK Opt-Out from EU Immigration and Asylum Law in Practice", in J.-Y. Carlier and P. De Briycker (eds), Immigration and Asylum Law of the EU: Current Debates, Bruylant: Brussels, pp. 161-165.

40 Article 2 of the Protocol says that "None of the provisions of Title Illa (current Title IV) of the Treaty establishing the European Community, no measure adopted pursuant to that Title, no provision of any international agreement concluded by the Community pursuant to that Title, and no decision of the Court of Justice interpreting any such provision or measure shall be binding upon or applicable in Denmark". For a full explanation of the legal regime applicable to these three countries in relation to other immigration-related issues see S. Peers (2006), EU Justice and Home Affairs Law, Second Edition, Oxford EC Law Library: Oxford.

409 Commission Communication, on a Community Immigration Policy COM (2000) 757, 22.11.2000.

410 Commission Communication, on a Open Method of Coordination for the Community Immigration Policy, COM(2001)387, Brussels, 11.7.2001. 
What then have been the more relevant legislative measures so far adopted in the scope of the Freedom, Security and Justice acquis on regular immigration? The following might be highlighted: ${ }^{41}$

- Directive $2003 / 86 / \mathrm{EC}$ of 22 September 2003 on the right to family reunification. ${ }^{412}$

- Directive 2003/109/EC of 25 November 2003 concerning the status of third country nationals who are long-term residents. ${ }^{413}$

- Directive 2004/1 14/EC of 13 December 2004 on the conditions of admission of third country nationals for the purpose of studies, pupil exchange, unremunerated training or voluntary service. ${ }^{414}$

- Recommendation 2005/762/EC of 12 October 2005 to facilitate the admission of third country nationals to carry out scientific research in the European Community. ${ }^{45}$

- Directive 2005/71/EC of 12 October 2005 on a specific procedure for admitting third country nationals for the purpose of scientific research, ${ }^{416}$

- Decision 2006/688/EC of 5 October 2006 on the establishment of a mutual information mechanism concerning Member State measures in the areas of asylum and immigration. 417

Regulation No. 862/2007 of 11 July 2007 on Community statistics on migration and international protection and repealing Council Regulation (EEC) No. 311/76 on the compilation of statistics on foreign workers. 418

While most of these measures might play an important role in relation to the legal status of TCNS in the EU, the first two deserve special attention because of their major role in the common EU immigration policy, their implications for the security of residence of TCNs in the EU and their particular use of integration as a norm. The Directives 2003/109 and 2003/86 fall within the category of secondary legislation in EU law. They are therefore legally binding upon Member States. Even though their nature alludes to a policy convergence of "minimums", and their substance might indeed present some critical elements, they are not a special kind of EU

411 For a complete overview see Acquis of the European Union (Title IV of the TEC, Part II of the TEC, Title Vl of the TEU), European Commission, DG JFS, Update October 2007.

412 Council Directive 2003/86/EC of 22 September 2003 on the Right to Family Reunification, OJ L 251/12, 3.10.2003.

413 Council Directive 2003/109/EC of 25 November 2003 conceming the Status of Third-Country Nationals who are Long-term Residents, OJ L 16/44, 23.1.2004.

414 Council Directive 2004/1 14/EC of 13 December 2004 on the Conditions of Admission of Third-Country Nationals for the Purposes of Studies, Pupil Exchange, Unremunerated Training or Voluntary Service, OJ L 375, 23.12.2004.

415 Council Recommendation 2005/762/EC of 12 October 2005 to facilitate the Admission of Third-Country Nationals to carry out Scientific Research in the European Community, OJ L 289/26, 3.11.2005.

416 Council Directive 2005/71/EC of 12 October 2005 on a specific procedure for Admitting Third-Country Nationals for the Purposes of Scientific Research, O.I L 289/15, 3.11.2005.

417 Council Decision 2006/688/EC of 5 October 2006 on the establishment of a Mutual Information Mechanisms conceming Member States' Measures in the Areas of Asylum and Immigration, OJ L 283, 14.10.2006.

418 Council Regulation No. 862/2007 of 11 July 2007 on Community Statistics on Migration and International Protection and repealing Council Regulation (EEC) No. $311 / 76$ on the Compilation of Statistics on Foreign Workers, OJ L 199, 31.7.2007. 
law that might be regarded as less legally binding upon Member States when comparing them to other Directives dealing with other European policies. Further, the special roles of the EP and the ECJ as regards polices on regular immigration do not imply that these measures are prevented from benefiting from the mechanisms inherent to the foundations of the EU legal system. For instance, as we will see below, some of their provisions might be qualified as sufficiently clear and precise as to benefit from the legal doctrine and judicial interpretation on direct effect. ${ }^{419}$ Therefore, any TCN falling within their personal scope could rely on them before national courts in those cases where there might be an alleged unlawful interference by the Member State in relation to the rights, freedoms and conditions that they envisage. ${ }^{420}$

Member States must also comply with the obligations included in Article 10 TEC and implement on time and appropriately these Directives in their respective national legal immigration systems. ${ }^{421}$ Further, while according to Article 249 TEC a Directive "shall be binding as to the result to be achieved, upon each Member State to which it is addressed, but shall leave to the national authorities the choice of the form and methods", it is clear that their hands remain tied as regards the actual degree of discretion over these hamonised areas at times of national implementation. The legitimate number of interferences exercised by the Member States in relation to the set of EU-wide rights and freedoms need to remain limited to the permitted conditions and requirements contained in these Directives. Member Sates will need to abstain from adopting any measure that would be against their objectives, effective rights and common criteria. Otherwise, as we will study in detail in Chapter 7, they will face the transnational set of substantive (e.g. general principles of EU law) and institutional guarantees (e.g. judicial review by Community Courts) characterising the current landscape of the EU legal system. ${ }^{422}$

In the next Sections the study is centred on the scope and nature of the Directives on the right to family reunification and long-term resident status, and their explicit relationship to integration. We shall examine their objectives, material and personal scope, the express references to integration and the ways in which the latter flourished from the negotiations since the presentation by the European Commission until the formal adoption by the Council. The analysis looks at the relationship between the rights and guarantees conferred by these Directives, the conditions under which the latter apply, and the role played by integration.

419 For a detailed study of the direct effect of Directives see for instance P. Craig and G. de Burca (2007), EU Law: Text. Cases and Materials, Fourth Edition, Oxford University Press: Oxford, Chapter 8 on "The Nature and Effect of EC Law: Direct Effect and Beyond", pp. 268-304; Refer also to S. Prechal (2005), Directives in EC Law', Second Edition, Oxford University Press: Oxford.

420 Case C-327/02, Panarotova and others, [2004] ECR 1-11055, paragraph 27.

421 Article 10 TEC states that "Member States shall take all appropriate measures, whether general or particular, to ensure fulfilment of the obligations arising out of this Treaty or resulting from action taken by the institutions of the Community. They shall facilitate the achievement of the Community's task. They shall abstain from any measure which could jeopardize the attainment of the objective of this Treaty".

422 See Articles 234 and 226 TEC. 


\section{The Directive on the Right to Family Reunification}

The Directive on the right to family reunification $2003 / 86^{423}$ establishes the common standards and criteria for TCNs residing lawfully in the territory of a Member State to be reunited with their family members. The legislative history and final shape of the Directive, which has become the first legally-binding regulatory output after the entry into force of the Amsterdam Treaty, has already received wide attention in the literature. ${ }^{424} \mathrm{~A}$ book has even covered the transposition and implementation of the Directive one year after its deadline for transposition in the EU-25. ${ }^{425}$ The aim of this section is not to expand further on the already existing and well-engaged scientific dialogue about the Directive, but rather to look specifically at the perspectives underlying integration in its substantive provisions, and review their origins, forms and implications. This exercise will indirectly facilitate a synthesised reminder about some of the relevant features characterising the objectives, scope, rights and conditions of this measure.

The Directive 2003/86 was the first product of the common immigration policy, and as such, experienced the difficulties inherent to being a pioneering act. It took years of long negotiations and discussions spanning seven different Presidencies of the Council before its adoption. ${ }^{426}$ The rule of unanimity greatly contributed to this. The Council finally reached a political agreement on the text (February 2003), and then formally adopted it on December 2003. During all that time the original proposal put forward by the European Commission in December 1999 was subject to substantial transformations inside the rooms of the Council, and to two successive amended versions, one of which entailed a major mutation of its nature. The Commission presented the Proposal for Council Directive on the Right to Family Reunification on 1 December $1999 .{ }^{427}$ Point 2.2 of the Explanatory Memorandum stated that

423 Council Directive 2003/86/EC of 22 September 2003 on the Right to Family Reunification, Of L 251/12, 3.10.2003.

424 Among others we may highlight for instance H. Oosterom-Staples (2007), "The Family Reunification Directive: A Tool Preserving Member State Interest or Conducive to Family Reunification Unity?", in A. Baldaccini, E. Guild and H. Toner (eds), Whose Freedom, Security and Justice? EU Immigration and Asylum Law and Policy, Hart Publishing: Oxford, pp. 451-488; H. Labayle (2007), 'Le Droit des Etrangers au Regroupment Familial, Regards Croisés du Droit Interne et du Droit Européen', Revue Française de Droit Administrative, 1, pp. 1-37; K. Groenendijk (2006), 'Family Reunification as a Right under Community Law', European Joumal of Migration and Law, Vol. 8, No. 2, pp. 215-230; S. Peers and N. Rogers (eds) (2006), EU Immigration and Asylum Law: Text and Commentary, Martinus Nijhoff Publishers: Leiden, Chapter 19: Family Reunion, pp. 573-613; H. Schneider and A. Wiesbrock (2005), "The Council Directive on Family Reunification: Establishing Proper Rights for Third Country Nationals?", in H. Schneider (ed.), Migration. Integration and Citizenship: A Challenge for Europe's Future, Volume 11: The Position of Third Country Nationals in Europe, Forum Maastrich: Maastricht, pp. 35-70; D. Schaffrin (2005), "Which Standard for Family Reunification for Third-Country Nationals in the European Union", in J.Y. Carlier and P. de Bruycker (eds), Immigration and Asylum Law of the EU: Current Debates, Bruylant: Brussels, pp. 90-143; S. Peers (2004), "Family Reunion and Community Law", in N. Walker (ed), Europe's Area of Freedom, Security and Justice, Oxford University Press, pp. 143-197; E. Guild (2004), The Legal Elements of European Identity: EU Citizenship and Migration Law: Kluwer Law Intemational: The Hague, Chapter 6: Family Migration in EU Law, pp. 95-124; J. Apap and S. Carrera (2003), Towards a Proactive Immigration Policy for the EU?, CEPS Working Document No. 198, Centre for European Policy Studies: CEPS, Brussels.

425 K. Groenendijk, R. Fernhout, D. Van Dam, R. Van Oers and T. Strik (2007), The Family Remification Directive in EU Member Srates: The First Year of Implementation, Wolf Legal Publishers: Nijmegen.

426 The proposal was presented at the very end of the Finish Presidency, and passed the tour de table through the Portuguese, French, Swedish, Belgian, Spanish, Danish and Greek Presidencies.

427 Proposal for a Council Directive on the Right to Family Reunification, COM(1999) 638 final, 1 December 1999. For a study on the first version of the Proposal see G. Brinkmann (2001), 'Family 
... family reunification is a necessary way of making a success of the imegration of third-country nationals residing lawfully in the Member States. The presence of family members makes for greater stability and deepens the roots of these people since they are enabled to lead a normal family life. (Emphasis added.) $)^{428}$

Also, the Commission was very careful in its first drafting and noted that the rules on family reunification were already substantially outside the scope of national law and Member State complete discretion by falling within the context of a whole series of international human rights instruments. ${ }^{49}$ The objective of the proposal was provided in point 7.1 of the Explanatory Memorandum and recital 4 of the Preamble which referred to the milestones embraced by the Tampere Programme and to the EU fair and near-equal treatment paradigm of TCNs regularly residing in the $\mathrm{EU}^{40}$ The Preamble continued by stating that

Family reunification is a necessary way of making family life possible. It helps to create a sociocultural environment facilitating the integration of third-country nationals in the Member State, which also serves to promote economic and social cohesion... The integration of family members should be promoted. To that end, they should be granted a status independent of that of the applicant after a period of residence in the Member State. They should have access to education, employment and vocational training. (Emphasis added.)

Further, the first version of Article 1 stated that the Directive aimed at establishing "a right to family reunification for the benefit of third-country nationals residing lawfully in the territory of the Member States and citizens of the Union who do not exercise their right to free movement". It therefore explicitly acknowledged the creation of an EU right to family reunification that would apply not only to those TCNs meeting the criteria prescribed by the Directive, but also to those European citizens not exercising their right to free movement, and therefore falling outside the scope of application of EU legislation on free movement of persons and family reunion harmonised now in Council Directive 2004/38. ${ }^{431}$ The 1999 version also contained a wider

Reunion, Third Country Nationals and the Community's New Powers', in E. Guild and C. Harlow (eds), Implementing Amsterdam: Immigration and Asylum Rights in EC Law, Hart Publishing: Oxford, pp. 241266; See also P. Boeles (2001), 'Directive on Family Reunification: Are the Dilemmas Resolved?', European Joumal of Migration and Law, Vol. 3, pp. 61-71.

It also referred to the family reunification of EU citizens "A Union citizen exercising the right to free movement may be accompanied or joined by his family; the terms for integration of the family in the host country are the sine qua non for the exercise of free movement in objective conditions of freedom and dignity".

See Point 3 of the Explanatory Memorandum titled "The International Legal Framework", where the European Commission mentioned among others The Universal Declaration of Human Rights and the International Covenants of 1966 on Civil and Political Rights and on Economic and Social Rights, The International Convention on the protection of the rights of all migrant workers and members of their families, the 1951 Convention relating to the Status of Refugees, the European Convention on Human Rights, the Convention on the Rights of the Child of 20 November 1989, the European Social Charter and the European Convention of 1997 on the Legal Status of Migrant Workers.

430 In particular, the Explanatory Memorandum stated that the Tampere European Council Conclusions of 1999 called for "[...] a more dynamic integration policy should aim to offer them rights and obligations comparable to those enjoyed by Union citizens [...] To attain this objective, the Commission considers it necessary to allow third-country nationals residing lawfully in the territory of the Member States to enjoy the right to family reunification, subject to certain conditions. This is indispensable if these people are to lead a normal family life and will help them to integrate into society in the Member States".

431 Directive 2004/38/EC on the Right of Citizens of the Union and their Family Members to Move and Reside Freely within the Territory of the Member States amending Regulation (EEC) No. 1612/68 and repealing Directives 64/221/EEC, 68/360/EEC, 72/194/EEC, 73/148/EEC, 75/34/EEC, 75/35/EEC, 90/364/EEC, 90/365/EEC and 93/96/EEC, 29 April 2004, OJ L 158/77, 30 April 2004. For an analysis of 
scope in relation to the coverage granted to family members, and the conditions were overall rather generous and liberal. ${ }^{432}$ Apart from the explicit references that we have highlighted in the Explanatory Memorandum and the Preamble, the term integration did not appear anywhere else in the text of the Commission's proposal.

The EP's resolution drafted by the MEP G. Watson was published in September 2000, and proposed few amendments to the text. ${ }^{433}$ A relevant suggestion was the inclusion of a nonregression clause underlining that the implementation of the Directive should in no circumstances be used by Member States to lower the level of protection already guaranteed in their domestic laws dealing with "family reunification and the integration of families". It also stressed that family reunification "helps to create socio-cultural stability which, with due respect for the cultures and traditions of third-country nationals, facilitates the integration of those nationals in the Member State". The European Commission followed it up with an amended version of the Proposal COM(2000) 624 on 10 October 2000, which attempted to include some of the ideas advocated by the EP and that rejected others such as the non-regression provision. ${ }^{434}$ The new initiative kept to a great extent the same logic and approach characterising the first version. $^{435}$

The proposal faced fierce struggles inside the Council as a result of the strategies advocated by different Member State representatives who did their best to limit the standards of protection offered by this act and accommodate them as much as possible to those already provided, or in some cases even planned to be introduced, in their national immigration legislation. The Laeken European Council on 14-15 December 2001 acknowledged the difficulties in the negotiations, and formally requested that the Council submit by 30 April 2002 at the very latest another amended proposal. ${ }^{436}$ The European Commission presented a new Proposal for Directive on the right to family reunification, $\operatorname{COM}(2002) 225$ on 2 May 2002, 37 which constituted a substantially watered-down edition of the two previous ones. The EESC Opinion of the new draft stated that

the Directive see S. Carrera (2005), "What does free movement mean in theory and practice in an enlarged EU?', Earopean Law Journal, Vol. 11, No. 6, November, pp. 699-721.

The original version of Article 5.1 stated that the Member State shall authorize the entry and residence of the following family members: the applicant's spouse or unmarried partner living in a durable relationship with the applicant; the minor children (without further specifications as regards age) and including adopted children of the applicant, spouse or unmarried partner; the relatives in ascending line of the applicant, spouse or unmarried partner; children of the applicant or his spouse or unmarried partner, being of full age, who are objectively unable to satisfy their needs by reason of their state of health.

433 European Parliament legislative resolution on the proposal for a Council directive on the right to family reunification $\mathrm{COM}(1999) 638, \mathrm{C} 5-0077 / 2000$, OJ Cl35/178 and C135/174, 7.5.2001.

434 The European Commission took out the personal scope of the proposal persons with subsidiary protection, as recommended by the EP Resolution.

435 Amended Proposal for a Council Directive on the Right to Family Reunification, COM(2000)624 final, 10.10 .2000 , Brussels. For a study of the revised 2000 proposal see R. Cholewinski (2002), "Family Reunification and Conditions Placed on Family Members: Dismantling a Fundamental Human Right', European Joumal of Migration and Law, Vol. 4, no. 3, pp. 271-290; On aspects related to social protection of third country family members see G. Brinkmann (2002), 'Family Reunification of ThirdCountry Nationals: Access of Family Members to Social Protection Benefits', European Journal of Migration and Law, Vol. 4, No. 3, pp. 291-308.

436 Presidency Conclusions of the Laeken European Council, 14-15 December 2001, SN 00300/01, Brussels.

Amended Proposal for a Council Directive on the Right to Family Reunification, COM(2002)225 final, $1999 / 0258$ CNS, 2.5 .2002 , Brussels. 
The changes reflect the prevailing attitude which emerged in the Council debate. In particular, there is an obvious concern to ensure that the legislation in force in some Member States is reflected in the articles of the directive. As a result, a provision which had been conceived of as a framework of principles has become a lowest common denominator of the laws already applying in the Member States (Emphasis added.) ${ }^{438}$

The revised measure started by making reference to the fact that after the presentation of the first amended proposal in October 2000 "the negotiations in the Council, particularly in May 2000 and May and September 2001, were tricky and success did not ensue". The European Commission therefore deemed it necessary to figure out a "new approach to enable the negotiations to succeed". Therefore, it called for a new method to approach the harmonisation of family reunification through several stages, the amended proposal being only one of them. ${ }^{439}$ This was inspired by a 'principle of flexibility' on the basis of the following parameters:

First, the introduction of a several derogations, and the use of the so-called 'standstill clauses' to guarantee that Member States would not use the former if their legal regimes at the time of adoption, or in some cases of implementation, of the Directive did not already provide for them.

Second, the inclusion of a deadline clause for the implementation of a second step in the harmonisation process envisaged by the European Commission. The proposal said in this regard that two years after the expiration of the deadline for Member States to transpose the Directive in their national legislations, those provisions offering "the greatest degree of flexibility, which are those that lie at the heart of the negotiations, will be reviewed by way of priority so as to achieve progress towards harmonisation of admissions policy". This has become current Article 19 which states that

Periodically, and for the first time not later than 3 October 2007, the Commission shall report to the European Parliament and the Council on the application of this Directive in the Member States and shall propose such amendments as may appear necessary.

Following the urgent call at the Seville European Council Conclusions of June $2002,{ }^{440}$ the Greek Presidency of the Council managed to reach a political compromise, which was proudly acknowledged in the Thessaloniki European Council/Presidency Conclusions of 19-20 June 2003, which stated that "the European Council welcomes the fact that agreement has been reached on the Directives on family reunification and long-term resident status, which are essential instruments for the integration of third country nationals". 441 The final version of the Directive 2003/86 was officially adopted in September 2003, and was published in the OJ on 3

438 Opinion of the EESC, on the Amended proposal for a Council Directive on the right to family reunification, SOC/1 16, 17.7.2002, 2002/C 241/21, OJ C241/108, 7.10.2002, which stated in Point 1.3. that "The new Commission Proposal, while formally affirming the right to family reunification, makes it subject to a series of procedures which are more restrictive than those envisaged in the 1999 draft Directive".

The 2002 version also made an express reference to the need to improve the consistency between this measure and the, at that time, proposal for Council Directive on the status of third country nationals who are long-term residents. It was therefore proposed that "the upper limit for the grant of autonomous status of family members be set at five years' residence... This new limit will harmonise the period for obtaining permanent residence documents and autonomous status and will allow adequate flexibility to reflect different national situations."

Point 37 of the Conclusions urged the Council to adopt "the provisions on family reunification" by June 2003. See Presidency Conclusions of the Seville European Council, 2 I-22 June 2002, SN 13463/02, Brussels, 24 October 2002.

${ }_{441}$ See Paragraph 28 of the Thessaloniki European Council Conclusions, Council of the European Union, 11638/03, Brussels, l October 2003. 
October 2003, entering into force the next day, and setting 3 October 2005 as the ultimate deadline for Member States to transpose it. ${ }^{442}$ This Directive does not apply to the UK, Ireland and Denmark. Overall, the final text offers a harmonised framework of 'minimums' which is confimed when looking, for example, at Article 3.5, which states that the Directive shall not affect the possibility for Member States to adopt or maintain more favourable provisions. It is also astonishing that the EP was not given the opportunity to examine the last version of the Directive adopted by the Council or to present its comments and observations. ${ }^{443}$ The strategy taken by the Council to skip the TEC consultation with the EP led to the presentation on 16 December 2003 of an action for annument before the ECJ which materialised in the Case C540/03 European Parliament v. Council. This judgement, which will be reviewed in detail in Chapter 7, had major implications for the scope of the rights and margin of appreciation granted to Member States by Directive 2003/86. ${ }^{44}$ The first Commission Report on its application was expected to be out by the end of 2007 . Nothing has been officially published until present, yet the report will see the light before the end of 2008. In this Section, our analysis will be limited to the actual common criteria stipulated by the Directive as regards the personal and material scope, and the conditions thereby expressed for exercising the European-wide rights and guarantees in relation to the EU concept of family reunification.

\subsection{The Material and Personal Scope}

The general purpose of the Directive is to determine the conditions for the exercise of a right to family reunification by those TCNs regularly residing in the territory of the Member States. ${ }^{445}$ Family reunification is defined in Article 2.d as

the entry into and residence in a Member State by family members of a third country national residing lawfully in that Member State in order to preserve the family unit, whether the family relationship arose before (i.e. family reunification) or after (i.e. family formation) the resident's entry.

The Directive will apply where the sponsor ${ }^{446}$ holds a residence permit for a period of validity of at least one year and "who has reasonable prospects of obtaining the right of permanent

442 Article 20 "Member States shall bring into force the laws, regulations and administrative provisions necessary to comply with this Directive by not later than 3 October 2005 . They shall forthwith inform the Commission thereof. When Member States adopt these measures, they shall contain a reference to this Directive or be accompanied by such a reference on the occasion of their official publication. The methods of making such reference shall be laid down by the Member States".

443 The last Resolution dealt with the 2002 Commission's Proposal, where interestingly the EP recommended deleting the paragraph of Article 4.1 dealing with the application of integration conditions to children over the age of 12 . See European Parliament legislative resolution on the amended proposal for a Council directive on the right to family reunification $\operatorname{COM}(2002) 225-\mathrm{C} 5-0220 / 2002$, OJ $\mathrm{C} 64 \mathrm{E} / 373,12.3 .2004$.

444 Case C-540/03, European Parliament v. Cotmcil, 27 June 2006, [2006] ECR I-5769. See J. Apap and S. Carrera (2003), Family Reunification - A case for anmulment before the ECJ?, CEPS Commentary, Centre for European Policy Studies: Brussels, who argued that "Although non-binding in character, consultation of the European Parliament nevertheless represents a fundamental stage in the EU legislative process. The consultation aims to guarantee democratic control and respect for the rule of law as well as the human rights and civil liberties dimension in the still rather obscure European legislative procedure".

445 Article 1 .

446 Article 2.c defines sponsor as "... a third country national residing lawfully in a Member State and applying or whose family members apply for family reunification to be joined with him/her". 
residence" ${ }^{447}$ Differing from the 1999 version, this instrument does not cover EU citizens who have exercised their freedom to move, something which has perpetuated, and to some extent invigorated, a sort of 'reverse discrimination', because the right to family reunification granted by the Directive 2003/86 to certain TCNs does not exist in any other EU law instrument for those nationals of the Member States not moving. ${ }^{448}$ This is a natural consequence of the rule concerning the 'wholly internal situation' in EU law. The status of European citizen is first acquired at the national level, because of the link with the state of nationality; however, some of rights conferred by it can only be exercised outside the traditional state. The exercise of these rights becomes a reality by moving across the traditional territorial borders, and hence migrating. ${ }^{449}$ The static or non-movable national of a Member State does not benefit from the full set of freedoms and rights guaranteed by European citizenship. (See Chapter 2 of this book).

While the right to family reunification is intrinsically attached to the sponsor's right of residence, the family members are also beneficiaries of a whole set of rights derived from that of the sponsor. Article 4 distinguishes between those categories of family members who shall or may be authorised entry and residence by the Member States. The nuclear family - the spouse and minor children - receives a higher level of protection, and the Member States shall grant it the benefit of family reunification subject to the compliance of the conditions set by the Directive. This is specified by paragraph one of Article 4, which bestows that Member States have the obligation to allow the entry and residence of the following family members:

1. Sponsor's spouse; ${ }^{450}$

2. Unmarried minor children of the sponsor and her/his spouse (including children adopted); and

3. Unmarried minor children adopted when the sponsor or the spouse has custody and they are dependent on her/him.

The Member States may, and therefore have the faculty, to allow entry and residence of:

1. First-degree relatives in the direct ascending line of the sponsor or the spouse when there is dependency and who do not enjoy "proper family support in the country of origin";

2. Adult unmarried children when they are not capable "to provide for their own needs on account of their state of health" (Article 4.2);

3. Unmarried partners, with whom the sponsor is in a duly attested stable long-term relationship or who is bound to the sponsor by a registered partnership (Article 4.3). ${ }^{451}$

447 Article 3. Peers and Rogers (2006) argue that the interpretation of permanent residence needs to be read in line with the concept of 'permanent' provided by the Council Directive 2003/109 or the acquisition of a permanent status under a more generous national regime of long-term residence. See S. Peers and $N$. Rogers (eds) (2006), EU lmmigration and Asylum Law: Text and Commentary, Martinus Nijhoff Publishers: Leiden, Chapter 19: Family Reunion, pp. 573-613.

For a discussion see H. Oosterom-Staples (2007), "The Family Reunification Directive: A Tool Preserving Member State Interest or Conducive to Family Reunification Unity?", in A. Baldaccini, E. Guild and H. Toner (eds), Whose Freedom, Security and Justice? EU Immigration and Asylum Law and Policy, Hart Publishing: Oxford, pp. 451-488.

E. Guild (2004), "Citizens, Immigrants, Terrorists and Others", in Peers, S. and A. Ward (eds.), The EU Charter of Fundamental Rights, Politics, Law and Policy, Hart Publishing: Oxford, pp. 231-47.

Article 4.5 provides an important exception consisting of "In order to ensure better integration and prevent forced marriages Member States may require the sponsor and his/her spouse to be of a mininum age, and at maximum 21 years, before the spouse is able to join him/her". 
Further, paragraph 4 of the same provision provides that in the event of a polygamous marriage, and when the sponsor has already one spouse living with him in the Member State, the family reunification of a further spouse will not be allowed and Member States may limit the reunion of further children. ${ }^{452}$ Recital 10 of the Preamble is also relevant in this context, because it states that

It is for the Member States to decide whether they wish to authorise family reunification for relatives in the direct ascending line, adut ummarried children, ummarried or registered partners as well as, in the event of a polygamous marriage, minor children of a further spouse and the sponsor. Where a Member State auhorises family reunification of these persons, this is without prejudice of the possibility, for Member States which do not recognise the existence of family ties in the cases covered by this provision, of not granting to the said persons the treatment of family members with regard to the right to reside in another Member State, as defined by the relevant EC legislation. (Emphasis added.)

As regards the normativity of integration, the 2003 final version includes eight explicit references to integration. Four of them appear in recitals $3,4,12$ and 15 of the Preamble, and the other four are respectively spread over Articles 4.1, 4.5 and 7.2. Their scope and content is analysed below. It is worth recalling that integration did not form part of the main text of the 2000 draft proposals. In fact, the very first occasion where the discussions in the Council rooms referred to integration in relation to the Directive's body took place on 4 January $2001{ }^{453}$ While discussing Article 10 (currently Article 8), which at that time stated that "The Member States may require the applicant to have resided lawfully in their territory for a period not exceeding one year, before having his family members join him", Austria raised the point that asking for one year was not sufficient to allow integration in the host country. Answering to this concern the European Commission said that perhaps

... a distinction had to be made between the requirement of residence in the territory of the Member State for a certain period, which was needed to qualify for family reunification, and assessment of the applicant's degree of integration and level of income. ${ }^{45.4}$

451 Article 4.3 states that "Member States may decide that registered partners are to be treated equally as spouses with respects to family reunification".

452 The Article 4.3 says that "By way of derogation from paragraph 1.c, Member States may limit the family reunification of minor children of a further spouse and the sponsor". These provisions need to be read with Recital 11 of the Preamble of the Directive which states that "The right to family remification should be exercised in proper compliance with the values and principles recognised by the Member States, in particular with respect to the rights of women and of children; such compliance justifies the possible taking of restrictive measures against applications for family reunification of polygamous households". It is worth noting that this recital did not appear in the actual text of the Directive until the Council Discussions held on July 2003, a very late phase in the negotiations of the Directive. See Council Document 10502/03.

$45311524 / 01$.

454 This same point continued during the discussions held under the Swedish Council Presidency, where it was said that concerning the length of the period of the sponsor's lawful residence in a Member State before having his/her family members join him "The original Commission proposal states that Member States may require the sponsor to have resided lawfully in the territory for a period not exceeding one year before being entitled to exercise his/her right to family reunification. Some Member State, feeling that this time-limit is too short to ensure the integration of the sponsor in the host State, suggested taking into account a longer period". 


\subsection{Rights, Criteria and Integration}

\subsubsection{The Rights}

Some authors have claimed that this legislative measure grants a directly applicable and/or subjective EU right to family reunification. ${ }^{45}$ This appears to come from the very title of the Directive and Article 1 , as well as from other instances such as Recitals 6,9 and 16 of the Preamble. ${ }^{456}$ Indeed, the fact that the right to family reunification is being subjected to a number of conditions, derogations and exceptions does not preclude the recognition by the Directive of such an EU right. Further, in addition to the right to family reunification, the ECJ in the Case C540/03 European Parliament v. Council held that

Article 4.1 of the Directive imposes precise positive obligations, with corresponding clearly defined individual rights, on the Member States, since it requires them, in the cases determined by the Directive, to authorise family reunification of certain members of the sponsor's family, without being left a margin of appreciation. (Emphasis added.) ${ }^{457}$

The opinion expressed by the Luxembourg Court confirms the existence of other related rights to that of family reunification. As a way of illustration, Article 14 of the Directive provides that the sponsor's family members will be entitled "in the same way as the sponsor" to have access to education, employment and self-employment activities ${ }^{458}$ and vocational guidance, training and retraining. Article 15 then establishes that after five years of residence the spouse or unmarried partner and the child not having reached the age of majority will be entitled to an autonomous residence permit independent from that of the sponsor. ${ }^{459}$ This, according to Recital 15 of the Preamble promotes "the integration of the family members". ${ }^{460}$ Article 13 continues by saying that as soon as the family reunification has been accepted, the Member State will need to authorise the entry and grant the persons every facility for obtaining the visas, and shall grant

455 K. Groenendijk (2006), 'Family Reunification as a Right under Community Law', European Journal of Migration and Lan', Vol. 8, No. 2, pp. 215-230; S. Iglesias Fernández (2007), 'El Valor de la Directiva 2003/86/CE sobre Reagrupación Familiar a la Luz de los Derechos Fundamentales y de la Sentencia del TJCE en el Asunto 540/03', Revista de Derecho Comunitario Europeo, No. 26, Enero/Abril, pp. 125153.

Recital 6 provides that "To protect the family and establish or preserve family life, the material conditions for exercising the right to family reunitication should be determined on the basis of common criteria"; Recital 9 says that "Family reunification should apply in any case to member of the nuclear family, that is to say the spouse and the minor children". Recital 16 states that "since the objectives of the proposed action, namely the establishment of a right to family reunification for third country nationals to be exercised in accordance with common rules".

See Chapter 7 of this book for a detailed analysis of the ruling.

As regards the access by TCNs covered by the Directive to employment see K. Groenendijk (2005), "Access of Third-Country Nationals to Employment under the New EC Migration Law", in F. JulienLaferriere, H. Labaye nad O. Edström (eds), The European Immigration and Asylum Policy: Critical Assesment Five Years affer the Amsterdam Treaty, Bruylant: Brussels, pp. 141-174.

Article 15.3 states that "In the event of widowhood, divorce, separation, or death of first-degree relatives in the direct ascending or descending line, an attonomous residence permit may be issued, upon application, if required, to persons who have entered by virtue of family reunification. Member States shall lay down provisions ensuring the granting of an autonomous residence permit in the event of particularly difficult circumstances".

460 Recital 15 says that "The integration of family members should be promoted. For that purpose, they should be granted a status independent of that of the sponsor, in particular in cases of breakup of marriages and partnerships, and access to education, employment and vocational training on the same terms as the person with whom they are reunited, under the relevant conditions". 
them a first residence permit of at least one year of validity and that shall be renewable. ${ }^{46 t}$ When this last element was discussed in the Council on 9 August 2002, ${ }^{462}$ Germany, the Netherlands and Austria advocated that the renewal of the residence permit should be linked with their participation in "integration measures". The European Commission proposed the introduction of an optional clause that would include the participation by the former in "integration courses". Finally, another procedural guarantee established by the Directive to the sponsors and/or the family members is the right to mount a "legal challenge" in those cases where the application for family reunification has been rejected or the residence permit has not been renewed or has been withdrawn, and hence an expulsion (removal order) has been ordered. ${ }^{463}$

From all these provisions, it might be argued that some of them would benefit from direct effect because of their precision and clarity. To start with, Article 4.1 foresees that the Member States shall (have to) authorise entry and residence subject to the conditions stipulated in Chapter IV and Article 16 to "the nuclear family". A similar consideration could be applied, for example, to Articles 5.5, 13.1, 14.1,15 and 17 .

\subsubsection{Conditions and Exceptions}

The rights and guarantees provided by the Directive to the sponsor and her/his family members are subject to a number of conditions in the control of Member States. The conditions are mainly stipulated in Chapter IV ("Requirements for the exercise of the right to family reunification") and Article 16 ("Penalties and redress") of the Directive. For instance, an application for family reunification will be rejected, and the renewal of a residence permit on these grounds will be refused or withdrawn, on the basis of public policy, public security and public health. ${ }^{464}$ Furthermore, the person submitting the application will also need to show evidence that the sponsor has "normal accommodation". ${ }^{65}$. This requirement is different from that applicable to third country family members of a person holding the EC status of Long-term Resident, who, according to Article 16.4.c, do not need to show evidence of accommodation. Also, they will need to provide proof of sickness insurance and stable and regular resources sufficient to maintain the family without recourse to the social assistance system. ${ }^{466}$ The Member States may additionally require that the sponsor has resided regularly in their territory for a period not exceeding two years before having her/his family reunified. ${ }^{467}$

46! Article 13.3 specifies that "The duration of the residence permits granted to the family member(s) shall in principle not go beyond the date of expiry of the residence permit held by the sponsor".

462 Council Document $10857 / 02$.

463 Article 18 stipulates that "The procedure and the competence according to which the right referred to in the first subparagraph is exercised shall be established by the Member States concened".

464 See Article 6 and Recital 14 that reads as follows "The notion of public policy mar cover a conviction for committing a serious crime. In this context has to be noted that the notion of public policy and public security covers also cases in which a third country national belongs to an association which supports terrorism, supports such an association or has extremist aspirations".

465 Article 7.1.a defines 'the normality' of the accommodation as "comparable family in the same region and which meets the general health and safety standards in force in the Member State concerned".

466 Article 7.1.c says that "Member States shall evaluate these resources by reference to their nature and regularity and may take into account the level of minimum national wages and pensions as well as the number of family members".

Article 8.1 of the Directive. 
The Directive presents several derogative clauses applying exceptions to the general rules, and which are sometimes subject to the so-called "standstill clauses" limiting the timeframe for the Member States to introduce these exceptions in their respective immigration legislation. This is the case, for instance, with Article 4.6, which grants to Member States the possibility to require that the applications for the family reunion of minor children be made before the age of 15 "as provided for by its existing legislation on the date of the implementation of this Directive". 468 Another illustrative example is Article 8, which stipulates that the Member State may extend the waiting period to three years of lawful residence before giving the authorisation to reunite the family where their legislation "in force on the date of adoption of this Directive takes into account its reception capacity". ${ }^{469}$ Exceptions also apply to the right to have access to employment and self-employment by the family members of the sponsor. According to Article 14.2, Member States can carry out a labour market test during a period of 12 months to examine the situation in their labour markets before granting the necessary authorisation (work permit). Article 14.3 further provides that they may also restrict access to employment and selfemployment by first-degree relatives in ascending line or adult unmarried children.

In any case, conditions and exceptions must comply with the guarantees enshrined in Articles 5.5 and 17 of the Directive, which are greatly inspired from the legal framework provided by the European Convention of Human Rights and the jurisprudence of the European Court of Human Rights. Article 5.5 obliges the Member State to have in due consideration the best interests of the minor children when examining an application. Before rejecting an application or refusing/withdrawing a residence permit and issue a removal order, "the nature and solidity of the person's family relationships and the duration of this residence in the Member State and of the existence of family, cultural and social ties with his/her country of origin" will have to be duly examined in light of Article 17.

Finally, a factor which characterises the Directive 2003/86 on the right to family reunification are the functions of integration in the relationship between the rights and conditions that it provides. Paradoxically, integration moves from the side of the rights to that of the obligations and requirements. It acts both as an exception and a conditional prerequisite for having access to entry and stay for the purpose of family reunification. Integration becomes another functional border which will need to be successfully crossed by the sponsor and/or her/his family members to have access to the EU rights and liberties/guarantees recognised by the Directive. The actual content and scope of the nomative functionalities displayed by integration in this act is now subject to analysis by taking into account the origins of these provisions during the discussions held in the Council negotiations.

\subsubsection{Integration as a Condition: Article 4.1}

It has been stressed above that the minor children of the sponsor and of her/his spouse fall within the group of family members whose entry and residence the Member States shall authorise. The

468 Article 4.5 says that "By way of derogation, Member States Member States may request that the applications concerning family reunification of minor children have to be submitted before the age of 15 , as provided for by its existing legislation on the date of the implementation of this Directive. If the application is submitted after the age of 15 , the Member States which decide to apply this derogation shall authorise the entry and residence of such children on grounds other than family reunification".

469 Article 8 provides that "By way of derogation, where the legislation of a Member State relating to family reunification in force on the date of adoption of this Directive takes into account its reception capacity, the Member State may provide for a waiting period of no more than three years berween submission of the application for family reunification and the issue of a residence permit to the family members". 
Directive applies the rule according to which the minor children must be below the age of majority set by the law of the Member State and must not be married. "By way of derogation", expression typically used by the Directive when denoting the application of an exception to a general norm, Article 4.1 states that

... where a child is aged over 12 years and arrives independently from the rest of his/her family, the Member State may, before authorising entry and residence under this Directive, verify whether he or she meets a condition for integration provided for by its existing legislation on the date of implementation of this Directive. (Emphasis added.)

This provision needs to be read in conjunction with Recital 12 of the Preamble which stipulates that

The possibility of limiting the right to family reunification of children over the age of 12 , whose primary residence is not with the sponsor, is intended to reflect the children's capacity for integration at early ages and shall ensure that they acquire the necessary education and language skills in school (Emphasis added.)

The 2000 versions of the European Commission's proposal did not contain any reference remotely close to this article. Its relevance, however, was later on confirmed by the action presented by the EP before the ECJ challenging its validity on the basis that it violated fundamental rights (Article 7 of the Charter of Fundamental Rights of the EU) and human rights (Article 8 of the European Convention on Human Rights), and particularly the right to family life and the right not to be discriminated against on grounds of age. Setting aside the discussion as to whether Article 4.1 violates fundamental and human rights, what interests us in this Chapter is ascertaining the origins of this provision during the negotiations conducted in the Council and the grounds upon which some Member States justified its inclusion. While discussing the first revised 2000 draft of the Commission's initiative on 17 September 2001, and more specifically, the question regarding the age of minor children who can benefit from the right to family reunification, Germany and Austria expressed that

Since entry into the territory of the Member State for family reunification up to the age of 18 would not allow full integration of the child concerned into the host Member State...the age threshold to be stipulated should be revised downwards. ${ }^{470}$

On that same occasion, the Belgian, Spanish, French and Portuguese representatives were of the view that the lengths of the various time limits and waiting periods applicable to the sponsor and the family members (both nuclear family members and other family members) should be fairly short and

...once the examination of the request for family reunification was completed and the family member granted the right to enter and stay in the territory of the Member State, the conditions he was obliged to meet should be reduced to a minimum to ease his rapid integration into the host country. (Emphasis added.)

While a consensus about the adequacy of amending the age threshold was not existing among the different Member States, the second revised proposal for the Directive of the European Commission COM(2002)225 stated, "It has been felt that the Member States should retain some room for manoeuvre to examine whether the child meets the conditions for integration beyond a certain age, provided their legislation provided for this at the time of adoption of the Directive and a case-by-case approach is followed". Therefore, based on the positioning of Germany and Austria, a new Article 4.1.c was introduced reading as follows:

\footnotetext{
470 Council Document 11881/01.
} 
By way of derogation, where a child is aged over 12 years, the Member State may, before authorising entry and residence under this Directive, verify whether he or she meets a condition for integration provided for by its existing legislation on the date of adoption of this Directive.

The doubts raised by the introduction of this amendment become transparent when looking, for instance, at the Opinion of the EESC of July 2002. The latter stressed that "It is not entirely clear what the 'condition for integration' might be, but it seems clear that this derogation is intended to meet the requirements of Member States which increasingly wish to select the potential of very young migrants to meet their own production needs". ${ }^{71}$ In fact, apart from some dissent by Austria in relation to the exact age to be included in the Article, ${ }^{472}$ France was the only country that continued expressing some doubts about this derogation. ${ }^{473}$ The French representatives felt that the derogation contained in this provision was too broad and that some restrictions to its application should be envisaged. In particular, France suggested adding the words "and arrives independently from the rest of his family" after "where a child is aged over 12 years", 474 something which did not please Germany, which then suggested the addition of the following clause as a recital in the Preamble:

The possibility of limiting the right to family reunification of children over the age of 12 is intended to reflect the children's capacity for integration at early ages and shall ensure that they acquire the necessary education and language skills in school. For this reason, Member States may make the right to family reunification of children over the age of 12 conditional upon proof of prerequisites for integration, if at the time of the application the child's primary residence is not with the sponsor (Emphasis added. ${ }^{475}$

France, Portugal and Sweden did not support this proposal, yet a revised version was finally adopted by deleting the last sentence, and adding "whose primary residence is not with the sponsor". 476 is therefore of utmost relevance to read the final form of the Article along with Recital 12 of the Preamble. The compromise reached at the Council shows the importance that the Preambles of Directives actually have, even though it may be argued that their actual legal nature remains different from the measure's text. The inclusion of Recital 12 did play a key role in this case in reaching the necessary political compromise.

471 EESC, Opinion on the Amended proposal for a Council Directive on the right to family reunification, SOC/1 16, 17 July 2002, 2002/C 241/21, OJ C241/108, 7.10.2002

472 On 26 November 2002, Austria stated that in accordance with Austrian law, the third-country nationals concerned may be granted family reunification up to the age of eighteen, but need to submit the relevant application not beyond the age of fifteen. See Council Document 14272/02. On the 23 January 2003 Austria propose a compromise suggestion for a new sub-paragraph to be introduced in paragraph 1 and that would read as follows "By way of derogation, Member States may request that the application for family reunification has to be submitted before the age of fifteen. If the application is submitted after the age of fifteen, the Member States which decide to apply this derogation shall examine other grounds for granting a residence permit". This compromise suggestion was not supported by the Working Party on Migration and Expulsion. Council Document 5508/03, 23 January 2003.

473 France maintained a reservation on the last sub-paragraph of paragraph 1. Council Document 5508/03, 23 January 2003.

47.4 Council Document 5881/03, 3 February 2003.

475 Council Document 6585/03, 23 February 2003.

476 See Council Document 6912/03, 28 February 2003. Another express reference to integration also appeared during this meeting in Article 4.5 which says that "In order to ensure better integration and to prevent involuntary marriages Member States may require the sponsor and his/her spouse to be of a minimum age, and at maximum 21 years, before the spouse is able to join him/her". 
A distinctive feature of Article 4.1 was the inclusion of a specific standstill clause according to which the Member States were only allowed to introduce this exception in their national legislation until the expiry of the date of implementation of the Directive, which was 3 October 2005. According to a study by the Centre for Migration Law (CML, Radboud University of Nijmegen), ${ }^{477}$ one year after the deadline for implementation of the Directive none of the Member States had implemented this provision in their national legislation, not even Germany and Austria! Therefore, as the study concludes, Article 4.1 now serves as an explicit prohibition on the introduction of this exception to the right to family reunification.

\subsubsection{Integration as a Measure: Article 7}

Integration acts as a legal measure for the exercise of the right to family reunification and all other related rights. Article 7.2 of the Directive provides that

2. Member States may require third country nationals to comply with integration measures, in accordance with national law.

With regard to the refugees and/or family members of refugees referred to in Article 12 the integration measures referred to in the first subparagraph may only be applied once the persons concerned have been granted family remification. (Emphasis added.)

Special attention needs to be paid to the second subparagraph, because by stating that for the cases of refugees and their family members the integration measures will only apply once they have been granted family reunification, it might imply that for the all TCNs not falling within this legal category, integration measures may actually apply even before they have been granted family reunification, and this might well happen when they are still abroad in their country of origin. While some did not anticipate the actual scope that this article could have in national arenas, $^{478}$ this possibility has been more than confimed when looking at the way in which the Directive has been implemented by some Member States. Among other countries, ${ }^{479}$ and as we will study in Chapter 6, France constitutes a paradigmatic example where the requirement provided in Article 7.2 and the condition of 'integration abroad' has been introduced as a criteria for obtaining a visa to enter the country on the basis of family reunification.

477 K. Groenendijk, R. Fernhout, D. Van Dam, R. Van Oers and T. Strik (2007), The Family Reunification Directive in EU Member States: The First Year of Implementation, Wolf Legal Publishers: Nijmegen, pp. 17 and 18.

Peers and Rogers (2006) stated in relation to Article 7.2 that "logically, non-resident family members cannot be required to comply with this condition in advance". S. Peers and N. Rogers (eds) (2006), EU Immigration and Asylum Law: Text and Commenary, Martinus Nijhoff Publishers: Leiden, Chapter 19: Family Reunion, pp. 573-613.

For an analysis of the implementing legislation of the Council Directive 2003/86 see K. Groenendijk, R. Fernhout, D. Van Dam, R. Van Oers and T. Strik (2007), The Family Remification Directive in EU Member States: The First Year of Implementation, Wolf Legal Publishers: Nijmegen, pages 17 and 18 . The Netherlands is another illustrative case concerning the use of "integration abroad" as a legal condition for being authorized entry in the country based on family reunification. See also S. Carrera (2006), Programas de integración para inmigrantes: una perspectiva comparada en la Unión Europea, Revista Migraciones, N. 20, Universidad Pontificia de Comillas, Madrid, pp. 37-73; 1. Michalowski (2004), "Integration Programmes for Newcomers - A Dutch model for Europe?", in A. Böcker, B. de Hart and I. Michalowski, Migration and the Regulation of Social Integration, IMIS-Beiträge Special Issue, No. 24, IMIS, Universität Osnabrück; S. Carrera (ed.), The Nexus between Immigration. Integration and Citizenship in the EU, Collective Conference Volume, April 2006. 
This provision was also absent from any of the proposals put forward by the European Commission. It only appeared when discussing the second amended 2002 version in the working groups of the Council, and therefore fell outside the scope of any of the opinions issued by the EESC, European Parliament and Committee of Regions. It can consequently be considered purely as a Council-output. What are its origins and foundations? It was at the meeting of the Working Party on Migration and Expulsion of 23 October 2002 that the Danish Presidency surprisingly suggested introducing a new paragraph 2 in Article 7 that read word for word exactly as the current version. ${ }^{400}$ While Germany, the Netherlands and Austria immediately supported this suggestion, Belgium, France and Sweden wondered about the opportunity of introducing such a requirement on integration, even if on an optional basis. Austria took the view that a general requirement on integration could also provide for a requirement of appropriate language abilities. ${ }^{48 !}$ It is interesting to note that in the next meeting of the Working Party on Migration and Expulsion on 12 November 2002, the opposition previously expressed by France as regards the introduction of integration requirements in this Article disappeared, leaving only Belgium and Sweden in the group of those expressing concerns about the need for it to be introduced. Yet they ended up accepting it as well. ${ }^{482}$

A very important phase during the negotiations was related to the appearance of the second paragraph of Article 7 about refugees and their family members and "pre-departure integration measures' for other TCNs. On the Migration and Expulsion Working Party meeting of 23 January 2003 the negotiations focused among other issues on the status of refugees. ${ }^{483}$ The point of discussion was in particular Article 12.1 of the Directive which at that time read as follows:

By way of derogation from Article 7 , the Member States shall not require the refugee/family member(s) to provide, in respect of applications concerning those family members referred to in Article 4(1), the evidence that the refugee fulfils the requitements set out in this provision.

Germany and the Netherlands maintained reservations on this provision. On the one hand, Germany pointed out that, according to its national legislation, the family members of a refugee were requested to meet the relevant requirements in order to be reunited in Germany in cases where they can be reunited with the sponsor in another State. Moreover, it expressed opposition for the family members of a refugee to be required to meet the integration condition of Article 7.2. On the other hand, the Netherlands noted that, according to Dutch law, the family members of a refugee were not asked to meet the condition of appropriate financial resources in those cases where the application for family reunification is submitted within three months of the date of entry of the refugee. This led to discussions held on 3 February $2003,{ }^{484}$ which had unexpected results with potentially major implications, and the adoption of Article 7.2 as follows: "With regard to the refugees/family members of refugees referred to in Article 12 the integration measures referred to in the first sub-paragraph may only be applied once the persons concerned have been granted family reunification".

\footnotetext{
480 Council Document, 13053/02, 23 October 2002.

481 Council Document, 13053/02, 6 November 2002.

482 Council Documents 13968/02, and 14272/02, 26 November 2002.

483 Council Document, 5508/03

48. Council Document, 5881/03.
} 


\section{The Directive on Long-Term Residents Status}

The Directive concerning the status of third country nationals who are long-term residents 2003/109 recognises an EC status of long-term resident for those who have resided for five years in the territory of a Member State in a regular status, and provides a set of rights and freedoms attached thereto. ${ }^{485}$ It recognizes to 'the long-tem resident Other' a right to move from one Member State to another and while doing so enjoy its framework of protection. The measure is also rooted in the EU fair and near-equality paradigm enshrined in the Tampere milestones of 1999, and accordingly aims at granting to TCNs a status "as near as possible" to that enjoyed by European citizens. ${ }^{46}$ It also constitutes the victory of the European tradition recognising the need to grant secure juridical status to those regularly residing for a long-term period. There has been a shared tradition among a significant number of Member States to link the length of residence with the degree of rights and security, and their gradual attainment, by those categorised as non-nationals. ${ }^{487}$ This trend has also influenced the transnational responses at the European level in the freld of regular immigration. As we have shown in Chapter 2, European action on immigration has been concerned mainly with ensuring security of residence and quasiequality status for regularly residing TCNs. This approach has created a process of interdependence between the duration of residence in the EU and the degree of equality being granted, which became consolidated with the adoption of this Directive.

The academic legal literature has extensively discussed the nature, legal history and effects subsumed with the adoption of this measure. ${ }^{488}$ Similarly to Section 2, we shall rather focus on

485 Council Directive concerning the Status of Third-country Nationals who are Long-term Residents, 2003/109, [2004] OJ L 16/44, 23.1.2004

480 Paragraph 21 of the Tampere European Council Conclusions stated that "The legal status of third country nationals should be approximated to that of Member States' nationals. A person, who has resided legally in a Member State for a period of time to be determined and who holds a long-term residence permit, should be granted in that Member State a set of uniform rights which are as near as possible to those enjoyed by EU citizens; e.g. the right to reside, receive education, and work as an employee or selfemployed person, as well as the principle of non-discrimination vis-à-vis the citizens of the State of residence. The European Council endorses the objective that long-term legally resident third country nationals be offered the opportunity to obtain the nationality of the Member State in which they are resident".

487 K. Groenendijk, E. Guild and H. Dogan, (1998), Security of Residence of Long-Term Migrants: A Comparative Study of Lau and Practice in European Comtries, Council of Europe, Strasbourg; See also K. Groenendijk (2006), "The Legal Integration of Potential Citizens: Denizens in the EU in the final years before the implementation of the 2003 directive on long-term resident third country nationals", in R. Bauböck, E. Ersboll, K. Groenendijk and H. Waldrauch (eds), Acquisition and Loss of Nationaliny, Volume 1: Comparative Analyses: Policies and Trends in 15 European Countries, Amsterdam University Press: Amsterdam, pp. 385-410;

Among others we may highlight K. Groenendijk (2007), "The Long-Term Residents Directive, Denizenship and Integration", in A. Baldaccini, E. Guild and H. Toner (eds), Whose Freedom, Security and Justice? EU Immigration and Asylum Law and Policy, Hart Publishing: Oxford, pp. 429-450; $\dot{\mathrm{S}}$. Peers and N. Rogers (eds) (2006), EU Immigration and Asylum Law: Tew and Commentary, Martinus Nijhoff Publishers: Leiden, Chapter 20: Long-Term Residents, pp. 614-639; S. Carrera (2005), "Integration as a process of inclusion for migrants? The case of long-term residents in the EU". in $\mathrm{H}$. Schneider (ed.), Migration. Inegration and Cirizenship: A Challenge for Europe's Funtre, pp. 109-138; L. Halleskov (2005), 'The Long-Term Residents Directive: A Fulfillment of the Tampere Objective of Near Equality', European Journal of Migration and Law, Vol. 7, No. 2, 2005, pp. 181-201; S. BoelaertSuominen (2005), 'Non-EU nationals and Council Directive 2003/109/EC on the status of third-country nationals who are long-term residents: Five paces forward and possibly three paces back', Common Market Law Review, Vol. 42, No. 4, August, pp. 1011-1052; E. Guild (2004), The Legal Elements of 
the perspectives underlying integration in its provisions, and assess their origins, shapes and effects. We shall additionally offer a synthesis of the most important elements inherent to its scope, rights and conditions, and the role played by integration.

The European Commission first published the Proposal for Council Directive concerning the status of third country nationals who are long-term residents COM(2001) 127 on 13 March $2001{ }^{48^{4}}$ The legal bases of the initiative were Articles 63.3 a and 63.4 TEC. ${ }^{490}$ Similarly to the Council Directive 2003/86 on the right to family reunification, it was the subject of long discussions inside the Council and its working groups, ${ }^{491}$ until it was adopted on 25 November 2003. Another point in common with the Directive on family reunification is that the end product was a significantly watered down version of the original put forward by the Commission. The increasing restrictions it gathered as it moved towards a final compromise reveal relevant features of the attitudes of some Member States towards the 'Other' and her/his acquisition of secure residence and mobility rights.

The 2001 draft started by pointing out in Point 1.5 of the Explanatory Memorandum that

With this proposal, the Commission is giving practical expression to its intention and to its commitment to a matter that is crucial in terms of securing the genuine integration of thirdcountry nationals settled on a long-term basis in the teritory of the Member States.

It also alluded to a Study on "The Legal Status of Third-Country Nationals who are Long-Term Residents in a Member State of the European Union" carried out by the CML (Radboud University of Nijmegen) on behalf of the European Commission in April 2000. ${ }^{492}$ This report

European ldentity: EU Citizenship and Migration Law, Kluwer Law International: The Hague, Chapter 12: Integration and Identity: Long Resident Third Country Nationals, pp. 215-234; S. Peers (2004), 'Implementing equality? The Directive on Long-term Resident Third Country Nationals', European Law' Review. 29(4), p. 437-440; J. Durán Ruiz (2004), El Derecho Comunitario y la Consecución de la Cindadania: la Directiva relativa al Estatuto de los Nacionales de Terceros Estados que son Residentes de Larga Duracion, Ponencia presentada en el $4^{\circ}$ Congreso sobre la Inmigración en España. Cindadania y Participación. Mesa 4: Ciudadania: Marco Jurídico y Politicas en materia de Inmigración, Girona, del 10 al 13 de noviembre de 2004; E. Crespo Navarro (2004), 'La Directiva 2003/109/CE del Consejo relativo al estatuto de los nacionales de terceros Estados residentes de larga duración y la normativa espanola en la materia', Revista de Derecho Commitario Europeo. No. 18, mayo-agosto 2004, pp. 531 552; J. Handoll (2003), "The Long Term Residents Directive", in J. Carlier and P. de Bruycker (eds), Immigration and Asy'lum Law of the EU: Currem Debates, Bruylant: Brussels, pp. 144-160; Apap, J. and S. Carrera (2003), Towards a Proactive Inmigration Policy for the EU?, CEPS Working Document No. 198, Centre for European Policy Studies: CEPS, Brussels, December 2003; K. Fach Gómez (2003), -Propuesta de Directiva relativa al estatuto de los nacionales de terceros paises residentes de larga duración en la Unión Europea', Revista de Derecho Migratorio y Extranjeria. No. 2, pp. 53-64; Handoll, J. (2003), "The Status of Third-Country Nationals", in P. de Bruycker (ed), The Emergence of $A$ European Immigration Policy, Bruylant: Brussels, pp. 269-362.

Commission Proposal for a Council Directive concerning the Status of Third-country Nationals who are Long-term Residents, COM(2001)127 final, Brussels, 13.3.2001.

Article 63.3.a TEC provides that "The Council... shall adopt: 3. measures on immigration policy within the following areas: a. conditions of entry and residence [...]. 4. Measures defining the rights and conditions under which nationals of third countries who are legally resident in a Member State may reside in other Member States".

The Council found a first political agreement at the 2514th Council Meeting JHA, Luxembourg, 5-6 June 2003, 9845/03 (Press 150).

492 K. Groenendijk, E. Guild and R. Barzilay (2000), Sucly on The Legal Stans of Third-Coumtry Nationals who are Long-Term Residents in a Member State of the European Union, Centre for Migration Law, Radboud University of Nijmegen, Nijmegen: The Netherlands. 
assisted the European Commission in the elaboration of the initiative. The document presented a comparative assessment of the similarities and differences existing among the EU Member States as regards the legal status of long-term resident TCNs. It was presented and discussed in a seminar organised by the French Presidency of the EU on 5-6 October 2000 in Paris. The French Presidency, which lasted from July to December 2000 , was actually very active in the field of immigration. Based on that seminar, ${ }^{493}$ the Presidency submitted a set of draft Council conclusions on conditions for harmonising the status of long-term resident immigrants, which were discussed at the JHA and Civil Protection Council meeting of 30 November and 1 December $2000{ }^{494}$

Furthermore, point 5.2 of the Explanatory Memorandum pointed out that

To permit fair treatment of third-country nationals and promote their full integration, as called for by the Tampere European Council, the Commission considers that there should be a common status of long-term resident so that all third-country nationals residing legally can acquire it and enjoy it on much the same terms in all the Member States. Criteria must therefore be determined for the acquisition of the status and the rights that go with it, on the basis of equal treatment with citizens of the Union in the spirit of the Tampere conclusions. (Emphasis added.)

The term integration appeared only twice in the main wording of the Directive, i.e. Recitals 4 and 12. No further references were included in the original version of the Directive. The Commission stated in Recital 4 that the integration of long-term residents is a key element in promoting social and economic cohesion. The dominant functionality of the category of integration was also transparent in Recital 12 of the Preamble, where it was stressed that

In order to constitute a genuine instrument for the integration of long-term residents into the socicty in which they live, long-term resident status should ensure equality of treatment with citizens of the Member State in a wide range of economic and social matters. (Emphasis added.)

Overall, the 2001 proposal of the European Commission followed the traditional Community approach(es) generally identified in Chapter 2 during the preliminary phases of European cooperation on immigration, and it was formally consistent with the political goals agreed to at Tampere. Unexpected transformations took place, however, during the negotiations inside the Council.

\subsection{The Negotiations of the Commission's Proposal and the "Integration Condition Clause"}

The proposal was first presented by the European Commission to the Working Party on Immigration and Expulsion of the Council on 21 June 2001. From then until November 2003, the measure was subject to long debates. A clear example on how the initiative got watered down was the role attributed to integration. A group of Member States pushed for a particular understanding of integration in line with their respective legislative framework and/or national

493 The seminar concluded that while national legislations have their own features stemming from the different legal traditions, they nevertheless have some common grounds, particularly in all making allowance for the length of standing and closeness of ties established in the receiving country.

494 JHA and Civil Protection Council Meeting 2314 ${ }^{\text {th }}$, Brussels, 30 November and I December 2000, Press $457,13865 / 00$. While an agreement was not reached, discussions were held about some policy guidelines around the criteria for having access to the status, its substance, entitlement of freedom of residence in other Member State, and the need for collateral policies (such as non-discrimination) and the exchange of information. 
political agendas. By doing so, they fundamentally mutated the meaning and functions of this term within the proposal.

In the first reading of the text at the Working Party on Migration and Expulsion on 2-3 July $2001,{ }^{495}$ Germany and Austria advocated for the introduction of the Member States' possibility to determine the persons' level of integration into the society of the receiving country as one of the conditions included in Article 6 (currently Article 5), which originally dealt with "The Conditions as to Resources and Sickness Insurance". In their view, the level of integration could be assessed "on the basis of language knowledge, the existence of contributions to the pension schemes, etc". France expressed its opposition to apply further requirements in addition to the one of the length of residence because this could conflict with the very aim of integration stated in the Tampere Conclusions. This viewpoint was also supported by the European Commission, which expressed its reservations to take into account "more subjective requirements" such as the level of integration, since "it felt that after five years' residence the person concemed could already be expected to be sufficiently integrated". 496

The proposal was subject to a second reading in the Working Party Migration and Expulsion meeting of 5 October 2001. Germany stressed again the need to introduce further conditions in Article 5, and in particular the one consisting of "an adequate linguistic knowledge and to be integrated in the social security system". France and Sweden, however, did not like the idea because in their opinion, and reflecting on the same point previously raised by the Commission, after staying legally within the territory of a Member State for five years the person concerned was already supposed to be integrated. ${ }^{497}$ In addition, the Belgian Presidency referred to the difficulties linked to the definition of the parameters for the assessment and 'measurement' of the concept of integration. 498

In the meantime, the EESC and the Committee of Regions welcomed the Commission's proposal in their respective opinions adopted on 17 October $2001^{499}$ and on 19 September $2001{ }^{500}$ The EP had also delivered its opinion concerning the proposal on 5 February 2002 with

405 Council of the European Union, 10698/01, Brussels, 2 August 2001. The Working Party on Migration and Expulsion at the Council deals with the political discussions about the issues related to admission, residence, integration and the expulsion of third country nationals.

496 Council Document, $10312 / 01$, Brussels, 12 July 2001.

497 France referred to the criterion of integration, which it felt could take the place of all the other criteria used by the Directive, including that of the length of the period of residence. It felt that application of that criterion would make it impossible to grant the status of long-term resident even before the end of the five-year period.

498 A remark was made by the representative of France in this regard, which felt that the criteria for the assessment of the degree of integration ought to be determined by the Member State concerned. It observed that if such an approach were employed it would be more appropriate to use objective and hamonised criteria, since under the Community status TCNs would be able to move about in other Member States.

499 The EESC expressed its favourable position towards the proposal from the European Commission. Yet, it emphasized the need to grant long-term resident status solely on the grounds of the period of legal residence and not subjecting it to further conditions like "evidence of economic resources or sickness insurance". It also considered important to discuss legalising the situation of TCNs who are inside the EU in an irregular status whose rights should be also effectively recognized. EESC Opinion, on the Proposal for a Council Directive concerning the status of third-country nationals who are long-term residents, SOC/069, Brussels, 17 October 2001.

500 The Committee of Regions welcomed the Commission's proposal and emplasized in paragraph 7 that "local and regional authorities will need to be involved in both the formulation and the application of 
a few amendments and concerns related to enhancing the protection of TCNs against the discretion of the Member State at times of granting EC Status. ${ }^{501}$ The discussions continued to be held inside the Council. At the meeting of the Working Party on 22 March 2002, Article 5.1 was once more one of the points of contention. It was proposed to introduce in this provision a subparagraph creating the possibility for Member States to ask the immigrant to provide evidence "that they themselves and their dependent family members have met integration and accommodation conditions". 502 The introduction of "setting an integration condition to be met by the person concerned" was supported during the debates by Austria, Germany and the Netherlands. Belgium, France and Sweden again expressed their opposition to this conditionality. In particular, the French representatives were of the view that after five years of permanent residence the conditions applicable for having access to the status should be "as lenient as possible". Belgium considered the concept of integration was simply 'too vague'. The position of the European Commission as regards the inclusion of further conditions in the Directive was that this would undermine its very purpose. ${ }^{503}$

On 28-29 May 2002, ${ }^{504}$ the Working Party (WP) on Migration and Expulsion carried out the third reading of the proposal and examined some amendments that had been put forward by the Spanish Presidency. ${ }^{505}$ The Danish Presidency also presented some questions to SCIFA (Strategy Committee on Immigration, Frontiers and Asylum) in this regard. ${ }^{506}$ One referred to the previous discussions as to whether there should be any more 'conditions' added to those already included in Article 5 of the proposal, and if so, what would they be about. Two other questions were posed as to the extent to which 'equal treatment' should apply to all the areas included in Article 12 without exception, and finally whether the Directive should grant the right of mobility to a second Member State.

Based on that, during the meetings held on 21-22 May 2002, ${ }^{507}$ SCIFA acknowledged that among the different Member States there was already some clear positioning regarding all these

policies on migration, given their capacity to contribute experience and best practice to the integration of third-country nationals". Opinion of the Committee of Regions on the Proposal for a Council Directive concerning the status of third-country nationals who are long-term residents, 19 September 2001, 2002/C19/06, OJ C19/18, 22.1.2002.

501 European Parliament Legislative Resolution on the Proposal for Council Directive concerning the Status of Third-country Nationals who are Long-term Residents, OJ C284E/102, 21.11.2002.

502 Council of the European Union, 7558/02, Brussels, 27 May 2002. Moreover, discussions were held as to whether the "conditions" provided by Article 6 should be compulsory or optional.

503 The European Commission opposed the idea of introducing a distinction between compulsory and noncompulsory conditions. It pointed out that the long-term resident status is a right and that the Directive needs to set a limited number of defined conditions which have to be met in order to obtain it.

504 Council Document, 10462/02, Brussels, 3 July 2002.

s05 The Seville European Council Conclusions of 21 and 22 June 2002 had called for a reinvigoration and speeding up of the decision-making process dealing with immigration and asylum related issues, see point 37 of the Conclusions. Presidency Conclusions from the Seville European Council, 21-22 June 2002, Presidency Conclusions, 13463/02, Brussels, 24 October.

506 SCIFA is also known as the Article 66 Committee of the TEC. It is generally composed by Senior Officials such as the heads of Unit of the respective Ministries of Interior of the Member States (except for the cases of Spain and the Netherlands. In fact, it is quite common that officials participating in the SCIFA are also those who negotiate the initiative under the Working Group on Migration and Expulsion. The political and strategic decision took place both at SCIFA and the Working Group levels. 
technical questions. ${ }^{508}$ As regards the conditions provided by Article 5, Germany, Austria and the Netherlands continued to be clearly in favour of adding the term "integration conditions". In this regard, doubts were raised as to the difficulty of finding objective criteria to evaluate whether this requirement was fulfilled by the immigrant. The Netherlands stated its willingness to draft together with Germany and Austria a "joint suggestion" concerning the determination of appropriate criteria which would enable the assessment of whether the condition of integration was met.

The joint suggestion to introduce integration criteria was presented by the German, Dutch and Austrian delegations on 25 September 2002. ${ }^{509}$ They stressed in this document that "The primary aim of integration is the promotion of the self-sufficiency of so-called 'newcomers' and one of the main parts of integration policy is an integration programme". 510 The notion of selfsufficiency appeared very strongly here. Therefore, they argued that the introduction of the need to pass these integration programmes would constitute the actual condition for granting longterm resident status." Further, the joint position stated that "sufficient knowledge of the country" should be an essential criterion for granting the status. This, in their opinion, would be compatible with their respective national legislations, where 'newcomers' were obliged to follow 'mandatory integration programmes' from the moment that the person concerned was legally residing in the Member State, and the level of integration was also being used as one of the conditions for granting the settlement permit. Moreover, it was pointed out that the Netherlands was working on a legislative proposal to impose on specific groups of immigrants the obligation to cover the costs of integration programmes "before entering the Netherlands". 512 Therefore, the concrete suggestion put forward by these three Member States consisted of adding to Article 5 the following paragraph:

Member States may request third country nationals who are long term residents to comply with integration conditions such as a sufficient knowledge of the language and a basic knowledge of the legal, cultural, economic and societal order of the country of residence.

Article 16 (currently Article 15) would then be accordingly modified in the following manner: "The exercise of the right to reside in a second Member State by a long-term resident may be subject to compliance with integration conditions. The Member State may request the third country national to pay the costs of the integration programme". Finally, they could also use as a requirement the need for the immigrant to provide evidence of the payment of the costs incurred in the integration programme. Having that as a basis, Coreper II (Committee of Permanent

508

Italy and Greece for instance opposed the five year residence period for granting the long-term resident status, as in Greece the period provided by law was ten years, and in Italy six years.

509 Council of the European Union, 12217/02, Brussels, 23 September 2002.

510 It is worth recalling here that the idea of 'self-sufficiency of newcomers' was then taken by the Handbook on Integration for Practitioners and Policy Makers elaborated on behalf of the European Commission in November 2004.

s11 It was also stated that "Integration programmes are meant to give an impetus to the independent functioning of newcomers".

512 Article 3.98a.2 of the Decree amending the Aliens Act of 17 February 2006, Stb 2006, 94; and Justitie, Immigratie- en Naturalisatiedienst, The Civic Imegration Examination Abroad, March 2006. The Newcomers Integration Act (Wet Inburgering Niennkomers, WIN), Staatsblad 1997, 604. The new 'Act on Integration Abroad' (Wet inburgering buttenland) entered into force on 15 March 2006; L.F.M. Besselink (2006), "Unequal Citizenship: Integration Measures and Equality", in S. Carrera (ed), The Nexus bencen Immigration. Integration and Citizenship in the EU, CHALLENGE Collective Conference Volume, Centre for European Policy Studies, CEPS: Brussels. 
Representatives of the Member States) asked the JHA Council on September $2002^{513}$ whether agreement could be reached on whether it would be possible for a Member State to set as a condition for the acquisition of the status that the immigrant would comply with integration measures according to national law. ${ }^{514}$

The JHA Council signalled the difficulties provoked inside the SCIFA concerning the issue of integration, ${ }^{5 / 5}$ and suggested a compromise presenting an 'optional' integration requirement that would apply only in relation to Article 5 . As to the possibility to apply integration as a condition when granting residence in a second Member State, the Council stressed that this would "imply that the person concemed might be required to pass an integration test twice in cases where both the first and the second Member State consider that he/she should be subject to this condition". Therefore, in order to avoid the existence of excessive requirements, and "in order to ensure the fair treatment of third country nationals", the Presidency proposed the insertion of a clause in Article 15 whereby the immigrant would not be subject to the integration condition more than once, and that would read as follows: "when he/she applies for long-term resident status in the first Member State or when he/she applies for a residence permit in the second Member State, 516

The proposal went back to the Working Group on Migration and Expulsion which discussed the suggestions presented by the Presidency on 30 October 2002 and 13 November $2002 .{ }^{517}$ Article 5 received the current title of "Conditions for acquiring long-term resident status", and the wording of Article 5.2 became the following: "Member States may require third-country nationals to comply with integration measures, in accordance with national law". Germany and Austria were still not satisfied with that sentence, and at the meeting on 6-7 February 2003 , they proposed to replace the word "measures" with "conditions". In addition, together with the Netherlands, they asked for the introduction in Article 15 of the requirement on integration following precisely the same fashion as the one that would be used in Article 5. This would subsequently also imply adding the proof of payment for the cost of the integration programme among the conditions being provided by Article $16 .^{519}$

The next step in the negotiations was the submission by the Presidency to the SCIFA of the question as to whether the word "measures" should be replaced by "conditions", and if the latter should also be included in Article 15. ${ }^{520}$ On 10-11 March and 28 March 2003 the Working Group on Migration and Expulsion and SCIFA re-examined the proposal for the Directive and

513 European Council, List of Council Preparatory Bodies, 15180/05, Brussels, 5.12.2005.

514 It also said that "Meanwhile, a similar condition should not be set out in connection with the question regarding mobility in article 16". Council of the European Union, 12383/02, Brussels, 30 September 2002.

515 Council Document, 12624/02, Brussels, 9 October 2002.

516 A new paragraph 2 should be added to Article 16 which would state the following: "2. Member States may require third-country nationals to comply with integration measures, in accordance with national law. This condition shall not apply where the third-country nationals concemed have been required to comply with integration requirements in order to be granted long-term resident status, in accordance with the provisions of Article 6(2)".

517 Council Document, 13700/02, Brussels, 9 December 2002.

518 Council Document, 6424/03, Brussels, 18 February 2003.

519 A similar amendment was proposed by these three countries to introduce the obligation to proof the payment of the costs involved to the integration programme for family members as stated in Article 18 of the proposal.

\$20 Council Document, 7393/1/03, Brussels, 14 March 2003. 
the word "measures" was finally replaced by "conditions" in Article $5{ }^{521}$ As regards Article 15 there was still disagreement from Germany, Austria and the Netherlands, so the Presidency suggested introducing an optional requirement in paragraph 3 to Article 15 following this wording:

3. Member States may require third-country nationals to comply with integration measures, in accordance with national law. This condition shall not apply where the third-country nationals concerned have been required to comply with integration requirements in order to be granted long-term resident status, in accordance with the provisions of Article 5(2).

While finally agreeing to introduce the word measures instead of conditions, the three countries suggested adding to another sentence in this paragraph stating that the condition would apply if it could not be expected that the immigrant would be able to fulfil the integration requirements in that Member State as well. ${ }^{522}$ Belgium, France, Italy and Sweden opposed the introduction of that sentence and supported the one put forward by the Presidency. The Presidency presented a revised version of Article 15.3 reading as follows: "Without prejudice of the second subparagraph, the persons concerned may be required to attend integration courses, with a view in particular to improve their language abilities". 523 The last version of that paragraph following the next meeting of SCIFA on 30 April 2003 reads as follows: "Without prejudice to the second sub-paragraph, the persons concerned may be required to attend language courses", 524 which was finally unanimously agreed at the SCIFA meeting of 12-13 May 2003. ${ }^{525}$

After long discussions and consequent delays in the decision-making process, the Council reached political agreement to the proposal at its meeting of 5 June $2003 .^{526}$ It is surprising to see how Austria, Gemany and the Netherlands managed to modify the relevant provisions of the initiative according to their shared priorities. This is even more remarkable when looking at how weak the justification was in the joint suggestion presented by their delegations in September $2002 .^{527}$ The need to pass a mandatory integration programme was exclusively grounded in the fact that their respective national regimes considered and used integration in such a way! Therefore, the more important political motive being signalled for adopting this innovative approach over the integration of TCNs was that the Directive would be in this manner fully compatible with their existing national immigration laws. In fact, behind the political strategy advocated by these three countries during the negotiations was a sharp willingness to limit the scope of Europeanisation in this field, and to subject the ultimate interpretation of some of the most important clauses provided by the Directive to the national arena. These three Member States wanted to keep as much sovereignty as possible when

521 Council Document, 7642/03, Brussels, 28 March 2003.

532

In particular, they wanted to add to the paragraph: "Member States may require third-country nationals to comply with integration measures, in accordance with national law. This condition shall not apply where the third-country nationals concerned have been required to comply with integration requirements in order to being granted long-term resident status, in accordance with the provisions of Article 5.2", the following sentence "and if it can be reasonably expected that the third-country national would fulfil the integration requirements in the second Member State as well."

523 Council Document, 8213/03, Brussels, 8 April 2003.

524 Council Document, 9025/03, Brussels, 6 May 2003.

525 Council Document, 9389/03, Brussels, 16 May 2003. See also 9754/03, Brussels, 26 May 2003; and 10009/03, Brussels, Bussels, 2 June 2003.

526 Council Document, 10214/03, Brussels, 10 June 2003. The Netherlands maintained a parliamentary scrutiny reservation on the whole proposal.

527 Council Document, 12217/02, Brussels, 23 September 2002. 
granting the EC Status of Long-term Resident, so in addition to other conditions, subjecting the acquisition to something as subjective and as national as integration was a perfect tool to achieve that goal.

For instance, and as we will see below, the Directive provides no harmonised definition of what can be understood by "integration conditions" and "measures". The final decision about the conceptualisation, scope and actual examination of that requirement will be taken at the national realm under the discretion of the Member States. Similarly to the way in which European citizenship was linked by the TEU to holding the nationality of a Member State, this Directive follows a similar fashion by creating a nexus between the EC long-term resident status and being integrated in the traditional concept of the State at hand. The level of integration would be determined by a programme and/or a test on knowledge of life in the country. This represents another way for the State to recuperate some of the discretion and sovereignty lost in the Europeanisation processes in the field of regular immigration.

The Council Directive 2003/109 was adopted on 25 November 2003, ${ }^{528}$ and prescribed the 23 January 2006 as the deadline for Member States to implement it in their national legislation. ${ }^{529}$ This Directive does not apply to the UK, Ireland and Denmark, and is without prejudice of more favourable provisions existing in the EU or mixed agreements with third countries, already existing agreements between a Member State and a third country, and a number of immigrationrelated treaties of the Council of Europe. ${ }^{530}$ Recital 17 of the Preamble states that those Member States applying more favourable provisions by issuing permits with a permanent or unlimited validity on conditions may continue doing so. ${ }^{531}$ In the same vein as the Council Directive $2003 / 86$, yet perhaps not as far-reaching, the final form of the text presents a legal framework of 'minimums'. That notwithstanding, the Directive 2003/109 does offer a common European regime on the status of long-term residents with potentially substantial implications for the course of Member States' immigration legislation and the rights enjoyed by TCNs settled on a long-term basis in the EU, who are no longer "invisible subjects"s32 in the European polity." Article 24 foresees that no later than 21 January 2011, the European Commission will present a Report on the application of the Directive, where, if necessary, amendments will be put forward.

528 The adoption of the Directive by the Economic and Financial Affairs Council passed quite unnoticed. Economic and Financial Affairs Council, 14492/1/03, Bnussels, 25 November 2003. See also Council Documents: 4679/03, Brussels, 14 November 2003; 14679/03, Brussels, 19 November 2003; $\quad$ and 15544/03, Brussels, 10 December 2003.

529 By mid-January only 5 Member States (Austria, Lithuania, Poland, Slovenia and the Slovak Republic) had notified their implementing measures to the Commission. See European Commission, Press Release, Stans of Third-Counny Nationals who are Long-term Residents in the EU: Deadline for Rules to take effect on 23 Janwary 2006, IP/06/56, 20 January 2006, Brussels.

Article 3.3 of the Directive.

Yet, the Preamble says, "However, for the purposes of this Directive, it should be provided that permits issued on more favourable terms do not confer the right to reside in other Member State".

T. Kostakopoulou (2001), "Invisible Citizens? Long-Term Resident Third-Country Nationals in the EU and their Struggle for Recognition", in R. Bellamy and A. Warleigh (eds), Citizenship and Governance in the European Union, Continuum Studies in Citizenship, Continuum: London, pp. 180-206.

The European Commission stated that "Although precise data about the number of third country nationals who have been legally residing in an EU Member State for at least 5 years is not currently available, an extrapolation of existing data, based on the third country national population in the EU25 minus the net migration figures for recent years, indicates that at least 10 million of legally residing thirdcountry nationals could qualify as beneficiaries of this Directive", See European Commission, Press Release, MEMO 06/15, 20 January 2006, Brussels. 
Now we shall focus on the criteria stipulated by the Directive as regards the personal and material scope, and the conditions established for enjoying the rights that it bestows.

\subsection{The Material and Personal Scope}

The Directive establishes the terms for conferring and withdrawing long-term resident status and the rights linked to it, as well as the terms of residence in another Member State from the one that has granted the status. ${ }^{534}$ It stipulates the norms for conferring security of residence and mobility (right to reside in another Member State) inside the EU. Article 4 provides that Member States shall grant the status of long-term resident to all those TCNs who have legally and continuously resided in the territory of a Member State for a period of five years immediately prior to the submission of the relevant application. ${ }^{535}$ The five-year period was finally adopted by the Council, even though some Member States expressed their opposition during negotiations. ${ }^{536}$ Recital 6 of the Directive establishes that the main criterion for having access to this EC status is the duration of residence in the territory of a Member State, and calls for "a degree of flexibility" in those circumstances where the person involved might have to leave on a temporary basis. A similar time frame is being used in other European and international legal venues covering the rights of TCNs such as the International Labour Organization Convention on Migration for Employment, the European Convention on Establishment as well as the Council of Europe's Recommendation concerning the security of residence of long-term migrants. ${ }^{537}$

Who is included and who is excluded from the EC Long-term Resident Status? The Directive applies to those TCNs ${ }^{538}$ 'legally residing' in the territory of an EU Member State. ${ }^{539}$ According

\section{Article 1,}

535 As regards the requirement of 'continuity', Article 4.3 establishes that "Periods of absence from the territory of the Member State concemed shall not interrupt the period referred to in paragraph 1 and shall be taken into account for its calculation where they are shorter than six consecutive months and do not exceed in total 10 months within the period referred to in paragraph 1". It continues by saying that "In cases of specific or exceptional reasons of a temporary nature and in accordance with their national law, Member States may accept that a longer period of absence than that which is referred to in the first subparagraph shall not interrupt the period referred to in paragraph 1. In such cases Member States shall not take into account the relevant period of absence in the calculation of the period referred to in paragraph I".

536. In particular Greece and Italy were not in favour insofar as their national legislations provided for longer time-limits, 10 and 6 years respectively. See Council of the European Union, 11360/02, Brussels, 30 July 2002.

537 E.g. ILO Convention concerning Migration for Employment (Revised 1949), which came into force on 22.1. 1952; Council of Europe Convention on Establishment, European Treaty Series No. 19, which came into force on 20.3.1990; Council of Europe, Committee of Ministers, Recommendation Rec(2000) 15 of the Committee of Ministers to member states concerning the security of residence of long-term migrants, adopted by the Committee on 13 September $2000,720^{\text {th }}$ meeting.

Article 2 of the Directive defines third country nationals as "any person who is not a citizen of the Union within the meaning of Article 17.1 of the Treaty". Article 17.1 TEC reads as follows "...Every person holding the nationality of a Member State shall be a citizen of the Union...".

Article 3.3 says that the Directive shall apply without prejudice to more favourable provisions existing in: "(a) bilateral and multilateral agreements between the Community or the Community and its Member States, on the one hand, and third countries, on the other; (b) bilateral agreements already concluded between a Member State and a third country before the date of entry into force of this Directive; (c) the European Convention on Establishment of 13 December 1955, the European Social Charter of 18 
to Article 3.2, it does not cover the following categories of TCNs who reside in the EU on the bases of: ${ }^{540}$

\section{Study or vocational training.}

Subsidiary forms of protection and those who are refugees. While the 2001 Commission's Proposal did recognise that refugees could qualify for long-term resident status, the course of the negotiations in the Council decided otherwise. The European Commission committed itself in a Joint Statement from the Council and the Commission presented in the JHA Council meeting of 8 May 2003 to present another proposal for a Directive extending this EC status to refugees and persons under subsidiary protection. On 6 June 2007 the initiative was presented. ${ }^{541}$

- Temporary grounds such as au pair, seasonal workers, workers posted by a service provider for cross-border provision of services, or where their residence permit has been formally limited. ${ }^{542}$

Diplomatic or consular protection. ${ }^{543}$

Concerning the normativity of integration, the final 2003 version includes five explicit references. Two appear in Recitals 4 and 12 of the Preamble, and the other three, products of the driving forces which led the negotiations at the Council, are stipulated in Articles 5.2 and 15.3. Their nature and content are studied below in conjunction with the rights and conditions presented by the Directive.

\subsection{Rights, Conditions and Integration}

\subsubsection{The Rights}

The set of rights conferred by the Directive 2003/109 can be summarised as follows: First, a secured right of residence granting a legal status comparable to that enjoyed by nationals of the Member State concerned, and a reinforced protection against expulsion linked to effective legal redress mechanisms; and second, a right to move to and reside in a second Member State different from the one originally granting the long-term resident status and to receive the same legal treatment of 'near-equality'. What are the precise rights conferred on those TCNs holding long-term resident status in a Member State?

First, Article 8 clarifies that the status of long-term resident shall be "permanent" subject to the conditions explained below. As a general rule, those meeting the conditions stipulated by the

October 1961, the amended European Social Charter of 3 May 1987 and the European Convention on the Legal Status of Migrant Workers of 24 November 1977".

540 Article 3.2 of the Directive.

5:1 Proposal for a Council Directive amending Directive 2003/109/EC to extend its scope to beneficiaries of international protection, $\operatorname{COM(2007)} 298$ final, Brussels, 6.6.2007.

542 On how the last part of this exception was introduced in the negotiations at the Council and its legal implications see Chapter 12 on "Integration and Identity" of the book E. Guild (2004), The Legal Elements of European Identity: EU Citizenship and Migration Law, Kluwer Law Intemational: The Hague, pp.215-234.

${ }^{543}$ This category would include persons enjoying a legal status governed by the Vienna Convention on Diplomatic Relations of 1961, the Vienna Convention on Consular Relations of 1963, the Convention of 1969 on Special Missions or the Vienna Convention on the Representation of States in their Relations with International Organizations of a Universal Character of 1975. 
Directive will be issued a long-term resident's EC residence permit valid for five years and "it shall be, upon application if required, automatically renewable on expiry". "544 In contrast with the initial version of the Directive, ${ }^{545}$ the new period of validity of the residence permit has generously been reduced from ten to five years. ${ }^{546}$ The expiry of a long-term resident's EC residence permit shall in no case entail withdrawal or loss of long-term status. ${ }^{547}$ The holder will enjoy nearly-equal treatment with the nationals of the receiving State in a broad range of dimensions. While it is true that Article $1 /$ establishes that long-term residents shall enjoy "equal treatment" with nationals in a number of areas, ${ }^{548}$ Member States have been recognised the possibility to limit in some important respects this equality. Article 11.1 stipulates that long-term residents will enjoy equality of treatment with nationals in the following domains: access to employment and self-employment, education and vocational training (including study grants), recognition of diplomas and other qualifications, social security, tax benefits, access to public goods and services (including housing), freedom of association and affiliation (including membership to employers or workers organisations) and free access to the entire territory. The last paragraph of Article 11.5 allows Member States to apply equal treatment in areas different from these. But the receiving Member State will be allowed to apply exceptions relation to:

1. Access to employment or self-employed activities in cases where they involve occasional involvement in the exercise of public policy and where these posts are reserved for nationals of the State, European citizens and European Economic Area (EEA) nationals "in accordance with existing national or Community legislation". Boelaert-Suominen $(2005)^{549}$ has sustained that the word "existing" could implicitly hide a stand-still clause, which would mean that Member States would not be allowed to introduce new restrictions from the time of adoption of the Directive (25 November 2003). ${ }^{550}$

5.4 Article 8.2. Paragraph 3 of the same article states that "A long-term resident's EC residence permit may be issued in the form of a sticker or of a separate document. It shall be issued in accordance with the rules and standard model as set out in Council Regulation (EC) No 1030/2002 of 13 June 2002 laying down a uniform format for residence permits for third-country nationals. Under the heading 'type of permit', the Member States shall enter 'long-term resident - EC"”.

5.5 The time-period was changed in the meeting of the Working Party on Migration and Expulsion in the beginning of 2003. Council of European Union, 6424/03, Brussels, 18 February 2003.

546 Article 8.2 reads as follows: "Member States shall issue a long-term resident's EC residence permit to long-term residents. The permit shall be valid at least for five years; it shall, upon application if required, be automatically renewable on expiry".

547 See also the new Article 9.6, which provides that the expiry of a long-term resident's EC residence permit shall in no case entail withdrawal or loss of long-term status. The resident permit is to follow the patterns provided by the Council Regulation laying down a Uniform Format for Residence Permits for Third-country Nationals, (EC) 1030/2002, [2002] OJ L 157, 15.6.2002, as well as the Proposal for a Council Regulation amending Regulation (EC) 1030/2002, COM(2003) 0558 final, 24.9.2003.

548 These areas cover: access to employment and self-employment activities, education and vocational training (including study grants), recognition of diplomas and other qualifications, social security, social assistance and social protection as defined by national law, tax benefits, access to public goods and services, freedom of association and affiliation and membership of organizations representing workers or employers and free access to the entire territory of the member state.

549 S. Boelaert-Suominen (2005), Non-EU nationals and Council Directive 2003/109/EC on the status of third-country nationals who are long-term residents: Five paces forward and possibly three paces back', Common Market Law' Review, Vol. 42, No. 4, August, pp. $1011-1052$.

sso See Article 11.3. Refer to K. Groenendijk (2005), "Access of Third-Country Nationals to Employment under the New EC Migration Law", in F. Julien-Laferriere, H. Labaye nad O. Edström (eds), The European Immigration and Asyltum Policy: Critical Assesment Five Years after the Amsterdam Treaty, Bruylant: Brussels, pp. 141-174, at pp. 157-160. 
2. Access to education and vocational training will be subject to showing evidence of adequate language proficiency. ${ }^{551}$

3. Access to social assistance and social protection to "core benefits" understood as "at least minimum income support, assistance in case of illness, pregnancy, parental assistance and long-term care". 552

4. Public policy and public security considerations covered by national provisions, as regards, for example, free access to the totality of the territory of the state. ${ }^{533}$

Second, Article 10 covers the procedural safeguards that may be exercised against a decision rejecting the issue or withdrawal of the status. It states that "the person concerned shall have the right to mount a legal challenge in the member state concerned". The actual meaning behind the concept of legal challenge is not clarified by the Directive. Its practical content and definition has been left to national law.

Third, protection against expulsion. ${ }^{554}$ Article 12 obliges Member States to expel a long-term resident only when s/he constitutes "an actual and sufficiently serious threat to public security and public policy". 555 They will not be allowed to take into account economic considerations. Further, before adopting the removal order the Member States will have to pay attention to the following factors: the duration of residence in their territory, the age of the person, the consequences for the person and her/his family, as well as "the links with the country of residence or the absence of links with the country of origin". Paragraphs 4 and 5 additionally call for the provision of a judicial redress procedure and legal aid to those lacking adequate resources "on the same terms as apply to nationals of the State where they reside".

Fourth, the Directive recognises a right to move and reside in a second Member State different from the one which has granted the EC status to TCNs. Those persons meeting the conditions in a Member State for acquiring the EC status of long-term resident shall be recognised as beneficiaries of the freedom to move and reside for a period exceeding three months in the territory of Member States other than the one that granted the status in the first place. ${ }^{556}$ For the first time in the European integration processes one of the core 'freedoms' and privileges so closely attached to the nationals of the EU Member States and to the sphere of European citizenship, the freedom of movement has been expanded to those TCNs' long-term residents. Recital 18 proclaims that the recognition of a right to reside in another Member State contributes to the achievement of the internal market as an area where the free movement of persons is

551 According to Article 11.3.b "Member States may require proof of appropriate language proficiency for access to education and training. Access to university may be subject to the fulfilment of specific education prerequisites".

Article 11.4 and Recital 13 of the Preamble, which also clarifies that "the modalities for granting such benefits should be determined by national law".

Article 11.1.h.

\$54 Article 12 reads as follows: "I. Member States may take a decision to expel a long-term resident solely where he/she constitutes an actual and sufficiently serious threat to public policy or public security. 2 . The decision referred to in paragraph 1 shall not be founded on economic considerations. 3 . Before taking a decision to expel a long-term resident, Member States shall have regard to the following factors: (a) the duration of residence in their territory; (b) the age of the person concented: (c) the consequences for the person concerned and family members; (d) links with the country of residence or the absence of links with the country of origin".

Refer to Recitals 8 and 9 of the Preamble. 
formally ensured. The Directive therefore establishes a nexus between the EU freedom of movement to the status of long-term resident, and allows for that mobility to take place on economic (employment or self-employment) or educational (studies or vocational training) considerations, or for other purposes. ${ }^{557}$ Furthermore, as stipulated in Article 16, when the longterm resident exercises the right of residence in another Member State, and the family was already constituted in the first issuing State, the members of the family foreseen in Article 4.1 of the Council Directive 2003/86 shall be authorised to accompany or join her/him. ${ }^{558}$ When the family was not constituted in the first Member State, the latter Directive will apply. Recital 20 of the Preamble states that

With regard to the family members who may be authorised to accompany or to join the long-term residents, Member States should pay special attention to the situation of disabled adult children and of first-degree relatives in the direct ascending line who are dependent on them. (Emphasis added.)

Most of these provisions would benefit from direct effect due to their clarity and precision. Member States will not be allowed to apply derogation except on the basis of the following conditions.

\subsubsection{Conditions for the Acquisition}

The applicant will need to fulfil a list of requirements to qualify for the long-term resident's EC residence permit. They are mainly provided by Articles 5,6 and 7 of the Directive. In short, the following may be highlighted:

1. Article 5.1 provides that Member States will have the possibility to ask the immigrant to provide evidence of "stable and regular" resources which are considered as sufficient to maintain her/himself and the family members without recourse to social assistance ${ }^{559}$ and sickness insurance with respect to all risks. ${ }^{560}$

2. Public Policy and Public Security. Member States may refuse to grant EC status if the person is considered to be a 'threat' on grounds of public policy and public security. While considering that decision, Member States will be allowed to examine the "severity or type of offence against public policy or public security, or the danger that emanates from the person concerned, while also having proper regard to the duration of residence and to the existence of links with the country of residence". the Preamble where it is said that the notion of public policy may also cover a conviction for

\footnotetext{
557 Article 14.2 and Recital 19 of the Preamble.

558 Article 16.4 .

559 The original proposal by the European Commission only included stable resources in the former Art. 6 . the word regular appeared in the meeting of the Working Party on Migration and Expulsion of 6 and 7 February 2003. See Council of the European Union, 6424/03, Brussels, 18 February 2003.

560 Article 5.1 reads as follows "(a) stable and regular resources which are sufficient to maintain himself/herself and the members of his/her family, without recourse to the social assistance system of the Member State concerned. Member States shall evaluate these resources by reference to their nature and regularity and may take into account the level of minimum wages and pensions prior to the application for long-term resident status; (b) sickness insurance in respect of all risks normally covered for his/her own nationals in the Member State concerned". Refer to Recital 7 of the Directive.
}

561 See also paragraph 2 of Article 6, which stipulates that "the refusal referred to in paragraph I shall not be founded on economic considerations". 
committing a serious crime. ${ }^{562}$ The flexibility and level of discretion given to Member State authorities to determine whether a person may constitute a threat to public security and policy might be subject to concerns. This was actually one of the main points raised both by the Resolution of the EP ${ }^{563}$ and the Opinion of the $\operatorname{EESC}^{564}$ about the proposal for the Directive.

4. Article 7 stipulates as additional requirements the need for the applicant to present together with the formal application the necessary documentary evidence proving that all the conditions stated in Articles 4 and 5 are met. ${ }^{565}$ This provision also includes the possibility for Member States to request documentary evidence with regard to appropriate accommodation. ${ }^{566}$

5. Conditions applicable when moving to a second Member State. The Directive offers a series of conditions for the EC long-term resident to be allowed to move and reside, and while doing so be treated "nearly-equally" in comparison with nationals of the receiving State and

562 Paragraph 8 reads as follows "Moreover, third-country nationals who wish to acquire and maintain longterm resident status should not constitute a threat to public policy or public security. The notion of public policy may cover a conviction for committing a serious crime". It is interesting to see how during the Council discussions it was originally proposed to include in Article 6 (now Article 7) the following paragraph, "The notion of public policy and public security covers also cases in which a third-country national belongs to an association which supports the international terrorism, supports such an association or has extremistic aspirations". This was later on included in the minutes of the Council. Italy opposed to that by arguing that this provision should also include a reference to the cases of persons who have been convicted for serious crimes, which became later on Paragraph 8 of the Preamble. See Council of the European Union, 6424/03, Brussels, 18 February 2003; and Council of the European Union, 8213/03, Brussels, 8 April 2003.

563 The EP proposed to add in Article 17 (former Article 19) the following paragraph "2a. When applying paragraphs 1 and 2, Member States shall ensure consistency as far as possible with the provisions of Directive 64/221/EEC, unless a departure from its terms is justified by overriding security considerations". European Parliament Legislative Resolution on the Proposal for Council Directive concerning the status of third-country national who are long-term residents, OJ C284E/102, 21.11.2002.

564 The EESC said that "The reference to public order and domestic security in Article 7 must not result in arbitrariness. A clearer definition is needed of how great a threat to public order or domestic security warrants refusal of the status. Particular account will have to be taken of all the rulings passed down on these questions by the European Court of Justice". EESC Opinion, on the Proposal for a Council Directive conceming the status of third-country nationals who are long-term residents, SOC/069, Brussels, 17 October 2001.

565 Article 7.1 provides that "To acquire long-term resident status, the third-country national concerned shall lodge an application with the competent authorities of the Member State in which he/she resides. The application shall be accompanied by documentary evidence to be determined by national law that he/she meets the conditions set out in Articles 4 and 5 as well as, if required, by a valid travel document or its certified copy".

Austria, Germany, Greece and Italy were the main four actors advocating for the introduction of the requirement of appropriate accommodation for granting the EC Status of long-term resident among the conditions included in Article 6 (now Article 5). Belgium, France, Luxembourg, the Netherlands, Portugal and Spain opposed it. Even when Germany proposed to include it as an optional condition, France and Luxembourg declared that they would also oppose it. The Presidency suggested on April 2003 including the reference to accommodation in the Preamble of the Directive. Finally it was agreed to include in its current form on 24 April. Council Documents: 12983/01, Brussels, 26 October 2001; 7558/02, Brussels, 27 May 2002; 13700/02, Brussels, 9 December 2002; and 6424/03, Brussels, 18 February 2003. A similar condition exists when moving to a second Member State. See Article 15.4 of the Directive. 
European citizens. ${ }^{567}$ Concerning the set of requirements applicable, there are some features which are substantially different when comparing it with the rules covering the acquisition of the long-term resident status in the first Member State. To start with, the provision in the Directive dealing with the treatment of the long-term resident immigrant in the second Member State, Article 21, does not bear the same title as its homolog applicable in the Member State granting the status: While Article 11 refers to "Equal Treatment", Article 21 refers only to "Treatment granted in the Second State". 568 The exclusion of the word "equal" might be the devil in the detail.

As regards the applicable administrative procedures, it is worth remembering that the long-tem resident's $E C$ residence permit and the rights attached to it are confined to the particular Member State in which the TCN is residing regularly for a period of five years. Therefore, this residence permit cannot validly be used in the second Member State. EC status must also be granted there. ${ }^{569}$ Article 15 of the Directive says that after a period of three months from entry into the territory of the second Member State the immigrant will have to follow the same administrative procedures in order to (re)check whether s/he fulfils the conditions to receive a residence permit in that particular state. ${ }^{570}$ It is unfortunate that the competent national authorities of the second Member State will have another period of four months to process the application. ${ }^{57}$ Further, once the person acquires EC Status in the second Member State, pursuant to Article 23 s/he will in principle no longer be entitled to maintain this secure status in the first Member State. ${ }^{572}$

Among the most important differences which are relevant for our study, we can highlight the following: First, the degree of 'near-equality' is even lower than in the first Member State which granted EC status. ${ }^{573}$ This is the case, for instance, in the important area of economic activities. Article 21.2 allows Member States to apply a number of restrictions according to national law for having access to employment and self-employment. ${ }^{574}$ Moreover, Article 14.4 establishes

567 While in terms of security of residence and equality in the first Member States the comparison needs to be made between the immigrants and the nationals of the State, when 'the Long-term Resident Other' moves this comparison needs to be made against the status of European citizen.

568 This is in contrast with the original version of the Directive proposed originally by the European Commission. See former Article 16 of the initiative.

569 See the current version of Chapter III of the Directive, "Residence in the other Member States", Articles 14-23.

570 This article establishes that "Member States may require the persons concerned to provide evidence that they have: (a) stable and regular resources...(b) sickness insurance...".

571 As specitied by Article 19 on examination of applications and issue of residence permit.

572 Article 9.4 of the Directive, which continues by saying that "in any case after six years of absence from the territory of the Member State that granted long-term resident status the person concerned shall no longer be entitled to maintain his/her long term resident status in the said Member State. By way of derogation from the second subparagraph the Member State concerned may provide that for specific reasons the long-term resident shall maintain his/her status in the said Member State in case of absences for a period exceeding six years".

573 Article 14.3 stipulates that "In cases of an economic activity in an employed or self-employed capacity referred to in paragraph 2.a, Member States may examine the situation of their labour market and apply their national procedures regarding the requirements for, respectively, filling a vacancy, or for exercising such activities. For reasons of labour market policy, Member States may give preference to Union citizens, 10 third-country nationals, when provided for by Community legislation, as well as to thirdcountry nationals who reside legally and receive unemployment benefits in the Member State concerned".

574 Article 21.2 says that "Member States may provide that the persons referred to in Article 14.2.a shall have restricted access to employed activities different than those for which they have been granted their 
that the Member States may limit the total number of persons entitled to a right of residence for that purpose if such limitations were already set out for the admission of immigrants in the legislation that existed at the time of adoption of the measure. ${ }^{575}$ The restrictions applicable in the second Member State may function as a perfect barrier to the movement of long-term residents. When considering the low level of opportunities and the high degree of uncertainties linked with mobility to another Member State, the long-term resident immigrant may well prefer to stay in the first Member State where s/he acquired EC Status. The borders applicable in the field of employment might undermine arguments advocating for the existence of a right of free movement as provided by the Directive.

The second Member State may ask the person moving for a medical examination, and the results may constitute justification (public health) for not granting residence. ${ }^{576}$ This condition was not present in the initial version of the Directive, but was later introduced during the discussions held at the Council. During the deliberations, France and Luxembourg raised concerns about the fact that persons who had already obtained the status of long-term residents in a Member State could be forced to undergo further medical tests when moving to another Member State. ${ }^{577}$

\subsubsection{I.Integration as a Condition: Article 5.2}

The second paragraph of Article 5 presents the conditionality of integration by saying that "Member States may require third-country nationals to comply with integration conditions, in accordance with national law". In this way, the Directive has offered wide discretion to the Member States to ask would-be long-term residents to comply with mandatory integration programmes before having access to the common framework of protection and security of residence. The way in which integration conditions are used here remains critical for the protection and security of TCNs. Article 5 does not provide any legal definition on how "integration conditions" are to be understood, something which does not help to overcome the subjectivity inherent to this requirement. The final interpretation and scope of the latter has been left to the variety of national immigration legislations and approaches of the Member States at times of implementation. They will also be the ones exercising ultimate discretion to test and

residence permit under the conditions set by national legislation for a period not exceeding 12 months. Member States may decide in accordance with national law the conditions under which the persons referred to in Article 14.2.b or c may have access to an employed or self-employed activity".

In addition, Article 14.5 provides that "Member States may decide, in accordance with national law, the conditions under which long-term residents who wish to move to a second Member State with a view to exercising an economic activity as seasonal workers may reside in that Member State. Cross-border workers may also be subject to specific provisions of national law".

576 Article 18 titled "Public Health": "Member States may refuse applications for residence from long-term residents or their family members where the person concerned constitutes a threat to public health". Paragraph 4 says that "A Member State may require a medical examination, for persons to whom this Directive applies, in order to certify that they do not suffer from any of the diseases referred to in paragraph 2. Such medical examinations, which may be free of charge, shall not be performed on a systematic basis".

577 Council Document, 11702/01, Brussels, 22 October 2001. The discussions were also around the question as to whether the medical examination should be free of charge or not. In particular, Greece was opposed to that. Council Documents: 5580/02, Brussels, 22 March 2002; and 9636/02, Brussels, 18 July 2002. 
scrutinise whether the immigrant is successfully integrated into their receiving societies and therefore qualifies for the supranational EC long-term resident status. ${ }^{578}$

In light of this, the function that integration plays in Article 5.2 has paved the way for Member States to introduce into their national legal systems the functionality attributed by the Directive to integration, and require TCNs to participate in an integration programme and, considering the discussions the negotiations of the text in the Council, even cover the financial consequences linked to it. France constitutes a good example of the temptations offered by this provision to Member States whose domestic legislation did not foresee its use as a legal condition or a tool of immigration control. As we will see in Chapter 6, using as a justification the obligation to transpose the Directive 2003/109, integration has become a contractual criterion having a binding legal nature and taking the shape of the welcome and integration contract or CAI. This contract will need to be fulfilled by the TCN before having access to the status of permanent resident, and before enjoying the EU rights stipulated by the Council Directive 2003/109 to the EC Status of TCN long-term resident.

\subsubsection{Integration as a Measure: Article 15.3}

Article 15.3 provides that

Member States may require third-country nationals to comply with integration measures, in accordance with national law.

This condition shall not apply where the third-country nationals concerned have been required to comply with integration conditions in order to be granted long-term resident status, in accordance with the provisions of Article 5(2).

Wilhou prejudice to the second subparagraph, the persons concerned may be required to attend language courses.

As we have explained above, this Article was of one of the main points of contention between the Member States during the negotiations of the proposal for Directive in the Council. Germany, the Netherlands and Austria proposed to apply another "integration condition", similar to the one of Article 5.2, to those long-term resident TCNs exercising their right to move from the Member State that first conferred the secure status and reside in a second Member State. The final political compromise replaced the term "conditions" with "measures" because using "conditions" would imply "that the person concerned might be required to pass an integration test twice in cases where both the first and the second Member State consider that he/she should be subject to this condition".579 The word "measures" would only comprise the need "to attend integration courses, with a view in particular to improve their language abilities". ${ }^{580}$ Further, according to the Joint Submission issued by Germany, the Netherlands and Austria of 25 September 2002, integration conditions would imply the need for the immigrant to pass a mandatory integration programme and provide proof of having paid the costs involved in the latter.

The differences involved between the use of the word measures or conditions is of utmost importance when assessing the discretion that the Council Directives 2003/109 and 2003/86

578 S. Carrera (2005), "Integration as a process of inclusion for migrants? The case of long-term residents in the EU", in H. Schneider (ed.), Migration. Integration and Citizenship: A Challenge for Europe's Future, pp. $109-138$. 
have left to Member States when performing national transposition and implementation. The position of Groenendijk (2006) in this respect has been that "integration conditions" would allow Member States to impose more far-reaching obligations on the TCN such as passing an integration test. On the contrary, his argument continues, "integration measures" would only allow Member States to require the long-term resident "to make a certain effort" by participating in language or integration courses. ${ }^{581}$ In his opinion, it is certain that the distinction between measures and conditions is central for the legitimate national framework under which the nomative understanding of integration provided by these Directives can be implemented by the Member States.

We would also stress another important element which will be key to the analysis carried out in the next Chapters when looking at: the two national arenas in Spain and France, the implementation of the integration clauses of EU immigration law in their national legislation and the lawfulness of the latter in relation to the general principles of EU law. In our view, another key feature distinguishing both terms is the mandatory or binding nature subsumed in using each of them. The non-faculative nature inherent to the conditional functionality constitutes one of the core distinguishing features between integration conditions and measures. When looking at both Council Directives 2003/109 (Article 5.2) and 2003/86 (Article 4.1), the use of the expression "integration conditions" offered the possibility to Member States to apply integration as an obligatory requirement which in case of non-fulfiment would justify the non-access to security of residence of the EC status of long-term resident, the EU-right to family reunification and/or all the other EU rights intertwined with the other two. Indeed, the obligatory character would legitimise, in case of non-compliance by the TCN, the application of financial penalties (such as cutting off social assistance) or an automatic sanction consisting of the refusal of the application for a permanent residence permit, the non-renewal of the temporary residence permit and eventual expulsion. On the contrary, the reference made to "integration measures" by Article 15.3 of the Directive on the long-term resident status and Article 7.2 of the Directive on the right to family reunification would prohibit Member States from introducing mandatory integration conditions for the TCN in order to enjoy the rights and guarantees that they offer.

Finally, it is striking to see when looking at the different official translations of the Directive into some of the official languages of the EU how in some particular cases the wording "integration conditions" has been mistranslated as "integration measures". This has occurred, for instance, in the Spanish version of the Directive which at times has used integration measures (medidas de integración) instead of conditions (condiciones de integración). ${ }^{582}$ Taking into account what the use of conditions really implies, and the importance that was given to each of these terms in the high-level political discussions that were held within the Council in this regard, it is very surprising that more careful attention was not paid during the official translation procedures and the final output of these Community measures.

581 K. Groenendijk (2006), 'Family Reunification as a Right under Community Law', European Joumal of Migration and Law, Vol. 8, No. 2, pp. 215-230.

582 Article 5 of the Spanish version of the Directive says that "Los Estados miembros podran requerir a los nacionales de terceros paises que cumplan las medidas de integración de conformidad con la legislacion nacionar". The expression "integration conditions" is being translated correctly in a majority of the rest of official languages such as for instance, "conditions d'intégration" in French, "condizioni di integrazione" in Italian, "condições de integração" in Portuguese, etc. 


\section{New Legislative Proposals on Regular Immigration}

On the basis of the Tampere Programme that called for "the need for approximation of national legislations on the conditions for admission and residence of third country nationals", 583 and in line with the statement included in the Communication COM(2000)757 emphasising that "Channels for legal immigration to the Union should be made available for labour migrants" and that "the Commission will be adopting early next year proposals for Directives dealing with the conditions of entry and residence to the EU of third country nationals for the exercise of employment and self-employment...", 584 a Proposal for a Directive establishing the basic conditions and rules of admission concerning migrants for employment purposes was presented on 11 July $2001 .^{585}$ The main goal of this initiative was to facilitate regular immigration and simplify entry and residence procedures for reasons of employment and self-employment in the Union. After years of high-level discussions, the European Commission was forced to withdraw the proposal. ${ }^{586}$ Political agreement was impossible among Member State representatives, and since then the development of a common European policy dealing with the conditions for admission and residence of TCNs for economic purposes - labour immigration - is a missing piece in the EU legal puzzle on immigration. ${ }^{587}$

While trying to keep previous political commitments related to the establishment of an AFSJ, and after reconsidering the strategy to be followed, the Commission presented on 1 November 2004 a Green Paper on an EU approach to managing economic migration COM(2004) $811 .^{588}$

583

The literature has been very prolific also here. Among others the following may be underlined: S. Carrera (2007), Building a Common Policy on Labour Migration: Towards a Comprehensive and Global Approach in the EU?, CEPS Working Document No. 256, Centre for European Policy Studies: Brussels; B. Ryan (2007), "The European Union and Labour Migration: Regulating Admission or Treatment?", in A. Baldaccini, E. Guild and H. Toner (eds). Whose Freedom, Security and Justice? EU Immigration and Asylum Law and Policy, Han Publishing: Oxford, pp. 489-515; K. Groenendijk (2005), "Access of Third-Country Nationals to Employment under the New EC Migration Law", in F. Julien-Laferriere, $\mathrm{H}$. Labaye and $O$. Edström (eds), The European Imnigration and Asylum Policy: Critical Assesment Five Years affer the Amsterdam Treaty, Bruylant: Brussels, pp. 141-174; E. Guild (2004), "Mechanisms of Exclusion: Labour Migration in the European Union", in J. Apap (ed.), Justice and Home Affairs in the EU: Liberty' and Security Issues after Enlargement, Cheltenham: Edward Elgar, pp. 211-34; E. Guild and H. Staples (2003), "Labour Migration in the European Union", in P. de Bruycker (ed.), The Emergence of a European Immigration Policy, Bruylant: Brussels, pp. 171-247; E. Guild (2003), "Intersecting Worlds? Understanding the Legal Framework of European Labour Migration in Susan Strange's Modern World", in D. Bigo, and E. Guild (eds), Controlling Frontiers: Free Movement into and within Europe, Aldershot: Ashgate; E. Guild (2001), "Primary Immigration: The Great Myths", in E. Guild and C. Harlow (eds), Implementing Amsterdam: Immigration and Asylum Rights in EC Law, Oxford: Hart, pp $65-94$.

European Commission, Green Paper on an EU Approach to Managing Economic Migration, COM(2004) 811 final, Brussels, 1.11.2005. 
The Green Paper aimed at spurring debate among EU institutions, Member States and civil society about the 'added value' and the most appropriate form of Community rules for admitting TCNs for employment purposes. It was coupled with a public hearing organised by the European Commission in June 2005, in which the contributions submitted by all the main stakeholders involved were discussed. New political momentum was hence found to re-launch the debate on an EU labour migration policy. In their contributions to the consultation process a majority of Member States expressed their support for a policy that would offer 'fast-track procedures' for attracting 'highly skilled migrants'. In the submissions presented by some of them it was stated that this category of immigrants should be preferred over others "in order not [to] fall down in the competition for the most highly skilled workers with comparable economic regions (USA, Japan and China)", 589

A Policy Plan on Legal Migration COM(2005) 669 was published by the European Commission on 21 December 2005 presenting the list of actions and legislative initiatives that it intends to adopt until 2009 in the area of regular immigration. ${ }^{590}$ The Policy Plan focused on immigration for employment-related purposes. In particular, it explained that the Commission would submit in 2007 a proposal for a directive aiming at establishing a common general framework of rights for all immigrants who are legally employed and who already have been admitted to EU territory. Furthermore, the Plan advocated a 'fragmented or selective approach', which would be consolidated through the presentation of four specific proposals dealing with the following categories of TCNs: highly skilled or qualified workers, seasonal workers, intra-corporate transferees and remunerated trainees. ${ }^{591}$ In the words of the Commission, "this package of initiatives would mainly address the conditions and procedures of admission for this small selection of economic immigrants".

The Commission's plans for 2007 as regards the area of regular immigration were fine-tuned by its Legislative and Work Programme for $2007,{ }^{592}$ which was adopted in November 2006 . The Programme foresaw the presentation of a proposal for a directive on the conditions of entry and residence of highly skilled workers that would establish a "common special procedure to quickly select and admit such immigrants, as well as attractive conditions to encourage them to choose Europe". The Work Programme also explained how it would aim at presenting an "EU green card system" that would allow a "swifter response to react to changing needs". In addition, "A European regime for economic immigrants would give them a secure legal status making clear the rules attached and the rights they should enjoy." In light of this, the European Commission envisaged the presentation of a couple of proposals for a directive on 'highly skilled immigrants' with another one offering a common general framework of rights for all immigrants who are

589 See for instance the contribution presented by the Federal Republic of Germany, The Federal Government's Response to the Green Paper on an EU approach to managing economic migration. European Commission,

DG for Justice and Home Affairs, Brussels (2005), (retrieved from http: //europa.eu.int /comm. /justice home /news/consulting _public/economic_migration/news_contributions_economic_migration_en.htm).

European Commission, Communication, Policy Plan on Legal Migration, COM(2005) 669, Brussels, 21.12.2005.

591 The first two proposals are expected to be presented between 2007 and 2008 , and the last ones by 2009 . It seems likely that the highly skilled directive will be the only legal instrument that member states will consider at the EU level. See also European Commission, Communication on Implementing The Hague Programme: The Way Forward, COM(2006) 331 final, Brussels, 28.6.2006.

592 European Commission, Communication Commission Legislative and Work Programme 2007, $\operatorname{COM}(2006) 629$ final, Brussels, 24.10.2006. 
'legally employed'.593 The Commission presented the initiatives on 23 October $2007 .{ }^{594}$ This Section analyses them by using a similar approach to the one taken when addressing the Council Directives $2003 / 109$ and $2003 / 86$. We shall look at the normative framing of integration in these proposals in relation to the rights and conditions that they offer to TCNs.

\subsection{An EU Framework on Highly Qualified Employment and the EU Blue Card}

The Proposal for a Council Directive on the conditions of entry and residence of third country nationals for the purposes of highly qualified employment $\operatorname{COM}(2007) 637^{595}$ aims at establishing a common fast-track and flexible procedure for the admission and residence of more than three months of those third country workers meeting the conditions for being labelled as 'highly skilled workers' (HSW) and their family members, including the facilitation to move (conditions of residence) to a second Member State (intra-EU mobility). ${ }^{596}$

\subsubsection{The Material and Personal Scope}

The connecting factor for the measure to become operational would be the application by a TCN to be admitted to a Member State of the EU for the purpose of highly qualified employment, which is defined as "the exercise of genuine and effective work under the direction of someone else for which a person is paid and for which higher education qualifications or at least three years of equivalent professional experience is required". The Directive would not apply to those TCNs staying as applicants for international protection or under temporary protection schemes, refugees, those applying as researchers, family members of EU citizens exercising their freedom of movement, EC long-term residents, or those falling within the framework of an international agreement of trade and investment-related natural persons, or those in the process of being expelled. $^{597}$

As regards the material scope, the proposal leaves broad room for the application of other more favourable provisions included in EU or Mixed Agreements with third countries, agreements between Member States and third countries, ${ }^{598}$ as well as "any future agreement...that would list which should not fall under this directive in order to assure ethical recruitment, in sectors suffering from a lack of personnel, by protecting human resources in the developing countries,

593 The objective of this directive will be "to promote better integration of economic immigrants in the labour market and to establish fair and clear rules and rights for them. A secure legal status for economic immigrants - where their rights both as workers and as members of the host society will be clearly identified and recognized - will protect them from exploitation, therefore increasing their contribution to the EU's economic development and growth", as provided in the Commission's Legislative and Work Programme (2006).

594 European Commission, Press Release Making Europe more atractive to highly-skilled migrants and increasing the protection of lanfilly residing and working migrants, 1P/07/1575, Brussels, 23 October 2007.

Proposal for a Council Directive on the conditions of entry and residence of third-country nationals for the purposes of highly qualified employment, COM(2007) 637 final, Brussels, 23.10.2007.

596 Article 1. For a first assessment of the proposal see E. Guild (2007), EU Policy on Labour Migration: A First Look at the Commission's Blue Card Initiative, CEPS Policy Brief No. 145, November 2007, Centre for European Policy Sudies: Brussels. 
signatories to these agreements". ${ }^{599}$ Moreover, it also allows Member States to retain the right "to adopt or retain" more favourable provisions conceming conditions of entry and residence, "except for entry into the first State". Article 7 and Recital 9 of the Preamble affirm that Member States will retain the competence to determine the actual volume of admissions of TCNs for the purposes of highly skilled employment.

The category of integration appears a few times in the text of the proposal. Apart from some references in the Explanatory Memorandum, ${ }^{600}$ one has been expressly introduced in the main text of the act, Article 16.4. The precise content of this last provision is analysed below.

\subsubsection{Rights, Conditions and Integration}

\subsubsection{The Rights}

A TCN fulfilling the conditions stipulated by the Directive, "and for whom a positive decision has been issued by the competent authorities", will be issued an EU Blue Card, which shall be valid for two years and renewable for at least the same duration. ${ }^{601}$ According to Article 8.4 , the EU Blue Card will entitle its holder to enter, re-enter and stay in the territory of the issuing Member State, and to pass through other Member States. Furthermore, the holder and her/his family will enjoy a package of rights, which as the Explanatory Memorandum specifies, "should depend on the length of stay". ${ }^{62}$ The following rights are recognised by the proposal:

1. Labour market access. For the first two years of regular stay in the State as a holder of an EU Blue Card access to the domestic labour marker will be restricted to the exercise of the paid employment activities meeting the conditions stipulated by Articles 5 and 6 . After the first two years of legal residence, the TCN will enjoy "equal treatment" with nationals regarding access to highly qualified employment. ${ }^{603}$

2. Equal treatment in relation to nationals "at least" covering:

a. working conditions (pay, dismissal, health and safety at work);

b. freedom of association, affiliation and membership in workers' organisations;

c. education and vocational training including study grants;

d. recognition of diplomas, certificates and other professional qualifications;

e. social assistance;

f. payment of acquired pensions when moving to a third country;

g. tax benefits;

\section{Article 3.3.}

600 For instance, when exposing the different policy options that the European Commission considered in the Impact Assessment of this measure, it is said that "The effective integration of third-country highly qualified workers into the labour market and society would be the best way to maximise their contribution to economic growth and competitiveness, and it would really improve the EU's ability to deal with the present and expected challenges".

Article 8.2 states that "If the work contract covers a period less than two years, the EU Blue Card shall be issued for the duration of work contract plus three month".

602 See explanations of Articles 13,14 and 15, page 10.

603 Article 13 of the initiative. 
h. access to goods and services, and the supply of goods and services, including housing and assistance by employment offices;

i. free access to the entire territory of the Member State involved.

3. After two years of legal residence in the first Member State as an EU Blue Card holder, the proposal recognises a right to move 10 a second Member State (intra-EU mobility) for the purpose of highly qualified employment. ${ }^{604}$

4. Family members will not be subject to the conditions stipulated by the Council Directive 2003/86 studied above. In particular, family reunification will not be dependent on the prospects of the highly qualified worker to obtain a right of permanent residence. As stated in Recital 8 of the Preamble,

Favourable conditions for family reunification and for access to work for the spouses should be a fundamental element of any scheme aiming to attract highly qualified workers. Specific derogations to Council Directive 2003/86/EC of 22 September 2003 on the right to family reunification should be foreseen in order to reach this aim.

Favourable conditions in comparison to the regime provided in the Directive 2003/86 include: The residence permits for the family members will be issued no later than six months from the lodging of the application; 'integration abroad' will not be allowed; and the time limit of 12 months with respect to access by the family to the labour market will not apply. ${ }^{605}$ Also, for the purposes of calculation of the five years of residence required for the acquisition of an autonomous residence permit, consecutive residence in different Member States may be cumulated.

5. The HSW who is a Blue Card holder, and has acquired the EC status of long-term resident, will enjoy full "equal treatment" with nationals as regards access to employment and self-employment. ${ }^{606}$ Further, following Article 17 of the proposal, s/he will be issued a residence permit, "Long-term resident - EC/EU Blue Card Holder", which will grant an additional right in comparison to those with the EC status of long-term residents when moving across Member States. ${ }^{607}$ The holder will enjoy preferential treatment in terms of admission to the second Member State over potential HSW newcomers and Blue Card holders who are not yet long-term residents. ${ }^{608}$ This is inspired by Recital 16 of the Preamble which emphasises that

604 See Chapter V on "Residence in Other Member States". Article 19.2 states that "No later than one month after entering the territory of the second Member State, the holder of the EU Blue Card shall notify his/her presence to the competent authorities of that Member State and present all the documents providing that he/she fulfils the conditions set out in Articles 5 and 6 for the second Member State".

Article 16.

Article 13.3.

Recital 16 of the Preamble states that "The geographical mobility within the EU should be controlled and demand-driven during the third-country worker's first period of legal stay. Once EC long-term resident status has been granted, Member States should give preference to these workers when they exercise their right to intra-EU mobility. Derogations from Council Directive 2003/109/EC of 25 November 2003 on the status of third-country nationals who are long-term residents 2 should be included in order not to penalise geographically mobile highly qualified third-country workers who have not yet acquired EC longterm resident status, and to encourage geographical and circular migration".

Article 20 of the proposal states that "1. Article 14.4 of Directive 2003/109/EC shall not apply to holders of the residence permit "long-term resident - EC / EU Blue Card holder". 2. In cases where a Member State decides to apply the restrictions on access to the labour market provided for in Article 14.3 of Directive 2003/109/EC, it shall give preference to holders of the residence permit "long-term resident - 
Derogations from Council Directive 2003/109/EC of 25 November 2003 on the status of thirdcountry nationals who are long-term residents should be included in order not to penalise geographically mobile highly qualified third-country workers who have not yet acquired EC long-term resident status, and to encourage geographical and circular migration.

Derogations from the Council Directive 2003/109 include, for instance, the possibility for a holder of an EU Blue Card to cumulate periods of residence in different Member States for fulfilling the requirements of regular residence, the periods of absence from the territory of the Community might be extended, etc. ${ }^{609}$

\subsubsection{The Conditions}

Those non-EU nationals meeting the following criteria will be issued an EU Blue Card (residence permit allowing them to work):

1. A work contract or a binding job offer of at least one year.

2. Valid travel document, valid residence permit and health insurance.

3. Not constituting a threat to public policy, public security and public health.

4. Fulfil the conditions provided by national law to EU citizens for exercising the regulated profession.

5. For those professions which are unregulated, present documents proving relevant higher professional qualifications. ${ }^{610}$

6. The gross monthly salary must not be inferior to a national salary threshold which shall be at least three times the minimum gross monthly wage. ${ }^{611}$ In this respect Recital 10 of the Preamble of the initiative states that

The definition of a common minimum denominator for the national wage threshold is necessary to ensure a minimum level of harmonisation in the admission conditions throughout the EU. Member States should fix their national threshold accordingly to the situation of their respective labour markets and their general immigration policies.

7. Family Members. The normative understanding of integration is provided in Article 16.4 that stipulates

By way of derogation from Articles 4(1), last subparagraph, and 7(2) of Directive 2003/86/EC, the integration measures referred to therein may only be applied afier the persons concerned have been granted family reunification. (Emphasis added.)

EC / EU Blue Card holder" over other third-country nationals applying to reside there for the same purposes".

Article 17.

The proposal defines in Article 2 'higher professional qualifications' as those qualifications attested by evidence of higher education qualifications or of at least three years of equivalent professional activities.

Article 5.2 of the Proposal provides that "...the gross monthly salary specified in the work contract or binding job offer must not be inferior to a national salary threshold defined and published for the purpose by the Member States which shall be at least three times the minimum gross monthly wage as set by national law. Member States where minimum wages are not defined shall set the national salary threshold to be at least three times the minimum income under which citizens of the Member State concerned are entitled to social assistance in that Member State, or to be in line with applicable collective agreements or practices in the relevant occupation branches". 
The Member States are therefore granted the possibility to apply "integration measures" only after the family members have been granted family reunification and are already inside their territory, and not before. This is especially relevant for situations falling within the scope of Article $7.2,{ }^{612}$ because as we have studied above, Article 4.1 was subject to a standstill clause which has already expired and Member States are not allowed to introduce it anymore. The introduction of this provision by the European Commission confirms our fears that the Council Directive 2003/86 did foresee the usage of "integration abroad" as one of the requirements that Member States could add in their respective national implementing measures before granting the rights attached to family reunification. Further, it is in our view critical, from a nondiscrimination and fundamental rights point of view, that the mechanism of 'integration abroad' be subjected only to those not falling within the privileged category of highly skilled workers. We recall the importance played by salary level, and not so much the actual level of education or experience, in determining the highness of the skills presented by the person at hand. ${ }^{613}$ By doing so the European Commission acknowledges the burden inherent to the application of "integration measures" and the extent to which its application only makes family reunification difficult.

8. As stipulated in paragraphs 5 and 6 of Article 13 of the initiative, Member States will have the possibility to apply a number of derogations to the right of labour access which may consist of: First, limitations when having access to employment and self-employment activities when they entail a link with the exercise of public authority or in the safeguarding of the general interest; and second, restrictions to access employment and self-employment when taking into account the principles of national or Community preference. In addition, following Article 15.2, Member States may also restrict access to study grants and to public housing in those cases where the holder of the EU Blue Card has been staying, or has the right to stay, in its territory for at least three years. The third paragraph of this last Article provides that the Member States might not apply the principle of equal treatment as regards access to social assistance until the EU Blue Card holder has being effectively granted EC Long-term resident status. Finally, the privilege consisting of "intra-EU mobility" will still be 'demand-driven' and dependent on the fulfilment of a whole series of conditions stipulated in Article 19. ${ }^{614}$

This Proposal for Directive will institutionalise a common European policy on labour immigration based on a logic selection, a predominant economic approach and the 'needs-based scenario' of the EU in terms of labour shortages, gaps and demand for 'resources'. This framework may lead to situations where the non-EU national is treated solely as an economic unit. It will also justify a questionable disparity in the treatment of those workers defined as highly or not highly skilled. Only those deemed profitable, talented or highly skilled will be offered a path of facilitated administrative procedures for admission, residence and family

612 Article 7.2 of the Council Directive 2003/86 reads as follows: "Member States may require third country nationals to comply with integration measures, in accordance with national law. With regard to the refugees and/or family members of refugees referred to in Article 12 the integration measures referred to in the first subparagraph may only be applied once the persons concemed have been granted family reunification".

613 For a study of national legislations of highly skilled third country nationals and the importance given to the salary level see S. Carrera (2007), Building a Common Policy on Labour Migration: Towards a Comprehensive and Global Approach in the EU?, CEPS Working Document No. 256, Centre for European Policy Studies: Brussels

614 See Article 19. 
reunification, and a more secure legal status. As the EESC has stated in its Opinion on the Commission's proposal adopted the 9 July $2008,{ }^{615}$ an EU policy offering

...preferential conditions to highly qualified immigrant workers, by allowing them more favourable treatment than established in Directives 2003/86 and 2003/109, could lead to different categories of immigrants being treated differently. It must be ensured that these exceptions do not affect the overall consistency of European immigration policy and the principle of equal reatment. (Emphasis added.) ${ }^{616}$

Further, the proposal leaves Member States much discretion when defining and specifying the conditions and privileges attached to the EU Blue Card, and when moving to a second Member State. This becomes evident, for instance, when looking at the requirements stipulated in Article 5 , particularly at the salary level, which will vary greatly according to the Member States' economic and labour market situations. ${ }^{617}$ It might also lead to competition and tensions between Member States as to who 'attracts' a higher number of 'the useful third country HSW' by offering them better conditions, rights ('equal treatment') and facilities. Finally, the European Commission has also envisaged the possibility to introduce a complementary measure that would aim at facilitating intra-EU mobility for an HSW by setting up an EU Blue Card database containing information of those holding an EU Blue Card. ${ }^{618}$

\subsection{Towards a Common Framework of Rights?}

\subsubsection{The Material and Personal Scope}

The second initiative is the Proposal for a Council Directive on a single procedure for a single permit for third country nationals to reside and work in the territory of a Member State and on a common set of rights for third country workers legally residing in a Member State COM(2007) 638. ${ }^{619}$ The European Commission has embraced the objectives of this proposal from a dual perspective: ${ }^{620}$ First, a procedural approach arguing for the introduction of a single application

615 EESC, Opinion on the Proposal for a Council Directive on the conditions of entry and residence of third country nationals for the purposes of highly qualified employment, SOC/300, Brussels, 9 July 2008.

616 Point 4.6 of the Opinion.

617 The EESC expressed concerns about the use of the salary level as a condition. It stated that the salary is not an appropriate criterion for determining the status of a highly skilled worker. It was of the opinion that "The concept of "highly qualified" should be linked to higher education certificates and qualifications or equivalent vocational skills rather than the salary that the worker is to receive. Moreover, making salary one of the requirements for access to the EU Blue Card will make it hard to achieve a common policy in the EU. The major differences in national minimum wage levels that currently exist between the Member States hinder harmonization". See points 4.2 and 4.3 respectively of the Opinion.

618 According to the Commission Staff Working Document, Accompanying Document to the Proposal for a Council Directive on the conditions of entry and residence of third country nationals for the purpose of highly qualified employment, SEC(2007) 1403, Brussels, 23.10.2007, "This would be a supporting data processing instrument for the implementation of EU Blue Card mobility. Moreover, it could be an effective tool for helping to match labour supply and labour demand across the EU MS and supporting intra-EU mobility, if adequately connected with existing EU databases (i.e. EURES) and/or a possible EU skill matching database".

619 Proposal for a Council Directive on a single application procedure for a single permit for third-country nationals to reside and work in the territory of a Member State and on a common set of rights for thirdcountry workers legally residing in a Member State, COM(2007) 638 final, Brussels, 23.10.2007.

620 Article 1 states that "The purpose of this Directive is to determine: (a) a single application procedure for issuing a single permit for third country nationals to reside and work in the territory of a Member State, 
and examination procedure giving access to a combined EC residence-work permit; second, a substantive approach advocating for a common framework guaranteeing a shared set of rights to all those TCNs enjoying the status of workers and lawfully residing in a Member State and not yet entitled to the EC status of long-term resident.

As regards the procedural approach, Article 4 calls for the need to establish a "single application procedure" ${ }^{621}$ for applying to reside and work in the territory of a Member State. According to the second paragraph of this same article, the decision granting, modifying or renewing the single permit shall constitute one combined title encompassing both residence and work permit within one administrative act. ${ }^{622}$ The single procedure leading to a combined (single) permit aims at simplifying the administrative procedures and requirements for would-be employers and third country workers seeking to enter the EU to work there. The 'one-stop-shop' system would also intend to reinforce 'the control function' by the Member State and the EU as a whole over the phenomenon of immigration. Articles 6.2 and 7 provide for a general prohibition on the Member State issuing additional documents, particularly work permits of any kind, as proof of access to the labour market. ${ }^{623}$ The provision of a single document encompassing a work and residence permit would play a positive role in reducing the administrative burdens and facilitate the related procedures of issuing, suspension or withdrawal of the legality of entry and stay. The single document option would also prevent the odd situations whereby regular workers have irregular residence status or vice versa. However, it would have been desirable that once the single permit would have been granted, the life of the two permits (work and residence) would become divorced from one another. This would be an efficient way to avoid the third country worker slipping back into an irregular status once the employment situation has ended.

The substantive approach advocated by the Proposal is rooted in the rights-based rationale of the Tampere Programme of $1999 .^{624}$ Beyond this perspective, no other normative use of integration is presented by the text of the initiative. ${ }^{625}$ The right to equal treatment is subject to a number of conditions which rather reduce it to a right of 'near-equality'. The measure conditions the right to security and liberty by the TCN to both her/his legality of residence and employment. The level of protection offered by the EU framework will therefore present a limited personal scope

in order to simplify their admission and to facilitate the control of their status and; (b) a common set of rights to third country workers legally residing in a Member State".

621 Article 2 defines single application procedure as "any procedure leading, on the basis of one application for the authorization of a third-country national's residence and work in the territory of a Member State, to a decision on the single permit for that third-country national".

Article 2 defines single permit as "any authorization issued by the authorities of a Member State allowing a third-country national to stay and work legally in its territory".

Further Article 7 of the proposal stipulates that "1. When issuing residence permits in accordance with Regulation (EC) No. 1030/2002 Member States shall indicate the information relating to the permission to work irrespective of the type of the permit. 2. Member States shall not issue any additional permits, in particular work permits of any kind as proof of the access given to the labour market".

Recital 2 of the Preamble states that "The European Council, at its special meeting in Tampere on 15 and 16 October 1999, acknowledged the need for harmonisation of national legistation governing the conditions for admission and residence of third-country nationals. In this context, it stated in particular that the European Union should ensure fair treatment of third-country nationals residing lawfully on the territory of the Member States and that a more vigorous integration policy should aim to grant them rights and obligations comparable to those of citizens of the European Union".

When dealing with the consistency with other policies in the Explanatory Memorandum the European Commission argues that "this proposal contributes to the integration of immigrants and their families forming part of the response needed to prepare Europe's economy and society for the onset of ageing". 
restraining the number of potential beneficiaries of the framework of rights. The proposal would establish a (strict) nexus between the 'near-equality of treatment' and the regularity of the residence and work of the TCN. The Directive would cover TCNs seeking to reside and work in the territory of a Member State, and to third country workers regularly residing in a Member State. ${ }^{626}$ Article 2.2 defines third country worker as "any third-country national who has been admitted to the territory of a Member State and is allowed to work legally in that Member State". The following TCNs would fall outside the personal scope of the measure: family members of EU citizens having exercised the freedom to move, those covered by the Council Directive 96/71/EC as long as they are posted, those falling within the framework of an international agreement of trade and investment-related natural persons, seasonal workers, ${ }^{627}$ refugees, applicants for international protection or under temporary protection schemes, EC long-term residents, and those in the process of being expelled.

\subsubsection{Rights, Conditions and Integration}

\subsubsection{The Rights}

The initiative starts from the premise that any $T C N$ who is residing and working regularly in a Member State should enjoy "at least the same common set of rights in the form of equal treatment with the own nationals", irrespective of the initial purpose of or basis for admission. ${ }^{628}$ Article 11 establishes the rights which shall be entitled on the basis of the single permit, which will include "as a minimum" the right to:

1. Enter, re-enter and stay in the territory of the MS issuing the single permit.

2. Passage through other Member States in order to exercise the right in point 1 .

3. Free access to the entire territory of the issuing Member State within the limits of national law for reasons of security.

4. Exercise the activities authorised under the single permit.

5. Information about his/her own rights linked to the permit.

Further, Article 8 would oblige the Member States to give the TCN applicant a written notification specifying the reasons of a possible rejection, refusal, modification, non-renewal, suspension or withdrawal of the single permit, and the available redress procedures. National law would therefore also allow TCNs to challenge the decision before the domestic courts.

The non-EU national holding the single EC permit would move to the harmonised legal category of 'EC third country worker' and would benefit from the set of rights aiming at the implementation of the principle of equal treatment set in Chapter III of the initiative. It is at this point that the proposal advocates for the substantive approach highlighted above. The European Commission acknowledges the existence of a "rights gap" between third country workers (already admitted) and EU national workers, especially in employment-related fields. The horizontal legislation proposed by this initiative would aim at expanding a sui generis equality of treatment by granting a more secured legal status to those non-EU nationals falling within the

\footnotetext{
626 Article 3.

627 Article 3.2.d states that "who have been admitted to the territory of a Member State for a period not exceeding six months in any 12 month period to work on a seasonal basis".
}

See Recital 10 of the Preamble. 
category of "workers who are legally residing in the EU". ${ }^{629}$ The right to near-equal treatment would apply to the following list of employment-related fields, which are framed as "minimum requirements" without affecting the possibility for the Member States to maintain or adopt more favourable provisions: ${ }^{630}$

1. Working Conditions (including pay, dismissal, health and safety at the workplace).

2. Freedom of association, affiliation and membership of an organisation representing workers or employers.

3. Education and vocational training.

4. Recognition of diplomas, certificates and other professional qualifications.

5. Branches of social security.

6. Payment of acquired pensions when moving to a third country.

7. Tax benefits.

8. Access to goods and services made available to the public, including housing and employment assistance.

\subsubsection{The Conditions}

Member States will have the possibility to apply a number of derogations to the principle of near-equality. Article 12.2 establishes that they may restrict equality in relation to five specific circumstances:

1. Requiring proof of appropriate language proficiency for having access to education and training. Access to university may be subject to the fulfilment of specific educational prerequisites.

2. Study grants.

3. Public housing where the TCN has been staying or who has the right to stay in its territory for at least three years.

4. Working conditions, the freedom of association, affiliation and membership and tax benefits to those who are employed.

5. Restricting "branches of social security" to third country workers who are employed, except unemployment benefits.

While the rights-based approach of the proposal is welcome, it presents two major weaknesses:

629 Recital 9 of the Preamble highlights that "In the absence of horizontal community legislation, the rights of third-country nationals vary, depending on the Member State in which they work and on their nationality. They do not have the same rights as nationals of the Member State, or other EU citizens. With a view to pursue a further development of a coherent immigration policy, to lower the rights gap between EU citizens and third-country nationals legally working and complementing the existing immigration acquis a set of rights should be laid down in particular in the form of specifying the policy fields where equal treatment with own nationals is provided for third-country workers legally admitted in a Member States but not yet long term residents".

See Article 13 on "More Favourable Provisions". 
First, the nexus between the regular administrative status of stay and employment for benefiting from 'a comparable' status with that of the nationals endorses the categorisation, and her/his security, of the 'third country worker' as an economic unit which needs to be 'active' and legal.

Second, the consolidation of a piecemeal approach regarding the EU framework of rights which might potentially undermine the existence of a consistent approach in relation to the principle of equality of TCNs in the EU. This will lead to the harmonisation at EU level of a 'rights-gap' substantiated by a principle of discrimination between the level, nature and derogations applicable to the EU rights granted to regularly resident third country workers and those foreseen as 'highly skilled workers' holding an EU Blue Card. The EESC Opinion on this proposal stated $^{6 / 3}$

its concern at and disagreement with the possibility of the directive allowing Member States to restrict the right to equal treatment, in relation to working conditions (including pay and dismissal, health and safety in the workplace and social security) and as regards freedom of association... Such restrictions conld also contravene the principle of non-discrimination. Emphasis added. $)^{6,32}$

\section{The Treaty of Lisbon and the Renewed Institutional Framework of EU Immigration Law}

What major innovations would the new configurations provided by the Treaty of Lisbon create in the area of regular immigration? The Treaty would put a formal end to the Pillars Structure that currently characterises JHA Policies. ${ }^{633}$ The direct consequence would be the expansion of the Community method to domains of police and judicial cooperation in criminal matters. The liberalisation of the Community method would also finally benefit the area of regular immigration, which as stated in the beginning of this Chapter still continues to be subject to the unanimity rule in the Council and falls outside the co-decision procedure. ${ }^{634}$ The co-decision procedure provided in Article 251 TEC, and which would pass to be denominated as the ordinary legislative procedure', would become applicable to this domain. Regular immigration

631 EESC, Opinion on the Proposal for a Council Directive on a single application procedure for a single permit for third-country nationals to reside and work in the territory of a Member State and on a common set of rights for third-country workers legally residing in a Member State, SOC(307), 9 July 2008, Brussels.

632 See Paragraph 4.11 of the Opinion. It continued by arguing that "In any event, where restrictions are in place, they should always be interpreted in line with oher binding intemational legislation that is more generous, specifically the Universal Declaration of Human Rights, the International Pact on Civil and Political Rights or the European Convention on Human Rights, and with various ILO Conventions and Community and national laws that are more generous". Paragraph 4.12.

633 For an analysis of the exceptions to the end of the Pillar division in the AFSJ see S. Carrera and F. Geyer (2008), "The Reform Treaty and Justice and Home Affairs: Implications for the Common Area of Freedom, Security and Justice", in E. Guild and F. Geyer (eds), Security versus Justice? Police and Judicial Cooperation in the European Union, Ashgate: Hampshire, pp. 289-307; See also S. Carrera and F. Geyer (2008), 'El Tratado de Lisboa y un Espacio de Libertad, Seguridad y Justicia: Excepcionalismo y Fragmentación en la Unión Europea', Revista de Derecho Comunitario Europeo, Nümero 29, pp. $133-$ 162.

634 The Council adopted a Decision on 22 December 2004 by which all the immigration-related fields contained in Title IV TEC, with the exception of regular immigration, were moved to the Community method. See Council Decision 2004/927/EC of 22 December 2004 providing for certain areas covered by Title IV of Part Three of the Treaty establishing the European Community to be governed by the procedure set out in Article 251 of that Treaty, OJ L 396/45. 
would therefore be subject to QMV in the Council, something which would be likely to foster the achievement of pluralistic compromises in an EU-27. Similarly to the comments in Chapter 3 in relation to the EU Framework on Integration, the roles of the EP, national parliaments, Commiltee of Regions and the ECJ would be significantly strengthened in relation to the current institutional scenario. The legally binding nature conferred to the Charter of Fundamental Rights would also cover this area.

The new Article 79 of the TFU would constitute the new legal base for developing common European policies on regular immigration. ${ }^{635}$ Further, Article 79.5 TFU reads as follows:

This Article shall not affect the right of Member States to determine volumes of admission of third-country nationals coming from third countries to their territory in order to seek work, whether employer or self-employed.

From the wording stated in this provision one could implicitly conclude that apart from the determination of volumes of admission, the Community would be recognized the competence to legislate in the field of immigration for employment purposes. It could be expected that the new procedural configurations established by the Treaty of Lisbon would prevent new legislative proposals from experiencing the traumatic and prolonged negotiations within the Council of previous initiatives. That notwithstanding, it is certain that the intergovernmental logic pursued by some Member States will certainly not disappear, and that any new proposals will still be equally subject to heated debates and competing strategies within the Council. Member State hesitations towards the harmonisation of labour immigration policies will surely emerge during the negotiations of the upcoming proposals for directives. In fact, the initiative to establish a common framework of rights might perhaps become the victim if the proposal on highly qualified employment is to succeed under the mandate of the French Presidency of the EU.

\section{Conclusions}

The normative approaches guiding integration in EU immigration law have experienced various dynamics and transformative processes since 1999. This Chapter has addressed the ways in which EU immigration law, and more particularly those EU acts dealing with regular immigration, has made use of integration. After looking at the decision-making rules and institutional structures conferred by Title IV TEC to the Union to exercise its competences on regular immigration, we have offered a synthesized overview of the FSJ acquis so far adopted in this policy area. The current procedural and institutional arrangements have to a great extent provoked, and in a way facilitated, the changing relationship between integration and EU immigration law, and the shift in the functions played by the former. The operability of the unanimity rule at the Council and the consultation to the EP have introduced certain national approaches on immigration and integration in EU law on regular immigration

We have studied the nature granted to integration with respect to the rights and conditions stipulated by the Council Directives 2003/109 and 2003/86. It has been shown that the understanding of integration that they pursue has brought innovative features in EU law when comparing it with previous European legal and policy responses as studied in Chapter 2. The normative use of integration by these two Directives mutated significantly toward a more

6.35 Article 79.1 TFU will read as follows: "The Union shall develop a common immigration policy aimed at ensuring, at all stages, the efficient management of migration flows, fair treatment of third-country nationals residing legally in Member States, and the prevention of, and enhanced measure to combat, illegal immigration and trafficking of human beings". 
restrictive fashion during the negotiations inside the Council. The original focus on integration that characterized the first versions of both initiatives was substantially modified. A group of Member States pushed for an approach in line with their respective legal systems, policy priorities and politics on mobility and diversity. The references to integration measures and integration conditions in the wording of the Directives, and the possibility to apply integration abroad' in the context of the right to family reunification, has led to deep transformations in the classical understandings of integration in EU law and policy. Similarly to the environment described in the EU Framework on Integration, the category of integration has become another regulatory technique for the State to manage the access by the non-national to the security of residence and protection against expulsion at EU level. It acts as a legal measure or a norm, a control mechanism in hands of the Member States, conditioning the access and exercise of EU rights by TCNs.

Furthermore, it is striking to see how the introduction of these innovative normative elements of integration in both measures was exclusively justified on the fact that the national laws and politics of few Member States made use of integration in this manner. One of the most decisive motives for adopting this new integration approach was that the Directives would be in full compliance with existing national immigration laws and policy initiatives of particularly powerful Member States during the Council negotiations. The Member States wanted to keep as much sovereignty, and discretionary power, as possible at times of granting EU rights, freedoms and guarantees to TCNs. The dependency of these rights and freedoms to a requirement as subjective as 'integration' was conceived as a perfect instrument for achieving that goal. Indeed, the political strategies pursued by some Member States during the negotiations of the Directives need to be understood as a sharp willingness to limit the impact of Europeanisation over these areas, and condition the final interpretation of 'integration' to the national arenas.

The next Section of the book examines the nomativity of integration at the national level by looking at the cases of France and Spain. The Chapters start by offering some theoretical elements pertaining to the public strategies and 'models' in the management of diversity in both countries. We shall provide a historical overview of the political and legislative developments influencing the major transformations and reconfigurations of the normative nexus between nationality, immigration and integration in their respective legal systems. The framing and functionalities of integration in their current regulations on nationality and immigration will be examined. Most importantly, we shall assess the extent to which national polities, politics and policies on integration are being affected, or not, by European integration processes (the EU Framework on Integration and EU immigration law). 


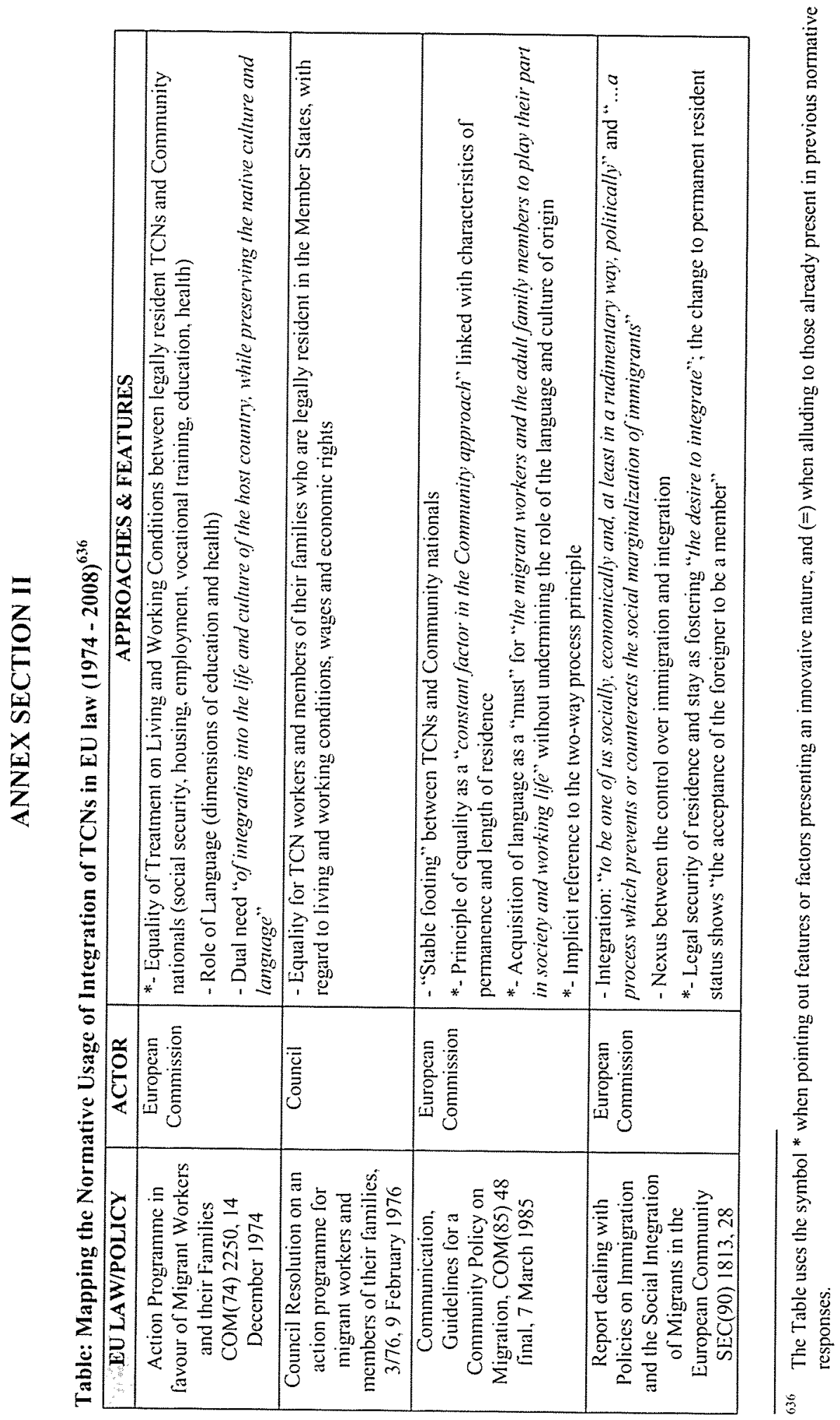




\begin{tabular}{|c|c|c|c|c|}
\hline 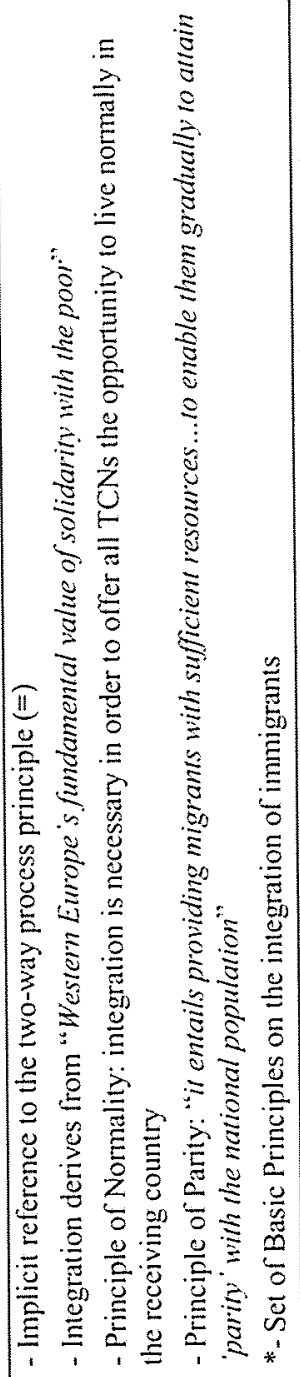 & 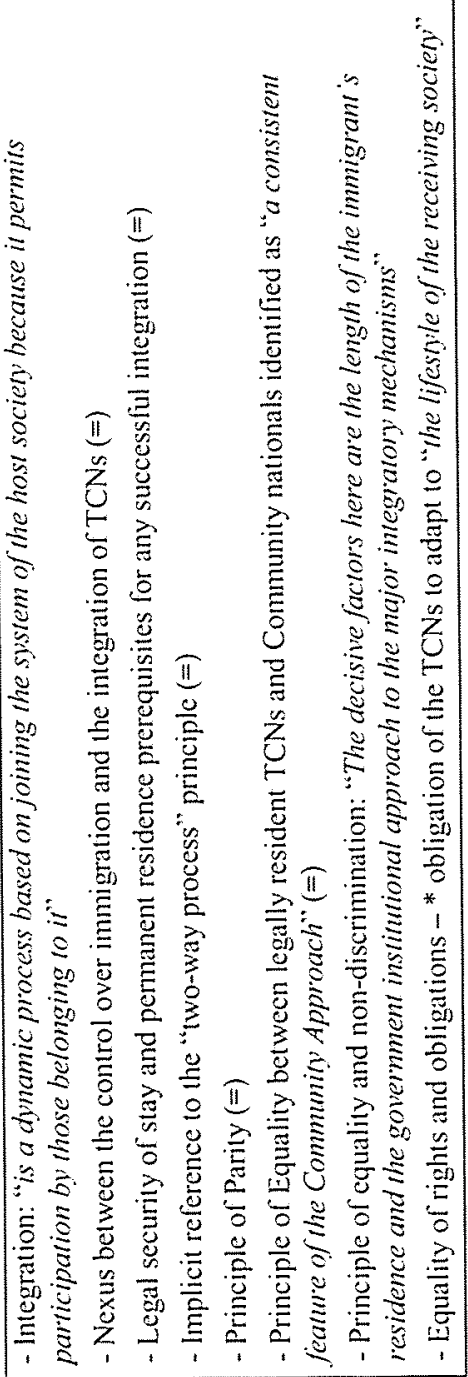 & 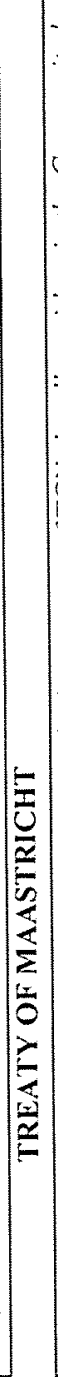 & 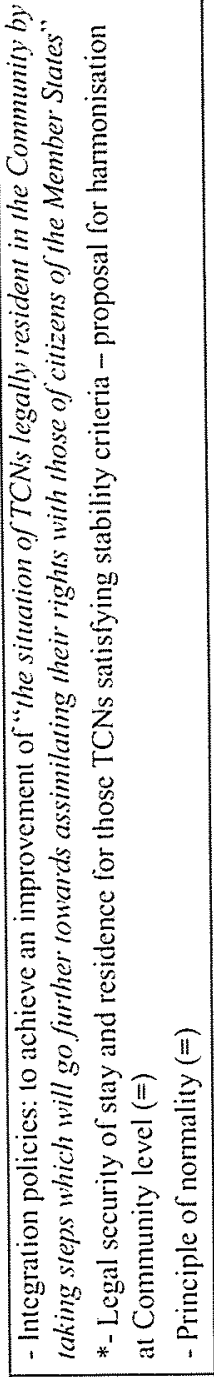 & 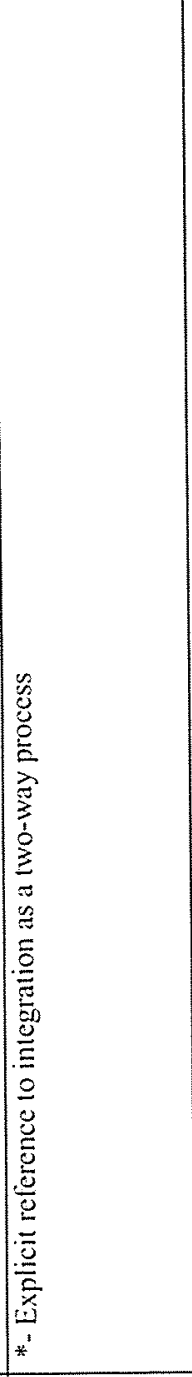 \\
\hline & 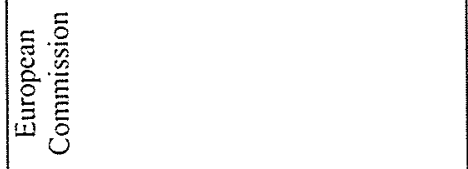 & & 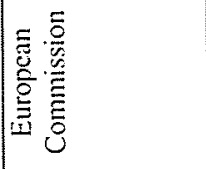 & $\frac{1}{11}$ \\
\hline 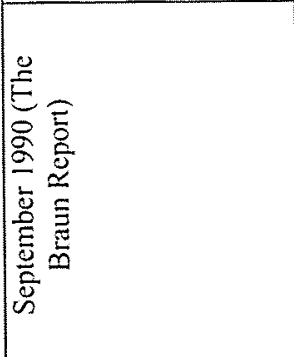 & 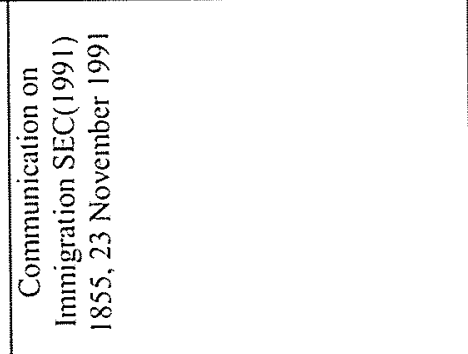 & & 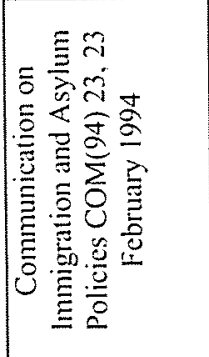 & 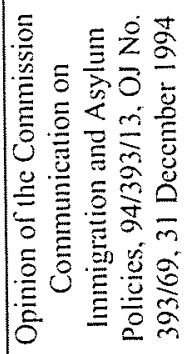 \\
\hline
\end{tabular}




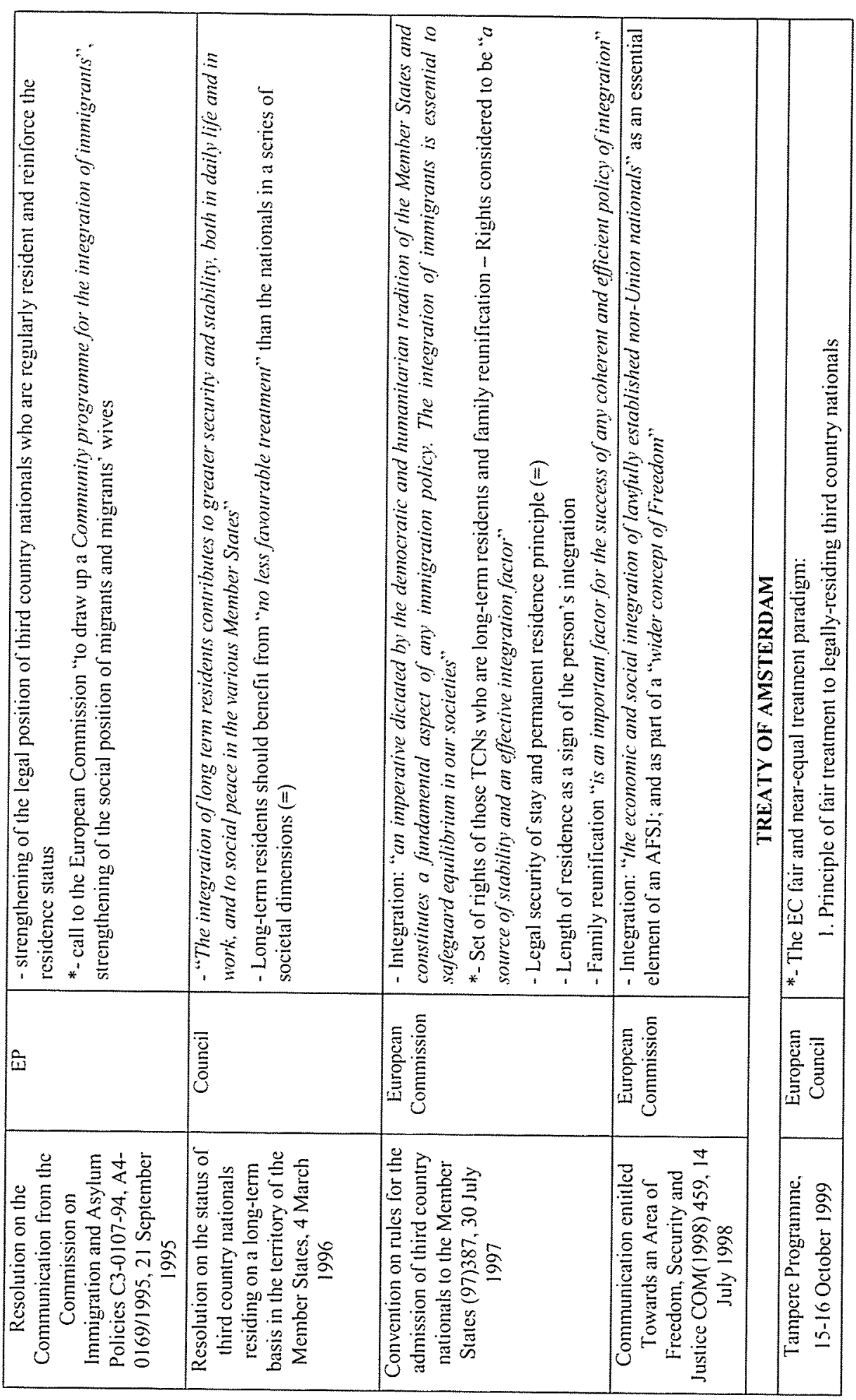




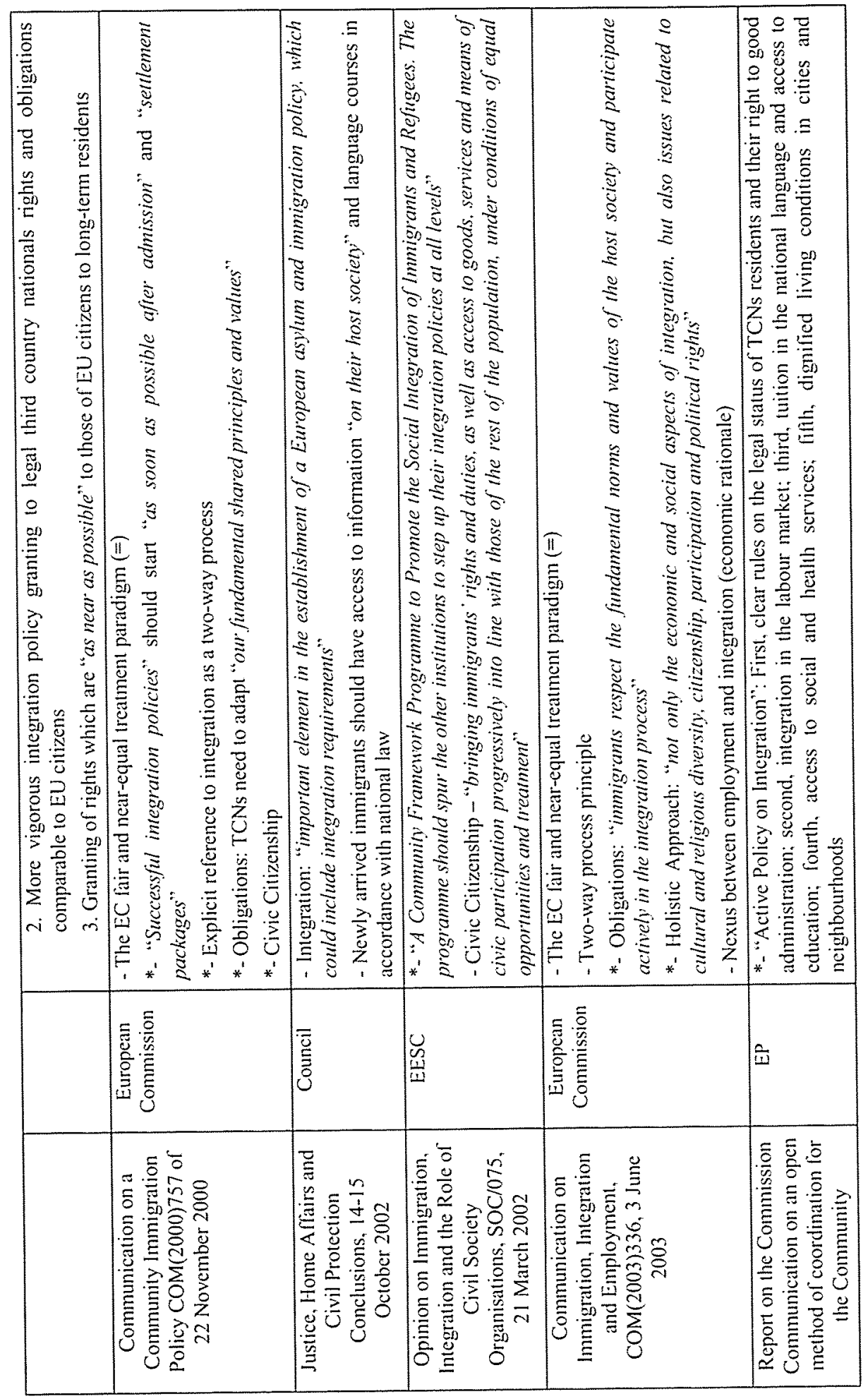




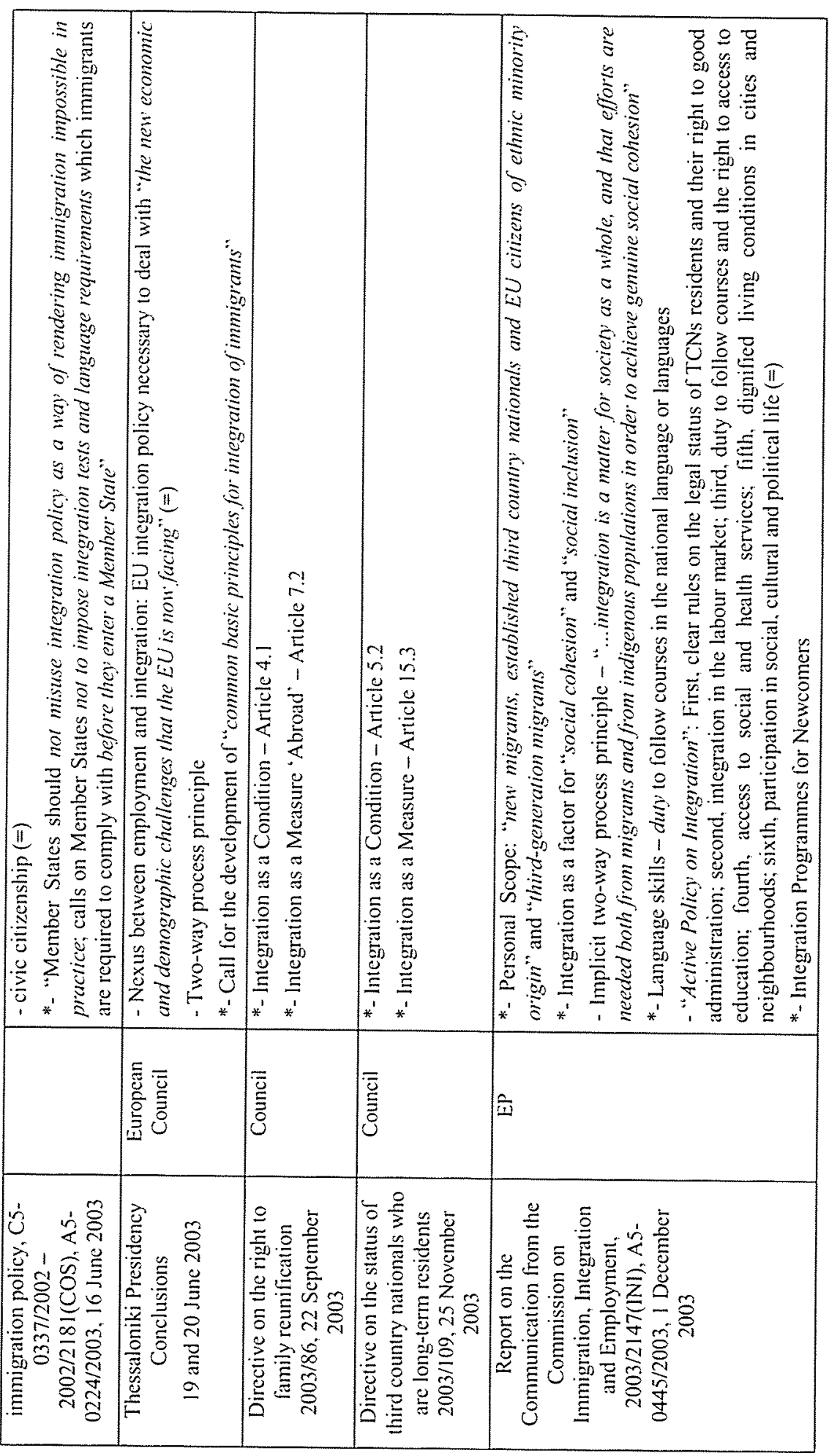




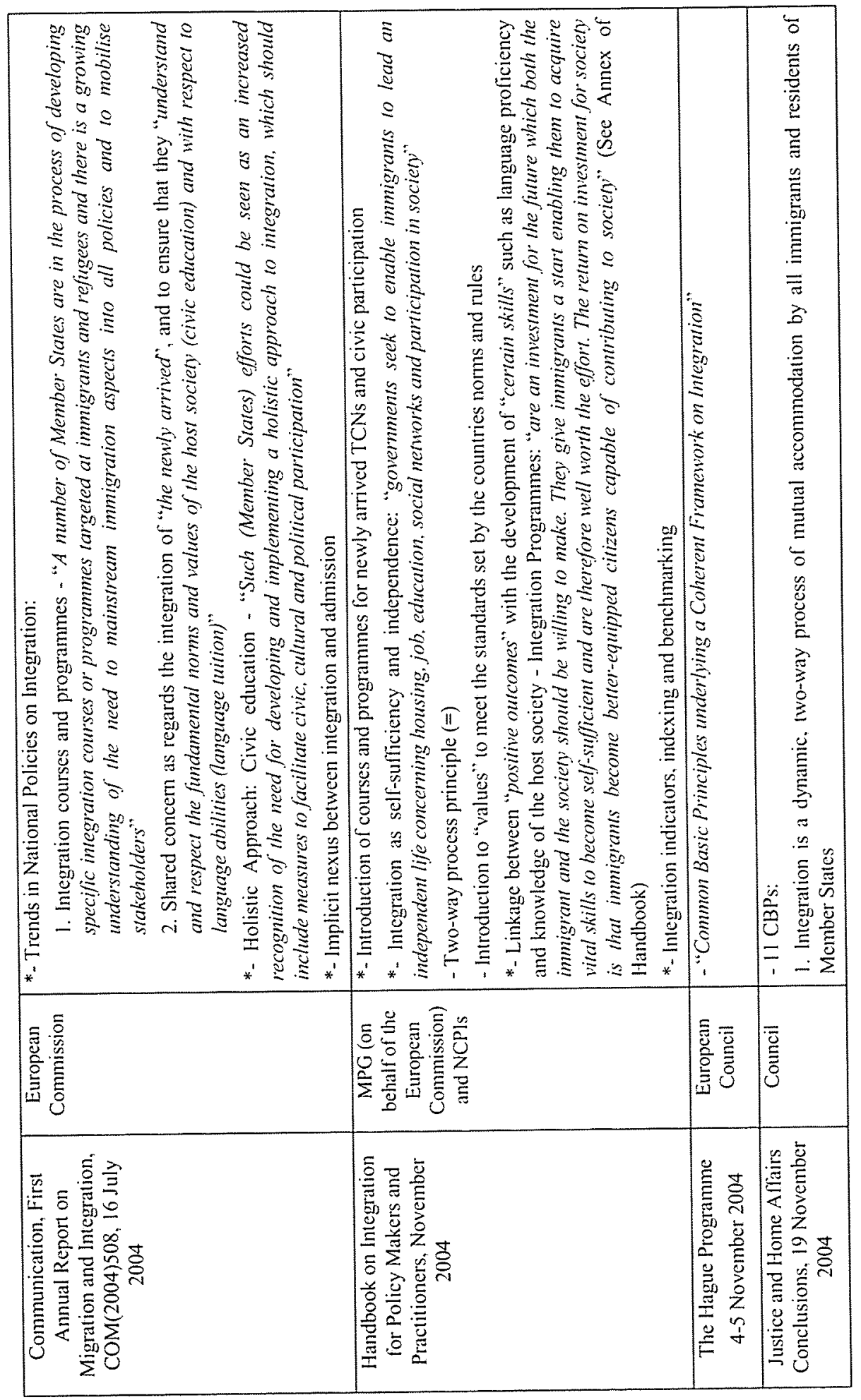




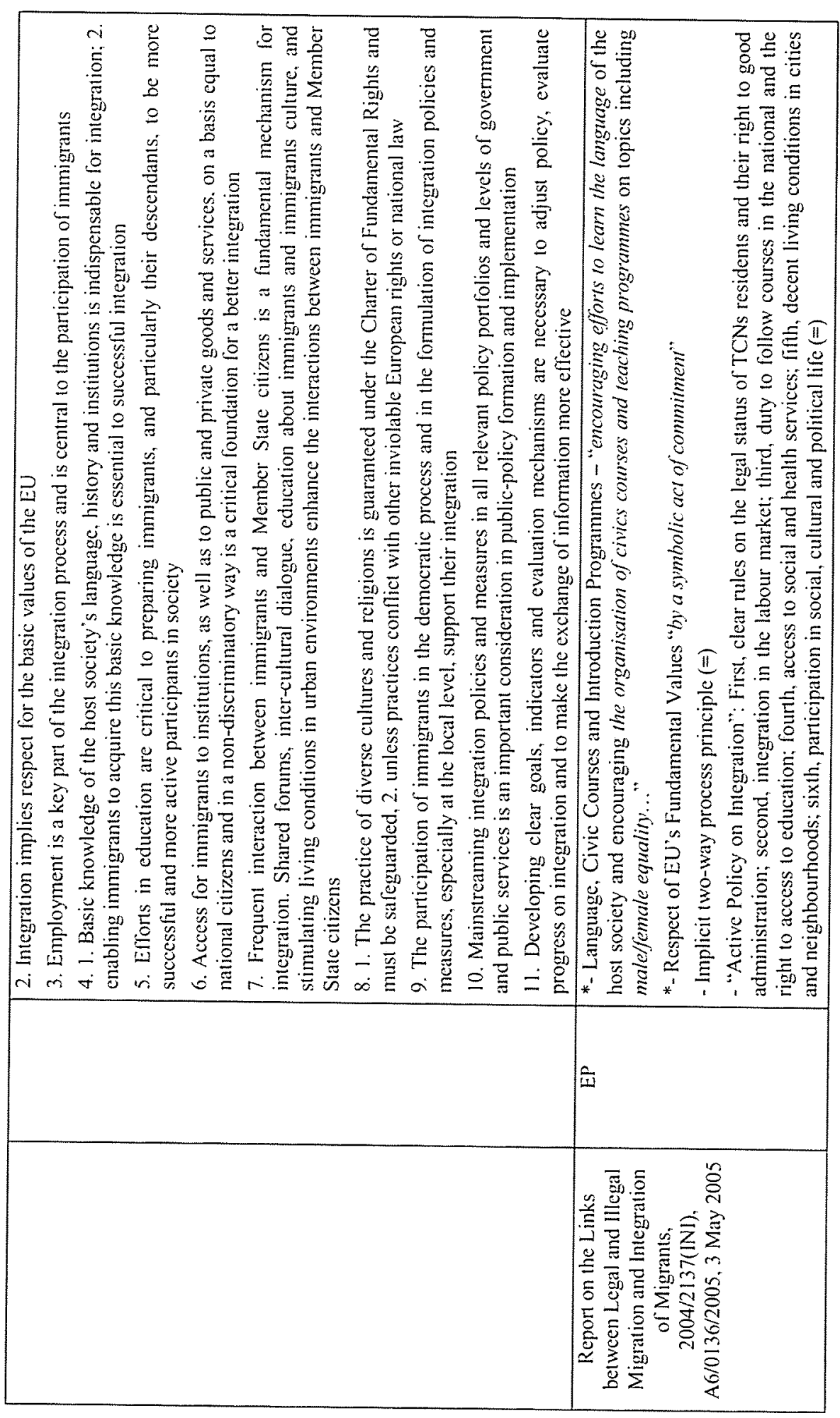




\begin{tabular}{|c|c|c|c|}
\hline 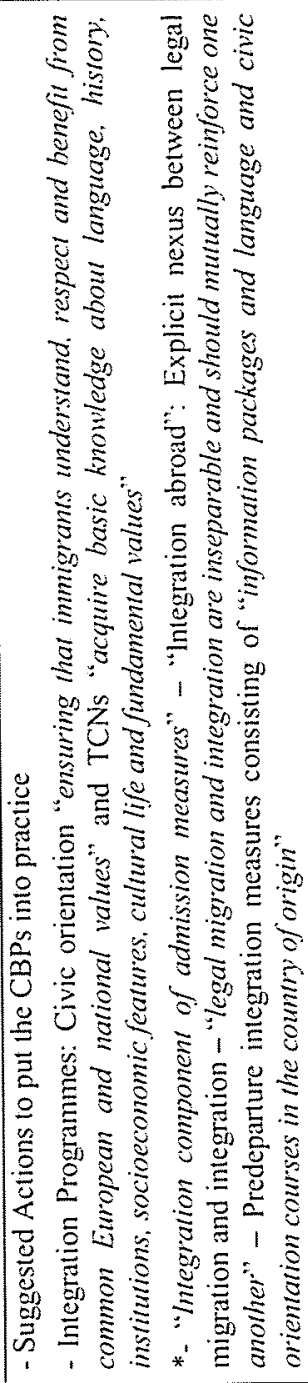 & 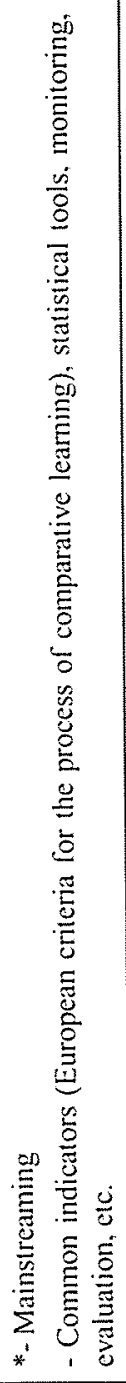 & 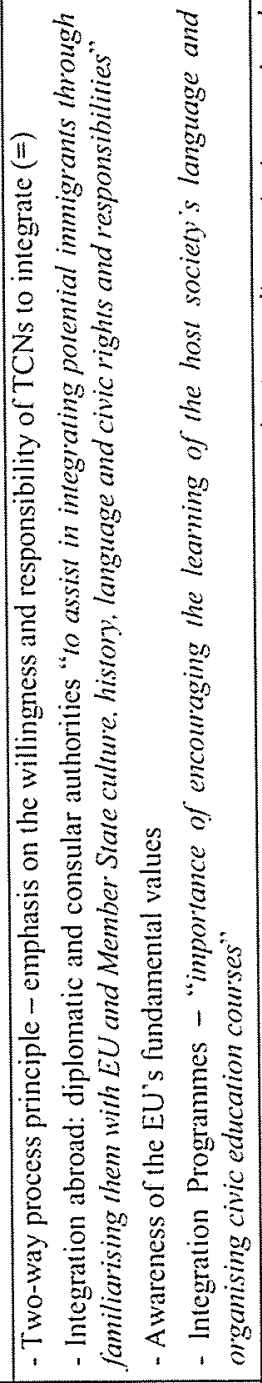 & 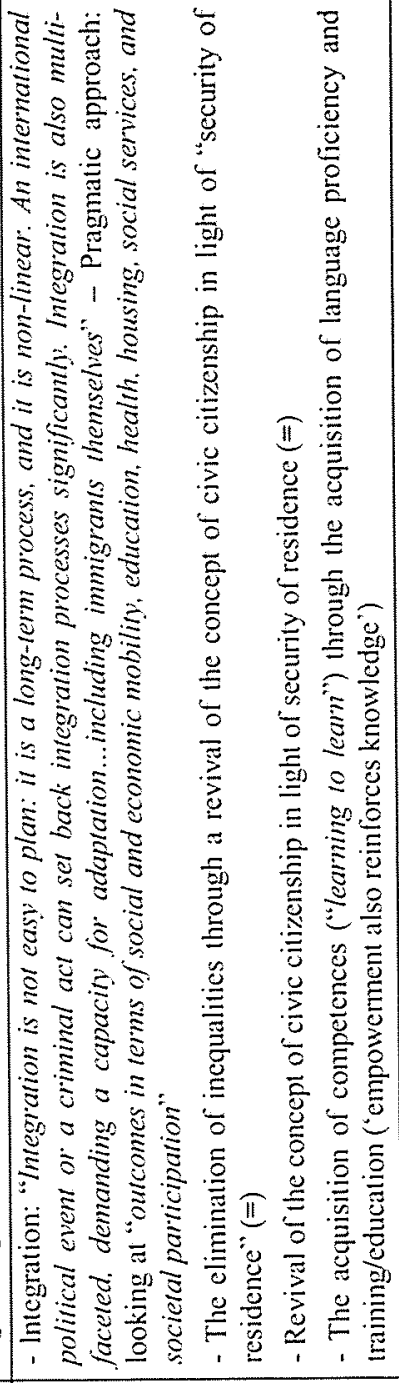 \\
\hline 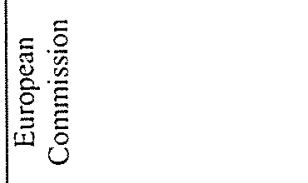 & & 言 & 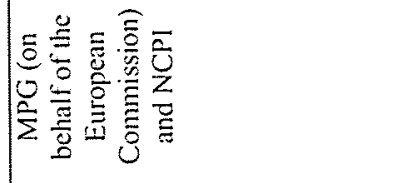 \\
\hline 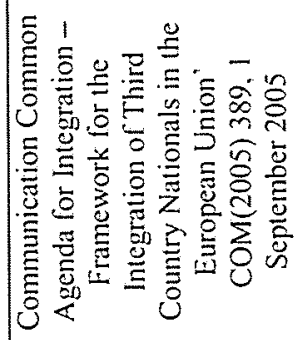 & & 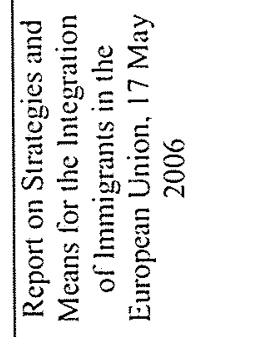 & 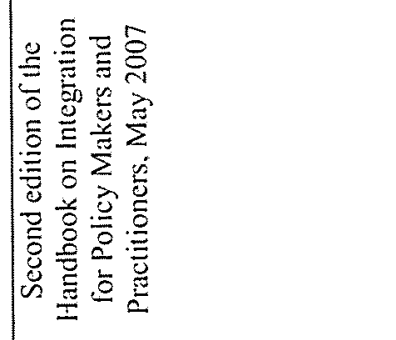 \\
\hline
\end{tabular}




\begin{tabular}{|c|c|c|c|}
\hline 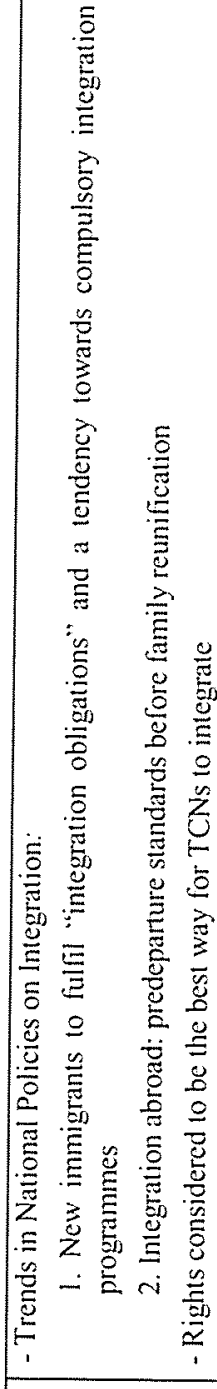 & 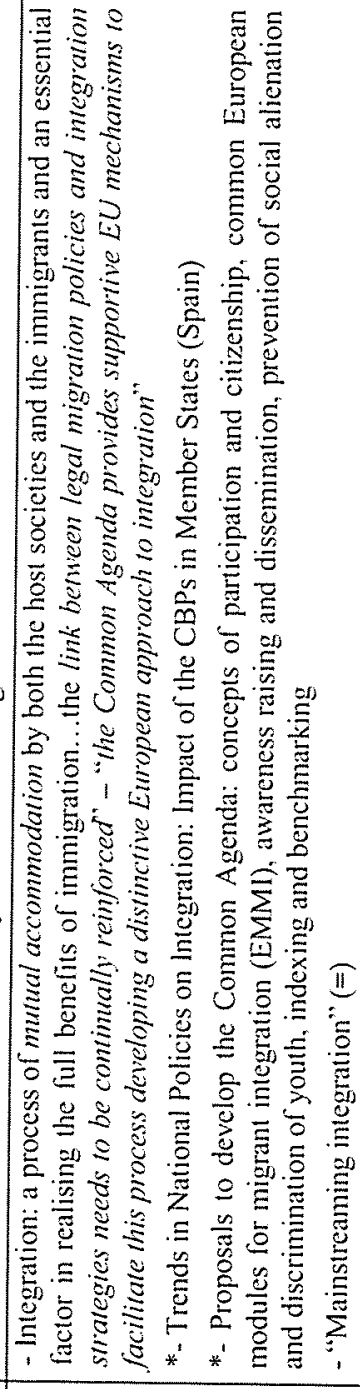 & 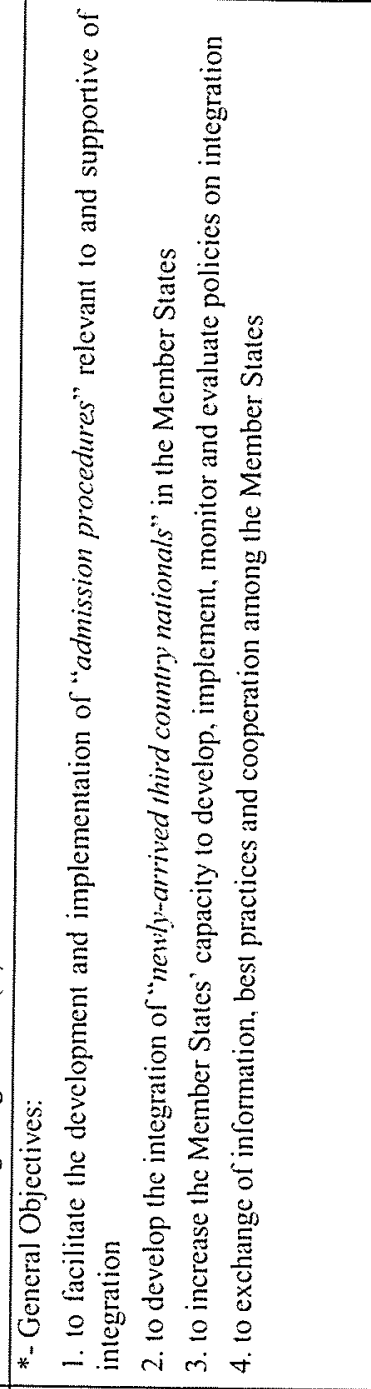 & 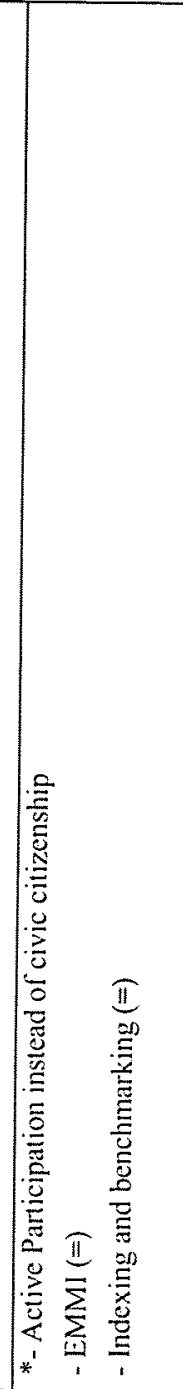 \\
\hline$\frac{\overline{\bar{g}}}{\bar{c}}$ & 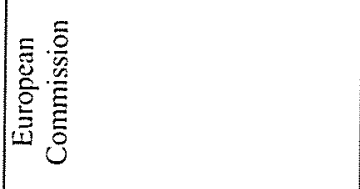 & 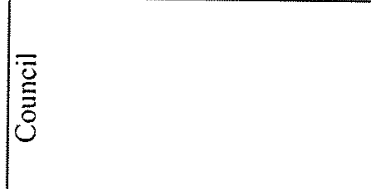 & 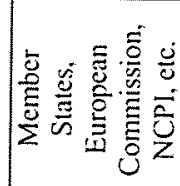 \\
\hline 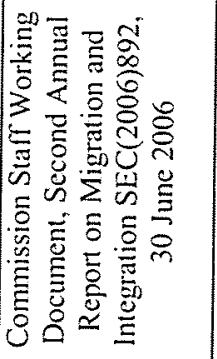 & 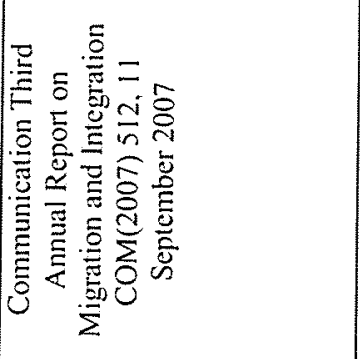 & 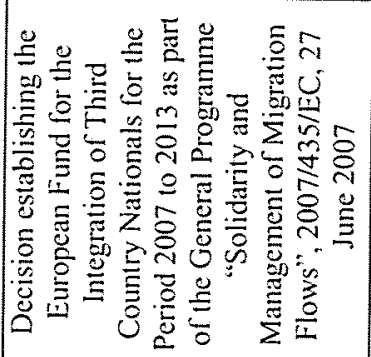 & 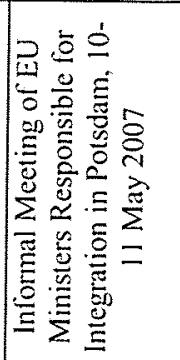 \\
\hline
\end{tabular}




\begin{tabular}{|c|c|c|c|}
\hline 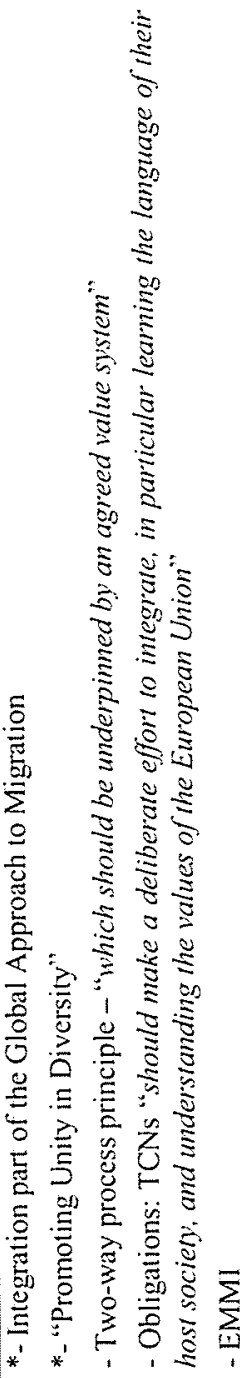 & 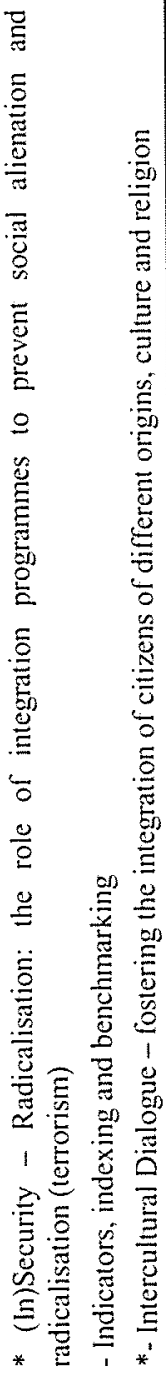 & 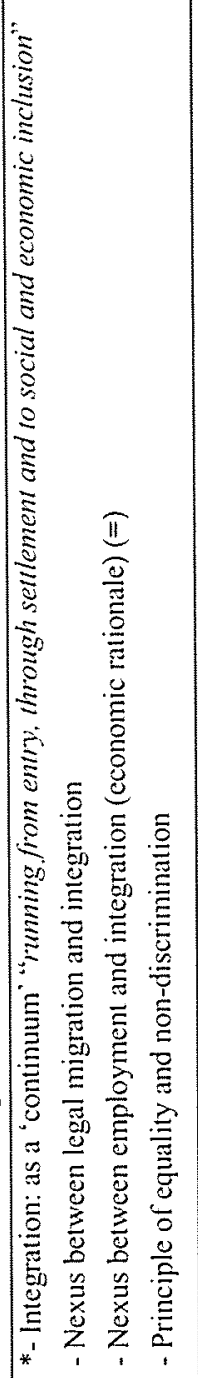 & 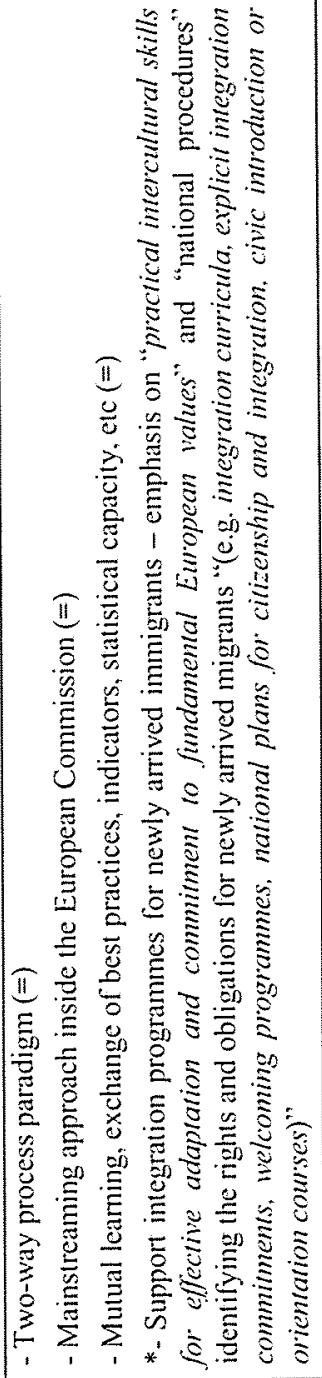 \\
\hline & & 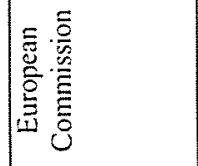 & 㫄 \\
\hline 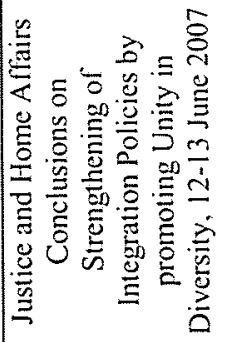 & & 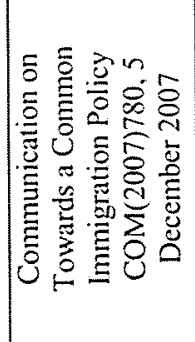 & 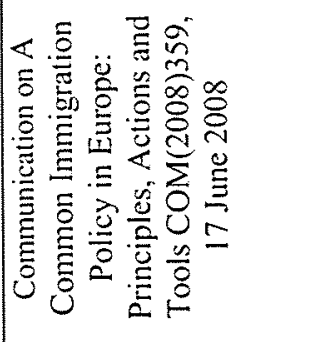 \\
\hline
\end{tabular}





\section{SECTION III - THE NORMATIVITY OF INTEGRATION IN NATIONAL LAW: THE CASES OF SPAIN AND FRANCE}

\section{Chapter 5: \\ The Intersection between Integration and the Legal Framework on Nationality and Immigration in Spain}

\section{Introduction}

This Chapter studies the changing interaction between the integration of TCNs and the policy and legal frameworks on nationality and immigration in Spain. It starts by offering an overview of the evolution experienced by this country from being deemed as a source of emigration to a destination of immigration, and the different phases which might be identified until the transformation of this phenomenon into an institutional and structural issue of major political and social relevance. The Spanish strategies and techniques pursued in the management of integration and diversity will be subject to review. A substantial degree of 'Europeanism' may be perceived as a determining component of 'the Spanish non-national model of integration of TCNs'. The policy and regulatory responses adopted during the last twenty years in the domains of immigration and integration have been inspired, and to some extent influenced, by the common principles structuring the EU policy responses over these areas. We shall study the ways in which this 'Europeanism' has affected the normativity of integration in the legislation and policy covering immigration and nationality in the Spanish legal system.

Section two moves toward the assessment of the dynamics surrounding the evolution of Spanish law on immigration since the adoption of the first unified law in 1985, and the ways in which regular immigration and nationality have interacted with integration. It will study the origins and transformations affecting that relationship as well as the features that integration has acquired during these different historical phases. This Section will also pay attention to some important moments affecting the links between the Spanish law on nationality and integration. Special consideration will be also given to the impacts that Europeanisation processes, and especially the EU Framework on Integration, have experienced in the politics and national processes of policy formulation on immigration.

Section three analyses the current articulation between the category of 'the social integration of TCNs" and the domains of regular immigration and nationality. "Integration into the Spanish society" has been traditionally used as one of the key requirements conditioning the acquisition of nationality by naturalisation on the bases of residence. As regards the realm of immigration, however, apart from very few exceptions provided within the Law on the Rights and Liberties of Immigrants and their Social Integration of 2000, integration has not played the role of sine qua non for having access to a secure legal status. Spain has been until recently characterised by the lack of a nation-wide policy strategy on integration which has materialised in the absence of the normativity of integration from the legal regime covering regular immigration, and more specifically from the rules dealing with entry, residence, settlement and family reunification. It was only at the beginning of 2007 when the Government adopted a Strategic Plan on Integration and Citizenship, which offers for the first time in Spanish history a global vision of the State's view on the way in which the integration of TCNs should be understood and practiced in its territory. The lack of a clearly defined policy at the national level until this stage has not 
prevented the Autonomous Communities from elaborating the so-called 'Integral Plans on Immigration and the Social Integration of Immigrants' providing in their own levels of governance for specific priorities, programmes and actions addressing the reception and provision of public social services to TCNs. We will assess the implications of this division of competences on immigration, and the ways in which integration is being understood and treated in each of them. Finally, Section four assesses the extent to which the transposition of EU immigration law, and particularly the articles of the Council Directives on the Status of Third Country Nationals who are Long-term Residents 2003/109 and on the right to family reunification 2003/86 dealing with integration, has transformed the approaches and perspectives performed by this category in Spanish law.

\section{The Construction of Immigrant Spain and the Spanish "Non-Model" on Integration}

The transformation of Spain from a country of emigration to a country of immigration has been subject to substantial academic attention. ${ }^{637}$ A country which used to be characterised by a high number of internal migratory movements ${ }^{638}$ and labour emigration to other European countries especially during the $1950 \mathrm{~s}$ and $1960 \mathrm{~s},{ }^{639}$ it experienced a fundamental transformation from the mid-1980s onwards. Spain became a destination of international human mobility. ${ }^{640}$ Cachón (2006) has identified three different phases which have embraced this profound change in status,

637 C. Pereda y M. A. Prada (cords.) (1987), Los Inmigrantes en España, Monográfico de Documentación Social, 66, Madrid: F. Muñoz Pérez y A. Kzquierdo Escribano (1989), 'L'Espagne, pays d'immmigration', Population, 2, INED: Paris; A. Lzquierdo Escribano (1992), La lmmigración en España (1980-1990), Ministerio de Trabajo y Seguridad Social, Madrid; A. Izquierdo Escribano (1996), La Immigración Inesperada: La Poblaciion Extranjera en España (1991-1995). Trotta: Madrid; Colectivo IOE (1999), "La inmigración extranjera en España, 2000", en VVAA, La inmigración extranjera en España. Los retos educativos. Barcelona: Fundación La Caixa, pp. 3-68; J. Arango (1999) "Becoming a Country of Inmigration at the End of the XXth Century: the Case of Spain", en R. King, G. Lazaridis and C. Tsardanidis, (eds.), Eldorado or Fortress? Migration in Southern Europe, Macmillan Press: London, pp. 253-276; M. Pajares (1999), La inmigración en España. Icaria. Barcelona; J. Arango y N. Garcia-Pardo (2000), Push and Pull Factors of Imernational Migration: Moroccan and Senegalese Immigrants in Spain, Eurostat Working Papers: La Haya, pp. xxi y 167; V. Pérez-Diaz, B. ÁlvarezMiranda y C. González-Enriquez (2001), España ante la Inmigración, Colección de Estudios Sociales, Núm. 8, Fundación La Caixa; J. Arango (2002), La Fisonomia de la Inmigración en España, Red Internacional de Inmigración y Desarrollo, disponible en www.migracionydesarrollo.org

During the 1950s and 1960s there were internal migratory movements whose consequences can be seen in Autonomous Communities such as Madrid and the Vasque Country. This led to a process of depopulation in Castilla León, Castilla La Mancha, Aragón, etc. See V. Pérez Diaz (1969), Emigración y Sociedad en la Tierra de Campos: Estudio de un Proceso Migratorio y um Proceso de Cambio Social, Madrid: Escuela Nacional de Administración Pública.

The higher rates of mobility to other European countries (maily to Germany, France, Belgium and Swirtzeland) were reached between 1962 and 1964. See J. Babiano y A. Fernández Asperilla (2003), 'Elementos del proceso de la inmigración espanola de los años sesenta. La voz de un pasado reciente', en Cindadania y Derechos Sociales y Politicos de los Inmigrantes, Gaceta Sindical: Reflexión y Debate, Confederación Sindical de Comisiones Obreras, junio 2003, p. 279; J. Rubio (1974), La Inmigración Española a Francia, Ariel: Barcelona.

F. Muñoz-Pérez et A. Izquierdo Escribano (1989), 'L'Espagne, Pays d'Immigration', Population, 44' année, $N^{\circ} 2$, Mar. - Avr. 1989, pp. $257-189$. These two authors identify a substantial increase in the number of legally residing immigrants in Spain during the mid-eightees: from a total number of 160,000 in the beginning of the 1970s to 242,000 in 1985 and 335,000 in 1987. 
and the consolidation of 'immigrant Spain'. ${ }^{641}$ While the distinction between each of these stages is first based on the increasing volume of TCNs arriving and settling in the country, Cachon argues that this quantitative dimension does not constitute the more relevant factor behind the qualitative transformation experienced by this country, which was caused, in his view, by a number of structural innovations resulting from the progressive enhancement and diversity characterising human mobility, and whose features may be summarised as follows:

A first phase would correspond with the period before 1985. The sort of human mobility taking place until that year was mostly European, South and North American. Immigration from Africa and Asia was not very high. A substantial majority of the TCNs residing in Spain were coming from 'cultures' considered to be not too far from the one which was supposed to predominate in Spain. Further, in a majority of cases TCNs were coming from wealthier and economically more developed countries. A considerable fraction of this sort of human movement consisted of retired people willing to settle along the Spanish coasts. Immigration was therefore a "nonissue". As we will see below, the entry of Spain into the European Economic Community (EEC) in 1986 provoked a substantial change in this respect because of the necessity to adopt a harmonised immigration law aiming at complying with the requirements linked with European membership. The status of EU Member State involved the need to show an enhanced strategy at times of securing, controlling and managing borders and the phenomenon of immigration. This has been also pointed out by López Sala $(2005),{ }^{642}$ who has argued that the consolidation of Spain as a country of destination of human mobility along with its integration in the EEC made that the Spanish immigration law has been since then very much dependent on the initiatives coming from the EU.

The second phase, from 1986 through 1999, was a period during which Spain became a de facto immigration country. In addition to the increase in numbers of TCNs staying in the country and the diversification of the nature of immigration, this phenomenon was converted into a social issue. EEC Membership marked the start of a process of economic growth and stability, which, among other multidimensional factors, ${ }^{643}$ made Spain an attractive destination. Human mobility became more diverse and of a new kind in comparison with previous ones when looking, for instance, at the growing heterogeneity concerning the countries of origin (Africa, Asia and Eastem Europe). ${ }^{644}$ These new features had deep implications in the social structures, public attitudes, national politics and policy processes. The innovative nature of this "new immigration" also posed a series of dilemmas for the Spanish state in terms of the policies to be put in place to manage immigration and its consequences. "The integration of immigrants" therefore gradually appeared in the policy scene in the early 1990s as part of the Parliamentary discussions which opened a general debate about the situation of TCNs in the country and the need to enact a more innovative immigration policy meeting the perceived new social realities.

641 L. Cachón (2006), "Los Inmigrantes en el Mercado de Trabajo en España (1996-2004)", en E. Aja y J. Arango (coord.), Veinte Años de Immigración en España: Perspectivas Juridica y Sociológica (1985 2004), Fundació Cidob: Barcelona, Spain, pp. 175-201.

A. M. López Sala (2005), Immigrantes y Estados: La Respuesta Politica ante la Cuestión Migratoria, Anthropos: Barcelona, pp. 171-175.

643 L. Cachón (2002), 'La formación de la 'España Inmigrante': Mercado y Ciudadania', Revista Española de Investigaciones Sociológicas, $N^{\circ}$ 97, enero-marzo, pp. 95-126; See also L. Cachón (2007), "Diez Notas sobre la Immigración en España 2006", en J. Arango (coord.), Immigrates: El Continente Movil, Vanguardia Dossier, Número 22, Enero/Marzo 2007, pp. 68-74.

644 L. Cachón (1995), 'Marco Institucional de la Discriminación y Tipos de Inmigrantes en el Mercado de Trabajo en España', Revista Española de Imvestigaciones Sociológicas, $N^{\circ} 69$, Enero-Marzo 1995, pp. 105-124. 
Finally, Cachón identifies a third phase, from 2000 to the present, when immigration flows have not only increased, reaching at the end of 2007 a total of 3.979.014 immigrants holding a residence permit $\left(38,87 \%\right.$ EU citizens and $61,13 \%$ TCNs), ${ }^{645}$ but when there has been also a transformation with respect to the aspects of this phenomenon, which is now characterised by a higher degree of diversification. It is in this period when immigration is institutionalised as a 'social problem' and as a 'structural challenge' to the Spanish societal and political apparatus. Immigration experiences a process of 'public formulation' and intense political debate which makes it one of the key policy priorities and issues of concern. ${ }^{646}$ As we will highlight below, this contested nature is revealed by the intense discussions surrounding the elaboration and constant revisions of immigration laws and the instability of the legal status granted to TCNs since the year 2000. As Zapata-Barrero (2003) has pointed out, it passed from being an issue of a technical and administrative nature (of pure academic, administrative and associative interest) to one with a wider structural dimension subject to the interests of the different political parties and society at large. ${ }^{647}$ By and large, it became another facet of the national political spectacle. This third phase culminates with the adoption of the Law on the Rights and Liberties of Immigrants and their Social Integration, in January 2000 (Ley Orgánica 4/2000 de Derechos y Libertades de los Extranjeros y su Integración Social, LODYLE), which after various and contested legislative amendments and reforms provided the main regulatory framework regarding immigration. This Law constitutes the final output of the official attitudes, political struggles and policy responses that have affected the phenomenon of immigration in recent years.

\subsection{The Spanish 'Non-National Model' on Integration}

It is also during this third period, and specifically the early 1990s, that the issue of the integration of TCNs starts to be gradually transferred from the political dimension to the policy and legal realms at the various levels of governance composing the Spanish nation-state (State,

645 The more relevant countries of origing at the end of 2006 were the following: Morocco (648.735), Rumania (603.889), Ecuador (395.808), Colombia (254.301), UK (198.638), Bulgaria (127.058), Italy (124.936), China (119.859), Peru (116.202), etc. In terms of the number of immigrants with authorization of residence by Autonomous Communities, the three having a larger number are Cataluna (860.575), Madrid (712.011) and Valencia (517.408), followed by Murcia, Baleares and Aragón. During 2007, the number of immigrants has increased in 957.206 persons $(31,68 \%)$. Anuario Estadistico de Immigración 2007, Ministerio de Trabajo y Asuntos Sociales, Secretaria de Estado de Immigration y Emigración, Madrid, retriavable from http:/extranjeros.mtas.es It is worth underlying that when comparing the data of 2006, there has been a substancial increase of Rumanian nationals from 211.325 till 603.889; See also Amario Estadistico de Immigración 2006, Ministerio de Trabajo y Asuntos Sociales, Secretaria de Estado de Immigration y Emigración, Madrid, retriavable from http://extranjeros.mtas.es

646 E. Aja y J. Arango (2007), La Inmigración en España 2006, Anuario de Inmigración y Políticas de Inmigración, CIDOB: Barcelona.

647 R. Zapata-Barrero (2003), "Cambio Structural y Redes de Actores en las Políticas de Acomodación de los Inmigrantes en España: Una Perspectiva desde el Territorio", en G. Aubarell (dir.), Perspectivas de la Inmigración en España: Una aproximación desde el Territorio, Icaria: Antrazyt Editorial, Barcelona, pp. $327-348$

649 L. Cachón (2003), 'La Inmigración en España: Los Desafios de la Construcción de una Nueva Sociedad', Revista Migraciones, Número 14, pp. 219-304; See also Pajares, M. (2005), La Integración Ciudadana: Una Perspectiva para la limigración, Barcelona: Icaria Antrazyt. 
Autonomous Communities and local/regional authorities) ${ }^{649}$ Fundamental questions start to be posed as to the way in which the State may better respond to the inclusion of TCNs in Spanish society, and better ways 'to manage' diversity. ${ }^{650}$ The search for a national strategy creates a number of issues which are inherently intertwined with the traditional structures of the Spanish State, its conceptions of nationhood and its perceptions of national identity. These questions are also linked to definitional aspects of the Spanish nation within which any Otherness is supposed to integrate. The territorial and political organisation of the state has been characterised since the instauration of democracy by an officially recognised national diversity as regards communities, identities and feelings of belonging which has materialised in the institutionalisation of a decentralised system. The decentralisation has ended up in the formal recognition of the appropriateness to share the competences between the central State and the Autonomous Communities $(\mathrm{AACC})$ over certain areas. This territorial heterogeneity has aimed at framing a diversified number of identities which are by nature plural, and which at times have gone as far as expressing claims for independence from the central State authority through ordinary politics or acts of political violence.

Successive Spanish govemments have been unwilling to open a frank debate about what it means to be Spanish today, and what constitutes the content and fundamentals of Spanish nationhood. As Pérez et al. (2001) have explained, ${ }^{651}$ there has been a lack of tradition to openly debate the meanings and substance of the national identity within which TCNs should or could be integrated, which has materialised in the lack of an identifiable and clearly postulated 'model' of integration in Spanish immigration law. Only in February 2007 was a nation-wide policy plan adopted in this regard. The Spanish strategy has been to practice a 'non-national model', a nonformalistic model preventing sensitive definitional aspects in relation to the Spanish nation from being addressed and which would potentially provoke deep conflicts. Any discussion about the predominant cultural identity(ies) would be intrinsically intertwined with conflict. Collective identity might have a homogeneous, integrated and cohesive cover, but inside there is a diverse puzzle of identities, peoples and societies questioning the foundations and making transparent the limits of the nation-state.

Perhaps there has been a fear to define a national model of integration because of the lack of a strong and commonly shared concept of 'the perfect Spanish citizen' and citizenry. What does it mean to be Spanish today? What would be the principle elements of the archetype attached to the perfect citizen in Spain? Would that be the proficiency of the Spanish language? Would it entail veneration of the Constitution of 1978 and the monarchy? Would it extol football or bullfighting? Or would perfection be expressed by a certain life style, and if so, would that life style involve the practice of Catholicism and the conception of the traditional Catholic family? The list may grow very long indeed and vary greatly according to the imagination, visions and perceptions of 'who' may be in charge of writing it. The answer to these questions would be linked not only to the 'who' in each of the decentralised public authorities, but also to the

650 R. Zapata-Barrero (2002), El Timno de los Immigrantes, Esferas de Justicia y Politicas de Acomodación, Imserso: Madrid; R. Zapata-Barrero (2002), Una Cultura Poliglota de la Integración, La Vanguardia, 14 Enero; R. Zapata-Barrero, C. Adamuz Garcia y I. Martinez Luna (2002), "Estructuras Institucionales y Redes de Actores en las Politicas de Acomodación de los Inmigrantes en España: Cultura de Acomodación y Cambio Estructural", en F. J. Garcia Castaño et al. (eds), La Immigración en España: Contextos y Ahternativas, Actas del IIl Congreso de Inmigración en Espana (Ponencias), Granada: Laboratorio de Estudios Interculturales, pp. 83-110.

651 V. Pérez-Diaz, B. Álvarez-Miranda y C. González-Enríquez (2001), España ante la Inmigración, Colección de Estudios Sociales, Núm. 8, Fundación La Caixa. 
multiplicity of communities, life styles and multilayered societies that exist and are in constant evolution.

The Spanish case provides a good illustration of the dilemmas posed by diversity, which are not limited to those posed by people coming from 'the outside', or by the mobility of non-nationals who by definition are framed as different and who by settling in the receiving society inject their difference into its perceived 'mainstream society'. Spain recognises itself as being far from cohesive, unique, homogeneous and integrated. The Constitution of 1978 transformed Spain into a polity divided into different $A A C C$ and established a decentralised mosaic of governance which involved the instauration of a federal State with various degrees of autonomies and distribution of competences. This organisation may be conceived as the more direct expression of the State institutionalisation as a unit within which there are various societies and communities. Therefore, the dilemmas subsumed with heterogeneity exist even without the multifaceted processes created by intemational human mobility. The non-existence of an official nation-wide model of integration might thus be based on the lack of an effective formula conceptualising 'the perfect Spanish citizen', a formula which may be broad enough as to be accepted by the majority of citizens across the imagined nation.

However, the State has portrayed its image of what 'the Spanish citizenry' is, and has even gone so far as to define the extent to which 'Other cultures' resemble or differ from it. This has been translated into the enactment of some legal provisions, such as those related to the acquisition of Spanish nationality. The need for any applicant of naturalisation by residence to show a "sufficient degree of integration within Spanish society" in order to have access to nationality sends a clear message in this regard. However, there is not a clear definition as to the real meaning of what 'the Spanish society' into which this person will need to integrate really is. As we will study in this Chapter, it is very interesting to see how the actual decision as to whether an applicant is 'well integrated' is left primarily to the discretion of the judge of the Civil Registry and, in final instance, of the Ministry of Justice. The way in which integration is used in the law of nationality is intended to protect, using the words of De Lucas (2006), the "iron cage" of citizenship status, ${ }^{652}$ and what we would call mainstream citizenry perfection. It is the ultimate border between the Other and the citizen and its definition is determined by the discretional power of the State. Another example of this pretension of the State regarding the existence of a perfect nation is the traditional positioning in the law as regards nationals from certain countries whose 'cultures' are considered to be closer to Spanish perfection based on historical ties. These include nationals from South America, Guinea Equatorial, Andorra, Portugal, Philippines and sefardies. ${ }^{653}$ Because of this proximity rationale, based on the presumption that the above nationals are more similar to the Spanish, the nationals from these countries are given privileged treatment by the laws of nationality and immigration.

652 J. de Lucas (2006), "La Integración de los Inmigrantes: La Integración Politica, condición del modelo de integración", en J. de Lucas y L. Diez Bueso (coord.), La Integración de los Immigrantes, Centro de Estudios Politicos y Constitucionales, Foro para la Inmigración y la Ciudadania: Madrid, pp. 11-43; See also J. de Lucas (1994), El Desafio de las Fronteras: Derechos Humanos y Xenofobia frente a una Sociedad Plural, Ediciones Temas de Hoy: Madrid.

653 The definition of Sefardi provided by the Real Academia Española de la Lengua is the following: "(Der. del hebr. séfarad. ropónimo que la tradición identificó con la Peninsula lbérica). l. adj. Se dice de los judios oriundos de España, o de los que, sin proceder de España, aceptan las prácticas especiales religiosas que en el rezo mantienen los judios españoles. U. t. c. s. 2. adj. Perteneciente o relativo a ellos. 3. m. Dialecto judeoespañor", retrievable from hitp://buscon.rae.es 
In contrast with the case of France (Chapter 6), nationality has not constituted one of the most politicised issues of concern and contestation in Spain. ${ }^{654}$ When moving to the immigration realm, however, things have proved to be rather different. A heated political debate leading to constant legal transformations have characterised this policy area. In fact, it is only when the phenomenon of immigration is positioned as an institutional and structural issue that the conceptual problems which we have identified with the fundamentals and features of the perfect Spanish citizenry call for a definitional response on what it really means to be Spanish. There is an increasing need on the part of the State to define and show 'a model' to deal with the consequences of immigration and the dispersion and consolidation of increasing diversity and heterogeneity. In this respect, the official strategy has been to refer to the EU. ${ }^{65}$ This strategy has consisted of considering Europe as source of inspiration, and to ascertain which features and principles composing the Union might be transferred to the national arena. ${ }^{656}$

From a historical perspective, there has been a constant quest by the Spanish nation to be as European as possible. Pérez et al. (2001) have also highlighted that this 'Europeanism' might be linked to an old obsession, which became very strong during the Franco era, consisting of the desire to be accepted by European counterparts as an equal member of the club. "The dream to come back and belong to Europe" formally materialised in 1986 with EU membership. The dream still remains when dealing with questions of nationhood and identity. This kind of Europeanism now represents another mechanism of governance. The need to show the existence of a national model of integration allowed the EU Framework on Integration, and its various soft-law tools, to exert influence on the policy processes on immigration and the politics dealing with the integration of TCNs.

The Spanish strategy consists of searching the European arena for 'lessons learned' or answers to its current dilemmas. However, this approach raises a number of questions. First, while diversity appears to be considered, at least formally and subject to various interpretations, as an inherent element of what has been labelled as the EU, we may wonder the extent to which EU law and policy might provide a valid response which is compatible within the parameters of a nation-state which continues searching for its own identity. Are the understandings and approaches provided by the European Framework on Integration compatible with the traditional configurations of the nation-state? If Spain decides to apply 'the European' as the model against which to test its own 'integration dilemmas', we would therefore need to analyse the conceptual questions as regards, for instance, what it means to be European and the definition of Europe and European identity, which may be subject to an even wider debate and critical reflection than the

654 For an overview of the main historical developments in respect of nationality law sce $\mathrm{R}$. Rubio Marin (2006), "Spain", in in R. Bauböck, E. Ersboll, K. Groenendijk and H. Waldrauch (eds), Acquisition and Loss of Nationality. Volume 2: Country Analyses. Policies and Trends in 15 European Countries, IMISCOE Research, Amsterdam University Press: Amsterdam, pp. 477-515.

655 C. Wihtol de Wenden (1999), L'Immigration en Europe, La Documentation Française: Paris, pp. 148152. Withol de Wenden makes a brief, but significant, reference to the influence that the European Union and the Council of Europe had in the origins of the development of a policy on the integration of TCNs in Spain.

${ }_{656}$ This has even been the case in the academic thinking and argumentation dealing with this subject. See for instance R. Aparicion López (2006), 'Stratégies d'intégration des groupes d'immigrés en Espagne', |èrés| Oure-Terre, 2006/4, No 17, pp. 167-177, when she makes reference to the understanding of integration as a 'two-way process' making reference to the European Council Conclusions of 2004. 
one posed exclusively by the Spanish case. ${ }^{657}$ This exercise would end up revealing even larger contradictions and paradoxes, and deconstructing other illusions and premises upon which the EU is being built.

As we have seen in Section II of this book, the current EU legal system on immigration, and the dominant common approach(es) and features surrounding the EU Framework on Integration, are being greatly influenced by specific national approaches, philosophies, political strategies and legislations currently existing in some Member States, which have been particularly successful during negotiations at times of developing transnational policies and laws. These national policies are intertwined with a complex web of networks, a policy hybrid which has taken the form of a quasi-OMC, and that presents some critical aspects in need of consideration when transferring some of its elements to the domestic level. The Spanish 'non-model', and its peculiar form Europeanism, appears not to take into consideration the fact that when elaborating common policies on immigration and integration, other Member States do not tend toward the European but instead try to resist as much as possible the Europeanisation processes over this and other related areas by practising intergovernmentalism and engaging in competition. In fact, this has been the reason why the European Commission, and other actors such as the EESC, have advocated for an alternative method of cooperation to move integration processes forward at the expense of reinforcing certain national perspectives on integration which might actually use it as a tool of a restrictive immigration policy. Also, it is far from clear how this influence will affect implementation in the national arena, or the search for answers to the conceptual dilemmas which have been raised when considering pluralism in the context of nationhood(s), citizenry(ies) and national identity(ies).

The Europeanism which has characterised Spain in the last years has presented at least two versions, each of those having important distinctive factors: The first version corresponds to what has been explained above, and which has materialised in the non-model and searching for inspiration in EU immigration policy. Independent of the juridical softness inherent to some of these European policies, their influence in the development of the processes of policy formulation has been significant. This kind of Europeanism has become transparent, for instance, during the elaboration of some policy measures covering integration in the early $90 \mathrm{~s}$, and has taken its more prominent form in the Strategic Plan on Integration and Citizenship of February 2007. The impact of the EU has also been substantial on the Integral Plans of the AACC, which will be reviewed in Section 3.3 below.

There has been, however, another version of Europeanism. The EU has been at times used as the justification for developing policies of a rather rigid nature towards immigration and the social processes of diversity. There have been some national policies which have been justified in order to meet the compromises acquired at the European level, policies which have at times followed the experiences and laws practiced by other members of the EU, as well as on some legal measures developed at the European level, ${ }^{658}$ and which have fostered a securitisation of

657 J. de Lucas (2006), "Identidad y Constitución Europea ¿Es la identidad cultural europea la clave del proyecto europeo?", en J. de Lucas (coord.), Europa: Derechos, Culturas, Tirant Lo Blanch: Valencia, pp. 123-152; J. de Lucas (1994), Europa: ¿Convivir en la diferencia? Editorial Tecnos: Madrid.

See European Commission, Communication on integrating migration issues in the European Union's relations with third countries, $\operatorname{COM}(2002) 703$ final, Brussels, 12.2.2002, or the Commission Communication on Policy Priorities in the Fight against Illegal Immigration of Third-Country Nationals, COM(2006) 402 fimal, Brussels, 19.7.2006; For an analysis of the European policy on irregular immigration and its connotations see B. Bogusz, R. Cholewinski, A. Cygan and E. Szyszczak (eds), Irregular Migration and Human Rights: Theoretical, European and International Perspectives, Leiden: Martinus Nihjoff; See also T. Balzacq and S. Carrera (2006), "The Hague Programme: The Long Road to 
migration. ${ }^{659}$ This sort of Europeanism has been mainly present in two moments: First, in the mid-1980s, with the adoption of the Law 7/85 before the entry of Spain in the EEC, and, second, in the legislature of the Partido Popular (PP) after obtaining the majority in the Congress at the 2000 national elections, and which reached its summit with its various legislative reforms affecting the Law on the Rights and Liberties of Immigrants and their Social Integration 4/2000 as well as during the Spanish Presidency of the European Union during $2002 .^{660}$

For the purposes of this book the first version will be the main subject of our study, yet some aspects of the second will be also highlighted. It is striking to see that when comparing both sorts of Europeanism, the one consisting of the use of the EU for 'giving a hand' to the development of a Spanish non-model of integration of TCNs has been pursued during the periods when the Partido Socialista Obrero Español (PSOE) has been in power, first with Felipe González (1982-1996) and then with Jose Luis Rodriguez Zapatero (2004-present). The other kind of Europeanism was often advocated by the Government of the Partido Popular (PP) led by Jose Maria Aznar (1996-2004). That notwithstanding, the security approach has recently been expanded to the current Spanish policies on the control of irregular immigration and Spain's southern borders under the auspices of FRONTEX, the European Agency for the Management of Operational Cooperation at the External Borders of the Member States of the European Union. ${ }^{661}$ Further, as we will show when analysing the approach and policy strategy pursued by the current Government in recent years, there seems to be an attempt to follow an approach centred on facilitating an understanding of integration as a complex social phenomenon, and not as a legal mechanism functioning as a tool for practising a stringent immigration policy. The next section aims at offering a broad overview of the changing nature of the Spanish policies framing the articulation between immigration and integration by reviewing the evolution which has characterised immigration law in the country.

\section{Evolution of the Spanish Legislation on Immigration and its Changing Articulation with Integration}

This section looks at the evolution and dynamics that Spanish legislation on regular immigration has experienced in the last twenty-three years. It focuses on the origins of the institutionalisation of immigration and integration as major institutional issues in the political debate and their introduction in the various policy and legal responses. It assesses the key changes affecting the functions that this term has experienced during these processes. What have been the more important legislative measures on immigration since the adoption of the first harmonised Law $7 / 1985$ until the Royal Decree 2392/2004 amending the Law on the Rights and Liberties of

Freedom, Security and Justice", in T. Balzacq and S. Carrera (eds), Security versus Freedom: A Challenge for Europe's Future, Aldershor: Ashgate Publishing, pp. 1-32.

J. Huysmans (2000), 'The European Union and the Securitization of Migration', Joumal of Common Market Studies, Vol. 38, No. 5, pp. 751-777.

660 Presidency Conclusions of the Seville European Council, 21-22 June 2002, 13463/02, Brussels, 24 October.

661 For an analysis of the nature, effects and vulnerabilities of the joint operations coordinated by FRONTEX in the Canary Islands, and the change in discourse and policy of the current Government see S. Carrera (2007), The EU Border Management Strategy: FRONTEX and the Challenges of Irregular Immigration in the Canary Islands, CEPS Working Document No. 261, Centre for European Policy Studies: Brussels; Refer also to, S. Carrera (2007), "FRONTEX and The EU's Integrated Border Management Strategy", in J. Lodge (ed), Are you who you say you are? The EU and Biometric Borders, Wolf Legal Publishers: Nijmegen, pp. 67-100. 
Immigrants and their Social Integration (Ley Orgánica 4/2000 de Derechos y Libertades de los Extranjeros y su Integración Social, LODYLE) of 2000? What has been the relationship between the law on immigration and "the social integration of immigrants" during the different phases? What son of role has the EU played in policy formulation?

\subsection{The First Phase: Democratic Spain and the 1985 Immigration Law}

The legal framework on immigration was not adapted to the general regime established by the Spanish Constitution of 1978 as late as $1985 .{ }^{662}$ The Constitution did not only bring major transformations as regards the legal status of Spanish citizens, but it also influenced the juridical regime applicable to those not holding Spanish nationality. One of the more important imnovations introduced by the new Constitutional setting was the instauration of a general framework where the rule of law was applicable to all public authorities, including the administrations in charge of immigration. The mechanisms constituting democratic Spain in this way challenged the discretion that until then had characterised the way in which the State had conducted its competences over this area. The field of nationality and immigration were included in Title I of the Spanish Constitution ("on the Fundamental Rights and Duties"), Chapter 1 ("on the Spanish and Foreigners"). In particular Article 13.1 stipulates that "The immigrants will benefit from the public liberties guaranteed by the present Title (Title I) in the terms established by the Treaties and the law in Spain" ${ }^{663}$ Further, the second paragraph of this same provision continues by stating that the rights to participate in public affairs - in particular the right to vote and stand as a candidate, and to work in public administration ${ }^{664}$ - will be enjoyed only by Spanish nationals, with the exception of the right to vote in municipal elections, which is granted on the basis of reciprocity provided by Treaty or in a specific law.

We have identified, following the analysis of Cachon (1999), the mid-1980s as the period of origin of a fundamental process of structural transfomation of Spain into a country of immigration. ${ }^{665}$ This change of status coincided with the mandate of the Government of Felipe Gonzalez (PSOE). In 1985 the first unified and complete immigration law was adopted. ${ }^{666}$ The Law 7/1985 on the Rights and Liberties of Immigrants in Spain (Ley Orgánica 7/1985 sobre Derechos y Libertades de los Extranjeros en España, LOE) of I July 1985, or "Ley de Extranjeria" (Foreigners Law), a label which has remained to denominate the Spanish law on immigration to the present day, was adopted in the phase of pre-accession to the EEC on 1 January 1986. ${ }^{667}$ EEC membership had important implications regarding the nature and objectives of this law. Spain felt under the obligation to show its commitment towards border

662 For a historical perspective of the evolution of the legal status of immigrants in Spain since the XVII century see M. D. Adam Muñoz (2005), "El Estatuto Juridico del Extranjero en el Sistema Español: Una Perspective Histórica", en M. D. Adam Muñoz y l. Blázquez Rodriguez (coord.), Nacionalidad, Extranjeria y Cindadania de la Unión Europea, Editorial Colex: Madrid.

Title I of the Spanish Constitution goes from Article 10 until Article 55.

Article 23.

L. Cachón (1999), Prevenir el Racismo en el Trabajo en España, Ministerio de Trabajo y Asuntos Sociales, Secretaria General de Asuntos Sociales, Instituto de Migraciones y Servicios Sociales, IMSERSO: Madrid.

Before the adoption of this law there were two legal texts which respectively provided the Spanish regulation of immigration: The Decree $N^{\circ} 522,14-2-1974$ and the Decree $N^{\circ} 1031,3-5-1980$.

The Law $7 / 1985$ was implemented by Royal Decree $1119 / 1986$ of 26 May. 
control, ${ }^{668}$ as it would soon become a border country of Europe and responsible for the management of immigration. Therefore, the main rationale was the introduction of a restrictive legal framework allowing more control-oriented measures and aiming at making the borders more secure and facilitating the procedures of expulsion of irregular immigrants. All this along within a system still allowing the administration broad discretion. ${ }^{669}$ The improvement of the legal status of TCNs was not among the main goals of this law. ${ }^{670}$ Further, it conceived human mobility as a phenomenon of a temporary nature by making no provision for the status of permanent residence and of family reunification.

The prevalence of a securitarian paradigm, as well as the widening of sanctions (which included a wide regime on expulsion and detention), led to the appearance of more irregularity by forcing people to enter and stay in Spain without respecting the rigid rules which simply did not match the institutionalisation of immigration as a social reality. ${ }^{67} \mathrm{Aja}$ (2006) has explained that because of the restrictiveness of the regime provided by Law 7/1985, the channels for regular immigration were significantly reduced, and almost non-existent in practice. ${ }^{672}$ Indeed, the only regular channels available to enter Spain were mainly tourism or irregular routes. These social realities called for more responses by the State.

\subsection{The Second Phase: The Birth of the Intersection between Immigration and Integration}

In 1990, the Gonzalez government presented a Communication to the Congress entitled "The Situation of Immigrants in Spain: The Basic Lines for the Spanish Immigration Policy". This law was adopted in the form of a proposal of non-law on 9 April 1991. ${ }^{673}$ The proposal marked the first policy response calling for the need to develop a global immigration policy. The initiative identified three major principles upon which future Spanish immigration policy should be based: a policy of immigration and "integration of immigrants", strengthening border security and development aid to third world countries. The initiative also urged the government to take a number of steps such as the ratification in 1991 of the Schengen Agreement and the Convention implementing it, a modification of the Law on Asylum and Refugees, the creation of Directorate

668 E. Aja (2006), 'La Politica Inmigratoria del Estado como Marco de la Actividad de las Comunidades Autónomas', en E. Aja, J. A. Montilla y E. Roig (coords.), Las Commidades Autonomas y la Inmigración, Novedades de Derecho Público 9, Instituto de Dret Public, Tirant lo Blanch, Valencia, pp. 153-184.

J. de Lucas (1992), Europa: ¿Convivir con la Diferencia? Racismo, Nacionalismo y Derechos de las Minorias, Editorial Tecnos: Madrid, pp. 83-94.

670 The LOE $7 / 1985$ was subject of various criticisms which included the presentation by the ombudsman of a case before the Constitutional Tribunal claiming the unconstitutional nature of some of the provision contained in the law especially those related to the limitations of rights. The Constitutional Tribunal annulled in the judgement STC1 15/1987 some of the limitations that had been introduced by the law.

671 On the impact of the Spanish immigration laws in the labour insertion of immigrants in this country see C. Solé y S. Parella, 'La Inserción de los Inmigrantes en el Mercado de Trabajo. El Caso Español', en C. Solé (coord.), El lmpacto de la Inmigración en la Economia y en la Sociedad Receptora, Anthropos: Barcelona, pp. 11-50.

672 E. Aja (2006), "La Evolución de la Normativa sobre Immigración", en E. Aja y J. Arango (eds), Veinte Años de Imnigración en España: Perspectivas Juridica y Sociológica [1985-2004], Fundación CIDOB, Barcelona, Spain, pp. 17-44.

673 Proposición no de Ley, La Situación de los Extranjeros en España. Lineas Básicas de la Politica Española de Extranjeria, 9 Abril 1999. 
General of Migration and the Inter-ministerial Commission of Immigration, and a new process of regularisation of irregular TCNs. ${ }^{674}$ It appears that the actual increase of irregular immigration once again created a need for the government to do something. This urgency led to a process of regularisation of irregular immigrants in 1991. The regularisation has been followed by many other similar measures, and has therefore conformed as a typical feature of the Spanish policies on irregular immigration. ${ }^{675}$

The Proposal for non-law represented the first instrument where the category of "integration of immigrants" appeared as pant of the government discourse and of the Spanish political debate. While the relevance of the initiative in terms of the identification of integration as a policy priority in the political agenda is clear, the instrument did not present any specific measure destined to achieve this goal and remained void of content. Its importance is that it represented an official acknowledgement of the stable presence or nature of immigration, and its consequences, as a reality in Spain. As regards the meanings of integration in the Communication, the concluding paragraph of the Proposal stated that

during the nineties the consolidation of Spain as a country of immigration will make necessary the design and practice of a global and coherent immigration policy which will protect and preserve our economic interest and social cohesion, which will take into accoum our cultural and historical links, and which will guarantee, in compliance with the values of democratic Spain, the complete integration of the collective of immigrants who are resident and who chose our country as their place of life and work. (Emphasis added.)

The initiative attributed the following distinctive features to the future immigration policy: First, it made a clear priority of the Spanish State's economic interest and social cohesion, which would need to be protected and preserved. Second, it reinforced the dichotomy between "us" and "them" when using expressions such as "our economic interest and social cohesion", "our country", "our cultural and historical links", etc. Third, it called for a "complete integration" in "the values of democratic Spain", something which has cultural connotations and which could be understood as an acculturation attempt calling for the disappearance of diversity inherent to the phenomenon of human mobility and settlement into the traditional conceptualisation of Spanish societies. It also used a sort of discourse which appeared to take for granted that only the immigrants face difficulties to integrate into democratic values because of their "cultural difference". Fourth, it referred to the need to take into account the "cultural and historical links" that Spain had with other countries. Here we see a reference to the list of countries that have been ever since considered to have been considered to present closer 'cultural ties' with Spain because of particular historical reasons, and which include: South America, Andorra, Guinea Equatorial, Filipinas and Portugal. Since the beginning of the 1980 s they enjoy a privileged legal status and are treated as being more easily integrated into the perfect Spanish citizenry without posing major dilemmas. ${ }^{676} \mathrm{Fifth}$, it considered the need to integrate only those TCNs residing regularly.

674 R. Aragón (1996), 'Diez Años de Política de Inmigración', Revista Migraciones, $N^{\circ} 0$.

675 P. Santolaya (2006), "Los inmigrantes en situación irregular: derechos expulsión y regularización', en E. Aja y J. Arango (eds), Veinte Años de lnmigración en España: Perspectivas Juridica y' Sociologica [1985 - 2004], Fundación CIDOB, Barcelona, Spain, pp. 129-14]; See also A. Izquierdo, Escribano (1992), La Inmigración en España (1980-1990), Ministerio de Trabajo y Seguridad Social, Madrid, pp. 133-151. 51/1982, de 13 de julio, de modificación de los articulos 17 al 26 del Código Civil, BOE 181/1982, 30 
The Communication made use of a sort of integration focusing on cultural aspects. It aimed at fostering the preservation of the cultural cohesion of Spain and maintaining the links with a number of countries considered to be 'culturally closer' because of various historical considerations. ${ }^{677}$ Following a similar line of action, the Spanish government adopted on 17 December 1990 a new legislative reform of the Spanish legal regime on nationality. ${ }^{678}$ Law $18 / 1990$ regarding the reform of the Civil Code in the field of nationality introduced, among other innovations, a fourth paragraph to its Article 22 which deals with the acquisition of Spanish nationality by residence. The new version of this provision foresaw for the first time in Spanish legal history the conditionality of integration as a requirement for passing successfully naturalisation by residence. In particular, in addition to the different applicable criteria as regards the length of residence, and which will be explained in detail in Section 3, the new Law provided that any applicant for naturalisation by residence would need to prove "a sufficient degree of integration into the Spanish society".679

Another important step in the intersection between integration and immigration policy was the Plan for the Social Integration of Immigrants (Plan para la Integración Social de los Inmigrantes, P.I.S.I.), which was adopted by the Council of Ministers on 2 December $1994 .{ }^{680}$ The Plan constituted a catalogue of good intentions and a declaration of general principles intending to serve as a general framework of reference for the development of "policies favouring the integration of the immigrant population". The relevance of P.I.S.I. consisted of the official recognition of the need to focus not only on those aspects related to the control of migration flows, but also on aspects concerning "the social integration of immigrants". ${ }^{881}$ It also called for better coordination between all the public administrations in the area of integration, ${ }^{682}$ a more active role for $\mathrm{AACC}$, and more participation by civil society, NGOs and immigrant associations.

July 1982) constituted the first time where the Code provided an institutionalised recognition for the nationals of all these countries to have a favourable treatment in the acquisition of the Spanish nationality by residence, which as we will see below, is since then of two years in Spanish territory following Article 22.1 of the Civil Code. J. Fernández Rozas (1987), Derecho Español de la Nacionalidad, Tecnos, Madrid.

677 These considerations include for instance the Spanish history of colonialism, emigration, etc, with these countries. For an in depth exploration see F. J. Moreno Fuentes (1999), "La Migration et le Droit de la Nationalité Espagnole", P. Weil et R. Hansen (dir.), Nationalité et Citovenneté en Europe, La Decouverte: Paris, pp. 117-144.

Ley 18/1990, sobre reforma del Código Civil en materia de nacionalidad. Boletín Oficial del Estado, 1990-12-18, núm. 302, págs. 37587-37589. See A. Alvarez Rodriguez (1990), Nacionalidad y Emigracion, La Ley: Madrid.

Article 22.4 reads as follows: "4. El interesado debera justificar, en el expediente regulado por la legislación del registro civil, buena conducta civica y suficiente grado de integración en la sociedad española".

Dirección General de Migraciones del Ministerio de Asuntos Sociales Aprobación del Plan para La Integración Social de los Inmigrantes (P.I.S.I.). Consejo de Ministros del 2 de diciembre de 1994.

The Plan stated that "El fenomeno migratorio es un tema complejo, que requiere un tratamiento equilibrado entre los aspectos de dirección y control de flujos y los relacionados con la integración social de los inmigrantes. Hasta ahora se ha prestado atención preferente a los primeros, tanto por razones logicas come de urgencia social, ahora es necesario insistir en los segundos".

In this way the Plan justified the new administrative structure implemented since 1993 by the Government, time when the competence over the field of immigration was transferred from the Ministry of Labour to the Ministry of Social Affairs. 
As regards the main elements of integration, the functions attributed by the Plan were different in nature when comparing it to the way in which it was previously carried out by the 1990 Proposal. In particular, the overwhelming prevalence of the cultural dimension diminished in the Plan, which advocated for a different understanding of integration, placing an emphasis in the following elements: First, it advocated that integration represent a long-term process destined to achieve the gradual incorporation and participation of TCNs in the economic and social life of the receiving country in a climate of mutual respect and acceptation. Second, it called for the consideration of the TCN in her/his totality, not only as worker but also as a citizen with needs in different societal sectors such as education, culture, health, social participation, etc. Third, the process of integration requires a constant dialogue between the different public administrations and social partners. Fourth, it called for the elimination of discrimination in the exercise of rights and duties and when accessing social services; the promotion of coexistence based on the respect of democratic values and tolerant attitudes; the guarantee of a legal and socially stable status for the immigrant; the elimination of barriers to integration, etc. For the achievement of these objectives the P.I.S.I. proposed 26 measures which remained general and promotional in nature rather than practical or operational. ${ }^{683}$

What might have been the reasons for this substantial change in the conception of integration? A decisive aspect which distinguishes this Communication was that during its elaboration process the government took on board some ideas coming from European policy developments. As we have explained in Chapter 2 when assessing the relationship between integration and EU law, the publication by the European Commission of an important Communication on "Immigration and Asylum" COM(94)23 of 23 February 1994 included the strengthening of integration policies for regularly resident TCNs, which was considered as a key element for any comprehensive approach to immigration. ${ }^{684}$ While this measure lacked a binding legal nature and fell within the category of soft-law, it did have some influence in the elaboration of the Plan for the Social Integration of Immigrants in Spain. The P.I.S.I. constituted a first prominent example of the Europeanism characterising the Spanish non-model of integration described in Section I of this Chapter, and which was later consolidated in subsequent policy instruments. One of the more important elements of the Plan was the introduction into the Spanish framework of some of the conceptual elements attributed to the integration of TCNs by European policy.

The Socialist Government adopted a Royal Decree 155/1996 implementing the LOE 7/85 on 2 February $1996,{ }^{685}$ which presented some innovations intending to put into practice some of the policy priorities put forward by the Proposal of non-law of 1991, and the P.I.S.I. of 1994 as regards the integration of immigrants. The Decree identified as one of its main objectives

683 The general measures put forward by the Plan were of normative, socio-economic, educational and culturat nature, as well as related to social participation. Among the more important we may point out the creation of two institutional bodies related to the area of "integration of immigrants": The Forum for the Social Integration of Immigrants (Foro para la Integracion Social de los Inmigrantes) and the Permanent Observatory of Immigration (Observatorio Permanente de la Imnigración. OPI).

Commission Communication on Immigration and Asylum Policies, COM(1994) 23 final, 23 Febrary 1994, Brussels. See E. Guild and J. Niessen (1996), The Emerging Immigration and Asy/um Law of the European Union, Kluwer Law International: The Hague; See also EESC Opinion, on the Communication from the Commission on Immigration and Asylum Policies, 94/C393/13, OJ No C393/69, 31.12.1994.

Real Decreto 155/1996, de 2 de febrero, por el que se aprueba el Reglamento de ejecución de la Ley Orgánica 7/1985, BOE No 47, 23 febrero 1996. 
...the improvement of the stability and legal security of immigrant workers, as essential requisites for their integration, and following the orientations provided by the Plan for the Social Integration of Immigrants. (Emphasis added.)

This was translated into the creation of the status of permanent resident in Spanish immigration law, which constituted the first occasion when the non-temporary nature of immigration was officially recognised by the Spanish legal system. ${ }^{686}$

\subsection{The Third Phase: Immigration as an Institutional and Structural Issue}

It is in between the second and third phases highlighted in Section 1 that a wider debate takes place about the need for changing the nature and rationale in Spanish immigration policy. The state of affairs was loudly calling for a legislative reform and the adoption of a different institutional perspective more appropriate to the social processes of dynamic transformation affecting Spain, which had rapidly become a destination of international human mobility. This, however, was not absent of conflict, which, as we will explain below, surrounded the elaboration of successive legislative reforms of the 2000 Law on the Rights and Liberties of Immigrants and their Social Integration.

\subsubsection{The Lav on the Rights and Liberties of Immigrants and their Social Integration}

The 1996 national elections put an end to the PSOE Government that had remained in power during fourteen years. The PP took the stick and Jose Maria Aznar became President. During the first term of government (1996-2000), the PP did not obtain an absolute majority in the Congress, something which had great significance in the events driving the evolution of Spanish immigration law. On 10 March 1998 three legislative proposals were presented to the Congress by the following political parties: (Convergencia $i$ Unio, CiU), Izquierda Unida and the Grupo Mixto ${ }^{687}$ The Proposals, which one year later were unified into a unique act, advocated a shift in the focus that until then had guided Spanish immigration policy. The goal was to prioritise the promotion of "the social integration of TCNs", the prevention of discrimination and the granting of equality of rights to TCNs comparable to those of Spanish nationals. The Explanatory Memorandum of the initiative acknowledged the need to move from an immigration policy centred merely on security and control, to one fostering "social integration" and the prevention of discrimination.

Aja (2006) has identified the following key proposals that were put forward by this initiative: ${ }^{688}$ First, it created a clear legal status of rights for TCNs inspired by the principle of equality of

686 A new kind of residence permit of permanent nature was introduced. This administrative document would be granted to those TCNs providing evidence of legal and continuous residence in the Spanish territory during six years. Article 52 of the Decree, titled "Permanent Resident Permit". This period of time would be of five years if the third country would meet the requirement for being granted with a renewed work permit. According to Article 79 of the Decree.

687 Boletin Oficial de las Cortes Generales, Congreso, Serie B, N*175-1 y 179-1, 18-3-1998; No 189-1, 2-4. 1998). For an explanation of the precise content of each proposal and the parlamientary debate see $V$. Pérez-Diaz, B. Álvarez-Miranda y C. González-Enriquez (2001), España ante la lmmigración, Colección de Estudios Sociales, Núm. 8, Fundación La Caixa.

68 E. Aja (2006), "La Evolución de la Normativa sobre Inmigración", en E. Aja y J. Arango (eds), Veinte Años de Inmigración en España: Perspectivas Juridica y Sociológica [1985-2004], Fundación CIDOB: Barcelona, Spain, pp. 17-44. 
rights and treatment between the nationals and legal residents, with the exceptions of suffrage (right to vote and stand as a candidate) and access to public authority employment. Second, it recognised a right to family reunification. Third, the proposal was progressive with respect to the rights which were foreseen for irregular immigrants regarding not only access to health care and education, but also the provision of an individual regularisation process and a change in the system of sanctions (which included foreseeing the non-expulsion of those irregulars who had subsequently become 'illegal'). Indeed, these features involved an important transformation in the approach which had until then characterised the legal and policy frameworks on immigration, and the status granted to TCNs. For the first time a legislative proposal took into account the need to deal with the principle of equality of treatment for TCNs independent of their status of residence. Integration was equalised to these principles. However, it was precisely this progressive nature that provoked the opening of heated discussions in and outside the Spanish Congress.

During the parliamentary debates the PP government had not presented any altemative text to the unified proposal, nor had it played a critical role during the discussions by presenting any substantial amendments. In fact, during the 15 months of negotiations, the government had very much supported the initiative. However, once it reached the Senate, where the PP had an absolute majority, the situation changed. The Ministry of Interior proposed numerous amendments (a total of 112) which overall aimed at making it more restrictive in nature. ${ }^{689}$ The amendments adopted in the Senate were, however, not very welcome, and therefore they were not approved once the text came back to the Congress. This created an interesting scenario. Even though the govemment had expressed clear opposition to the spirit and final shape of the Proposal, the Ley Organica $4 / 2000$ de Derechos y Libertades de los Extranjeros y su Integracion Social, LODYLE (Law on the Rights and Liberties of Immigrants and their Social Integration) was adopted on 11 January 2000. And this happened without the government having the capacity to stop it, as the PP did not enjoy an absolute majority in the Congress. ${ }^{690}$

Nevertheless, during the period preceding the 2000 national elections the electoral programme of the PP already included among its main political priorities the LODYLE reform. The PP won the elections, receiving an absolute majority in both the Congress and the Senate. While it had patiently watied and delayed the adoption of the Royal Decree necessary to transpose Law $4 / 2000$, right after the re-election, the government adopted a brand new Law. This provoked express oppositions from a majority of the other parliamentary groups in Congress, as well as from a wide range of stakeholders and key actors in civil society, NGOs, practitioners and social partners.

The new Law 8/2000 amending the Law 4/2000 on the Rights and Liberties of Immigrants and their Social Integration was adopted on 22 December $2000 .{ }^{691}$ It implied that the achievement of

689 BOCG, Congreso, Serie B, N 330-6, 22-12-1999.

690 Ley Orgánica $4 / 2000$, de 11 de enero, sobre derechos y libertades de los extranjeros en España y su integración social, BOE N*10, 12 enero 2000. J. de Lucas (2001), 'Las Propuestas sobre Política de Inmigración en Europa y la Nueva Ley de Extranjeria 4/2000 en España', en VV.AA. (Colomer ed.), Emigrantes y Estabilidad en el Mediterráneo, Nomos/Coma, Valencia; J. de Lucas (2000), 'El Marco Jurídico de la Inmigración. Algunas Proposiciones acerca de la Necesidad de Reformar la Ley Orgánica 4/2000', Jueces para la Democracia, 38/2000.

691 Ley Orgánica 8/2000, de 22 de diciembre, de reforma de la Ley Orgánica 4/2000, de 11 de enero, sobre derechos y libertades de los extranjeros en España y su integración social, BOE $N^{\circ} 307,23$ Diciembre 2000. The Law $8 / 2000$ was implemented in a relatively short period of time by the Royal Decree $864 / 2001$ of 20 July implementing the Law 8/2000. Real Decreto 864/2001, de 20 de julio, por el que se aprueba el Reglamento de ejecución de la Ley Orgánica 4/2000, de 11 de enero, sobre derechos y 
the previous version in relation to the equality paradigm concerning integration was simply lost. The only express reference that was kept in the law to the "social integration of immigrants" was in the title. As Diez Bueso (2006) has pointed out, ${ }^{692}$ integration understood as granting a secured juridical status no longer constituted the premises of the Law. It represented an important regression as regards the status of both regular and irregular TCNs. Further, most of the rights were now granted only to those holding an authorisation of stay and residence, and therefore falling within the administrative category of 'legality'. The rights of those 'undocumented' or 'just present' in the Spanish temitory without complying with the prescribed administrative formalities were the main victims of the legislative reform. For instance, freedom of association was limited to those holding an authorisation of residence and stay; the right to education was diminished by recognising only those holding an authorisation of residence and stay as having the right to access non-mandatory education; social assistance for access to public housing was reserved to those having the legal status of residence; ${ }^{693}$ the categories benefiting from the right to family reunification were limited; ${ }^{694}$ the requirement of continuity for the acquisition of permanent residence was introduced, ${ }^{695}$ etc. Those rights linked to the exercise of professional activity, which included the rights of trade union membership and demonstration, were granted only to those holding an authorisation to work. This last derogation represented one of the core points of contention between the PP and the PSOE during the parliamentary debate of the new Law. ${ }^{696}$ The restrictive nature of the Law as regards the limitation of some specific rights of TCNs depending on their administrative status of stay and their possession of an authorisation to work led to the presentation of a case for annument before the Spanish Constitutional Tribunal, ${ }^{697}$ which after more than six years was decided on 20 December $2007 .{ }^{698}$ The rulings of the Constitutional Tribunal have declared unconstitutional, and therefore annulled, the administrative limitations applicable to the exercise of rights foreseen in the following articles of the amended version of the Law 4/2000: 7.1 (freedom of demonstration and affiliation), 8 (freedom of association), and 11.1/1.2 (right to membership of an organisation representing workers).

Law $8 / 2000$ did, however, maintain some of the rights that had been introduced by the previous version, such as the granting of legal effects to the inscription (so-called "empadronamiento") in the municipal registry of population (padron municipal de habitantes). Those TCNs inscribed in the municipal registry of population have access to some rights independent of their regular or irregular status of stay and residence in the Spanish territory. These rights include access to

libertades de los extranjeros en España y su integración social, reformada por Ley Orgánica 8/2000, de 22 de diciembre, BOE N ${ }^{\circ} 174,21$ Julio 2001.

L. Diez Bueso (2006), "Los Derechos de los Inmigrantes y sus Garantias (1990-2004)", en E. Aja y J. Arango (coord.), Veime Años de Immigración en España: Perspectivas, Juridica y Sociológica (19852004), Fundació Cidob, Barcelona, Spain, pp. 205-218.

Article 13 of the LODYLE.

Article 17.1.

Article 32.2 .

BOCG, Senado, Serie III B, No 4 (c), 10.12,1999.

The case for annulment was jointly presented by el Consejo de Gobiemo de la Junta de Andalucia, la Junta de las Comunidades de Castilla-la-Mancha, la Comunidad de las Islas Baleares, la Junta de Extremadura and el Principado de Asturias, by the Vasque Parliament and that of Navarra, la Diputacion General de Aragon, y por el Grupo Parlamentario PSOE in the Congres. The case was admitted by the Constitucional Court on the 22 of May 2001 (BOE 1 June 2001).

Tribunal Constitucional, STC 236-259/2007, 20 December 2007, BOE 22/01/2008, retrievable from http://www.tribunalconstitucional.es 
health care in the same conditions as the Spanish nationals, ${ }^{699}$ and the right to access mandatory or basic education. ${ }^{700}$ Concerning the right to education, the new Law also included the obligation of public authorities to guarantee access to kindergarten for those children of TCNs who apply for it. ${ }^{701}$ Further, the new version of Article 9.4 introduced the possibility for public authorities to offer TCNs who are residents education aimed at facilitating their "social integration, with the recognition and due respect of their own cultural identity".

What was the official justification provided by the government for so drastically changing the nature and spirit of the Law? Surprisingly, one of the main arguments put forward by the PP was political compromises at the EU level. The government alleged in the Explanatory Memorandum that in order to meet the agreement reached at the Tampere European Council Conclusions of May $1999,{ }^{703}$ the adoption of a new version of the Law was required. Here we may perceive a clear sign of the other sont of Europeanism which, as we have argued above, has also constituted a major factor in the strategies advocated by some Spanish governments. The EU was co-opted as the perfect excuse for carrying out legislative reform with a rather strong, rigid and restrictive tone towards immigation. Some authors have eloquently criticised this political strategy by the government of that time. ${ }^{705}$ First, the Tampere Programme already existed (May 1999) at the time of the adoption of the previous Law 4/2000 (January 2000). Second, the fact that the Spanish legislation was going to confer a number of rights on TCNs of irregular status and expand rights for those of regular status would not have contradicted the Council Conclusions. In fact, both the Tampere Council Conclusions and Law 4/2000 coincided in many respects with this approach of equality of treatment. Finally, the Tampere Programme was not legally binding, so the Spanish government was not under any obligation whatsoever to present a new Law. In fact, in the view of de Lucas (2002), ${ }^{706}$ the main reason for what he refers as the "contrareforma" or radical transformation introduced by the newly elected Spanish government was not at all technical or based on any legal grounds. It was rather of pure political nature. In his opinion, the adoption of Law 4/2000 was considered by the PP as one of the more

699 Articulo 12 of the LODYLE. Those TCNs not being inscribed in the municipal registry of population will have the right to have access to the public health system in cases of emergency in the same conditions as the Spanish nationals. Also, minors will always have that right independently of their administrative status and inscription in the registry.

Article 9.

701 Article 9.2 of the LODYLE.

703 Tampere European Council, 15-16 October 1999, Presidency Conclusions, SN 200/99, Brussels.

705 S. Peña (2001), "La Historia Reciente de la Legislación Espanola sobre Derechos y Libertades de los Extranjeros y Algunas de las Actuaciones que han Provocado", en J. de Lucas, S. Peña y A. Solanes (coords.), Inmigrantes: Una Aproximacion Juridica a sus Derechos, Germania: Valencia, pp. 17-32; A. Álvarez Rodriguez (2000), 'La Nueva Ley de Extranjeria: ¿Ruptura e incumplimiento de Tampere? ¿innovación o seguimiento del modelo italiano?', Revista Migraciones, No. 7, pp. 92-93.

706 J. de Lucas (2002), "La Dimensión Politica de la Inmigración: Una Dimensión Pendiente", en VV.AA. (Centro Pignatelli, ed.), La Inmigración, Una Realidad en España, Centro Pigantelli/Gobierno de Aragón: Zaragoza. 
important defeats from the previous legislature. ${ }^{707}$ This experience, in his view, synthesises very well the common spirit that has often driven Spanish immigration policy, and which has provoked its constant failure. Instead of trying to build comprehensive immigration policies, ${ }^{708}$ efforts have instead used immigration for political ends. Immigration has at times been misused as a tool in the game of national politics, and the laws and policies framing it have often been driven by the interests of political parties.

The PP Government launched another series of legislative initiatives dealing with, or having implications regarding, integration. They brought about another important move in the meaning and functions of integration within the Spanish legal system. The more significant legislative act implementing that policy shift was the so-called GRECO Plan (Global Programme of Regulation and Coordination of Foreigners and Immigration) 2001-2004, adopted by the government on 30 March $2001 .^{709}$ While the Plan did not present a common definition of integration, the underlying meaning that was attributed to it becomes transparent when looking at the nature of some of its priorities and proposals. ${ }^{710}$ The GRECO Plan identified as one of its main lines of action and as a key objective for the overall immigration policy the need for a certain type of TCNs "to adapt and to integrate" to the receiving society. Further, the Plan only referred to the integration of those TCNs having the status of regular residents, and their families, and who contribute actively in the economic growth of Spain. In fact, while some originally expected that with this Plan the government was going to develop some aspects of immigration policy related to the social inclusion of TCNs, this was not the case. ${ }^{712}$ The Plan lacked a clear approach and any concrete proposals for making this happen. It was also not accompanied by the necessary financial framework to be put into practice.

As de Lucas (2001) has argued, the general policy advocated by the PP Government on immigration followed the model of 'the good immigrant': a certain type of TCN who would be welcomed in order to meet the economic needs or gaps deemed to exist in the Spanish labour market and who would be 'easily assimilable or integrable' from a cultural point of view according to stereotypes mostly of ethnic nature of who belongs or not to a culture similar to

707 J. de Lucas (1999), ¿Qué Politicas de Inmigración? Reflexiones al Hilo de la Reforma de la Ley de Extranjeria en España', Tiempo de $P a z, N^{\circ} 55$.

708 J. de Lucas (2002), 'Política de Inmigración: 30 Propuestas', Claves de Razón Práctica, No 121, Abril 2002, pp. 32-36.

Resolución de 17 de abril de 2001, de la Delegación del Gobiemo para la Extranjería y la Inmigración, por la que se dispone la publicación del Acuerdo del Consejo de Ministros del dia 30 de marzo de 2001, por el que se aprueba el Programa Global de Regulación y Coordinación de la Extranjería y la Inmigración, BOE $\mathrm{N}^{\circ} 101,27$ April 2001.

C. Blanco Fernández de Valderrama (2001), 'La Integración de los Inmigrantes. Fundamentos para Abordar una Política Global de Intervención', Revista Migraciones, 10(2001), pp. 207-248.

712 M. Pajares (2006), "Las Politicas Locales en el Ámbito de la Inmigración", en E. Aja y J. Arango (coord.), Veinte Años de Immigración en España: Perspectivas Juridica y Sociológica (1985 - 2004), Fundació Cidob: Barcelona, Spain, pp. 369-393; M. Pajares (2004), Inmigración y políticas de integración social. Fundación Altemativas: Madrid. 
'ours'. 713 As a way of illustration, de Lucas makes reference to three examples substantiating this criticism: ${ }^{714}$

First, the GRECO Plan expressly referred to the difficulties for 'certain immigrants' to adapt to the values of human rights because of 'the culture' to which they belong. In particular, when referring to the general framework of societal coexistence, the Plan made reference to the Spanish Constitution and Laws as the guiding principles, and to the effort to respect them as the basis of a democratic society (guided by respect, tolerance and equality), whose level of effort for their compliance would depend on 'the cultural roots' of the TCNs in question.

Second, Article 3.2 of Law 8/2000 stipulated that the rules relating to the fundamental rights of TCNs would be interpreted according to the Universal Declaration of Human Rights and to International Treaties in force in Spain, without the possibility for the person involved to allege any religious belief or ideological or cultural conviction in order to justify the acts or behaviours being held against them. ${ }^{716}$ Furthermore, Article 47 of Chapter IV of Law 8/2000 exempted from the administrative fee for granting any administrative authorisation and expedition of permits, and particularly those related to the exercise of economic activities in Spain, nationals from South America, Filipinas, Andorra and Guinea Equatorial, as well as sefardies, descendants (until the third generation) of native Spanish nationals and foreigners bom inside Spanish territory. $^{717}$

Finally, as regards Royal Decree $864 / 2001,{ }^{718}$ Article 13.2 foresaw that among the requirements for having access to a visa the Diplomatic Mission or Consular Office could carry out a personal interview with the applicant for the purposes of proving her/his identity, the validity of personal documentation, the regularity of residence in the country from where the application has been made, and other circumstances of the applicant him/herself, especially those related to the economic, professional and academic dimensions. ${ }^{719}$

All these examples shed light on the argument of de Lucas, according to which the official vision promulgated by the PP followed a rationale which appeared to require a kind of integration following a pattem of acculturation of TCNs into the model of the ideal immigrant and what we would call the perfect Spanish citizen. Moreover, the Aznar government enacted other series of legislative initiatives in the areas of nationality and immigration which generally showed the resistance of the Spanish authorities to acknowledge the need to provide a proper legal framework offering some answers to the social realities, and which included immigration

71.3 A. Zlobina, N. Basabe and D. Páez (2004), 'Adaptación de los Inmigrantes Extranjeros en España: Superando el Choque Cultural', Revista Migraciones, 15, pp. 43-84.

714 J. de Lucas (2001), "Una Oportunidad Perdida para la Política de Inmigración: "La contrarreforma" de la Ley 8/2000 en España", en J. de Lucas, S. Peña y A. Solanes (coords.), Immigrantes: Una Aproximación Juridica a sus Derechos, Germania: Valencia, pp. 33-56.

716

717

718

719

Article 3.2 .

Article 47.

Real Decreto 864/2001, 20 de Julio, por el que se aprueba el Reglamento de ejecución de la Ley Orgánica $4 / 2000$, de 11 de enero, sobre derechos y libertades de los extranjeros en España y su integración social, reformada por Ley Orgánica 8/2000, de 22 de diciembre, BOE No 174, 21 Julio 2001.

Article 13.2 of the Decree states that "La Mision Diplomática "Oficina Consular podra requerir la comparecencia personal del solicitante y, cuando se estime necesario, mantener ana entrevista personal. con el fin de comprobar: La identidad del solicitante, la validez de la documentación personal o de la documentación aportada la regularidad de la residencia en el pais de la solicitud, y otras circunstancias del solicitante, en especial las economicas, académicas o profesionales". 
and diversity as two of their main elements. Instead, as we will see below, their focus was mainly centred on the continuation of an archaic vision of the law on nationality and the adoption of restrictive immigration legislation driven by the obsession of control as the most plausible solution. The following three laws may be highlighted:

First, Law 36/2002 modifying the Civil Code in the field of nationality of 9 October $2002 .^{720}$ This Law represented a not very ambitious reform, missing the opportunity to revise and liberalise Spanish law on nationality. ${ }^{721}$ The latter continued to be, on the one hand, fragmented as regards the main rules covering this area and to perpetuate their dispersion across a set of obscure and complex legislative texts, and, on the other, partial due to the ongoing lack of provisions addressing the situation of those TCNs settled in Spain and who continued to face multiple difficulties to have access to Spanish nationality. In fact, Law 36/2002 only focused on promoting the recovery of Spanish nationality by the emigrant population ${ }^{722}$ and facilitating its acquisition by their descendants. ${ }^{723}$ However, it left aside any possible amendment facilitating, for instance, the conditions for naturalisation. ${ }^{724}$

Second, the PP adopted a new Law 11/2003 entitled "on concrete measures dealing with citizen security, domestic violence and the social integration of immigrants". ${ }^{25}$ This Law was also subject to various criticisms because of its restrictive nature by focusing mainly on reinforcing the rights of citizens and criminalising the phenomenon of immigration. The measure placed in the same basket the dimensions of citizens' security, domestic violence and "the social integration of immigrants". ${ }^{726}$ In particular, and "based on the accumulated experience gained by

220 Ley 36/2002, de 8 de octubre, de modificación del Código Civil en materia de nacionalidad, BOE $N^{\circ}$ 242, 9 Octubre 2002. Previously the Civil Code had been amended by the following Laws: 18/1990, $15 / 1993$ y $29 / 1995$.

221 E. Cano Bagaza (2005), "La Ley 36/2002, de 8 de Octubre, de modificación del Código Civil en Materia de Nacionalidad', en M. D. Adam Muñoz y I. Blázquez Rodriguez (coord.), Nacionalidad. Extranjeria y' Ciudadania de la Unión Europea, Editorial Colex: Madrid, pp. 11-24.

In particular the new Law revised Article 24.1 and 24.3 of the Civil Code, which deal with the lost of the Spanish nationality.

E. Sagarra Trias, "Modificación de la regulación de nacionalidad española en el Código Civil", Real e Ihistre Colegio de Abogados de Zaragoza, retriavable from www.reicaz.es

Among the initiatives that had been presented for the revision of the Spanish Civil Code by IU and the PSOE, apart from that elaborated by the Government of the Partido Popular, proposed for instance the need to promote the acquisition of the Spanish nationality by ius soli for those born in Spanish territory and the parents are not Spanish nationals when at least one of the progenitors would have habitual residence in Spain. They also called for the reduction of the time period of legal residence for the acquisition of nationality by residence, especially that of ten years and the one of five years. None of these initiatives were taken on board by the Government. See Proposición de Ley de modificación del Código Civil en material de nacionalidad presentada por el Grupo Parlamentario Federal de lzquierda Unida, BOCG, Congreso de los Diputados, VI Legislatura, Serie B, 7 diciembre 1998, $\mathrm{N}^{\circ} 261-1$, and the Proposición de Ley de modificación del Código Civil en materia de nacionalidad presentada por el Grupo Socialista del Congreso, BOCG, Congreso de los Diputados VI Legislatura, Serie B, 22 febrero de $1999, N^{*} 278-1$.

Ley Orgánica 11/2003, de 29 de septiembre, de medidas concretas en materia de seguridad ciudadana, violencia doméstica e integración social de los extranjeros, BOE $N^{\circ} 234,30$ Septiembre 2003. This Law was a follow up of a Plan for the fight against criminality (Plan de Lucha contra la Delincuencia) that had been presented by the Government in December 2002.

P. Laurenzo Copello (2004), 'Ultimas Reformas en el Derecho Penal de los Extranjeros: Un Nuevo Paso en la Política de Exclusión', Jueces para la Democracia, No. 50, pp. 30-35. 
Spain as a country of immigration", Law 11/2003 foresaw the following amendments: the penalty for immigrants who are 'illegal residents' and have committed a crime will be expulsion from the Spanish territory, and the increase of the criminalisation of facilitating human trafficking and smuggling. ${ }^{728}$ As to the way in which this Law dealt with integration, the following two issues were covered: On the one hand, it identified the existence of criminality emerging from "cultural or religious practices" which are contrary to the Spanish legal system, and hence proposed the penalisation of genital mutilation or "ablacion"; on the other hand, it called for the need to adapt civil institutions to the "new cultures" present in Spain, and therefore proposed the amendment of the Civil Code and the rules applicable to divorce and separation to protect women. $^{729}$

Third, another contested initiative was Law $14 / 2003,{ }^{730}$ which modified not only a number of provisions of the LODYLE but also other measures, such as the Law providing the Bases for the Local Administrative Regime. ${ }^{731}$ It amended the regulation on the municipal registry of population and transformed it into a security instrument by allowing the police to have direct access (without the consent of the person involved) to all dossiers and data stored in the municipal registries of population for purposes of control related to the stay of TCNs.

\subsubsection{The 2004 and 2008 National Elections}

In March 2004 the Socialist Party (PSOE) led by Zapatero rather unexpectedly won the national elections after the events of 11 March in Madrid. The sudden change of government involved not only a profound transformation as regards the nature and functioning of national politics, but also a change in the policy paradigm of the phenomena of immigration and social inclusion in the country. The paradigm materialised in an official attempt to implement a more social approach in immigration policy. The government adopted on 30 December 2004 a new Royal Decree 2392/2004 amending the LODYLE. ${ }^{732}$ This legislative reform was the result of negotiations and open dialogue with other parliamentary groups, as well as with social partners

728 New version of Articles 318 and 318 bis of the Spanish Penal Code, which now foresee penalties between four and eight years of imprisonment.

In particular, it proposed the reform of Article 103 of the Civil Code.

730 Ley Orgánica 14/2003, de 20 de noviembre, de Reforma de la Ley orgánica 4/2000, de 11 de enero, sobre derechos y libertades de los extranjeros en Espana y su integración social, modificada por la Ley Orgánica 8/2000, de 22 de diciembre; de la Ley 7/1985, de 2 de abril, Reguladora de las Bases del Régimen Local; de la Ley 30/1992, de 26 de noviembre, de Régimen Juridico de las Administraciones Públicas y del Procedimiento Administrativo Común, y de la Ley $3 / 1991$, de 10 de enero, de Competencia Desleal.

731 Ley 7/1985, de 2 de abril, Reguladora de las Bases del Régimen Local by adding a new "Disposición adicional Séptima".

732 Real Decreto 2393/2004, de 30 de diciembre del 2004, por el que se aprueba el Reglamento de ejecución de la Ley Orgánica 4/2000, sobre derechos y libertades de los extranjeros en España y su integración social, BOE, 7 de Enero 2005. For an analysis of the Royal Decree see C. Vidal Fueyo (2006), 'Luces y Sombras del Vigente Reglamento de Extranjeria", en M. Aparicio, M. Illamola Dausà, D. Moya Malapeira y S. Rodera Ranz (coord.), Las Fronteras de la Ciudadania en España y en la Unión Europea, Actas del Il y 11 I Encuentro de Jóvenes Investigadores en Derecho de Inmigración y Asilo, Documenta Universitaria, Edicions a Petició: Barcelona, pp. 89-100. 
(trade unions and employers' organisations) ${ }^{733}$ and civil society, something which constituted a rather exceptional feature in the processes of policy formation in the Spanish legal system. ${ }^{734}$

Among the most important innovations introduced by this Decree we may highlight the transfer of the dossier of immigration from the Ministry of Interior to the Ministry of Labour and Social Affairs. This symbolic transfer constituted a clear message as regards the governmental perspective in relation to immigration-related matters in contrast with previous approaches. Further, the reform focused on reducing the numbers of irregular immigrants in the country through a series of measures aiming at improving the Spanish policy on regular and labour immigration. ${ }^{735}$ Further, Decree 2392/2004 carried out an "exceptional measure" consisting of a new process of normalisation aiming at the regularisation of immigrant workers under irregular status of residence who were already working in Spain in the black-market economy. ${ }^{736}$ It also intended to provide a more favourable regulation of the so-called ordinary regularisation through the expansion of a legal concept which is now characteristic of the Spanish legal regime and has been denominated as "arraigo". This legal construct means a special sort of social or labour settlement which will be taken into consideration for granting on exceptional occasions an authorisation of residence to an immigrant regardless of his/her legal status. In addition, the former Ministry of Labour and Social Affaires adopted in February 2007 a Strategic Plan on Integration and Citizenship 2007-2010 which for the first time in Spanish history intends to play a role at times of offering a nation-wide policy framework on this policy area.

The national elections of 9 March 2008 gave another victory to Zapatero. ${ }^{737}$ The domain of immigration was placed among one the key policy priorities in the new legislature. Differently from previous policy strategies and official discourse, a clear preference has been now conferred to a kind of immigration linked mainly with 'employment', and more particularly one matching with the perceived "labour market needs in Spain". ${ }^{738}$ The policy linkage between immigration and employment has most prominently materialized in the establishment of a new Ministry of Employment and Immigration (Ministerio de Trabajo e Immigración), under the direction of Celestino Corbacho. ${ }^{739}$

733 Informe sobre la Audición 'Inmigración e Integración: El Papel y las Iniciativas de los Interlocutores Sociales y la Sociedad Civil Organizada', organizada por el Comité Económico y Social Europeo (CESE), en colaboración con la Organización Intemacional del Trabajo (OIT) y la Fundación Europea para la Mejora de las Condiciones de Vida y de Trabajo, en Dublin los dias 22 \& 23 de Junio del 2006.

P. Santolaya (2005), "España", en E. Aja y L. Diez (coord.), La Regulación de la Inmigración en Europa, Colección de Estudios Sociales Núm. 17, Obra Social, Fundación "La Caixa": Barcelona, pp. 242-274; A. Balch (2005), "Spain", in J. Niessen and Y. Schibel, Immigration as a Laborr Market Strategy - European and North American Perspectives, Migration Policy Group: Brussels.

For an analysis see J. Arango y R. Sandell (2004), Immigracion: Prioridades para una Nueva Politica Española, Informes Elcano, Real Instituto Elcano, Madrid; S. Carrera, (2006), Legal Migration Law and Policy Trends in a Selection of Member States, Briefing Paper prepared for the European Parliament, Policy Unit, Citizens Rights and Constitutional Affairs, Brussels.

J. Apap and S. Carrera (2005), Spain's new regularization procedure: Is this the way forward? CEPS Commentary, Centre for European Policy Studies: CEPS, Brussels, February 2005; J. Arango y R. Sandell (2004), Inmigración: Prioridades para una Nueva Politica Española, Informes Elcano, Real Instituto Elcano: Madrid.

For an overview of the results see www.elpais.com/especial/elecciones-generales

738 Refer PSOE, Programa Electoral, Elecciones Generales 2008, Motivos para Crecer, pp 37-41, available at www.psoe.es

739 For a description of the new structure composing the Ministry, and the Secretaria de Estado de Immigración y Emigración, see Real Decreto $1129 / 2008$ por el que se desarrolla la estructura orgánica básica del Ministerio de Trabajo e Inmigración y se modifica el Real Decreto 438/2008 del 14 abril, por 
This has been accompanied with a change in the discourse which, perhaps due to the critical economic difficulties that the country appears to be facing, now focuses most prominently on intiatives prioritizing the return of TCNs, restricting the conditions of family reunification and practising a selective labour immigration policy. ${ }^{740}$ As regards the category of integration, the Minister emphasized in a speech delivered in the Spanish Congress the 22 July 2008 that the latter constitutes one of "the most important challenges facing the Spanish society" and which required "an effort from the natives and the foreigners". "71 He called for a "renewed political impulse" in all the aspects related to integration policies, and expressly referred to the Strategic Plan on Integration and Citizenship 2007-2010 and an upcoming legislative proposal ensuring the political participation of TCNs in the national elections.

\section{Integration in the Legal Framework on Nationality and Regular Immigration}

This section studies the nomativity of integration within the Spanish law on nationality and regular immigration. It first addresses the ways in which the rules on nationality utilise integration as a naturalisation requirement. It then moves into the analysis of the intersection between the law on regular immigation and integration. After looking at the few instances where the latter expressly appears inside the latest version of the Law 4/2000 on the Rights and Liberties of Immigrants and their Social Integration, we shall examine its nature, features and principles as promulgated by the Strategic Plan on Integration and Citizenship of 2007. Finally, this section shall study the Integral Plans of Immigration developed by the AACC.

\subsection{The Law on Nationality: Integration as Condition for Naturalisation}

The legal regime on nationality provides one of the most prominent venues where the normative functions of integration display their full effects in Spanish law. The rules dealing with the acquisition of nationality offer one of the most important instances where integration acts as a juridical condition for TCNs applying for naturalisation by residence. What are the precise provisions embracing this particular functionality of integration? What are the administrative procedures putting it into practice, and the ways in which the condition of "sufficient integration into the Spanish society" is being examined and applied?

Nationality law in Spain is characterised by its fragmentation and dispersion. There is not a unique law providing the whole set of rules applying in this area. ${ }^{742}$ The following group of sources comprise the actual normative framework on nationality: The Constitution of 1978 (Article 11), the Civil Code of 1889 (Articles 15-26), the Law of Civil Registry of 1957 (Articles

el que se aprueba la estructura básica de los departamentos ministeriales, 4 Julio 2008, BOE Núm. 165, pp. 29969-29979.

El Pais, Cambio de Rumbo en la Politica de Inmigración - El Gobierno ofrecera incentivos para repatriar a un millón de inmigrantes, 15.6.2008; Also, El Pais, Trabajo endurecerá la Reagrupamiento Familiar: Corbacho quiere fienar la llegada de padres y swegros, 15.6.1008. Both press articles are retrievable from www.elpais.es

741 Gobierno de España, Ministerio de Trabajo e Inmigración, Comparecencia del Ministro de Trabajo e Inmigración, Sr. Celestino Corbacho Chaves, I Parte, La Politica de Inmigración del Gobierno, Comisión de Trabajo e Inmigración, Congreso de los Diputados, 22 Julio 2008, Madrid.

For a historical overview of the evolution of the Spanish law on nationality and the resistance that there has been in unifying all the legal provisions composing it into one law see F. J. Moreno Fuentes (1999), 'La Migration et le Droit de la Nationalité Espagnole', P. Weil et R. Hansen (dir.), Nationalité et Citoyemeté en Europe, La Decouverte: Paris, pp. 117-144. 
$1,2,15,16,18,63$ and 67) and the Decree approving the Regulation of the Law on Civil Registry of 1958 (Articles 220-224), ${ }^{743}$ resolutions of the General Directorate of the Registries and Notary (La Dirección General de los Registros y del Notariado, DGRN), intemational treaties (Conventions of Double Nationality) as well as the case law of the Spanish Supreme Court and other national tribunals, such as La Audencia Nacional. Another feature is the possibility to acquire the status of national following a criterion based on the regular residence by the applicant during a period of time. This constitutes one of the more important paths for TCNs to acquire Spanish nationality. ${ }^{744}$ According to statistical data provided by the Ministry of Justice and the former Ministry of Employment and Social Affairs, the number of acquisitions of Spanish nationality by residence has increased in recent years, and reached a total of 62.339 in 2006.

Table 1: Acquisitions of Spanish nationality by Residence

\begin{tabular}{|c|c|c|c|c|c|c|c|}
\hline 1999 & $\mathbf{2 0 0 0}$ & $\mathbf{2 0 0 1}$ & $\mathbf{2 0 0 2}$ & $\mathbf{2 0 0 3}$ & $\mathbf{2 0 0 4}$ & $\mathbf{2 0 0 5}$ & $\mathbf{2 0 0 6}$ \\
\hline 16,373 & 11,996 & 16,735 & 21,805 & 26,555 & 38,335 & 42,829 & 62.339 \\
\hline
\end{tabular}

Sources: Ministerio de Justicia ${ }^{745}$ and Anuario Estadístico de Inmigración ${ }^{746}$

Article 22 of the Civil Code deals with the acquisition of nationality based on residence criteria, and establishes a number of additional requirements for it to take effect. The conditions mainly relate to the length and nature of residence (residence factor), and with "the sufficiency of the level of integration of the applicant in Spanish society" (integration factor). As regards the residence factor, as a general rule the time-period of residence necessary for the acquisition of nationality is ten years. There are, however, a number of exceptions applying to this rule, which may be summarised as follows: First, the period of residence will be reduced to five years for those who have been granted asylum, or who have obtained the status of refugee. Second, a period of two years will be applicable to those holding the nationality of the following countries: South America, Andorra, Philippines, Guinea Equatorial and Portugal, or those considered to be Sephardic Jews (commidad sefardita). ${ }^{747}$ Nationals from Brazil and Puerto Rico will also

${ }^{743}$ Decreto por el que se aprueba el Reglamento de la Ley de Registro Civil, 14 noviember 1958, BOE $N^{\circ}$ 296, 11 diciembre 1958.

744 J. Carrascosa (2003), "Sistema Español de Nacionalidad", en F. M. Marino (dir.), Derecho de Extranjeria, Asilo y Refigio, Ministerio de Trabajo y Asuntos Sociales, Secretaría General de Asuntos Sociales, Instituto de Migraciones y Servicios Sociales (IMSERSO): Madrid, pp. 329-414. www.mjusticia.es

746 Ministerio de Trabajo y Asuntos Sociales (2006), Secretaria de Estado de Immigración y Emigración, Observatorio Permanente de la Inmigración, Amario Estadistico de Inmigración, Madrid. Retrievable from http://extranjeros.mtas.es/es/general/DatosEstadisticos_index.html The statistical data provided in this table is avaialable in the 1999-2006 editions of the Anuario.

Concerning the proof of belonging to this community see for instance the Press Release published by the Ministry of Justice on the 6 July 2007, where it was announced the granting by the Council of Ministers, on the proposal by the Ministry of Justice, of the Spanish nationality to a group of 30 members of the "conmmmity of sefardies Jews", 18 of whom had the Turkish and 12 Venezuelan nationality. The note explains that the common factor shared by all of them was that they demonstrated "the exceptional links" with Spain because of their belonging to this community which was reflected in their customs and the maintenance of the Spanish language. See Ministerio de Justicia, Oficina de Prensa, Nota de Prensa, "Concedida la Nacionalidad Española a 30 miembros de la Comunidad de Judios Sefardies", 6 Julio 2007. 
benefit from that exception. ${ }^{748}$ Finally, only one year of residence will be required of those who, according to Article 22.2 of the Civil Code, were: 1. born in Spanish territory; 2. did not exercise the right 10 option; 3. have been under the guardianship or custody of a Spanish citizen or institution during two consecutive years; 4 . have been married during one year with a Spanish citizen at the time of application; 5. are a widow of a Spanish national; or 6. were born outside Spain to parents of Spanish origin.

The exact length of residence in Spanish territory will also be subject to specific conditions. In this respect, Article 22.3 of the Civil Code states that it will need to comply with the following conditions: First, it will only include 'legal residence', and therefore the person submitting the application will need to hold the necessary residence permits; second, it will need to be continuous and immediately previous to the formal application of nationality. ${ }^{749}$ These requirements linked with the length and nature of the residence need to be read along with 'the factor of integration' in Spanish society. Before the 90s, there were already some administrative practices carried out by the Civil Registries, consisting of the verification of the naturalisation applicant's Spanish proficiency. ${ }^{750}$ This was based on Article 221 of the Decree approving the Regulation of the Law on Civil Registry of 1958 which stated that

The Representative, in the file (expediente registral) dealing with the acquisition of nationality by residence, will hear personally the applicant, especially for the purpose of verifying the degree of adaptation to the culture and way of life of the Spanish people. (Emphasis added.) ${ }^{731}$

The Law 18/1990 concerning the reform of the Civil Code in nationality matters introduced 'the conditionality of integration' as a cause for rejecting the acquisition of Spanish nationality. ${ }^{752}$ It added a new paragraph 4 to Article 22 of the Civil Code which now reads as follows:

The applicants will need to justify, in the file regulated by the legislation of the Civil Registry, good civic conduct and a sufficient degree of integration in Spanish society. (Emphasis added.) ${ }^{753}$

In light of this, the Law transformed the previous informal administrative practices to the status of Law. By doing so, it institutionalised for the first time in Spanish legal history a link between residence and integration for any TCN to become a Spanish national. The nature and length of residence were considered insufficient measures of citizenship eligibility. The TCN would in addition need to show that s/he had lost "sufficiently" her/his difference in favour of a particular

748 Resolution of the Direccion General de los Registros y del Notariado, 31 January 1973.

749 For a study of the interpretation that has been given by the various rulings of the Spanish Superior Tribunal (Tribunal Supremo) to the 'continuous' and 'immediatly previous' nature of residence, see Ministerio de Trabajo y Asuntos Sociales, La Nacionalidad Española: Análisis de la Normativa Vigente, Subdirección General de Publicaciones: Madrid, Chapter IV on "Adquisición de la Nacionalidad Espanola", pp. 87-113. The nulings have allowed for sporadical absences from the country based on labour or study purposes.

750 Instrucción de la DGRN sobre certificado de nacionalidad española, IDGRN de 14 de abril 1999, BOE del 30 abril 1999. See also Instrucción de 28 de febrero de 2006 de la DGRN sobre competencia de los registros municipales en materia de adquisición de nacionalidad española y adopciones internacionales, BOE N $N^{\circ} 71,24$ marzo 2006 .

751 Article 221 of the Decree reads as follows: "El Encargado, en el expediente de concesion de la nacionalidad por residencia, oira personalmente al peticionario, especialmente para comprobar el grado adaptación a la culnura y' estilo de vida españoles".

752 Ley núm. 18/1990, sobre reforma del Código Civil en materia de nacionalidad. BOE, 18.12.1990, n. 302, pp. 37587-37589.

Article 22.4 stipulates that "El interesado deberá justificar, en el expediente regulado por la legislación del Registro Civil, buena conducta civica y suficiente grado de integración en la sociedad española". 
conception of Spanish society. This new legal setting was complemented by another administrative instrument taking the form of an Instruction of the General Directorate of the Registries and the Notary (DGRN) of 20 March 1991, ${ }^{754}$ which acknowledged the importance that "the condition of integration" had acquired in the evaluation processes of the naturalisation procedure. ${ }^{755}$ Following the spirit of the 1990 reform, the Instruction prescribed the need for the Representative/Judge of the Civil Registry to be particularly vigilant at times of the evaluation, by carrying out a personal meeting or interview with the applicant where her/his degree of integration in Spanish society would be duly examined.

This has been complemented by another Instruction of 26 July 2007 of the DGRN dealing with the handling of applications being submitted for the acquisition of Spanish nationality by residence, ${ }^{758}$ which confers on the personal hearing between the applicant and the public Representative a special relevance by considering it to be "the essential and only method to verify the compliance with the integration requirement". The Instruction also explains that the Representative of the Civil Registry will verify and state in the file of the applicant her/his degree of integration as judged by "direct and personal observation" during the personal interview. Furthermore, Article 221 of the Decree approving the Regulation of the Law on Civil Registry of 1958 provides the possibility for the Representative to hold an additional interview separately with the wife or husband of the applicant for naturalisation to ascertain the circumstances and reasons underlying the change of nationality by her/his spouse.

While the requirements related to residence included in Article 22 may be evaluated without major difficulties according to the interpretation provided by the relevant tribunals, a number of questions can be raised concerning the way in which the conditions foreseen in paragraph 4 are evaluated in practice. The phrase "sufficiently integrated into the Spanish society" belongs to

754 Instrucción de la DGRN de 20 de Marzo de 1991, BOE, n. 73 de 26.3.1991, apartado V stated that "En este expediente el Encargado debe extremar su cello para comprobar, oyendo personalmente al peticionario, su grado de integración en la sociedad española". See A. Álvarez Rodriguez (2005), 'La interpretación de la Dirección General de los Registros y del Notariado en materia de nacionalidad: recensión y comentario de las decisiones dictadas de enero a octubre de 2005', Revista de derecho migratorio y extranjeria, ISSN 1695-3509, No. 10, 2005, pp. 213-233.

In particular the Instruction stated that "Especialmente debe destacarse en orden a esta ramitacion que, segin resulta de la letra del articulo 21.2 del Código. la concesion por residencia ha de obtenerse "en las condiciones que señala el anticulo siguienes y entre ellas se cuenta la de que uel interesado debera justificar, en el expediente regulado por la legislacion del Registro Civil, buena conducta civica y suficiente grado de imegración en la sociedad españolas (articulo 22.4 del Cádigo Civil). Por consiguiene. el Ministro de Justicia podra denega la concesión no sólo upor motivos razonados de orden priblico o interés nacional», sino por la ansencia de los requisitos expresados, o por la falta de cualquiera de los demás que detalla el articulo 22. De aqui se dedice que ha cobrado una mayor importancia el tramite establecido en el iltimo parrafo del articulo 221 del Reglamento, es decir; la obligacion del Encargado de oir personalmente al peticionario, "especialmente para comprobar el grado de adaphación a la culnura y estilo de vida españoles". See J. M. Espinar Vicente (1994), La Nacionalidad y la Extranjeria en el Sistema Juridico Español: Tratados y Manuales, Civitas: Madrid, pp. 126-129.

Instrucción de 26 de julio de 2007, de la Dirección General de los Registros y del Notariado, sobre tramitación de las solicitudes de adquisición de la nacionalidad española por residencia, BOE n.189, 8.8.2007.

759 Ruling of the Audiencia Nacional (Sección 3, Sala de lo Contecioso-Administrativo) of 6 April 2004 (2004/248095). 
what has been qualified as an 'indeterminate juridical concept', which requires an adequate caseby-case interpretation by the administrative and judicial authorities in relation to the circumstances present in each particular case. ${ }^{759}$ The indeterminate or blurred nature leads to a lack of a transparent and precise list of requirements which will need to be met in addition to knowledge of Spanish language. This leads to broad discretional power on the part of the Representative of the Civil Registry where the person has her/his domicile. The Representative will be in charge of evaluating and delivering the positive or negative resolution to the Ministry of Justice, which will be the last instance for confirming the decision about the granting or rejection of naturalisation. 760

In which way is "the sufficiency" of the degree of integration into Spanish society being tested? What are the most relevant criteria being used for this purpose? And what has been its judicial interpretation? The condition of integration into Spanish society consists mainly of an evaluation of the applicant's Spanish proficiency. The Superior Tribunal has rejected the acquisition of Spanish nationality in various cases on the basis of a lack of knowledge and sufficient proficiency in Spanish by the applicant. ${ }^{761}$ As a way of illustration, in a ruling of 29 October $2004,{ }^{762}$ a Moroccan national residing regularly in Melilla since 1989, and who was a widow of a Spanish national and had five sons holding Spanish nationality, asked for the acquisition of Spanish nationality on the basis of Article 22.2.e of the Civil Code which allows widows of Spanish nationals to acquire Spanish nationality after one year of residence in Spain. ${ }^{763}$ The delegation of the Spanish government in Melilla rejected the application for naturalisation on the basis that the applicant had not shown "a sufficient degree of integration in Spanish society". This decision was taken even though the report from the Responsible of the Civil Registry (Juez del Registro Civil) had concluded that she was 'sufficiently integrated'. The lack of integration was based on the following: First, she did not speak Spanish well; and, second, she lived in a part of the city of Melilla considered to be prominently Muslim and maintained Muslim customs and traditions. The applicant appealed the negative decision to the Audiencia Nacional which actually confimed the latter based on the very same reasons. ${ }^{764}$ The Superior Tribunal confirmed the negative decision because of her absolute lack of Spanish proficiency, something which in the opinion of the Tribunal would make impossible any minimum contact and relation to 'Spanish society'. 765

This line of reasoning was later confirmed by another ruling of 9 April 2007, ${ }^{766}$ where the Superior Tribunal stated that even though the applicant had been residing in Spanish territory

760 Articles 220-224 of the Reglament of the Civil Registry (Reg/amento del Registro Civil) deal with the main rules applicable to the Representative of the Civil Registry (Encargado del Registro Civil).

See for instante the following rulings of the Audiencia Nacional: Sala de lo Contencioso-Administrativo, Sección 4, 4 enero 1999 (RAJC, 1999, núm. 3421; Sala de lo Contencioso-Administrativo, Sección 4, de 19 enero 2000 (inédita); Sala de lo Contencioso-Administrativo, Sección 4, 22 noviembre 2000 (inédita); Sala de lo Contencioso-Administrativo, Sección 4, de 23 diciembre 2002 (JUR, 2003/26371).

Tribunal Supremo, Sala Tercera, Sección 6, 29 Octubre 2004, Recurso de Casación: 7900/2000. Article 22.2.e of the Civil Code.

764 Sala de lo Contencioso-Administrativo, Sección 4, de 9 diciembre 1999, JUR recurso 1029/1998.

The Tribunal added that "sus costumbres son musulmanas, lo que tiene una total incardinacion en mestro ordenamiento Constitucional, como se ha dicho, sin embargo no se ha acreditado su imtegración en la sociedad española; circunstancia que sin duda alguna se desprende de su absoluto desconocimiento del castellano, lo que se raduce en la imposibilidad de tener una relación minima con la sociedad".

Tribunal Supremo, Sala Tercera, Sección 6, 9 April 2007, Recurso de Casación: 279/2003. 
during a long period of time, and both husband and sons had Spanish nationality, her 'integration in Spanish society' was not satisfactory because of insufficient knowledge of Spanish, which, in its opinion, constitutes "the main path of communication and social integration, and significantly limits her inclusion in other societal and economic sectors". Further, the Tribunal concluded that the denegation of the acquisition of Spanish nationality was well founded taking into account her lack of knowledge of Spanish, and not so much to the fact that she could not read or write it correctly.

Therefore, the predominant case law concerning the examination of the degree of integration seems to grant considerable importance to the language capacities of the person asking for the acquisition of nationality. The fact that the person has been residing regularly and continuously in Spanish territory and that spouse and sons/daughters already hold Spanish nationality are considered to be insufficient signs of integration. This, in our view, is critical. It is difficult to sustain that someone who resided in Spain for many years, bcing a widow or wife/husband of a Spanish national and having Spanish sons and daughters does not meet a "sufficient degree of integration into the Spanish society", even though her/his level of Spanish might not be adequate.

In addition to the importance granted to the Spanish language, the test also requires the integration into a wider set of 'cultural and social values' which are supposed to predominate in 'mainstream Spanish society'. ${ }^{768}$ The relevance of these cultural and social dimensions has been confirmed by the above-mentioned Instruction of 26 July 2007, which declared the approximation between the concept of integration and that of "the adaptation to the culture and way of life of Spanish people". The same Instruction requires a reference in the application for Spanish nationality by residence to the circumstances provided by Article 220.5 of the Decree approving the Regulation of the Law on Civil Registry of 1958. This provision foresees the possibility to verify the extent to which

...the candidate speaks Castilian or other Spanish language, as well as other circumstance of adaptation to the Spanish culture and way of life such as studies, social and charitable activities, as well as other elements which s/he may consider necessary. (Emphasis added.)

In light of this, the actual degree of integration in Spanish society appears to be equivalent to the requirement of 'acculturation' by the TCN into a particular conception of Spanish culture and way of life. At times, the level of sufficiency has been proved by showing evidence of a lack of an administrative or criminal record, stable employment, sufficient means of subsistence, etc. ${ }^{770}$ The Superior Tribunal has also rejected the acquisition of the Spanish nationality on the basis of

768 Inter alia see the following judgments: Sala de lo Contencioso-Administrativo, Sección 3, 25 octubre 2001 (JUR, 2002/10008); Sala de lo Contencioso-Administrativo, Sección 3, 19 noviembre 2002. Recurso 264/2001 (JUR, 2003/25888; Sala de lo Contencioso-Administrativo, Sección 3, 19 noviembre 2002. Recurso 414/2001 (JUR, 2003/25891).

770 E. Rubio Torrano (2004), 'La Buena Conducta Civica en La Adquisición de la Nacionalidad Española', Aranzadi Civil, Sección Tribuna, Núm. 1/2004, pp. 1-3. 
polygamy. ${ }^{771}$ The latter has been considered to be contrary to public order and therefore constituting evidence of a lack of 'sufficient degree of integration by the applicant. The economic status of the applicant might also play a role in considering whether s/he is integrated. This has been confimed by Guzmán Peces (2005), who after studying a number of judgements from various Spanish jurisdictions dealing with the requirement of integration for naturalisation by residence, ${ }^{773}$ has identified in a majority of them the use of a similar legal argumentation following this line of reasoning:

... Integration does not only derive from the degree of proficiency of the language, but also from the harmonisation of the way of life of the applicant with the social principles and values, which partly come from the Constitutional legal regime, as well as the degree of implication in the economic, cultural and social relations, as well as the family life, all of which will need to be proved by the applicant... ${ }^{774}$

It can therefore be concluded that in order to test the "sufficient degree of integration in Spanish society" stipulated by Article 22.4 of the Civil Code the following items will be taken into account: a working knowledge and proficiency of the language, the adaptation of the applicant to the "Spanish social and culture principles, values and way of life", other economic considerations such as proving stable employment status and sufficient means of subsistence as well as family life in the Spanish territory. What are the mechanisms that the Representative of the Civil Registry is going to use to evaluate whether an applicant for naturalisation by residence is sufficiently integrated into "Spanish social and cultural principles, values and way of life"? There are no further details provided by law in this regard. This remains an overly subjective requirement which is going to be examined following the state of mind and perceptions of the public authority on what it means to be Spanish, which may include, for instance, issues such as knowing who won the Spanish football league the previous year, knowledge of Spanish history, being able to list the names of the members of the royal family or government, etc. Apart from the serious doubts as to whether every Spanish citizen would satisfactorily pass an examination of this kind, the legal uncertainty and lack of proportionality that this sort of administrative practices might entail leaves the individual in an unacceptable insecure position in relation to public authorities and the State.

771 Tribunal Supremo, Sala Tercera, Sección 6, 19 Junio 2008, Recurso de Casación: 6358/2002.

773 M. Guzmán Peces (2005), "La Integración en la Adquisición de la Nacionalidad Española por Residencia: Comentario de la Sentencia de 29 de Octubre de 2004 del Tribunal Supremo", en M. D. Adam Muñoz y I. Blázquez Rodriguez (coord.), Nacionalidad, Extranjeria y Ciudadania de la Unión Europea, Editorial Colex: Madrid, pp. 41-50. She highlights the following nulings: Sentencia de la Audiencia Nacional (Sala de lo Contencioso-Administrativo) de 28 octubre 2003, JUR 2004/131624; Sentencia de la Audiencia Nacional (Sala de lo Contencioso-Administrativo) de 15 enero 2002, JUR 2003/58266; Sentencia de la Audiencia Nacional (Sala de lo Contencioso-Administrativo) de 31 octubre de 2000, JUR 2000/312497.

This same paragraph has been confirmed by the Superior Tribunal in the Judgement, Sala Tercera, Sección 6, 9 April 2007, Recurso de Casación: 279/2003. 
The scope of the requirement on "the cultural and social integration" is subject to the limits stipulated by the 1978 Spanish Constitution and its provisions related to human rights. The Superior Tribunal has also interpreted the concept of "sufficient degree of integration in the Spanish society" as contained in Article 22.4 of the Civil Code on some occasions. For instance, in a judgement of 28 May $2004,{ }^{775}$ the Superior Tribunal annulled a negative decision on the acquisition of Spanish nationality by the Ministry of Justice (DGRN) which had found that the applicant, a Moroccan national residing also in Melilla, lived in a Muslim part of the city, maintaining all the Moroccan customs and traditions. The Superior Tribunal held that these traditions referred by the Administration were mainly related to the religion of the applicant and her family, as well as of the majority of the population of Melilla, something which was in compliance with the fundamental right recognised by the Spanish Constitution in Article 16 (freedom of religion). Also, it stated that this should not be taken as a ground for denying the acquisition of Spanish nationality by residence, and hence concluded that nationality should be granted.

\subsection{Immigration Law and Policy: The Social Integration of Immigrants}

Integration was not subject to a national normative framing by the Spanish central state until the begimning of 2007 . While there have been some provisions and specific legal categories presented by Law $4 / 2000$ on the Rights and Liberties of Immigrants, it was not until the adoption of the Strategic Plan of Citizenship and Integration that a nation-wide policy strategy became institutionalised.

\subsubsection{The "Ley de Extranjeria" and Integration}

Apart from the reference in its title and in a few other indirect instances, ${ }^{776}$ Law $4 / 2000$ on the Rights and Liberties of Immigrants and their Social Integration (LODYLE) does not provide a State policy framework on integration, nor is the latter used as a juridical condition for benefiting from any of the rights and having access to administrative statuses foreseen for TCNs. ${ }^{77}$ That notwithstanding, the LODYLE does present an interesting legal category denominated "arraigo" which, even though it is of different nature, does imply a settlement based on a certain 'link' between a TCN and Spain. This close linkage may be of economic,

775 Tribunal Supremo, Sala Tercera, Sección 6, 28 mayo 2004, Recurso de Casación 1230/2000. See also Ministerio de Trabajo y Asuntos Sociales e ilustre Colegio de Abogados de Madrid (2004), 'Tribunal Supremo: Concesión de la Nacionalidad Española a Súbdita de Marruecos que mantiene las Costumbres y Tradiciones Musulmanas", 28 Mayo 2004. J. A. Caballero Gea (2005), Asilo. Extranjeria. Imigración. Homologación de titulos extranjeros. Nacionalidad: Sintesis y Ordenación de la Doctrina de los Tribumales, Dykinson: Madrid, pp. 541-543.

776 Among the references made to integration by the Law we may underline for instance the one presented in Article 9 of the LODYLE which deals with the right to education and that in its paragraph 4 provides the possibility for the public authorities to promote that those third country nationals who are residents may receive education aimed at facilitating their social integration, with the recognition and due respect of their own cultural identity. Article 9.4 also stipulates that "Los poderes publicos promoverán que los extranjeros residentes que lo necesiten puedan recibir una enseñanza para su mejor integración social. con reconocimiento y respeto a su identidad culturat'.

777 For a detailed study on the rights of TCNs in Spain see J. Tajadura Tejada (2004), 'Constitución y Extranjería: Los Derechos de los Extranjeros no Comunitarios en España, Revista de Derecho Migratorio y de Extranjeria, No. 7, pp. 9-52. 
family, social, labour, academic or other nature. ${ }^{778}$ The provision of evidence of the existence of that settlement allows the person involved to have an exceptional authorisation of residence regardless of the regularity of her/his status of residence in the country. ${ }^{779}$ After the adoption by the current government of Royal Decree 2392/2004 amending the LODYLE of 30 December $2004,{ }^{780}$ Article 45 of the latter (Section 3 on "Temporary Residence on Exceptional Circumstances") offers the possibility to grant a temporary authorisation of residence to those persons who, regardless of their administrative status, may be able to prove: ${ }^{781}$

1. "Arraigo laboral" (labour setllement), where the person proves two years permanent residence in Spanish territory and one year of employment; ${ }^{782}$ or

2. "Arraigo social" (social settlement), when s/he can show evidence of three years of continuous residence, a labour contract or a formal offer at the time of the presentation of the application, as well as family links with TCNs who are regular residents. The last requirement on family links might be replaced by a report delivered by the municipality where the person has her/his habitual domicile validating that s/he is "socially inserted" in Spain. 78 ,

3. The descendants of parents of Spanish origin as stipulated in Article 17 of the Civil Code. $^{784}$

The main objective behind this legal category is to grant an alternative path to irregular TCNs to regularise their administrative status of stay in Spain. It is true that, as Diez Bueso has argued (2006), ${ }^{785}$ while these authorisations of residence should facilitate regularising those persons showing a certain economic, social, family and cultural linkage with Spain, the set of requirements provided by the LODYLE are so demanding that it is at times difficult for them to effectively work in practice, especially regarding labour settlement. Statistical data provided by the Spanish Ministry of Labour and Social Affairs shows that a total of 7,427 temporary permits were granted to TCNs based on "arraigo" during 2006. The higher number of authorisations

778 The concept of arraigo has been used by the Superior Tribunal in the following last judgements: STS, Sala de lo Contencioso Administrativo, 20 avril 2007, Recurso 9481/2003; and STS, Sala de to Contencioso Administrativo, 27 diciembre 2006, Recurso 7957/2003. Retrieved from www.poderjudicial.es

See Article 31.4 of the LODYLE.

Real Decreto 2393/2004, de 30 de diciembre del 2004, por el que se aprueba el Reglamento de ejecución de la Ley Orgánica 4/2000, sobre derechos y libertades de los extranjeros en España y su integración social, BOE, 7 de Enero 2005. For an analysis of the Royal Decree see C. Vidal Fueyo (2006), "Luces y Sombras del Vigente Reglamento de Extranjeria", en M. Aparicio, M. Illamola Dausa, D. Moya Malapeira y S. Rodera Ranz (coord.), Las Fronteras de la Ciudadania en España y en la Union Europea, Actas del II y $I 1$ Encuentro de Jóvenes Investigadores en Derecho de Inmigración y Asilo, Documenta Universitaria, Edicions a Petició: Barcelona, pp. 89-100.

Article 45 of the Royal Decree 2393/2004, which bears the tille of "Autorizaciones de Residencia Temporal por Circumstancias Excepcionales".

Article 45.2 of the Decree 2393/2004 amending the LODYLE.

Article 45.2.b.

Article 45.2.c.

L. Diez Bueso (2006), "Veinte Años de Normativa sobre Extranjeria en España: ¿Hacia una Política de Integración?", en J. de Lucas y L. Diez Bueso (coord.), La Integración de los Immigrantes, Centro de Estudios Politicos y Constitucionales, Foro para la Inmigración y la Ciudadania: Madrid. 
was granted under the category of social settlement: $6,619 .^{786}$ The model of social settlement has increasingly become one of the more important mechanisms for the regularisation of the legal status of TCNs who are already in Spain with an irregular status of stay. ${ }^{78}$

As we have mentioned, social settlement includes an express reference to the possibility to substitute the proof of family links with TCNs residents with a report by the municipal authority of the applicant's domicile validating his/her "social insertion" into Spanish society. Therefore, this legal category might be seen as creating a nexus between a form of integration and the acquisition of the exceptional temporary residence permit. Within the context of "arraigo" the criteria of social insertion plays the role of an additional item for irregular TCNs to be allowed to move into a temporary legality. Article 46.2.c of the Royal Decree provides the specific rules which apply to the procedure for granting an authorisation of residence based on social settlement following a report by the municipal authority. According to this provision the report will need to include a verification of the following elements:

...the length of residence of the applicant in her/his domicile, the means of subsistence, the degree of knowledge of the language, the insertion in the social networks of her/his environment, her/his participation in the socio-laboral insertion programmes provided by public or private authorities as well as all other possible elements which may prove the "arraigo"? ${ }^{78}$

Some of the main aspects signalled above conceming the examination of the sufficiency of integration to the Spanish society by an applicant of naturalisation by residence might be also identified here. For instance, in addition to the length of residence, the authorities will take into account language proficiency, social relations and economic considerations of the applicant. It appears that, contrary to the domain of nationality and naturalisation, the irregular TCNs will not be, at least formally, required to show her/his integration into 'the socio-cultural principles and values of Spain'. The temporality inherent to the regular status conferred to the applicant of social settlement might well be the justification upon which this distinction has been made. Also, we need to take into account that the category of social settlement is mainly destined to be an instrument providing a response to the phenomenon of irregular immigration, yet it does use "insertion" as a criterion for granting security of residence to the undocumented TCNs.

\subsubsection{The Strategic Plan of Citizenship and Integration}

The domain of integration was not subject to a nation-wide policy strategy until February 2007 , when the Strategic Plan on Citizenship and Integration 2007-2010 (Plan Estratégico de Ciudadania $e$ Integración) was adopted by the Forum for the Social Integration of Immigrants. ${ }^{789}$ The Strategic Plan aims at providing a general policy framework for the coordination and promotion of actions carried out by the different public administrations, civil society as well as the TCNs and their organisations in Spain. The Plan advocates that

786 Ministerio de Trabajo y Asuntos Sociales (2007), El Gobierno concedió 7.427 autorizaciones de residencia temporal por arraigo, Nota de Prensa, Gabinete de Comunicación, 13 Febrero 2007.

787 E. Ortega Martin (2005), Mamual Practico de Derecho de Extranjeria, Europa de Derecho, Editorial Juridica: Madrid, page 40.

788 According to Article 46.5 of the same Royal Decree, the competent municipal authority may also require the personal attendance of the applicant to a personal interview.

789 Plan Estratégico de Ciudadania e Ltregración, Secretaria de Estado de Inmigración y Emigración, DG de Integración de Inmigrantes, Junio 2006. 
...the governance of the process of integration needs to be one of the key axes for the construction of a society fairer and cohesive, able to generate a feeling of common belonging between all the citizens. (Emphasis added.)

It is an act lacking legally binding effects for the competent public authorities composing the State at its various levels, and therefore might be framed within the status of 'soft-law'. Yet its relevance in terms of policy formulation and general politics on immigration cannot be overemphasised. Under the general direction of the Secretary of State of Immigration and Emigration of the former Ministry of Labour and Social Affaires (now Ministry of Employment and Immigration), the Forum for the Social Integration of Immigrants was in charge of elaborating a first substantive draft of the Strategic Policy Plan, which was published on 21 June 2006. The Forum, which belongs to the General Directorate of the Integration of Immigrants of the Secretary of State of Immigration and Emigration, constitutes a consultation, information and advice body in the field of "the social integration of immigrants" to the Spanish government. $^{791}$ Among other functions, and according to Article 3 of the Royal Decree $3 / 2006,{ }^{792}$ the Forum is competent to elaborate on the request of the State, or in its own initiative, reports, plans or programmes dealing with integration. ${ }^{793}$ The Forum is composed of 30 members, 10 of which represent, respectively: First, public administrations from the State, ${ }^{794}$ Autonomous Communities ${ }^{795}$ and local levels; second, immigrants and refugee associations; and third, social organisations such as the Red Cross, Caritas, trade unions, etc. ${ }^{796}$ The elaboration of the first draft, which was subject to an on-line public consultation process, ${ }^{797}$ involved the active participation of the main stakeholders in the social processes of inclusion of TCNs, such as public administrations (e.g. the AACC), civil society, NGOs, immigrant organisations, social partners, etc.

The Plan starts by delimiting its own concept of integration. In this respect it makes an express reference to the Common Basic Principles for Immigrant Integration Policy (CBPs) adopted by the JHA Council on 19 November $2004 .{ }^{798}$ It alludes to the way in which the CBPs define integration as a dynamic, two-way process of mutual accommodation by all TCNs and residents

791 Foro para la Integración Social de los Inmigrantes (2007), Informe sobre la Situación de la Integración Social de los Immigrantes y Refugiados en 2007, A probado en Pleno Ordinario el 8 Noviembre 2007.

Real Decreto 3/2006, de 16 de Enero, por el que se regula la composición, competencias y régimen de funcionamiento del Foro para la integración social de los inmigrantes, BOE No 14, 17 Enero 2006; See also Ministerio de Trabajo y Asuntos Sociales, Secretaria de Estado de Inmigración y Emigración, Dirección General de Integración de Inmigrantes (2007), Memoria 2006: Foro para la lntegración Social de los Inmigrantes, Madrid. See also Real Decreto 2816/1998, de 23 de Diciembre, por el que se modifica el Real Decreto 490/1995, de 7 de Abril, de creación del Foro para la Integración Social de los Inmigrantes, BOE No 13, 15 Enero 1999.

Other important functions include: the promotion and elaboration of studies about integration of immigrants, cooperate and coordinate action along with the compentent authorities of the different geographical levels of governance (Autonomous Communities and local authorities).

It includes one representative from the following Ministries: Interior, labour and social affairs, education, public administrations, external affairs and cooperation.

Only two Autonomous Communities are represented: Madrid and Cataluña.

Article 4 of the Royal Decree 3/2006.

http://ww.mtas.es/migraciones/Integracion/PlanEstrategico/Indice.htm

Council of the European Union, Justice and Home Affairs Council Meeting $2618^{\text {th }}$, Brussels. 'Common Basic Principles on Immigrants Integration', 14615/04, 19 November 2004. 
of the Member States, and that integration implies respect for "the basic values of the EU", 799 When explaining each of these European conceptual premises, it is interesting to see the way in which the principle dealing with "the respect for the basic values of the EU" (CBP2) is elaborated by the Plan. What are the values of the EU? In this respect, reference is made to Articles $1^{800}$ and $10^{801}$ of the Spanish Constitution of 1978 as the legal provisions providing substance to the expression "basic values of the EU" when moving to the Spanish arena, and which contain references to Spain as a liberal democracy promoting the values of liberty, equality, justice and political pluralism, as well as human rights as provided by international treaties.

Further, two more aspects also coming from the European Framework on Integration are highlighted by the Plan as representing essential elements of the focus that Spanish integration policy needs to follow: i.e. the holistic and proactive approach. The Plan refers in this regard to the Commission Communication on immigration, integration and employment, COM(2003) 336, June 2003. ${ }^{802}$ This Communication, as we have studied in Chapter 3 , had identified the need for a holistic approach on integration that would take into consideration "not only the economic and social aspects of integration, but also issues related to cultural and religious diversity, citizenship, participation and political rights". In light of this, we can see how the conceptual spirit of the Plan follows quite closely the pseudo-definition, or set of common principles, provided by some of the key instruments composing the EU Framework on Integration, and which finds its major achievement in the CBPs. ${ }^{803}$ Therefore, even though the list of basic principles were primarily intended "to assist member states in formulating integration policies for immigrants by offering them a simple non-binding but thoughtful guide of basic principles against which they can judge and assess their own policies", we can see how in the Spanish case they have played an important role in its conceptual premises or understanding of what 'integration' means, as well as in its content, which we now explain in detail.

The Plan is structured on six premises, three principles and ten general goals: ${ }^{804}$ The premises constitute the foundational pillars: first, integration is a two-way process of mutual accommodation (two-way process paradigm); second, the responsibility and management of the integration processes needs to be shared between the different public administrations, social actors, TCNs and their organisations; third, the Plan has been conceived as a general framework of cooperation capable of making more dynamic policies, uniting initiatives and providing coherency to the different actions of the public sector and civil society; fourth, there is a need to adopt a global and integrated focus of both immigration and integration policies (nexus between regular immigration and integration); fifth, it needs to go along with the implementation of

799 The Annex of the Plan lists the CBPS.

800 This article reads as follows: "Spain constitutes a social and democratic liberal State, which promotes as the superior values of its legal system liberty, justice, equality and political pluralism".

sol Article 10.2 states that: "The rules conceming fundamental rights and freedoms recoginized by the Constitution will be interpreted according to the Universal Declaration of Human Rights and the International Treaties dealing with the same fields ratified by Spain".

802 Commission Communication, on Immigration, Integration and Employment, COM(2003) 336, 3 June 2003, Brussels.

803 Commission Communication, A Common Agenda for Integration - Framework for the Integration of Third Country Nationals in the European Union, COM(2005) 389, (Brussels, 1 September 2005).

$\$ 94$ S. Carrera (2006), Programas de integración para inmigrantes: una perspectiva comparada en la Unión Europea', Revista Migraciones, N. 20, Universidad Pontificia de Comillas, Madrid, pp. 37-73. 
policies addressed to the entire citizenry, intended to provide 'the immigrant community' access to public services and integrate them into other public policies with special relevance in the social integration processes; and sixth, the Plan advocates for a transversal incorporation of all the questions related to the integration of the immigrant population in all the relevant public policies (mainstreaming).

Moreover, the following three principles provide the overall orientation of the Plan: ${ }^{805}$

1. The principle of equality and non-discrimination, which implies the equality of "rights and duties" within the constitutional framework.

2. The principle of citizenship, which consists of the recognition of full civic, social, economic, cultural and political participation of "the immigrant citizens", and where the Strategic Plan mentions the concept of "civic citizenship" put forward by the European Commission the Communication on a Community Immigration Policy COM (2000) 757, of November $2000,{ }^{806}$ and the EESC's Opinion on Immigration, Integration and the Role of Civil Society Organizations of March 2002,, ${ }^{807}$ which have been analysed in Chapter 3 of this book.

3. The principle of interculturalism as a mechanism for the interaction between persons of different origins and cultures with the respect of cultural diversity.

The ten objectives are related to the recognition of equal rights of TCNs, the quantitative and qualitative adequacy of public policies to the new realities brought by immigration, the guarantee of access by TCNs to public services, the establishment of a reception system for newcomers, fostering the knowledge of "the European and Spanish values and principles" (including official language(s) and social norms), the fight against discrimination, racism and xenophobia, the introduction of the gender dimension, the promotion of co-development policies with the countries of origin, favouring the understanding and positive nature of diversity and stimulating the development of public policies on the respect of diversity by the different administrations. The objective consisting of fostering the knowledge of the European and Spanish values and principles (including official language(s) and social norms) is understood as follows:

To foster among the immigrants the knowledge and respect of the common values of the European Union, of the rights and obligations of the residents in Spain, of the official languages in the different territories of the State and of the social norms of coexistence in Spanish society. (Emphasis added.) ${ }^{\text {sos }}$

Finally, the Plan deals with twelve dimensions, or concrete areas of intervention, which include: reception, education, employment, housing, social services, health, minors and youth, equality of treatment, gender, participation and co-development. It offers a diagnosis of the state of affairs and the challenges and opportunities posed by each of them to TCNs. It then puts forward precise programmes to achieve the general objectives in each of these sectors, as well as guidelines to evaluate the programmes that will be developed.

805

L. Cachón (2007), "El Plan Estratégico de Ciudadania e Integración 2007-2010", en E. Aja y J. Arango (eds), La Inmigración en España en 2006. Anuario de Inmigración y Politicas de Inmigración, CIDOB Publicacions: Barcelona, pp. 246-266.

806 Commission Communication on a Community Immigration Policy $\operatorname{COM}(2000) 757,22.11 .2000$.

807

EESC, Opinion on Immigration, Integration and the Role of Civil Society Organisations, SOC/075, Brussels, 21 March 2002, rapporteur: Mr. Pariza Castanos.

See page 124 of the Strategic Plan. 
The Strategic Plan on Citizenship and Integration represents the last bastion of the official strategy advocated by the Spanish state to have a 'non-national model' in the field of integration, and to look at the EU as the source of inspiration. The Plan consolidates the rationale according to which Spain needs to be as European as possible, and that the EU may in fact provide good answers ("lessons learned') to its own dilemmas. It therefore institutionalises one version of the Europeanisms which have characterised the construction of immigrant Spain explained in Section 1. This particular Europeanism has consisted of using soft-law mechanisms developed in the context of the EU Framework on Integration in the conceptualisation and content of its own policy strategy of governance of diversity and immigration. One aspect of the influence played by the EU in this field has been the insertion of the general objective for TCNs to know and respect the common values of the EU and Spain, the official language(s) of the place of residence (which in some AACC may include in addition to Spanish, Catalan, Vasque, Galician, etc.), as well as of "the norms" of Spanish society.

These objectives, which have never formed part of the legal history of immigration policy in Spain, have been inspired by the CBPS 2 and 4.1 according to which integration implies "respect for the basic values of the EU" and a that "Basic knowledge of the host society's language, history and institutions is indispensable for integration". It is unclear how any eventual legal response based on the policy framework put forward by the Plan will translate into practice the need for TCNs to know (basic knowledge) and respect these elements. Even more uncertain would be to measure whether they are respected. Further, the issue of language is particularly sensitive in Spain, and it would be rather beyond any proportionality to demand somebody to know and respect the official language(s), which in some AACC include two. It is therefore hoped that the Spanish authorities will not take the path of implementing those "European principles". This would fundamentally transform the classical normativity of integration that has been identified to the present day in the Spanish legal system. It would make the State fall into the trap of searching for a supposed 'national model' based on a false homogeneity, which would later be imposed on a de facto heterogeneous reality(ies), value(s) and society(ies). Such action would lead to conflict and instability. This might become most critical when taking into account what happened in the latest municipal and local elections of 27 March 2007, when there was a significant increase in the number of anti-immigration political parties. ${ }^{809}$

Finally, the Forum for the Social Integration of Immigrants delivered an Opinion about the Project of the Strategic Plan of Citizenship and Integration 2007-2010 on 5 February $2007 .^{810}$ The Opinion reiterated the Europeanism underlying the Plan. It made reference to the compliance and compatibility of the Strategic Plan with the Hague Programme and its general framing within the EU Framework on Integration. As it has been explained above, the Strategic Plan does not constitute a proper mechanism of law because of its non-legally binding nature upon the State and enforceable nature regarding the individual. A similar comment applies to the Opinion of the Forum. Their precise legal effects are far from being clear apart from constituting a sound inspiration and political message for the coordination and development of public policies as regards the integration of TCNs. Only time will tell about the actual impact of the Plan in the development of a specific legislative agenda. It appears that there has been a lack of dialogue with the competent political leaders, and particularly at the level of the former Ministry of Labour and Social Affairs, during phases of planning, elaboration and final adoption, 
something which has weakened its impact. However, as it has been stressed above, the new Minister of employment and immigration, Corbacho, has expressly mentioned the Plan as one of the key components of a "renewed political impulse" to be given to the Spanish immigration policy. 811

\subsection{The Autonomous Communities and Integration}

The lack of State policy on integration has not prevented the AACC from elaborating their own policy plans providing for specific programmes and priority actions addressing the provision of public social services to TCNs and their 'integration'. In this Section we shall assess the implications of the division of competences between the State and the AACC, and the ways in which integration is being framed, understood and implemented in the Integral Plans of Immigration and the Social Integration of Immigrants.

\subsubsection{Redistributing the Competences over Immigration?}

Article 149.1.2 of the Spanish Constitution confers the exclusive competence to the State over immigration policy. 812 However, the close links that some of the domains attributed to "the social integration of immigrants' have with some of the competences granted by the Constitution to the AACC have made it an area of shared responsibility between the two levels of governance. Article 148 of the Constitutional text provides that the AACC shall enact legislation over areas such as the provision of public services, health, education, culture, housing, etc. These tasks, which have been developed within the framework of their respective Statuses of Autonomy, ${ }^{813}$ have led to the concurrent existence of policies and to an increasing interadministrative relationship between the State and the AACC around these domains. ${ }^{814}$ During the last years there has been a sort of re-delimitation or redistribution of competences resulting from an increasing scope of responsibility of the Communities over certain sectors related to immigration. ${ }^{815}$ While the State still keeps the exclusive competence over the legal status of TCNs, and it provides the minimum common normative denominator over all the sectoral themes related to public social policies, the AACC have been recognised as having the capacity to develop the latter further and to broaden the regulation, provision and recognition of these sectoral services, not only as regards Spanish nationals but also TCNs residing in their territory.

Gobiemo de España, Ministerio de Trabajo e Inmigración, Comparecencia del Ministro de Trabajo e Inmigración, Sr. Celestino Corbacho Chaves, I Parte, La Política de Inmigración del Gobierno, Comisión de Trabajo e Immigración, Congreso de los Diputados, 22 Julio 2008, Madrid.

This article stipulates that the central State has the exclusive competence over the following fields: nationality, immigration, emigration and asylum.

Article 148 states that "l. Las Commidades Autónomas podrán asumir competencias en las siguientes materias: 17. el fomento de la cultura, de la imestigación y, en su caso, de la enseñaza de la lengua de la Comunidad Autónoma: 20. Asistencia social: 21. Sanida e higiene; etc".

For an in-depth analysis of the current mechanisms of cooperation between the State and the AACC in the area of "the social integration of immigrants" see E. Roig (2006), "Relaciones Intergubemamentales en Materia de Inmigración: Desarrollo de un Modelo en Construcción", en E. Aja, J. A. Montilla y E. Roig (coords.), Las Commidades Auónomas y la Immigración, Novedades de Derecho Público 9, Instituto de Dret Public, Tirant lo Blanch, Valencia, pp. 77-152. 
As Montilla (2006) has argued, ${ }^{816}$ immigration, and especially policies related to the social processes of integration of TCNs, represents a transversal phenomenon within the Spanish legal system where, as the table below explains, there is an ongoing interaction of responsibilities between the central State and the different AACC administrations. This interaction reaches its summit in the area denominated as "the social integration of immigrants" where they enjoy a shared competence. ${ }^{817}$

Table 2: Division of Competences in the Field of Immigration

\begin{tabular}{|c|c|}
\hline STATE & AACC \\
\hline $\begin{array}{c}\text { Exclusive competence: The legal status of TCNs } \\
\text { - entry, stay and residence, access to } \\
\text { employment, etc. }\end{array}$ & $\begin{array}{c}\text { Provision of certain public services (education, } \\
\text { health, housing, social services, culture, etc.) to } \\
\text { TCNs }\end{array}$ \\
\hline \multicolumn{2}{|c|}{ Shared competence: The social integration of immigrants } \\
\hline $\begin{array}{c}\text { Title II of the LODYLY on "Regimen Juridico de } \\
\text { los Extranjeros" - Articles 25-49 }\end{array}$ & $\begin{array}{c}\text { Sectoral titles attributed by the Constitution } \\
\text { and the Statuses of Autonomy }\end{array}$ \\
\hline
\end{tabular}

The strict division of competences over the area of immigration has provoked the appearance of a number of dysfunctions in the field. ${ }^{818}$ The State holds the exclusivity to determine the legal status of TCNs. However, this has deep implications for the actual provision of public services by the AACC. Their withholding of legal status from TCNs makes it difficult at times to achieve an adequate provision of public services. All the social-related rights depend to a great extent on the administrative status of TCNs. The Spanish legal system, however, disentangles both legal dimensions and competences. The exclusive attribution of the responsibilities over the field of immigration continues constituting an area of discussion both at the academic and political levels, and is experiencing a slow but progressive decentralisation process, with the exception of those competences related to border control. ${ }^{819}$

\subsubsection{The Integral Plans of Immigration and the Social Integration of Immigrants}

The AACC have developed a number of policies related to "the social integration of immigrants" dealing with the provision of a wide range of social services, and which have been officially encapsulated in the shape of Plans denominated as "Integral Plans of Immigration"

816 J. A. Montilla (2006), "Las Funciones y Competencias de las Comunidades Autónomas en Inmigración", en E. Aja, J. A. Montilla y E. Roig (coords.), Las Commidades Autónomas y la Immigración, Novedades de Derecho Público 9, Instituto de Dret Public, Tirant lo Blanch, Valencia, pp. 23-75.

817 S. Carrera (2006), 'Programas de integración para immigrantes: una perspectiva comparada en la Unión Europea', Revista Migraciones, N. 20, Universidad Pontificia de Comillas, Madrid, pp. 37-73; See also M. Del Camino Vidal Fueyo (2007), "Las Politicas Autonómicas en Materia de Inmigración en el Año 2006", en E. Aja y J. Arango (eds), La Immigración en España en 2006, Anuario de Inmigración y Politicas de Inmigración, CIDOB Publicacions: Barcelona, pp. 112-126.

818 E. Roig (2002), 'Autonomia e Inmigración: Competencias y Participación de las CCAA y los Entes Locales en Materia de Inmigración', Anuario de Derecho Constinucional y Parlamentario, 14, page 201.

819 See instante during the negotiations and final shape of the new Statute of Autonomy of Cataluna. For an analisys see M. J. Larios Paterna (2006), "Cataluña", en E. Aja, J. A. Montilla y E. Roig (coords.), Las Commidades Autónomas y la Immigración, Novedades de Derecho Público 9, Instituto de Dret Public, Tirant lo Blanch, Valencia, pp. 285-316. 
(Planes Integrales de Inmigracion) or "Plans for the Social Integration of Immigrants" (Planes para la Integración Social de la Población Inmigrante). The Plans constitute the institutional framework around which the public policies are being implemented. The first experience in this process was the Plan adopted by Cataluña in 1993, ${ }^{820}$ and as Table 3 shows below, currently sixteen $A A C C$ have their own Integral Plans of Immigration, with the only exceptions being Asturias, Ceuta and Melilla. ${ }^{821}$

Table 3: Integral Plans of Immigration by AACC

\begin{tabular}{|l|l|}
\hline \multicolumn{1}{|c|}{ AACC } & \multicolumn{1}{|c|}{ PLANS } \\
\hline Andalucia & II Plan Integral para la Inmigración en Andalucia 2006-2009 \\
\hline Aragón & Nlan Integral para la Inmigración 2004-2007 \\
\hline Asturias & $\begin{array}{l}\text { II Plan Integral de Atención a las Personas Inmigrantes de las Illes Balears } \\
\text { 2005-2007 }\end{array}$ \\
\hline Baleares & II Plan Canario para la Inmigración 2005-2007 \\
\hline Canarias & Plan de Interculturalidad 2005 \\
\hline Cantabria & $\begin{array}{l}\text { Plan Regional para la Integración Laboral de Inmigrantes en Castilla-la- } \\
\text { Mancha 2006 }\end{array}$ \\
\hline Castilla la Mancha & Plan Integral de Inmigración en Castilla León 2005-2009 \\
\hline Castilla León & Pla de Ciudadania e Immigració 2005-2008 \\
\hline Cataluña & None \\
\hline Ceuta & Plan Integral de Inmigración \\
\hline Extremadura & Plan Galego da Inmigración 2007-2010 \\
\hline Galicia & I Plan Integral de Inmigración de La Rioja 2004-2007 \\
\hline La Rioja & Plan de Integración 2006-2008 \\
\hline Madrid & None \\
\hline Melilla & $\begin{array}{l}\text { II Plan para la Integración Social de las Personas Inmigrantes de la Región } \\
\text { de Murcia 2006-2009 }\end{array}$ \\
\hline Murcia & Plan para la Integración Social de la Población Inmigrante 2002-2006 \\
\hline Navarra & Plan Vasco de Inmigración 2003-2005 \\
\hline Pais Vasco & Plan Valenciano de Innigración 2007 \\
\hline Valencia & \\
\hline
\end{tabular}

The Integral Plans of Immigration show a number of common characteristics and features when looking at their structure, founding strategic principles and conceptual understandings of integration, as well as the sectoral areas which are being covered. As regards their structure, the Plans tend to be divided into the following sections: they start by explaining the legal regime and the division of competences between the State and the AACC in the fields of immigration and integration of TCNs, as well as the main policy developments at the European level concerning these fields. They also offer some statistical data and analysis of the socio-demographic situation in their respective $A A C C$, which at times include the number of TCNs residing regularly,

820 The first Plan was the so-called Pla Interdepartamental d'Immigracio 1993-2000, Comision Interdepartamental de Immigración, Generalitat de Catalunya. For a study of the case of Catalunya in the field of integration see S. Gil Araíjo (2006), Las Argucias de la lntegración: Construcción Nacional y Gobieno de lo Social a través de las Politicas de Integración de Inmigrantes: Los Casos de Cataluña y Madrid, Tesis Doctoral, Departamento de Cambio Social, Facultad de Ciencias Politicas y Sociologia, Universidad Complutense de Madrid; See also C. Solé y A. Izquierdo (coords.) (2005), Imegraciones Diferenciadas: Migraciones en Cataluma, Galicia y Andalucia, Anthropos Editorial: Barcelona.

821 C. Bonino Covas, J. R. Medina y F. Rocha Sánchez (2003), Los Planes de las CCAA para la Integración Social de las Personas Inmigrantes, CCOO: Madrid. 
working, etc. Further, they expose the principles and the strategic objectives that are pursued. In their main body a list of sectoral social areas for action are identified, and concrete measures and programmes are presented to be developed in the field with the allocated budget. Finally, they conclude with an evaluation mechanism (some of them even present a set of indicators) and a follow up procedure which will be applicable once their period of application comes to an end.

The Plans show several similarities concerning their principles, which according to Montilla (2006) can be distinguished between general and operational/specific. ${ }^{822}$ Those principles of a general nature, which provide the inspiration for the Plan, often consist of the following tenets: normalisation or inclusion of TCNs in the general system of social welfare resources, services and benefits; equality of rights, duties and opportunities; an integral and global approach to interculturalism understood as the way in which public policies take into account cultural diversity; and transversally incorporating the field of integration in all the relevant or related policies.

The operational or specific principles may be summarised as follows: First, participation of social agents and civil society in the elaboration, implementation and evaluation. For instance, the Integration Plan of the Community of Madrid ${ }^{823}$ was elaborated by a group of researchers from the Research Institute of Migration Studies of the University of Comillas in Madrid in close collaboration with external experts, civil society, immigrant organisations, NGOs as well as practitioners from the various public administrations. Second, coordination between the different autonomic public authorities dealing with areas related to integration. For example, one of the main objectives of the Immigration Plan of Valencia ${ }^{824}$ is improving the coordination among the different administrative departments of health, education, social services and housing, establishing rational and regulated planning of available resources, guaranteeing the unity of the policy action on the social integration of immigrants by the Valencian Government. Finally, decentralisation of the functions in charge of implementing the various public policies among the different local administrations and the relevant social organisations. ${ }^{825}$

What is the normative concept of integration used by the Plans? The theoretical understanding of integration is also influenced by the policy developments occurring at the EU level and the Framework on Integration. In a majority of cases integration is understood as a two-way process in need of a multidimensional approach. For example, returning to the Integration Plan of the Community of Madrid, the way in which it approaches integration is from the perspective of 'shared responsibility' aiming at establishing bidirectional and reciprocal relations between TCNs and the receiving society. The idea of "mutual accommodation" and the principle of

822 J. A. Montilla (2006a), "Inmigración y Comunidades Autónomas", en E. Aja y J. Arango (eds.), Veinte Años de Immigración en España: Perspectivas Juridica y Sociológica [1985 - 2004], Fundación CIDOB: Barcelona.

823 Plan de Integración 2006-2008, Conunidad de Madrid, retriavable from: www madrid.org For a study of the Plan of Madrid see I. Gómez (2006), 'Madrid', en E. Aja, J. A. Montilla y E. Roig (coords.), Las Comunidades Autónomas y la Inmigración, Novedades de Derecho Público 9, Instituto de Dret Public, Tirant lo Blanch, Valencia, pp. 373-420.

824 Plan Valenciano de Inmigración 2007, Gobierno de Valencia, retriavable from: www.bsocial.gva.es For an analysis of the Plan Valenciano see A. Solanes (2006), "Valencia", en E. Aja, J. A. Montilla y E. Roig (coords.), Las Comunidades Amónomas y la Immigración, Novedades de Derecho Público 9, Instituto de Dret Public, Tirant lo Blanch, Valencia, pp. 317-341.

825 About the local policies in Spain in the field of integration of immigrants see M. Pajares (2006), "Las politicas locales en el ámbito de la inmigración", en E. Aja y J. Arango (eds.), Veinte Años de Inmigración en España: Perspectivas Juridica y Sociológica (1985 - 2004), Fundación CIDOB: Barcelona. 
reciprocity coming from the CBPS are evident. ${ }^{826}$ A similar situation may be perceived in the case of Cataluna, where the Citizenship and Immigration Plan 2005-2008 makes special reference to the CBPS as the "European understanding of integration". It stresses that integration is a dynamic, two-way process of mutual accommodation by all TCNs and residents of Member States, and that it implies respect for the basic values of the EU. ${ }^{827}$ It also mentions the need to apply a "holistic approach" presented by the European Commission in its Communication COM(2003) $336 .^{828}$ The two-way process tenet also appears in the Plans of other AACC. ${ }^{829}$ Also in line with the understandings of integration provided by the EU Framework on Integration, the Immigration Plans deal with it from a multidimensional perspective. This perspective approaches the issue from a number of specific areas of action, which among others include: ${ }^{830}$ employment, training, education, housing, health, social services, culture, legal assistance, political participation, etc.

Montilla (2006) has also referred to the excessive differences that exist when comparing the priority domaims identified by the Plans and the lack of a grounded reasoning for justifying the prioritisation of some instead of others. ${ }^{831}$ That notwithstanding, the Europeanisms reigning also at the level of the AACC might well constitute a common denominator, which will be sooner or later fostered by the Strategic Plan of Citizenship and Integration. Moreover, in addition to these

\$20 The Plan expressly says that: "Las medidas y actuaciones que se proponen en este Plan buscan estimular las relaciones bidireccionales y reciprocas enre la sociedad de acogida y la población inmigrada, de modo que se eviten las sinuaciones de dependencia, subordinación o privilegio. Caminar con el horizonte y la erigencia de la reciprocidad significa el reconocimiento de deberes y derechos, de forma que puedan estimularse la responsabilidad compartida, la horizontalidad en las relaciones y la comunicación murua", page 35.

827 Pla de Ciutadania i Immigració, 2005-08, Generalitat de Catalunya, Departament de Benestar i Familia, Secretaria per a la Immigració, Generalitat de Catalunya, 28 Juny 2005, page 42.

828 In particular the Plan states that "En aquest marce el Pla de cintadania i immigració 2005-2008 comparteix l'opinió de la Comissio Europea que defensa "un enfocament holistic" de la integració dels immigramts, en que es tinguin en compte totes les dimensions clan per aconseguir l'estabilitat i la cohesió: la participació i la mobilitar en el mercal de treball, el coneixement de la llengua i l'edacacio. la integració residencial, lacces a la salut i ets serveis socials, l'accès a drets civics $i$, en general. laccés a un entorn de participació cultural i social".

829 This is the case for example in the Plan Integral de Inmigración en Castilla y León 2005-2009, Junta de Castilla y León, which states that "Difundir unos medios y' un sistema de integración no debe tener como unico sujeto al immigrante. la sociedad castellano leonesa debe recibir un mensaje que le motive en su implicación en la integración del inmigrante. Prever medidas que faciliten el acercamiento y el entendimiento social debe ser uno de los objetivos iniciales a conseguir, buscando que el castellano leones astma el fenómeno migratorio como cance de enriquecimiento culnural". Or the Plan Vasco de Inmigración 2003-2005, Departamento de Vivienda y Asuntos Sociale, Gobierno Vasco, which presents the following definition of "integration": "Integración es m concepto bidireccional, que implica un proceso dinamico de adapración reciproca entre la población inmigrada y la población originaria. Al mismo tiempo, se mata de ana adapración multilateral, puesto que el carácter permamente y polifacético de la inmigración y de la movilidad social exige una phuralidad de procesos de ajuste y equilibrio que permitan configurar una sociedad realmente integrada $y$ respetuosa con los derechos humanos inherentes a todas las personas".

830 C. Bonino Covas (2003), "Los Planes de las Comunidades Autónomas para la Integración de las Personas Inmigrantes", en Cirdadania y Derechos Sociales y Politicos de los lmmigrantes, Gaceta Sindical: Reflexión y Debate, Confederación Sindical de Comisiones Obreras, Junio 2003, pp. 179-207.

831 J. A. Montilla (2006a), "Immigración y Comunidades Autónomas", en E. Aja y J. Arango (eds.), Veinte Años de Immigración en España: Perspectivas Juridica y Sociologica [1985-2004], Fundación CIDOB: Barcelona. 
traditional sectors for action, the Plans equally present as a priority area what they denominate as "strategy of promotion of interculturalism" in the receiving society as regards cultural diversity and "the positive effects brought by immigration, as well as actions addressing the fight against discrimination, racism and xenophobia". This is how the two-way process paradigm of the EU CBPs supposedly materialises in practice. ${ }^{832}$ An interesting feature which also deserves mention is how the notion of "civic and plural citizenship" is another distinctive innovative element presented in some of the Plans. As stated above, the idea of civic citizenship also comes from the European arena, and particularly from the Commission Communication and the EESC. Even though nationality issues are among the areas of exclusive competence of the central State, the Citizenship and Immigration Plan 2005-2008 of Cataluña goes as far as pointing out as one of its main principles the need to develop

...a new concept of (pluralist and civic) citizenship which tries to advance towards equal rights and responsibilities for all Catalan men and women, regardless of nationality or legal situation, within the limitations of the area covered by the current framework. The link required to access and to understand citizenship is residency. (Emphasis added.) ${ }^{833}$

All these elements provide evidence of the ways in which the AACC have also been influenced by the policy developments at the EU level as regards the conceptualisation, understanding and functions of integration in the EU Framework on Integration. In addition to this Europeanism, the Plans also contain a peculiar characteristic which aims at strengthening the perpetuation of their own imagined 'Communities', 'societies', 'language' and 'identity', apart from that coming from the central State. For example, in several Plans include express references to their own culture and society to which any TCNs will need to integrate in addition to the one provided by "Spain'. They contain constant allusions to "the Vasque culture or society", "the Catalan culture or society", 834 "the Valencian society", etc. Further, the role that language plays in the Integral Plans of Immigration is prominent, especially in those AACC such as Cataluna, Valencia, Pais Vasco and Galicia. A TCN will at times be obliged to "integrate", and hence to show knowledge of and respect for Spanish language, principles and values, as well as those of the Autonomous Community where s/he resides. In this respect, for example, the Vasque Plan of Immigration 2003-2005 stipulates that

In the framework of cultural rights, the context granted by the Plan to the area of Interculturalism includes a double dimension: On the one hand, it consists of ensuring and facilitating the full access by immigrants to the Vasque culture, and particularly the learning of the two official languages as part of the integration processes. ${ }^{835}$

In a similar tone, the Citizenship and Integration Plan of Cataluña states that

Any policy of equality and accommodation of the resident citizenry in Catalonia includes a linguistic policy. One of the main objectives of the (Catalan) Government is to ensure the

832 The Plan de Integración 2006-2008 of Madrid includes for instance the following specific action programmes of 'sensibilization': promotion of courses dealing with immigration and interculturalism, information campaigns on the positive implications of immigration in the media, support of cultural activities promoting interculturalism, the inclusion of modules on immigration and interculturalism in the formation of police and security authorities, etc.

833 Page 158 of the Plan.

834 The Citizenship and Immigration Plan of Cataluna states that "The Catalan culture is the dymamic product of a cultural mix and the historic result of a variety of factors, traditions, languages and respresentative worlds. Interculturalism based on empathy and mutual discovery is an attitude which needs to be promoted", page 160 . 
practice of the Catalan language as a vehicle for social, economic, political and cultural communication... When immigrants use the Catalan language as a vehicle for communication it can greatly increase their level of integration. ${ }^{836}$

The actual possibility for these policy statements to materialise in practice has been recently included in the political debate currently taking place in Cataluna in the phase that preceded the national elections of 9 March 2008. One of the main political parties there, CIU, proposed to consider an amendment of the current inmigration legislation on the occasion of the transposition of the Council Directive 2003/109. This reform would impose any TCNs applying for a permanent residence permit to pass a mandatory exam ensuring the learning of both official languages (Spanish and Catalan), as well as "the societal values of the receiving society". CIU would wish that the AACC would have the competence to check and evaluate "the sufficient degree of integration" giving access to security of residence. ${ }^{837}$ A similar proposal was made by the government of Valencia. ${ }^{838}$ Any eventual implementation in that direction would be difficult to comply with the general principles of EU law, and more particularly with that of proportionality (See Chapter 7 of this book).

It appears that the Integral Plans of Immigration have created a web of sub-normativities of integration providing what Zapata (2006) has called their "philosophie publique propre"839 at the level of the AACC, which follow similar patterns and present a series of communalities with respect to their structure, principles and theoretical understanding of integration. The EU is exerting in this context a visible influence in their conception and rationale. Yet, the Plans also present a number of features which distinguish them from each other and that relate very strongly to their own perceived Communities and nations. The Plans provide their own conceptions of what the AACC conceive as their 'society' and 'the way of life' to which TCNs would need to integrate before having access to legal security. In light of this, the AACC are exercising a key role in the evolution of the Spanish non-national model of integration, diversifying its meanings, principles and features, and providing a direct expression of the complexities which exist in Spain in relation to its own dilemmas - dilemmas which are related to a diversity which exists even without taking into account the consequences of the phenomenon of immigration.

\section{The Directives 2003/109 and 2003/86: Transposing Integration "Measures" and "Conditions" in Spanish Law?}

The Europeanisms identified in this Chapter as regards the influence of the EU Framework on Integration in the elaboration of the Strategic Plan on Citizenship and Integration 2007-2010, and in some of the Integral Plans adopted by the AACC, collide with the actual level of compliance by the Spanish State with its 'obligations to act' within the scope of EU immigration law. The Directive 2003/109 on the status of third-country nationals who are long-term residents in its national law has not yet being implemented in Spanish law. The deadline for implementation was

\footnotetext{
836 Page 160.

837 La Vanguardia, CIU propone exigir Catalan y Castellano para obtener la residencia permanente en Cataluña, 16 January 2008, retriavable from hitp://www.lavanguardia.es
}

El País, El Gobiemo de Camps copia el contrato para immigrantes de Rajoy, 28 April 2008, http:/www.elpais.con/articulo/espana/Gobiemo/Camps/copia/contrato/inmigrantes/Rajoy/elpepuesp/20 080428elpepunac_21/Tes

R. Zapata (2006), 'Immigration, autonomie politique et gestion de l'identité : le cas de la Catalogne', |éress| Outre-Terve, 2006/4, No17, pp. 189-209. 
23 January 2006. Neither has further legislative action been taken with respect to Directive 2003/86 on the right to family reunification, which the Government considers in 'full' compliance with the current Spanish immigration legal system on family reunification, as the latter offers a more liberal or favourable regime than the one stipulated by this Community act. This, in its opinion, has made an express transposition of the Directive unnecessary.

The European Commission appears to have been convinced as regards the right to family reunification. Yet it started judicial proceedings against Spain before the ECJ on 7 February 2007 based on Article 226 of the TEC for breaching its obligations under EU law for not having implemented Directive 2003/109. ${ }^{840}$ In Case C-59/07 the ECJ held on 15 November 2007 that Spain was in violation of its obligations under EU law for not having adopted the necessary legislative and administrative measures deemed necessary to duly transpose this Directive in its legal system. ${ }^{841}$ The ECJ was of the opinion that the current national legislation in force on permanent residence could not be considered to be in compliance, not even partially, with the provisions stipulated by the Directive. ${ }^{842}$ This was especially the case with respect to the harmonised provisions related to the conditions for acquiring the EC Status of Long-Term Resident, as well as in what concerns the right to move out of the Member State that granted this status to reside in a second Member State. ${ }^{83}$

Spanish immigration law therefore has not yet transformed its traditional legal regime as regards the use and understanding of integration of TCNs in line with the integration-related provisions contained in the Council Directive 2003/109. ${ }^{844}$ The government held several informal

840 The Spanish Government notified the European Commission a number of arguments sustaining its position. However, this letter was mainly offering the reasons for the dealy in the transposition of the Council Directive on right to family reunification, which in the Government's view it was fully compatible with the existing Spanish immigration law. See Foro para la Integración Social de los Inmigrantes (2007), Dictamen del Foro para la Integración Social de los Inmigrantes sobre el Proyecto de Plan Estratégico de Ciudadania e Integración 2007-2010, FIS/2007/DI, 5 Febrero 2007.

841 Case C-59/07, European Commission v. Spain, 15 November 2007.

842 By doing so the ECJ rejected the allegations by the Spanish authorities that a strict transposition would imply amending the Ley Orgánica $4 / 2000$ sobre derechos y libertades de los extranjeros en España y su integración social of 11 January 2000 , something which would require unanimity in the Spanish Congress. According to paragraph 22 of the judgement: "C'est en vain que le Rovaume d'Espagne allegue les difficultés liées au caractère organique de ladite loi. En effer, selon ine jurisprudence constante, an Etat membre ne saurait exciper de dispositions, pratiques ou situations de son ordre juridique interne pour justifier l'inobservation des obligations et délais prescrits par une directive".

843 For an overview of the legislative transformations that would be necessary to introduce in the Spanish legal system for compliance with the Directive 2003/109 see A. Alvarez Rodriguez (2007), 'Directiva 2003/109 versus Legislación Española Actual: ¿La Transposición exige la modificación de la LO 4/2000?', Revista de Derecho Migratorio y de Exrranjeria, No. 15, pp. 9-42.

For an analysis of the legal regimes on permanent residence and family reunification see inter alia $\mathrm{L}$. Parejo (2003), "El Régimen de Permanencia de los Extranjeros", en F. M. Mariño (dir.), Derecho de Extranjeria, Asilo y Refingio, Ministerio de Trabajo y Asuntos Sociales, Secretaria General de Asuntos Sociales, Instituto de Migraciones y Servicios Sociales (IMSERSO): Madrid, pp. 515-566; E. Ortega Martin (2005), Manual Práctico de Derecho de Extranjeria, Europa de Derecho, Editorial Juridica: Madrid; C. Sánchez Rodas-Navarro (2006), 'Cuestiones Atinentes al Derecho a la Reagrupación Familiar de los Extranjeros de Terceros Paises en España como Instrumento para su Inserción SocioLaboral', Revista del Ministerio de Trabajo y Asumos Sociales, No. 63, pp. 297-314; A. Quirós Fons (2006), La reagrupación familiar de extranjeros en España: Régimen aplicable y propuestas, Tesis Doctoral, Universidad de Murcia, Departamento de Derecho Financiero, Internacional y Procesal, retriavable from wwwtesisenrednet; M. A. Cabellos Espiérrez y E. Roig Molés (2006), "El Tratamiento Jurídico del Extranjero en Situación Regular", en E. Aja y J. Arango (coord.), Veime Años de 
discussions with external experts about how to better implement EU immigration law. In the event of transposition, and as Álvarez Rodriguez (2006) has highlighted, ${ }^{845}$ it is unlikely that the government will decide to move towards the use of integration as a legal condition, or even as a contract for having access to security of residence. It is expected that the transposition would rather aim at keeping as much as possible the list of requirements currently applicable to the acquisition of authorisation of permanent residence for TCNs in Spain, and carry out an implementation of 'minimums'. However, it is better not to underestimate the tone of the current political debates on immigration and integration in some AACC such as Cataluña and Valencia.

Furthermore, during the electoral campaign preceding the national elections of 9 March 2008, the leader of the PP, Mariano Rajoy, proposed on 7 February that if he won, an "integration contract" would be introduced to Spanish immigration legislation. The contract would have obliged TCNs "to respect the laws, the Spanish customs, leam the language, pay taxes, work actively to integrate in the Spanish society and come back to their country if after a period of time they would not find employment". " However, as stated above the PSOE again won the elections and this measure has not been introduced. It is therefore at present uncertain how the newly elected government led by Zapatero will transpose the integration conditions and measures provided in Articles 5.2 and 15.3 of the Council Directive 2003/109.

\section{Conclusions}

During the last twenty years Spain has experienced various transformative processes as a consequence of the phenomenon of international human mobility. A state that traditionally held the status of a country of emigration, it has now become a destination of migration in the EU. The 'unexpected' nature of this change has provoked a feeling of 'lack of experience' and 'slow reaction' in the management of these social processes. This has been accompanied by the obligation to implement EU law in terms of border and immigration controls. Both factors have provoked that the Spanish immigration policy has been first, inherently reactive, and second, greatly influenced by Europe.

This Chapter has started by offering some theoretical reflections about the Spanish 'non-national model on integration'. Since the instauration of democracy, Spain has been characterized by the institutionalisation of national diversities in terms of territorial and political organisation. The sharing of competences between the State and the AACC has also involved the State's recognition of the existence of multiple particularities, communities and identities within its imagined nation. The Spanish authorities have often avoided opening a frank and plural debate about the nature and limits of the purported national identity. This resistance has led to the lack of an identifiable public philosophy on integration. In fact, the strategy has been to implement a 'non-national model' looking at the EU as one of its main sources of veneration and inspiration.

Inmigración en España: Perspectivas Juridica y Sociológica (1985 - 2004), Fundació CIDOB: Barcelona, Spain, pp. 113-129.

A. Álvarez Rodriguez (2006), La Transposición de Directivas de la UE sobre Inmigración: Las Directivas de las Reagrupación Familiar y de Residentes de Larga Duración, Documentos CIDOB Nümero 8, Serie Migraciones, Barcelona.

El Pais (2008), Mariano Rajoy quiere obligar a los inmigrantes a firmar un 'contrato de integración': El PP incluye la higiene entre las obligaciones para los extranjeros, 7 February 2008, www.elpais.es For a critique of the proposal see M. Pajares (2008), El Contrato de Integracion, Periódico de Catalunya, 9 February 2008, retriavable from www.elperiodico.com Refer also to R. Rubio Marin (2008), Inmigrantes y Contratos Electoralistas, El Pais, 29 February 2008, www.elpais.es 
This sort of 'Europeanism' has inflicted various visible consequences and multifaceted effects in the processes of policy formation in the domains of immigration and integration both at State and AACC levels. We have highlighted the existence of the following two concerns in relation to this non-model: First, it might lead to identity debates subject to even greater contradictions and larger conflicts, and second, it facilitates the importation of national practices, programmes or 'models' from other EU Member States which are alien to the traditional normative approaches existing in the Spanish legal system, and which often call for the implementation of restrictive immigration policies.

The institutional and substantive normative developments destined to manage the phenomenon of migration have been very prolific since 1985. We have offered a synthesized overview of the main phases affecting the changing articulation between integration, immigration and nationality within the Spanish legal and political tradition. This historical cartography has been complemented with the identification of predominant approaches on integration and the analysis of their functions in the main nomative responses adopted through these phases. While the category of integration started to appear timidly in some policy instruments and debates sourranding immigration during the 1990s, it was not until the third phase in the construction of 'immigrant Spain' (from 2000 until present) where the former becomes part of specific legal and public policy responses. We have also examined the ways in which the Spanish laws on nationality and regular immigration currently frame and make use of integration. The latter has functioned as a legal condition in the acquisition of the Spanish nationality via naturalisation since 1990. The applicant needs to prove a "sufficient degree of integration in the Spanish society" in order to be granted with the privilege of becoming a national. The qualification of this rule as an indeterminate juridical concept' makes high the discretion left in the hands of the public authorities carrying out the examination. The subjectivity inherent to the legal category of integration into "the Spanish social and cultural principles, values and ways of life" provokes a certain tension when putting it in relation to the principles of proportionality and legal certainty.

Integration has not experienced a nation-wide framing until the adoption of the Strategic Plan of Citizenship and Integration in 2007. The Plan presents multiple references to the EU Framework on Integration. The CBPs, for instance, have played an important role in the conceptual premises and approaches of integration provided by the Plan. By making use of EU soft-law tools, the Plan needs to be seen as another illustration of the Spanish tendency to look at the EU. A critical consequence product of these processes has been the introduction of certain innovative approaches to integration which conceive it as the need for TCNs to know and respect "the common values of the EU and Spain", and "the host society's language, history and institutions". The Integral Plans of Immigration and Social Integration of Immigrants of the AACC have also shown some references to the EU Framework on Integration. This influence can be seen in respect of some aspects composing their theoretical understandings of integration, and in the identification of certain policy initiatives.

Finally, the peculiar transposition carried out by Spain of EU law on regular immigration, and specifically that related to the Council Directives 2003/86 and 2003/109, contradicts in many respects the Europeanism that we have identified in the Spanish authorities' strategies in relation to EU policy initiatives on integration. The Directive on the status of third country nationals who are long-term residents 2003/109 has not yet been transposed. Moreover, the Spanish authorities have considered that the Directive dealing with the right to family reunification $2003 / 86$ is in full compliance with the already existing legal regime on immigration, and therefore it has not been necessary to pass any amendment in relation to current legal configurations. The impact of European integration processes in the domain of regular immigration in Spain has been so far minimal, if not at all absent. Time will tell as to the precise ways in which the transposition of 
CHAPTER 5

the Directive 2003/109 will take place, and whether the functions of integration provided in Articles 5.2 and 15.3 will become part of Spanish immigration law. 


\section{Chapter 6:}

\section{The Legal Framework on Nationality, Immigration and 'The Republican Integration' in France}

\section{Introduction}

This Chapter studies the nature and impact of the normative articulation between integration and the laws of nationality and immigration in France. After offering some theoretical reflections concerning the French Republican paradigm of integration, a historical overview of the intersection between the legal frameworks on nationality and immigration with the latter is provided in Section two. The political debates and regulatory developments surrounding this nexus have been, until the beginning of the $21 \mathrm{st}$ century, mostly related to the domain of nationality. In recent years, however, this doctrine has experienced major transfomations and reconfigurations within the context of the field of immigration. When does the normativity of integration appear as part of the French political debate and legal tradition? We shall study the origins, main phases and major dynamics affecting the changing relationship between 'the Republican integration' and the rules on nationality and immigration in France.

Section three addresses the ways in which integration is being used and practiced in nationality law by looking at the key provisions contained in the civil code dealing with the condition of assimilation for naturalisation. The relationship between immigration legislation and integration is then analysed in Section four. As we will argue, the Republican integration has experienced a number of multifaceted processes of normativisation, expansionism and externalisation: First, it is currently presented in a mandatory contractual relationship between the State and the TCN taking the form of the so-called "welcome and integration contract" (contrat d'accueil et d'intégration, CAl). The CAI applies as a prerequisite for the non-national to have access to permanent residence and the right to family life. Second, integration has been subject to a gradual expansionist logic from its classical venue within the realm of nationality law to the regime covering the wider area of immigration. It now functions as a normative condition for the regular nature of the entry, permanent settlement and family reunification of TCNs. Third, there is a consistent trend calling for the application of integration as a requirement already in the country of origin to obtain a visa for the purposes of family reunification ('integration abroad'). We will address the main features and scope of these various processes in the French legal system.

Finally, we shall look at the extent to which the transposition of EU immigration law, and particularly that of the Council Directives on the status of third country nationals who are longterm residents 2003/109 and on the right to family reunification 2003/86, has opened the door for the French State to lower down legal standards of protection and security for non-nationals by using the regulatory mechanism of integration. The latest legal reconfigurations affecting 'the Republican integration' might shed some light on the hypothesis regarding the instrumentalisation of the Europeanisation processes by some Member States in their national arenas. There appears to be a predominant sort of Europeanism in France consisting of the use of the EU, and common immigration policy, as justification to enact new legislative initiatives aiming at better managing in a rather stringent fashion the phenomena of immigration and diversity. 


\section{The French Republican Paradigm of Integration: Fundamentals and Implications}

France represents a paradigmatic example of the modern liberal state that requires the Other to 'assimilate' into its traditional conception of nationhood in order to be included and transformed into the perfect citizen. The normative relationship between assimilation, integration, nationality and citizenship has traditionally been embraced within the 'French Republican Model of Integration'. Access to French nationality is conceived as the final step of a successful process of integration by the non-national into this privileged status. Republican integration was later transferred from the laws on nationality to the regulatory framework of immigration.

The Republican paradigm of integration, often denominated as assimilationist or universalistic, has been identified as the official public response advocated by the French State to face the dilemmas attributed to human mobility and diversity. This response, qualified at times as a 'model', appears to have equality at its roots, a sort of privileged equality only applying to those individuals falling within the category of citizens. The Republican tradition has generally been based on the principles of assimilation, nationalisation and neutralisation/privatisation. Indeed, its classical doctrine advocates for the assimilation of the non-national into the dominant features and values of the perceived mainstream French nation. Its ideology forces the elimination of diversity and the socialisation or "la fiancisation" of the Other toward founding principles of the Republic which find their historical roots in the emancipatory philosophy of the Enlightenment and the French Revolution of 1789. French Republicanism practices both a process of alienation of heterogeneity and social complexities, and a process of nationalisation, or normalisation of Otherness, through the acquisition of French nationality and the innovative normative practice of integration in immigration law. The diversity consequence of the phenomenon of human mobility is therefore subsumed and deconstructed by the State through an institutionalised process of assimilation intending to mechanically transform 'the immigrant' into the perfection assumed in the concept of 'the citizen'. The key to this transformation rests in the hands of the State to grant secure status in the country after passing an integration evaluation into the imagined French society. ${ }^{847}$ These conceptual premises lead to a problematic relationship between Republicanism and the existence cultural identities, and diversity in general. Any identity and society(ies) diverging from 'the canon' or the 'perfect citizenry' are considered to be a deviation in need of correction, discipline and naturalisation. They are treated as a threat to the nation, which is 'one', of the foundations of universalism, unitarism, secularism and homogeneity, and which is legitimised to practice a series of corrective actions against any fragmentation from its sacral wholeness.

Republican thought also calls for neutral treatment by the State in relation to any version of public difference. The traditional French commitment to culture and ethnic-blind universalism consisting of the need to neutralise any fragmentation, anomaly or distance from the canon citizen, and to treat individuals as individuals, regardless of their cultural identities, provokes a series of tensions and questions in need of reflection. An individual will be only allowed to cross the bridge leading to societal membership after meeting a series of civic standards and social parameters of living which are considered to be inherent to French Republicanism and national historical memory. Privilege and equality are thus only ensured to those showing in the public sphere the artificial prototype of 'the Frenchman' who lives in full respect of and compliance with Republican values, principles and way of life. Republicanism is therefore hostile to any public recognition of cultural difference. As Laborde (2001) has argued, it is based on the privatisation of cultural identities as the universalistic paradigm guiding the relationship between 
cultural groups and the Republic. Public neutrality and the separation of the public and the private realms constitute the conditions for the individual to access the public sphere, and to be a member of the polity. ${ }^{848}$

The classical principles that have often been cited as the pillars of classical French Republicanism and its traditional doctrine, and which have been identified as substantiating the four key Republican ideals (Liberté. Egalité, Fraternité et Laïcité), ${ }^{849}$ can be summarised as follows: $:^{850}$

1. Universalism as proclaimed in the Universal Declaration of the Rights of the Man and of the Citizen of 1789, which became the Preamble of the French Constitution of 1791. This principle endorses a juridical and political concept of 'the modern democratic French citizen' based on the understanding of the human subject as 'universal' and recognised as the member (citizen) of the political community which shares a common political project; only those individuals falling within the legal category of citizens exist in the eyes of the State. ${ }^{85}$

2. Unity or unité (l'intégration nationale) as synthesised in the sentence "La Republique une et indivisible". This principle goes against any version or form of differentialism, proclaims the necessity of societal integration and deplores any official version of "le droit à la difference" and of multiple identities/societies. ${ }^{852}$

3. The principle of secularism or "lä̈ite", which has been transferred to the level of Constitutional principle, and which defends not only the strict separation between the Church and the State, but also the demarcation between the private religious life and the public secular life. Any form of religious and cultural difference or practice need to remain hidden within the private realm. ${ }^{853}$

848 C. Laborde (2001), "The Culture(s) of the Republic: Nationalism and Multiculturalism in French Republican Thought', Political Theory, Vol. 29, No. 5, pp. 716-735.

849 Article 1 of the French Constitution which establishes that "La France est me Republique indivisible. laique, démocratique et sociale". Article 2 of the French Constitution, Titre I "De la Souveraineté", reads as follows: "La langue de la République est le français. L'emblème national est le drapeau tricolore, bleu, blanc, rouge. L'hymme national est la Marseillaise. La devise de la République est Liberté, Égalité. Fraternité. Son principe est gowvernement du peuple, par le peuple et pour le peuple".

sso A. Geddes (2003), The Politics of Migration and Immigration in Europe, London: Sage Publications, pp. $52-78$

851 The Preamble of the French Constitution stipulates that "Le peuple français proclame solemellement son atrachement aux Droits de l'homme et aux principes de la souveraineté nationale tels qu'ils ont été définis par la Déclaration de 1789, confirmée et complétée par le préambule de la Constitution de $1946 \ldots .$.

8s2 The Socialist Government of F. Mitterand's adopted in 1981 what has been qualified as 'a differentialist discourse' which consisted in recognizing a "droit a la difference" in France mainly in relation to the decentralization of the competence over cultural policies to the regions. As Brubaker explains, the Front National also opted for using this 'idiom' but framed it into the dimension of 'immigration' and turned it into a threat of ethnic, cultural and religious difference to the French nation by saying "droit $\dot{a}$ la difference? Mais oui, bien sî", chez vous". R. Brubaker (2003), "The Return to Assimilation? Changing Perspectives on Immigration and its Sequels in France, Germany and the United States", in C. Joppke and E. Morawska (eds), Toward Assimilation and Citizenship: Immigrants in Liberal Nation-States, Basingstoke: Palgrave Macmillan, pp. 39-58.

853 This principle has come several times to the centre of the French political stage for instance in relation to "les affaires du foulard" in respect of "l'école laïque". 
4. Assimilation, or in its moden teminological version, "intégration à la française", 854 understood as the process by which TCNs need to abandon their own cultural identity(ies), individualism and social, ethnic, religious and cultural particularities (to be socialised or to become 'Frenchmen' who are members of the common Republican polity, and to leave any private sign of difference away from the canon citizen). The project of democratic modernity involves the integration of all the individuals in the perceived nation. S/he will have to adhere to the mainstream universalistic values, political principles and socio-cultural neutral stereotypes enshrined by the Republican tradition, and therefore become the political and juridical being incarnated as the French citizen. The assimilation processes foster the disappearance of any Otherness into the political and legal understanding of the nation and the self.

The French State's response towards immigration and diversity is indeed related to the classical vision of the existence of a bounded nationhood and the defence of an assimilationist rationale to be predominant in the public sphere. As Brubaker (1992) points out, ${ }^{855}$ while French nationhood is constituted by a supposed political and universal unity, it is centrally expressed in the striving for cultural unity. This political cohesion has involved the cultural assimilation of minorities and those holding the juridical notion of 'immigrants' or 'foreigners'. There has been a deliberate policy of making similar the Other based on a political conceptualisation of national membership and aiming at turning immigrants into citizens, transforming the abnormal nonnational ${ }^{856}$ into the juridical construction of what a French citizen is supposed to be. ${ }^{857}$ The use of assimilation as a tool in the shape of a conditional norm for having access to French nationality accentuates and reinvigorates the closeness inherent to the status of nationality, and the politics of inclusion and exclusion affecting those who are considered to be far from 'perfect' because of their otherness and heterogeneity. It represents the last resort in the hands of the liberal state to manage membership and privilege.

In Brubaker's view, "domestic closure against non-citizens rests on this understanding and selfunderstanding of modern states as bounded nation-states. The closure of suffrage (and other institutions) to non-citizens, based on the axiom that the nation-state may, in fact must, discriminate between members and non-members, is one expression of this 'nomal', 'legitimate', 'rational' nationalism". ${ }^{858}$ The French Revolution not only invented the nationstate, but also represented the origins of the status of national citizenship. By inventing the perfect citizen, and the legally homogeneous national citizenry, the French Revolution simultaneously created the category of the foreigner as a legal categorisation and political epithet. It legitimised the modern logic and practices of exclusion surrounding the notion of TCNs, and justified the institutionalised discrimination carried out by the nation-state between those falling within the categorisation of national and all the rest. The Revolution signified the official recognition of the practices of discrimination based on nationality. Those outside the

854 J. Jennings (2000), 'Citizenship, Republicanism and Multiculturalism in Contemporary France', British Journal of Political Science, Vol. 30, No. 4, pp. 575-597.

855 R. Brubaker (1992), Citizenship and Nationhood in France and Germany, Cambridge: Harvard University Press.

856 M. Foucault (1999), Les Anormanx, Cours au Collège de France. 1974 - 1975, Hautes Études, Gallimard Le Seuil: Paris.

E. Weber (1976), Peasants into Frenchmen: The Modernization of Rural France, 1870-1914, Standford: Standford University Press.

Brubaker conceives citizenship as a form of 'social closure' by which citizens alone enjoy an unconditional right to remain and reside in the territory of the State. Non-citizens or even 'privileged non-citizens' remain 'probatory residents' always subject to exclusion or deportation. See R. Brubaker (1992), Citizenship and Nationhood in France and Germany, Cambridge: Harvard University Press. 
category of nationals could therefore be unquestionably and legitimately discriminated against. They should be excluded from the benefits, rights and protection that the perfect citizen enjoys. Assimilation is at the crossroads, playing the role of mutating her/him into the stereotype of national, and setting the dividing line between othemess from membership. Assimilation is the condition which must be met to being crossing the various intermediate frontiers separating the status of foreigner and citizen.

The French Republican paradigm has been subject to broad academic attention. One could, for instance, distinguish between those authors who have argued that the classical Republican model remains an appropriate and valid strategy to be adopted by the French state. This 'model', in their view, involves a positive universalism and equality among citizens. This line of thought, whose bearers have been labelled integrationists, liberal nationalists or Republicans, ${ }^{859}$ understands that liberty and equality require the self-determination and independence (autonomy) of the individual as a citizen free of any sort of particularism and distinctiveness. They defend a community of citizens of the Republic who have left their cultural, religious and social differences to their own private spheres. Only those falling within the category of citizens will be considered as members of the political community and the nation, and will therefore enjoy civil equality or undifferentiating treatment in the public domain. Other authors, often called multiculturalists, have on the other hand emphasised the critical tension that exists between this particular vision of universalism and equality and the respect of cultural diversities and individual identities. ${ }^{860}$ They have argued for a renewal of the institution of citizenship which would imply a public recognition of difference and particular identities. The cultural and religious loyalties, in their view, cannot simply be hidden behind the line separating the public and the private spheres, and public neutrality by the State only legitimises the continuation of existing structures of domination and discrimination in relation to any version of otherness. ${ }^{861}$

There have been other versions of these two academic lines of liberal thought and a wide range of diversified positions placing themselves nearer or farther away from each of them. We may highlight, for instance, the writings of Schnapper, who has been considered a forebear of modern Republicanism, ${ }^{862}$ a kind of Republicanism that in a way acknowledges the limitations inherent to the Republic in its French traditional form when intending to respond to the challenges posed by diversity and heterogeneity, but that still presents the 'Republican Model of integration' as an

8s9 R. Debray (1989), Que vive la République, Paris: Odile Jacob; E. Todd (1994), Le Destin des Immigrés: Assimilation et Ségrégation dans les Démocraties Occidentales, Paris: Seuil; A. Finkielkraut (1987). La Défait de la Pensée, Paris: Gallimard.

860 F. Khosrokhavar (1996), "L'universel abstrait, le politique et la construction de l'islamisme comme une forme d"altérité", M. Wieviorka (ed.), Une sociéré fragmentée: Le multiculturalisme en débat, Paris: La Découverte, pp. 113-51; M. Wieviorka (1996), Une socièté fragmentée? Le multiculturalisme en débat, Paris: La Découverte; M. Wieviorka (1998), 'Le multiculturalisme est-il la réponse?', Cahiers Internationaux de Sociologie 105 (1998): 233-68; J. Roman (1995), 'Un multiculturalisme á la française', Esprit, June 1995, pp. 145-60.

861 On the different academic lines of thought see D. Schnapper (2007), Qu'est-ce que l'intégration?, Folio Actuel 125, Gallimard: Paris, pp. 88-99; See also J. Jemnings (2000), 'Citizenship, Republicanism and Multiculturalism in Contemporary France', British Journal of Political Science, Vol. 30, No. 4, Oct. 2000, pp. 575-597; and C. Laborde (2001), 'The Culture(s) of the Republic: Nationalism and Multiculturalism in French Republican Thought', Political Theory, Vol. 29, No. 5, (Oct. 2001), pp. 716735 .

862 J. Hollifield (2004), 'France Republicanism and the Limits of Immigration Control', in W. Cornelius, P.L. Martin and J. Hollifield (eds), Controlling Immigration: A Global Perspective, Standford: Standford University Press, pp. 183-214; J. Hollifield (1992), 'L'Etat Français et l'immigration', Revue Française de Science Politique, pp. 943-963. 
ideal and optimal response to ensure the continuation and legitimacy of the French nation. Schnapper (1994) has expressed that the Republic needs to be understood as a 'community of citizens' and that any form of cultural, ethnic or religious particularism should not constitute a political identity recognised within the public sphere. In her view, the public recognition of ethnic diversity would constitute a fundamental challenge to the very principles of integration embodied in the French civic community; a set of principles upon which the nation-state has been built. ${ }^{863}$ Even though Schnapper acknowledges some of the limitations inscribed in the Republican doctrine of culture-blind neutrality when facing it with the actual diversities existing within the nation, she still makes use of the usual traditional premises of the Republican utopia by arguing that

La nation est une forme politique qui transcende les diffèrences entre les populations, qu'il s'agisse des différences objectives d'origine sociale, religieuse ou nationale, ou des différences d'identité collective, en les intégrant en une entité organisée par un projet politique commun. Elle crée un espace politique, donc juridique, administratif et social, à l'intérieur duquel sont réglés les relations, les rivalités et les conflits entre les individus et les groupes...L'unification politique et l'effort d'homogénéisation culturelle qui lui est lie entrainent la disparition ou la réinterprétation des particularismes. Toute construction nationale accrôtl l'homogénéité inteme et la différentiation entre nations. ${ }^{86 t}$

A very interesting account of contemporary reflection as regards the relationship between the sort of nationalism embodied by French Republicanism and various forms of multiculturalism has been provided by Laborde (2001), who has argued that the (left-wing) Republican critique of multiculturalism is not primarily based on nationalist arguments, but rather justified by a commitment to liberal universalism. In her view, contemporary Republican thought and 'culture-blind universalism' is in part self-contradictory with its own ideals. Laborde argues that the Republican conundrum consists of a strategy which, by promoting and defending national identity and 'Frenchness', also undermines its foundations against multiculturalism. On the one hand, the Republican principles call for leaving culture, religion, communitarism and difference to the private sphere, but on the other they reinvigorate and politicise the French national identity in the public one. Only the cultural identity qualified as French is therefore subject to the State's politics of recognition. ${ }^{865}$

Another theoretical account of the French case has been provided by Balibar (2004) on what he identifies as 'national Republicanism', 866 by which he means the complex web of practices and restrictive discourses toward the status of TCNs in France - the authoritarian management of "the immigration problem"- and the social questions posed by immigration policies since the social movements experienced at the end of the 1970s and 1980s. Balibar argues that national Republicanism demands, among other things, a very specific stigmatisation of the foreigner. In his view, Republican self-evidence, according to which the status of French citizenship ought to confer rights that those not qualifying for that privilege do not possess, leads to a kind of justification according to which "national citizens can be persuaded that their rights do in fact exist if they see that the rights of foreigners are inferior, precarious, or conditioned on repeated

863

D. Schnapper (1994), La Communauté des Ciroyens: Sur l'idée moderne de nation, Paris: Gallimard.

D. Schnapper (1992), L Europe des Immigrés, Essai sur les Politiques d'lmmigration, François Bourin: Paris, page 17 ; D. Schnapper (1991), La France de L'intégration. Sociologie de la nation en 1990 , Gallimard: Paris, Bibliotheque des Sciences Humaines.

C. Taylor (1994), Multiculturalism and the Politics of Recognition. Princeton, NJ: Princeton University Press.

E. Balibar (2004), We, the People of Europe, Reflections on Transnational Citizenship, Princeton, NJ: Princeton University Press. 
manifestation of allegiance (often baptized as 'signs of integration')." There is a form of "national preference" by which an immigrant is deprived of rights and can be excluded as a function of capacities of integration that are discretionally established by the nation-state according to subjective criteria of cultural distance, and which end up being in this way a rather 'mission impossible' for the Other to be able to truly comply with. "L'idéale Républicaine de l'homogéneité" involves the disappearance of any particularity and cultural identity different from that perceived as the mainstream through a mechanism and process of assimilation which forces the imposition of a Republican hegemony and a very specific kind of nation in the public sphere of society.

The study of Republican integrationist doctrine in France leads us first to look at the laws of nationality. This has been the venue where the category of assimilation has been used as a juridical condition for the first time in French law. ${ }^{867}$ There has been a rooted connection between the dimension of assimilation and the rules on the acquisition of nationality in French legal tradition. Assimilation has been commonly envisaged as a necessary requisite for passing successfully a process of naturalisation into the French nation. The naturalisation of the nonnational is understood as the last step of her/his process of nationalisation, and the most appropriate institutionalised way for her/him to benefit from a full national belonging, recognition and inclusion. Assimilation is therefore inherent to the naturalisation of the nonnational towards the perfection inherent to citizenship in relation to the foundations of the Republican nation-state. "Devenir Français" is presented as the culmination of Republican integration and the "parcours d'intégration".

As we will analyse in detail below, among the set of conditions for any foreigner to be naturalised in France, Article 21.24 of the Civil Code demands the non-national to assimilate and abandon any socio-cultural-religious diversity and identity in the public sphere. Any deviation from the canon will need to be subsumed and digested by the political and juridical Republican machinery which will convert her/him into a French citizen. This mechanism of transforming Others into citizens will be evaluated exhaustively by the State. The latter will examine the extent to which the applicant has a sufficient knowledge of the French language as well as of the rights and duties granted by the French nationality. As Weil (1991) has argued, ${ }^{868}$ French nationality functions as a legal obligation consisting of the person's adherence to common French identity based on Republican values. A person will be considered to be French if s/he can be socially absorbed by the Republican model of belonging. In Weil's own words, "Au total, le Code de la nationalité conduit le Français sociologique à l'être juridiquement". By acquiring nationality, and by showing adherence to the set of Republican values, the nonnational becomes the juridical being incarnated in the status of French citizen.

The subjectivity inherent to the ways in which the French Republican tradition has been understood through the various historical processes, and the importance attributed to the processes of becoming a citizen, have provoked a multiplicity of political struggles and processes of becoming a citizen, legislative reforms affecting the features of the laws on nationality. ${ }^{869}$ This dynamism, which has often been dependent on the political agenda of the government at hand, has made of the French law on nationality a rather complex set of obscure and complex rules. In

867 P. Weil and J. Crowley (1994), "Integration in Theory and Practice: A Comparison of France and Britain", in M. Baldwin-Edwards and M. Schain (eds), The Politics of Immigration in Western Europe, London: Frank Cass.

s68 P. Weil (1991), La France et ses Érangers - L'aventure d'une Politique de l'Immigration. 1938-1991, Paris: Calmann-Lévy.

D. Colas (2004), Citoyenneté et Nationalité, Folio Histoire, Gallimard: Paris. 
fact, the set of conditions for naturalisation (conditions de recevabilité) within French nationality law have represented one of the most contested issues of debate and reform.

Lately, the applicability of the condition of assimilation has experienced a transformation from its classical conceptual premises. After the entry into force of the Loi $n^{\circ} 2003-1119$ relative à la maîtrise de l'immigration, au séjour des étrangers en France et à la nationalité of 26 November 2003, the latter has moved from its usual domicile in the French Law on nationality via naturalisation to the realm of immigration and the conditions of entry and residence for TCNs. This expansionism has somehow confirmed a renewed institutional enthusiasm for official Republicanism, as well as its significance not only at the level of thetoric and political discourse related to the phenomenon of immigration, but also its configuration into its legal selting. At present, any immigrant will need to fulfil the Republican condition of integration for having access to the permanent residence permit (la carte de resident) allowing for stable residence or an "installation durable" in France. Further, this doctrine has been framed within a particular version of the pacte republicain, which has taken the shape of a contractual setting - the welcome and integration contract (contrat d'accueil et d'intégration, CAI) - to ensure that the immigrant duly fulfils her/his legal obligation to be absorbed by and disappear within French mainstream society.

The reconfiguration of the use of integration from the realm of nationality to the one of immigration involves a fundamental shift unique in French history regarding the relationship between nationality, immigration and integration. The last does not only play the role of a barrier for the non-national to become a formal juridical part of the nation and an equal member of the polity. It now also performs the function of a frontier dividing those TCNs who may have access to a higher degree of security as regards their legal status of residence from all the rest who will be considered as 'too different' or who may show a 'lack of will' to lose their own differences or cultural/religious identity(ies) in favour of the one considered to be dominant and mainstream in Republican France. The applicability of the condition of integration to acquire the status of permanent resident confers to the State another instrument for the management of the community of legitimate beneficiaries of rights and protection offered to the members of the nation-state. Not only the access to the status of national and to the full set of rights that it confers, but also the one intertwined to a stable and durable residence in the country will now be at stake at the nexus between integration and immigration law. The presentation of integration within the normative regime of immigration also operates as a legal mechanism separating those TCNs who have access to some rights according to the length of regular residence, from those remaining in a temporary status of living or in a temporal juridical status of protection (la carte de sejour temporaire) which generates the perpetuation of insecurity towards the eventuality of expulsion from France. The Republican philosophy therefore penetrates the configuration of the immigration laws and, specifically, the conditions for the granting of security residence and access to rights.

The new adherence to the Republican way of living has been further mutated with the entry into force of the last Sarkozy law, Loi relative à l'immigration et à l'intégration, $N^{\circ} 2006-911$. This law has converted the CAI into a mandatory requisite for any TCN to have access to a secure legal status of residence. The contractual nature of integration and its use as a non-facultative element to benefit from security of residence in France brings about a process of normativisation of the Republican integration doctrine. The current understanding of integration as a legally binding contract leaves no chance to the Other to decide whether or not to lose her/his identity in favour of the hegemonic and supposedly bounded French one. The very idea of an obligatory contract on the part of the immigrant undermines the ideal framing of integration as a "two-way process' with reciprocal rights and obligations on the parts of the immigrant, the State and the 
receiving 'society'. It is clear who has the onus and bears the burden in this contractual relationship. Diversity will have to disappear to have access to a certain degree of protection and security of stay and residence. Even those non-nationals who may not aim at becoming French will be forced to prove their adherence to its values and principles in order to be allowed to stay permanently (and attain security of residence) in French territory.

Finally, the Republican tradition has experienced another important transformation with the Projet de Loi relatif à la mâtrise de l'immigration, à l'intégration et à l'asile, which was presented to the National Assembly on 4 July 2007 by the current Sarkozy government. This Law will bring about another fundamental change of the 'French assimilationist model' by encapsulating it into a legal context with a rank of Law. This transformation will consist of the institutionalisation of 'the Republican integration abroad'. The would-be-immigrant, including the TCN spouse of a French citizen, will need to be integrated (knowledge of language and the values of the Republic) in the country of residence abroad as a condition for having access to a visa. The external dimension of Republican integration will in this manner strengthen the control by the French state from outside, in the countries of origin before the person actually shifts to the legal category of immigrant. The integration abroad functions as a mechanism of 'policing at a distance', using Guild and Bigo's (2003) concept. ${ }^{870}$ The externalisation of integration plays the role of a security tool of control in the hands of French state and its immigration policy. 'The borders abroad' of France will be strengthened and diversified in the conception of "intégration à la française". ${ }^{871}$ Before entering French territory any would-be immigrant asking for family reunification will need to show her/his integration by passing satisfactorily a specific evaluation about her/his level of knowledge of the French language and of the values of the Republic. Furthermore, once admitted on the grounds of family reunification to the French territory, the TCN family member and the immigrant already settled in France on the bases of a permanent residence permit will be obliged to follow and pass satisfactorily a welcome and integration contract for the family (Contrat d'accueil et d'intégration pour la famille). This contract aims at integrating them into the conception of the rights and duties of parents in France or 'the perfect French family'. The normativisation processes of Republican integration under the umbrella of immigration law raises a number of open questions concerning the testing grounds against which the Other will be tested or evaluated by the French State in order to ascertain the extent to which $\mathrm{s}$ /he is integrated. What do the values of the Republic really mean? What are the rights and duties of French parents?

It is also worth recalling that Europe has been often used as the justification by the French State for the reconfiguration and reformulation of the functions, nature and scope of the Republican doctrine of integration within its national legal system of immigration. This sort of Europeanism has constituted the raison d'etre and open door for the implementation of a more rigid regulatory framework towards immigration and diversity. The introduction of the condition of Republican integration in the areas of security of residence and family reunification has been deemed necessary at the official level in order to meet the compromises subscribed by France in the EU (la nécessité européene), and particularly for an adequate transposition into French law

870 D. Bigo and E. Guild (2003), La Mise à L'É Ecart des Érrangers: La Logique du Visa Schengen, Cultures \& Conflits, Paris: L'Harmattan; D. Bigo and E. Guild (2005), "Policing at a Distance: Schengen Visa Policies", in D. Bigo and E. Guild (eds), Controlling Frontiers, Hants/Burlington: Ashgate, pp. 233-263.

871 E. Guild (2003), "The Border Abroad - Visas and Border Controls", in K. Groenendijk, E. Guild and P. Minderhoud (eds), In Search of Europe's Borders, Kluwer Law International: The Hague, 2003, pp. 87. 104; E. Guild (2001), Moving the Borders of Europe, Inaugural Lecture delivered at the official ceremony of the assumption of the Professorship of the CPO Wisselleerstoel at the University of Nijmegen, 30 May. 
of Council Directives 2003/109 on the long-term resident status ${ }^{872}$ and 2003/86 on the right to family reunification. 873

As we will see in the next section, French political and legal history in the domains of nationality and immigration shows how the Republican paradigms of assimilation and integration have been subject to heated political disputes leading to a multiplicity of reforms and amendments of the laws on nationality and immigration. In which phases does Republican integration of immigrants appear in the French political debate and legal system? What are the possible origins and major transformations affecting the relationship between integration and the laws on nationality and immigration?

\section{A Historical Overview of Integration in France}

French Republicanism has been traditionally inspired by a process of assimilation as a mechanism of civilising, modernising, socialising and transforming otherness into the prototype of political being envisioned by French citizenship. Al the end of the 19 th century these processes were mainly articulated through school and the military. ${ }^{874}$ Both dimensions played a fundamental role as State instruments for the construction and defence of unified French nationhood. ${ }^{875}$ The expansionist, integrationist and absorptive nature of the Republican nation has also found expression in the tool offered by nationality law and the predominance that it has given to the principle of jus soli, according to which nationality is granted in relation to the person's country of birth (birthright principle of soil), and not according to the nationality of the parents - jus sanguinis (birthright principle of blood). ${ }^{876}$ The consolidation of the principle of $j u s$ soli as the paradigmatic feature of the law on nationality in France originates mainly from the mid-XIX century. 877

Two decisive moments in French legal history may be distinguished in this regard: First, the law of 29 January-7 February 1851; and second, the law of 26 June 1889. ${ }^{878}$ The 1851 law established the principle of 'the double jus soli', according to which French citizenship is granted to a child bom in French territory if at least one of the progenitors was also born in France. On the other hand, it also transformed into French citizens all third-generation immigrants at birth. The law of June 1889, on the other hand, declared French any foreigner

872 Council Directive concerning the Status of Third-country Nationals who are Long-term Residents, 2003/109, 25 November 2003, OJ LI6/44, 23.1.2004.

873 Council Directive on the Right to Family Reunification 2003/86, of 22 September 2003, OJ L251/12, 3.10 .2003$.

87. Primary education was made mandatory, secular and inherently nationalistic. In fact, the school represented one of the principal sites or locations of individual emancipation in republican secular thought.

875 G. Noiriel (2006), Le Crenset Français: Histoire de l'immigration XIV-XX siecle, Editions du Seuil: Paris, Édition Mise Á Jour et Augmentée d'une Préface.

876 According to the principle of jus sangwinis the nationality of a person is determined according to the nationality of the parents of the person involved (birthright principle of blood).

s7 From 1804 (Code Civil) until the entry into force of the law of 1851 the principle of jus sanguinis was the applicable rule in French nationality law, see P. Weil (1997), Mission d'étude des législations de la nationalité et de l'immigration, Paris: La Documentation Française, pp. 5-6.

878 P. Lagarde (1996), "Le Droit Français de la Nationalite", in B. Nascimbene (ed.), Nationality Law's in the European Union, Le Droit de la Nationalité dans I'Union Europeenne, Butterworths: Giuffrè Editore, pp. 309-336. 
born inside French territory if at the age of majority s/he had a domicile in France and did not renounce it at that stage (principle of the "simple jus soli"). ${ }^{879}$ Brubaker (1992) explains how there existed an interest by the French State to institutionalise this expansionist definition of nationality and the status of national. ${ }^{880}$ This open feature of the legislation on nationality was, in his view, not only based on the demographic needs or military imperatives of the country during that period, but most importantly "by a certain way of thinking and talking about membership of the French nation-state". Its liberal nature was therefore ideologically and politically based, and significantly driven by a strategy consisting of allowing French-bom children of foreigners to claim French citizenship as a matter of right. This was conceived as necessary in order to strengthen French Republican nationhood, and to expand its universalistic and democratic greatness. This strategy was equally a way to integrate them as part of France, and to turn them into citizens of the Republic.

While the Republican tradition of jus soli has represented one of the paradigmatic features characterising French nationality law, the regulations dealing with nationality have too often been subject to legislative reforms that have converted them into a rather opaque and complex set of rules with multilayered features. A number of successive revisions have emerged due to constant political debates and struggles coming from the right to the left of the French political spectrum. The conditions for naturalisation have particularly constituted one the most contested issues within this context. ${ }^{881}$ It is worth noting that even though the fields of immigration and nationality have experienced a number of processes of politicisation and institutionalisation in France, especially within the last thirty years, most of the subsequent legislative reforms dealing with assimilation have been related mainly to the law of nationality and not so much to the law of immigration. This was the case until the beginning of the XXI century, when, as we will study below, the Republican tradition and the 'French Model of Republican Integration' was transferred to the conditions of entry and stay of TCNs in France.

The 1850s was a period of industrialisation (la société industrielle and the 'trente glorieuses'), and France appears to have faced rather slow population growth, making it necessary to recruit labour from abroad. Hollifield (2004) has pointed out how the Ordonnance $n^{\circ} 45-2658$ relative aux conditions d'entrée et de séjour des étrangers en France of 2 November 1945 provided the main outline of immigration policy in post-war France. ${ }^{882}$ This law followed a rather utilitarian approach by addressing mostly the country's demographic and economic needs. ${ }^{883}$ In fact, the

879 For a study of the implications and discriminatory effects of the application of this Law in Algeria see P. Weil (2004), 'Histoire et Mémoire des Discriminations en matière de nationalité Française', Vingtième Siecle. Revie d'Histoire, 84, octobre-décembre 2004, pp. 7-8.

s80 R. Brubaker (1992), Cinizenship and Nationhood in France and Germany, Cambridge: Harvard University Press.

881 P. Weil (1991), La France et ses Étrangers - L aventure dime Politique de l'Immigration, 1938-1991, Paris: Calmann-Lévy ; P. Weil (2002), Qu'est-ce qu'un Français? Histoire de la naionalité française de la Révolution à nos jours, Paris : Grasset.

882 J. Hollifield (2004), "France Republicanism and the Limits of Immigration Control", in W. Comelius, P.L. Martin and J. Hollifield (eds), Conmolling Immigration: A Global Perspective, Standford: Standford University Press, pp. 183-214.

883 However, as Sassen (1999) has argued, while in practice the economic interest prevailed, the opinion over immigration in France was divided between those who saw it as an economic need and considered that immigrants could be 'assimilated', and those who viewed the phenomenon of immigration as a threat to the French culture, economy and society. In Sassen's view, racism was not absent. About fifty laws on immigration were proposed between 1883 and 1914 which aimed at taxing immigrants or their employers and restricting entries. They were seen as competing with French workers, as poor, as "malfaitems". S. Sassen (1999), Guests and Aliens, The New Press: New York. 
rationale of French immigration policy during this phase followed input-output tables containing targets for the impontation of foreign labour, and the immigrant was treated only as a labour force subject. As to the lack of State-centred organisation of labour immigration between the 1940 s and the early 1970s, Hollifield continues by explaining the way in which French employers and professional organisations practiced what came to be known as immigration from within'. They went directly to the sending third countries to find the necessary labour, brought the immigrant workers to France and only then sought an adjustment, or regularisation, of their administrative status in the country. This sort of human mobility for employment-related purposes took place under precarious paths and outputs in terms of, for instance, housing and safety conditions. During the 1960 s the 'immigration from within' represented $90 \%$ of the total immigration for employment purposes taking place in France. The principal countries of origin of this son of labour mobility were Portugal, Spain and the former French colonies such as Algeria, Tunisia and Morocco. ${ }^{84}$

The decline of the industrial society together with the economic crisis of the 1970s, which was a consequence of the Arab oil embargo and the Yom Kippur war, developed what has come to be known as 'the zero immigration policies' in a significant number of European countries. France was not an exception to that trend, ${ }^{855}$ inspired by the paradigm of protection and closed nature of the doors and borders of the State to the phenomenon of immigration. The French ministre de l'intérieur and the ministre du travail enacted two circulars of 5 and 9 July $1974^{886}$ to stop labour immigration and family reunification. ${ }^{887}$

The social consequences of the generalised economic recession, the effects of the 'stopimmigration strategy' and the permanent settlement of immigrant workers in France led to the birth of the Republican paradigm of 'insertion' within French immigration policy as well as of 'assimilation' within the legal context of nationality. The late $1970 \mathrm{~s}$ and the early $1980 \mathrm{~s}$ represented an important stage in the transformation of political discourse of the nexus between assimilation/insertion and nationality/immigration and its materialisation within the French legal

884 In Hollifield's view, "the controversies surrounding immigration from the 60 s until present stem largely from the turbulence of decolonization (and Algerian independence in 1962) and the dismantling of the French Empire"; See also M.C. Blanc-Chaléard (2006), "Old and New Migrants in France: Italians and Algerians", in L. Lucassen, D. Feldman and J. Oltmer (eds), Paths of Integration: Migrants in Western Europe (1880-2004), IMISCOE Research, Amsterdam University Press: Amsterdam, pp. 46-62.

C. Wihtol de Wenden (2002), Ouverture et Fermeture de la France aux Étrangers: Un Siècle D'Évolution', Vingtième Siècle: Revue d'Histoire, 73, janviers-mars 2002, pp. 27-38.

Circulaire du 5 juillet 1974 du secrétaire d'Etat auprès du ministre du travail, et de la circulaire susvisée du ministre d'Etat, ministre de l'intérieur, du 26 novembre 1974, ayant eu pour objet de suspendre provisoirement l'immigration de travailleurs étrangers; Circulaires $n^{\circ} 11-74$ du 9 juillet $1974, \mathrm{n}^{\circ} 17.74$ du 9 août 1974 et n²2-74 du 27 décembre 1974 du secrétaire d'Etat auprès du ministre du travail, suspendant provisoirement l'introduction en France des familles des travailleurs étrangers.

Geddes (2003) has highlighted that these two circulars created in fact more illegality inside the country because those who had previously not encountered substantial barriers for regularizing their legal status once being in French territory now faced a major number of obstacles when trying to do so. Moreover, he sustains that "The suspension [of immigration through legal channels] also encouraged permanent settement and helped change the composition of the French immigrant-origin population with: more women, younger and older people, reduced economic participation because of the broader age distribution, but at the same time, increased engagement with the French welfare state, increased unemployment, service sector employment and small business employment". A. Geddes (2003), The Politics of Migration and Immigration in Europe, Sage Publications Ltd: London. 
system. As Lochak (2006) has argued, ${ }^{888}$ it is at the end of the 1970 s when the term 'social insertion' of immigrants first makes its appearance in France. The French public authorities grasped the non-temporary nature of the labour immigration that had been previously encouraged and promoted, and its settled nature. Therefore, the category of insertion became part of the State's worries and attention. This occurred before the culmination of the issue as a structural aspect subject to political debate during the $80 \mathrm{~s}$, and which has lasted until nowadays. In Lochak's view, "I'insertion, puis l'intégration, n'ont jamais cessé d'être l'objectif official des politiques d'immigration". 889

The appearance of the term integration as an institutional and structural issue in French Republicanism has been studied by Favell (1998). ${ }^{890}$ This author has argued that in addition to the growing power of regionalism, the decline of the nation as a source of social solidarity and the developments related to Europe, a specific sector of the French political arena, i.e. Le Pen and Le Front National (FN), led to the prioritisation of the need to integrate immigrants. ${ }^{891}$ According to Favell, Republican integrationist philosophy was reinforced in the early 1980 s by the right-wing FN, and was later progressively expanded to cover the discourse of the whole French political spectacle. ${ }^{892}$ In his view, its discourse constructed a perceived 'crisis of integration' or 'integration problem' of immigrant communities in France, blaming it for previous State policies allowing for cultural difference and the sectarian demands of immigrants, especially Muslims. The FN also held that these policies had devastated the very institution of the classical Republican citizenship which constituted one of the core pillars of the French nation and its identity. It additionally identified the 'new' Muslim immigrant population as the most problematic inassimilable Other experiencing major integration problems. The traditional instruments of Republican assimilation, i.e. mainly school and military service, were no longer deemed sufficient to overcome this kind of extreme cultural and religious Otherness or intrusiveness in the French nation.

In this way Noiriel (2006) has explained how the significant role of the extreme right-wing in the French political scene from 1983 onwards centred the debate on the axe of immigration and integration, and reactivated the discourse about French national identity. ${ }^{893}$ It also portrayed a bound national identity, memory and Republican nationhood that was in need of protection against immigration and diversity. In his opinion, one of the principal arguments advocated by

888 D. Lochak (2006), 'L'intégration comme injonction. Enjeux idéologiques et politiques liés à l'immigration', in Identifier et Surveiller: Les Teclmologies de Sécurité, Cultures \& Conflits, $N^{\circ} 64$ Hiver, L'Harmattan: Paris, pp. 131-147; D. Lochak (2005), 'L'intégration alibi de la précarisation', Plein Droit 59-60: pp. 3-6.

889 Lochak (2006) continues by saying that "Lorque Paul Dijond. secretaire d'Etat aus Travailleurs immigrés. définit en 1976 les objectifs de la nouvelle politique d'immigration', il ne manque pas de metre en avant la nécessité d'oumer à l'insertion des immigrés dans la societé française". See page 138.

A. Favell (1998), Philosophies of Integration: Immigration and the Idea of Citizenship in France and Britain, London: Macmillan.

891 Mitterrand's proportional representation allowed the Front National to have representation in the French National Parliament in 1985.

892 M. Edelman (1988), Constructing the Political Spectacle, The University of Chicago Press: Chicago and London; M. Edelman (1964), The Symbolic Uses of Politics, University of lllinois Press, Urbana and Chicago: Illini Books.

893 G. Noiriel (2006), Le Creuset Français: Histoire de l'immigration XIV-XX siècle, Editions du Seuil: Paris, Édition Mise Á Jour et Augmentée d'une Préface. G. Noiriel (2007), Immigration, antisémitisme et racisme en France (XLXe-XXe siècle) : Discours publics, humiliations privées, Fayard: Paris; G. Noiriel (2000), Petite Histoire de l'intégration: la française, Le Monde Diplomatique. 
the FN was that immigrants could not be integrated because they did not share the same history as the "Français de souche". This populist positioning also attempted to present the issue of immigration as a 'new problem' for French society, something which offered an alternate version of French history with respect to the phenomenon of immigration. ${ }^{894}$ It is surprising that the extreme nationalist discourse was centred on the 'new inassimilation' of particularly the Muslim immigration, ${ }^{895}$ as this sort of mobility was already taking place in the country during at least the two previous decades. ${ }^{896}$ Nevertheless, the FN urged for new legislative amendments to be implemented in the field of nationality that should accentuate the condition of loyalty paid by immigrant communities to French territory, culture and history, and that should also impose strong cultural assimilation and integration as a condition for political participation and citizenship. $^{897}$

Geisser (2006) has on the other hand interestingly argued that the French left led by $F$. Mitterrand also had an important role in propagating the "rapatriement" of integration during the 1980s, and in the transfer of the colonial doctrine of assimilation to its post-colonial acceptation and its modem reformulation in the form of integration. ${ }^{898}$ The French government of that time equally used in its rhetoric 'the crisis of integration' as a therapeutic mechanism for facing the political crisis which took place between 1983 and 1986 and the falling apart of the "grande utopie socialiste" 899 In Geisser's view, this new invocation of integration in French history by the left constituted another tentative of re-nationalisation of the French identity supposedly threatened by centrifugal forces of various shapes, natures and forms. In his view,

Faire l'histoire de l'intégration, c'est donc se livrer à ume forme de 'généalogie républicaine' d'une thétorique de crise(s) politique(s), voire d'un discour's dramatique d'fin d'empire. ${ }^{900}$

The usage of the term social insertion, ${ }^{901}$ which had been commonly preferred to assimilation, was therefore abandoned for the one of integration. The latter has ever since become the

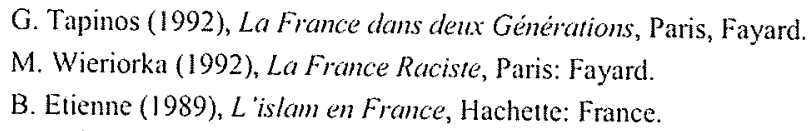
Club de l'Horloge. 1985. L'identité de la France. Paris: Albin Michel.

V. Geisser (2006), "L'Intégration Républicaine: Réflexion sur une Problématique Post-Colonial", P. Blanchard et N. Bancel (eds), Culture Post-Coloniale 1961-2006: Trace et Memoires Coloniales en France, Éditions Autrement: Paris, pp. 145-165. Geisser argues that "...l'hypothése que le miterrandisme d'Etat a consitué le principal passewr symbolique et idéologique de la doctrine colonial de l'inégration à son acceptation post-coloniar"... "c'est en fait toute une génération d'hommes politiques, d'administrateurs, de hauts fonctionnaires et surtout d'intellectuels marqué pour les éprouves et les drames de la décolonisation qui contribueron à ce 'rapatriement de l'intégration' dans la France post-colonial".

F. Mitterrand (1972), Changer la vie. Programme du Gouvernement du Parti Socialiste, Flammarion: Paris.

In addition to the period of the 1980s, Geisser identifies other two previous phases where a similar usage of 'assimilation' was made in French contemporary history: One was "la remise en cause des fondements de l'empire colonial français aux lendemains de la Seconde Guerre Mondiale" (1944-1946), and the other "la recherche d'une 'solution française' à la crise algérienne" (1954-1958).

In Weil's words 'insertion' consisted of a process by which "l'implantation dans la societé française s'effectue non sur un fondemenet individual, mais sur un fondement communautaire. Cette communauté est parfois représentée auprés des pawoirs publics par des dirigeants qui cherchent à maintenir la spéciticite du groupe". See pages 245 and 246 of P. Weil (1991), La France et ses Etrangers $L$ 'aventure d'une Politique de l'lmmigration, 1938-1991, Paris: Calmann-Lévy. 
commonly used word in political discourse coming from both "la gauche" and "la droite". It has been institutionalised in various legislative measures which have first included the field of nationality, and lately that of immigration. ${ }^{92}$ The immersion and expansionist usage of integration also found a progressively prominent place in scientific and academic research, social action and associative movements in France. The next historical phases further consolidated its use, prioritisation and expansion until its current form stipulated by the French legal system.

The legislative elections of 1986 opened the door for the right to hold the government. Instead of focusing efforts on developing specific policies addressing social problems that immigrant communities were actually facing (such as precarious situations regarding access to housing, employment, education, etc.), ${ }^{903}$ Chirac declared his wish to submit to the legislature " $a$ modification of the nationality code tending to make the acquisition of French nationality' depend on a prior act of will". 904 The then Minister of Interior, Pasqua, proposed a "Projer de Loi" $11^{\circ} 444$ on 12 November 1986, which came to be known as the first Pasqua Law. This bill intended to amend Article 44 of the "code de la nationalite française" of 1945,905 and impose on young TCNs the condition of affirming their commitment to France by requesting in a formal manner French nationality and by expressing a loyalty oath or oath of allegiance. It was also proposed that formal assimilation conditions should be introduced such as knowledge of the French language, and a broad list of crimes that would prevent the acquisition of nationality. ${ }^{906}$ The official justification provided by the government to introduce this revision was the need to verify "the real citizenship" of the applicant involved and "the desire to live together". 907 The exclusionary nature of the proposed reform put forward by the Pasqua Law was not very well received on various fronts. The controversy and concerted public protests that took place against it, along with the difficulties that the government encountered in adopting a new bill on educational reform," forced Chirac to finally withdraw the "Projet de Loi" $n^{\circ} 444$.

Even though the reform did not succeed, it is interesting to see how as a result of this controversy the centre-right ended up using a line of discourse calling for the need for

902 For a study concerning the use of 'integration' by the right and the left political parties in France from the 1970s until the 1990s see F. Gaspard (1992), 'Assimilation, Insertion, Intégration: Les Mots pour "devenir François", Hommes et Migrations, Mai 1992.

In Weil's view, "ces politiques n'ont jamais été ni prioritaires ni cohérentes" in France. He points out as regards the issue of employment, for instance, that between 1975 and 1982 the number of immigrants in situation of unemployment raised from 84.180 to 218.140. P. Weil (1991), La France et ses Etrangers L'aventure d'une Politique de l'Immigration, 1938-1991, Paris: Calmann-Lévy.

As quoted in R. Brubaker (1992), Citizenship and Nationhood in France and Germany, Cambridge: Harvard University Press, page 151.

905 Article 44 of the code de la nationalite français granted an automatic acquisition of the French nationality at the age of majority of the child of a foreign couple who was born in France and who had lived in the country during five years.

The Pasqua Law also proposed the removal of the extension granted in 1973 to Moroccans and Tunisians in Article 23 of the former code de la nationalité français.

"Le gowvernement justifie son projet par le souci de vérifier la citoyenneté réelle. le "désir de vive ensemble" as cited in P. Weil (1991), La France et ses Etrangers - L'aventure d'une Politique de l'Immigration, 1938-1991, Paris: Calmann-Lévy.

In addition to President Miterrand's intervention against the legislation, and the ruling of the Council of State (Conseil d'Etat) putting the Government in notice that the rights of the immigrants should be respected, organizations such as SOS Racism and France plus carried out the so-called "Marche des Bewrs" between 1983 and 1985 . 
integration and the promotion of the classical universal ideals of French nationhood and citizenship as the basis for reform of nationality laws. The political issue became a sort of selfinterrogation of the French state, community and citizenry. The solution to the perceived "integration crisis" was found by returning to the paradigms substantiating the Republican legacy of national integration, or in Brubaker's words (2003), in the resurgence of a neorepublican, neo-universalist and neo-assimilationist discourse - a return to assimilation ${ }^{909}$ and the defence of a universal ideal of integration through public virtues and civic incorporation in the old revolutionary fashion. The integration of immigrants, particularly of North African Muslims from Algeria, Morocco and Tunisia, became the greatest test of the theory of French political nationhood, and hence its elevation reached the centre-stage in the French politics of the 1980s.

The actual strategy pursued by Chirac was the establishment in June 1987 of an extraordinary "Commission de la Nationalite" or "Commission de sages" chaired by Marceau Long, Vice President of the Council of State, to study the sort of legislative reforms that the nationality code appeared to need. In parallel, a "Haut Conseil à l'Intégration" ( $\mathrm{HCl})$ was set up in 1988, which has ever since elaborated and developed all the conditions for the construction of the "modele français republicain d'intégration". As we will highlight below, some of the reports published by the $\mathrm{HCl}$ have also offered a detailed study and diffusion of the role of integration understood as a legal or contractual tool for making the Republic (its values and principles) compatible with diversity. ${ }^{910}$ However, at this particular time in history Favell (1998) identifies the emergence of a full French public philosophy of national integration a la française, and he takes the example of the final report by the "Commission de la Nationalité "Être Français aujourd'hui et demain" published on 7 January 1988. ${ }^{911}$ The report put forward sixty policy recommendations, ${ }^{912}$ which overall endowed substantial strength to the link between the status of national and integration as the condition for having access to equality and legal security. In this regard, it was highlighted that

Il est essentiel pour la société française de reussir au cours des vingt prochaines années l'intégration de la population étrangère régulièrement établie stu son sol. Un tel objectif

909 R. Brubaker (2003), "The Return to Assimilation? Changing Perspectives on Immigration and its Sequels in France, Germany and the United States", in C. Joppke and E. Morawska (eds), Toward Assimilation and Citizenship: Immigrants in Liberal Nation-States, Basingstoke: Palgrave Macmillan, pp. 39-58.

910 Haut Conseil à l'intégration, Pour un modèle d'intégration, La documentation française, 1991.

911 "Etre Français aljourd'hit et demain", Rapport remis au Premier ministre par Marceau Long, Président de la Commission de la Nationalité, La Documentation Française. "La commission était notamment invitee par le Premier minister à 'faire connaitre son sentiment [sur] cette proposition fundamtental' du projet du Gouvemement consistant à subordonner désormais l'acquisition de la citoyemeté en application du droit du sol' à 'la nécessité d'une declaration par laquelle l'étranger manifeste sa volonté d'acquerir la nationalite française", as cited in the repont that was published in Reve critique du droit international prive, 77 (1) janv. - mars 1988, p. 122 et ss.

The Report stated that "La Commission estime que doivent être simultanément reconmus le droit à la nationalité française des jeunes nés en France et y ayan résidé pendan une période significative (la résidence de cinq ans prévue par les textes achels devrait ètre maintenue) et la nécessité qu'ils expriment la volonté d'n bénéficier, par une décision individnelle très simplifiée. La volonté de jouir d'une nationalité à laquelle ils ont droit doit pouvoir être exprimée par les jeunes concernés dans des formes très simples. Une réforme en ce sens devra aménager à la fois le respect de leur droits et les modalités d'une expression consciente de ce droit", Revue critique du droit international privé, 77(1) janv. - mars 1988, page 124. 
s'impose. Il est conforme à une radition politique et juridique plus que séculaire dans notre pays. 913

The so-called 'headscarf affairs' of 1989 and 1993 have also been identified as important enclaves in the institutionalisation of the paradigm of integration within the classical Republican doctrine at this stage in France. The wearing of the religious veil in state public schools by Muslim girls was subject to political, media and academic attention. The study of the nature, implications and significance of these cases to the foundations of French Republicanism and its conceptual premises (secularism, unitarism, universalism, etc.) have been subject to broad academic attention. ${ }^{9 / 4}$ It is necessary, however, to point out how some authors have identified these moments as "le passage du discours à l'institutionnalisation" of integration in France and the consolidation of 'the French model of Republican integration'.

The right's victory in the 1993 elections provided the perfect scenario for the consolidation of the integrationist philosophy of the 1980s without any social resistance. This took place in the form of a more restrictive law on immigration and acquisition of French nationality. The final report published by the "Commission de la Nationalite" was invoked for the introduction of a conception of the acquisition of the nationality based on election or choice of the person involved rather than on an automatic right of acquisition. Minister of Interior Pasqua presented a new bill substantially reforming the existing legal provisions on nationality and immigration legislation (Pasqua's Laws). ${ }^{915}$ The new Law was then published on 22 July 1993 and entered into force on January 1994. It abrogated the former "code de la nationalité française" of 1945 , and integrated it into the civil code (Articles 17 to 33-2).

This law introduced a series of substantial changes related to the acquisition of nationality by birth and residence in France. ${ }^{916}$ In particular, one of the most important innovations was the abolition of the automatic acquisition of French nationality at the age of majority, which had been until then envisaged by Article 44 of the "code de la nationalité française" (and the right of refusal granted one year ex ante naturalisation). ${ }^{917}$ According to the new Article 21.7 of the civil code, ${ }^{918}$ in order to acquire French nationality, children between 16-21 years of age born in

913 As quoted in I. P. Moinet (2006), Célébrer la bienvente dans la République française, Rapport sur les cérémonies célébrant l'acquisition de la nationalité française Rapport à la Ministre déléguée à la Cohésion Sociale et à la Parité, Mme Catherine Vautrin.

See for instance B. Etienne (1989), L'islam en France, Hachette: France: F. Gaspard and F. Khosrokhavar (1995), Le Foulard et la Re'publique, Paris: La Decouverte; P. Weil (2005), La Republique et sa Diversité: Immigration. Intégration. Discrimination, La Republique des Idees Seuil.

Favell also mises the fact that nowhere was there any suggestion that these were laws inspired by the Le Penist rhetoric. "The most abiding triumph of Le Pen in the 80 s was thus to impose on the contemporary French political consciousness and vocabulary a kind of fixed opposition between the term "ètrangers" and those with full membership, "citoyens"... and induce a rethoric of "integration". If for whatever reasons,,.. , the new member of society fails to match up to the high ideal of citoyen français spelt out in the rapports and surrounding discussions, there is always the likelihood that this problematic member will slip from being an accepted "citoyen" to the category of "étranger" forever marginalized"..."to become a citizen technically does not mean that you have become an unconditional full citoyen as such. Such a term can only apply to those who in some sense fulfil the model that is set out for them in the ideal type scenario of full integration". A. Favell (2000), page 160.

916 R. Hansen (2003), 'Citizenship and Integration in Europe', in C. Joppke and E. Morawska (eds), Toward Assimilation and Citizenship: Immigrants in Liberal Nation-States, Basingstoke: Palgrave Macmillan, pp. 87-109.

917 P. Lagarde (1993), 'La nationalité française rétrécie', Rev. Crit. Dr. Int. Privé, p. 535.

918 Article 21.7 provides that "tout érranger né en France des parents étrangers peut, à partir de l'äge de 16 ans et jusqu'à l'àge de 21 ans, acquérir la nationalité française à condition qu' il en manifeste la volonté. 
French territory to foreign progenitors, and having habitual residence of at least five years in France, would need to present a formal request (voluntary nature of the acquisition of nationality or "elective theory" for the acquisition of nationality), and to express their wish to do so ("manifester leur volonté de devenir français" - declaration of will or of option). The law also introduced another modification by abrogating Articles 52 and 54 of the "code de la nationalité" which allowed the parents of a minor to submit a declaration of acquisition of French nationality on behalf of the minor after having proved an habitual residence of at least five years in French territory. ${ }^{919}$ As Lagarde (1996) has explained concerning this last innovation of the Pasqua Law, ${ }^{920}$ it would have been very difficult for the applicant at this age "de rassembler sans le concours de ses parent" all the necessary documents for the "recevabilite" of her/his manifestation of will. The crystallisation of the Republican philosophy based on the idea that the acquisition of French nationality would address all the challenges and dilemmas experienced at the societal level meant that discrimination, inequality of opportunities or belonging were not conceived as legitimate and relevant issues for the Republican Pact. ${ }^{921}$

A new period of cohabitation (the third one in French history) started after the June 1997 elections. ${ }^{922} \mathrm{~J}$. Chirac was elected as President of the Republic and the representative of the left coalition L. Jospin was appointed as Prime Minister. Similar to the rooted dynamic tradition in past French political history, L. Jospin announced new measures that would review the French law on nationality, and he commissioned in July $1997 \mathrm{P}$. Weil to write a report that would provide the foundation for new legislation. ${ }^{923}$ Weil's report (1997) cited a number of deficiencies of the 1993 reform. Among those it considered to be problematic, it was said that

...si le jeune ne sollicite pas entre seize et vingt et un ans un senvice administratif qui, à cette occasion, l'informe de ses droits, il risque de demeurer étranger sans le vouloir ou sans le savoir:

Overall, the previous revision was considered as reversing the long French Republican tradition of transforming immigrants into 'Frenchmen'. It was hence recommended to return to the automatic acquisition of French nationality at the age of majority without the voluntary element that had been introduced in the 1993 reform. Further, in order to ensure the autonomy of the child involved, and that s/he would not become French without knowledge about it, the report pointed out the need

... d'adopter une procédure qui permente effectivement à l'État républicain d'afficher clairement sa volonte de recomaitre et d'adopter comme firancais, sans distinction d'origine sociale on nationale ou de domicile, tous les enfants nés en France de parents étrangers, tout en assurant

qu'il réside en France à la date de sa manifestation de volonté et qu 'il justifie d'une résidence habituelle en France pendant les cing années qui la précédent".

N. Guimezanes (1996), 'Les Lois Pasqua et leur mise en application', La Semaine Juridique Edition Générale № 42, 16 Octobre 1996, 13967.

P. Lagarde (1996), "Le Droit Français de la Nationalite", in B. Nascimbene (ed.), Nationality Laws in the European Union, Le Droit de la Nationalité dans l'Union Européenne, Butterworths: Giulfrè Editore, pp. 309-336.

C. Bertossi (2004), "Politics and Policies of French Citizenship, Ethnic Minorities and the European Agenda", in A. Gomy and P. Ruspini (eds), Migration in the New Europe: East-West Revisited, Basingstoke: Palgrave.

922 This took place after J. Chirac had dissolved the General Assembly on the $21^{\text {st }}$ April 1997.

923 P. Weil (1997), Mission d'étude des législations de la nationalité et de l'immigration, Paris: La Documentation Française. 
mieux dans le même temps le droit à l'autonomie du jeune, son droit à manifester sa volonté d'être ou de ne pas ère français en étant bien informé. ${ }^{924}$

Highly inspired by the spirit of Weil's report, the Guigou Law (in reference to the then Minister of Justice) was adopted in March 1998. ${ }^{925}$ This law amended Article 21.7 of the civil code in a way that made the acquisition of French nationality again automatic at the age of 18 as long as the person could show habitual residence in French territory for at least five years after the age of 11 . The philosophy of manifestation or declaration of will was in this way reversed, and the rooted French integrationist and universalistic tradition was hence re-established.

The role of the FN in French politics became prominent in the course of 2002. The results of the first round of the presidential elections of 21 April gave the FN, and its leader Le Pen, 17\% of the vote. The extreme right-wing party was again at the very centre of the political scene. These somehow unexpected electoral results led to a series of spontaneous social reactions and street protests inside France, and raised concern abroad. The French Presidency was then disputed between Chirac and Le Pen in the second round held on 5 May 2002. Partly a consequence of the intense reactive consciousness at the national and European levels against the rise of the French extreme right-wing party, and independent of the public negative image and reputation of Chirac, the "Union pour un Movemen Populaire" (UMP) obtained a vast majority of $82.21 \%$ of the vote $(82.2$ million). Le Pen received $17.79 \%$ which represented around 5.5 million votes.

The victory of the UMP meant that the previously contentious period of cohabitation with the Socialist Party (Jospin) came to an end. Raffarin became the Prime Minister of a brand new right-wing government, having Sarkozy as the Minister of Interior and Public Security. While the elections gave victory to the right-wing led by Chirac, we can see various similarities to the period previously highlighted in the early 1980s. The nationalistic discourse and propaganda carried out by Le Pen had an important societal impact, and to some extent success, taking into account the wide public support and number of votes received by the FN. The fields of immigration and diversity were re-politicised and presented as one of the main causes of insecurity, instability and criminality inside the country, and as a menace threatening the stability and cohesion of the Republican nation. While the FN did not succeed in the final elections, the rhetoric about the need to strengthen the integrationist role of the Republican French state was somehow welcome and adopted by the newly elected government.

These developments meant that even though after the mid-1990s (and particularly between 1997 and 2002) there was some shift in political discourses and some legal measures passed to guarantee antidiscrimination in France, ${ }^{927}$ the role of the doctrine of Republican integration as a legal condition of assimilation into the classical French tradition was then reinvigorated and expanded to cover not only the usual dimension of nationality (Republican citizenship), but also the field of immigration ("I'entrée et le sèjou des étrangers"). As we will see below, the reconfiguration of Republican integration, or the neo-republican integrationist philosophy, has

924 Ibid.

925 Loi n⿳⺈ 98-170 du 16 mars 1998, Article. 2 Joumal Officiel du 17 mars 1998 en vigueur le 1 septembre 1998.

927 C. Bertossi (2002), Dilemme de la citoyenneté-Intégration / anti-discrimination en Europe: le cas français, Working Paper présenté lors de la Rencontre du CEDEM du 18 avril 2002, ULg, Liège, Belgique, page 20 . 
materialised through the enactment of a series of legislative measures which have come to be known as Sarkozy's laws.

The results of the French Presidential elections of April-May 2007, and the victory of Sarkozy, did not only consolidate the classical principles constituting the pillars and ideals of French classical Republicanism, but also its reformulation in the fashion of an expansionist "intégration républicaine" and a renewal of national identity and French patriotism. The discourse, political strategy and electoral project advocated by Sarkozy during the electoral campaign were quite transparent in this respect. Among the wider set of priorities, he launched the question " $Q u$ 'estce qu'être français?" accompanied by a securitarian discourse and rhetoric of crisis threatening the French national identity by immigration. Sarkozy stressed the menace posed, for instance, by the so-called "immigration subie", or suffered immigration, which included not only irregular immigration but also phenomena as wide as family reunification and asylum. A suffered immigration that did not correspond with the one denominated as "immigration choisie", which was on the other hand welcome because of its usefulness and economically profitable nature for the economy and labour market of the country. The former was a sort of immigration suffered because, in addition to its financial burden on the country, it involved an identity crisis: immigration that was too different in nature from the canon of Frenchness and distant from Republican values and principles. These discursive strategies justified the call for renewal inspired by the Republican tradition to protect the French nation, defend the perfect citizenry and save the imagined French Republican identity. ${ }^{928}$ This kind of governance would call for a more restrictive policy of greater control or mastery (maitriser) of the conditions of entry and stay by TCNs in France and their access to French nationality, paying particular attention to the domain of family reunification. ${ }^{929}$ Sarkozy argued for the creation of a linkage between the phenomenon of immigration and his vision of the French nation. On television in March 2007 he referred to the creation of a new ministry that would institutionalise that nexus. ${ }^{930}$ The initiative of the ministry was also one of the key items of his electoral programme that stated

...j'ai proposé la création d'un ministère de l'Immigration et de l'Identité nationale car l'intégration passe par le partage de norre cullure auram que par son enrichissement. Un seul ministère doit trater l'ensemble des questions relatives à l'immigration, à l'intégration et au codéveloppement.

The usurpation of a discourse and rhetoric traditionally used by the FN led by Le Pen was driven by a clear electoral strategy advocated by the UMP to gain a substantial number of votes from Le Pen's supporters. The success of Sarkozy by implanting this plan was confirmed not only by the actual results of the elections, but also by Le pen himself in his declaration after the publication of the final results of the first round of the elections on the evening of 22 April 2007. In his speech he referred to the successful strategy implemented by the now French President

928 See for instance the way in which it was explained in his electoral programme when saying that "Notre fierré repose d'abord sur l'identité de notre nation. Nous incarnons l'idéal national, parce que justement notre pays est consinué d'une multinde de peuples, de régions, de traditions et de cultures locales, depuis la métropole jusqu'à l'Outre-mer, enrichie par les vagues successives d'immigration, fédérée autour d'une ambition et d'une foi communes: être un grand pays, uni par les droits de l'homme et nos valeurs républicaines. Si je suis èlu, je ne cesserai d'affirmer notre fierté d'être français. N. Sarkozy (2007), Mon Projet. Ensemble tout devient possible", retriavable from www.sarkozy.fr

J. de Lucas (2007), Voces y Ecos de las Elecciones en Francia, Página Abierta No 183, Julio 2007, retriavable from Pensamiento Critico, www.pensamientocritico.org

930 Sarkozy said that "Je veux un ministère de l'Immigration et de l'Identité nationale" in the Television programme A vous de juger, France 2, 8 mars 2007. See "Sarkozy veut un ministère de l'immigration et l'identité nationale", Liberation, vendredi 9 mars 2007, retriavable from www liberation.fr 
consisting of the use of notions, ideas and a kind of language characteristic of the FN. This included, for example, a constant reference in his public statements and discourses of language with strong ideological connotations such as patriotism, nation, national identity, immigration as a security issue, etc. That, in the words of Le Pen, was an "ideological victory" for the FN in the battle of ideas in the 2007 presidential elections.

Sarkozy's electoral programme, and nationalistic strategy, led to the introduction of terms like national identity and slogans such as "fiers d'être français" (proud to be French) into the wider political and public spectacle. These processes of re-nationalisation claimed to be defending "the imagined France and the unitarian dream", in the words of Birnbaum (1998), ${ }^{931}$ and the citizenry from a set of constructed threats which included the unwelcome and undesired immigration "subie", and the heterogeneity/plurality of identities and rival societies characterising France. It also signified the strengthening of the Republican doctrine of integration as a structural issue and its amplification to cover the realm of immigration law with the idea of integration abroad. Sarkozy's electoral promises regarding immigration, integration and national identity materialised in two concrete steps: First, the establishment of the promised ministry, and second, a new legislative proposal in the domain of immigration.

As to the first measure, the "Minisière dl'immigraton, de l'intégration, de l'identité nationale et du co-développement" was created by the Decree n' 2007-999 of 31 May 2007. ${ }^{932}$ Among its various competences, which comprise a very wide set of policies related to immigration and nationality under the umbrella of national identity, the following may be highlighted: conditions for the reception (entry and stay) of TCNs; integration of immigrant populations in France; naturalisations and the registry of declarations of nationality by marriage; ${ }^{933}$ education, "maitrise" and promotion of the French language; 'the policy of memory' and promotion of citizenship and the principles and values of the Republic; and co-development policy. ${ }^{934}$ In an article entitled "Ma vision de lidentité nationale" by Hortefeux, Minister of Immigration, Integration, National Identity and Co-development, which appeared in the French journal Liberation on 27 July $2007,{ }^{935}$ some of the conceptual premises upon which this new Ministry has been built were further clarified in light of the wide-ranging debate surrounding its instauration, ideological premises and nature. When referring to his vision of French national identity, Hortefeux declared that French national identity constitutes a defence against communitarism (understood as the expansion of particularism, diverse identities and plurality of feelings of belonging in France) by reinforcing French values and principles. ${ }^{936}$ Also, he said that

931 P. Bimbaum (1998), La France Imaginée: Déclin des rêves unitaires?, Gallimard: Paris

932 Décret n $2007-999$ du 31 mai 2007 relatif aux attributions du ministre de l'Immigration, de l'Intégration, dl'Identité nationale et du Codéveloppement, JO n 125, 1 juin 2007, page 9964, texte $n^{\circ} 11$.

933 Article 1 of the Decree "ll est associé à l'evercise par le agarde des sceanx, ministre de la justice, de ses atributions en matière de déclaration de nationalité et de délivrance des certificats de nationalité française".

934 Article 1 states that "Il est chargé de la politique de co-développement et, en liaison avec le ministre des affaires étrangères et européennes et le ministre de l'économie, des finances et de l'emploi, participe à la défmition et à la mise en ourre des autres politiques de coopération et d'aide au développement qui concourent au contrôle des migrations".

B. Hortefeux, Ma Vision de l'ldentité Nationale, Liberation, Brice Hortefeux contribue au débat organisé par Liberation toute la semaine dernière, Vendredi 27 Juillet 2007, page 20.

936 In particular he said that "Cette identité-là a même le double mérite de constituer un rempart contre le communautarisme et d'incarner des valems qui nous dépassent". 
...nous pensons même que c'est la réfërence à l'idenité qui donne du sens à l'immigration et qui permet l'imégration.

The way in which this sentence includes the innovative institutional nexus between immigration, integration and national identity raises a number of questions in need of reflection. There is only one cultural identity subject to the politics of recognition by the French state, which is the one defined as French. The adherence to this mainstream identity is understood as the prerequisite not only for having access to the status of citizen through the acquisition of French nationality, but also for immigration and integration to take place within the context allowed by national law. Following this reasoning, immigration and integration lack any sense without putting them under the framework of French identity and by adhering to it. Integration into the supposedly homogenous national identity, and its classical Republican values and tradition, is therefore conceived as the necessary passarelle not only for the immigrant to potentially become part of the French citizenry, but now also for her/him to move from the category of unwanted and legally constrained immigration (immigration subie) to the one falling within the label of 'selected or selective' immigration (immigration choisie), as well as to have access to a secure legal status guaranteeing security of residence and family reunification.

Another political priority that was pointed out by Sarkozy's electoral programme was "maitriser l'immigration" (control or master immigration), through, for instance, the implementation of a more rigid set of conditions applicable to the right of family reunification and the instauration of the concept of integration abroad. ${ }^{937}$ The frequency of family reunification was presented as being numerically too great. The instrument chosen to limit this phenomenon was a new "Projet de Loi relatif à la maitrise de l'immigration, à l'intégration et à l'asile", 938 of $4 \mathrm{July} 2007$. The main provisions of this measure are studied in detail below. This initiative introduced a significant transformation of Republican integrationist philosophy by expanding it through, first, requiring TCNs to be integrated before entering French territory as a condition for having access to a visa on the basis of family reunification; and, second, the creation of a mandatory welcome and integration contract for the family ("Contrat d'accueil et d"intégration pour la famille").

Finally, it is worth making reference to the Press Conference given by Sarkozy on 8 January 2008 in Paris, ${ }^{939}$ where within the framework of the so-called "politique de civilisation" the French government announced a new proposal related to integration and offered more transparency as regards the real objectives pursued by the new laws and policies on immigration. First, Sarkozy proposed to reform the Preamble of the French Constitution in order to "rendre possibles de veritables politiques d'intégration" between men and women. Furthermore, he stated that

937 "Je demanderai à ceux qui veulent venir s'installer en France de faire l'effort d'apprendre le français avant, parce que c'est une condition essentielle d'une intégration réussie et parce que cela sera un signe de lew volonte de respecter notre culture" N. Sarkozy (2007).

935 Projet de Loi relatif à la maitrise de l'immigration, à l'intégration et à l'asile, Assemblée Nationale $N^{\circ}$ 57,4 juillet 2007.

939 Conférence de Presse du Président de la République, M. Nicolas Sarkozy, Mardi 8 janvier 2008, Palais de l'Elysée, retraivable from http://www elysee.fr/accueil

9:0 A new Law amending the French Constitution has been adopted the 23 July 2008, and has amended Article 1 of the Constitution Loi constitutionnelle $n^{\circ} 2008-724$ du 23 juillet 2008 de modernisation des institutions de la Ve République, JORF $n^{\circ} 0171$ du 24 juillet 2008 page 11890 . The new version of Article 1 now includes the following sentence: "La loi favorise l'égal accès des femmes et des hommes anx mandats électorax et fonctions électives, ainsi qu'aux responsabilités professionnelles et sociales". We may refer here to the importance atributed to the principle of gender equality in the interpretation of the concept of assimilation as a condition for assimilation. 
La politique des quotas, nous devons la mettre en auwe, en fonction d'accueil et d'intégration. mais quand même, on accueille des gens qu'on peut accueillir; parce qu'on a envie de les intégrer; si on accueille des gens qu'on ne peut pas intégrer, eh bien, on ne peut pas les accueillir. ${ }^{941}$

After having offered a broad historical overview of the changing relationship between integration, nationality and immigration as well as its possible origins and main transformation in the political debate and French legal system, the next section studies the current legal provisions related to acquisition of French nationality through naturalisation and the functions that assimilation plays therein. As we will see, assimilation into French society constitutes one the most relevant conditions for the immigrant to be naturalised and become a citizen. The moving to "the perfect citizenry" depends on the adherence by the non-national to the integrationist philosophy of belonging and nationhood as conceived by the French Republican tradition.

\section{The French Legal System on the Acquisition of Nationality: Naturalisation and Assimilation}

The requirement of assimilation into French sociery plays a fundamental role for the acquisition of nationality via naturalisation. Naturalisation is granted on a discretionary basis by the government to any TCN who claims it, if the applicant meets a series of conditions ("conditions de recevabilite") which are stipulated in the civil code - paragraph 5 "Acquisition de la nationalité française par décision de l'autorité publique" ("Acquisitions par décret"). One of the main requirements is assimilation to the French community ${ }^{942}$ as provided in Article 21.24 of the civil code, which reads as follows

Nul ne peut être naturalisé s'il he justifie de son assimilation à la communauté française. notamment par tme connaissance suffisante, selon sa condition, de la langue française et des droits el devoirs conférés par la nationalité française.

The former version of this provision only referred to the need for having a sufficient knowledge of French language. ${ }^{943}$ The "Loi $n^{\circ} 2003-1119$ relative à la maitrise de l'immigration, au séjour des étrangers en France et à la nationalité" of 26 November 2003 required the applicant to provide evidence of her/his assimilation to the French Community in the form of sufficient knowledge of the rights and duties conferred by the status of French nationality, and taking duly into consideration the special conditions of the applicant. ${ }^{944}$ The Law $2003 / 1119$ also provided

941 In order to address this initiave, a Commission sur le cadre constitutionnel de la nowvelle politique de l'immigration was set up in the beginning of 2008 , chaired by $P$. Mazeaud in order 'to reflect' about all these issues. The Report was delivered in July 2008. Commission sur le cadre constitutionnel de la nouvelle politique de l'immigration (2008), Pour Une Politique des Migrations Transparente. Simple et Solidaire, July 2008, available at www.immigration.gouv.fr See Arrêté du 30 janvier 2008 relatif à la commission sur le cadre constitutionnel de la nouvelle politique d'immigration, JORF $\mathrm{n}^{\circ} 0032$ du 7 février 2008 page 2321.

$942 \mathrm{H}$. Waldrauch (2006), 'Acquisition of Nationality', Chapter 3, NATAC, retrievable from the IMISCOE website at http://www.imiscoe.org/natac/acquisition_bookchapters.html

943 The former version of Articles 21-24 of the Code Civil, Titre I-bis, De la nationalité française, Loi n. 93933 du 22.7.1993, lacked the last part of the sentence about rights and duties and only stipulated that "Nul de pett être naturalisé s'il ne justifie de son assimilation à la communauté française, notamment par une connaissance suffisante selon sa condition de la langue française".

944 Loi 2003-1119 relative à la maitrise de l'immigration, au séjour des étrangers en France et à la nationalité 2003-11-26, JORF 27 novembre 2003, Article 68. According to Weil and Spire (2006), "the 
in Article 21.24 of the civil code that the condition of sufficient knowledge of French language shall not be applicable to refugees and stateless individuals over 70 years old and residing regularly and habitually in France for a minimum of 15 years. ${ }^{945}$ According to data provided by the "direction de la population et des migrations sous-direction des naturalisations" of the French "ministere de l'emploi, du travail et de la cohésion sociale", the number of acquisitions of French nationality reached in 2006 a total of 117,154, among which 77,655 were granted on the basis of naturalisation. ${ }^{946}$ The main nationalities of origin are Morocco, Algeria and Tunisia.

Table 1: Acquisitions of French nationality by naturalisation 1999-2006

\begin{tabular}{|c|c|c|c|c|c|c|c|}
\hline 1999 & $\mathbf{2 0 0 0}$ & $\mathbf{2 0 0 1}$ & $\mathbf{2 0 0 2}$ & $\mathbf{2 0 0 3}$ & $\mathbf{2 0 0 4}$ & $\mathbf{2 0 0 5}$ & $\mathbf{2 0 0 6}$ \\
\hline 59,836 & 68,750 & 57,627 & 56,942 & 67,326 & 87,497 & 89,100 & 77,655 \\
\hline
\end{tabular}

Sources: ministère de l'emploi, du travail et de la cohésion sociale direction de la population et des migrations sous-direction des naturalisations and DPM/ Justice, and Rapport Annuel de la sous-direction des naturalisations 2007.

The administrative procedures putting into practice Article 21.24 of the civil code have been developed in specific secondary laws. In particular, the "Circulaire $n^{\circ} 2000-254$ relative aux nanuralisations, réintégrations dans la nationalité française et perte de la nationalité française" of 12 May $2000^{947}$ aims at presenting the main rules which need to be observed by the prefecture of the place of residence of the applicant of naturalisation "pour la constitution des dossiers de demande de naturalisation ou de réintégration". The Circular provides administrative regulations specifying the procedures linked with the actual handling of the application for naturalisation. Also, it institutionalises an oral process of assimilation ("procès-verbal d'assimilation") which will be held by an official at the prefecture and that is intended to verify the assimilation of the person to the French community. As regards the examination of the status of the applicant and her/his assimilation to French society, point D.3.b of the Circular, which is entitled "Assimilation à la communauté française", states that the public authorities will need to

deputies who drafted this amendment stated that it was to ensure that newly naturalized citizens understood the significance of "becoming a citizen". See P. Weil and A. Spire (2006), "France", in R. Bauböck, E. Ersboll, K. Groenendijk and H. Waldrauch (eds), Acquisition and Loss of Nationality. Volume 2: Country Analyses, Policies and Trends in 15 European Countries, IMISCOE Research, Amsterdam University Press: Amsterdam, pp. 187-211.

The deputy who drafted this amendment explained in the National Assembly that it would be particularly applicable to the Chinese and Indonesian communities. As cited in J.P. Thiellay, "Le Volet "Nationalite" de la loi du 26 novembre 2003: un durcissement en catimini', L'Actualité Juridique de Droit Administrative, 17 Janvier 2005, pp. 67-70.

Rapport Annuel de la sous-direction des naturalisations (2007), Acquisitions et pertes de la nationalité française; Francisation des Noms et Prénoms, Données Chiffrées et Commentaires, Année 2006, Ministère de l'Emploi, de la Cohésion Sociale et du Logement. Retraivable from www travailsolidarite.gouv.fr A total of 87,878 have obtained the nationality by decision granted by public authority (par decret), and 29,276 have acquired it "par déclaration an titre de mariage".

Circulaire DPM $n^{\circ} 2000-254$ du 12 mai 2000 relative aux naturalisations, réintégrations dans la nationalité française et perte de la nationalité française, ministère de l'emploi, et de la solidarité Direction de la population et des migrations ministère de l'intérieur Direction des libertés publiques et des affaires juridiques.

Circulaire DPM n²000-254. 
verify two main elements: First, the linguistic assimilation, and second the cultural or social assimilation of the applicant.

Concerning the first of the conditions, that of linguistic assimilation, the Circular 2000-254 categorises as an essential element in order to qualify for naturalisation a sufficient knowledge of the French language, which is evaluated taking into account the qualifications of the applicant (mainly the level of education that s/he had received in the country of origin), her/his social situation and her/his possibilities of experiencing rapid progress taking into account the existence of a favourable environment (such as the fact that the children are already enrolled in school, living in a "milieu fiancophone", attendance of French language courses, etc.). Those applicants showing an unsatisfactory knowledge of French language, or whose level is not considered to be sufficient for everyday life, will be considered as 'insufficiently assimilated'. 949 The evaluation will take place through a personal interview with an official of the prefecture following the terms stipulated in Article 43 of the Decree of 30 December $1993 .{ }^{950}$ Further, the applications presented by certain categories of persons, such as former combatants, elderly or refugees will be examined taking into account the special circumstance of these specific categories of people ("font-elles l'objet d'un examen bienveillant").

Additionally, the "Arreté relatif au compte rendu de l'entretien individuel relatif aux déclarations de nationalité, aux décisions de naturalisation, de réintégration, de perte, de déchéance et de retrait de la nationalité française" of February 2005 has provided concrete rules specifying the nature of linguistic assimilation. ${ }^{951}$ According to this Arrête, the naturalisation policy mainly aims at "welcoming into the French population the new citizens sufficiently integrated who respect the rules and main values of our society". It establishes that the latter consists in testing whether the person meets the necessary level of oral comprehension and expression (no written dimension is included in the language test) for her/him to handle without any problem, and in an independent manner, simple situations of communication which may occur during her/his daily life in France. Linguistic assimilation will be checked in relation to the capacity of the applicant to communicate in French while dealing with situations such as, for example, access to transport and to the bank, post office and town hall, relations with doctors, professors, etc. As stated above, the level of required knowledge will depend on the particular situation of the person involved and taking into account her/his intellectual or educational qualifications. The Arrête also points out that the oral "entretien" or interview will last between 20 and 30 minutes in order to duly test the applicant's language skills.

The linguistic dimension may at times be coupled with elements related to the social and cultural integration and the applicant's way of life. ${ }^{952}$ An evaluation of the assimilation to French customs and traditions ("Assimilation aux us et coutumes") may also be carried out. In this

950 Décret no 93-1362 du 30 décembre 1993 relatif à la manifestation de volonté, aux déclarations de nationalité, aux décisions de naturalisation, de réintégration, de perte, de déchéance et de retrait de la nationalité française, J.O. $n^{\circ} 303$ du 31 décembre 1993. Article 43.

951 Arrêté du 22 février 2005 relatif au compte rendu de l'entretien individuel prévu à l'article 15 du décret no 93-1362 du 30 décembre 1993 relatif aux déclarations de nationalité, aux décisions de naturalisation, de réintégration, de perte, de déchéance et de retrait de la nationalité française.

952 The Arrête states that "L'assimilation à la communauté française du postulant est appréciée à partir d'un faisceau d'indices tangibles et convergents. L'élément essentiel est sa connaissance de la langue française qui est évaluée en tenant comple de sa qualification (et notamment du degré d'instruction reçue dans le pays d'origine) et de sa simation sociale ainsi que ses possibilités de progrès rapide découlant d'un enviromement favorable (enfants scolarisés, milieu francophone, cours de langue française...). Cette appréciation doit être complétée par des éléments sur l'intégration sociale et culturelle et sur le mode de vie du demandeur". 
regard, French law leaves a broad range of discretion to the official to decide whether the oral process of linguistic assimilation is sufficient to verify the assimilation of the person, or whether it is still necessary to check her/his 'way of life' in order to ensure that s/he is fully assimilated. If that is considered necessary, a social inquiry will be requested from the "direction départementale des affaires sanitaires et sociales, en ayant recours le cas échéant à une assistante sociale du service social d'aide anx émigrants". This official inquiry has the purpose of facilitating all necessary information regarding the social situation of the applicant's life and family.

In light of this, Circular 2000-254 demands from the official involved to take into consideration the existence of situations of polygamy, which are characterised as a very grave lack of integration and which would directly justify 'd'irrecevabilite' of the application for naturalisation. Monogamy appears to be officially considered as a French value and a general principle that must be respected. In fact, in March 1988 the Conseil d'Etat held that the fact that a TCN practices polygamy constitutes a "defaut d'assimilation", justifying opposition by the "ministre à l'accès à la nationalité française" to the concession of French nationality. 953 Moreover, the Circular states that "La circonstance que l'intéressé soit marié sous un régime de droit autorisant la polygamie ne permet pas à elle seule de conclure à un défaut d'assimilation et d'entrainer l'irecevabilité de la demande". Therefore, the simple fact of being married according to a law which allows the existence of polygamy does not represent per se a justifiable reason for concluding a lack of assimilation.

Circular 2000-254 "relative anx naturalisations, réintégrations dans la nationalité française et perte de la nationalité française" also calls for the need to check how the applicant treats his spouse and children, and whether the person shows traditions and customs which are fundamentally contrary to the 'values of the French society', in particular, the principle of gender equality. It even delves into what the applicant may be wearing; it will not suffice to mention "le port du foulard", it will be additionally necessary to specify whether the headscarf is the one traditionally used in the Maghreb or in Turkey, or "du hidjab qui couvre entièrement la tête et le cou et qui, à l'instar du tchador, est un signe d'appartenance $\dot{a}$ un islam fondamentaliste". It concludes by saying that in these last cases the official will be under the obligation to inform the applicant about the potential negative implications of these specific ways of using the headscarf. This rule needs to be read together with the respective judgements held by the Conseil d'Etat regarding the notion of "defaut d'assimilation" or lack of assimilation. ${ }^{955}$ In fact, wearing a headscarf was ruled to be not a valid reason for rejecting naturalisation by the Administrative Tribunal. The Conseil d'Etat ruled on 23 March 1994 that "la circonstance, à la supposer établie, que son épouse porterait le foulard islamique' ne

953 Conseil d'Etat, Ministre des affaires sociales et de l'emploi c. Diagne, T. p. 783, 11 mars 1988. Regarding the issue of polygamy see also Conseil d'Etat, M. Webina Orombia, Mme Webina Orombia, M. Kanou té, Leb. p. 68, 11 février 1994.

955 See for instance Conseil d'Etat, A. Faiza, Décision $N^{\circ} 286798,27$ Juin 2008, where it was held that "Considerant qu'il ressort des pièces du dossier que, si Mme A possède une bonne maitrise de la langue francaise, elle a cependant adopté ume pratique radicale de sa religion, incompatible avec les valeurs essentielles de la communaute française, et notanment aveo le principe d'égalité des sexes : qu'ainsi. elle ne remplit pas la condition d'assimilation posée par l'article 21-4 précité du code civil'. 
saurait, en tout état de cause, constimer un défaut d'assimilation du requérant". ${ }^{956}$ It is for this particular reason that the Circular points out that it will be necessary for the official to specify precisely the sort of headscarf that the woman will be using.

Further, six months after the presentation of the naturalisation application, the prefecture will transmit the complete final dossier and the avis or opinion of admissibility delivered by the official to the Central Administration ("sous-direction des naturalisations"), which holds the final discretion for the granting of a favourable decision of naturalisation of the person involved, and that according to Article 21-25-1 of the civil code will give a definitive answer within 18 months. The new "Loi relative à l'immigration et à l'intégration" No. 2006-911 of 24 July 2006, however, has amended this last provision by decreasing the waiting period to 12 months for those applicants who can prove an habitual residence of six months in France. ${ }^{958}$

Finally, the Loi No. 2006-911 has also introduced two new articles into the French civil code (Articles 21.28 and 21.29) institutionalising and harmonising at the national level the ceremony of reception into French citizenship ("cérémonie daccueil dans la ciroyenneté française"), which until then was often practiced in a rather dispersed and non-official manner by some prefectures. ${ }^{960}$ The ceremony's objective is the framing of the simple administrative act by which French nationality is acquired "dans une lumière

cérémoniale", and it has been in this way contextualised as the coronation of the person's successful integration and a celebration of absorption into the French Republican nation. ${ }^{961}$ As the French Minister of Immigration, Integration, National Identity and Co-development expressed in a reception ceremony held in the Department of Seine-Saint-Denis,

C'est à la fois l'aboutissement d'un parcours et le début d'une histoire. Aujourd'hui, la France devient votre patrie... Être Français se mérite. L'accès à la citoyenneté n'est pas un droit, mais un homeur...Avant de devenir Français, vous avez réussi voure parcours d'intégration. Vous avez démontré que vous maîrisiez la langue de norre pays, que vous respectiez les règles et que vous adheriez aux valeurs de notre République. Par vorre comportement, vous avez démontré que vous ètiez prét à devenir, à part entière, membre de la communauté nationale. ${ }^{962}$

The Inter-ministerial Circular 2007-63 related to the ceremonies of reception into French citizenship ("Circulaire interministérielle aux cérémonies d'accueil dans la citoyenneté

956 Majid Karshenas Najaf Abadi, 2/6 SSR, Conseil d'Etat statuant au contentieux $N^{\circ} 116144,23$ Mars 1994.

958 Circulaire interministérielle DPM/N3/DLPAJ/DAPAF no 2006-446 du 10 octobre 2006 sur la mise en cuvre des dispositions de la loi no $2006-911$ du 24 juillet 2006 relative à l'immigration et à l'intégration concernant la procédure de naturalisation, Article 84.

959 Article 21.28 .

960 The acquisition of French nationality by declaration consequent of the marriage of the applicant with a French citizen was exempted until the entry into force of this law of any ceremony.

961 J. P. Moinet (2006), Célébrer la bienvenue dans la République française, Rapport sur les cérémonies célébrant l'acquisition de la nationalité française Rapport à la Ministre déléguée à la Cohésion Sociale et à la Parité, Mme Catherine Vautrin, avril 2006.

962 Allocution de Brice Hortefeuw lors de la remise de décrets de naturalisation, retriavable from the web page of the Ministry of Immigration, Integration, National Identity and Codevelopment, Salle de Presse, Discourses at www.premier-ministre.gouv.fr 
française") of 9 February $2007^{963}$ specifies the following administrative and organisational aspects concerning the ceremonies: the persons who will be invited to the ceremony, including those acquiring French nationality and representatives of French society, ${ }^{964}$ the timeframe and deadlines for the celebration of the ceremonies, ${ }^{965}$ the different modalities and ways to organise them $^{966}$ and the links with the majors of the town hall where the applicant has her/his residence. ${ }^{967}$

The application of general assimilation requirements for a positive decision regarding naturalisation may raise a number of questions in relation to the high degree of legal uncertainty that it involves for applicants because of the great discretion of the French public administrations when deciding whether to check that the candidate possesses only the adequate knowledge of language, or whether it is necessary to delve further into testing the social and cultural dimensions. Moreover, the 'cultural or social assimilation' will be based on the cultural difference of the person involved, and her/his way of life, something which may be considered as being too subjective in nature to be left to the public official involved in the evaluation of 'the degree of Frenchness' of the non-national. As we will see in the next section, the requirement of Republican integration, along with its inherent subjectivities and uncertainties, has not remained static but has been recently enlarged to cover not only the acquisition of nationality through naturalisation, but also immigration law. Meeting the Republican condition of integration, as foreseen in a contractual bond between the immigrant and the state, represents at present one of the requirements for the immigrant to gain access to a security of residence and enjoy family life.

\section{The Normative and Contractual Framing of Integration in French Immigration Law}

963 Circulaire interministérielle DPM/N3 no 2007-63 du 9 février 2007 aux cérémonies d'accueil dans la citoyenneté française.

964 According to Article I of the Circular these invitees will include, in addition to the main organiser which will be in principle the official representative of the State in the department (or "outre-mer"), deputies and senators elected the department, the major of the commune of residence of the "new French" if s/he does not manifest any willingness to organise the ceremony as well as other invitees left to the choice of the organisers.

965 The deadline of six months for the organisation of the ceremony after the acquisition of the nationality will start running for those cases of acquisition by naturalisation from the publication of the décret in the Official Journal.

960 Annex 1 of the Circular presents a format of organisation of ceremony. For instance, the European anthem will be played in addition to "la Marseillaise". It also provides the possibility to show a film illustrating the history of France and the Republic, as well as the principles upon which French citizenship is founded. The room will need to be decorated with "les emblemes de la République francaise. comme le drapean, un buste ou portrait de Mariame". Moreover, a dossier will be given to the "Noureau Français" at the ceremony which will comprise among other documents the welcome letter by the President of the Republic, a brochure explaining the organisation of the public authorities in France as well as the rights and duties of the citizen, the Universal Declaration of the Rights of the Man and the Citizen of 1789 , extracts of the Constitution of the $V$ Republic, the text of the national anthem as well as the decree of naturalisation.

967 The Circular specifies the obligation provided by the new version of Article 21-29 of the code civil according to which the representative of the State in the department, or in Paris, the prefet de police need to communicate to the major, in her/his quality of officer of the civil status, the identity and address of the persons residing in the commune who will benefit from the ceremony of reception. 
This section looks at how French immigration law applies to the constructed category of integration. Since 2003 the Republican paradigm of integration has expanded from the former contextualisation under the umbrella of nationality law toward the one of immigration and, more particularly, the acquisition of the status of permanent resident and the granting of family reunification. Integration is no longer conceived only as a necessary ingredient for the ostentation of the status of citizen. The neo-republican integrationist doctrine covers those who, while perhaps not willing to fully adhere to the French Republican tradition and its nationality, may nevertheless aim to reside for a longer period of time in the country, and hence gain a major degree of security of residence. The current "politique d'accuei" has transferred the integrationist tradition into a contractual bond labelled "contrat d'accueil et d'intégration" (CAI), which is concluded between the would-be-permanent resident TCN and the French state. Its main features, objectives and scope will be now subject to study.

The modern mutation creating a close relationship between integration and the legislation on immigration, and converting it into a mandatory contract has taken place through the adoption of two successive legislative measures denominated as 'Sarkozy's laws I and II': "Loi $n^{\circ} 2003-$ 1119 relative à la maitrise de l'immigration, au séjour des étrangers en France et à la nationalite" of 26 November 2003; and "Loi $n^{\circ} 2006-911$ relative $\dot{a}$ l'immigration et $\dot{a}$ l'intégration" of 24 July 2006. Furthermore, a new "Loi relatif à la maitrise de l'immigration, à l'intégration et à l'asile" of 23 October 2007 has introduced an expansionist and external dimension to the set of functions played by Republican integration: expansionist because it will now cover the domain of family reunification; and external due to the need by TCNs aiming to become an immigrant according to French law to show her/his integration abroad before acquiring a visa.

\subsection{The Sarkozy Law I: The Birth of the Nexus between Integration and Immigration}

The "Loi relative à la maitrise de l'immigration, au sejour des étrangers en France et à la nationalite" $N^{\circ} 2003-1119$ was adopted on 26 November 2003. This measure represented the fifteenth revision of the "Ordonnance $n^{\circ} 45-2658$ relative anx conditions d'entrée et de séjou" des étrangers en France" of 2 November 1945. It abrogated this Ordonnance by substituting it with "une veritable codification" taking the shape of the "code de l'entrée et du séjour des étrangers et du droit d asile" (CESEDA). ${ }^{969}$ Law 2003-1119 presented as one of its objectives the granting of a significant degree of importance, unique until that stage in French legal tradition, to Republican integration ("I'intégration républicaine") as a requirement for TCNs to obtain a residence permit or the permission to settle regularly in France. If we look at the current administrative formalities for having access to the territory through established legal channels, and for residing regularly inside French territory, there are two kinds of residence permits ("itre de séjour") which may be granted: ${ }^{970}$

First, the permanent residence permit or "carte de résident" that is valid for a period of ten years, and which according to Article L 314-8 of the "Code de l'entrée et du sejour des etrangers et du droit d'asile" is given to any foreigner able to prove continuous and regular residence for a period of at least five years inside French territory. Other conditions are to prove sufficient

969 Ordonnance $n^{\circ} 2004-1248$ of 24 November 2004, which entered officially into force the $1^{\text {st }}$ of March 2005.

970 Gisti (2005), Le guide de l'entrée et du séjour des étrangers en France, La Découverte: Paris. 
sources of subsistence or the conduction of a professional activity, not representing a threat to public order and not practising polygamy. ${ }^{971}$ This permit confers to the holder an automatic right to access employment in France without restriction concerning the labour sector or geographical area.

Second, the temporary residence permit or "carte de sejour temporaire" that is only valid for one year and renewable for a maximum period of four years. ${ }^{972}$ There are various classes of temporary residence permits depending on the different legal categories of TCNs, such as visitors, students, scientists, professions of cultural or artistic nature and the private or family life category. ${ }^{973}$ Law No. 2006-911 has amended this provision by adding in Article 12 a new temporary residence permit that authorises the exercise of professional activity to all these juridical statuses. $^{974}$

The innovative elements related to the "carte de résident" that were introduced by Law 20031119 can summarised as follows:

First, the previous period of residence that was required by the 1945 Ordonnance was three years. The new law lengthened this timeframe to five years for all those TCNs holding the "carte de sejour temporaire" to obtain the "carte de résident". The official justification given for this increase was, according to the Explanatory Memorandum of the Projet de loi, because it was necessary in order to anticipate the adoption of the Proposal for Directive on the status of third country nationals who are long-term residents. This constitutes a first sign of the predominant sort of Europeanism pursued by the French authorities in the policy domain of immigration.

Second, the conditions for granting the "carte de resident" were also restricted by Article 21 of Law 2003-1119. This provision introduced the necessity for the TCN to meet a condition consisting of 'Republican integration' in the terms stipulated by Article 6 of the former Ordonnance of November 1945. Article 6 stipulated that the condition of integration of a TCN into French society will be measured mainly taking into account "sa connaissance de la langue française et des principes qui régissent la République française, qui doit étre suffisante, ainsi que de son comportement au regard de l'ordre public". Further, in order to measure the integration of the applicant "Le préfet (ou, à Paris, le préfet de police) pouvant, saisir pour avis le maire de la commune de résidence de l'étranger qui sollicite la carte de résident". 975

As explained above, this is a condition that until the entry into force of this law was not present in the context of immigration law, and was exclusively applicable as one of the requirements "de recevabilite" to acquire French nationality through naturalisation. Concerning the nature of this amendment, Laferriere (2005) has questioned the effectiveness of the double restriction

\footnotetext{
971 X. Vandendriessche (2005), Le Droit des Étrangers, Connaissance du droit, Éditions Dalloz: Paris, p. 79.

972. Code de l'entrée et du sejour des etrangers et du droit d'asile, Article L.313-4.

973 The main competent authority is L'Agence nationale de l'accueil des érangers et des migrations which was first established the 25 July 2005 . This agency has centralized two previous administrative bodies which formerly dealt with these fields: l'Office des migrations internationales (OMI) and le Service social d'aide anx émigrants (SSAE). See http://www.anaem.social.fr

These categories of immigrants have now access to the labour market subject to a series of conditions regarding the labour sector as mentioned in the residence permit.

975 C. Daadouch (2004), Le droit des étrangers, édition à jour de la loi du 26 novembre 2003, Collection Droit, Mode d'emploi, Editions MB Formation: Paris, p. 32 ; See also N. Guimezanes (2003), 'La loi nº 2003-1119 du 26 novembre 2003 relative à la maitrise de l'immigration, au séjour des étrangers en France et à la nationalité', La Semaine Juridique Edition Générale n 50, 10 Décembre 2003, act. 592.
} 
introduced by Law 2003-1119 in order to qualify for "la carte de résident". 976 As he argues, if the TCNs would not be considered to be sufficiently integrated s/he would remain covered by the rules applicable to the "carte de sejou temporaire". This temporary residence permit is valid for a limited period of one year, and can only be renewed four consecutive years. Therefore, after a period of five years the TCN would be required to leave the country because of her/his non-compliance with the Republican condition of integration. This, as we study in detail in Chapter 7, represents a questionable state practice because in principle the expulsion of the TCN would not take duly into account circumstances such as the period of time of her/his presence in the territory or the family links that could have emerged in France during this period. Its compatibility with human and fundamental rights would be open to debate. ${ }^{977}$

Law 2003-1119 also established a series of technical measures "destinées à permetre de mieux maîtriser les flux d'immigration; à celui du séjour en favorisant une meilleure intégration des étrangers en situation régulière mais d'une manière telle que le sort de beaucoup d'entre eux dewait s'en retrouver plutôt précarisé". ${ }^{978}$ Indeed, the way integration was used in this law aimed at better managing immigration, or, in another words, intended to limit the sustained, stable residence of TCNs. Further, while one of its main purported objectives was the simplification of various provisions that were until then applicable, the subordination of the possession of residence permits to 'better integration' in French Republicanism created a major vulnerability and insecurity in relation to the legal nature of the status of TCNs resident in France by placing them in the vulnerable position of being subject to a highly subjective decision. Also, falling into irregularity of stay will be facilitated by adding this legal requisite.

\subsection{The Contrat d'Accueil et d'Intégration: Integration as a Contractual Bond}

The welcome and integration contract $(\mathrm{CAI})^{979}$ seeks to institutionalise and formalise the integration of TCNs into the French nation for having access to security of residence in France. ${ }^{900}$ The application of the CAI originally started to be tested in twelve departements on 1 July 2003. ${ }^{981}$ In fact, the origins of the development of a contractual policy in the area of

976 F. J. Laferrière (2005), "La Loi No 2003-1119 du 26 Novembre 2003 relative à la maitrise de l'immigration, au sejour des étrangers en France et à la nationalité", in J.Y. Carlier and P. de Bruycker (eds), Immigration and Asylum Law of the EU: Current Debates / Actualite du Droit Européen d l'immigration et de l'asile, Bruylant Brussels, pp. 530-557.

977 F. J. Laferrière (2004), 'Une modification d'ampleur de l'ordonnance du 2 novembre 1945', l'Actualité juridique - Droit administratif(A.J.D.A.), $\mathrm{n}^{\circ}$ 5/2004, 9 February 2004.

D. Turpin (2004), 'Les nouvelles lois sur l'immigration et l'asile dans le contexte de l'Europe et la mondialisation', Revue Critique de DIP, 93(2) avril-juin 2004, see p. 315.

979 We use the English translation of the term provided by the Ministére des affaires sociales, du travail et de la solidarite in the harmonized model of contract.

980 S. Carrera (2006), A Comparison of Integration Programmes in the EU: Trends and Weaknesses, CHALLENGE Research Paper, Centre for European Policy Studies, CEPS: Brussels, March 2006.

981 Bouches-du-Rhône, Haute-Garonne, Gironde, Hérault, Jura, Nord, Bas-Rhin, Rhône, Sarthe, Vienne, Hauts-de-Seine and Val d'Oise. Note DPM/ACI I $\mathrm{N}^{\circ} 78$ relative aux modalités de mise en oenre de l'expérimentation du contrat d'accueil er d'integration, 23 avril 2003. See also L'accueil des étrangers en France: Le contrat d'accueil et d'intégration, Direction de la population et des migrations Bureau de l'action sociale, culturelle et territoriale. L'expérimentation de mise en place du contrat d'accreil et d'intégration. 31 July 2003, retrievable from: http:/www.social.gouv.fi/hm/pointsur/accueil/som cai.htm; D. Lochak (2006) has identified as the rooted origins of the rhetoric of the contractualisation of integration in a note distributed by the deputy of the UMP in Seine-et-Marne Yves Jego on the 9 October 
integration may be found in a speech delivered by the then President Chirac in Troyes on 14 October $2002^{982}$, where he emphasised that

Derrière ce mot d'imégration, les réalités sont multiples. Il y a la nécessité d'accueillir dans de bomes conditions les nowveaux arrivants, ceux qui rejoignent notre pays légalement et qu'il faut aider à mieux s'insérer dans notre socièté. Je souhaite ainsi, qu'à l'instar de ce qui existe chez certains de nos voisins, chaque nouvel arrivant s'engage dans un véritable contrat d'intégration comprenant notamment la possibilité d'accéder à des formations et à un apprentissage rapide de notre langue.

J.-P. Raffarin also expressed in March 2003 "sa volonté de forger une véritable politique publique de l'intégration, de rassembler la communauté des citoyens autour d'un projet partagé, un projet républicain et lä̌". Based on both official statements and the favourable political momentum, a meeting of an inter-ministerial committee on integration ("comité interministériel à l'intégration") ${ }^{983}$ took place on 10 April 2003 where 55 policy measures dealing specifically with the field of integration were agreed. Among others, they included "la mise en place d'un Contrat d'Accueil et d'Intégration". "In the words of F. Fillon, Minister of Social Affairs, Employment and Solidarity, it was necessary to establish a relationship based on trust and reciprocal obligations between France and those people aiming to settle for an indefinite period.

The step from the political discourse to its materialisation into law did not take long. The "Loi relative à la maitrise de l'immigration, au sejour des étrangers en France et à la nationalité" of November 2003 envisaged the juridification of the welcome and integration contract, and gave it a voluntary or facultative nature. ${ }^{985}$ Those TCNs admitted to reside in French territory for the first time and having the prospect of long-term settlement would be offered the possibility to conclude this contract with the French State. The preliminary explanatory information and the model of welcome and integration contract ("contrat type commm") would be presented to the inmigrant in a language that s/he would understand. ${ }^{986}$ The CAI would be based on reciprocal obligations between the immigrant and the State. The latter would assume the responsibility, according to Article 2 of the official common model, to provide the newcomer with the following services: a welcome meeting, a medical examination prior to issuing the residence permit, a personal interview with a social advisor for an assessment of the case, the social and language evaluation of the immigrant by the social worker and the provision of individualised support, a civic training day presenting fundamental rights and the major principles and values

2002 which was titled "Pour une nouvelle politique d'integration". This note proposed "une nowvelle logique de contractualisation entre le nonvel arrivant et la République", page 141.

982 Discours de monsieur Jacques Chirac Président de la République, Troyes - Aube, hundi 14 octobre 2002, available at www.elysee.fr

983 http://www.social.gouv. fr/htm/dossiers/comiteinterm/sommaire.htm The comité interministériel à l'intégration was established on December 1989. See Décret n89-881 du 6 décembre 1989, Décret portant création du comité interministériel à l'intégration, JORF du 9 décembre 1989. See also the Décret $n^{\circ} 2003-84$ du 30 janvier 2003 modifiant le décret n $89-881$ du 6 décembre 1989 portant création du comité interministériel à l'intégration

95.4 See Vers une refondation du modèle français d'intégration, Actualités, 10 April 2004, available at: hitp://www premier-ministre.gouv.fr/

985 S. Zappi (2003), French Government Revives Assimilation Policy, Migration Information Source, Migration Policy Institute, I October 2003. Retriavable from: http://www.migrationpolicy.org/

986 N. Guimezanes (2006), 'Le Statu Légal des Migrants', Revute internationale de droit comparé, Études de Droit Contemporain, Contributions françaises au $17^{\circ}$ Congrès international de droit comparé, Utrecht, 16-22 juillet 2006, cinquante-huitième année, $n^{\circ} 2$, Avril-Juin 2006, pp. 593-620. 
of the Republic, as well as of French institutions; language training adapted to the requirements of the new arrival, specific information on access to the public employment service and to professional training; an information day on life in France depending on requirements and requests in the form of units on the themes of health, schooling, housing, training and employment; and the monitoring and assessment of experiences and of any problems encountered. 987

Article 3 of the CAI provided that the TCN would need to attend a civic training/information day, to attend the prescribed language classes and any necessary interviews that for the monitoring of the continuation of the contract. ${ }^{988}$ The contracts, which would cover a period of one year, would specify language courses (between 200 and 500 hours) covering one-year periods and being renewable twice (for a total of three years). During this time 'the newcomer' would need to improve his/her language ability by one level at the minimum, but otherwise to the level required for naturalisation, and would therefore acquire a certificate attesting to participation at the training day and, depending on individual progress, "wne attestation ministérielle de competences linguistiques" (AMCL) ${ }^{989}$ While as a premise integration was seen as voluntary, once the immigrant signed the CAI, a contractual obligation was bom consisting of the obligation to attend civic training and language courses, as well as to go to any interviews that may be set for the monitoring of the performance of the contract. In fact, non-attendance of these civic and language courses constituted a breach of contract and could negatively affect the official decision on whether to grant the "statut de résident".990

"Le Haut Conseil à l'intégration" (HCI ${ }^{991}$ delivered on 26 January 2004 to the Prime Minister its annual report dealing specifically with the issue of "Le contrat et l'integration" and "la mise en place" of a civic training as a complementary element. ${ }^{992}$ In fact, the $\mathrm{HCl}$ had already supported in 2002 the creation of a "contrat républicain" at the national level based on the shared responsibility between the State and "les citoyens issus de l'immigration". 993 In its report of 2004, it reiterated that linguistic formation is a key, yet insufficient, ingredient of the integration policy, and therefore supported an intervention by Minister of Social Affairs Fillon in December 2003,994 calling for the need to couple the contract of integration with a "volet de

987 See the English version of the CAI, which has been translated into other seven different languages including Russian, Arab, Chinese, Rumanian, Turkish, Vietnamese and Indy.

988 For further information, refer to the Agence Nationale de l'Accueil des Etrangers et des Migrations at www.anaem.social.fr Ministère du Travail des Relations Sociales, de la Famille et de la Solidarité www.travail-solidarite.gouv.fr; the Ministre de l'Intérieur, www.interieur.gouv.fr; and the prime minister/government portal at www.premier-ministre.gouv.fr.

989 The International Centre for Migration Policy Development (ICMPD), Integration Agreements and Voluntary Measures: Compulsory or Volumary Nanure - Comparison of compulsory integration courses. programmes and agreements and volumary integration programmes and measures in Austria. France. Germany, the Netherlands and Swizerland, ICMPD, Vienna, May 2005.

S. Carrera (2006), "Integration of Immigrants Versus Social Inclusion: A Typology of Integration Programmes in the EU", in T. Balzacq and S. Carrera (2006) (eds.), Security versus Freedom: A Challenge for Europe's Future, Ashgate Publishing: Aldershot, 2006. http://www.hci.gouv. fr/

992 Haut Conseil à l'intégration (2003), Le contrat et l'intégration, Rapport à Monsieur le Premier Ministre, retraivable from htp://www hci.gouv.fr/rubrique.php3?id_rubrique $=16$

993 Haut Conseil à l'intégration (2002), Les parcours d'intégration, La Documentation française, coll. Rapports officiels, available at http://www.hci.gouv.fr/

994 Audition Publique de Monsieur François Fillon, Ministre des affaires sociales, du travail et de la solidarité, Haut Conseil à l'Intégration, 8 Décembre 2003. 
formation civique". In the opinion of Lochak (2006), ${ }^{995}$ this report by the HCI represented a key development in the building of the Republican French 'model' of integration as it combined for the first time the two semantic fields "La Republique" and "l'Intégration", something which as we have seen has exerted a major ideological impact in subsequent political and legal developments. In her view, the $\mathrm{HCI}$ advocated for an understanding of the Republic according to which the latter performs by its own nature an integrationist function ("ce qui est républicain est nécessairemént intégrateu") and, reciprocally, integration can be anything but Republican ("I'intégration he peut être que républicaine").

In 2004, fourteen new departments were already applying the CAI. ${ }^{996}$ On 31 December 2004, there were a total of 45,640 'newcomers' who had signed a contrat d'accueil et d'intégration: 8,027 during the second trimester of 2003; and 37,613 in 2004. ${ }^{997}$ Among those who had signed it, the main nationalities were from the Maghreb ( $50 \%$ from Morocco, Tunisia and Algeria). ${ }^{998}$ The adoption of Circulaire 2005-23 of 13 January 2005 generalised the applicability of the CAI to the whole French territory and all the departments from 1 January $2006 .{ }^{999}$ However, it was not until 2005 that it found a proper legal basis in French law. The Law $n^{\circ} 2005-32$ of 18 January 2005 de programmation pour la cohésion sociale harmonised for the first time the appreciation of the condition of Republican integration envisaged by the previous Law 20031119 and the necessity to take mainly into consideration when evaluating the latter the signature and the respect of the CAI by TCNs. ${ }^{1000}$ Article 146 of Law 2005-32 completed the "Code de l'action sociale et des familles" by including a new chapter entitled "Personnes immigrées ou issues de limmigration" and defined the CAl in Article L 117.1 of the mentioned code in the following manner:

Il est proposé à lout étranger admis pour la première fois au séjour en France en vue d'une installation durable de conchure, individuellement, avec l'Etat un contrat d'accueil et d'intégration. Ce contrat a pour objet de preciser les conditions dans lesquelles l'étranger signataire beneficie d'actions tenant compte de sa situation et de son parcours persomel et destinées a favoriser son intégration dans le respect des lois et des valeurs fondamentales de la République française. Ces actions comprennen notamment, lorsque le besoin en est établi. une formation linguistique sanctionnée par une validation des acquis.

In 2005 the number of persons who signed the $\mathrm{CAI}$ reached 66,478 . Since its experimental launching in July 2003 to the end of 2005, approximately 112,100 contracts had been signed.

995 D. Lochak (2006), 'L'intégration comme injonction. Enjeux idéologiques et politiques liés à l'immigration', in Identifier el Sumeiller: Les Technologies de Sécurite, Cultures \& Conflits, $N^{\circ} 64$ Hiver, L'Harmattan: Paris, pp. 131-147

In particular, and according to information provided by the Direction de la population et des migrations Bureau de l'action sociale, culntrelle et territoriale, the CAI was implemented in Ain, Alpes-Maritimes, Aude, Ille-et-Vilaine, Isère, Loire, Loire-Atlantique, Moselle, Pas-de-Calais, Paris, Tarn, Vendée, Essome and Seine-Saint-Denis. L'accueil des étrangers en France: Le contrat d'accueil et d'intégration, Direction de la population et des migrations Bureau de laction sociale, culturelle et territoriale, 3 March 2005, available at: http://www.social.gouv.fr/htm/pointsur/accueil/som_cai.htm

Haut Conseil à l'intégration (2006), Le Bilan de la Politique d'lntégration 2002-2005, available at htt://www.hci.gouv.fr/

In particular, until the end of 2004: 10208 Algerians, 6019 Moroccans and 2607 Tunisians. See Haut Conseil à l'intégration (2006), pp. 247-259.

See also the Protocole d'accord DPM/OMI/FASILD relatif a la mise en oeuvre du service public de l'accueil et du contrat d'accueil et d'intégration du 16 mars 2005.

Cimade (2006), 'Le Contrat d'Accueil et d'Intégration : un marché de dupes?', Canses Communes, numéro 49 - Janvier / Février 2006, available at www.cimade.org 
According to data provided by the former "Ministère de l'Emploi, de la Cohésion Social et du Logement", ${ }^{1001}$ the main nationalities among the signatories continued to be those of Algeria, Morocco, Tunisia and Turkey. As regards government data regarding $2006,{ }^{1002}$ it appears that these four countries still are among those presenting a higher number of nationals signing the CAI.

Table 4: Balance of the Number of CAI

\begin{tabular}{|l|c|c|c|c|}
\hline & $\mathbf{2 0 0 3}$ & $\mathbf{2 0 0 4}$ & $\mathbf{2 0 0 5}$ & $\mathbf{2 0 0 6}$ \\
\hline Number of People Audited & 9,254 & 41,734 & 71,927 & 99,703 \\
\hline Number of Signatories of CAI & 8,029 & 37,593 & 66,478 & 95,664 \\
\hline $\begin{array}{l}\text { Number of Persons inscribed to the } \\
\text { Civic Formation }\end{array}$ & 8,017 & 37,350 & 65,766 & 94,534 \\
\hline $\begin{array}{l}\text { Number of Persons inscribed to } \\
\text { Linguistic Formation }\end{array}$ & 2,774 & 11,407 & 17,161 & 24,436 \\
\hline $\begin{array}{l}\text { Inscriptions to journées "vivre en } \\
\text { France" }\end{array}$ & 1,468 & 8,322 & 12,887 & 21,537 \\
\hline
\end{tabular}

Source: Secrétariat général du comité interministériel de contrôle de l'immigration, Rapport au Parlement, Les orientations de la politique de l'immigration, quatrième rapport établi en application de l'article L. III-10 du Code de l'entrèe et du séjour des étrangers et du droit d'asile, December 2007.

\subsection{The Sarkozy Law II: The 2006 Law on Immigration and Integration}

The second law transforming the main characteristics of integration in French law has been the "Loi relative à l'immigration et à l'intégration" No. 2006-911 of 24 July $2006 .{ }^{1003}$ This law presents a series of important amendments to the "Code de l'entrée et du sejour des étrangers et du droit d'asile". First, it substantially mutates the functionality of integration as a mandatory contractual condition. ${ }^{1004}$ Second, it has been justified in order to meet the commitments of France to transpose EU immigration law into its national legal system, in particular the Council Directive on the status of third country nationals who are long-term residents $2003 / 109 .^{1005}$

1001 C. Régnard (2006), Rapport Annuel de la Direction de Population et des Migrations, Immigration et Présence Érangère en France en 2005, Ministère de l'Emploi, de la Cohésion Social et du Logement, pp. 96-112.

1002 Secrétariat général du comité interministériel de contrôle de l'immigration, Rapport au Parlement, Les orientations de la politique de l'immigration, quatrième rapport établi en application de l'article L. 111 10 du Code de l'entrée et du séjour des étrangers et du droit d'asile, December 2007, La Documentation Française, Retriavable from http://www.ladocumentationfrancaise.fr

1003 JORF, No. 170, 25 July 2006, page 11047. The law was presented before the Conseil constitutionnel which only presented one reservation to Article 45 of the law, and which declared the rest of provisions in conformity with the Constitution. See Conseil Constitutionnel, 20 juillet 2006, $n^{\circ} 2006-539$ DC, JO 25 juillet 2006, p. 11066.

1004 Uni(e)s contre une immigration jetable (2006), Analyse du projet de loi modifiant le code de l'entrée et du sejour des Étrangers et du droit d'asile (CESEDA), 11 April 2006, retriavable from www.contreimmigrationjetable.org

1005 Council Directive concerning the Status of Third-country Nationals who are Long-term Residents, 2003/109, 25 November 2003, OJ L16/44, 23.1.2004. 


\subsubsection{Integration as a Contractual Mandatory Bond and a Tool of Migration Control}

One of the most relevant innovations of Law 2006-911 has been the reconfiguration of the nature of the welcome and integration contract (CAI) into a mandatory bond. ${ }^{1006}$ The granting of the right of permanent residence. will be conditional to fulfilling the Republican condition of integration and the requirements stipulated in the contract. ${ }^{1007}$ The notion of reciprocity of obligations between the TCN and the State implicit in the foundations of the original version of the CAl has been therefore unbalanced on the side of the TCN with the entry into force of Law 2006-911. The new versions of Articles L. 311.9 and 314-2 of the CESEDA prescribe the subordination of the granting of the first carte de resident to the fulfilment of the condition of Republican integration to French society by the TCN. The degree of integration will be evaluated taking into account the commitment of the person involved to respect the principles governing the French Republic, the respect of these principles and the knowledge of French language. Article L. 314-2 further stipulates that for the appreciation of the condition of integration, the competent public authority will need to take into account the commitment of the applicant to the CAI (as provided in Article L. 311-19 of the code) and the favourable opinion by the "maire de la commune de residence". 1008 Those older than 65 years will be exempted from the condition related to the knowledge of the French language. The "Agence Nationale pour "Accueil des Etrangers et les Migrations" (ANAEM), ${ }^{1009}$ which is the competent institution designated for the organisation and finance of the courses, as well as of the services included in the Contract, ${ }^{1010}$ will also be in charge of monitoring the performance of the CAI.

Decree $N^{\circ} 2006-1791$ of 23 December 2006 has fine tuned and developed the features, objectives, procedures and scope of the CAI, as well as the precise functions of the ANAEM from 1 January $2007 .^{1011}$ The latter presents the contract to the TCN in a language that s/he understands during the course of a personal interview where the contract will be signed. ${ }^{1012}$ The $\mathrm{CAI}$ is concluded for a period of one year. ${ }^{1013}$ The "entretien individuel" will also serve to

1606 N. Guimezanes (2006), 'Loi de 24 juillet 2006 relative à l'immigration et à l'intégration', La Semaine Juridique-Edition Générale, № 36, 6 Septembre 2006, pp. 1623 and 1624.

1007 Article 45 says that the article L. $411-5$ of the Code de l'entrée et du séjour des étrangers et du droit d'asile is modified as follows: "3. Le demandenr ne se conforme pas anx principes fondamentaux reconnus par les lois de la République". See http:/www anaem.social.fr.

1008 E. Putman (2006), 'Loi du 24 Juillet 2006: Une Immigration selon les Mérites?', Revue Juridique Personmes \& Famille, 12, pp. 6-8.

1009 The competent authorities originally in charge of the monitoring of its implementation were /'Office des migrations internationales (OMI), le Fonds d'action et de soutien pour l'integration et la lutte contre les discriminations (FASILD), le Service social d'aide aux émigrants (SSAE) and le préfet (DDASS).

1010 Article R. 311-21.

1011 Décret $n^{\circ} 2006-1791$ du 23 décembre 2006 relatif au contrat d'accueil et d'intégration et au contrôle des connaissances en français d'un étranger souhaitant durablement s'installer en France et modifiant le code de l'entrée et du séjour des étrangers et du droit d'asile (partie réglementaire), NOR: SOCN0612582D, J.O $n^{\circ} 303$ du 31 décembre 2006 page 20346 , texte $n^{\circ} 39$. This Decree will apply to all the CAI signed after the 1st January 2007. See Article 2.

1012 Article R. $311-20$ of the Decree 2006-1791.

1013 Article R. 311-27 of the Decree states that the contract can be prolonged for one year more on the condition that the immigrant has obtained the renewal of her/his titre de sejour. The prorogation will be give by le prefet following the proposal by the ANAEM. The prorogation will be take place automatically provided that the compulsory language course is still duly and regularly followed at the end of the first year of the contract. 
determine the level of knowledge of the French language by the TCN through the use of a multiple choice exam. ${ }^{1014}$ The "Arrêté relatif aux formations prescrites aux étrangers signataires du contrat d'accueil et d'intégration et à l'appréciation du niveau de connaissances en français" of 19 January 2007 has stipulated the official model of multiple choice exam to be used in these cases, and the ways in which the capacities of oral and written expression and comprehension will be evaluated. ${ }^{1015}$ The required level of French language knowledge is the equivalent of the initial diploma of French language contained in Article D. $338-23$ of the Education Code. The test, which will last for 15 minutes and will be carried out by a social worker, will aim at verifying the proficiency in oral and written expression and comprehension of the TCN in ordinary life circumstances. The evaluation of the oral proficiency will last for a maximum of ten minutes and will be graded with a maximum of 70 points. The test of written proficiency will last five minutes, and will include, for instance, verifying whether the individual is able to understand simple instructions, basic information, to take a telephone number or an address, to complete a form, to leave a simple message, etc. This part will be graded up to 30 points. Therefore, from the total of maximum grade of 100 points including both sections, the immigrant will need to get a final grade equal, or superior, to $50 / 100 .^{1016}$ If that is the case, according to Article 311-23.2 of the Decree, a ministerial certificate will be issued exempting $\mathrm{him} / \mathrm{her}$ from attending the language course.

If the person does not reach the required level of language proficiency, Article 311-24 of the Decree states that the CAI will impose on her/him 'the obligation' to attend a French language course. The institution that will be in charge of offering this training is designated by the ANAEM. This language course will not exceed 400 hours. The proof of attendance will be validated by a nominative certificate delivered by the ANAEM following the information provided by the training institution. The proficiency in French acquired within the framework of the language course will no longer be validated by the "attestation ministérielle de competences linguistiques" (AMCL), but rather by an initial diploma of French language ("diplôme initial de langue française", DILF), contained in Article D. 338-23 of the Education Code after passing an exam on oral and written comprehension and expression capacities. ${ }^{1017}$ The financial burden or fees linked with the DILF in the context of the CAI are covered by the French State.

In addition, the CAI also foresees a civic training course and an informative session about life in France. ${ }^{1018}$ The civic training, provided in Article L. $311-9$ of the code, according to Article R. 311-22 of the Decree $N^{\circ} 2006-1791$, will specifically comprise the presentation of the French institutions and of the values of the Republic, which mainly include equality between men and women, secularism, the rule of law, fundamental freedoms, the safety of people and goods as

1014 Article R. $311-23$ of the Decree.

1015 Arrêté du 19 janvier 2007 relatif aux formations prescrites aux étrangers signataires du contrat d'accueil et d'intégration et à l'appréciation du niveau de connaissances en français prévues aux articles R. 311-22 à R. 311-25 du décret no 2006-1791 du 23 décembre 2006 relatif au contrat d'accueil et d'intégration et au contrôle des connaissances en français d'un étranger souhaitant s'installer durablement en France et modifiant le code de l'entrée et du séjour et du droit d'asile (partie réglementaire) NOR : SOCN0710178A, J.O du 30 janvier 2007, Texte 13 sur 103.

1016 In the oral part the minimum grade that will be asked is of $35 / 70$.

1017 It is stated that "Ce diplôme correspond au niveau Al.I évoqué supra et présente l'intérêt de constituer la première étape d'un parcouss de centification des compétences en français en tant que langue étrangère que prolongent le diplôme d'étude et le diplôme approfondi de langue française (DELF et DALF)".

1018 See Guide du formateur de la Journée d'information 'vivre en France', Ministère de l'emploi, de la cohésion sociale et du logement, Direction de la population et des migrations, January 2006. 
well as the exercise of citizenship which allows the mandatory and free access to education. The total duration of this training will be six hours. ${ }^{1019}$ The participation in this course will be validated with a nominative certificate of regular attendance granted by the ANAEM. ${ }^{1020}$ Further, the contract also foresees a session offering information concerning 'the lifestyle in Republican France' as stipulated in Article R. 311-25 of the Decree. The session aims at providing the signatory of the CAI sufficient knowledge about practical life in France and access to public authorities and services which mainly include training, employment, housing, health, education, minor policies as well as community life. The session will last a minimum of one hour and a maximum of six hours. ${ }^{1021}$ Attendance will also be certified by the ANAEM in an "attestation d'assiduite".

The CAI will end on the month following the finalisation of the compulsory period of training regardless of the successful or negative nature of the validation, or at the latest one day after the exam leading to the delivery of the nominative diploma. ${ }^{1022}$ Article R. 311-28 of Decree 20061791 provides that the contract may be declared terminated by the prefect of the place of residence of the TCN, following the advice of the ANAEM, when there is evidence of nonattendance or non-compliance with the contractual obligations and there is no legitimate reason exempting the person from them. The prefect will inform the TCN of the termination and its negative consequences on granting or renewing "la carte de séjour" provided in Article L. 311-9 of the "code de l'entrée et du séjour des étrangers et du droit d'asile" as well as in the appreciation of the Republican condition of integration stipulated in Article L. 314-2 of the same code. At the end of the contract the ANAEM will verify whether the TCN has complied with all the obligations included in the welcome and integration contract, which will be deemed to be respected when the TCN has been granted with all the certificates and "attestation d'assiduite" above mentioned. ${ }^{1023}$ The ANAEM will then issue a certificate recapitulating the compliance with the provisions of the CAI and the ways in which they have been evaluated and graded. This certification will be sent to the prefect of the place of residence of the TCN.

The contractual logic of the Republican condition of integration has become in this manner another tool for controlling immigration, a technique which seems to be inspired by a double paradigm: 'controlling by integrating' and 'integrating for controlling'. The phenomenon of immigration is controlled by making use of integration as another condition of a restrictive policy. On the other hand, integration is required for controlling the management of diversity and plural identities in Republican France. The failure to integrate into French society, understood as the violation by the TCN of the obligations provided by the CAI, will lead to insecure residence status of the TCN, who will not be granted the permanent residence permit, or will justify the negative decision regarding the renewal of the temporary administrative status of stay, and hence the consequent expulsion from the country. Republican integration creates in this manner more vulnerability and insecurity for TCNs rather than contributing to their inclusion in the different societal dimensions structuring the imagined French nation.

\footnotetext{
1019 Article 1 of the Arrêté du 19 janvier 2007.

1020 Article R. 311-21.

1021 Article 2 of the Arrêté du 19 janvier 2007.

1022 Article R. 311-27 of the Decree 2006-1791.

1023 Article R. 311-29 of the Decree 2006-1791.
} 


\subsubsection{The Directives 2003/109 and 2003/86: Transposing Integration Measures and Conditions in French Law?}

One of the main objectives of the Sarkozy Law II was the implementation of the legal elements of EU law on regular immigration. The "Loi relatif à l'immigration et a l'intégration" transposes into French law the Council Directive on the status of third country nationals who are long-term residents 2003/109. Chapter V of the Law, entitled "Dispositions relatives aux étrangers bénéficiant du statut de résident de longue durée au sein de l'Union européenne", establishes between Articles $24-29$ the provision implementing the Directive. ${ }^{1024}$ Article 24 creates a new Article L. 313-4-1 in the CESEDA according to which the TCN who has already acquired the EC Status of Long-Term Resident in another EU Member State will need to meet two main conditions in order to obtain a residence permit in France: stable resources and health insurance. Also, the application for the acquisition of the French residence permit will need to be presented no later than three months after her/his entry into French territory. The kinds of residence permit that the $\mathrm{TCN}$ will be able to acquire are: ${ }^{1025}$

1. Temporary Residence Permit ("carte de sejour temporaire") under the categories of:

1.1. Visitor ("carte de séjour temporaire mention "visiteur"), as stipulated in Article L 313-6.

1.2. Scientist ("carte de séjour temporaire mention 'scientifique") as provided in Article L 3138.

1.3. Artistic and cultural profession ("carte de séjour temporaire mention "profession artistique et culturelle") regulated in Article L 313-9.

1.4. Employee or seasonal worker ("Salarie" or "travailleur" temporaire" which is provided by Article L 313-10.1, 2 and 3).

1.5. Private and Family Life ("Vie privée et familiale"), Article L 313-11-1 which is granted to the spouse and the minor children of those third country nationals who had already obtained the EC Status of Long-Term Resident in another Member State.

2. To those persons holding the "carte de resident" or a permanent residence permit according to Article 314.8 of the code, the new Law envisages that in addition to the two conditions of stable resources and health insurance, the TCN will also need to provide evidence of her/his intention to settle long-term in France through, for example, the conditions under

1024 See Gisti (2008), Le guide de l'entrée et du séjour des étrangers en France, La Découverte: Paris, pp. 95-105.

Uni(e)s contre une immigration jetable, Analyse du projet de loi modifiant le code de l'entrée et du sejour des Érangers et du droit d'asile (CESEDA), 11 April 2006, retriavable from www.contreimmigration jetable.org

See Loi relatif à la maitrise de l'immigration, à l'intégration et à l'asile $n^{\circ}$ 2007-1631, version consolidée 21 novembre 2007, retriavable from http://www.legifrance.gouv.fr See also the versions Projet de Loi relatif à la maitrise de l'immigration, à l'intégration et à l'asile, Assemblée Nationale $N^{\circ} 57,4$ juillet 2007 ; and Projet de Loi relatif à la maîtrise de l'immigration, à l'intégration et à l'asile, $\mathrm{N}^{\circ} 11$, Sénat, adopté le 23 octobre 2007. V. Guiraudon (2008), Integration Contracts for Immigrants: Common Trends and Differences in the European Experience, Commentary, Real Instituton Elcano, 7 may 2008, retrievable from www.realinstitutoelcano.org 
which s/he performs professional activities and the availability of sufficient sources for subsistence, and independence from State social welfare system.

3. The residence permits mentioning competences and skills ("La carte de séjour portant la mention compétences et talents") stipulated by Article L 315-1.

The administrative rules for putting into practice Article 24 of the new law will be developed later by a Décret. Further, Article 28 of the Law, which amends accordingly Article 314.7 of the CESEDA, provides that "la carte de résident portant la mention 'résident de longue durée-CE"" will be withdrawn if "the long-term resident Other" has resided outside the EU for a period exceeding three consecutive years. The EC status will be also withdrawn if the TCN acquires the same status in another Member State or if s/he has been residing outside French territory for a period of six consecutive years.

Furthermore, the "Loi relatif à la mâtrise de l'immigration, à l'intégration et à l'asile" $n^{\circ} 2007$ 1631 of 20 November 2007 has substantially transformed the scope and expanded the nature of integration in French immigration law. ${ }^{1028}$ This initiative was presented only one year after the previous Sarkozy Law 2006-911 was adopted by the French Senate on 23 October 2007, validated on 15 November 2007 by the Constitutional Council (Conseil constitutionnel), ${ }^{1029}$ and published in the official joumal on 21 November of the same year. The law introduces a significant transformation of the Republican integrationist philosophy, which will now cover the domain of family reunification and be subject to a process of externalisation through the practice of the concept of "integration abroad'. ${ }^{1030}$ Cimade (2007) argued that this act constitutes a new regression in the right to family life in France, and that the obstacles that it will pose in practice will rather prevent sustainable settlement in satisfactory conditions by the family members of TCNs already settled in the country. ${ }^{1031}$ Furthermore, one of the key official justifications offered by the government for the legislative reform to take place is the need to transpose into French law the Council Directive on the right to family reunification 2003/86. ${ }^{1032}$ As we have studied in Chapter 4 of this book, Article 7.2 of the Directive offered the possibility to Member States to introduce into their respective legal systems integration measures to the family members as criteria for granting family reunification even when they are still in the country of origin. $^{1033}$

1029 See Décision $N^{\circ} 2007-557$ DC, 15 novembre 2007, available at http://www.conseil-constitutionnel.fr

1030 According to the Explanatory Memorandum "Le présent projet de loi prévoit que le membre de famille qui demande à rejoindre la France bénéficie dans son pays de résidence ou, s'agissant d'un conjoint de français, dans celui où il sollicite le visa, d'une évahuation de son degré de comaissance de la langue et des valeurs de la République"..

1031 Cimade (2007), Analyse du Projet de Loir Relatif a l'Immigration, a l'Intégration et a l'Asile, Version du Projet de Loi du 4 Juillet 2007, retriavable from www.cimade.org

1032 Council Directive on the right to family reunification 2003/86, of 22 September 2003, OJ L251/12, 3.10.2003. Following the wording of the original Explanatory Memorandum of the first version of the proposal in Article 1 "fait application de ce dispositif de préparation au parcours d'intégration républicaine aux étrangers de plus de seize ans pour lesquels est sollicité le bénéfice du regroupement familial. Ces dispositions sont dans le droit fil de la directive 2003/86/CE du 22 septembre 2003 relative au droit au regroupement familial qui, dans son anticle 7, paragraphe 2, prévoit que les États membres pewent exiger des ressortissants de pays tiers qu'ils se conforment aux mesures d'integration dans le respect du droit national".

1033 Article 7.2 of the Council Directive states that "Member States may require third country nationals to comply with integration measures, in accordance with national law". The measure should have been introduced in the French legal system no later than $5^{\text {th }}$ October 2005 , deadline for the transposition of the Directive by all the Member States. See Article 20 of the Council Directive. 
The first paragraph of the Explanatory Memorandum of the original "Projet de Loi" began by making reference to the total number of "titres de sejour" on the basis of family reunification that had been granted in France and to its relevance when comparing it to other French channels of regular immigration, such as that of employment and education. ${ }^{1034}$ According to official data offered by the 2005 Annual Report of "La Direction de la Population et des Migration" of the former Ministry of Employment, Social Cohesion and Housing entitled "Immigration and Foreign Presence in France in 2005", 1035 the following figures correspond with the different classes of entries within the context of family reunification in France from 2000 until 2005:

Table 4: Titres de Sejour on the basis of Family Reunification in France 2000-2006

\begin{tabular}{|c|c|c|c|c|c|c|}
\hline $\mathbf{2 0 0 0}$ & $\mathbf{2 0 0 1}$ & $\mathbf{2 0 0 2}$ & $\mathbf{2 0 0 3}$ & $\mathbf{2 0 0 4}$ & $\mathbf{2 0 0 5}$ & $\mathbf{2 0 0 6}$ \\
\hline 21,404 & 23,081 & 27,267 & 23,808 & 23,744 & 23,502 & 20,005 \\
\hline
\end{tabular}

Source: Rapport Annuel de la Direction de Population et des Migrations, Immigration et Présence Étrangère en France en 2005, Ministère de l'Emploi, de la Cohésion Social et du Logement; and Secrétariat général du comité interministériel de contrôle de l'immigration (2007). ${ }^{1036}$

The years 2005 and 2006 have actually experienced a decrease in the number of residence permits being granted on the basis of family reunion, when comparing it to data from previous years. The government, however, still considers that the number of these entries is 'too high' and that they call for an institutional response to make the conditions even stricter. Therefore, one of the core underlying goals of the proposal was to limit the number of entries by TCNs on the grounds of family reunification (which has been encapsulated in the label "immigration subie") by using the concept of 'Republican integration of the family into the French society' as a condition in French immigration policy. The more relevant amendments proposed by the new Loi in relation to our subject of analysis may be summarised as follows: ${ }^{1037}$

First, Article 1 of the Law adds a new Article L. 411-8 in the CESEDA that states that every TCN over 16 and under 65 years old subject to an application for family reunification will be evaluated in her/his country of residence on her/his degree of knowledge of the French language and the values of the Republic (Republican integration abroad). ${ }^{1038}$ Further, it is stipulated that

1034 The number of immigrants residing legally in "la France métropolitaine" reached the 4.9 millions by mid 2004. The main nationalities of origin have been, in order of importance in term numbers: Algeria, Morocco, Turkey, Tunisia, Vietnam, Senegal, Chine and Mali. See C. Borrel (2006), Enquêtes Anmuelles de Recensement 2004 et 2005: Près de 5 million d'immigrés à la mide de 2004, Insee, Cellule Statistiques et études sur immigration, Insee Première No 1098, August 2006.

C. Régnard (2006), Rapport Annuel de la Direction de Population et des Migrations, Immigration ef Présence Étrangère en France en 2005, Ministère de l'Emploi, de la Cohésion Social et du Logement, pp. 96-112.

Secrétariat général du comité interministériel de contrôle de l'immigration (2007), Les orientations de la politique de l'immigration - Quatrième rapport établi en application de larticle L.1II-10 du code de l'entrée et du séjour des étrangers et du droit d'asile, La Documentation française: Paris. Available at www.ladocumentationfrancaise.fr

Article 7 of the new law has also modified Article L. 311-9 of the CESEDA.

The precise of wording of the new provision is the following "Pour lui permettre de préparer son intégration républicaine dans la société française, le ressortissant étranger âgé de plus de seize ans et de moins de soixante-cing ans pour lequel le regroupement familial est sollicité bénéficie, dans son pays de résidence, d'une évaluation de son degré de comnaissance de la langue et des valeurs de la République. 
depending on the result of the evaluation, the administrative authority will organise in the country of origin a course whose duration will not exceed two months. At the end of this time the person will again be subject to an evaluation of the knowledge of the language and Republican values. It is interesting to see the kind of rhetoric used by this legal act, which may lead the reader to think of the non-mandatory nature of Republican integration abroad for obtaining a visa and benefiting from family reunification. The official language uses terms referring to the possibility "allowed" or "permitted" to the would-be-immigrants to "benefit from" this training, which will supposedly help them to integrate in the Republican tradition. There are very few formal references implying any kind of obligation or compulsory nature. In light of this, for instance, the Explanatory Memorandum even states that

Cetle obligation de moyens n'ajoute ancune condition de fond pour' l'obtention d'un visa de long séjour ou le bénéfice du regroupement familial mais elle évite l'arrivée en France de migrants privés de tout repère et facilite l'accomplissement du parcours d'intégration républicaine.

However, the proposal's soft wording is deceiving. While reference is made to the existence of an "obligation de moyens", and not to an obligation of result, the notion of obligation is still there. Further, Article 411-8 expressly provides that family reunification, and the delivery of the visa, will be "subordinated" to the presentation of a certificate of attendance to the training or integration course which will last a maximum of two months. ${ }^{1039}$ Therefore, as Guimezanes (2007) has argued, it is clear that the certificate of attendance will constitute a 'condition', and not a 'measure', for the actual delivery of the visa. ${ }^{1040}$ This discursive tactic is perhaps well founded on the distinction made by Council Directive 2003/86 between integration 'conditions' and 'measures'. As we argued in Chapter 4, the use by Article 7.2 of the term measures implied that the Member States would be prevented from implementing it into their national legislation as a mandatory requirement for having access to the EU-rights and guarantees provided by the Directive. It appears that this new Law attempts to hide, without success, the binding character that integration abroad will have in order for the family member to be issued a visa. It is evident that the successful evaluation of Republican integration abroad will be from now onwards taken as a criteria for the person to be reunited, and hence, for the Council Directive 2003/86 to become operational. There are still many uncertainties and practical issues in need of specification, such as who is going to cover the costs of the courses promoting Republican integration abroad, or the role that French consular and diplomatic missions in third countries are going to play in the evaluation process of 'the knowledge' of the applicant for family reunification: how knowledge of French language and of Republican values will be examined in practice.

Second, according to Article 10 of the Law any TCN spouse of a French citizen less than 65 years old will also be subject to the 'condition of Republican integration abroad' before obtaining a visa. Article 211-2-1 of the code will be reformulated to include that "Pour hii permettre de préparer son intégration républicaine dans la société française", the spouse of a French national will 'benefit' from an evaluation of her/his level of knowledge of the French

Si cette évaluation en établit le besoin, l'autorité administrative organise à l'intention de l'étranger, dans son pays de résidence, une formation dont la durée ne peut excéder deux mois, au terme de laquelle il fait l'objet d'une nouvelle évaluation de sa connaissance de la langue er des valeurs de la République. La délivrance du visa est subordonnée à la production d'ume attestation de suivi de cette formation".

1039 The precise conditions will be later on fixed by a Decree, where it will be specified the precise period of time of the formation and the legitimate reasons for the immigrant to be exempted this obligation.

1040 N. Guimezanes (2007), 'Premier Aperçu du Projet de Loi Maîtrise de l'immigration', La Semaine Juridique Edition Générale № 28, 11 Julliet 2007, act. 321. 
language and the values of the Republic. If the competent authorities so determine, a course of a maximum duration of two months will be organised. The previous comment concerning the misleading character of the language being used by the initiative also applies in this respect. While the Law reiterates terms such as "permitting and allowing to prepare" Republican integration as an option for and benefit to the spouse of a French citizen, the act then states that the evaluation of 'the knowledge' by the spouse will constitute grounds for delivering the visa.

Third, Article 7 has invented another version of the welcome and integration contract related this time to the official conception of Republican integration of the family in French society ("Contrat d'accueil et d'intégration pour la famille", CAIF). A new Article 311-9-1 imposes on those TCNs holding a permanent residence permit and her/his family having benefited from family reunification, and "lorsqu'un ou plusieurs enfants on bénéficié de la procédure de regroupement familiar", to both conclude with the French state a contract which will oblige them to follow a course on "the rights and duties of parents in France", and to ensure a proper schooling of their children. In those cases where the contractual conditions are not respected either by the TCN or her/his spouse, the measure foreseen in Article 222-4-1 of the "code de l'action sociale et de familles" consisting of the application of a contract of parental responsibility will apply and they may be penalised with a financial sanction consisting of the cessation of family social benefits ("allocations familiales") granted by the French state, and eventually administrative sanctions consisting of a refusal to renew the "carte de séjour temporaire" or grant the "carte de resident", and hence to eventual expulsion from the country. $^{1041}$

Apart from the adequacy, proportionality and compliance with fundamental rights of the functionality of integration within a mandatory contract which will need to be fulfilled for the family not to be penalised by the French State, a similar comment applies to the non-facultative nature implied by the CAIF; the compliance between this Law and the Council Directive 2003/86 remains critical. Article 2 of the Law is very clear as regards the conditional nature of this factor as it includes among the conditions for rejecting family reunification, in addition to stable and sufficient resources and normal housing, ${ }^{1042}$ that the applicant does not follow "the essential principles which, according to the laws of the Republic, regulate family life in France".

\section{Conclusions}

The relationship between integration/assimilation and the legal/policy frameworks on nationality and immigration has been subject to various dynamics and logics throughout French legal history. The French Republican paradigm of integration has deeply influenced the public philosophies and managerial strategies practiced by the State over the phenomenon of human mobility and the diversity of identities within the imagined nation. This Chapter has started by 'setting the scene' concerning the existing academic debate addressing the fundamentals and theoretical implications subsumed in these public strategies and responses. Differently from the case of Spain, France shows a rooted tradition in defending the existence of a 'national model on integration' based on a particular reading of Republicanism. The French Republican thought

1041 Finally, the knowledge of the values of the Republic has been added to Article 313-11 of the code as a condition for proving the 'insertion' of the immigrant into French society necessary for the granting of the "titre de séjour" based on personal and family links. This kind of residence permit had been actually introduced by the previous Law 2006-911, and its delivery is here further restricted by subjecting it to the insertion of the applicant in relation exclusively with the knowledge of the Republican values.

See new Article L411-5. 
offers a strong vision of a certain national historical memory and a commitment to culture and ethnic-blind universalism. It sustains the existence of a kind of Republican values, way of life and customs whose relationship with diversity and heterogeneity provokes a fundamental tension. The constitutive factors of French Republicanism, and the managerial public model of integration that it bestows, demand the privatization of cultural differences and the disappearance of alternative identities and public ways of life. The principle of equality and the recognition of membership represent the privileges resulting from the assimilation and naturalisation of those considered as 'the abnormal' into the perfection attributed to French citizenship. Assimilation or, in its current version, integration functions as the norm in hands of the State to oblige the non-national to loose all her/his identities in favour of the one perceived as 'mainstream' in the French nation.

We have then provided a historical account of the main regulatory and political developments affecting the articulation between integration, nationality and immigration since the $1880 \mathrm{~s}$ until our present days. The appearance of integration as an institutional and structural issue has been situated in the 1980s as a consequence of two main factors: first, a significant role played by the extreme right-wing (FN); and second, the strategy from the left to provide some sort of 'identitarian therapy' to the political crisis and the post-colonial phases. Integration has since then contaminated the whole political spectacle and other academic and societal sectors. It has additionally became institutionalised as 'the Republican integration' thanks to interventions and reports issued by national actors such as the $\mathrm{HCl}$, and 'experts' taking part in study committees on nationality and immigration.

Similarly to the normativity of integration in the Spanish legal system, the French Republican integrationist doctrine finds its origins in nationality law, and more specifically, as one of the requirements for acquiring French nationality by naturalisation. In fact, the set of conditions for naturalisation has represented one of the most contested issues of political debate and legislative reform in French law. The category of assimilation functions as one of the conditions for the non-national to cross the bridge leading to citizenship. While this condition only included the need to show a 'sufficient knowledge' of the French language, the legal criterion consisting of the knowledge of 'the rights and duties conferred by the status of French nationality' was later on introduced in 2003. The evaluation of the condition of linguistic assimilation does not pose major legal uncertainties. However, the examination of the cultural and social assimilation of the applicant raises a number of concerns. French law leaves a very large level of discretion to the public authorities at times of testing the assimilation to 'the French customs and traditions' whose compatibility with the principles of legal certainty and proportionality remains critical.

The conceptual and structural configurations that had been traditionally attributed to the Republican integration have experienced important transformations since 2003. Integration has been transferred from nationality law to the rules regulating the conditions for admission and residence of TCNs (regular immigration). Integration has become a constitutive norm of French immigration law and policy. The reconfiguration of the framing of integration from the realm of nationality to the one of immigration involves a decisive shift in French legal tradition concerning the approaches driving the normative use of integration. The Republican conditionality of integration does not only play managerial and disciplinary functions in hands of the State to correct any anomaly or deviation from the perfect citizenry and national identity. Republican integration acts as a criterion for TCNs to attain security and rights. The subjectivity, lack of certainty and wide degree of discretion enjoyed by public authorities identified in the context of nationality law at times of carrying out that test becomes even more acute and disproportionate. The latest legal developments have reinforced and strengthened the nomative nexus between integration and immigration, and have led to the emergence of a neo-Republican 
integrationist doctrine. The Sarkozy's Laws of 2003 and 2006, and the new Loi relative a la maitrise de l'immigration, à l'intégration et à l'asile of 2007 have fostered the development of three parallel processes of normativisation (CAI), expansionism (CAIF) and externalisation (integration abroad). All these processes present integration as a mandatory or binding condition in the side of TCNs for having access to rights and protection linked with the policy dimensions of admission, security of residence and family reunification.

The innovative normativity of integration in French immigration law has been justified by the French government as a consequence of its obligation to transpose in its national legal system EU law on regular immigration, and more precisely, the Council Directives 2003/109 on the status of third country nationals who are long-term residents and the 2003/86 on the right to family reunification. The EU has been instrumentalised for backing up the development of innovative national political priorities of sensitive and restrictive nature. The effects of this kind of Europeanism, and the nature of the implementation carried out in France of these EU measures, might be critical when putting them in relation to the general principles of $E U$ law. The next Section of the book addresses the consequences of the interplay between those national implementing laws falling within the scope of EU law on regular immigration and the general principles of proportionality and fundamental rights. 


\section{SECTION IV - THE INTERPLAY BETWEEN EU AND NATIONAL IMMIGRATION LAW: THE GENERAL PRINCIPLES OF EU LAW}

\section{Chapter 7: \\ Testing Member States' Actions against the Principle of Proportionality and Fundamental Rights}

\section{Introduction}

This Chapter focuses on the relationship between the normative articulation of integration as a consequence of the transposition of EU immigration law in the national arena, and the general principles of EU law. The field of immigration has gradually experienced major processes of harmonisation materialising in a set of common laws at European level. The Europeanisation of this domain means that Member States are no longer free in their politics, strategies and laws on the management of human mobility and diversity. Areas such as the status of TCNs who are long-term residents and that of family reunification fall now within the scope of the institutional and substantive mechanisms inherent to the EU legal system. A set of mechanisms offering a framework of protection beyond the classical demarcations of the nation-state are available to the individual subject to administrative measures and executive/normative practices resulting from these transnational harmonisation processes. Along with the obligation to transpose EU law into their respective national legislation, Member States will also need to comply with the so-called general principles of EU law.

The stage of practical implementation becomes one of the testing grounds for the system of checks foreseen by the EU system of governance to become operational and effective. Derogations and exceptions from the application of rights and freedoms provided at the EU level, including those conferred by European immigration law to TCNs, will be subject to the confinements allowed by EU law. The general principles of EU law, which have been developed, interpreted and proactively expanded by the ECJ, function as common sources ensuring the legality of the different levels comprising EU decision-making, and limiting the discretion, normative power and sovereignty of Member States within the EU configuration at times of restricting and derogating European rights and freedoms. By doing so, they intend to bring a higher level of security to the individual, and to contribute toward an EU legal system whose fundamentals are truly based on the rule of law. The principle of proportionality, in close connection with the one of fundamental rights, constitutes one of the most important bastions in this endeavour.

A certain tension arises when putting in relation certain features of the modern understanding of integration as foreseen by the transposition of European immigration law at the national level, and the general principles of EU law. It is in the implementation phase, where the administrative acts falling within the scope of EU immigration law will need to be reviewed in light of the general principles because of the substantial level of discretion left to Member States by some of its provisions. The use of minimum standards as a legal technique in the domain of regular immigration makes the principles fundamental instruments for ensuring that Member States' actions comply with EU law and the rule of law. The case of France represents a paradigmatic example for assessing the ways in which EU immigration law is implemented at the national level and becomes part of its legal system. When examining the modern articulation between 
integration and immigration in the French legal system in Chapter 6, we argued that the latest legislative developments have institutionalised a number of logics of normativisation, expansionism and externalisation affecting the nature and functions of Republican integration. These processes have been officially justified on the basis of the obligation to act and transpose the Council Directives 2003/109 and 2003/86. This sort of Europeanism advocated by France, and the logic by which integration is driven by these multifaceted processes potentially make it interfere with European rights proclaimed by EU immigration law, and raises a number of uncertainties when putting them in relation to the general principles of EU law.

Section one of this Chapter begins by studying the general principles of EU law and their application to the common EU immigration policy and the evolving area of European immigration law. It offers some reflections about the literature addressing the theoretical understandings of the principles and the role that they might perform inside the EU legal system. These general sources of European law provide valuable mechanisms with far-reaching potentials for ensuring the respect of the rule of law and fundamental rights within the realm of immigration law in the EU. Section two studies the conjunction between the principles of proportionality and fundamental rights in the context of Member States' actions at times of implementing European immigration law. The connection between proportionality and fundamental rights represents a core ground of contestation for the legality of current national politics, laws and practices as regards the latest trends affecting the usage by immigration law of the integration of TCNs in cases such as France. Both principles focus on the protection of the individual against the acts and practices of the Union and the Member State when acting within the EU framework. This Section assesses the meaning, nature, scope and some of the latest judicial developments in respect of these two principles, and the role that the review exercised by the ECJ has meant towards their consolidation as fundamental tenets of the EU regulatory system. We shall examine the way in which Member States' actions within the scope of European immigration law, and particularly at times of transposing it in their domestic laws, might be subject to judicial review.

The use of the legal technique of 'minimum harmonisation' and the interpretation of integration as a legal conditionality by the Council Directives on the status of third country nationals who are long-term residents and on the right to family reunification has left the door open for Member States to apply stricter immigration rules on admission, residence and family reunion of TCNs. France provides a significant case study in this respect as it appears to have instrumentalised European immigration law to legitimise the implementation of stringent immigration policies. Given the lack of a 'formal transposition' in the Spanish legal system of the Council Directives 2003/109 and 2003/86, Section three seeks to apply the the tests of proportionality and fundamental rights to the transposition of these Directives only with respect to French law. It shall examine the legality of the processes of normativisation, expansionism and externalisation affecting the "intégration républicaine" in relation to the general principles of EU law.

\section{The General Principles of EU Law and the Rule of Law in EU Immigration Law}

The EU legal system is being articulated with a compendium of substantive and institutional mechanisms, decision-making techniques and logics deemed to be necessary for guaranteeing that its foundations are anchored in the rule of law, democracy and the respect of fundamental rights. Article 6 TEU expressly stipulates that "the Union is founded on the principles of liberty, democracy, respect for human rights and fundamental freedoms, and the rule of law, principles which are common to the Member States". In the same vein, at the Tampere European Council 
Conclusions of October 1999, the European Council acknowledged that "From its very beginning European integration has been firmly rooted in a shared commitment to freedom based on human rights, democratic institutions and the rule of law". ${ }^{1043}$ This commitment has also been highlighted in the jurisprudence of the ECJ, ${ }^{1044}$ which has considered the rule of law as one of the constitutive elements of the European integration processes. The rule of law in the ordre communautaire implies the existence of a web of multilayered elements limiting, reviewing and making accountable the performance by the executive and various normative powers in which the EU is being structured, and ensuring the security of the individual by offering her/him the necessary tools and protection to resist and challenge possible illiberal practices of transnational and national forms of governance. This is what Simon (1991) has referred to as "le droit au droit". ${ }^{1045}$ In the EU legal configuration the ECJ case law has played a fundamental role in ensuring the judicial control of harmonised public actions and transnational legal techniques put forward by the European Institutions and implemented by the Member States in their national realms. The interpretation and review developed by the ECJ over the common legislative measures has made use not only of material laws as formally proclaimed in primary and secondary sources, but also of a set of unwritten, judge-rendered principles considered to embrace the EU legal system and to provide the theoretical substance for its interpretation and development. These principles of administrative legality are called the general principles of EU law, and have attained the status of a distinct, objective source of European law. The general principles perform a number of significant functionalities inside the EU legal framework, making the rule of law and the security and liberty of the individual one of their premises.

De Witte (2000) has defined them as "unwritten principles, recognized by the European Court of Justice, that have a status of higher law by the fact that they may be invoked as a standard of review of Community acts". ${ }^{1046}$ In his view, they are important instruments for the protection of the individual against the laws and practices carried out by the European and national administrations considered to have intrusive, and potentially damaging, consequences over EU rights, interests and/or fundamental freedoms. The general principles have been considered as high ranking fundamental rules in the Union. They embrace the EU legal system, and provide an autonomous source of interpretation and review in the hands of the judiciary. The principles facilitate the democratic process by which the practices of the liberal state and the EU are made accountable and subject to judicial review.

1043 Tampere European Council, 15-16 October 1999, Presidency Conclusions, SN 200/99, Brussels.

1044 Case 294/83, Les Verts v. Parliament, 23 April 1986, [1986] ECR 01339, Paragraph 23 provided that "it must first be emphasized in this regard that the European economic community is a community based on the rule of law, inasmuch as neither its member states nor its institutions can avoid a review of the question whether the measures adopted by them are in conformity with the basic constitutional charter, the treaty". See also Case 19/61, Mannesmann AG / ECSC High Authority, 13 July 1962, [1962], ECR 675 , where the ECJ made reference to a principle of justice, and Case $155 / 79, A M \& S / C o m m i s s i o n, 18$ May 1982, [1982] ECR 1575, where it stated the need to respect the maintenance of the rule of law.

1045 D. Simon (1991), 'Y a-t-il des Principes Généraux du Droit Communautaire?', Droits, Revue Française de Theorie Juridique, 14, pp. 73-86. This author argues that this is one of the main axes composing the "Rechtstaatilichkeit" in the Community legal order. He says that the Community legal system provides a set of principles protecting individual rights which have been developed by the European judiciary for the guarantee of legal security.

1046 B. de Witte (2000), "Institutional Principles: A Special Category of General Principles of EC Law", in U. Bernitz and J. Nergelius (eds), General Principles of Community Law, European Monographs, Kluwer Law International: The Hague, pp. 143-159. 
The general principles have been subject to extensive academic attention. ${ }^{1047}$ It is our intention to provide a summarised discussion serving as a conceptual basis for the actual goals of this Chapter. In order to gain a global understanding of their relevance and scope, the literature has offered various possible categorisations of the principles. Schermers and Waelbroeck (2001), for instance, have distinguished among three different subgroups: ${ }^{1048}$ First, the compelling (or constitutional) legal principles, which would stem from the common European legal heritage and would form part of the natural law (e.g. principle of proportionality or the protection of fundamental rights); second, the regulatory principles common to the laws of the Member States, which would not contain any element of justice, faimess and equity, but they would be of pure regulatory nature; ${ }^{1049}$ and third, the general principles native to the EU legal system that would develop independently of the national legal orders and which, because they are followed by the ECJ, would end up being embodied gradually into the general rules of the EU system (e.g. freedom of movement).

This and other divisions were later criticised by Trimidas (2006), who has referred to them as vague and ambiguous in nature. ${ }^{1050}$ After raising doubts about the necessity to classify the general principles in different categories, this author has also presented an alternative based on what he denominates as "the results reached in concrete cases", and which may be summarised as follows: First, principles deriving from the rule of law, and which would be characterised by their derivative nature resulting from the case law of the ECJ. These principles would imply that the public authorities would be subject to substantive and procedural limitations. The ECJ would also use them to supplement and refine the material provisions inserted in the Treaties. They would include, for example, the principle of proportionality, fundamental rights, etc. A second category would include the systematic principles which underline the constitutional structure of the Union and define the EU legal edifice. These would refer to the relationship between the EU and the Member States, and to some extent to the legal positioning of the individual in this respect.

Actually, the dual classification put forward by Trimidas appears to be somehow inspired by the one presented by de Witte (2000), who differentiates between the general principles of EU law and the general principles of institutional law. The latter would not serve to protect the position of the individual by reviewing EU acts, but would rather regulate the EU institutional relations

1047 T. Trimidas (2006), The General Principles of EU Law, Oxford University Press: Oxford, Second Edition; H. G. Schermes and D. F. Waelbroeck (2001), Judicial Protection in the European Union, Kluwer Law International: The Hague; J. Schwarze (1992), European Administrative Law, Sweet and Maxwell: London; U. Bernitz and J. Nergelius (2000), General Principles of European Commumity Law, European Monographs, Kluwer Law International: The Hague; P. Craig (2006), EU Adiministrative Law, Oxford University Press: Oxford; B. J. Boulouis (1993), Droil Institutionnel des Communautés Europeenes, Fourth Edition, Montcherstein: Paris; M. Akehurst (1981), 'The Application of General Principles of Law by the Court of Justice of the European Communities', British Yearbook of Imernational Law, pp. 29-51; A. Amull (1990), The General Principles of EEC Law and the Individual, Leicester University Press: Leicester; and R.E. Papadopoulou (1996), Principes Génératox de Droit et Droit Communautaire, Origines et Concrétisation, Bruylant: Bruxelles.

lots H. G. Schermes and D. F. Waelbroeck (2001), Judicial Protection in the European Union, Kluwer Law International: The Hague.

1049 In this regard the two authors make reference to Case 8/56, Alma, 10 December 1957 [1957-1958] ECR 98, where the ECJ accepted that "a written declaration of intent becomes effective as soon as it arrives in due course within the control of the addressee".

1050 T. Trimidas (2006), The General Principles of EU Law, Oxford University Press: Oxford, Second Edition. 
both at horizontal (principle of institutional balance) and vertical levels (Article 5 TEC ${ }^{1051}$ and the Protocol on the application of the principles of subsidiarity and proportionality attached to the TEC by the Treaty of Amsterdam). Following this division, our interest for the purposes of this book will be mainly centred on those principles considered to be 'general' in EU law and having a role of interpretation and of review of the legality of administrative decisions and practices. These are the ones really at stake in the attempt to make the protection of European individual rights effective in the EU and at times of reviewing the legality of derogations and interferences by Member States in relation to these European rights and freedoms.

While the general principles are mainly of an unwritten nature, there are few examples where the Treaties have expressly made an indirect or direct reference to them as a source of EU law. Hence, Article 220 TEC states that "the Court of Justice and the Court of First Instance, each within its jurisdiction, shall ensure that in the interpretation and application of this Treaty the law is observed". In this regard, "the law" might well refer to something of a higher ranking in the juridical hierarchy reigning over the EU legal regime. ${ }^{1052}$ In the same vein, Article 230 TEC stipulates that the ECJ has jurisdiction "in actions brought by a Member State, the European Parliament, the Council or the Commission on grounds of lack of competence, infringement of an essential procedural requirement, infringement of this Treaty or any rule of law relating to its application, or misuse of powers". Finally, and within the specific context of non-contractual liability by the EU, Article 288.2 TEC establishes that "in the case of non-contractual liability, the Community shall, in accordance with the general principles common to the laws of the Member States, make good any damage caused by its institutions or by its servants in the performance of its duties".

Apart from these express references in substantive EU law, the European Courts have been the ones holding the responsibility for the creation and development of the principles as general sources without the need for any specific reference in the Treaties. The strategy advocated by the ECJ in the proactive judicialisation, and to some extent innovative expansionism, of EU law comprises one of the characteristic features of the European judge when comparing her/him to similar judiciary practices at the national and international levels. While doing so, the ECJ has enjoyed a high degree of liberty and autonomy. The lack of a common written body of general principles of administrative law in the Union led to the judgement of the ECJ on July 1957 in the Joined Cases 7/56, 3/57 to 7/57 Algera, where it stated that "unless the court is to deny justice it is therefore obliged to solve the problem by reference to the rules acknowledged by the legislation, the learned writing and the case-law of the member countries". 105 S The ECJ embarked in this way on the endeavour of developing a European set of general principles to fill any lacunae inherent to the EU legal system. Some authors have argued that this was in fact a strategy to preserve the primacy of EU law over national law. ${ }^{1054}$ As we will discuss in Section

1051 Article 5 TEC says that "The Community shall act within the limits of the powers conferred upon it by this Treaty and of the objectives assigned to it therein...Any action by the Community shall not go beyond what is necessary to achieve the objectives of this Treaty".

1052 T. C. Hartley (2007), The Foundations of European Community Law: An Introduction to the Constitutional and Administrative Law of the European Commminty, Oxford University Press: Oxford, Sixth Edition.

1053 Joined Cases 7/56, $3 / 57$ to 7/57, Dineke Algera. Giacomo Cicconardi, Simone Couturaud, Ignazio Genuardi, Félicie Steichen v. Common Assembly of the European Coal and Steel Community, 12 July 1957, [1957] ECR 00039.

1054 J. Coppel and A. O'Neill (1992), 'The European Court of Justice: Taking Rights Seriously?, Common Market Law Review, 29, p. 669; For a critique of this idea see J. H. H. Weiler and N. Lockhart (1995), 
2.2 below, this might well have been the case in the context of reviewing the relationship between EU action and fundamental rights.

The role of the ECJ in fostering the prevalence of the general principles has been impressive. While doing so, it has followed certain legal systems and constitutional traditions of the Member States composing the EU as well as other international regulatory sources considered to be common to them. The roots of the principles are vastly diverse. Both the national and the international spheres have provided sources of plural and diversified inspiration upon which they have been originated and later on matured. Independent of their actual origins, and leaving aside the discussions as regards which one of the Member States may have played a more prominent role, it is worth recalling that the judicial use of these legal sources has made of them a compendium of independent transnational principles no longer attached to a particular setting or venue, but characteristic of the Union's legal order. The judicial techniques practiced by the EU Courts have provoked the emergence of common rules considered to be of a fundamental nature and to benefit from supranational status. Therefore, the general principles have ended up being guided by two parallel logics: one of autonomy from their original sources, and another one of supremacy over the latter on the basis of the doctrine of the supremacy of EU law as a key ingredient of the new EU legal order. ${ }^{1055}$ The consolidation of these general rules as principles in the entire EU legal order leads to the emergence of an impressive process when returning to the legal systems of the Member States. The domestic realm will then benefit from a wider set of sources than those predominating solely in their traditional juridical venues when moving in those areas subject to Europeanisation processes. The individual, and the protection of her/his civil liberties and fundamental rights, henceforth benefits from the relationship between the national, intemational and European sources and principles of law. ${ }^{1056}$

The general principles of EU law might play several functions within the configuration and structures comprising the EU legal order. Emilou (1996) has argued that they have been applied mainly in one of the following roles: ${ }^{1057}$ First, as guides for the interpretation of the Treaties and secondary legislation; second, as means for ensuring the protection of basic rights recognised at the EU level against unlawful interference by the Union, the European Institutions or the Member States; third, as mechanisms for reviewing the legality of acts of the European institutions and of national implementing measures by the Member States; and fourth, as instruments filling the gaps in EU law when its material provisions do not provide a satisfactory

'Taking Rights Seriously' Seriously: The European Court and its Fundamental Rights Jurisprudence', Common Market Law Review, 32, pp. 59-82.

For a detailed study of the relationship between EU law and national law, and the principle of supremacy of the former see for example P. Craig and G. de Búrca (2007), EU Law: Text, Cases and Materials, Oxford University Press: Oxford, Sixth Edition, Chapter 10, pp. 344-378; See also S. Prechal (2007), "Direct Effect, Indirect Effect, Supremacy and the Evolving Constitution of the European Union", in C. Barnard (ed.), The Fundamentals of EU Law Revisited: Assessing the Impact of the Constitutional Debate, Oxford University Press: Oxford, pp. 109-152; J. Steiner, L. Woods and C. Twigg-Flesner (2006), EU Law, $9^{\text {th }}$ Edition, Oxford University Press: Oxford, Chapter 4, pp. 69-88; G. Davies (2006), 'Subsidiarity: The Wrong Idea, in the wrong place, at the wrong time', Common Market Law Review, Vol. 43, No. 1, pp. 63-84; K. Alter (2001), Establishing the Supremacy of European Law: The Making of an International Rule of Law in Europe, Oxford University Press: Oxford; De Witte, B. (1999), "Direct Effect, Supremacy and the Nature of the Legal Order", in P. Craig and G. de Búrca (eds), The Evolution of EU Law, Oxford University Press: Oxford, pp. 177-213.

1056 D. Simon (1991), 'Y A-T-1l des Principes Généraux du Droit Communautaire?', Droits, Revue Française de Theorie Juridique, 14, pp. 73-86.

1057 N. Emiliou (1996), The Principle of Proportionality in European Lav: A Comparative Perspective, Kluwer Law International: The Hague. 
answer to the case at stake. It is to a great extent in the context of the second and third functions where the principle of proportionality and fundamental rights might play a decisive role with respect to the protection offered by the EU legal system to TCNs subject to the normative understanding of integration provided by European immigration law. The general principles provide a set of transnational legal sources for examining the impact of EU and Member States' actions affecting the rights and liberties of the individual, including those being labelled as TCNs. They can be used as instruments for practising a sort of liberal test assessing the extent to which the practices of the EU and the Member State comply with the rule of law and do not exceed any permissible exception or derogation.

\subsection{The General Principles and Member States' Actions in the Scope of EU Immigration Law}

The ECJ has repeatedly confirmed that the general principles of EU law do not only apply to the acts of the EU per se and its institutions, but also to the Member States while implementing European law in their national arenas. Both dimensions will be interpreted and tested in light of the general principles. In particular, their applicability becomes particularly relevant when Member States need to comply with their obligations under the Treaties (obligation to act included in Article $10 \mathrm{TEC}$ ), and more precisely in the transposition of EU law in their national legal regimes. ${ }^{1058}$

While the ECJ has not yet had the occasion to explore whether a derogation by a Member State to rights and freedoms provided by European immigration law fall within the scope of the general principles of EU law, it would be contested not to think that those immigration-related sectors having become European law should equally benefit from their scope of protection. The utility of the principles in European immigration law has been qualified by Boeles (2007) as potentially constituting an essential guide for the EU and the Member States to solve sharp conflicts within the scope of this branch of EU law. ${ }^{1059}$ Moreover, there should be no doubt that TCNs falling within the scope of EU immigration law also need to benefit from the mechanisms of transnational legal protection, including of course the general principles and their judicial interpretation. 1060

The ECJ has recognised jurisdiction over all those policies where it has an express EU competence. ${ }^{1061}$ It is therefore a natural consequence to conclude that the judicial review that it exercises covers without distinction legal acts resulting from the common EU immigration

1058 Article 10 TEC states that "Member States shall take all appropriate measures, whether general or particular, to ensure fulfilment of the obligations arising out of this Treaty or resulting from action taken by the institutions of the Community. They shall facilitate the achievement of the Community's task. They shall abstain from any measure which could jeopardize the attainment of the objective of this Treaty".

1059 P. Boeles (2007), 'Some Thoughts on General Principles of Community Law' and Other Conceivable Impact on European Migration Law', Presentation at the Meeting of the Scientific Research Group "Transposition of and Legal Protection under Future European Migration Law", 5 October 2007, Antwerpen.

1060 According to Guild and Peers (2006), "the exclusion of third-country nationals from the scope of EC law is the exception, not the rule...the jurisprudence of the Court of Justice consistently counter the "guetto" approach to third country nationals". E. Guild and S. Peers (2006), "Out of the Ghetto? The Personal Scope of EU Law", in S. Peers and N. Rogers (eds), EU Immigration and Asylum Law: Text and Commentary, Leiden: Martinus Nijhoff Publishers, The Netherlands, pp. 81-1 14. 
policy. In Chapter 4 it has been explained how the ECJ enjoys full jurisdiction to review and interpret measures of the EU institutions having their legal basis in Title IV of the TEC on "Visas, Asylum, Immigration and Other Policies related to the Free Movement of Persons". There is only one limitation to this general jurisdiction, which is stated in Article $68 \mathrm{TEC}$ and which restricts the possibility for presenting a preliminary ruling following the procedure stipulated in Article 234 TEC to those national courts and tribunals of the Member States against whose decisions there is no judicial remedy under national law. ${ }^{1062}$ Yet, this exception does not preclude its competence to review these measures and practices, and while doing so applying the general principles of EU law.

Further, the Europeanisation of immigration with the entry into force of the Amsterdam Treaty in May 1999, and its framing within the so-called First Pillar, has over the last nine years resulted in the transference of a great degree of competence to the EU in relation to particular elements related to this domain. We recall that the EU's integrationist machinery has led to the adoption of various Council Directives covering certain regular immigration-related areas such as the degree of legal security attached to the length of regular residence by a non-EU citizen in a Member State, the movement of these TCNs who are long-term residents to a second Member State, family reunification, etc. In fact, the communitarisation of immigration, and the state's obligation to implement EU immigration law, involves a difficult realisation by some Member States that much competence has since been transferred to the Union. The right of Member States to exercise discretion in immigration policies has therefore been deeply affected and constrained by these integration processes. ${ }^{1063}$ The European regulatory setting offers at present a transnational level of protection to the individual falling in the juridical category of TCN, independent of the at-times restrictive, ever-changing and nationally-oriented interests of Member States. Here the principles of EU law also play a key role. The protection and set of guarantees that are provided by European law, ${ }^{1064}$ which conveniently include the general principles, prevent Member States from not meeting European standards and rights in their national arenas. As Groenendijk (2006) has pointed out,

The application of the new EC migration law at the national level... will diminish the "exceptional" nature of immigration law...and will make national authorities and others aware that many special administrative techniques and barriers applied only in immigration law, such as extremely high fees, exclusion of judicial control, or excessively one-sided interpretations of general rules of administrative law... are no longer possible. ${ }^{1065}$

1062 Article 68.1 TEC states that "Article 234 shall apply to this Title under the following circumstances and conditions: where a question on the interpretation of this Title or on the validity or interpretation of acts of the institutions of the Community based on this Title is raised in a case pending before a coun or tribunal of a Member State against whose decisions there is no judicial remedy under national law, that court or tribunal shall, if it considers that a decision on the question is necessary to enable it to give judgment, request the Court of Justice to give a ruling thereon". See S. Peers (2007), "The Jurisdiction of the Court of Justice over EC Immigration and Asylum Law: Time for a Change?", in A. Baldaccini, E. Guild and H. Toner (eds), Whose Freedom, Security and Justice? EU Immigration and Asylum Law and Policy, Hart Publishing: Oxford, pp. 85-108.

E. Guild (1999), 'Discretion, Competence and Migration in the European Union', Eturopean Joumal of Migration and Lan', Vol. 1, No. 1, pp. 61-87.

1064 P. Boeles (2006), "What rights have migrating third country nationals?", in J.W. de Zwaan and F. Goudappel (eds), Freedom, Security and Justice in the European Union: Implementation of The Hagne Programme, The Hague: T.M.C Asser Press, pp. 151-63.

1065 K. Groenendijk (2006), "Citizens and Third Country Nationals: Differential Treatment or Discrimination?", in J.Y. Carlier and E. Guild (eds), The Fimure of Free Movement of Persons in the EU, 
In addition, the role of the ECJ at times of reviewing and interpreting the provisions offered by these harmonised laws will be of increasing relevance. The reach of the general principles become even more interesting when addressing the legality of the laws enacted by Member States based on their obligation to transpose European regulations. It is in the implementation phase where the new legal measures in the context of European immigration law will need to be examined in light of the general principles, all the more so when taking into account the significant level of discretion left to Member States by the sort of EU immigration law which has so far been developed. A proper assessment of Member States' action will verify the extent to which the commonly agreed rights, paradigms and standards provided by the common immigration policy are maintained and properly transposed in the domestic realm. This will be one path for guaranteeing that the rights recognised by the EU legal system are respected consistently and coherently all across the Union, and that any interference complies with the general principles of EU law. The individual who is subject to the Europeanisation processes can therefore rely on the general principles to resist laws and practices eventually undermining an EU right or freedom before national courts and authorities. ${ }^{1066}$ They constitute mechanisms of special significance at times of resisting any interference by Member States considered to be unlawful because of its contested proportionate nature or its lack of compliance with fundamental rights.

It is clear that the general principles of EU law have the potential of playing an important reparative and innovative role in the context of European immigration law by filling the gaps, clarifying obscurities and legal uncertainties, interpreting material provisions, facilitating the evaluation and review of implementing national legislation and expanding the framework of protection of EU rights in the national legal spheres of the Member States. In particular, the principles of proportionality and fundamental rights are among those having at the centre of their attention the protection of the individual against acts and practices of the EU and the Member States when acting within the framework of EU law. The consequences of the normativity of integration in immigration law in the national arena, as a consequence of the impact of EU law, might lead to the refusal of a residence permit and the issuing of an expulsion order to TCNs. The principles of proportionality and fundamental rights might well offer a set of guarantees beyond the classical configuration of the nation-state against any unacceptable practices and exceptions surrounding admission and expulsion, and derogations to rights envisaged in European immigration law.

\section{The General Principles of Proportionality and Fundamental Rights: The Review of Member States' Actions within EU Immigration Law}

The connection between the general principles of proportionality and fundamental rights represents a core ground of contestation for the legality of current politics, laws and practices at the national level interfering with European rights recognised in the sphere of EU immigration law. This Section looks at the meanings and some of the latest developments with respect to these two principles as regards Member States' actions within the context of EU law. The ECJ has played a paramount role toward the actual configuration of the principles inside the EU legal order, and their application to Member States as a consequence of the operability of Articles 226

Collection du Centre des Droits de L'Homme de la'Université Catholique de Louvain, Brussels: Bruylant, pp. 79-101.

1066 E. Brouwer (2007), Digital Borders and Real Rights: Effective Remedies for Third-Country Nationals in the Schengen Information System, Martinus Nijhoff Publishers: Leiden, Chapter 10, pp. 303-313. 
(infringement proceedings) and 234 (preliminary ruling) TEC. ${ }^{1067}$ We shall start by examining the ways in which the ECJ has understood the interaction between the principle of proportionality and the Member States' actions when implementing EU law. This will be followed by an analysis of fundamental rights as general principles of EU law, with a special focus on the right to respect for family life of TCNs and the ways in which Member States' actions have been interpreted by the ECJ in this regard.

\subsection{The Principle of Proportionality: Protecting TCNs' Rights in the EU}

Proportionality has become one of the most relevant tenets composing the general principles of EU law. The principle of proportionality has been subject to a rich academic reflection. ${ }^{1068}$ Special attention will be paid here to its relationship with Member States' actions in relation to EU immigration law. This principle has been traditionally used to review the legality of administrative actions undertaken by the EU and Member States falling within the scope of EU law. It constitutes a fundamental source for the judicial oversight of the interplay among the various layers of executive and normative powers in which the EU is enshrined. Proportionality involves a particular articulation of the rule of law for the coverage of the discretionary powers by public authorities affecting those rights and freedoms of the individual enjoying a European scope of recognition and application. This principle provides hence a unique instrument for the protection of liberty and security of the individual at EU level. As Schwarze (1992) has put it, proportionality is "a manifestation of the principle of the rule of law, and...it provides a certain degree of 'guarantee of substance' in relation to the protection of specific fundamental rights provided under the framework of Community Law". ${ }^{1069}$ It is precisely this "guarantee of substance' of rights which is at stake when the Member States act in the various processes of implementation of EU law.

While the principle made its début in the Case $8 / 55$ Fédechar, ${ }^{1070}$ the ECJ did not make use of it as an express ground for review until the beginning of the 1970s in the Case 11/70 Internationale Handelsgesellschaft. ${ }^{1071}$ Since then, it has evolved as one of the fundamentals

1067 Article 226 TEC provides the infringement procedure by the European Commission in those cases where it considers that a Member State has failed to fulfill an obligation under the Treaties. Article 234 TEC states the preliminary ruling procedure. See respectively Chapters 12 on "Enforcement Mechanisms against Member States" and 13 on "Preliminary Rulings" of P. Craig and G. de Búrca (2007), EU Law: Text. Cases and Materials, Fourth Edition, Oxford University Press: Oxford.

1068 Among others refer to E. Ellis (1999), The Principle of Proportionality in the Laws of Europe, Hart Publishing: Oxford; T. Trimidas (1996), 'The Principle of Proportionality in Community Law: From the Rule of Law to Market Integration', The Irish Jurist, 31, p. 83; J. Schwarze (2003), 'The Principle of Proportionality and the Principle of Impartiality in European Administrative Law', Rivista Trimestrale di Diritto Pubblico, pp. 53-75.

1069 J. Schwarze (1992), European Administrative Law, Sweet and Maxwell: London.

1070 Case 8-55, Féderation Charbonnière de Belgique v High Authority of the European Coal and Steel Community, 16 July 1956, [1956] ECR 00245, where the ECJ stated that "The parties differ in law as to the method to be followed in assessing the level of estimated production costs. The court considers that, before giving a ruling, it is necessary to establish what might reasonable be regarded as "the approximate figure of production costs at the end of the transitional period" on the basis of estimates for each type and category of coal prepared in the light of the facts and circumstances known when that assessment is made". See also Case 19/61, Mannesmann AG / ECSC High Authority, 13/07/1962, [1962] ECR 675.

1074 Case 11-70, Internationale Handelsgesellschaft $m b H$ v Einfuh- und Vorratsstelle fiit Getreide und Futtermittel, 17 December 1970, [1970] ECR 01125, paragraph 12 provided that "it therefore appears that the requirement of import and export licenses involving for the licensees an undertaking to effect the 
upon which the EU administrative order is substantiated, interpreted and developed. As regards the notion of the principle of proportionality, we can refer to the ECJ in the Case C-331-88 Fedesa, where it stipulated in paragraph 13 that

The Court has consistently held that the principle of proportionality is one of the general principles of EU law. By virtue of that principle, the lawfulness of the prohibition of an economic activity is subject to the condition that the prohibitory measures are appropriate and necessary in order to achieve the objectives legitimately pursued by the legislation in question; when there is a choice between several appropriate measures recourse must be had to the least onerous, and the disadvantages caused must not be disproportionate to the aims pursued. (Emphasis added.) ${ }^{1072}$

According to this understanding, which was confirmed by the ECJ in subsequent judgements, ${ }^{1073}$ the conceptual framing of the principle would imply an examination of a measure's appropriateness, necessity and proportionality. It would address the way in which a right recognised at EU level is affected by the act pursued by the Union, its institutions and/or Member States. The measure claimed to be interfering with or derogating a European right or freedom would be subject to this particular test of legality. While the jurisprudence of the ECJ has not reached a consolidated line of reasoning in relation to the principle of proportionality, the literature has argued that within the EU legal system this principle is composed of the following three-pronged phases of evaluation (sub-elements or subsidiary/secondary principles): ${ }^{1074}$ suitability, necessity and proportionality stricto sensu.

proposed transactions under the guarantee of a deposit constitutes a method which is both necessary and appropriate to enable the competent authorities to determine in the most effective manner their interventions on the market in cereals".

1072 In the same line of reasoning see for instance Case 265/87, Hermam Schräder HS Krafffumer GmbH \& Co. KG v Hauptzollamt Gronau, 11 July 1989, [1989] ECR 2237; Case C-331/88. The Queen v Minister of Agriculture, Fisheries and Food and Secretary of State for Health, ex parte: Fedesa and others, 13 November 1990, [1990] ECR I-04023. See also the previous definitions used by the ECJ in the following rulings, which were of more limited nature: Case 66/82, Fromançais $S A$ v Fonds d'orientation et de régularisation des marchés agricoles (FORMA), 23 February 1983, [1983] ECR 395, paragraph 8 stipulated that "in order to establish whether a provision of community law is consonant with the principle of proportionality it is necessary to establish, in the first place, whether the means it employs to achieve its aim correspond to the importance of the aim and, in the second place, whether they are necessary for its achievement". See also Case C-118/89, Firma Otto Lingenfelser v Federal Republic of Germany, 27 June 1990, [1990] ECR 1-02637, paragraph 12 said that "With regard to the question whether the provision which is the subject of the question referred to the Court for a preliminary ruling complies with the principle of proportionality, ..., it is necessary to ascertain whether the means which that provision applies to achieve its aim correspond to the importance of that aim and whether they are necessary in order to achieve it". See also, Case 125/83, OBEA v Corman, 1 October 1985, [1985] ECR 3039.

1073 Among others, see Joined Cases C-133/93, C-300/93 and C-362/93, Antonio Crispoltoni v Fattoria Autonoma Tabacchi and Giuseppe Natale and Antonio Pontillo v Donatab Srl., 5 October 1994, [1994] ECR I-04863, where the Court held in paragraph 40 that "The principle of proportionality, which is one of the general principles of Community law, requires that measures adopted by Community institutions do not exceed the limits of what is appropriate and necessary in order to attain the objectives legitimately pursued by the legislation in question; when there is a choice between several appropriate measures recourse must be had to the least onerous, and the disadvantages caused must not be disproportionate to the aims pursued".

1074 This three step examination appears to be greatly inspired by the way in which the principle of proportionality is understood by German legal system. See for example J. Schwarze (1992), European Administrative Law, Sweet and Maxwell: London; and N. Emiliou (1996), The Principle of Proportionality in European Law: A Comparative Study, Kluwer Law International: The Hague. 
1. The principle of suitability assesses whether a measure is suitable and the most appropriate one for achieving a desired policy goal. The test of suitability has been at times considered secondary in nature within the entire proportionality test. In those policy areas which are highly technical, the examination of the appropriateness and suitability of the means advocated by a legislative act might involve addressing a 'complex economic examination', something which would make it difficult for the applicant to prove the actual unsuitability of the administrative act in practice. It would consequently put a heavy onus of proof on her/him before the EU Courts.

2. The principle of necessity comprises the examination as to whether the measure was really necessary to achieve the intended goal. It also includes an evaluation of the existence of less restrictive options ('the search of the least onerous option') to achieve that same end.

3. The principle of proportionality stricto sensu looks at the extent to which the measure has imposed an excessive burden upon a recognised right when taking into account the public objective in view. It implies that the relation between the means and the end has to be reasonable. There has been some discussion in the literature as to whether this third stream is truly part of the proportionality test taking into account the way in which the latter has been carried out by the ECJ. ${ }^{1075}$ Craig (2006) has argued that if the test of proportionality would only comprise the suitability and necessity dimensions, this could lead to situations where after passing satisfactorily these two tests a law could be considered lawful even if the burden imposed by it would be completely disproportionate to its desired objective and would interfere 'unreasonably' with a certain right. ${ }^{1076}$ Moreover, from a study by de Búrca $(2000),{ }^{1077}$ it appears that the ECJ will only proceed toward the third step of the test of proportionality in those cases where the applicant expressly argues that the burdens imposed by the contested measure are excessive in relation to the goal.

\subsubsection{The Principle of Proportionality and Member States' Action "within the Scope of EU Law"}

Which authorities would fall within the scope of judicial review on grounds of the potential disproportionality of a measure? Similar to what has been stated above in relation to the general principles of EU law, the principle of proportionality is not constrained to the $\mathrm{EU}$ and its institutions, but also applies as a testing ground for establishing the parameters within which Member States are allowed to act when applying and implementing EU law in their respective legal systems. It provides the boundaries for legitimate executive action and the demarcating line for the legality of Member States' discretion. This is not only appropriate for ensuring proper protection of the individual whose European and/or fundamental rights might be endangered in the phase of implementation, but also in the interest of the EU political project itself in order to ensure the existence of a solid, consistent and coherent common European policy all across the Union. An interest which would be negatively affected if the essence and existence of the rights

1075 See for instance T. Trimidas (2006), who argues that "while the tripartite test has received some judicial support, in practice the ECJ does not distinguish in its analysis between the test of necessity and the one of proportionality stricto sensu".

1076 P. Craig (2006), EU Administrative Law, Oxford University Press: Oxford.

1077 G. de Búrca (2000), "Proportionality and Subsidiarity as General Principles of Law", in U. Bernitz and J. Nergelius (eds), General Principles of Earopean Community Law, European Monographs: Kluwer Law International: The Hague, pp. 95-112. 
that it seeks to bestow become deformed and mutated in the national arena through a sort of transposition against its principles and guiding parameters.

The applicability of the principle of proportionality to Member States' action was confirmed by the ECJ in the Case $77 / 81$ Zuckerfabrik, ${ }^{1078}$ where it first held that while interpreting a national rule following the conditions established in a Regulation, it should be considered whether the former is compatible with "superior mules of Community law", in particular the principle of proportionality. ${ }^{1079}$ This was later confirmed in Joined Cases C-286/94, C-340/95, C-401/95 and C-47/96 Garage Molenheide, ${ }^{1080}$ where the ECJ ruled that in accordance with the principle of proportionality "the Member States must employ means which, whilst enabling them effectively" to attain the objective pursued by their domestic laws, are the least detrimental to the objectives and the principles laid down by the relevant Community legislation". In this judgement the ECJ followed a line of reasoning which has become characteristic in subsequent cases of a similar nature and which sustains that it is primarily for the national courts to determine whether the contested national measures are compatible with EU law, ${ }^{1081}$ and that "the competence of the Court of Justice being limited to providing the national court with all the criteria for the interpretation of Community law which may enable it to make such a determination" "082 "The prominent position conferred to the national courts in this task, however, has indeed not prevented the Luxembourg Court from providing very precise guidelines to them as a way to proceed in their application of the review of legality of the measure in relation to the general principles.

The applicability of the general principles of EU law in Member States' actions was reiterated in the Case C-313/99, Gerard Mulligan, where the ECJ stressed that it is settled case law that where EU rules leave Member States to choose between various methods of implementation, the Member States will be required to exercise their discretion in accordance with the general

1078 Case 77/81, Zuckerfabrik Franken GmbH v Federal Republic of Germany, 18 February 1982, [1982] ECR 00681 .

The ruling stated in the paragraph 21 that "in the circumstances national rules whereby the recipient of a premium which has been paid without the conditions laid down by community law as to events subsequent to the denaturing having been observed might be asked to refund the premium even if the use contrary to the intended purpose was attributable to third parties, does not conflict with the relevant community provisions". Then it went into stressing in paragraph 22 that "it must now be considered whether such rules are compatible with superior rules of community law, in particular with the principles of legal certainty and proportionality invoked by the plaintiff in the main action".

Joined cases C-286/94, C-340/95, C-401/95 and C-47/96, Garage Molenheide BVBA, Peter Schepens, Bureau Rik Decan-Business Research \& Development NV (BRD) and Sanders BVBA v Belgische Staat, 18 December 1997, [1997] ECR I-07281.

See for instance J.H. Jans, R. de Lange, S. Prechal and R.J.G.M. Widdershoven (2007), Emropeanisation of Public Law, Europa Law Publishing: Groningen.

See paragraph 49 of the judgment. See also in this regard Case C-55/94, Gebhardv Consiglio dell'Ordine degli Avvocati e Procuratori di Milano, 30 November 1995, [1995] ECR [-4165, where it stated in paragraph 19 that "In view of the wording of the preliminary questions, it should be remembered that the Court has consistently held that it does not have jurisdiction to rule on the compatibility of a national measure with Community law. However, the Court is competent to provide the national court with all criteria for the interpretation of Community law which may enable it to determine the issue of compatibility for the purposes of the decision in the case before it". In the same vein see also Case C63/94, Groupement National des Négociants en Pommes de Terre de Belgique (Belgapom), 11 August 1995, [1995] ECR 1-0000, paragraph 7. 
principles of EU law. ${ }^{1083}$ In addition to this, the general principles not only apply in the various stages structuring the obligation to transpose Regulations, but most importantly to those characterising the application of Directives. In the Cases C-315/92 Verband Sozialer ${ }^{1084}$ and C$77 / 97$ Unilever ${ }^{1085}$ the ECJ was of the opinion that the measures that Member States are required to adopt for the implementation of a specific provision of a Directive must observe the principle of proportionality.

The ECJ has not yet faced a case dealing with the proportional character of a national implementing measure in the domain of European immigration law. Yet, from the case law that has been highlighted, one might expect that a similar obligation would apply to Member States when acting in the context of common EU immigration policy. It would be challenging to argue that the material scope of this principle of administrative legality would not cover all EU rules falling within the context of the First Pillar. This, we recall, would include all those immigration-related measures having their legal base in Title IV TEC. Any national measure constituting an eventual disproportionate effect, and therefore constituting a restriction of or interference with a right granted by European immigration law, should be reviewed in relation to the general principles of EU law and subject to the scrutiny of the European Courts. The processes of European integration on immigration already provide to TCNs a transnational framework of protection beyond the nation-state. Mechanisms such as the general principles of EU law should come sharply into play in those cases where it is contested the extent to which 'European rights' are being endangered or unlawfully limited at the national level.

\subsubsection{Legitimising Exceptions by the State: The Free Movement of Persons}

It has been sustained by various contributions studying the principle of proportionality that its meaning involves a mechanism of 'balance of conflicting interests' which include: those of a private nature (individual right or freedom with a European scope) and those considered of public interest pursued by an administrative measure. ${ }^{1086}$ Moreover, this balance metaphor of proportionality reflects the idea that some rights and freedoms may be legitimately derogated when weighed against the public interest pursued by an act. The question that needs to be addressed by the Court when confronted with such a conflict will be whether the European right

1083 Case C-313/99, Gerard Mulligan. Tim O'Sullivan. Tom Power. Hugh Duncan y Minister for Agriculture and Food, 20 June 2002, [2002], ECR 1-5719, paragraph 35. This has been later on confirmed in the Joined Cases C-480/00 to 482/00, C-484/00, C-489/00 to C-491/00 and C $-497 / 00$ to C-499/00, Azienda Agricola Ettore Ribaldi v Azienda di Stato per gli interventi nel mercato agricolo (AIMA), Ministero del Tesoro, del Bilancio e della Programmazione Economica and Others, 25 March 2004, [2004], ECR 12943, in Paragraph 43 stated that "Nevertheless, when adopting measures to implement Community legislation, national authorities must exercise their discretion in compliance with the general rules of Community law, which include the principles of proportionality, legal certainty and the protection of legitimate expectations". For a previous ruling stating the same line of reasoning see Joined Cases 201/85 and 202/85, Klensch and Others, 25 November 1986, [1986] ECR 3477, paragraph 10.

1084 Case C-315/92, Verband Sozialer Wettbewerb eV v Clinique Laboratoires SNC et Estée Lauder Cosmetics GmbH, 2 February 1994, [1994] ECR 1-00317, in paragraph 16 stated in relation to the implementation of an article of a Council Directive that "It should also be recalled that the Court has consistently held that rules must be proportionate to the goals pursued".

1085 Case C-77/97, Osterreichische Unilever GmbH v Smithkline Beecham Markenartikel GmbH, 28 January 1999, [1999] ECR I-00431.

1086 Inter alia N. Emiliou (1996), The Principle of Proportionality in European Law: A Comparative Perspective, Kluwer Law International: The Hague; P. Craig (2006), EU Administrative Law, Oxford University Press: Oxford. 
or freedom at stake admits any derogation, and in the positive, the nature and degree of exceptionalism that will be permitted to the State.

A glance at the application of the principle of proportionality to Member States' derogations to European freedoms might prove useful in this regard. The principle of free movement of European citizens provides an illustrative example. ${ }^{1087}$ The freedom to move, ${ }^{1088}$ which has been considered a key ingredient of the freedom rationale in the EU'S AFSJ, has some analogies with the nature and operability of some of the rights attached to the EC status of long-term resident granted to those TCNs falling within the scope of Council Directive 2003/109. This is especially so regarding the right to move to and reside in for a period exceeding three months the territory of Member States other than the one which granted him/her long-term residence status. ${ }^{1089}$ The right of free movement of EU citizens, which includes the right to enter, move and reside in the EU without any discrimination on grounds of nationality, may be limited on grounds of public policy, public security or public health, following the provisions stipulated in Chapter VI "Restrictions on the Right of Entry and the Right of Residence on Grounds of Public Policy, Public Security and Public Health" (Articles 27-33) of the Council Directive 2004/38 ${ }^{1090}$ on the right of citizens of the Union and their family members to move and reside freely within the territory of the Member States, as well as Articles 39.3 and 46.1 TEC. ${ }^{1091}$

The jurisprudence of the ECJ conceming the interpretation of these exceptions (derogations to freedom) has often been subject to the application of a strong and intense proportionality test over the alleged Member States' limitations or barriers to the full operability of the freedom of movement. The ECJ sustained in Case $41 / 74 \mathrm{Van} \mathrm{Duyn}{ }^{1092}$ that any derogation needs to be

1087 J. Apap (2002), Freedom of movement of persons: A practitioner's handbook, The Hague: Kluwer Law International, pp. 19-30; A.C. Oliveira (2002), "Workers and other persons: Step-by-step from movement to citizenship - Case law 1995-2001', Common Market Law Review, 39, pp. 77-127.

$10 \times 8$ Article 18.1 TEC states that "Every citizen of the Union shall have the right to move and reside freely" within the territory of the Member States, subject to the limitations and conditions laid down in this Treaty and by measures adopted to give it effect".

1089 See Chapter III on "Residence in Other Member States", Articles 14-23, Council Directive 2003/109/EC of 25 November 2003 concerning the status of third-country nationals who are long-term residents, OJ L $16 / 44,23.1 .2004$.

1090 Directive 2004/38/EC on the right of citizens of the Union and their family members to move and reside freely within the territory of the member states amending Regulation (EEC) No. 1612/68 and repealing Directives 64/221/EEC, 68/360/EEC, 72/194/EEC, 73/148/EEC, 75/34/EEC, 75/35/EEC, 90/364/EEC, 90/365/EEC and 93/96/EEC, 29 April 2004, OJ L 158/77, 30 April 2004. Article 27 of the Directive states that "... Member States, may restrict the freedom of movement and residence of Union citizens and their family members, irrespective of nationality, on grounds of public policy, public security or public health. These grounds shall not be invoked to serve economic ends"; For an analysis of the Council Directive 2004/38 see J.Y. Carlier and E. Guild (eds) (2006), The Future of Free Movement of Persons in the EU, Collection du Centre des Droits de L'Homme de la'Université Catholique de Louvain, Brussels: Bruylant; See also S. Carrera (2005), "What does free movement mean in theory and practice in an enlarged EU?', European Law'.Jounal, Vol. 11, No. 6, November, pp. 699-721.

1091 Article 39.3 TEC provides that the freedom of movement of workers shall entail a number of specific rights by subject to limitations justified on grounds of public policy, public security or public health. Article 46.1 TEC says that "the provisions of this chapter and measures taken in pursuance thereof shall not prejudice the applicability of provisions laid down by law, regulation or administrative action providing for special treatment for foreign nationals on grounds of public policy, public security or public health".

1092 Case 41/74, Yvonne van Duyn v Home Office, 4 December 1974, [1974] ECR 1337. See also Case 67/74 Carmelo Angelo Bonsignore v Oberstadtdirektor der Stad Köln [1975] ECR 297, paragraph 6; and Case C-357/98, The Queen v Yiadom, [2000] ECR 1-9265, paragraph 24. 
strictly interpreted. Further, following the judgment in the Case 30/77 Bouchereau, the Court held that derogations can be deemed justified only in those cases where there is a 'genuine and sufficiently serious threat' to the public policy, public security and public health of the State. ${ }^{1093}$ In the Case 36/75 Rutili it was held that "restrictions cannot be imposed on the right of a national of any member state to enter the territory of another member state, to stay there and to move within it unless his presence or conduct constitutes a genuine and sufficiently serious threat to public policy". ${ }^{1094}$ As de Búrca (1993) has explained in this respect

...the approach of the Court has been to say that the rules on freedom of movement, etc, are fundamental Community requirements, and that any purported derogation from them will be strictly scrutinized in order to ensure that they do in fact pursue a legitimate aim within the meaning of the Treaty, and that they are necessary to achieve this aim. (Emphasis added.) ${ }^{1095}$

Furthermore, the national authorities must always select the administrative measures and procedures which are 'the less restrictive' to the fundamental freedoms, and specifically the freedom to move. ${ }^{1096}$ It is settled case-law of the ECJ that limitations by the State must also be in compliance with the limits imposed by EU law, in accordance with the principle of proportionality. In light of this, in Case C-413/99, Baumbast, the ECJ established in paragraph 9l that

...those limitations and conditions must be applied in compliance with the limits imposed by Community law and in accordance with the general principles of that law, in particular the principle of proportionality. That means that national measures adopted on that subject must be necessary and appropriate to attain the objective pursued. (Emphasis added.) ${ }^{1097}$

Finally, the requirement for any restriction by a Member State in relation to a European freedom to comply with the principle of proportionality has been reiterated in the Case C-341/05, Laval tun Partneri. ${ }^{1098}$ Here the ECJ was asked to interpret the compatibility between the rules of the EC Treaty on the freedom to provide services and the prohibition of any discrimination on the

1093 Case 30/77, Régina viene Boncherean, [1977] ECR 1999, paragraph 35.

1094 Case 36775, Roland Rutili v Ministre de l'intérieur, 28 October 1975, [1975] ECR 01219.

1095 G. de Burca (1993), 'The Principle of Proportionality and its Application in EC Law', Yearbook of European Lar', Vol. 13, pp. 105-150.

1096 The ECJ has stated that the public policy exception must be interpreted restrictively in Joined Cases C. 482/01 and C-493/01, Georgios Orfanopoulos, Natascha Orfanopoulos. Melina Orfanopoulos, Sofia Orfanopoulos v Land Baden-Wirttemberg, and between Raffaele Oliveri v Land Baden-Wïmttemberg, 29 April 2004, [2004] ECR 15257. See also Case C-348/96, Criminal proceedings against Donatella Calfa, 19 January 1999, [1999] ECR I-11, paragraphs 22 to 24.

1097 Case C-413/99, Baumbast and R. v. Secretary of State for the Home Department [2002] ECR I-07091; Joined Cases C-259/91, C-331/91 and C-332/91 Allue and Others [1993] ECR 1-4309, paragraph 15; Case 67/74, Cammelo Angelo Bonsignore v Oberstaddirektor der Stadt Köln [1975] ECR 00297. See also Case C-40/05, Kaj Lyyshi v Umea universitet, 11 January 2007, [2007], ECR 1-99, where the ECJ reiterated its previous jurisprudence in paragraph 38 by saying that "Finally, although the requirement that candidates for STT courses must be employed in a Swedish school constitutes an obstacle to freedom of movement for workers, it could avoid the prohibition under Article $39 \mathrm{EC}$ if it pursued a legitimate aim compatible with the Treaty and were justified by pressing reasons of public interest. But even if that were so, application of that measure would still have to be such as to ensure achievement of the aim in question and not go beyond what is necessary for that purpose". See also Case C-19/92, Dieter Kraus y Land Baden-Wirttemberg [1993] ECR 1-1663, paragraph 32; Case C-224/01, Gerhard Köbler v Republik Osterreich [2003] ECR I-10239, paragraph 77.

1098 Case C-341/05, Laval im Parmeri Lid v Svenska Byggnadsarbetareförbundet, Svenska Byggnadsarbetareförbundets avd. 1. Byggettan. Svenska Elektrikerförbundet, 18 December 2007, no yet reported, paragraph 101. 
grounds of nationality, with the possibility for trade unions to force a foreign provider of services to sign a collective agreement in the host country with respect to terms and conditions of employment, such as the collective agreement for the building sector. The ECJ ruled that any derogation from the freedom to provide services will be warranted only if it pursues a legitimate objective compatible with the Treaty and is justified by overriding reasons of public interest. It continued by saying that if that is the case, it should also be suitable for securing the attainment of the objective that it seeks and not go beyond what is necessary in order to attain it. ${ }^{1099}$

In the same light, in the joined cases C-11/06 and 12/06 Morgan and Bucher, ${ }^{1100}$ the ECJ was asked whether the refusal by a Member State to award an education or training grant to one of its nationals for a full course of study in another Member State on the ground that the course did not represent the continuation of studies pursued at an education or training establishment located in the national territory for a period of least one year contravened the freedom of movement. The Court recognised that the restrictive effects created by the first-stage studies condition would only be justified in light of EU law if it was based on "objective considerations of public interest independent of the nationality of the persons concemed and if it is proportionate to the legitimate objective pursued by the provisions of national law". "I01 was held in paragraph 43 that

It may be legitimate for a Member State, in order to ensure that the grant of assistance to cover the maintenance costs of students from other Member States does not become an unreasonable burden which could have consequences for the overall level of assistance which may be granted by that State, to grant such assistance only to students who have demonstrated a certain degree of integration into the society of that State. (Emphasis added.) ${ }^{1102}$

However, the ECJ considered that

...the degree of integration into its society which a Member State could legitimately require must, in any event, be regarded as satisfied by the fact that the applicants in the main proceedings were raised in Germany and completed their schooling there. In those circumstances, it is apparent that the first-stage studies condition... is too general and exclusive in this respect. It unduly favours an element which is not necessarily representative of the degree of integration into the society of that Member State at the time the application for assistance is made. It thus goes beyond what is necessary to attain the objective pursued and cannot therefore be regarded as proportionate. (Emphasis added.) ${ }^{1103}$

\subsection{Fundamental Rights as General Principles: The Case of Family Life of TCNs}

This section studies the relevance of fundamental rights as general principles of EU law at times of examining the proportionality of national implementing measures in the field of EU

1099 For a similar kind of reasoning see Case C-398/95, Syndesmos ton en Elladi Touristikon kai Taxidiorikon Grafeion v Ypourgos Ergasias (SETTG) [1997] ECR I-3091, paragraph 21; and Case C-451/03, Servizi Ausiliari Dontori Commercialisti v Gituseppe Calafiori, [2006] ECR I-2941, paragraph 37; Case C-94/04, Federico Cipolla v Stefano Macrino, [2006] ECR 1-11421, paragraph 61.

1100 Joined Cases C-11/06 and 12/06, Rhiamon Morgan v Bezirksregienng Köln and lris Bucher v Landrat des Kreises Diiren, 23 October 2007, not yet reported.

1101 Paragraph 33. See in this regard Case C-406/04, Gérald De Cuyper v Office national de l'emploi, [2006] ECR 1-6947, paragraph 42.

1102 Case C-209/03, Bidar, [2005] ECR I-2119, paragraphs 56 and 57. Also, in paragraph 59 the ECJ stated that "the existence of a certain degree of integration may be regarded as established by a finding that the student in question has resided in the host Member State for a certain length of time". 
immigration law. The special legal status of fundamental rights as central elements in the processes of European integration would experience a substantial transformation with the entry into force of the Treaty of Lisbon. ${ }^{1104}$ The Treaty includes as one its innovative features a formal recognition of the Charter of Fundamental Rights of the EU ${ }^{1105}$ (hereafter "the Charter") as a legally binding bill of rights. ${ }^{1106}$ Article 6.1 of the revised version of the TEU contains a crossreference providing that the rights, freedoms and principles set out in the Charter will have "the same legal value as the Treaties". "107 Furthermore, paragraph 3 of the same provision reiterates, in a slightly different fashion from its current version, that

Fundamental rights, as guaranteed by the European Convention for the Protection of Human Rights and Fundamental Freedoms and as they result from the constitutional traditions common to the Member States, shall constitute general principles of the Union's law.

The altered regulatory nature of the Charter would strengthen the freedom dimension of the AFSJ. ${ }^{1108}$ It would render it directly legally binding upon the European institutions, Union bodies, offices and agencies. Any action carried out by the Member States within the scope of EU law would also need to strictly comply with fundamental rights. ${ }^{1109}$ Fundamental rights would therefore become material norms in Europe, consolidating themselves even further as inspiring and general principles of the Union's legal order. The potential of combining fundamental rights as general principles of EU law and as primary substantive norms will be enormous for the interpretation and validity of Member States' actions, including those related to EU immigration law.

The study of the sources and functions of fundamental rights as general principles of EU law and the role of the ECJ in the protection of human rights has been extensive. ${ }^{110}$ This section will

1104 Treaty of Lisbon amending the Treaty on European Union and the Treaty establishing the European Community, signed at Lisbon, 13 December 2007, 2007/C306/01, OJ C306/01, 17.12.2007.

1105 Charter of Fundamental Rights of the European Union, Notices from European Union Institutions and Bodies, European Parliament, Council and Commission, OJ C303/0I, 14.12.2007, as solemnly proclaimed on the 12 December 2007.

1106 On the implications of the 'constitutionalization' of the Charter as regards the relationship between human rights and civil liberties see E. Guild (2004), 'The Variable Subject of the EU Constitution, Civil Liberties and Human Rights', European Jomnal of Migration and Law, Vol. 6, No. 4, pp. 381-394.

1107 Article 6.1 says that "The Union recognises the rights, freedoms and principles set out in the Charter of Fundamental Rights of the European Union of 7 December 2000, as adapted at Strasbourg, on 12 December 2007, which shall have the same legal value as the Treaties".

E. Guild and S. Carrera (2006), The Hague Programme \& the EU's Agenda on "Freedom, Security and Justice": Delivering Results for Europe's Citizens?, CEPS Commentary, 7 July 2006, Centre for European Policy Studies: Brussels. See also S. Carrera and E. Guild (2006), "No Constitutional Treaty? Implications for the Area of Freedom, Security and Justice", in T. Balzacq and S. Carrera (eds), Security versus Freedom. A Challenge for Future's Europe, Ashgate: Aldershot, pp. 223-240.

Article 51 (Field of Application) reads as follows "The provisions of this Charter are addressed to the institutions, bodies, offices and agencies of the Union with due regard for the principle of subsidiarity and to the Member States only when they are implementing Union law. They shall therefore respect the rights, observe the principles and promote the application thereof in accordance with their respective powers and respecting the limits of the powers of the Union as conferred on it in the Treaties".

1110 See among others P. Craig and G. de Búrca (2007), EU Lav: Text, Cases and Materials, Oxford University Press: Oxford, Sixth Edition, Chapter 11; A. Williams (2004), EU Human Rights Policies: A Study in Irony, Oxford University Press: Oxford; P. Alston (2001), L'Union Européene et les Droits de I'Homme, Académie de Droit Européen Institut Universitaire Européen, Bruylant: Bruxelles; P. Alston, M. Bustelo and J. Heenan (1999), The EU and Human Rights, Oxford University Press: Oxford; J. Coppel and A. O'Neill (1992), 'The European Court of Justice: Taking Rights Seriously?', Common 
focus on the nexus between fundamental rights as general principles of EU law and Member States' action when implementing European immigration law. "III Special attention will be paid to the impact of applying the principle of proportionality at times of evaluating that relationship. We shall examine the role that ECJ has conducted in the intersection between these dimensions, and the potentials inherent to the general principle of fundamental rights in relation to the protection of European-wide rights closely attached to those labelled as human rights. In particular, the fundamental right of respect for family life and those European rights related to family reunion as provided by the Council Directive 2003/86 on the right to family reunification shall be central to our analysis of the conditions under which the interference by the State is being limited in the EU context. 1112 The Directive recognises a subjective right to family reunification and a package of related rights to the family members of the sponsor. These rights need to be regarded as European-protected rights, and therefore benefiting from the safeguards provided by the EU general principles and judicial review in case of disproportionate and unlawful interference by a Member State when implementing EU law.

\subsubsection{Fundamental Rights as General Principles of EU Law}

The incorporation of fundamental rights as unwritten and judge-rendered EU general principles finds its origin in the strategy carried out by the ECJ in order to provide an answer to challenges coming from national constitutional courts regarding the supremacy of EU law. The first EC Treaties, which mainly followed economically-driven integration logic, contained no express provisions on the protection of fundamental rights by the European institutions. If a Community act was supposed to prevail over one originating from national law, including national constitutional laws, the judicial review of European measures should therefore take place exclusively at the EU level and not in a national arena increasingly under pressure from potential encroachments of Community law on national constitutional prerogatives. 113 This was one of the main rationales behind the development by the ECJ of its own doctrine on the protection of fundamental rights as autonomous and self-standing general principles of EU law. The Case 29/69 Stander was the first occasion where the ECJ acknowledged that "fundamental human rights" are enshrined in the general principles and protected by the Court. "114 Besides, in the

Market Law Revies', 29, p. 669; J.H.H. Weiler and N. Lockhart (1995), 'Taking Rights Seriously' Seriously: The European Court and its Fundamental Rights Jurisprudence', Common Market Law Review, 32, pp. 59-82; A. Cassese, A. Clapham and J. Weiler (eds), European Union: The Human Rights Challenge, Nomos: Baden-Baden; A. Clapham (1991), Human Rights and the European Community: A Critical Overview, Nomos: Baden-Baden; E. Guild and G. Lesieur (1997), The European Court of Justice on the European Convention of Human Rights: Who said what when, Kluwer Law International: The Hague.

111 For a examination of the meaning of Article 51 of the Charter and the discussions about the meaning of Member States' action when "implementing Union law" see P. Ecckhout (2002), 'The EU Charter of Fundamental Rights and the Federal Question', Common Market Law Review, Vol. 39, No. 5, pp. 945 994.

1112 Council Directive 2003/86/EC of 22 September 2003 on the right to family reunification, OJ L 251/12, 3.10.2003.

1113 On the relationship between fundamental rights as general principles of EU law and the constitutional traditions of the Member States see the study carried out by $O$. de Schutter (2007), Promoting and Protecting Fundamental Rights in the European Union: The Relations between the European Comvention of Human Rights, the European Charter and the Member States 'Constitutions, Briefing Paper, European Parliament, DG Internal Policies of the Union, Brussels.

1114 Case 29/69, Erich Stander v City of Ulm - Sozialamt, 12 November 1969, [1969], ECR 00419. 
Case 11/70 Intemationale Handelsgesellschaft it held that fundamental rights form an integral part of the general principles of EU law "the observance of which is ensured by the Court". In paragraph 4 of this judgment it was further established that

...respect for fundamental rights forms an integral part of the general principles of law protected by the court of justice. The protection of such rights, whilst inspired by the constitutional traditions common to the member states, must be ensured within the framework of the structure and objectives of the Commmnity. "I15 (Emphasis added.)

Furthermore, the Case $4 / 73$ Nold acknowledged that "international treaties for the protection of human rights on which the Member States have collaborated or of which they are signatories" also supply additional guidelines on the protection of fundamental rights in the EU legal system. ${ }^{116}$ The special significance of the European Convention of Human Rights and Fundamental Freedoms of 4 November 1950 (ECHR) in this respect was first affirmed in the Cases $44 / 79$ Hater $^{1117}$ and $222 / 84$ Johnston, ${ }^{1118}$ where the ECJ referred to it as a fundamental international source of standards providing inspiration at times of examining the safeguard of fundamental rights in the EU. ${ }^{119}$ This understanding has since then become a consolidated feature in the ECJ's jurisprudence. ${ }^{1120}$ The ECJ has encountered numerous occasions for reviewing the conformity of EU rules with fundamental rights, and has later on expanded its jurisdiction toward the review of the compatibility of certain actions by the Member States with fundamental rights. The widening of its judicial oversight conducted over national measures within the scope of EU law as regards their relationship with fundamental rights has been coupled with the introduction of express references to fundamental rights inside the Treaties. ${ }^{1121}$

1115 Case 11/70, Internationale Handelsgesellschaft mbH v Einfuh:- und Vorratsstelle fir Gerreide und Futtermittel, 17 December 1970, [1970] ECR 01125.

ins Case 4/73, J. Nold, Kohlen- und Baustoffgroß3handlung v Commission of the European Communities, 14 May 1974, [1974] ECR 00491.

1117 Case 44/79, Hawerv Land Rheinland Pfalz, 13 December 1979, [1979] ECR 3727.

1118 Case 222/84, Johnston v Chief Constable of the Royal Ulster. Constabulary, [1986] ECR 1651, paragraph 18.

111. It was held in paragraph 15 that "fundamental rights form an integral part of the general principles of the law, the observance of which it ensures; that in safeguarding those rights, the court is bound to draw inspiration from constitutional traditions common to the member states, so that measures which are incompatible with the fundamental rights recognized by the constitutions of those states are unacceptable in the community; and that, similarly, international treaties for the protection of human rights on which the member states have collaborated or of which they are signatories, can supply guidelines which should be followed within the framework of community law. That conception was later recognized by the joint declaration of the European Parliament, the council and the commission of 5 April 1977, which, after recalling the case-law of the court, refers on the one hand to the rights guaranteed by the constitutions of the member states and on the other hand to the European Convention for the Protection of Human Rights and Fundamental Freedoms of 4 November 1950".

1120 Craig and de Burca (2007) put forward an interesting feature of the jurisprudence developed by the ECJ on human rights as part of the EC general principles, by saying that "by treating the ECHR as a source of inspiration rather than a formally binding, incorporated charter, the ECJ has retained the freedom to go beyond the Convention in recognizing rights as part of EC law". See page 384.

1121 The actual version of Article 6 of the TEU says that "1. The Union is founded on the principles of liberty, democracy, respect for human rights and fundamental freedoms, and the rule of law, principles which are common to the Member States. 2. The Union shall respect fundamental rights, as guaranteed by the European Convention of Human Rights and Fundamental Freedoms signed in Rome on 4 November 1950 and as they result from the constitutional traditions common to the Member States, as general principles of Community law". Article 46 of the TEU establishes that the powers conferred to the ECJ 
Furthermore, the sphere of transnational protection offered by the ECHR and the jurisprudence of the European Court of Human Rights (ECIHR) ${ }^{1 ! 22}$ have been considered a special source for assessing the compatibility between Member States' actions within the framework of the EU legal system and fundamental rights as general principles of EU law, including the respect for family life.

\subsubsection{Member States' Actions in relation to the Right of Respect for Family Life}

Family life is recognised as a human right by Article 8 of the ECHR. ${ }^{1123}$ It has also been included as a fundamental right in the EU by the Charter of Fundamental Rights, which in its Article 7 entitled "Respect for private and family life" states that "Everyone has the right to respect for his or her private and family life, home and communications". Moreover, according to the text provided by the Explanations relating to the Charter of Fundamental Rights, 124 the meaning and scope of this right are the same as those of the corresponding article of the ECHR.

When considering the relationship of the threshold of the ECHR on the rights of TCNs with that of EU law, and the processes of losing control by the State over family members in the context of Article 8 of the ECHR, Guild (2004) has explained that there are four main steps in need of consideration in what concems the protection of family life in the ECHR: ${ }^{125}$ First, the applicant will need to show evidence that family life exists in the state concerned; second, there will be an examination concerning the extent to which there has been interference with that family life by the national measure at stake, such as expulsion or refusal of issuing a residence permit; third, consideration will be given as to whether the interference is lawful and in accordance with the rule of law. The last step will look at the necessity of the interference in a democratic society, which will be determined in light of Article 8.2 of the ECHR. The State's action will be considered consistent with the Article only when the four steps lead to an affirmative answer.

In light of the above, when assessing the compliance of national implementing measures with the general principle of fundamental rights, the ECJ will therefore take into consideration the extent to which the national measure being contested interferes with human rights. ${ }^{126}$ The Luxembourg Court has offered various examples making an express reference to family life as a human right protected under the ECHR and developed by the ECHHR, as well as a fundamental right taking the form of a general principle of EU law. This doctrine has mainly been applied in

shall apply to Article 6.2 of the TEU. See also Article 7.2 of the TEU which establishes a sanction mechanism for "serious and persistent breach by a Member State of principles mentioned in Article 6.1".

1122 O. De Schutter (2005), "L'influence de la Cour européenne des droits de l'homme sur la Cour de justice des Communautés européennes", in G. Cohen-Jonathan \& J.-Fr. Flauss (dir.), Le rayonnement international de la jurisprudence de la Cour européeme des droits de l'homme, Bruxelles, BruylantNemesis, pp. 189-242.

1123 Article 8 of the ECHR states that "Everyone has the right to respect for his private and family life, his home and his correspondence".

1124 Explanations Relating to the Charter of Fundamental Rights, OJ 303/17, 14.12.2007.

1125 E. Guild (2004), The Legal Elements of European Identity: EU Citizensitip and Migration Law, Kluwer Law International, European Law Library, The Hague, Chapter 7 on "Identity Beyond Citizenship: the European Convention on Human Rights", pp. 125-147.

1126 For a detailed critical overview of the ways in which the ECJ has incorporated human rights in the EU legal order and some of the key results obtained see B. de Witte (2001), "Le Rôle Passé et Futur de la Cour de Justice des Communautés Européenes dans la Protection des Droits de L'hhomme", dans P. Alston, M. BUstelo et J. Heenan (dir.), L'Union Européenme et les Droit de l'Homme, Académie de Droit Européen, Institut Universitaire Européen, Bruylant: Bruxelles, pp. 895-935. 
cases dealing with TCNs who are family members of EU citizens. ${ }^{1127}$ For instance, in the Cases $249 / 86$ Commission v Germany ${ }^{128}$ and C-413/99 Baumbast ${ }^{1129}$ it was held that EU law must be interpreted in light of the requirement of respect for family life set out in the ECHR. In the same vein, in Case C-60/00 Carpenter, ${ }^{1130}$ when reviewing a decision to deport a non-national spouse of an EU citizen from the UK, it was decided that the latter constituted a non-legitimate interference to the exercise by the European citizen of his right to respect family life within the meaning provided in Article 8 of the ECHR. ${ }^{1131}$ This reasoning was later on confirmed in Case C-109/01 Akrich, where the ECJ ruled that where a European citizen married to a TCN with whom she is living in another Member State returns to the Member State of which she is a national in order to work there as an employed person and, at the time of her return, the spouse does not enjoy the rights of free movement because he has not resided lawfully on the territory of a Member State, the competent authorities of the first Member State, in assessing the application by the spouse to enter and remain there, must have regard to the right to respect for family life under Article 8 of the ECHR, provided that the marriage is genuine. ${ }^{1132}$

\subsubsection{Exceptions to Fundamental Rights by the State}

\subsubsection{The Exception as interpreted by the ECJ}

What are the legal standards that have been applied by the ECJ when reviewing the degree of interference by Member States with fundamental rights? The consolidated doctrine has been that any interference should be kept to the minimal possible level. In paragraph 18 of the Case C$5 / 88$ Wachauf $^{1 / 33}$ the Court held that

The fundamental rights recognized by the Court are not absolute, however, but must be considered in relation to their social function. Consequently, restrictions may be imposed on the exercise of those rights, in particular in the context of a common organization of a market, provided that those restrictions in fact comespond to objectives of general interest pursued by the

1127 Case C-127/08, Metock and Others, 25 July 2008, not yet reported, where the ECJ has for the first time ruled that according to the Council Directive 2004/38 (Article 3.1) "a national of a non-member country who is the spouse of a Union citizen residing in a Member State whose nationality he does not possess and who accompanies or joins that Union citizen benefits from the provisions of that directive, irrespective of when and where their marriage took place and of how the national of a non-member country entered the host Member State", paragraph 99.

1128 Case 249/86, Commission of the European Communities v Federal Republic of Germany, [1989] ECR 01263. Paragraph 10 of the judgement stated that "Regulation No $1612 / 68$ must also be interpreted in the light of the requirement of respect for family life set out in Article 8 of the Convention for the Protection of Human Rights and Fundamental Freedoms. That requirement is one of the fundamental rights which, according to the Court's settled case-law, restated in the preamble to the Single European Act, are recognized by Community law'.

1129) Case C-413/99, Bambast, $R$ v Secretary of State for the Home Deparment. [2002] ECRI-7091.

1130 Case C-60/00, Mary Carpenter v Secretary of State for the Home Department, [2002] ECR I-6279. paragraphs 38 and 41 .

133 For a detailed analysis of the judgment see H. Toner (2003), 'Comments on Mary Carpenter v. Secretary of State, 11 July 2002 (Case C-60/00)', European Journal of Migration and Law, Vol. 5, No. 1, pp. 163172.

1132 Case C-109/01, Secretary of State for the Home Deparment v Hacene Akrich, [2003] ECR 1-9607. For an analysis of the case see A.P. Van der Mei (2004), 'Comments on Akrich (Case C-109/01 of 23 September 2003)', European Jomnal of Migration and Law, Vol. 6, No. 3, pp. 277-280.

1133 Case 5/88, Hubert Wachauf v Bundesam für Emährung und Forstwirtschaff, 13 July 1989, [1989] ECR 02609. 
Commmity and do not constitute, with regard to the aim pursued, a disproportionate and intolerable interference, impairing the very substance of those rights. (Emphasis added.)

Therefore while rights are not absolute and need to be read in relation to 'the general interest' ('social function') of the objective of the legal measure being contested before the Court, the interference should not be disproportionate. ${ }^{134}$ The proportionality of the interference with a fundamental right is measured taking into account the extent to which the measure undermines the very substance of those rights. ${ }^{113}$ The links with the 'balancing of interests' identified as one of the key ingredients substantiating the principle of proportionality becomes henceforth evident. This same approach has been confirmed in various subsequent judgments of the $\mathrm{ECJ},{ }^{1136}$ such as, for instance, in the Case C-341/05, Laval un Parmeri, ${ }^{1137}$ where it was held that the exercise of fundamental rights needs to be reconciled in accordance with the principle of proportionality. 1138

Moreover, when addressing the grounds of derogation of those fundamental rights considered to be also a human right in the context of the ECHR, the ECI has made express references to the requirements developed by the jurisprudence of the ECtHR in relation to Article 8 of the ECHR. This has been confirmed by the Explanations relating to the Charter of Fundamental Rights, ${ }^{1139}$ and particularly those provided in relation to its Article 52.3 which state that the limitations to rights such as that of family life, which correspond between the Charter and the ECHR, are the same as those laid down in the ECHR and interpreted by the ECtHR. As a general rule, there will be interference considered to infringe on the Convention in those cases where the latter meets the requirements of paragraph 2 of Article 8, which states that

1134 This has been reiterated in the Case C-33/07, Ministerul Administratiei si Internelor - Direcfia Generalä de Paşapoarte Bucuressti v. Jipa, 10 July 2008, not yet reported, where the ECJ held in paragraph 29 that "When making such an assessment, the national court will have also to determine whether that restriction on the right to leave is appropriate to ensure the achievement of the objective it pursues and does not go beyond what is necessary to attain it. According to Article 27.2 of Directive 2004/38 and the Court's settled case-law, a measure which restricts the right of freedom of movement may be justified only if it respects the principle of proportionality".

1135 S. Peers (2004), "Taking the Rights Away? Derogations and Limitations", in S. Peers and Ward (eds), The EU Charter of Rights: Politics, Law and Policy, Hart Publishing, p. 141.

1136 Case C-280/93, Germany v Council [1994] ECR 1-4973, paragraph 78; Case C-293/97, Standley and Others [1999] ECR 1-2603, paragraph 54; Case C-491/01, The Queen and Secretary of Siate for Health $y$ British American Tobacco (Investments) and Imperial Tobacco, [2002] of 10 December 2002, OJ C 56 of 02.03.2002, paragraph 149; Case C-200/96, Metronome Musik GmbH v Music Point Hokamp GmbH., 28 April 1998, [1998] ECR I-01953, paragraph 21; Case C-22/94, The Irish Farmers' Association and Others, [1997] ECR 1-1809, paragraph 27; Case C-44/94, $R$ v Minister of Agriculture, Fisheries and Food, ex parte Fishermen's Organisations and Others, [1995] ECR 1-3115, paragraph 55; Joined Cases C-20/00 and C-64/00, Booker Aquaculture Ltd, trading as Marine Harvest McConnell, Hydro Seafood GSP Ltd and The Scotrish Ministers, 10 July 2003, OI C 200 23.08.2003, paragraph 68; Case C-177/90, Kiihn [1992] ECR 1-35, paragraph 16; Joined Cases C-184/02 and C-223/02, Kingdom of Spain and Republic of Finland $v$ European Parliament and Council of the European Union, 9 September 2004, OJ C 262, 23.10.2004, p. 3.

1137 Case C-341/05, Laval un Partneri Ltd v Suenska Byggnadsarbetareförbundet. Svenska Byggnadsarbetareförbundets avd. 1. Byggettan. Svenska Eleknikerförbundet, 18 December 2007, no yet reported.

Paragraph 94 of this judgment states that "the exercise of the fundamental rights at issue, that is, freedom of expression and freedom of assembly and respect for human dignity, respectively, does not fall outside the scope of the provisions of the Treaty. Such exercise must be reconciled with the requirements relating to rights protected under the Treaty and in accordance with the principle of proportionality".

Explanations Relating to the Charter of Fundamental Rights, OJ 303/17, 14.12.2007. 
There will be no interference by a public authority with the exercise of this right except such as is in accordance with the law and is necessary in a democratic society in the interests of national security, public safety or the economic well-being of the country, for the prevention of disorder or crime, for the protection of health or morals, or for the protection of the rights and freedoms of others.

\subsubsection{The Exception as interpreted by the ECtHR}

The protection that the ECIHR has offered to the security of residence and expulsion of TCNs in Europe has been widely addressed by the literature. ${ }^{1140}$ The most relevant cases by the ECtHR with respect to the right of family life have generally dealt with issues of admission, renewal of residence permit and expulsion/deportation of TCNs. The ECtHR has on several occasions assessed whether the interference by a State was necessary on the basis of this article. In particular, as regards the domain of expulsion, the Strasbourg Court sustained in Boultif v. Swizerland of November $2001^{1141}$ that when a person subject to deportation enjoys family life in that State, his/her expulsion may amount to an infringement of the right to respect for family life recognised in Article 8.1 of the Convention. This same reasoning was adopted by the ECJ in cases like Carpenter and Akrich, and was reiterated in its subsequent rulings, such as in Joined Cases C-482/01 and C-493/01 Orfanopolous, where the ECJ was asked whether the expulsion of an EU citizen with many years' residence in a host Member State and ordered on account of a criminal offence was compatible with the general principles of EU law of protection of family life and proportionality. 1142

As stated above, the legitimate aims that a Member State may use to derogate human rights recognised by the ECHR comprise national security, public safety or the economic well-being of the country, the prevention of disorder or crime, the protection of health or morals, or the protection of the rights and freedoms of others, all of which will need to be "in accordance to the law" and "necessary in a democratic society". As regards the condition related to "in accordance

1140 See C. Forder (2005), "Family Rights and Immigration Law: A European Perspective", in H. Schneider (ed.), Migration, Integration and Citizenship: A Challenge for Europe's Future, Volume II; Forum Maastricht: Maastricht, pp. 71-108; S. Peers (2004), "Family Reunion and Community Law", in N. Walker (ed), Europe's Area of Freedom, Security and Justice, Oxford University Press: Oxford, pp. 143197; See also P. van Dijk (2001), "Protection of "Integrated" Aliens against Expulsion under the European Convention of Human Rights", in E. Guild and P. Minderhoud (eds) (2001), Security of Residence and Expulsion: Protection of Aliens in Europe, Kluwer Law Internationals: The Hague, pp. $23-40$.

1141 Boultif y Switzerland, no. 54273/00, $\$ \$ 39,41$ and 46, 2 November 2001, ECHR 2001-1X. See also Moustaquim v. Belgitum, judgment of 18 February 1991, Series A no. 193, p. 18, $\$ 36$.

Joined Cases C-482/01 and C-493/01, Orfanopoulos and Oliveri, [2004] ECR I-5257. As regards the last of the elements, the judgement referred to the jurisprudence of the ECIHR by stating in paragraph 99 that "To assess whether the interference envisaged is proportionate to the legitimate aim pursued, in this instance the protection of public policy, account must be taken, particularly, of the nature and seriousness of the offences committed by the person concerned, the length of his residence in the host Member State, the period which has elapsed since the commission of the offence, the family circumstances of the person concerned and the seriousness of the difficulties which the spouse and any of their children risk facing in the country of origin of the person concemed". See in this regard Boultif v. Switzerland, no. 54273/00, $\$ 46$, ECHR 2001-LX; Refer also to Case C-112/00 Eugen Schmidberger, Internationale Transporte und Plonzïge v Republik Osterreich, 12 June 2003 [2003] ECR I-5659, paragraph 74) or freedom to provide services (Case C-36/02, Omega Spielhallen- und Automatenalfstellungs-GmbH v Oberbürgermeisterin der Bundesstadt Bonn, 14 October 2004, [2004] ECR I-9609, paragraph 35). 
to the law", the ECtHR highlighted in Liu and Liu v. Russia, ${ }^{1143}$ that this expression does not only require that the impugned measure should be based on national law but also refers to the quality of the law in question. This would demand, it continues arguing, that it would be accessible to the persons concerned and formulated in a manner offering sufficient precision to enable them to foresee the consequences which a given action may involve. In light of this, the contested law would need to indicate the scope of any such discretion by the competent authorities and the manner of its exercise with sufficient clarity to provide the individual an adequate level of protection against any arbitrary interference. ${ }^{144}$

On the other hand, the phrase "necessary in a democratic society" has been interpreted by the Strasbourg Court in light of the paradigm of proportionality, in the sense that the interference needs to be proportionate to the legitimate aims sought to be achieved. The ECtHR will here aim at ascertaining the extent to which the circumstance surrounding the interference struck a 'fair balance' between the relevant interests, namely the applicant's right to respect for her/his family life, on the one hand, and the aim pursued by the State, on the other. ${ }^{1145}$ The legitimate goal sought has to be weighed against the seriousness of the interference with the applicants' right to respect for their family life (weighing of interests exercise). In Boultif the ECtHR elaborated the following set of criteria for assessing the extent to which expulsion was "necessary in a democratic society" and "proportionate to the legitimate aim pursued" in those cases concerning the expulsion of TCNs following a criminal conviction: 1146

The nature and seriousness of the offence committed by the applicant;

The length of the applicant's stay in the country from which he or she is to be expelled;

The time elapsed since the offence was committed and the applicant's conduct during that period; ${ }^{1 / 47}$

The nationalities of the various persons concerned;

1143 Liu and Liu v. Russia, no. 42086/05, \$56, 6 December 2007, not yet reported.

1144 See inter alia Lupsa v. Romania, no. 10337/04, $\$ 32$ and 34, ECHR 2006-...; Al-Nashif v. Bulgaria, no. $50963 / 99, \S 119,20$ June 2002; and Malone v. the United Kingdom, judgment of 2 August 1984, Series A no. 82, $\$ \S 67$ and 68 .

1145 Slivenko v. Latvia [GC], no. 48321/99, \$99, ECHR 2003-X; Üner v. the Netherlands [GC], no. 46410/99, § 54; Dalia v. France, 19 February 1998, Reports of Judgments and Decisions 1998-1, p. 91 , $\S$ 52; Mehemi v. France, 26 September 1997, Reports 1997-VI, p. 1971, \$ 34; For the margin of appreciation that is left in hands of the Member States in this regard refer to $W^{\prime} v$. the United Kingdom, 8 July 1987, Series A no. 121-A, p. 27, \$60 (b) and (d); and Olsson, 24 March 1988, Series A no. 130, pp. $31-32, \S 67$.

1146 See $\$ 48$ of the judgment which states that "In assessing the relevant criteria in such a case, the Court will consider the nature and seriousness of the offence committed by the applicant; the duration of the applicant's stay in the country from which he is going to be expelled; the time which has elapsed since the commission of the offence and the applicant's conduct during that period; the nationalities of the various persons concerned; the applicant's family situation, such as the length of the marriage; other factors revealing whether the couple lead a real and genuine family life; whether the spouse knew about the offence at the time when he or she entered into a family relationship; and whether there are children in the marriage and, if so, their age. Not least, the Court will also consider the seriousness of the difficulties which the spouse would be likely to encounter in the applicant's country of origin, although the mere fact that a person might face certain difficulties in accompanying her or his spouse cannot in itself preclude expulsion".

1147 The first three criteria do not relate per se to the respect for family life. 
- The applicant's family situation, such as the length of the marriage, and other factors expressing the effectiveness of a couple's family life;

- Whether the spouse knew about the offence at the time when he or she entered into a family relationship;

- Whether there are children of the marriage, and if so, their age; and

- The seriousness of the difficulties which the spouse is likely to encounter in the country to which the applicant is to be expelled.

Uner v. The Netherlands of October 2006 confimed these guiding principles (the so-called Boultif criteria) and added two more to the list consisting of: 1148

- The best interests and well-being of the children, taking particularly into consideration the seriousness of the difficulies which any children of the applicant might encounter in the country to which the applicant is to be expelled; ${ }^{1 / 49}$ and

- The solidity of social, cultural and family ties with the host country and with the country of origin. In the opinion of the ECHHR the rationale behind this factor "...lies in the assumption that the longer a person has been residing in a particular country the stronger his or her ties with that country and the weaker the ties with the country of his or her nationality will be...the Court will have regard to the special situation of aliens who have spent most, if not all, their childhood in the host country, were brought up there and received their education there".

In addition, the Court stated in paragraph 59 of the same judgment that

that not all (settled) migrants, no matter how long they have been residing in the country from which they are to be expelled, necessarily enjoy "family life"... However, as Article 8 also protects the right to establish and develop relationships with other human beings and the outside world and can sometimes embrace aspects of an individual's social identity, it must be accepted that the tolality of social ties between settled migrants and the community in which they are living constitute part of the concept of "private life" within the meaning of Article 8. Regardless of the existence or otherwise of a "family life", therefore, the Court considers that the expulsion of a settled migrant constitutes interference with his or her right to respect for private life. It will depend on the circumstances of the particular case whether it is appropriate for the Court to focus on the "family life" rather than the "private life" aspect. (Emphasis added.) ${ }^{\text {tiso }}$

It is equally worth recalling that the ECtHR held in Berehab v. The Netherlands that the refusal of an independent residence permit and the ensuing expulsion based purely on the preservation of the country's economic well-being was disproportionate and infringed on Article 8 of the Convention. ${ }^{1151}$ This interference was justified in the opinion of the Court by concerns of the Dutch government on population density and regulation of the labour market, something which was considered to be outweighed in relation to the right of a father to continue his very close family ties and relations with his daughter in that country. It was held that a 'proper balance'

1148 Uner v. the Netherlands [GC], no. 46410/99, 18 October 2006, 58.

1149 See in this respect Tuquabo-Tekle and Others v. the Netherlands, no. 60665/00, $\$ 47,1$ December 2005.

1150 As Boeles and Bruins (2007) highlight in this regard, it is a question still to be answered whether the expulsion of non-settled migrant can or not constitute an unlawful interference to the right for private life as recognized in Article 8 of the ECHR. See P. Boeles and M. Bruins (2007), Case Reports of the European Court of Human Rights and the Human Rights Committee', European Journal of Migration and Law, Vol. 9, No. 2, pp. 253-276.

1151 Berrehab v. The Netherlands, no. 10730/84, 21 Jume 1988, Series A. 126/177, $\$ 26$ and 29. 
was not achieved because the refusal by the Dutch authorities to issue an independent residence permit and the ensuing expulsion threatened to break those family ties.

Concerning the dimension of admission (State's obligation to admit to its territory relatives of settled third country nationals), the jurisprudence of the ECtHR has been rather scarce. As it was concluded in the case Gïl v. Switzerland, Article 8 camnot be considered to impose on a State a general obligation to respect the choice by married couples of the country of their matrimonial residence and to authorise family reunion in its territory. ${ }^{1152}$ Furthermore, in Ahmut v. The Netherlands ${ }^{153}$ the Court assessed whether the Netherlands authorities were bound by duty to allow a TCN to reside with his father in the Netherlands. The Court examined the case as one involving an allegation of failure on the part of the Netherlands to comply with this positive obligation. After recalling the necessity of a "fair balance that has to be struck between the competing interests of the individual and of the community as a whole", it was stated that in those situations where there is a reasonable possibility for the family life to take place elsewhere, and depending on the particular circumstances of the persons involved and the general interest of the State, there will be no unlawful interference with the right to respect for family life. ${ }^{1154}$

There have been certain cases, however, where the ECtHR has recognised that the ECHR might entail a right of admission to specific categories of TCNs on the basis of respect for family life. For example, in Sen v. The Netherlands, ${ }^{155}$ it was accepted that when some of the children are residing in the host State together with their respective parents and they are enrolled in the school system of this State and have been living there for a substantial period of time, and where there are obstacles for transferring the family life to the third country, the other children left in the country of origin will be reunified with their parents and be granted a residence permit.

\subsubsection{Family Life of TCNs: The Case C-540/03 EP v. Council}

Until recently, the ECJ had not found the opportunity to confirm the relevance of the human right to family life as part of the EU general principle of fundamental rights to family members of TCNs. On 16 December 2003, the EP submitted an action for annulment before the ECJ "in the name of the peoples of Europe" challenging the three following provisions of the Council Directive on the right to family reunification: $4(1), 4(6)$ and $8 .{ }^{1156}$ These three articles offer to Member States the possibility to apply exceptions to the general rules envisaged by the main body of the Directive. They specifically deal with the following issues:

1. Article 4.1 provides the possibility for Member States to verify whether a child over 12 years old and arriving independently from the rest of the family meets a "condition for integration". 157

1152 Gïl v. Switzerland, 19 February 1996, Reports of Judgments and Decisions 1996-1, $\$ 38$.

1153 Ahmut v. The Netherlands, No. 21702/93, 28 November 1996, Reports 1996-VI.

1154 See $\$ 69-73$.

1155 Senv, the Netherlands, no. 31465/96, $\$ 31,21$ December 2001.

1156 Action brought on 22 December 2003 by the European Parliament against the Council of the European Union, Case 540/03, 2004/C47/35, OJ C47/21, 21.2.2004. See J. Apap and S. Carrera (2004), Family Reunification - A case for annulment before the ECJ?, CEPS Commentary, Centre for European Policy Studies, CEPS: Brussels. This was the first time that the EP brought a case for annulment outside its own prerogative.

1157 Article 4.1 states that "By way of derogation, where a child is aged over 12 years and arrives independently from the rest of his/her family, the Member State may, before authorising entry and 
2. Article 4.6, according to which Member States may ask the sponsor to apply for the family reunification of minor children before they reach the age of 15 .

3. Article 8 stipulates that the Member State may provide for a waiting period of no more than three years between submission of the application for family reunification and the issue of a residence permit to the family members.

In the view of the EP these three articles where unacceptable regarding fundamental rights (Article 7 of the Charter) and human rights (Article 8 of the ECHR), and particularly the right to family life and the right not to be discriminated against on grounds of age. It advocated that inasmuch as the Directive authorised such national legislation, it was the Directive itself which was infringing on fundamental rights. The ECJ published its decision in the Case C-540/03, EP v. Council of 27 June 2006. This ruling has major implications in the changing relationship between European immigration law and the general principles of EU law, as well as the level of discretion enjoyed by Member States in this context. ${ }^{158}$ In its judgement the Court started by addressing the issue of admissibility of the case, following the approach previously taken by the Opinion of the AG Kokott delivered on 8 September $2005 .{ }^{159}$ In support of the Council, Germany had stressed the importance of the final subparagraph of Article 4.1 of the Directive, which in its view contains one of the main points of the political compromise which allowed the final adoption of the Directive inside the Council and for which a unanimous vote was required. It is worth remembering in this point the central role played by Germany along with Austria and the Netherlands in gaining the inclusion of integration measures and conditions in the text of both Council Directives 2003/109 and 2003/86 (see Chapter 4). Further, Germany was of the opinion that the partial annulment of the contested provisions was impossible because of their non-severability from the whole Directive, as they would affect the very substance of this act. The Opinion of AG Kokott concluded that the action presented by the EP was inadmissible based on this same ground by stating that it was not possible to sever the provisions contested from the remainder of the Directive because

...the contested provisions contain a potential limitation on the duty imposed on Member States by the Directive to make family reunification possible. If the Court were to amul those provisions, there would be a right to family reunification without any special limitation also in respect of minor children of more than 12, or 15, years of age, and the right would not be subject to a waiting period. Annulment of the contested provisions would therefore alter the substance of the Directive: the Court would be trespassing on the preserves of the Community legislature. ${ }^{1160}$

The ECJ was of the opinion that the review of whether the provisions being challenged were severable or not demanded an examination of the substance of the case and the actual scope of those provisions. This, it argued, would be the only viable way to really ascertain the extent to which their annulment would alter the Directive's spirit and substance. It appears that the real strategy advocated by the ECJ behind this way of reasoning was actually to address in a very

residence under this Directive, verify whether he or she meets a condition for integration provided for by its existing legislation on the date of implementation of this Directive".

1158 Case C-540/03, European Parliament v. Council, 27 June 2006, [2006] ECR 1-5769.

1159 Opinion of Advocate General Kokott delivered on 8 September 2005, Case C-540/03. European Parliament Council, paragraphs 43 to 45 .

1160 It is also interesting to see the way in which the AG introduced her opinion in a rather disciplinary manner to the European Parliament by stating that " 3 . Although the Parliament clearly does not set great store by the contribution that the Advocates General make to the judicial process, the present case raises a number of new points of law, concerning notably whether the application is admissible at all and how the relevant fundamental and human rights may be exercised, and accordingly requires an Opinion." 
precise way the reach of the substance of these articles. A way that would naturally lead to the same conclusion as the one previously anticipated by the $A G$, and that would declare the case inadmissible. Taking into account the sensitivities at times of an eventual ruling acknowledging that a Council Directive infringes on human rights, the centrality of the provisions being contested for certain Member States and the prolonged negotiations surrounding the adoption of this Directive in the Council, the ECJ took a deferential line. The caution advocated by the Court did not however prevent it from interpreting proactively and in an expansionary manner the guarantees offered by fundamental rights and human rights to family life of TCNs, and restrictively the exceptions in the purview of Member States.

The ruling made reference to the settled-case law conceming the right to respect family life in accordance with Article 8 of the ECHR, and as confirmed in cases like Carpenter and Akrich. This right, in the opinion of the ECJ, "results in obligations for the Member States which may be negative, when a Member State is required not to deport a person, or positive, when it is required to let a person enter and reside in its territory". Therefore, the judgment continues, the removal of a person from the country where her/his family members live might be considered to constitute an infringement on that right. The ECJ then made a direct reference to various cases of the ECtHR regarding the respect for family life that in its view imposed on the positive obligation of the State, within its margins of appreciation, for a "fair balance to be struck between the competing interests of the individual and of the community as a whole". "The interpretative focus of the Court was therefore centred on the scope and implications of the ECHR, rather than of the EU itself and the European rights provided by Council Directive 2003/86. Let's now pay attention to the argumentation delivered by the ECJ to conclude that Article 4.1 of this Directive, which uses integration as a normative condition, could not be regarded as ruming counter to the fundamental right to respect family life. ${ }^{162}$

The ECJ was of the opinion that this provision preserved a limited margin of appreciation to the Member States of a similar nature to the one envisaged by the ECHR and the jurisprudence of the ECtHR for weighing competing interests in each particular case. It then considered that a condition of integration in itself was not contrary to Article 8 of the ECHR because the right to respect family life cannot be interpreted in a way obliging a Member State to allow family reunification in its territory. In addition to this, "In any event the necessity for integration may fall within a number of the legitimate objectives referred to in Article 8(2) of the ECHR". In fact, the Court was of the view that the objective of this provision was inspired by Recital 12 of the Preamble 1163 and therefore had the general objective of "facilitating the integration of third country nationals in Member States by making family life possible through reunification'. The importance that was given to the Preamble of the Directive, whose actual legal value could be open to debate, is of special significance when interpreting the main text of the Directive. 1164

1161 Sen v. the Netherlands, no. 31465/96, § 31, 21 December 2001; Gül v. Surtzerland, judgment of 19 February 1996, Reports of Judgments and Decisions 1996-I, p. 174, \$38; and Ahmut v. the Netherlands, judgment of 28 November 1996, Reports of Judgments and Decisions 1996.VI, p. 2030, $\$ 63$.

1162 For an analysis of the opinion expressed by the Court as regards the other two provisions see D. Martin (2007), 'Comments on European Parliament v. Council (Case C-540/03 of 27 June 2006)', European Journal of Migration and Law, Vol. 9, No. 1, pp. 144-153.

1163 Recital 12 states that "The possibility of limiting the right to family reunification of children over the age of 12, whose primary residence is not with the sponsor, is intended to reflect the children's capacity for integration at early ages and shall ensure that they acquire the necessary education and language skills in school".

1164 This was not the first occasion where the ECJ underlined the importance of the Preambles for interpreting the main body of a Community act being challenged. See for instance: Case C-443/03, Görz 
Finally, the ground of discrimination on the bases of age was also dismissed on the basis that the integration condition focuses on a "stage in the life of a minor child when the latter has already lived for a relatively long period in a third country without the members of his or her family, so that integration in another environment is liable to give rise to more difficulties".

Therefore, the Luxemburg Court did not agree with the EP that this, and the other two, provisions of the Directive should be struck down, and finally followed the same conclusions delivered by the $A G$ Kokott as regards the legitimacy to keep these conditions and limitations offering a margin of appreciation to Member States, as otherwise there would be an 'unconditional right to family reunification'. While at first sight the resulting conclusions of the judgment may be somehow deceiving, this ruling had three major consequences in the context of EU immigration law which may be summarised as follows:

First, one of its most relevant effects lies in the examination of the Court about the relationship between the respect of human rights and the EU principle of fundamental rights and EU law granting of wide-ranging discretion to Member States. ${ }^{165}$ The judgment has major implications in relation to the action of Member States in the context of the respect of fundamental rights while implementing European immigration law, and the discretion that the Directive leaves them in relation to derogations from these rights. When looking at the substance of each of the exceptional clauses, the ECJ interpreted them in conformity with fundamental rights in light of human rights in the ECHR. While doing so, the Court 'rewrote' the exceptions included in these provisions of the Directive. For instance, in paragraph 60 the ruling states that "Article 4(1) of the Directive imposes precise positive obligations, with corresponding clearly defined individual rights, on the Member States".

Further in paragraphs 63 and 64 the ECJ confirmed the importance for the Member State concerned to take into account Articles 5.5 and 17 of the Council Directive 2003/86 before rejecting an application or refusing/withdrawing a residence permit and issuing a removal order. These two articles, as we have seen in Chapter 4, oblige Member States to consider the best interests of the minor children when examining an application, and "the nature and solidity of the person's family relationships and the duration of this residence in the Member State and of the existence of family, cultural and social ties with his/her country of origin". Therefore, this ruling reduced the exceptions and margin of appreciation that the main body of the Council Directive on the right to family reunification might have offered to Member States in the phase of national implementation. In view of this judgment, Council Directive 2003/86 cannot be interpreted as allowing Member States to use the discretionary options offered in these Articles to infringe fundamental rights. Member States will therefore be unable to circumvent or attempt

Leffler v Berlin Chemie $A G, 8$ November 2005, [2005] ECR-9611, paragraph 38; See also Case C-1/04 Staubitz-Schreiber, 17 January 2006, [2006] 1-701, paragraphs 25 and 26.

1165 B. Masson (2006), 'L'harmonisation des conditions du regroupement familial: La Cour fait la leçon sur le titre IV CE (CJCE 27 juin 2006, Partement européen ef Conseil de l'Union européenne)', Revue Trimestrielle de Droit Europeen, Vol. 42, $\mathrm{N}^{\circ} 4$, pp. 673-685.

1167 See paragraph 60 of the ruling which states that "Going beyond those provisions, Article $4(1)$ of the Directive imposes precise positive obligations, with corresponding clearly defined individual rights, on the Member States, since it requires them, in the cases determined by the Directive, to authorise family reunification of certain members of the sponsor's family, without being left a margin of appreciation". In this respect Iglesias Femández (2007) has argued that by doing so the ECJ recognized the existence of a clearly defined subjective right to family reunification in EC law. S. Iglesias Fernández (2007), "El Valor de la Directiva 2003/86/CE sobre Reagrupación Familiar a la Luz de los Derechos Fundamentales y de la Sentencia del TJCE en el Asunto 540/03', Revista de Derecho Comunitario Europeo, No. 26, Enero/Abril, pp. 125-153. 
to undercut the degree of protection and legal security included in the level of harmonisation that has so far been achieved by the EC. In particular, as the ECJ held,

The Member States which wish to make use of the derogation camot employ an unspecified concept of integration, but must apply the condition for integration provided for by their legislation existing on the date of implementation of the Directive in order to examine the specific situation of a child over 12 years of age arriving independently from the rest of his or her family. (Emphasis added.)

Martin (2007) has presented some critical remarks concerning the choice taken by the ECJ to examine the validity of the Directive in relation to Article 8 of the ECHR and not with "a Community law fundamental right to family reunification", which in his view has been instituted in the EU with the entry into force of the Directive. This author argues that by doing so the ECJ constituted itself as a de facto Court of First Instance resulting from a situation which could potentially be submitted by any individual challenging the national legislation implementing the Directive before the ECtHR, which would issue the final and ultimate decision on the issue. While it is arguable whether the interaction between the ECJ and the ECtHR might actually have negative implications with respect to the level of protection granted to the TCNs in relation to the right for respect of family life, and the EU right to family reunification, the legal reasoning provided by the ECJ interpreting the limitations offered to Member States by the Directive does provide grounds for a number of critical issues. By not focusing the reasoning and interpretation of the three contested provisions on EU law and the set of European rights "clearly defined" by the Council Directive 2003/86, the ECJ might have lost a unique opportunity to foster the coherency and consistency of these 'European rights' all across the Union. This deferential approach also blinded the Court as regards the consistent European approach(es) that have been traditionally predominant during the various phases of European integration since the 1970s in EU law and policy, which as it has been shown in Chapter 2 of this book, the conditionality of integration did not appear until the adoption of Council Directives 2003/109 and 2003/86, and as a consequence of the influence by a small group of Member States. The ECJ could have consolidated and confirmed the objective existence of a clearly defined EU right of family reunification ${ }^{167}$ and promoted the classical understanding(s) and approaches of integration in the EU, which have been traditionally rooted in the principles of near-equality, security of residence and non-discrimination, instead of a logic mainly consisting of using it as a normative condition in immigration law.

Second, the ECJ sent the hot potato to the national courts at times of reviewing the national implementation of the Directive. If those courts would encounter difficulties relating to the "interpretation" or "validity" of the Directive, it is incumbent upon them to refer a question to the ECJ for a preliminary ruling in the circumstances set out in 234 TEC. By doing so the Court acknowledged it might be possible that in practice the domestic implementation of these derogatory provisions could go against fundamental rights, and even that a certain application of these provisions in the national arena would provide grounds for challenging the sustainability of their very substance. The reference to the national tribunals actually has been a common feature in the jurisprudence of the ECJ in relation to the proportionality of national measures implementing EU rules. In addition to the detailed interpretation of these three articles as provided by this ruling, the ECJ will give them further 'guidance' as to the path to be followed when the cases arise. Here also, the ECJ decided not to address the eventual conflict of national implementation with the European rights provided by the Directive itself, independent of those falling within the scope of fundamental rights.

Third, this is the first ruling where the ECJ has made an express reference to the Charter of Fundamental Rights of the EU by stating that even though the Charter lacks at present a legally 
binding nature, the EU legislature acknowledged its importance in the preamble of Council Directive 2003/86 where it stated that the latter observes the principles recognised by Article 8 of the ECHR and the Charter. 1168 Furthermore, the ECJ held that "the principal aim of the Charter, as is apparent from its preamble, is to reaffirm 'rights as they result, in particular, from the constitutional traditions and international obligations common to the Member States, the Treaty on European Union, the Community Treaties, the [ECHR], the Social Charters adopted by the Community and by the Council of Europe and the case-law of the Court... and of the European Court of Human Rights". 1169 In addition to the special relevance given by the Court to the legal value of the Preamble, this understanding of the Charter is somehow revolutionary when comparing it to the previous jurisprudence of the ECJ, as it appears to sustain the idea that the constitutional traditions and the set of international obligations are intertwined, and that the Charter is a sort of codification of the other two juridical realms. On the other hand, the ECJ stated for the first lime that the Convention on the Rights of the Child has to be taken into consideration when applying the general principles of EU law, and hence when applying the Directive as well. Finally, the judgment reiterated that Member States are bound to respect fundamental rights as general principles when implementing EU law, "and to apply these harmonised rules in accordance with these requirements".

\section{The Tests of Fundamental Rights and Proportionality: The Case of France}

As we have studied in Chapter 6 of this book, and in contrast to the case of Spain, France has practiced since 2003 a sort of Europeanism in relation to the implementation of European immigration law whose compatibility with the EU rule of law and fundamental rights raise a number of questions in need of reflection. The set of logics of normativisation, expansionism and externalisation driving French Republican integration provide us with an illustrative example of Member States' action within the scope of EU law potentially interfering with European rights and fundamental rights. This Section addresses the tensions that arise when putting in relation these three logics characterising the implementation of Council Directives 2003/109 and 2003/86 into French law and the system of checks foreseen by the EU system of governance, which comprises as one of its most solid bastions the general principles of EU law. In particular, it focuses on the compatibility between the main elements which have been identified in those domestic legislative measures transposing European immigration law in France, especially those regarding integration 'conditions' or 'measures', and the general principles of proportionality and fundamental rights.

1168 Recital 2 of the Preamble stipulates that "Measures concerning family reunification should be adopted in conformity with the obligation to protect the family and respect family life enshrined in many instruments of international law. This Directive respects the fundamental rights and observes the principles recognised in particular in Article 8 of the European Convention for the Protection of Human Rights and Fundamental Freedoms and in the Charter of Fundamental Rights of the European Union".

According to Groenendijk et al. (2006), the reminder sent by the ECJ about the binding nature of the European Social Charter and the European Convention on the legal status of migrant workers is of special significance for countries like France and Spain, which are party to the latter Convention, and since Article 12 of that legal instrument grants family reunification rights to migrant workers which are more favorable than those provided by the Council Directive 2003/86 See K. Groenendijk, R. Fernhout, D. Van Dam, R. Van Oers and T. Strik (2007), The Family Reunification Directive in EU Member States: The First Year of Implementation, Wolf Legal Publishers: Nijmegen. For a summarized analysis of the judgment see pages 8-10. 
In the last few years the Republican paradigm of integration has been subject to a number of multifaceted processes affecting its very substance, functions and scope. On the one hand, it has experienced a process of normativisation consisting of a mutation into a mandatory contractual relationship. The normative nature of integration in immigration law was first introduced with the entry into force of Law 2003-1119 "relative à la maitrise de l'immigration, au séjour des étrangers en France et à la nationalité" of 26 November 2003, and Law 2006-911 "relative à l'immigration et à l'intégration" of 24 July 2006. In accordance with these two legal acts, the granting of the right of permanent residence depends on the fulfilment of a mandatory condition of integration (la condition d'intégration) stipulated in the "contrat d'accueil et d'intégration" (CAI). On the other hand, the new "Loi relatif à la maîtrise de l'immigration, à l'intégration et $a$ l'asile" $n^{\circ} 2007-1631$ of 20 November 2007 has introduced an expansionist logic to the set of roles played by integration which now also covers the domain of family reunification with the creation of an additional contract called "Contrat d'accueil et d'intégration pour la famille" (CAIF). Further, this law has induced a process of externalisation through the practice of the concept of "Republican integration abroad" as an additional condition for being granted a visa for family reunion.

Invoking the obligation to act and transpose EU immigration law, the French State has fundamentally amended its legislation as regards the role that integration used to traditionally play in its regulatory system. Currently, integration does not only constitute one of the main requirements of "recevabilité" to acquire French nationality through naturalisation, but as represented in the Table 1 below, the neo-republican doctrine of integration now applies as an administrative requirement for TCNs to have access to legal security of residence, family life and protection against expulsion. It therefore functions as a mechanism of immigration control spreading its effects over three distinct levels of the management of immigration:

First Level: Integration has become a contractual criterion having a binding legal nature and taking the form of the CAI. This contract will need to be fulfilled by TCNs before having access to the status of permanent resident (permanent residence permit or "carte de résident"), and before enjoying the EU rights stipulated by Council Directive 2003/109 to the EC Status of TCN long-term resident (Long-term Resident's EC Residence Permit). The French authorities have grounded the contractual functionality of integration on Article 5.2 of Council Directive $2003 / 109$ on the status of third country nationals who are long-term residents. This provision allows Member States to require TCNs to comply with "integration conditions, in accordance with national law" for the acquisition of the EC status of long-term resident. ${ }^{110}$ The framing of integration by a contract between the French state and the TCN means that if this normative condition is not sufficiently fulfilled by the latter (something which will consist of a commitment and effective respect of Republican principles and values: civic education and a sufficient knowledge/proficiency of the French language), the French State will be legitimised to apply a sanction or penalty consisting of the refusal of the application for a permanent residence permit, the non-renewal of the temporary residence permit and eventual expulsion after the expiry of the latter and the irregularity of stay of the immigrant.

Second Level: Integration constitutes a mandatory requirement applying in the country of origin to any TCN aiming at benefiting from family reunification in France. Family reunification will

1170 The precise wording of Article 5.2 is the following "Member States may require third-country nationals to comply with integration conditions, in accordance with national law". For a discussion about the implications of these provisions see S. Carrera (2005), "Integration as a process of inclusion for migrants? The case of long-term residents in the EU", in H. Schneider (ed.), Migraion, Jmegration and Citizenship: A Challenge for Europe's Future, pp. 109-138. 
be subordinated to the presentation of a certificate of attendance to an integration course provided at the French consular and diplomatic missions in third countries, and that will consist of language proficiency and civic training (Republican integration abroad). This certificate of attendance will constitute another requisite for the actual delivery of the visa. The would-beimmigrant falling within the legal category of family member will need to be integrated before actually moving into this categorisation. The function of integration as a tool of immigration control in this way reaches beyond French territorial borders and into the territory of the third country. The control takes place 'at a distance' and aims to prevent a person from becoming an immigrant by managing her/his status before entering French territory. The introduction of integration abroad in the French legal system on immigration has been justified on the basis of Article 7.2 of Council Directive 2003/86 on the right to family reunification. ${ }^{171}$ This provision offers the possibility to Member States to introduce into their respective legal systems compliance with "integration measures" for granting family reunification even before they enter the country - integration abroad. ${ }^{172}$ The obvious consequence of non-attending or failing to be granted with the certificate in the country of origin will be the denial of a visa to enter and benefit from family reunification in France.

Third Level: The contractual understanding of integration invades the scope of family life. The TCN holding pemanent residence status and her/his family having already benefited from family reunification will be obliged to conclude another contract with the French state called the "welcome and integration contract for the family" (CAIF). This new contract obliges them to attend a course on "the rights and duties of parents in France", and which formally aims at ensuring "lintégration républicaine de la famille dans la société française". The contractualisation of the context of family reunification is also based on Article 7.2 of the Council Directive 2003/86 on the right to family reunification. In the event that the contractual conditions are not fulfilled either by the long-term resident Other or her/his spouse, they may be first sanctioned with a financial penalty consisting of the cessation of family social benefits, and eventually administrative sanctions which might consist of denying the renewal of the residence permit, and the consequent expulsion from the country.

117 Following the wording of the Explanatory Memorandum Article I "fait application de ce dispositif de préparation au parcours d'intégration républicaine anx étrangers de plus de seize ans pour lesquels est sollicité le bénéfice du regronpement familial. Ces dispositions sont dans le droit fil de la directive 2003/86/CE du 22 septembre 2003 relative au droit at regroupement familial qui. dans son article 7. paragraphe 2, prévoit que les Érats membres pernent exiger des ressortissants de pans tiers qu'ils se conforment an meswres d'integration dans le respect du droit nationar".

Article 7.2 of the Council Directive states that "Member States may require third country nationals to comply with integration measures, in accordance with national law". 
Table 1: The Three-pronged Level of Management by Republican Integration in France

\begin{tabular}{|c|c|c|}
\hline EU Law & Council Directive 2003/109 & Council Directive 2003/86 \\
\hline EU Legal Status & Long-term Resident - Articles 4-7 & $\begin{array}{c}\text { - Sponsor: Articles } 2 . c \text { and } 3 \\
\text { - Family members: Articles 4, 13,14 } \\
\text { and } 15\end{array}$ \\
\hline European Rights & $\begin{array}{l}\text { 1. Security of Residence (Articles 4-7), } \\
\text { quasi Equal Treatment (Article 11) \& } \\
\text { Protection against Expulsion (Article } \\
\qquad 12 \text { ) } \\
\text { 2. Movement and Residence second } \\
\text { Member State, Chapter llI }\end{array}$ & $\begin{array}{l}\text { 1. Right of Family Reunification } \\
\text { (Article 1, Recitals } 6,9 \text { and 16) } \\
\text { 2. Rights related to it and granting to } \\
\text { family members, Chapters IV and VI }\end{array}$ \\
\hline European Criteria & Article 5.2 "integration conditions" & Article 7.2 "integration measures" \\
\hline & FIRST LEVEL & SECOND LEVEL \\
\hline National Criteria & CAI (mandatory) & $\begin{array}{c}\text { Republican Integration Abroad } \\
\text { (mandatory) }\end{array}$ \\
\hline National Sanctions & $\begin{array}{l}\text { Non-issuing and/or renewal of } \\
\text { Residence Permit / Expulsion }\end{array}$ & Non-issuing of visa / Refusal of entry \\
\hline & \multicolumn{2}{|c|}{ THIRD LEVEL } \\
\hline $\begin{array}{l}\text { National } \\
\text { Criteria }\end{array}$ & \multicolumn{2}{|c|}{ CAIF (mandatory) } \\
\hline National Sanctions & \multicolumn{2}{|c|}{$\begin{array}{l}\text { 1. No social benefits } \\
\text { renewal of Residence Permit / Expulsion }\end{array}$} \\
\hline
\end{tabular}

There is therefore a three-pronged level of immigration control, where Republican integration functions as a "condition" in French law as a consequence of the national implementation of European immigration law. This system applies wholly to those TCNs falling within the personal scope of Council Directives 2003/109, and partially to those under 2003/86. We have argued that the connection between the principles of proportionality and fundamental rights represents a solid foundation of contestation for the legality of current laws and practices at the national level "within the scope of EU law" and of claims of interference with European rights recognised by EU law. The ways in which Republican integration is practiced represents an exception to or interference with a harmonised set of rights commonly recognised at the EU level within the ambit of EU immigration law. Is the transposition carried out by France in compliance with the general principles of EU law of proportionality and fundamental rights?

\subsection{First Level: The CAI as a Condition for EC Long-Term Resident Status}

The application of a mandatory welcome and integration contract (the CAI) for having access to the EC long-term resident status can be reviewed in the context of the principle of proportionality. As it has been explained in Section 2.1 above, the test of proportionality 
practiced by the ECJ has often comprised a three-step examination consisting of the subsidiary principles of suitability, necessity and proportionality stricto sensu. Perhaps the sub-elements of necessity and proportionality are the most relevant for this particular case, as it would be difficult to argue that the CAl is not suitable at the practical level.

\subsubsection{The Principle of Necessity and the CAI}

Is the CAl necessary to achieve the intended goal? Can the CAI be considered as the less restrictive and onerous option to achieve that end? France has based the development of this legal tool on Article 5.2 of Directive 2003/109. Following the reasoning and interpretation developed by the ECJ in the Case C-540/03, EP v. Council of 27 June 2006, it would be useful to consider the Preamble of the Directive in order to ascertain the actual goal and objectives of a provision included in its main body. The Preamble begins by making reference in Recital 2 to the Tampere European Council Conclusions of October $1999^{1173}$ and the fair and near-equality paradigm endorsed, for instance, in its paragraph 21 , which reads as follows:

The legal status of third country nationals should be approximated to that of Member States' nationals. A person, who has resided legally in a Member State for a period of time to be determined and who holds a long-term residence permit, should be granted in that Member State a set of uniform rights which are as near as possible to those enjoyed by EU citizens. (Emphasis added.)

The relevance given to a near-equality of rights is reinforced by Recital 12, which emphasises that "in order to constitute a genuine instrument for the integration of long-term residents into society", equality of treatment would need to be granted to those qualifying for the scope ratione personae of this act. Recital 6 of the Preamble also states that the main criteria for acquiring the EC status of long-term resident "should be" the duration of (legal and continuous) residence in the territory of the Member State. The length of stay should therefore constitute the connecting factor for acceding to the rights provided by the Directive. Further, as regards the conditions, Recital 21 continues by exposing the possibility for the Member States to verify whether the TCN fulfils the requirements for residing in its territory, which could include checking the extent to which the person involved constitutes a threat to public policy, public security and public safety. Finally, Recital 9 makes clear that economic considerations cannot be taken as a ground for the refusal of $\mathrm{EC}$ long-term resident status.

When putting in relation these interpretative premises of the intended goal of Council Directive 2003/109 with the aim pursued by the French government with the CAI, a certain tension arises. We have sustained the view that one of the overarching functions performed by the contractual mandatory logic of Republican integration is putting into practice a restrictive immigration policy aiming at limiting the number of beneficiaries of the legal security of residence and degree of protection inherent to the status of long-term resident in France. Adding to the list of criteria an obligatory contract makes it difficult to argue that the length of residence continues to be the main determining factor for the non-national to move toward this transnational legal category. It is additionally certain that the CAI makes it difficult to sustain that the fair and nearequality paradigm proclaimed in the Tampere Programme constitutes its inspiring rationale. It remains therefore doubtful the extent to which the mandatory and contractual fashion that the conditionality of integration has taken in the French transposition is necessary to achieve the goals of Directive 2003/109. Moreover, the binding nature of the welcome and integration contract is far from being "the less restrictive and onerous" option for TCNs, who should not be

Tampere European Council, 15-16 October 1999, Presidency Conclusions, SN 200/99, Brussels. 
obliged to become more French than the perfect Republican French citizen to have access to security of residence, but, in accordance with the Preamble of Directive, should instead be allowed the necessary tools to have access to equal rights and legal security "in order to constitute a genuine instrument for integration".

The restrictive nature of this national implementing measure is further invigorated by the set of sanctions that have been provided by the law in the event of non-compliance with the CAI and therefore not receiving the favourable certificate from the ANAEM. The applications from those TCNs not respecting the contract will be refused, and therefore the long-term resident's EC residence permit will not be issued. In this situation, the TCN might continue to be covered by a temporary residence permit which will be valid for one year and may be renewed only for another four years. After this time expulsion from the country would be necessary on the pure basis of her/his non-compliance with the Republican condition of integration. The compatibility of this sort of expulsion with the framework of protection offered by the ECHR and the jurisprudence developed by the ECtHR remains open. It appears that the administrative decision of removal from French territory would not take properly into consideration those circumstances included in the Boultif criteria and further developed by the Strasbourg Court in the case Üner v. The Netherlands of October 2006. For example, before the expulsion takes place, it should be first necessary to address the solidity of social, cultural and family ties with the host country and with the country of origin. The ECtHR has stated that the longer a person has resided in a country the more consolidated the ties are with the latter and the weaker are those with the country of origin. The Court further stated in paragraph 59 of the Üner judgment that

as Article 8 also protects the right to establish and develop relationships with other human beings and the outside world and can sometimes embrace aspects of an individual's social identity, it must be accepted that the totality of social ties between settled migrants and the community in which they are living constitute part of the concept of "private life" within the meaning of Article 8.

In light of this, the expulsion of a de facto third country long-term resident considered de jure non-assimilable to the values and principles of the French Republic could interfere with the right to respect for private life provided in Article 8 of the ECHR.

The less restrictive test is also destined to fail when looking at the double level of binding contractualisation that TCNs will encounter first when applying to acquire the EC LTR Status, and subsequently when attempting to access to EU rights related to family reunification. TCNs would be obliged as a first step to show evidence of integration according to the concept of the perfect French citizen to have access to security of residence provided by Council Directive 2003/109. As a second step, which will be studied in detail below, they will also need to show her/his absorption into the concept of the perfect French Republican family to enjoy the fundamental right to respect of family life and the European rights linked to family reunification.

Finally, it is worth pointing out that the applicability of the CAI could benefit from the funding schemes provided by the European Integration Fund (EIF), which has been studied in Chapter 3. While the EIF mainly targets the co-financing of concrete actions by the Member States supporting the integration of "newly-arrived third country nationals", Recital 13 of the Preamble of the Council Decision establishing the EIF ${ }^{1174}$ states that

1174 Council Decision establishing the European Fund for the Integration of Third-Country Nationals for the Period 2007 to 2013 as part of the General Programme "Solidarity and Management of Migration Flows", 2007/435/EC, 27 June 2007, OJ L 168/18, 28.6.2007. 
Reference, could be made in this context 10 Council Directive 2003/109/EC concerning the status of third-country nationals who are long-term residents which refers to the period of five years of legal residence as a requirement with which third-country nationals have to comply in order to qualify for long-term residence status.

It would be desirable to assess the necessity of the CAI in the context of European immigration law and the general principles before supporting financially any action destined to promulgate the continuation of this administrative practice having so many implications over EU rights.

\subsubsection{The Principle of Proportionality "strict sense" and the CAI}

A second element for a satisfactory measurement of the proportionality of a Member State action when implementing EU law is the tenet of proportionality stricto sensu. This feature of the proportionality test pays attention to the extent to which a measure has imposed an excessive burden upon a recognised right when taking into account a public objective. The ECJ will proceed in the assessment of this third stream in the proportionality test when the applicant expressly refers to the disproportionate nature of the measure being contested. The principle of proportionality strict sense becomes especially relevant in those contexts where an act is said to interfere with rights enshrined in European law. It plays an important role in order to ensure the rule of law as well as the consistency and coherence of any European policy granting common rights to the individual. Chapter 4 has reviewed the packages of EU-recognised rights to those TCNs meeting the conditions presented in Articles 4 to 7 . Among others, equality of treatment in a number of economic and social spheres (Article 11), protection against expulsion (Article 12) and residence enjoying the same benefits in a second Member State (Articles 14-23) constitute the main harmonised set of transnational rights with a European reach beyond the classical confines of the nation-state.

Article 5.2 of the Directive confers the power to Member States to apply "integration conditions, in accordance with national law" for acquiring long-term resident status. In this regard, some could argue that the Council Directive on the status of third country nationals who are long-term residents might be considered as 'minimum harmonisation', and therefore the actual relevance of the principle of proportionality would be open to debate when reviewing the degree of immigration management/control exercised by Republican integration in French immigration law. De Cecco (2006) has eloquently sustained that on the basis of Cases C-2/97 Borsana ${ }^{1175}$ and $\mathrm{C}-6 / 03$ Deponiez ${ }^{1176}$ the principle of proportionality is irrelevant when reviewing stricter national rules in those branches of EU law falling within the category of minimum harmonisation. ${ }^{1177}$ In the Case Borsana the ECJ interpreted Council Directive 90/394 on the protection of workers from the risks related to exposure to carcinogens at work ${ }^{1178}$ and an Italian implementing measure claiming to apply more stringent requirements on the employers. The Court was of the opinion that the national measure did not increase the protection offered by the Directive and therefore could not be regarded as infringing the overall coherency of the EC

\footnotetext{
1175 Case C-2/97, Societá iraliana petroli SpA (IP) v Borsana Srl, [1998] ECR I-8597.

1176 Case C-6/03, Deponiezweckverband Eiterköpfe v. Land Rheinland Pfalz, 14 April 2004, [2005] ECR I02753 .

1177 F. de Cecco (2006), 'Room to Move? Minimum Harmonization and Fundamental Rights', Common Marker Law Review, No. 1, Vol. 43, pp. 9-30.

1178 Council Directive 90/394/EEC of 28 June 1990 on the protection of workers from the risks related to exposure to carcinogens ar work (Sixth individual Directive within the meaning of Article 16.1 of Directive 89/391/EEC), OJ L 196, 26/07/1990.
} 
action over the domain being addressed. As the domestic measure "did not hinder the exercise of fundamental freedoms guaranteed by the Treaty", "179 the ECJ considered the assessment of its compatibility with the principle of proportionality to fall beyond its recognised competences. A similar approach appears to have been taken in the Case Deponiezweckwerband, where the national act being challenged was implementing a provision included in Council Directive 1999/31 on landfill waste. ${ }^{180}$ The ECJ similarly ruled its positive view concerning the domestic measure practising more protective standards, and held in paragraphs 61-64 that

...in adopting stricter measures, Member States still exercise powers governed by Community law, given that such measures must in any case be compatible with the Treaty. Nevertheless, it falls to the Member States to define the extent of the protection to be achieved... In that context, in so far as it is a matter of ensuring that the minimum requirements laid down by the Directive are enforced, the Community principle of proportionality demands that measures of domestic law be appropriate and necessary in relation to the objectives pursued. In contrast...that principle is no longer applicable so far as concerns more stringent protective measures of domestic law adopted by virtue of Article $176 \mathrm{EC}$ and going beyond the minimum requirements laid down by the Directive.

It could be argued whether the Council Directive 2003/109 actually represents an example of 'minimum hamonisation'. 181 While it is true that Article 5.2 does not expressly allow the Member State to introduce more protective conditions in their national immigration regulatory frameworks, it does generally grant it the privilege to practice a substantial degree of discretionary powers at times of domestic implementation of EU law in their legal systems and traditions. ${ }^{1182}$ However, in the event that one may wish to consider this act to implicitly fall within this legal technique, ${ }^{1183}$ the relevance of the two judgements of the ECJ highlighted above would anyhow be limited when moving into our case study due to the following reasons:

First, the public interest objective of the national measures addressed in these two rulings was tested by the ECJ taking into consideration only the first two of the three steps composing the test of proportionality. In other words, the Court only checked the secondary principles of suitability and necessity. In none of these cases was the sub-principle of proportionality stricto sensu expressly claimed by the applicants to be relevant, and consequently the ECJ did not analyse it.

1179 Paragraph 38 of the ruling states that "it must be pointed out that a national provision reinforcing the obligation laid down in Article 5 of Directive 90/394 by requiring the employer to reduce workers' exposure to the carcinogen irrespective of the assessment of risk applies in a non-discriminatory manner and does not hinder the exercise of the fundamental freedoms guaranteed by the Treaty". Paragraph 39 continues by saying "Accordingly, it must be held that a national provision such as Article 62 of Legislative Decree No 626/94, which requires the employer to reduce workers' exposure to the carcinogen irrespective of the assessment of risk constitutes a more stringent measure for the protection of working conditions, authorised by Article 118a.3 of the Treaty and Directive 90/394".

1180 Council Directive 1999/3//EC of 26 April 1999 on the landfill of waste, OJ L 182, 16.7.1999.

1181 On how Member States have used the Community method to retain a high degree of discretion over the development of EU immigration law, explaining the low minimum standards in many measures which have been adopted so far see S. Peers (2006), "The EU Institutions and Title IV", in S. Peers and N. Rogers (eds), EU Immigration and Asy'tum Law: Text and Commentary, Martinus Nijhoff Publishers: Leiden, pp. 47-79.

1182 Y. Schibel (2004), 'Transposing EU Law on Legal Migration', European Journal of Migration and Law', Vol. 6, no.4, pp. 395-404.

1183 See for instance Case C-11/92, The Queen v Secretary of State for Health. ex parte Gallaher Ltd. Imperial Tobacco Ltd and Rothmans International Tobacco (UK) Lid., [1993] ECR I-3545. 
Second, and as stated above, the goals pursued by the French implementing laws appear to be very far from those guiding Council Directive 2003/109, and therefore cannot be considered as increasing the protection of the rights envisaged by it.

Finally, the French national implementing measures reviewed in this subsection fall within the scope of a particular branch of EU immigration law granting European-wide rights to certain categories of TCNs. In those contexts where the rights of the individual (regardless of her/his nationality) are concemed, the third step - proportionality strict sense - becomes, we argue, most crucial, because even though a national measure may be considered to be suitable and necessary, it may be completely disproportionate and unreasonable when relating the pursued public interest with the impact of the interference with the substance of the EU right and the coherency with the common European policy being affected. The role of the general principles of EU law, especially the nexus between the principle of proportionality and that of fundamental rights, becomes even more relevant in those areas of EU policy affected by a minimal harmonisation approach and providing rights to the individual. France therefore should have paid close attention in order to ensure that the implementation of the provisions of the Directive were implemented in a form compatible with the general principles of the EU law of proportionality and fundamental rights. The nature and sanctions linked to the CAI reach very far, something which might undermine the substance of the European rights conferred by the Directive.

When facing a case challenging national implementing measures with features such as those of the CAI in France, the ECJ should address it in relation to the EU-recognised rights envisaged by EU law. Returning to the Preamble of Council Directive 2003/109, Recital 18 clarifies that the right attached to the EC status of LTR to move to and reside in a second Member State intends to contribute "to the effective attainment of an internal market as an area in which free movement of persons in ensured", constituting in this way a major factor of human mobility within the EU. The ECJ should therefore take the same line of reasoning as the one that has adopted when addressing the legitimate derogations to fundamental freedoms of the EU. This would not only be appropriate for ensuring proper protection of the individual (TCNs) whose European rights might be endangered during phases of implementation, but would also be in the interest of the EU political project itself in order to ensure the existence of a solid, consistent and coherent common European policy on immigration all across the Union.

Finally, it would not be desirable that the degree of judicial control exercised by the Luxembourg Court were deferential. The same intensity exercised in the cases on the freedom of movement would be necessary. The review exercised by the ECJ cannot be solely dependent on the nationality of the person involved, nor on her/his status of European citizen, at times of guaranteeing and protecting access to European fundamental freedoms to individuals. Instead, the nature of the judicial assessment would need to focus on the extent to which the person involved is a holder of a European right provided by a common EU policy. A strong proportionality test by the ECJ would therefore be welcomed in order to ensure that any derogation practiced by a Member State within the scope of EU immigration law and any application of exceptions and derogations to European rights are the least restrictive possible and are applied strictly. 


\subsection{Second Level: Republican Integration Abroad, Family Reunification and Family Life}

The concept and scope of the measure consisting of Republican integration abroad for being issued a visa on the basis of family reunification demands a joint examination in relation to the general principles of proportionality and fundamental rights. In this particular case, we consider that the three subsidiary principles of suitability, necessity and proportionality stricto sensu comprising the test of proportionality might be of interest.

\subsubsection{Integrating into the French Republic Abroad? The Suitability Test}

In light of the new Article L. 411-8 of the CESEDA every TCN over 16 and under 65 years old having applied for family reunification will be evaluated in the country of origin on her/his degree of language proficiency and 'the values of the Republic'. It is deemed unnecessary to embark on a detailed assessment of any complex economic situation to realise the multiplicity of practical obstacles that this kind of legal measure will face. The examination of the appropriateness of integration abroad proves to be difficult when taking into account not only the paradox inherent to the conceptual premises linked to the very term itself (integrating before even entering and residing in the country), but also when looking at the various uncertainties in need of clarification in relation to the ways in which this measure is going to be implemented in the ground.

For instance, who is going to cover the financial costs of the integration courses aiming to promote Republican integration beyond French territorial borders? What will be the role of the French consular and diplomatic missions in third countries as regards the evaluation process of 'the knowledge' of the applicant for family reunification as a condition for granting or refusing the visa? Which level of knowledge of the French language and Republican values will be required at such a preliminary stage? Is it at all appropriate to expect anyone to assimilate into the constructed French identity before having left her/his country of origin and entering France? Concerning the financial coverage of these measures, and as we have studied in Chapter 3 of this book, the EIF could be also used to cover this administrative measure. According to Article 1.2 of the Council Decision establishing the EIF, ${ }^{1184}$ non-nationals who are in a third country and who are complying with "pre-departure measures and/or conditions set out in national law, including those relating to the ability to integrate in the society of this Member State fall under the scope of this Decision". 1185 Further, it is expected that some answers to these practical barriers will be provided by the Decree that will stipulate the bits and pieces deemed necessary for the implementation of the external dimension of mandatory integration. Yet, the appropriateness subsumed in obliging anybody to integrate into a set of Republican stereotypes as one of the fundamental prerequisites for being admitted to France on the basis of family reunification will, in our view, remain very difficult, if not impossible, to overcome.

1184 Council Decision establishing the European Fund for the Integration of Third-Country Nationals for the Period 2007 to 2013 as part of the General Programme "Solidarity and Management of Migration Flows", 2007/435/EC, 27 June 2007, OJ L 168/18, 28.6.2007.

1185 Moreover, Article 12 states that there will be a Funds' annual allocation of 500.000 Euros each year per Member State. The remainder of the available annual resources will be broken down between the Member States as follows: On the one hand, $40 \%$ in relation to the average of the total number of legally residing third-country nationals over the previous three years; and on the other hand, $60 \%$ in proportion to the number of third-country nationals who have obtained an authorisation to reside on its territory over the previous three years. France will be certainly among those receiving more "financial support" from the EU. 


\subsubsection{Reviewing the Necessity of Mandatory Integrating Abroad}

Is the mandatory integration abroad necessary to achieve the intended goal? Can this condition be considered as the less restrictive and onerous option to achieve the pursued end? France has based this legal tool on Article 7.2 of Council Directive 2003/86 on the right to family reunification. The judgment held by the ECJ in the Case C-540/03, EP v. Council is also of importance when determining the need for having enacted the contested measure. It has already been highlighted above the way in which the Court expressed the view in this ruling that the objective of Article 4.1 of the Directive needed to be interpreted following the inspiration provided by Recital 12 of the Preamble and followed in its opinion the general objective of "facilitating the integration of third country nationals in Member States by making family life possible through reunification". Therefore, even though Article 7.2 might provide a legal justification to apply "integration measures" abroad, it will also need to be tested following a similar pattern as the one used by the Court. The Preamble of Directive 2003/86 begins by making reference to the Tampere European Council Conclusions and the fair and near-equality paradigm. In its Recital 2 it is stipulated that measures related to family reunification "should be adopted in conformity with the obligation to protect the family and respect family life" as recognised in international instruments such as Article 8 of the ECHR. Recital 4 continues by stating that

Family reunification is a necessary way of making family life possible. It helps to create sociocultural stability facilitating the integration of third country nationals in the Member State, which also serves to promole economic and social cohesion...

If we compare the stated objectives with the ones driving the introduction of Republican integration abroad in French immigration law, a friction arises. Indeed, while the Explanatory Memorandum and some of the provisions of the "Loi relatif a la maitrise de l'immigration, $\dot{a}$ l'intégration et à l'asile" $n^{\circ} 2007-1631$ of 20 November 2007 make use of rhetoric that extols the benefits and advantages that the externalisation of the conditionality of integration and the proposed training will impart to the TCN trying to join his/her family in France, the actual goal pursued by this measure appears to have a completely different rationale. In fact, the French government was rather transparent, as its official position was that the number of entries related to family reunification were "too high", which appeared to be a motive to tighten restrictions on it. This objective remains contradictory with the goal of making "family life possible" and "facilitating the integration of third country nationals via family reunification". Instead, integration abroad works the other way around. It rather intends to make use of Republican integration as the necessary step to be fulfilled before entering the country and for family reunification to take place. Moreover, the binding nature of integration abroad may not be the least restrictive and onerous measure for TCNs seeking to join her/his family. The restrictive nature of this measure is reinforced by the drastic sanction that will apply in the absence of the certification of attendance and successful integration, i.e. denial of visa and refusal of entry into French territory for the purposes of family reunification.

\subsubsection{The Principles of Proportionality "strict sense" and Fundamental Rights: Testing Integration Abroad}

The normative mechanism of the conditionality of integration abroad faces several difficulties for passing satisfactorily the test of proportionality stricto sensu. This element of the proportionality test focuses on the extent to which a particular measure has imposed an excessive burden in relation to a recognised right when taking into account a certain objective. The external dimension of Republican integration needs to be read in relation to two different 
dimensions of transnationally recognised rights which are intrinsically linked yet simultaneously distinct in scope and reach: First, those EU rights established by Council Directive 2003/86; and second, the fundamental right to family life enshrined in Article 7 of the Charter of Fundamental Rights and also considered to be a human right by Article 8 of the ECHR.

As regards the first of the categories, Article 1 of Council Directive 2003/86 and Recitals 6, 9 and 16 of the Preamble establish the conditions for TCNs residing lawfully in the territory of the Member States to exercise "a right to family reunification". The Directive additionally specifies a series of EU-recognised rights of those TCNs in the category of sponsor (Article 3) and of those denominated as family members (Articles 4, 13, 14 and 15). These rights are subject to the criteria stipulated in the Directive, which among others include in Article 7.2 the possibility by the Member States "to require third country nationals to comply with integration measures, in accordance with national law". As we sustained in Chapter 4 , it is necessary to emphasise that the word 'measures' was used instead of 'conditions'. One could argue that by doing so Directive 2003/86 was implicitly calling for the non-conditionality of any applicable integration criteria to be applied by Member States in the context of family reunification, something which undoubtedly conflicts directly with French national implementation.

Further, it is also true that this Directive confers a high level of discretion on Member States at times of national transposition, and could be argued to represent another example of implicit minimum harmonisation. That notwithstanding, and following the reasoning used by the ECJ in paragraph 60 of the Case EP v. Council, certain articles of the Directive impose precise positive obligations on Member States with corresponding clearly defined individual rights of TCNs, since "it requires them...to authorise family reunification of certain members of the sponsor's family, without being left a margin of appreciation". Therefore, the exceptions and margin of appreciation offered by this Directive to Member States in the phase of national implementation were limited by the interpretation put forward by the ECJ. In any case, the same comments put forward in this regard in Section 3.1.2 (The Principle of Proportionality strict sense and the CAI) and the recommendations that have been presented in relation to a potential judicial intervention by the ECJ are also valid and applicable in this context.

Concerning the second strand of recognised rights, the French implementing legislation has direct consequences for the fundamental right to family life, which is considered to be a human right in the framework of the Council of Europe. The EU general principle of fundamental rights and the Charter of Fundamental Rights come therefore sharply into place when reviewing the implementing act of France. As we have studied above, the ECJ has provided various instances referring to family life as a "human right" protected under the ECHR and developed by the ECIHR, as well as a "fundamental right" and a general principle of EU law. The consolidated doctrine supported by the EU Courts in relation to the legitimate margin of appreciation allowed by EU law to Member States' interference with "fundamental rights" has been that any derogation should be kept at the minimal possible level, and that the latter should not constitute a disproportionate and intolerable interference, impairing the very substance of those rights. Additionally, the ECJ has pointed out that when evaluating the legitimacy of the derogation of those fundamental rights considered to also be a "human right", the methods and four-step procedure used by the jurisprudence of the ECtHR in relation to Article 8 of the ECHR constitute a special interpretative source of inspiration. The ECHR states in Article 8.2 that the interference with a human right by a public authority will be considered legitimate only when it is "in accordance to the law" and "necessary in a democratic society". How do these terms relate to Republican integration abroad as an implementing measure within the scope of European immigration law? 
The ECHHR confimed in the case Liu and Litu v. Russia that the phrase "in accordance to the law" does not only require that any State interference with the right of family life is based in domestic law, but is also closely related to the very quality of the latter. In particular, the Strasbourg Court has expressed the view that national law needs to be accessible, transparent and clear enough in order to ensure that the individual has an adequate level of protection against interference by the State. It is uncertain the extent to which Republican integration abroad fulfils at all these qualitative requirements. After all, if there is one main factor characterising the very term of integration, it is the high level of discretion that it grants to the State for its understanding, interpretation and applicability. What do the values and principles of the Republic objectively mean? What are the legal mechanisms and guarantees in French immigration law for TCNs to mount a legal challenge against a decision rejecting family reunification in the country of origin on these bases? ${ }^{1188}$ Are the meaning of integration abroad and of the consequences in case of non-fulfilment sufficiently accessible, transparent and clear for the would-be immigrant? Further, it should not to be forgotten that the ECJ held in $E P v$. Council that

The Member States which wish to inake use of the derogation cannot enploy an unspecified concept of imtegration, but must apply the condition for integration provided for by their legislation existing on the date of implementation of the Directive. (Emphasis added.)

The compatibility of the refusal of admission as a sanction for not being integrated into the values of the Republic with the sphere of protection provided by the ECHR also remains open to discussion. While the ECtHR concluded in Giil v. Switzerland that Article 8 of the ECHR does not impose a general obligation on the State to authorise family reunion in its territory, there have been some specific cases where the ECtHR has recognised that it might actually entail a right of admission to certain categories of TCNs. In Sen v. The Netherlands, the Strasbourg Court accepted that when some of the children are residing in the State together with their parents and there are obstacles for transferring the family life to the third country, the children left in the country of origin will be reunited with their parents and be granted the necessary administrative documents. Refusing admission to any TCNs on the basis of failing integration abroad could amount to an unlawful infringement of the right for the respect of family life provided in Article 8.

On the other hand, the term "necessary in a democratic society" has been understood by the Strasbourg Court in a sense closely attached to the tenet of proportionality. Any interference with a human right, such as the right to family life, has to be proportionate. Here, the ECtHR has applied a balance metaphor of weighing the human right with the public interest pursued by the contested law. The legitimate goal sought might include, according to Article 8.2 of the ECHR, "national security, public safety or the economic well-being of the country, for the prevention of disorder or crime, for the protection of health or morals, or for the protection of the rights and freedoms of others". This will need to be weighed against the seriousness of the interference with the applicants' right to respect for their family life.

Is the balancing methodology carried out by the ECtHR sufficient when dealing with EUrecognised rights? Should the ECJ intensify its judicial review of the French Republican paradigm of integration as included in its national legal system on immigration and as applied within the context of EU law? If so, this review should also go beyond a pure balancing

1186 See in this respect Article 18 of the Council Directive 2003/86 which provides that "The Member States shall ensure that the sponsor and/or the members of his/her family have the right to mount a legal challenge where an application for family reunification is rejected or a residence permit is either not renewed or is withdrawn or removal is ordered". 
approach between EU and/or fundamental rights (security and liberty of the individual) and public goals (security of the State). The fact that national measures such as Republican integration abroad affect European-wide rights provided by an EU measure, which sometimes go even further than the rights envisaged by the ECHR and interpreted by the ECtHR, makes it necessary for the ECJ to adopt a more proactive and revolutionary role when assessing the margin of appreciation permitted to Member States interfering with the substance of EU rights, which at times might also be closely intertwined with fundamental rights. The combination of the legally binding nature of the Charter of Fundamental Rights along with the set of rights conferred by EU immigration law to $\mathrm{TCNs}^{1187}$ means that this approach is not only appropriate for the protection of liberty and the rights enjoyed by the individual in the EU, but that it is also necessary for the consistency and coherence of a common EU immigration policy itself.

This would be justified precisely because of the wider context that exists at the EU level as regards the reach of EU and fundamental rights when compared to those in the ECHR and interpreted by the Strasbourg Court. We share the view put forward by Groenendijk (2006) that the legitimate grounds provided by Council Directive 2003/86 extend beyond the framework of protection provided by the ECHR. ${ }^{1188}$ In particular, in his view, the scope of application of Article 17 goes beyond the balancing approach and the accepted margin of appreciation granted to Member States by the jurisprudence of the ECtHR. The Directive adopts a different approach. It first recognises the existence of a right to family reunification and a package of related rights, and then allows certain circumstances, and specific provisions, under which Member States may restrict them while taking into account Article 17. This, he continues arguing,

... is different from "balancing the interests" of the individual family members against the interest of the State in the enforcement of its national admission policy as required in Article 8 ECHR.

Taking this argument further, the balancing of interests implied in the very principle of proportionality prove to have limited effects when moving within the scope of EU rights and fundamental rights. The balancing or weighing approach must not involve a major shift from individual freedoms toward preventive and coercive measures by the State. In this regard the CHALLENGE research project (The Changing Landscape of European Liberty and Security) 1189 offers a multidisciplinary academic critique of the notion of the balance between security and freedom in the EU's AFSJ. ${ }^{1190}$ The balance metaphor implies that the liberty of the individual and the security of the State have the same value and are presented as competing paradigms in need of a proper equilibrium subject to wide-ranging discretion by public authorities. This scenario makes the liberty and the protection of the individual at stake.

In addition, the existence of the two judicial paths (ECtHR and ECJ) for challenging a national implementing measure considered to be unlawfully and disproportionably interfering with the European rights granted by the Directive makes the legal positioning of the individual stronger

1187 On the significance of the Charter towards a rights-based approach to migration law see S. Peers (2001), 'Immigration, Asylum and the European Union Charter of Fundamental Rights', European Joumal of Migration and Law, Vol. 3, No. 2, pp. 141-169.

1188 K. Groenendijk (2006), 'Family Reunification as a Right under Community Law', Ewropean Journal of Migration and Law, Vol. 8, No. 2, pp. 215-230.

1189 The CHALLENGE project (The Changing Landscape of European Liberty and Security), is a research project funded by the European Commission's Directorate-General for Research under the Sixth Framework Programme. For more detailed information see www libertysecurity.org

1190 D. Bigo, S. Carrera, E. Guild and R.B.J. Walker (2007), The Changing Landscape of European Liberty and Security: Mid-Term Report on the Results of the CHALLENGE Project, CHALLENGE Research Paper No. 4, February 2007, Centre for European Policy Studies, CEPS: Brussels. 
against the State and its degree of discretion. Yet it needs to be acknowledged that the actual complexities and paradoxes which could potentially emerge in practice because of the interplay of two jurisdictions competent to examine related and/or similar rights provide justification for further exploration and deliberation. The debate about potential 'conflict of interests' that the increasing role of the ECJ over fundamental rights may cause in relation to the framework of protection already provided by the ECHR is beyond the scope of this book. We shall simply refer to the tensions that might arise, particularly in contexts such as the one provided by Council Directive 2003/86, where an EU right of family reunification is intertwined with other related guarantees, and whose level of protection is wider in many respects than that offered by Article 8 of the ECHR and the ECtHR's jurisprudence. Indeed, it is not clear the extent to which frictions might suddenly arise as regards the level of protection that family life will enjoy in the context of the EU when comparing to that of the Council of Europe. It is true that Article 53 (Level of Protection) of the Charter states that

Nothing in this Charter shall be interpreted as restricting or adversely affecting human rights and lundamental freedoms as recognised, in their respective fields of application, by Union law and international law and by international agreements to which the Union or all the Member States are party, including the European Convention for the Protection of Human Rights and Fundamental Freedoms, and by the Member States' constitutions.

Further, the accession of the EU to the ECHR, as provided by the new Article 6.2 of the new version of the TEU as revised by the Treaty of Lisbon, ${ }^{1191}$ would also provide some remedies to potential conflicts. ${ }^{192}$ However, as regards those rights included in secondary EU legislation, and having close linkages with fundamental and human rights, the answer might not be as straight forward as some have argued. ${ }^{1193}$ A possible scenario of a Europe progressing at 'multiple and competing speeds' regarding the degree of rights protection bestowed by the EU and the Council of Europe might flourish. It is in this plausible context that the protection of the individual could remain very much at stake.

1191 New Article 6 TEU will read as follows: "The Union shall accede to the European Convention for the Protection of Human Rights and Fundamental Freedoms. Such accession shall not affect the Union's competences as defined in the Treaties". See also the Protocol relating to Article 6.2 of the TEU on the Accession of the Union to the European Convention on the Protection of Human Rights and Fundamental Freedoms atached to the Treaty of Lisbon. An eventual accession by the EU to the ECHR will need to be made by unanimity and with ratification by the Member States.

1192 According to the EU Committee of the UK House of Lords "Accession of the Union to the ECHR would greatly reduce the risk of inconsistencies, and provide a means of redress if they did occur, by making the Union and its institutions subject to the jurisdiction of the ECHR"...[...] The Strasbourg Court would then be recognized as the final authority in the field of human rights. This would assist to avoid any risk of conflict..., by placing fundamental rights on a single consistent foundation throughout the EU".

1193 For instance De Schutter argues that there would not be any difficulty for the Council of Europe to become a "standard receiver", and that Article 53 would ensure that the Charter would not be invoked as a pretext to limit the scope of the human rights obligations the EU Member States might be imposed. See O. de Schutter (2007), Promoting and Protecting Fundamental Rights in the European Union: The Relations between the European Convention of Human Rights, the European Charter and the Member States ' Constitutions, Briefing Paper, European Parliament, DG Internal Policies of the Union, Brussels; For a discussion see also C. Ovey and R. C.A. White (2006), Jacobs \& White: The European Convention on Human Rights, Fourth Edition, Oxford University Press: Oxfors, pp. 514-519; F. Sudre (2006), Droit etropén et imernational des droits de l'homme, Presses Universitaires de France: Paris, pp. 646-649. 


\subsection{Third Level: The CAIF and the Principles of Proportionality and Fundamental Rights}

The new "Loi relatif à la maitrise de l'immigration, à l'intégration et à l'asile" n 2007-1631 imposes on TCNs holding a permanent residence permit and the family members having benefited from family reunification to conclude a contract with the French State. This legal construct, which has been denominated as the welcome and integration contract for the family (CAIF), obliges 'the Other's family' to follow another course on "the rights and duties of parents in France". "194 The sub-elements of necessity and proportionality stricto sensu, in relation to that of fundamental rights, are the most important ones within the entire principle of proportionality for assessing this legislative measure.

\subsubsection{The Necessity of the CAIF}

For an examination of the necessity of the CAIF we refer to the interpretation offered in the subsection 3.2.2 of the objectives pursued by Council Directive 2003/86 in light of its Preamble. This needs to be read in relation to the critique provided in subsection 3.1 .1 above as regards the compliance of the CAI with the secondary principle of necessity. Having these comments as a basis, it would not be easy to argue that the CAIF is necessary to achieve the goals of Directive 2003/86. While it is true that Recital 17 of its Preamble refers to the need for the right to family reunification to be exercised in proper compliance with the values and principles of the Member States with respect to the rights of women and of children, and that it stipulates that "such compliance justifies the possible taking of restrictive measures against applications for family reunification of polygamous households", it appears to us that based on the mandatory nature, actual content ("rights and duties of the French family") and the wide personal scope (including TCNs long-term residents), the CAIF goes far beyond the intended goals of the Directive.

The less restrictive means test is also deemed to fail when illustrating the sanctions that will operate in those cases where the contractual conditions are not met either by the settled TCN or her/his spouse. The financial penalty provided by Article 222-4-1 of the "code de l'action sociele et de familles and consisting of the refusal of allocations familiales" is most critical. It may also be the case that the lack of integration will be taken as a basis for refusing the renewal of the residence permits, something which might eventually entail expulsion from the country. The compatibility of this sort of expulsion with the framework of protection offered by Directive 2003/86 as well as that of the ECHR and the jurisprudence developed by the ECtHR remains critical.

\subsubsection{The Principle of Proportionality "strict sense" and Fundamental Rights}

Does the CAIF impose an excessive burden in relation to a recognised right when taking into account the objective? As we have argued above when assessing the compliance of integration abroad with the general principles of proportionality and fundamental rights, the CAIF has equally direct implications as regards not only the EU rights envisaged by the Council Directive on the right to family reunification, but also to the fundamental right of respect for family life. In addition to what has been exposed in point 3.2 .3 as regards the European rights envisaged by Directive 2003/86, it can be added that according to Article 17 of this instrument, when Member States reject an application of family reunification, withdraw or refuse to renew a residence

1194 See the new Art. L. 311-9-1 of the code de l'entrée et du séjour des étrangers et du droir d'asile. 
permit or decide to expel the sponsor or her/his family members from its territory, the following must be taken into account:

...the nature and solidity of the person's family relationships and the duration of his residence in the Member State and of the existence of family, cultural and social ties with his/her country of origin...

Concerning the effects that the interference of the CAIF involves over the fundamental right of family life, the existing framework of protection in the ECHR and as interpreted by the ECtHR needs to be alluded to, as the ECJ has often been referred to it when reviewing the legitimacy and lawfuness of the Member States' interference with a fundamental right. What are the guarantees and the legal grounds of derogation of those fundamental rights also considered to be a human right in the context of the ECHR and in accordance with the jurisprudence of the ECtHR? The general framework of protection against expulsion advocated by the ECtHR follows the general rule according to which the expulsion of a person who enjoys family life in that State may amount to an infringement of the right to respect for family. This has also been sustained by the ECJ in cases such as, among others, Carpenter, Akrich and Orfanopolous. As regards the grounds for legitimate derogation, the ECtHR refers here also to the 'balancing approach' and the need for weighing the seriousness of the interference with the applicants' right to respect for their family life. In order to measure the lawfulness of an administrative measure interfering with the right to family life, the Strasbourg Court has developed what has been called the Boultif Criteria. As it has been already explained, in the Boultif ${ }^{195}$ and Üner Cases ${ }^{1196}$ the ECtHR developed a set of guiding criteria for reviewing the extent to which the expulsion of TCNs following a criminal conviction was "necessary in a democratic society" and "proportionate to the legitimate aim pursued". Among them the following would be the most pertinent for assessing the CAIF:

The applicant's family situation, such as the length of the marriage, and other factors expressing the effectiveness of a couple's family life;

- whether the spouse knew about the offence at the time when he or she entered into a family relationship;

whether there are children of the marriage, and if so, their age;

- the seriousness of the difficulties which the spouse is likely to encounter in the country to which the applicant is to be expelled;

- the best interests and well-being of the children, taking particularly into consideration the seriousness of the difficulties which any children of the applicant might encounter in the country to which the applicant is to be expelled; and of origin.

the solidity of social, cultural and family ties with the host country and with the country

In addition, as the ECtHR held in Berrehab v. The Netherlands, the ensuing expulsion based on the preservation of the country's economic well-being cannot be used as a legitimate ground for justifying expulsion once the requirements are met. ${ }^{197}$ It is uncertain the extent to which the $\mathrm{CAIF}$, and the national implementing legislation in France takes all these elements into

1195 Boultif $y$ Switzerland, no. 54273/00, $\$ \$ 39,41$ and 46, 2 November 2001, ECHR 2001-LX. See also Moustaquim v. Belgium, judgment of 18 February 1991, Series A no. 193, p. 18, 36.

1196

1197

Unerv. the Netherlands [GC], no. 46410/99, 18 October 2006, 58.

Berrehabv. The Netherlands, no. 10730/84, 21 June 1988, Series A. 126/177, § 26 and 29. 
consideration. Further, the additional requirement in relation to "in accordance to the law" leads us to raise the following questions: what is the conception of French family that is going to be used as justification for examining the extent to which 'the Other family' is integrated? What kind of definition and featuring elements of family will be used? What are the rights and duties that every French family is supposed to benefit from and respect in France? Is there a Republican tradition in relation to the understanding of 'the perfect family' in contrast with any deviation from this concept? What are the actual set of criteria that will be practiced for evaluating the integration of the Other family into a particular vision of the French family?

If the CAIF and the sanctions applicable do not respect the ECtHR criteria of proportionality and its criteria are not sufficiently "accessible, transparent and clear" to TCNs, the consequence will be a violation of the EU general principles of proportionality and of fundamental rights. The interference spurred by integration would be unlawful and illegitimate in the EU legal system. The use of the lack of integration into the Republican French family as the basis for expulsion might well constitute an infringement of the settled jurisprudence of the ECHR, and as confirmed by the ECJ, as well as of Article 7 of the Charter of Fundamental Rights. Furthermore, and in a similar way of reasoning as the one put forward in the previous analysis of the other two levels of immigration management, it is submitted that the ECJ needs to develop a proactive jurisprudence ensuring the protection of the substance of the EU rights provided by the Directive on the right of family reunification and the fundamental right of family life, as well as the overall consistency of the common immigration policy all across the Union.

\section{Conclusions}

This Chapter has moved back to the European arena to address the limits provided by the EU legal system to the level of discretion played by the Member States at times of implementing EU law on regular immigration, and particularly when applying integration as a legal tool conditioning the access by TCNs to EU right. The Europeanisation processes affecting the field of immigration do not only concern the impact that EU law might inject over national laws and policies. They also involve the operability of a system of checks limiting the scope of Member States actions in the application of exceptions, restrictions and derogations to European rights and freedoms. The role played by substantive and institutional mechanisms composing the EU legal system is of fundamental importance to guarantee the rule of law and the respect of fundamental rights. It is in this context where the general principles of EU law and the proactive role played by EU Courts (judicial review) are most crucial.

The EU, and its evolving immigration law, provides in certain respects a supranational setting of protection to TCNs beyond the ever-changing and nationalist logic characterizing the Member States' immigration policies. The set of rights and guarantees stipulated in European law prevent national authorities from going below the commonly agreed standards and principles. They have also their hands tight at times of acting against the very purpose and objectives of EU policies. The general principles of EU law play a key role at the interplay between the national and European levels of governance. They constitute a decisive tool for assessing the extent to which Member States' actions within the scope of EU law comply with European rights and standars as provided in the EU common immigration policy. The general principles also function as a mechanism guaranteeing the consistency and coherency in the application of EU rights all across the Union. TCNs can therefore rely on the general principles before national Courts to resist any law or practice by a public authority deemed to be undermining or limiting unlawfully rights recognized in EU immigration law. 
The normativity of integration in French immigration law has served as an exemplary case study to review implementing national legislation in the field of regular immigration against the general principles of EU law due to two main reasons: First, the logics of normativisation, expansionism and extemalisation affecting the category of integration in French immigration law practices an approach on integration which uses it as a legal mandatory condition in hands of the French State limiting access to EU rights. Second, the neo-Republican integration paradigm has been justified by the French State as a fulfilment of its obligation to transpose EU law, and more particularly the Council Directives 2003/109 and 2003/86. The connection between the general principles of proportionality and fundamental rights constitute central grounds for examining the legality of current French legislative measures and the sort of Europeanism laying behind.

This Chapter has therefore provided an in-depth examination of these two general principles in relation to Member States' actions in the context of EU law, and the proactive role played by the ECJ. The principle of proportionality now constitutes one of the most important general principles at times of reviewing the legality of Member States' discretion and defining the boundaries of legitimate public responses, including those taken in the application of EU Directives. While the Court of Luxembourg has not yet encountered the opportunity to deal with a case involving the interplay between the principle of proportionality and national legislation implementing EU immigration law, it has been argued that the general principles, and the ECJ's interpretations as regards their role in relation to other EU policies, would equally come into play in those cases contesting the extent to which a national act would endanger or limit in an illiberal manner European rights and freedoms of TCNs.

We have then offered an analysis of the nexus between fundamental rights, and particularly that of family life, as general principles of EU law and Member States' action at times of domestic implementation of European immigration law. The ECJ has provided various instances referring to family life as a human right protected by the ECHR and as interpreted by the case law of the ECtHR, especially in those cases involving TCNs who are family members of EU citizens. The standards applied by the ECJ when reviewing the degree of interference by Member States to fundamental rights has been closely linked with the principle of proportionality understood as the need for the public measure not undermine the very substance of the rights. In addition, and taking into account the exceptions in hands of public authorities as interpreted by the ECtHR, the aim or goal pursued by the State must be "in accordance with the law" and "necessary in a democratic society". It will also have to comply with the Boultif and Üner criteria.

The Case C-540/03 EP v. Council has been also subject to study due to its major implications in the changing relationship between EU immigration law and the general principles of EU law. The deferential approach advocated by the ECJ in this ruling did not prevent it from having huge implications at times of restricting the margin of appreciation and exceptions in hands of the Member States within the scope of European immigration law. The ruling also interpreted openly the right to family life of TCNs. It has been argued that instead of focusing its argumentation in the context of Article 8 of the ECHR, the ECJ could have taken this opportunity to foster the coherency and consistency of EU rights provided by European immigration law. It could have also defended the existence of an EU right to family reunification as provided by the Directive 2003/86 and promoted the classical approaches of integration identified in Chapter 2 of this book. Furthemore, the ECJ acknowledged that the domestic implementation of EU Directives in the domain of immigration could raise issues of validity in what concerns the compliance of the national implementing measures with fundamental rights. The national Courts will be the ones in charge of deciding, along with the guidance provided the 
ECJ, the extent to which the national measures could contravene the very substance of EU immigration law.

The last section of this Chapter has finally conducted the tests of fundamental rights and proportionality against the three-pronged level of the management of immigration product of the implementation of the Council Directives 2003/109 and 2003/86 in French immigration law: the CAI, the Republican integration abroad and the CAIF. The results of this testing exercise have been illustrative of the inherent tension between the normative processes driving the practice of the Republican integration in French law and the EU general principles of proportionality and fundamental rights. 



\section{SECTION V - CONCLUSIONS}

\section{Chapter 8: \\ The Interplay between the $\mathrm{EU}$ and National Levels over Integration: Conclusions and Recommendations}

This book has examined the intersection between integration, immigration and nationality in the EU. It has assessed the relationship between integration and the regulatory and policy frameworks on immigration and nationality at two levels of the EU legal system: the European and the national. The logics driving this evolving relationship remain in constant change, subject to a whole series of national and supranational dynamics. A certain tension arises when putting them in relation to proportionality and fundamental rights. We have addressed some of the ways in which the category of integration becomes a constitutive element of the processes of European cooperation related to the conditions of entry and residence of TCNs (regular immigration). The development of a Community method of cooperation in these fields (EU immigration law), along with other alternative methods diversifying and challenging the classical foundations of EU law (the EU Framework on Integration), result in the instauration of a policy setting beyond the classical configurations of the State which poses a whole array of questions and exposes a number of paradoxes in need of reflection. The potential of these processes on the laws in national arenas is significant, and it will expand and become more diversified over time. It is at the intersection of the EU and the national arenas that the protection and treatment of TCNs subject to these processes becomes more critical. This goes along with the necessity to ensure the accountability and review of the different levels of nomative and executive power, and in particular the margin of discretion enjoyed by Member States within EU configurations. The full operability of institutional and substantive mechanisms (such as the general principles of EU law) is fundamental when ensuring that Europe-wide rights and freedoms stipulated by common EU immigration policy remain guaranteed and consistent all across the Union.

There are three major themes that I have sought to address across the different chapters:

First, the normativity of integration in EU law and policy. There is an increasingly complex conjunction between the EU and the national levels as regards cooperation over the domain of immigration. The Member States agreed in 1999 to transfer important aspects related to the competence over this area to the supranational arena, and established the goal of building a common immigration policy as a fundamental part of the AFSJ. The Member States, however, introduced in Title IV TEC the necessary institutional structures, decision-making processes and substantive techniques destined to control the effects of this historic compromise. The result has been the emergence of a diverse mosaic of European approaches and normative frameworks regarding the integration of TCNs which have been developed through parallel venues, legal/policy tools and altemative methods of cooperation. Two main contexts have been identified and studied in Chapters 3 and 4: The EU Framework on Integration and European immigration law. The EU Framework on Integration presents a non-formally recognised or quasi- OMC making use of soft-law tactics and policy techniques such as benchmarking, and constituting a new multilevel setting of govermmentality in the Union. The EU immigration law is on the other hand currently composed of a list of legal measures providing a common set of rules, rights and guarantees to TCNs which are binding upon the Member States. Some of the 
features and approaches pursued by both regulatory realms as regards integration challenge several of the premises that have predominated in the EU normative responses on immigration since the beginning of the 1970s. For instance, the innovative features of the CBPs in the EU Framework on Integration result mainly from the way in which the quasi-OMC on integration works in practice. The latter allows for a complex web of competing strategies where the role of supranational networks, such as the NCPI and other key stakeholders, has been determinant. The EU Framework on Integration has so far provided a forum prioritising certain national programmes and policies through the exchange of practices and information. On the other hand, the new perspectives and functionalities attributed to integration by EU immigration law primarily find their origins in the strategies advocated by a few Member States to limit the scope of Europeanisation and the level of protection offered by the EU system on immigration, and accommodate it as much as possible to the one already existing in their respective immigration legislations. Integration functions in this way as a tool to preserve a high degree of discretion over the inclusion, exclusion and expulsion of TCNs.

Second, the nomativity of integration in national law. The usage given to integration by national law has traditionally resided in the context of nationality law. This has been the case both in Spain and France. The above study of these two countries has shown that the nation-state practices a public policy using indeterminate legal categories such as 'social integration' or 'assimilation' as a discretional criterion for conditioning the acquisition of nationality through naturalisation. The ways in which they have developed these strategies and techniques present interesting differences and distinctive theoretical factors. These classical configurations have recently experienced several processes transforming their fundamentals and usual venues. Integration is being transferred from the regulations on nationality to those of immigration. Interestingly, the Member States have attributed to the EU a decisive role in these processes. The Europeanisation surrounding immigration and integration has shown important effects in both national arenas. Spain and France present illustrative examples for comparing the ways in which EU immigration law and the EU Framework on Integration have affected their immigration laws and policy approaches on integration. The impact, and at times instrumentalization, of the EU has translated into a shift from the traditional understandings of the functions and roles attributed to the category of integration towards a more restrictive fashion. Indeed, various kinds of Europeanisms might be identified in the national arenas as regards the relationship between the EU and the State in the processes of European integration. They range from making use of the EU to achieve domestic political goals and attempt to provide responses to some of their own national dilemmas, to adopting legislative reforms offering stringent immigration rules justified by the need to act and transpose EU immigration law.

A third major theme of the book has been the intersection of EU and national law and the system of checks provided by the EU legal system, with particular attention paid to the potentials provided by the general principles of EU law. The Europeanisms identified in French and Spanish national arenas, and the ways in which European immigration law has been utilized as the justification for implementing a more stringent domestic immigration policy, pose a number of questions when putting them in relation to the system of checks inherent to the EU. National actions by public authorities within the scope of EU law are far from being free. The margin of appreciation by the State is limited. Even though these laws offer ample leeway for action to Member States, the establishment of an EU framework of immigration constitutes a level below which Member States are not allowed to fall. The role of the ECJ is decisive in this regard, as it has been shown in Case 540/03 EP v. Council. The legitimate number of interferences, derogations and exceptions exercised by Member States in relation to the set of Europe-wide rights and freedoms must remain within the confines of the conditions stipulated by EU law. 
Otherwise the supranational set of substantive (general principles of EU law) and institutional guarantees (judicial review) will become operational. The tension arising when putting in relation certain features of the modern understanding of integration in immigration law as provided, for example, by the national transposition processes in France calls for an examination against the general principles of proportionality and fundamental rights.

This Chapter offers the general conclusions of the book, and it has been structured as follows: Section one takes the reader through a synthesis of the core findings resulting from the research and assessment conducted in each of the different Chapters. Section two provides some thoughts using the analysis previously exposed as their foundations. Finally, Section three proposes a number of recommendations.

\section{The Interplay between the EU and the National Levels over Integration}

\subsection{The Normativity of Integration in EU Law and Policy}

Section II on "The Normativity of Integration in EU Law and Policy" has presented an examination of the dynamics affecting the relationship between the integration of TCNs and immigration. The various approaches, perspectives and normative usages experienced by integration at the EU level have been diverse and subject to a whole series of evolving policies, discourses and laws since the early 1970s. The follow-up to the Amsterdam Treaty and the political mandate given by the Tampere Programme constituted a decisive phase in the normativity of integration in EU law and policy. The European Commission, acknowledging the ongoing tensions and prevailing intergovernmental logics expressed by Member States toward the harmonisation of areas perceived as closely attached to their national prerogatives, adopted a Europeanisation strategy 'through other means' which has offered a parallel framework of cooperation to that already offered by the Community method and EU law, i.e. the EU Framework on Integration.

In Chapter 2, a number of distinctive European approaches on integration have been identified through the main phases of European cooperation. Our analysis reveals the complexities subsumed in a mapping exercise of this sort taking into account the highly evolving nature of the EU responses, strategies and official discourses regarding immigration and integration. That notwithstanding, and as synthesised in the tables offered in the Annex of Section II, there is some evidence of the existence of certain constant features. Before the official birth of the EU Framework on Integration in 2002-03, a series of approaches repeatedly appear in several legal and policy instruments. The personal scope presented by these measures exclusively covers the status and security of TCNs regularly staying in the EU. There seems to be a common understanding of integration as a process facilitating a secured juridical status of residence, and driven by principles of near-equality, non-discrimination, parity and normality and a rightsbased approach. Rights are considered to be a source of stability and an effective integration factor. The European Commission often identifies the principle of equality between regularly resident TCNs and EU nationals as a consistent feature of 'the European Approach'. It also considers the principles of permanent residence and family reunification of TCNs as two bastions of the European policy on integration. There is furthermore an incremental approach conferring a higher level of equality and more favourable treatment in terms of rights and protection depending on the duration or length of residence of the individual in the receiving country's territory. On the other hand, equality is understood by a majority of acts as involving not only rights, but also obligations on the part of TCNs. The notion of obligations gets transformed in some of the official responses. There is a progressive tendency to expand and 
increase the burdens on TCNs. For instance, it is often considered that TCNs should adapt themselves to 'the lifestyle and values of the receiving society'. The role of language acquisition is also considered to play a distinctive role, and even as a must for TCNs to fulfil their 'integration processes'.

Afler the transfer of immigration policy to EU competence in May 1999, the Tampere Programme tried to put some order into the piecemeal and fragmented approaches characterising the EU's policy on integration. The Council placed in the same basket some key ideas that it considered to characterise European approaches on integration, and added others inspired by what we have denominated as the EU fair and near-equality paradigm. This paradigm comprised the principles of fair treatment and non-discrimination, and advocated for granting 'rights and obligations' to regularly resident TCNs comparable and "as near as possible" to the status enjoyed by EU citizens. The presentation of the Communications on a Community Immigration Policy in 2000 and on an Open Method of Coordination for the Community Immigration Policy in 2001 paved the way for the instauration of a dual legal/policy framework on the integration of TCNs composed by the European immigration law and the EU Framework on Integration.

Chapter 3 has then focused on the EU Framework on Integration and it has assessed its origins, scope and implications. The official kick-off of the EU Framework on Integration experienced an express allusion to 'integration requirements' in the normative framing of integration by EU law. While the Communication on Immigration, Integration and Employment did acknowledge some of the distinctive features predominating in previous phases of European cooperation and developed them further, since 2003 significant transformations took place in European normative approaches to integration. The development of the EU Framework on Integration has implied a peculiar sort of OMC where the exchange of information and 'best practices' among Member States takes on overriding relevance. The European Commission has increased references within this EU Framework to national policies and philosophies of integration in its policy documents. This shift toward the national arenas has deeply affected the traditional foundations and features characterising the relationship between integration and EU law. The consolidation and progressive development of the $\mathrm{OMC}$ on integration has involved the introduction of numerous references to items previously alien to European approaches, and which have provided allusions to elements such as integration courses, integration abroad, predeparture integration measures, compulsory integration programmes, self-sufficiency and independence of the TCNs, civic introduction and orientation courses, etc.

The operability of the new multilevel setting of governmentality inherent to the EU Framework on Integration implied the setting up, and active development, of transnational networks of Member State representatives and other key stakeholders, and a complex interplay of strategies and politics in relation to the European institutions. The principles linked with the actual protection and security of TCNs became somehow secondary and dispersed. Instead, they fostered the belief that a more 'practical approach' was needed, an approach making use of softlaw/policy techniques such as the exchange of information, benchmarking, indexing and others. We have argued that this patchwork of strategic techniques is far from being politically neutral and involve responses proving to have potential impacts on various normative and executive levels in the Union. Further, these are highly malleable techniques in relation to the sort of ideology backing up their goals and ends. These tools tend equally to pay too much attention and give too much credit to existing 'best' national policies on integration in the Member States. This methodology might leave the door open to certain national practices that are actually using integration as a tool for controlling immigration, and as anstrument limiting the chamels of regular entry and stay of TCNs. 
The goal of Europeanisation in the field of integration, and the building of a distinctive 'European Agenda or Approach on Integration', has strengthened particular national approaches and the use of 'lessons learned' or 'best practices' in the area of integration which can apparently be benchmarked and indexed with graphs and statistics whose obscurity make them difficult to challenge by anyone. Current benchmarking techniques face various methodological deficits which call for critical reflection and plural discussion, something which until present has not taken place at EU level. There are a series of constraints inherent to benchmarking integration practices that emerge when applying an interdisciplinary approach, finding a common set of indicators, overcoming the shortcomings inherent to any comparative analysis, and presenting the benchmarking results in a transparent and comprehensive manner. Benchmarking rhetoric appears to take for granted that deficiencies do not actually exist. Addressing all these weaknesses might well raise ethical implications with respect to nondiscrimination and fundamental rights which must not be overcome by blind objectives of having access 10 'data to compare' and the monitoring of integration in the EU. Moreover, benchmarking is not an ideology-free or neutral tool, but rather carries heavy political baggage. How to ensure therefore that this technique remains independent and objective? What are the guarantees that it will not become another tool of governance to manage immigration and diversity? Moreover, what is 'best' and what is 'worst'? Best or worst are malleable adjectives often attributed according to a certain idcological understanding of and approach to 'the common standard' against which to test the norm, policy or practice at stake.

Furthermore, as we have explained in Chapter 3, the strategies, politics and soft-law/policy measures are mutually influencing and reinforcing (top-down and bottom-up). Indeed, the European Commission has shown that the CBPs have already exerted effects and a noticeable impact on some national politics and policies. Chapter 5 has illustrated that Spain is an exemplary case in this regard. It is also expected that this 'soft trend of Europeanisation' will gradually expand in the coming years thanks to the linking of the political agenda with the accompanying funding scheme provided for instance by the EIF. However, counteracting processes might also prove to be true, and some of the features characterising Member State laws might increasingly be transferred to the common EU Framework on Integration. Good examples are the policy proposals put forward by the European Commission for developing EMMI, the link between integration and admission policies, the use of integration as a 'condition' or 'measure' for having access to the common rights and guarantees provided by EU immigration law, integration abroad for family reunification for all those TCNs who are not highly skilled workers, etc.

The relationship between integration and European immigration law has been examined in Chapter 4 . We have analysed the ways in which integration is being framed in relation to the rights and conditions prescribed by EU law on regular immigration, and particularly by two of its main ingredients: Council Directives 2003/109 and 2003/86. While both acts find their original premises in the Tampere milestones and the EU fair and near-equality paradigm, the functions that integration has ended up playing in their provisions are of a rather different nature from the former. In contrast with the function that integration played in the original versions of both proposals presented by the European Commission, the negotiations of these Directives in the Council forced the mutation of the functionalities of integration. Similar to the trend perceived in the EU Framework on Integration, the category of integration acts as a security tool in the hands of the State to restrict immigration, the processes of harmonisation of this field and the liberty/security granted by European immigration law to TCNs.

The strategies pursued by countries like the Netherlands, Germany and Austria succeeded in transferring their national programmes, laws and policies on integration to the first two Council 
Directives composing the EU system on regular immigration. These two acts now contain express references to integration 'measures' or 'conditions' which do not act as elements promulgating and making possible the attainment of the fair and near-equality paradigm and social inclusion. On the contrary, they have great potential to become powerful criteria inside the EU, or even abroad, for the Other to have access to the principles of near-equality, parity, security of residence and the set of rights and framework of protection. This approach has been reiterated by a later Proposal for Directive on the conditions of entry and residence of third country nationals for the purposes of highly qualified employment COM(2007) 637, which acknowledges the possibility for Member States to apply integration measures only after granting the family reunification of highly skilled workers, and therefore prohibits them from applying integration conditions abroad only to the family of those labelled as HSW. This last initiative will institutionalise a questionable distinction in the treatment granted to those not falling within the privileged legal category of 'highly skilled and talented', and all the other TCNs whose family might need to face integration requirements in the countries of origin according to national law.

It would be difficult to present a clear-cut division of possible European approaches on integration in the EU legal and policy responses adopted in the different phases which have been analysed. A plausible one could perhaps consist of integration as a process of social inclusion, and integration as a security-control tool. The kick-off phase of the EU Framework on Integration and the negotiations of the first Council Directives on regular immigration in the Council marked a major shift in the perspectives that used to characterise the classical approaches on integration in EU law as a process of social inclusion. Tampere, we recall, combined into one paradigm the main aspects of these perspectives into fair treatment and nearequality. In is however from these phases that public policies and legal approaches on immigration of certain national arenas become increasingly predominant and prioritised at the EU level. While the Tampere milestones continued to be timidly present behind practices, discourses and some policy measures, the principles composing this paradigm have not been a priority. The security of the non-European citizen has become marginalised, and the security of the nation-state and the EU prioritised.

The functions and priorities pursued by integration have therefore been deeply transformed. It has become another mechanism in the hands of the State to ensure its security and perpetuation, and to practice a policy destined to restrain the security and liberty of those not holding its nationality. The lack of integration is being linked with insecurity leading to social exclusion, and not with the goal of facilitating security of residence and social inclusion. This innovative functionality makes it difficult to argue about the existence of any 'two-way processes' in the European approach to integration. The burden of integration is exclusively imposed on TCNs, who will be asked, and sometimes obliged, to relinquish their differences and identity(ies) in favour of the perceived mainstream in order to enjoy the set of rights and freedoms envisaged by the common EU immigration policy. The non-fulfilment of integration conditions will entail a TCN facing sanctions, which will vary from, for instance, not having access to territory of the Member State or being excluded from a secured juridical status granting security of stay and protection against expulsion.

The introduction in the EU legal system of policies and laws fostering the conditionality of integration' and/or 'integration abroad' reinforces the national jurisdiction of Member States over immigration-related issues. It also strengthens conservative perceptions and stereotypes of the national into which the TCNs will be asked to disappear. In this way Europeanisation processes bestow legitimacy on nationalistic approaches and dividing visions rooted in conservative perceptions that consider heterogeneity and diversity as deviations or threats in 
need of correction to what is considered as 'the right path of living and feeling', the perfection of the nation and its identity, the perfect citizen. Further, the innovative normativity of integration provided by European immigration law and the EU Framework on Integration are offering innovative ideas, and leaving doors open, to countries such as Spain to follow these 'best practices' and, while in the process of Europeanisation of their national immigration laws, having the opportunity to mutate the role that integration used to have in their respective national legal systems.

\subsection{The Normativity of Integration in National Law}

Section III has offered an analysis of "The Normativity of Integration in National Law: The Cases of France and Spain". These two countries constitute two paradigmatic examples in three respects: First, the public philosophies and theoretical premises embracing their strategies and techniques of management of citizenship, immigration and diversity; second, the dynamics affecting the origins and evolution in recent history of the relationship between immigration/national law and integration; and third, the effects delivered by the EU Framework on Integration and the European immigration law in their domestic realms.

\subsubsection{Spain: A 'Non-Model' becoming European?}

From the mid-1980s Spain has been transformed into a country of immigration where the multidimensional issues related to this phenomenon, and their consequences, have become gradually institutionalised in the social, political, policy and legal dimensions. Chapter 5 addressed the nature of the changing intersection of integration and the regulatory frameworks of nationality and immigration since the entry into force of the Spanish Constitution on 29 December 1978. The analysis mapped the key transformations affecting the functions played by 'the social integration of immigrants' through the main historical phases affecting the Spanish legal regime on immigration and nationality. It studied the origins of the institutionalisation of immigration and the social integration of immigrants as major institutional issues in the political debate, and their introduction in various policy and legal responses.

Spanish law has used the condition of fulfilling 'a sufficient degree of integration in Spanish society' as a requirement for naturalisation by residence according to Article 22.4 of the Civil Code. This criterion, which has been qualified as an indeterminate juridical concept, provides broad discretion to the competent public authorities to determine the extent to which an applicant is integrated into Spanish society. Among others, the degree of language proficiency, the adaptation to Spanish 'societal and cultural principles and values', economic considerations as well as social relations and family ties will be taken into account in the evaluation taking place during a personal interview. Integration as a criterion does not form an express part of the Law on the Rights and Liberties of Immigrants and their Social Integration 4/2000 (LODYLE), apart from its title. A Royal Decree 2392/2004 of 30 December 2004 amending the latter introduced a new legal category in Spanish immigration law denominated "arraigo social" (social settlement) and which applies as an exceptional circumstance for granting temporary residence to those TCNs who are in irregular status in Spanish territory. This temporary security will be granted when they provide evidence of three years of permanent residence, a labour contract or formal employment offer, and family links with TCNs who are regular residents or, alternatively, a report by the municipality validating that s/he is 'socially inserted' in Spain. Social insertion therefore plays a key role in determining whether the person involved can move toward temporary legal stay in the country. 
Apart from these instances, the Spanish legal system has been until recently exempted from a nation-wide policy strategy on the integration of TCNs. This has been the case even though since 2000 there appeared to be a shared understanding that integration needed to be transferred from politics to policy and law at the various levels of governance composing the Spanish nation-state. The State's answer to questions as regards which 'model' or managerial strategy of integration to develop has actually materialised in the adoption of a 'non-model'. The decentralisation, heterogeneity and autonomies characterising the territorial organisation and societal realities of Spain, along with its national diversities and feelings of belonging, have provoked an institutional unwillingness to define the nation into which TCNs would need to be integrated. There has been some sort of awareness at the official level of the dangers involved in setting a national strategy on integration, which would perhaps made them falling into the trap of defining 'the self', the nation, and indirectly those who do not fall within that particular definition of the citizenry. The public strategy has therefore been not to show a solid and consolidated 'model', but rather to practice one based on a non-formal public philosophy valid in a domestic scenario that is already hugely heterogeneous. We have also seen the fundamental role played by the AACC when diversifying even further the policies advocated by the State, and as regards the development of their own techniques of managing integration through the socalled Integral Plans of Immigration and the Social Integration of Immigrants.

Spain has often used the EU as the answer to its own identity dilemmas. In fact, this strategy is not at all new but follows a linear pattem in this country of a 'dream to come back and belong to Europe', and to be European. Spain, a country considered to have no experience with the phenomenon of immigration, looks to Europe in search of 'lessons learned' or 'best practices' from the experience of other traditional European countries of immigration. The Spanish nonmodel therefore utilizes the EU as a source of inspiration when seeking answers to its own dilemmas. This sort of Europeanism becomes visible in the 2007 Strategic Plan on Citizenship and Integration. The impact that the EU soft-law/policy approach on integration (the EU Framework on Integration) is having on legal responses is still narrow, yet this Plan shows the impact that the latter is alteady having on the actual processes of policy formulation on integration, which might eventually end up becoming proper law. The EU Framework on Integration has injected some of the innovative European approaches on integration into the Spanish policy setting. These approaches, based on the CBPs 2 and 4.1 , conceive integration as an 'effort' by the Other to know and respect the common values of the EU and Spain. This, we have shown, represents a set of features which did not exist in any previous policy and legal responses, and that if ever implemented in that form would fundamentally transform the classical approaches of integration in Spanish law. A potential implementation of these principles would pose a whole series of critical questions in the domestic arena. For instance, the issues of languages and societal and cultural principles/values are particularly sensitive in the Spanish case when requiring a TCN to know and respect them.

The Integral Plans of Immigration of the AACC are illustrative of the difficulties that such a situation could entail. In those AACC that have an official language in addition to Spanish (i.e. Catalonia, Vasque Country, Valencia, Galicia, etc.), and which promote the existence of their own culture, society and identity, such a move would impose a serious and disproportionate burden on anybody. Into how many languages and cultures would TCNs be obliged to integrate in addition to the one considered to be 'Spanish'? The proportionality of transposing these measures into the Spanish scenario could lead to the appearance of 'worst practices' and 'lessons not to be learned' as regards integration. Indeed, the Spanish authorities might not have realised the unintended consequences of looking so ardently to the EU as the solution for perpetuating and improving its own non-model. The EU Framework on Integration may end up aggravating 
the need to define and construct one model both at State and AACC levels, something which would lead only to conflict.

Further, the door remains open for Spanish authorities to implement the integration-related provisions foreseen by European immigration law, and particularly those of Council Directive $2003 / 109$ on the status of TCNs who are long-term residents. The ECJ has found Spain to be in violation of EU law for not having adopted the necessary administrative and legislative measures transposing this Directive in its national legal regime. Article 5.2 of this Directive stipulates that "Member States may require third-country nationals to comply with integration conditions". As we have seen, some political groups in certain AACC and at the national level have referred to the possibility offered by this Directive to consolidate a 'proper integration policy' and require TCNs to make 'efforts' and learn a couple of languages and other systems of social and cultural mores before obtaining permanent residency in the country. The way in which the newly elected Government will deal with this issue remains open.

\subsubsection{France: The Normativisation, Expansionism and Externalisation of the Republican Integration}

France constitutes a paradigmatic example where the State pursues a strong national identity strategy for the management of identity and diversity. The Republican paradigm has guided the French public philosophy on integration. As it has been argued in Chapter 6, French Republicanism practices both a process of alienation of heterogeneity and social complexities, and a process of nationalisation, or normalisation of otherness, through the acquisition of French nationality. It aims at neutralising any fragmentation or distance from the perfect citizen, and to treat individuals as individuals, regardless of their identities. The existence and perpetuation of a concept of the perfect citizen, and hence the perfect citizenry and the homogenous nation, constitutes a significant difference when compared to the situation in Spain. The neutrality, privatisation, assimilation or integration of diversity, and its disappearance into those principles and values considered to be Republican, constitutes the official public policy for equality. The so-called "intégration à la française", or in its current form, Republican integration, ensures that any otherness becomes hidden behind the sublime Republicanism and universalism idolised in the public spheres. The laws of nationality have represented the key instruments for these premises to be translated into legal measures. According to Article 21.24 of the Civil Code, "assimilation in the French Community" functions as one of the central criteria or "conditions de recevabilite" for any TCNs aiming at becoming a French citizen. Similar to the Spanish legal system, this is a subjective legal requirement which will be determined by the competent public authority during a personal interview. In light of Circular 2000-254 of May 2000, a person will be considered to be assimilated if s/he shows sufficient knowledge of the French language ('linguistic assimilation') and of French customs and traditions ('social and cultural assimilation'). As regards this last element it will be taken into consideration, for instance, how the applicant treats her/his spouse and children, and whether the person practices 'traditions' which are fundamentally contrary to 'the values and customs' of the French society. Furthermore, Law 2006-911 introduced the celebration of a welcoming ceremony into French citizenship ("cérémonie d'accueil dans la citoyenneté française"), which injects symbolism and formalism into the whole process of 'becoming French'.

It has been mainly since 2003 that the Republican paradigm of integration has experienced a number of processes transforming its functionalities and classical venues in France. Since this phase the neo-republican integrationist doctrine has made its appearance in French immigration law. Integration will act as a criterion for the acquisition of the status of permanent resident and 
the granting of family reunification to TCNs. This doctrine will be driven by a three-pronged logic of expansionism, nomativisation and extemalisation:

First, the condition of Republican integration has been subject to a gradual expansionism from its classical venue within the realm of nationality law to the regime covering the area of regular immigration. It now functions as a condition for the legality of the entry, permanent settlement and family reunification of TCNs. Even though immigration law uses the word 'integration', instead of 'assimilation' as prescribed in nationality law, the actual content of both terms and their purposes remain the same. Similar to any evaluation of the degree of assimilation, the condition of integration will test the language proficiency (oral and written) and civic formation of the applicant; the latter relates to the socio-cultural aspects related to 'life in France' and the principles of the Republic. In light of this, Republican integration does not only constitute a juridical condition for having access to French nationality and the first step for crossing the bridge leading to 'the perfect citizen' composing the nation. It also performs the role of a mandatory criterion for the non-national to attain a higher degree of legal security of entry, residence, inclusion and family reunification.

Second, this sort of conditionality is currently presented in a mandatory contractual relationship between the State and the TCN, taking the form of the welcome and integration contract (CAI). The $\mathrm{CAI}$ is a prerequisite for the non-national to access permanent residence. The axiom of integration as an obligatory contractual bond has been the result of two consecutive laws: the "Loi relative à la maitrise de l'immigration, au sejour des étrangers en France et à la nationalite" $\mathrm{N}^{\circ} 2003-1119$ of 26 November 2003, and the "Loi relative à l'immigration et a l'intégration" $N^{\circ} 2006-911$ of 24 July 2006. While the former considered it as a tool of voluntary nature, the latter transformed it into a binding requirement for acquiring the permanent residence permit, and consequently the EC status of long-term resident (Articles L. 311.9 and 314-2 of the CESEDA). The contractual approach also covers the domain of family reunification. Article 7 of the "Loi relatif à la maitrise de l'immigration, à l'intégration et à l'asile" $N^{\circ} 2007-1631$ of 20 November 2007 created a welcome and integration contract for the family (CAIF), which obliges settled TCNs and the spouse having benefited from family reunification to attend a course on 'the rights and duties of parents in France'. The process of normativisation in the context of immigration involves the natural consequence of applying sanctions in those cases where the TCN proves not to be 'well integrated'. The violation of the $\mathrm{CAl}$ will mean the non-renewal of the temporary residence permit, the non-granting of permanent residence status. It might also involve financial penalties for the family, as well as administrative sanctions consisting of a potential negative decision for the renewal of the "carte de sejour temporaire" or the granting of the "carte de resident", and hence also expulsion from the country.

Third, there is another trend calling for the application of integration as a requisite in the country of origin for obtaining a visa for the purposes of family reunification (Republican integration abroad). According to Article I of the "Loi relatif à la maitrise de l'immigration, à l'intégration et à l'asile" $N^{\circ} 2007-1631$ of 20 November 2007, the applicant for family reunification will be evaluated in French consulates or embassies abroad on her/his level of integration (knowledge of the French language and the values of the Republic). In those cases where the competent authorities consider the person to fall far too short of the perfect French citizen, the latter will have to attend a course after which an examination will be conducted on knowledge of the French language and Republican values.

The main goals driving these processes are to limit the sustainable and stable residence of TCNs and the entries for the purposes of family reunification in France. However, as their introduction 
in the French legal system has been justified on the basis of the obligation to act and transpose European immigration law, the degree of discretion enjoyed by the French authorities remains limited to the system of checks inherent to the EU legal system. Member States are bound to act in accordance with their provisions. Similarly, those individuals falling within their personal scope might rely on them (invoke their rights before national tribunals and authorities) at times of alleged interference or unlawful discretion exercised by a Member State in relation to EUwide rights and freedoms. The level of discretion enjoyed by Member States is therefore constrained by common standards and rights prescribed by their catalogue of provisions. They stand as a European framework below whose ceiling no Member State will be allowed to fall. The kind of Europeanism advocated by France, and the processes and logics driving the neorepublican doctrine of integration as expressed in the latest legislative developments affecting the relation between immigration and integration, may be critical when placed in relation to the general principles of EU law.

\subsection{The Interplay between the EU and National Levels: The EU General Principles and European Immigration Law}

Section IV on "The Intersection between EU and National Immigration Law: The General Principles of EU Law" studied the relationship between Member State action in the scope of European immigration law and the general principles of EU law. The common immigration policy represents a constitutive element of the EU legal system. Similarly to any other branch of EU law, the FSJ acquis on regular immigration benefits from the set of substantive and institutional mechanisms necessary for guaranteeing that its foundations are anchored on the rule of law and respect fundamental rights. The role that the ECJ has performed toward the consolidation and expansion of the EU system of checks has been proactive and to a large extent liberal. Its case law has created a framework of judge-rendered and unwritten doctrine of principles facilitating the interpretation of the Treaties and of secondary legislation, and guaranteed the protection of EU rights enjoyed by the individual against any unlawful interference by the Union, European Institutions and Member States within the scope of EU law. These independent and objective general sources, or supranational principles, have become one of the distinctive features of the Union's entire legal system. The individual subject to the results of Europeanisation processes benefits from their protection, and has the right to claim them before EU courts.

The actions of Member States within the scope of EU law also fall in the ambit of the general principles. The phase of implementation of European acts becomes a decisive moment in the workability of the executive and normative configurations upon which the EU functions and develops. The conversion of secondary legislation into national law constitutes a key stage, as it is here where the consistency with the objectives pursued by the common European policy will need to be preserved and secured. In policy areas such as regular immigration, where Member States have been allowed a very high degree of discretion and a substantial number of exceptions to common rules, a careful assessment of Member State actions is even more demanding in order to verify that the commonly agreed to rights and shared standards are maintained and properly transposed in the domestic realm.

EU general principles play an important reparative and increasingly innovative role in the context of European immigration law by filling gaps, clarifying obscurities and uncertainties, interpreting material provisions, facilitating the evaluation and review of implemented national legislation and expanding the framework of protection of EU rights in the legal spheres of Member States. In particular, the principles of proportionality and fundamental rights might be 
placed among those which primarily aim at protecting the individual, regardless of her/his nationality, who may suffer unlawful practices and restrictions of European rights and administrative guarantees by Member States within the scope of EU law. They enhance and substantiate the guarantees in the hands of TCNs to contest and challenge the legality and legitimacy of a domestic legal act claimed to be interfering with a European and/or fundamental right before EU courts. The EU system delimits in this way the liberal or illiberal nature of the practices conducted by the State within the scope of EU law.

The increasing judicialisation processes affecting European immigration law and the consequent interplay with the general principles of EU law constitute in this way core mechanisms for ensuring a coherent common immigration policy in the EU. The principles of proportionality and fundamental rights offer great potential in this regard. Chapter 7 analysed the ways in which the ECJ has understood and interpreted the interaction between the principle of proportionality and Member State actions when implementing EU law, and the effects that might be extended to European immigration law. The principle of proportionality, which has become one of the paradigmatic grounds of review exercised by European Courts, acts as a key testing ground of the administrative responses adopted by Member States in relation to their obligation to act in EU law. Even in those areas where secondary law leaves a substantial degree of discretion to Member States, including the application of Directives, they will also have to respect the general principles of EU law. While being expected to follow the guidelines stipulated by the ECJ, the role conferred on national tribunals in this regard is prominent. EU immigration law equally benefits from the same judicial protection and interpretation provided in the ECJ's case law. The ECJ has not yet faced a case dealing with a national implementing measure within the ambit of the FSJ acquis on regular immigration. This is actually not surprising, taking into account the limits provided by Title IV of the competence of the ECJ, where only those national tribunals against whose decisions there is no judicial remedy under domestic law will be allowed to present a preliminary ruling.

The principle of proportionality has been interpreted as involving a 'balancing of interests' between an individual right and a public interest sought by a legal measure. The balance metaphor is founded on the idea that there are some freedoms and rights which might accept derogations from the State. The position that the ECJ has adopted when reflecting the degree of exceptionalism permitted to Member States in the area of free movement of persons might also prove to be useful in the scope of the common EU immigration policy. There has been a consistent interpretation presented by the case law of the Luxembourg Court on the legitimate derogations permitted to Member States in relation to the principle of free movement of persons: First, the ECJ will not take a deferential approach and will scrutinise the case in detail; second, any exception needs to be strictly interpreted.

At a parallel level, we addressed the role played by fundamental rights as general principles of EU law in the context of European immigration law, with a special focus on the right to respect for family life of TCNs and the ways in which Member State actions have been interpreted by the Luxembourg Court. The analysis centred on the potential offered by fundamental rights as general principles in relation to Europe-wide rights, such as those contained in Council Directive 2003/86 on the right to family reunification, which presents close linkages with human rights, and particularly that of family and private life prescribed in Article $8 \mathrm{ECHR}$. When assessing the compliance between a national implementing act with the general principle of fundamental rights, the ECJ will take into consideration its relationship with human rights as provided by the ECHR and as interpreted by the ECtHR. The human right to family life has been a good example of that judicial practice. When assessing the grounds of legitimate exceptions to fundamental rights, the consolidated approach advocated by the ECJ has been that any 
interference must not be disproportionate, and that the very substance of the right should not be impaired. There has been a great deal of inspiration in this regard coming from Article 8.2 ECHR and the related rulings by the Strasbourg Court. The ECtHR has offered a proactive and interesting line of interpretation of this provision and the grounds for a lawful interference by public authorities. This has particularly included the interpretation of the phrases "in accordance to the law" and "necessary in a democratic society" in relation to the expulsion and admission of TCNs on the basis of family and private life. In general terms, while the Boultif and Uner criteria offer a sound supranational framework protection against unlawful expulsion of TCNs, which Member States also need to comply with, 'the balancing approach' still predominate, and the interpretation of the exception to the rule will be measured in accordance with the legitimacy of the aims sought to be achieved by a public measure.

The ECJ has finally found a chance to confirm the human right to family life as part of the EU general principle of fundamental rights to family members of TCNs in Case C-540/03, EP v. Council. This ruling will have major implications in the context of European immigration law regarding the confinements around which Member States will be allowed to manoeuvre in the practical implementation of this branch of EU law in their national arenas. While this judgement might present some critical elements, the ECJ has constrained the margin of appreciation left by Directive 2003/86 to Member States during the phase of transposition. The effects of the Court's findings are expected to spread to other Council Directives adopted in the area of regular immigration and presenting similar features, such as Directive 2003/109 on the status of long. term residents who are TCNs.

Finally, Chapter 7 conducted the practical exercise of applying the tests of proportionality and fundamental rights to the case of France. This country has provided us with an interesting example of Member State actions when implementing European immigration law, and limiting (or applying stringent derogations) to some of its rights and freedoms. France has shown a sort of Europeanism by making the transposition of EU laws on regular immigration the official justification for proposing a fundamental transformation of the role and functions of Republican integration in its national law. We have presented various grounds challenging the proportionality and fundamental rights compliance of the level of interference that these innovative approaches of integration, subsumed in the three-level management of immigration, inflict on the European rights envisaged in Council Directives 2003/109 and 2003/86. This sort of national action calls for a proactive, exhaustive and forward-looking role of the ECJ, which will increasingly be in a position to apply an intense review of national implementing measures in the context of European immigration law and the rights and freedoms conferred by it on TCNs. A strong and non-deferential review, similar to that performed in the context of the freedom to move of European citizens, would not only be appropriate for ensuring proper protection of the individual whose rights might be endangered during phases of national implementation. This would also be in the interest of the EU's political projections, which call for a common European policy on immigration that is consistent and coherent.

The judicial review by European Courts would need to overcome the dilemmas posed by the application of the 'balance metaphor' when measuring the legitimacy of State interference, or level of exceptionalism, with respect to EU and fundamental rights. Securing the EU rule of law and protecting fundamental and EU rights needs to go first if the Union wants to be loyal to its founding principles. The latter needs to be positioned as a premise and should reside at the heart of any European integration processes. The role of the ECJ in this endeavour will be of critical 
relevance to making the EU legal system, and its checks and guarantees as regards illiberal practices of the liberal regimes, ${ }^{198}$ work effectively.

\section{Reflections on the Normative Framework of Integration in the EU}

The analysis of the intersection of integration, immigration and nationality in the EU provides a sound foundation for reflecting on the approaches and public functions pursued by the legal construct of integration, and its normativity in EU and national law. The cases of Spain and France have shown that the habitual venue of integration has traditionally been laws on nationality. The main functions that integration plays in this legal context is securing and protecting the perfection of the citizenry, and searching for that perfection in all Others aiming at becoming a national. ${ }^{199}$ Additionally, the nomativity of integration in some national arenas and in the scope of EU law (EU Framework on Integration and European immigration law) is introducing innovative features to the classical understandings of this category. A new perspective is being developed promoting the use of integration outside the boundaries of nationality, and expanding its performance toward that of immigration. Integration becomes a security tool for controlling the movement of TCNs "inside" and "outside" the citizenry. These transformations can be identified in the dynamics affecting this category in the EU. As a consequence of the establishment of a common EU immigration policy, the State, however, is not on its own anymore when exercising discretion and the management of immigration and diversity. The processes of Europeanisation, and the development of common policy and law, entail that the mechanisms comprising the EU legal system become operational when reviewing and making accountable Member State actions within the scope of EU law. The role attributed to the judiciary and the general principles of EU law present great potential in relation to the limits of the normativity of integration in EU and national laws.

\subsection{In Search of the Perfect Citizen?}

\subsubsection{The Perfect National Citizen and Nationality Law}

What are the purposes behind the normativity of integration? In the context of nationality law, the use of integration as a legal condition aims at protecting, managing and safeguarding the notion of "the perfect citizen" belonging to the nation-state. This notion is based on a compendium of features and characteristics composed of subjective stereotypes, traditional perceptions and visions of the past and the present, principles and classic values deemed to rule 'the one and only' society, and conceptions of the self and the Other. By definition, any legal notion of the citizenry implies the existence, and exclusion, of any or certain degrees of otherness which fall outside this legality. The constructed normative concept of the perfect citizen is in direct opposition to the legal status of foreigner. The latter is viewed as falling outside the features defining the citizen. It is therefore seen as imperfect and in need of being remodelled, disciplined or 'naturalised' according to the pattems of the national canon of

1198 D. Bigo et al. (2006), Illiberal Practices of Liberal Regimes: The ( $\mathrm{h}$ )Securty Game, Collection Cultures \& Conflits, Centre d'Études sur les Conflits, L'Harmantan: Paris.

1199

On the differences between the legal terms nationality and citizenship see for instance G.R. De Groot (2006), "Nationality Law", in J. M. Smits (ed.), Elgar Encyclopedia of Comparative Law, Edward Elgar: Cheltenham, pp. 476-492; Also, De Groot, G.R. (2004), Towards a European Nationality Law - Vers un droit européen de nationalité, Inaugural lecture delivered on 13 November 2003 on the occasion of the acceptance of the Pierre Harmel chair of professeur invité at the University of Liège, Unigraphic, University of Maastricht. 
perfection. The role of the nation-state in the promulgation and protection of the canon citizen is decisive for its own existence and legitimacy. Integration becomes another tool in the hands of the State to manage the nation and to determine who belongs to its imagined community.

The intersection of integration and the laws on nationality aims at securing the perfect citizen, and preventing the erosion of the bond of citizenship and national identity. It also guarantees the continuance of the most deeply held values, fundamentals and principles predicated on the nation-State. One of the managerial mechanisms and techniques in the hands of the State is the enactment of noms, its nomative power. The use of the norm implies a technique of positive intervention aiming at transforming a reality in accordance with a certain political project. ${ }^{1200}$ The use of integration by the branch of law dealing with nationality forces an active and corrective process of 'nationalisation' aiming at disciplining difference and making possible the endurance of the homogeneous nation, culture and identity. It aims at tuming the abnormal into the natural. It pursues a process of normalisation of difference into the perceived mainstream nation and the cohesiveness of society. By adopting a set of laws on nationality which describe who qualifies for that privileged status, and by including integration as one of the main conditions, the State is exercising its discretion on who meets 'the cultural and social criteria' of the legitimate community of consumers eligible for its protection and security. Only those individuals matching the apparent distinctive features of its citizenry will potentially benefit on the basis of equality of the rights and security that the State claims to guarantee.

The notion of the non-national to be corrected emerges in sharp relief. S/he will need to fit into the imaginary 'way of life and society', and be more national than the constructed nationals in order to be allowed to cross the functional border toward the level of membership granted to the model of perfect citizen. This constitutes the nation-state strategy of searching and defending its vision of the perfect citizen: a person who is supposed to own and master one language, carry out a particular way of life, and agree with one set of shared cultural and social values, customs and principles. All these elements are presented as fitting within the wholeness and uniqueness of 'the self'. Perfection involves a process of taking for granted the homogeneous nature of the various societies existing within the confines of the State, and, on the contrary, trying to eliminate any fragmentation, deviation or difference challenging any preconception. It serves as a mechanism for practicing a process of re-nationalisation of the nation. In these ways the nation-state resists evolving and changing towards a de facto reconfiguration of its own societies and identities. The use of integration as a condition for naturalisation is driven by a strategy of transforming otherness into the perfect citizenry on the basis of the continuance of the nationstate as it is supposed to be. In light of this, the role of integration in the laws of nationality becomes another act of governance destined to protect and maintain the monopoly over who is and who is not the canon individual, ${ }^{1201}$ the perfect national citizen, and to make any deviation disappear into the perfection of the nation.

One of the main purposes of integration in nationality law is therefore not only to distinguish between who is 'the real' and 'the non-real' citizen. A distinctive function of integration in fact consists of legitimising the very existence of the perfect citizen and promoting her/his national

1200 M. Fotcatult (1999) explained how "La norme est portense, par conséquent, d'une prétention de pouvoir. La norme...c'est un élément à partir duquel un certain exercice dit potwoir se trotwe fondé et légitimé...la norme porte avec soi à la um principe de qualification et un principe de correction. La norme n'a pas pour fonction d'exchre, de rejeter. Elle est au contraire toujours liée à une techique positive d'intervention et de transformation, à une sorte de projet normatif'. See M. Foucault (I999), Les Anormaux, Cours au Collège de France. 1974 - 1975, Hautes Etudes, Gallimard Le Seuil: Paris, page 46. 
identity. An individual may well fit within the formal category of a real citizen after showing her/his adherence to the canon, but may still not fully comply with every single feature attributed to perfection. The search for perfection has no end. As the search for perfection lies exclusively in the imagination of the State and the administrative/legislative apparatus comprising it, there might always be some element, some sign, still ascribing to the person the abnormality attached to foreignness and otherness. Indeed, the limits of the scope and reach of integration in nationality law lies only in the minds and imagination of public authorities carrying out the examination at hand. This subjective and indeterminate nature leaves it to the State to delimit the factors and limits of perfection. This discretion is the key to its own continuation. It offers to the nation-state an innovative 'mode of legitimation' of its sovereignty. ${ }^{1202}$

Indeed, integration, as a condition for naturalisation, implies a wide margin of appreciation by the State, setting aside any certainty for the individual and making the applicability of the rule of law difficult, if not critical. The respect for diversity, human rights and fundamental freedoms makes of any search of this sort an issue of concern. The imagined nation is unreal. Every sociely progressively experience fundamental transformations putting into question the validity of the traditional techniques and tactics of the State to manage any dissenting element to its fundamentals and identity. Into what exactly is the category of immigrant supposed to integrate? The model of the perfect citizen is taken as the testing ground against which to evaluate whether an individual might constitute a danger to the canon model. These nationalistic claims also call for those not holding their nationality to 'normalise', 'modernise', 'civilise' and 'assimilate' into their societal vision of themselves. The State may of course resist acknowledging it but societies are increasingly experiencing a wide variety of life styles, profoundly enriching and diversifying the very concept of community. They also call into question conservative claims of 'we' and a 'homogeneous society of shared cultural values and principles' which needs to be safeguarded against a supposed threat posed by those labelled as 'foreigners and the non-modern', l'individu anormal, ${ }^{1203}$ who 'by definition' is seeing as coming from the outside, or still shows signs of outsider. Further, these claims take for granted the existence of 'the immigrant'. Yet, the question might also be posed as regards whom they are talking about when referring to this category. The individuals falling within the legal status of TCNs are far from being a homogeneous, hermetic and static unit. Societies are instead heterogeneous, diverse, dispersed, in constant change. They include nationals from all over the world, with widely differing backgrounds, prospects and identities.

Perfection does not exist. Imperfection is an inherent element of human nature and of societies. Today any attempt to conceptualise national identity is open to widely subjective interpretations of 'us' and 'our' supposed identity and societal values, in our visions about what is normal and what is abnormal. ${ }^{134}$ The search for perfection is based on premises which aim at oversimplifying pluralistic societies. Any vision of unity or any discourse advocating for

1202 J. Mabermas (1998), The Inchusion of the Other, Sudies in Political Theory, Edited by C. Cronin and P. De Greiff, The Mit Press: Cambridge, pp. 105-127.

1203 M. Foucault (1999), Les Anormanx, Cours au Collège de France. 1974 - 1975, Hautes Études, Gallimard Le Seuil: Paris. We refer here to his study of the "problematique de l'anomalie et les techniques autour de l'anomalie", and the analysis of different categories that Foucault atributes to the one of abnormal. See Cours de 22 Janvier 1975; See also M. Foucault (2001), Dits et Écrits 1954 - 1988, 11 (19761988), Édition Établie sous la Direction de D. Defert et F. Ewald avec la collaboration de J. Lagrange, Quarto Gallimard: Paris, p. 1690.

1204 S. Carrera (2005), "Integration as a Process of Inclusion for Migrants? The Case of Long-term Residents in the EU", in H. Schneider (ed.), Migration. Integration and Citizenship: A Challenge for Europe's Future, Forum Maastricht: Maastricht, pp. 109-138. 
perfectly integrated societies is inherently subjective, and might lead to illiberalism. ${ }^{1205}$ The nation-State resistance to imperfection never ends within the boundaries of democracy, fundamental rights and the rule of law.

\subsubsection{The Perfect National Citizen and Immigration Law}

In the context of immigration law the purposes of integration continue through other means. Integration becomes a tool for controlling the non-national "inside" the nation-state and "abroad". The change in the nomativity of integration from the classical contextualisation of nationality to the one of immigration raises a number of questions. Integration functions as another regulatory technique for the State to manage the access by the non-national not to the status of perfect citizen, but to the act of entry, the security of residence and protection against expulsion. TCNs may not be willing to become Spanish or French and renounce their own identity(ies) and differences, but the State will anyway demand to abandon the latter in favour of the national perfection. This 'effort' or 'responsibility' on the part of the Other functions as the sine qua non for him/her to benefit from security of admission and residence. The test of perfection therefore expands over the legal framework on immigration - an expansion which means that the Others will also be disciplined by the State if they want to 'legally' enter and live within its territory. Integration determines the 'legality' or 'illegality' of human mobility, and constitutes another frontier for being considered as a 'legal immigrant'.

Non-EU nationals aiming at becoming immigrants in accordance to national immigration laws will need to pass a course and/or an exam in order to show that they are 'successfully' integrated, and that they fully meet the criteria attached to the notion of the perfect national citizen before having access to a security. ${ }^{1206}$ The immigrant will be asked to renounce her/his cultural expressions and identity(ies). S/he will need to disappear into the presumed unity of the nation, and exhibit a transformation from the abnormal non-national ${ }^{207}$ into the juridical construction of what a 'Frenchman/woman' or 'Spaniard' is supposed to be. The expansion of the role of integration means that, similar to nationality law, the duration of residence will no longer constitute the determining factor that opens the doors to security and liberty within the confinements of the nation-state. An additional, subjective and indeterminate criterion will be added, which, as stated above, aims primarily at limiting the legal channels of human mobility exercised by those not holding the nationality of the receiving State. The nomativity of integration facilitates the State practice of a restrictive immigration policy.

1205 C. Joppke and E. Morawska (2003), "Integrating Immigrants in Liberal Nation-States: Policies and Practices", in C. Joppke and E. Morawska (eds), Toward Assimilanion and Citizenship: Immigrants in Liberal Nation-States, Basingstoke.

1206 According to Guild (2005), "The hallmark of the categorisation of 'immigrants' and 'national culture' is the integration discourse. There is a duty on some people...called immigrants, to abandon some of their cultural expression in favour of becoming more like the host community... the principle that there are some people who may be obliged to become more like others is central to the concept of integration". E. Guild (2005), "Cultural and Identity Security: Immigrants and the Legal Expression of National Identity", in E. Guild and J. Van Seim (eds), International Migration and Security: Opporthnities and Challenges, Routledge: New York, pp. 101-112.

D. Bigo (2005), "From foreigners to abnormal aliens: How the faces of the enemy have changed following September the 11 th with the process of policing beyond borders", in Van J., Selm E., Guild E. (dir.), International Migration and Security: Immigrants as an Asset or Threat?, Routledge: New York, pp. 64-81. 
The lack of integration is consequently articulated through the security apparatus of the State. The rhetoric on the 'failure of integration' of the Other into the defended perfection is subject to a logic of securitisation consisting of its political usage and legal framing as a legitimate justification for the insecurity of residence and expulsion of the non-national. Further, integration acts as an insecurity issue. The lack of integration is presented as a risk to the security and social cohesion of the EU and its Member States. It is intertwined with insecurity and other constructed threats. ${ }^{1208}$ The similarities to the 'insecurity continum of threats' elaborated by Bigo (1996) become obvious. The continum of threats institutionalises a connection between immigration and other aspects widely categorised as dangers to internal security and social cohesion, and which at times include notions as broad as acts of political violence denominated as terrorism. ${ }^{1209}$ The linkage between insecurity and immigration is not a static process. It is under constant transformations. It now includes the lack or failure of integration of TCNs as one of its constitutive elements. These processes of securitisation are also having a direct impact at the EU level in the relationship between immigration policy and the socalled 'fight against terrorism'. The lack of integration is often perceived as a cause of radicalisation. This continum might endanger human rights and liberty, and put TCNs into an even more vulnerable position. Research has shown that this might lead to a situation whereby the non-national is encapsulated into the category of suspect, criminal or even terrorist. ${ }^{1210}$ The security framing of non-integration needs to be deconstructed by acknowledging the multiplicity of factors in any social conflict, instability and act of political violence at the national and supranational levels.

Moreover, the nomativity of integration in the domain of immigration moves beyond the territorial borders of the nation-state toward the countries of origin. It goes abroad through a process of externalisation. The extemal dimension of integration is driven by logic according 10 which this category functions as a tool intending to increase the barriers for the human mobility by the non-national. The concept of integration abroad, as we have seen in Chapter 6 in the case of France, raises a whole set of concerns. The would-be immigrant is obliged to be integrated even before crossing the border and actually entering the territory of the State. Integration abroad is practiced as a condition for having access to the visa allowing TCNs to actually move

1208 On the ways in which the securitization of migration in the EU and its Member States has developed on the basis of internal security, cultural security and the crisis of the Welfare State see J. Huysmans (2000), 'The European Union and the Securitization of Migration', Journal of Common Marker Studies, Vol. 38, No. 5, pp. 751-777; On the construction of immigration as a security problem see also D. Kostakopoulou (2000), "The Protective Union: Change and Continuity in Migration Law and Policy in Post-Amsterdam Europe', Journal of Common Market Sndies, Vol. 38, No. 3, pp. 497-518.

1209 Bigo argues that "Tout se passe comme s'il existait un continum de menaces reliant terrorisme, drogue, criminalité organisée, mafia, jilière et passeurs, immigrants illégaux, immigration et demandeurs d'asile, transfërant l'illégitimité des premiers vers les secondes", and continues "...une conversation commencée sur la drogue out le terrorisme se terminera sur l'immigration et les demandeurs d'asile sans que l'interlocuterr ait conscience d'avoir changé de sujet...A chaque fois...l'accent est mis par les responsables et les analystes sur les relations enrre secteurs déjà découpés par la pratique...certe mise en réseau sémantique n'est pas sans conséquence. Elle structure des liens et produit un savoir nouveau sur ces interconnexions justifian le renforcement des pouvoirs de police au-delà du national". D. Bigo (1996), Police en Réseaux: L'expérience européeme, Paris: Presses de Sciences Po, pages 258-266; See also D. Bigo (2002), 'Security and Immigration: Toward a Critique of the Governmentality of Unease', Alternatives: Global, Local, Political, Vol. 27, Special Issue, February 2002, pp. 63-92

1210 Refer to A. Baldaccini and E. Guild (eds) (2007), Terrorism and the Foreigner: A Decade of Tension around the Rule of Law in Europe, Martinus Nijhoff Publishers: Leiden; See also E. Browwer, P. Catz and E. Guild (2003), Immigration, Asylum and Terrorism: A Changing Dynamic in European Law, Recht \& Samenleving 19: Nijmegen. 
into this legal category. The external dimension of integration strengthens the control by the State in the countries of origin, in the phase preceding the juridical process of becoming an immigrant and the before the act of mobility actually takes place. It aims at preventing the phenomenon of immigration and at 'controlling at a distance' (Bigo and Guild, 2003). ${ }^{121}$ The purpose of integration mutates into the representation of the nation-state's functional borders outside its territory. ${ }^{1212}$ It aims at managing the legal status of the Other before even being admitted, and imposes a process according to which anybody who wants to enter needs first to be 'like us' and demonstrate allegiance to 'our' principles, values and way of life. The nationState demands allegiance to its national identity abroad. The externalisation of integration is still based on some of the premises highlighted above regarding the conception of the perfect national citizen and citizenry, and according to which anyone coming from outside is by definition challenging the unity, harmony and homogeneity of the nation, and implies a danger to its fundamentals and identity. Integration, therefore, is practiced as a norm controlling the legal boundaries of immigration and diversity both 'at home' and abroad.

\subsubsection{The Perfect European Citizen}

The Europeanisation processes and politics have not only further developed these functions in the context of the common EU immigration policy, but they seem to have consolidated them by prioritising certain national policies and programmes that foster 'innovative approaches' to integration. The normativity of integration in the context of immigration in some Member States has been somehow transferred to the European arena. It has become accepted and internalised in EU law and policy. It is therefore being presented as a 'best practice' in need of promotion in the EU, including those States whose national legislations do not bestow these understandings and public philosophies. The EU has perhaps not realised the potential dangers subsumed in the use of the EU Framework on Integration. As we have argued, integration implies the continuance of the nation-state and its nationhood and identity, as well as its degree of discretion to determine and categorise people according to its subjective test of perfection in an increasing supranational legal and policy setting. Any attempt by the EU to liberalise these national prerogatives would not only be challenging when considering them in relation to the principle of subsidiarity, but would provoke the emergence of an even greater number of concerns.

The involvement of 'Europe' in issues related to "integration" within the scope of immigration can be understood as a strategy to promote European identity. It aims at sending a clear message about the existence of the perfect European citizen who holds a certain kind of identity, values and 'Europeaness'. It might also intend to challenge the predominance of the principle of subsidiarity over questions related to the identity of TCNs and the development of a consciousness of belonging to 'Europe'. The notion of perfection consequence of a Europeanisation of integration would exhibit a whole range of greater dilemmas and divisions.

121 D. Bigo and E. Guild (2003), La Mise à L'Écart des Étrangers: La Logique du Visa Schengen, Cultures \& Conflits, Paris: L'Harmattan; D. Bigo and E. Guild (2005), "Policing at a Distance: Schengen Visa Policies", in D. Bigo and E. Guild (eds), Comrolling Frontiers, Hants/Burlington: Ashgate, pp. 233-263.

1212 E. Guild (2003), "The Border Abroad - Visas and Border Controls", in K. Groenendijk, E. Guild and P. Minderhoud (eds), In Search of Europe's Borders, Kluwer Law International: The Hague, 2003, pp. 87104; E. Guild (2001), Moving the Borders of Etrope, Inaugural Lecture delivered at the Official Ceremony of the assumption of the Professorship of the CPO Wisselleerstoel at the University of Nijmegen, 30 May. 
What would it mean to be European? ${ }^{1213}$ And what would be the features of the European identity and values? ${ }^{1214}$ These definitional questions would be even more difficult to reconcile with the rich diversities and identities existing in an enlarged EU. The task of conceptualising and fostering a nomative content of European identity involves an even greater process of exclusion of what might be not European. The legal category of non-European becomes prominent and reinforced by the requirement to attain the perfection presumed to exist in the EU, its liberal democracies, and in their fundamental 'values'. This would inevitably lead to using the same stereotypes and societal/cultural/religious visions of "right way of being and acting like Europeans'. Indeed, the Europeanisation of integration would spur even broader debate and critical reflection than those at national levels. It is likely that it would reveal even greater contradictions and paradoxes, and deconstruct other illusions and premises upon which the EU has been built. ${ }^{1215}$

That notwithstanding, an interesting consequence of the Europeanisation processes on immigration-related areas, and particularly those falling within the Community method of cooperation and EU law, is that the exceptionalism and discretion enjoyed by the State as regards the normativity of integration is not as free as it used to be. The development of a common EU immigration policy and the adoption of common laws beyond the configurations of the nation-state within the EU legal system facilitate the existence of substantive and institutional mechanisms aiming at controlling and making accountable the executive and nomative powers of the EU and Member States when acting within the scope of EU law. As the EU integration machinery is covering issues related to integration, the margin of appreciation enjoyed by the State becomes, together with that of the Union and its institutions, constrained. The role of EU Courts (judicial review) and the general principles of EU law (such as those of proportionality and fundamental rights) constitute essential elements for ensuring the respect of the foundational principles of the liberal democracies of the EU (liberty, democracy, respect for human rights and fundamental freedoms and the rule of law). They also make possible the protection of the liberty and security of the individuals subject to these processes.

\section{Recommendations}

We shall now put forward a set of recommendations substantiated in the results provided across the different Sections of this book, and which have been organised according to the same structure. The recommendations are mainly directed at policy-makers and courts both at the EU and national levels, as well as to the stakeholders playing a role in the evolving intersection of integration, immigration and nationality in the EU.

1213 The decision has been taken to set up an Independent Reflection Group "to help the Union anticipate and meet challenges more effectively in the longer term (horizon 2020 - 2030" at the Brussels European Council Presidency Conclusions of 14 December 2007, Council of the EU, 16616/1/07.

1214 Treaty of Lisbon amending the Treaty on European Union and the Treaty establishing the European Community, signed at Lisbon, 13 December 2007, OJ 2007 C306/01, 17 December 2007. The new revised version of the TEU's Preamble says that: "DRAWING INSPIRATION from the cultural, religious and humanist inheritance of Europe, from which have developed the universal values of the inviolable and inalienable rights of the human person, freedom, democracy, equality and the rule of law."

1215 E. Balibar (2001), Nous, citoyens d Europe? Les Frontiers, L'État, le peuple, Paris: La D'couvert, 2001. 


\subsection{The Normativity of Integration in EU Law and Policy}

It is submitted that:

Before further developing EU immigration law and the EU Framework on Integration, there should be in depth-reflection as regards European approaches on integration. The Tampere Programme should be revitalised. The principles composing the fair and near-equality paradigm agreed to at the Tampere Programme need to continue representing the core theoretical premises, and main elements, of any legal and policy response adopted at the EU level. ${ }^{1216}$ The two-way process paradigm is proving to be not solid enough to preventing burdens and obligations in the form of immigration norms from falling solely on TCNs. Also, diversity is a strength of the EU, not a defect in need of correction. ${ }^{1217}$ Social cohesion in Member States depends on an understanding of integration as a right for the migrant to equality rather than as an obligation to abandon her/his identity. ${ }^{1218}$

The innovative nomativity of integration in EU law introduced by both the EU Framework on Integration and European immigration law is not fully consistent with the rooted approaches and perspectives that have traditionally characterised European cooperation on immigration policy. ${ }^{1219}$ The mere fact that some Member States aim at limiting the reach of Europeanisation and scope of protection offered by the EU legal system to TCNs, and at restricting the latter to the confinements of their own legislations, political strategies and public philosophies, cannot constitute valid reasoning for undermining the coherency of the entire system.

Building a nexus between integration and social inclusion in the EU. There needs to be a stronger nexus between the nomative dimensions of integration and social inclusion at the EU level. The focus should rather be on what are the obstacles and barriers towards social inclusion of vulnerable groups in society, and on providing these measures and facilitating access to all these sectors in the receiving society. The relationship between DG JFS with other DGs inside the European Commission, such as the one of Employment, Social Affairs and Equal Opportunities, has in recent years proved to be not simple and straight-forward. One of the main legislative outputs of inter-DG cooperation in the area of integration was the adoption of the Communication COM(2003)336 on immigration, integration and employment back in June 2003. DG JFS should work very closely with other related DGs. This should not remain in a mere mainstreaming symbolic initiative within the Commission services, ${ }^{120}$ but should really facilitate the building and development of a policy nexus particularly between these two, and other related, policy areas beyond the management of migration. This nexus would be of utmost importance to guarantee any possibility for constructing a solid European approach to

\footnotetext{
1216 See Section 2 of Chapter 2.
}

D. Bigo, S. Carrera and E. Guild (2008), What Future for the Area of Freedom. Security and Justice? Recommendations on EU Migration and Border Policies in a Globalizing World, CEPS Policy Brief No. 156, March 2008, Centre for European Policy Studies: Bnussels.

D. Bigo, S. Carrera, E. Guild and R.B.I. Walter (2007), The Changing Landscape of Erropean Liberty and Secwity: Mid-Term Repont on the Results of the CHALLENGE Project, CHALLENGE Research Paper No. 4, Centre for European Policy Sudies: Brussels. See page 21.

See point 3.2. of the Commission Communication, Third Annual Report on Migration and Integration, $\operatorname{COM}(2007) 512,11$ September 2007, Brussels on 'mainstreaming integration' across a wide range of EU policies such as employment, social inclusion/social protection, education, health, urban dimension, intercultural dialogue, fundamental rights, non-discrimination and equal opportunities, women, children, youth, entrepreneurs, pages 5-7. 
integration that fosters social cohesion, equality and human dignity. In addition, any discussion or debate about integration and social inclusion should be detached from the field of immigration law and security, as well as from the competence of the national Ministries of Interior and JHA.

- Deconstructing the nexus between integration and immigration in EU law and policy. The way in which integration is being framed at the EU level in the area of immigration law, and in the AFSJ, is problematic. The nexus between integration and immigration in EU law and policy is unquestioned at the EU and national official levels, and it is even qualified as a best practice' in the EU Framework on Integration. This nexus leads however to the stigmatisation of the vulnerable foreigner who depends on social solidarity and calls for inclusion, but who is prevented by the immigmation law from enjoying access to security and rights. Integration measures and conditions in EU immigration law and the EU Framework on Integration contribute to social exclusion and (in)cohesion, as they are used in a way to test whether an individual deserves secure immigrant status on the basis of whether s/he has already acquired social inclusion. Paradoxically, while those individuals holding an insecure immigration status would need more rights and protection, the use of integration as a norm prevent them from being socially included and acts as a mechanism for their exclusion. The integration debate needs to be disentangled from insecurity and immigration control. The use of integration as a mandatory criterion to limit the legal channels of regular migration is neither consistent with the way the EU has dealt with mobility and integration, nor is it coherent with the EU's new motto - 'united in diversity'.

- Deploring the nexus between integration and insecurity. The lack of integration cannot be linked with insecurity. The development of a linkage between 'failing integration' and the radicalisation of violence should be deplored. This nexus might endanger human rights and liberty in general, and put TCNs into a highly vuhnerable position vis-à-vis the State and the receiving society. The securitisation of the lack of integration needs to be deconstructed by stating that the inclusion or exclusion of a TCN, or a citizen who is still not considered fully as such because of his or her particular origin, is not a insecurity issue, and by acknowledging the multiplicity of factors in any social conflict, instability and acts of political violence at national and supranational levels.

\subsubsection{The EU Framework on Integration}

The legal outputs and network activities within the scope of the quasi-OMC on integration should not fall outside the system of institutional and substantive checks comprising the EU legal system. ${ }^{1221}$ The institutional structures of the EU should operate as close as possible to the usual means and methods of cooperation. The roles of the EP and of the ECJ should be strengthened. It is critical that the ECJ is completely absent from the review of the validity of the provisions included in these soft-law measures and tools, and even more so, as regards any potential national implementation by Member States. The general principles of EU Law should also play a decisive role in this context. The inclusion of an explicit legal base in the Treaty of Lisbon sheds some light in that direction, yet it is not at all clear what impact this provision would have in practical terms. $12 ? 2$

\footnotetext{
1221 On the reflections about the quasi-OMC on Integration see Section 3 of Chapter 3 .

1222 See Section 2 of Chapter 3.
} 
The European Integration Agenda/Strategy should not continue providing a supranational forum prioritising certain policies, programmes and practices at the national level considered to be 'best' or in need of promotion by some, and therefore deemed to be a source of inspiration for the entire EU-27. The direct consequence of the current methods such as the exchange of information is that the strategies and techniques of certain Member States become prioritised over others conceived to be 'less experienced' or 'too liberal'. The actual consequences of transferring these 'lessons leamed' to other Member States supposedly in need of being taught may raise critical questions and tensions. Moreover, what is best and what is worst? Best or worst are malleable adjectives often attributed according to a certain ideological understanding of and approach to a 'common standard' against which to test the norm, policy or practice at stake. The best practices may become 'worst practices' in the ground, and the main victims might end up being TCNs, as well as those not considered as fully perfect national citizens. ${ }^{1223}$ The theoretical grounds and actual political objectives of these policies need to be openly debated. This would be particularly relevant as regards the nomativity of integration in the scope of immigration law. The decision-making processes in the quasi-OMC on integration should be further liberalised through strong involvement of civil society, social partners and academia. In this respect the European Integration Forum has great potential. ${ }^{124}$

- New techniques such as benchmarking and indexing are far from neutral. ${ }^{1225}$ They have strong political implications and constitute noms of governmental discipline of politics, policies and eventually laws. Taking into account their malleability according to theoretical and political baggage, it is uncertain the extent to which the use of these soft-law techniques may become instruments of concern in policy areas where human rights and fundamental freedoms of TCNs are so much at stake. There is nothing preventing benchmarking from allowing assigning a speciously irrefutable value to certain State practices, programmes and political strategies of restrictive nature. How to ensure therefore that the benchmarking technique remains independent and objective? What are the guarantees that it will not become another tool in the hands of public authorities to manage immigration and diversity?

If the EU political agenda spurs a proper debate about the deficits inherent to benchmarking integration, and legitimises its use regardless of whether it is truly necessary, effective and desirable, then all the gaps and weaknesses that have been identified should be carefully tackled, studied and addressed. Also, while one focus of benchmarking is the identification of 'good or best practices', it would be perhaps desirable to first address whether the technique itself is good or bad, something which until now has not been addressed at EU level. Such a challenging endeavour could move beyond providing plausible answers to the question of 'what is' (mapping exercise) and 'what could be' (policy recommendations) in terms of integration policies and regulations in the EU, and rather address the question of 'what should be'. Furthermore, it would be welcome to instead address what State practices are currently being developed in terms of preventing, conditioning, limiting or undemining social inclusion and protection of legal security and access to rights by TCNs and other vulnerable groups.

The EIF should not be instrumentalised to prioritise the innovative normative framing of integration as a tool of immigration control and a restrictive immigration policy in the EU$27{ }^{1226}$ The EU should not back up questionable national practices implementing integration

\section{3}

Refer to Section 3 of Chapter 3.

Sections 1.10 and 3.2 of Chapter 3 .

See Section 4 of Chapter 3.

See Section 1.11 of Chapter 3. 
"measures" and "conditions" purely aiming at limiting immigration, the security of residence and family life of TCNs. The EIF should not be used to increase the security of the State over that of the individual.

- Initiatives such as common EMMI and pre-departure measures (integration abroad) should not form part of the common EU immigration policy or the EU Framework on Integration. ${ }^{1227}$ They are based on questionable national practices and policies aimed at restricting immigration and managing diversity. The transfer and implementation of integration would be difficult to reconcile with the rich diversity and interculturalism characterising the EU. It would also inevitably make use of the same stereotypes and societal/cultural/religious visions of what it means to be or not to be a perfect European citizen.

\subsubsection{European Immigration Law}

Council Directives 2003/109 on the status of third country nationals who are long-term residents and 2003/86 on the right to family reunification should be revised using the rendezvous clauses inserted in Articles 24 and 19. When looking at the way in which the use of integration as a "measure" and a "condition" takes place in the national arenas, it is argued that these articles are not compatible with the objectives of the Tampere Programme and the goals purported in their respective Preambles. 228

- The use of integration abroad for family reunification as stipulated in Article 7.2 of Council Directive 2003/86 is not compatible with the rule of law and fundamental rights. ${ }^{1229}$

The new legislative initiatives in the area of regular immigration, and particularly that relate to highly qualified employment, should be taken as an opportunity to abolish the use of integration measures for the purposes of family reunification inside or outside the EU. ${ }^{1230}$

\subsection{The Normativity of Integration in National Law}

It is submitted that:

\subsubsection{Spain}

Spain should not transfer to its national legal system the normativity of integration conceiving it as a "measure" or a mandatory "condition" as provided in European immigration law. Neither should it introduce CBPS 2 and 4.1, according to which integration implies "respect for the basic values of the EU" and a "Basic knowledge of the host society's language, history and institutions is indispensable for integration". 231 These particular functionalities of integration have never formed part of its national legislation dealing with the conditions of entry and stay of TCNs. Its introduction would actually create more conflicts and divisions about its own societal identity dilemmas.

The condition of sufficient degree of integration in Spanish society provided by Article 22.4 of the Civil Code should be in conformity with the principle of proportionality as enshrined

\footnotetext{
1227 See Section 1.12 of Chapter 3.

1228 Refer to Sections 2 and 3 of Chapter 4.

1230 Section 4.1 of Chapter 4.

1231 Refer to Section 3.2 .2 and 4 of Chapter 5 .
} 
in the general principles of EU law. ${ }^{1232}$ While Member States hold exclusive competence on nationality matters, the ECJ has stressed that Union citizenship is destined to be "the fundamental status' of nationals of the Member States. ${ }^{1233}$ Therefore, the creation of the status of European citizenship implies that they should also comply with the system of checks and guarantees characterising the EU legal system, and specifically the general principles of EU law. ${ }^{1234}$ The indeterminate and subjective nature of the criterion of integration as a condition for naturalisation in nationality law adversely affects the tenet of proportionality with respect to the conditions for having access to the supranational status of European citizenship, and the enjoyment of the European rights and freedoms attributed to it. If at all applicable, the scope of the criterion of integration should be transparently defined to avoid a lack of legal certainty and discrimination.

The Spanish authorities should however comply as soon as possible with their obligations to transpose European immigration law. Council Directive 2003/109 urgently needs to be implemented in its legal system. ${ }^{1235}$ The European-rights and guarantees provided to those TCNs who are permanent residents must be formally incorporated in its administrative and legislative framework. Tensions in national politics cannot constitute a valid excuse to prevent the achievement of that commitment.

\subsubsection{France}

French authorities should stop instrumentalising their obligations in the context of European immigration law for justifying the implementation of a restrictive immigration policy. ${ }^{1236}$ This sort of Europeanism represents a critical use of the European integration processes which legitimises the practice of questionable national politics regarding immigration and identity. The French State needs to realise that in fact the very existence of a common European policy prevents it from moving freely and discretely when dealing with Europe-wide rights of TCNs that have been harmonised by the European system on immigration.

The condition of assimilation in the French Community stipulated in Article 21.24 of the Civil Code should be in line with the general principles upon which the EU legal order has been built, specifically that of proportionality. ${ }^{1237}$ Similar to the comments spurred by the Spanish case, this requirement offers too much discretion to public authorities, and therefore leaves the individual in an unacceptable vulnerable status. The fact that the subjective requirement of

1232 Refer to Section 3.1 of Chapter 5.

1233 Case C-184/99, Grzelczyk . Centre Public d'Aide Sociale d'Onignes-Lowvain-la-Neme [2001] ECR I6193, paragraph 31.

1234 About the significance of the general principles of EU law in respect of the exclusive competence of the Member States over nationality-related matters see G. R. de Groot (2004), Towards a Ewropean Nationality Law - Vers un droit européen de nationalité, Inaugural lecture delivered on 13 November 2003 on the occasion of the acceptance of the Pierre Harmel chair of professeur invite at the University of Liège, Unigraphic, University of Maastricht. De Groot has stressed that " the conclusion that Member States continue to have full autonomy cannot be maintained however in all circumstances... it is my view that the nationality legislation of a Member State could conceivably violate general principles of Community law". In particular, De Groot has made reference to the principle of Community loyalty as expressed in Article 10 TEC. See pages 18 and 20.

See Section 4 of Chapter 5. 
assimilation functions as the crucial factor for having access to the status of European citizen means that the content of this criterion should not be left to the imagination of the competent authority carrying out the test. Member States should ensure that the conditions for having access to their nationality and European citizenship are compatible with the rule of law and the principle of proportionality, and therefore are in compliance with the tenets of objectivity, legal certainty and transparency.

- The binding contractual nature of the condition of integration provided by the CAI and the CAIF, ${ }^{1238}$ as well as the obligatory requirement of integration abroad for non-nationals aiming at benefiting from family reunification, should be challenged by those very TCNs who are subject to these practices, and who fall within the personal scope of Council Directives 2003/109 and 2003/86. As these European measures present provisions enjoying direct effect, they would have the right to present an action before national courts or other authorities abroad to challenge the alleged interference by the French State of their European rights and freedoms (effective remedy).

\subsection{The Intersection of EU and National Law: The General Principles of EU Law}

It is submitted that:

The Member States must comply with the EU general principles of proportionality and fundamental rights when implementing European immigration law in their national regimes, and applying exceptions and limitations to Europe-wide rights and freedoms. ${ }^{1239}$ The ECJ needs to take a robust approach in its review. It should continue its traditional reasoning regarding the doctrine of the EU general principles in relation to Member States' actions. It would be advisable that the ECJ further ensures and confirms the European rights and freedoms provided by the Council Directives on regular immigration to TCNs. It is advised that the judicial review would continue constraining the discretion of Member States when having an impact on an EU policy. Case C-540/03 is most welcome in this regard. ${ }^{1240}$

- The ECJ could additionally promote the classical understandings of integration in the EU when interpreting national immigration measures in the scope of EU law. The traditional approaches have been until recently rooted in the principles of near-equality and security of residence. It has only been recently that integration functions as a condition for practising a restrictive immigration policy and limiting the European rights conferred by EU immigration law.

- In the case of France there is tension when putting in relation the three-pronged level of management by Republican integration ${ }^{124 !}$ and the EU general principles of proportionality and fundamental rights. When facing an eventual case challenging national implementing measures such as the ones by the CAI and the CAIF in France, the ECJ should address it in relation to the EU-recognised rights envisaged by EU law. ${ }^{1242}$

- The degree of judicial control over Member State interference with rights envisaged in European immigration law should not be deferential. The ECJ could be encouraged to adopt the

\footnotetext{
1238 See Sections 4.3 .1 and 4.3 .2 of Chapter 6 .

1239 Sections 2.1 and 2.2 of Chapter 7.

1240 Section 2.2.4 of the same Chapter.

$12+1$ Section 3 of Chapter 7.

12+2 Refer to Sections 3.1, 3.2 and 3.3 of Chapter 7.
} 
same level of intensity as the one exercised in the cases of permitted derogations in the scope of free movement of persons. A strong proportionality test (suitability, necessity and proportionality stricto sensu) would therefore be welcomed in order to ensure that any derogation is the least restrictive possible and is applied strictly.

- In the event of the emergence of a national case dealing with the restrictions applicable to the EU right of family reunification such as those provided in French immigration law, it is advised that the ECJ rigorously reviews proportionality and fundamental rights. The latter should go beyond a 'balancing approach' between EU and/or fundamental rights (liberty) and public goals (security of the State). The fact that the national measures affect EU-wide rights makes it necessary for the judiciary to adopt a more proactive role while assessing the margin of appreciation left to Member States and ensure a consistent interpretation and degree of protection of these rights across the EU. 


\section{RESUMEN / SAMENVATTING}

\section{¿En Busca del Ciudadano Perfecto? La Intersección entre Integración, Inmigración y Nacionalidad en la UE}

La integración ha constituido uno de los pilares centrales en los procesos de construcción Europea. La Unión Europea (UE) ha logrado la instauración de un mercado interior común donde la integración se ha centrado en el afán de facilitar la movilidad y libre circulación de trabajadores comunitarios a la hora de cruzar las fronteras interiores, y mientras tanto ser beneficiarios del principio de igualdad, reunificación familiar y un estatuto juridico seguro. Este entendimiento clásico de la integración ha sido objeto de varios procesos que han afectado de manera significativa su naturaleza, funciones y significados en gran parte como consecuencia del desarrollo de una politica Europea de inmigración. Desde el reconocimiento de la competencia de la UE para legislar en el campo de la inmigración tras la entrada en vigor del Tratado de Ámsterdam en Mayo de 1999, las politicas comunes de inmigración se han desarrollado como parte del objetivo político de construir un Área de Libertad, Seguridad y Justicia (ALSJ). Este libro estudia la relación entre integración, inmigración y nacionalidad mediante un análisis del nexo cambiante existente entre la integración y los marcos legislativos de admisión, residencia y acceso a la nacionalidad por parte de nacionales de terceros países en la UE.

La interacción entre el derecho nacional y el Europeo en lo que se refiere al vinculo normativo entre la inmigración y la integración plantea dos cuestiones fundamentales: La primera versa sobre el grado de influencia que el derecho Europeo está ejerciendo en los procesos de formulación y toma de decisión de politicas en los Estados Miembros, y la medida en la que las políticas Europeas están afectando los sistemas legislativos a nivel nacional. La segunda se refiere a la relación entre las medidas y acciones adoptadas por los Estados Miembros dentro del marco del derecho europeo y el sistema de garantias destinadas al control de la legalidad de sus acciones y a velar por la protección de los derechos y libertades del individuo en el ordenamiento juridico Europeo ante posibles limitaciones y excepciones de derechos $y$ libertades.

En cuanto a la primera de las cuestiones, el reconocimiento en 1999 de la competencia Europea de legislar en el campo de la immigración supuso una reticente aceptación por parte de los Estados Miembros de ver su discrecionalidad, y en cierta medida soberania, afectada en estas políticas. La Europeanización de ciertas dimensiones administrativas ligadas a las politicas migratorias ha implicado el desarrollo de un marco legal que van más allá de las configuraciones clásicas del estado-nación. Este sistema jurídico supranacional se encuentra dotado de un conjunto minimo de derechos y garantías comunes cuyo ámbito de aplicación y relevancia supera lo nacional, e implica una serie de obligaciones y responsabilidades por parte de las autoridades de los Estados Miembros a la hora de su aplicación. Una de las preguntas clave consecuencia de estos acontecimientos es la medida en la que los procesos de convergencia de políticas comunitarias están realmente afectando los ordenamientos juridicos y las políticas de inmigración de los Estados Miembros (el grado de Europeanización). Nos interesa especialmente vislumbrar el alcance de la influencia que los elementos sustantivos e institucionales de la politica común de inmigración Europea están desplegando sobre los marcos normativos de los Estados Miembros, y analizar en este contexto la manera en la que la UE puede estar directa o indirectamente afectando sus enfoque sobre la integración de nacionales de terceros países. Se plantea igualmente la cuestión referente a la manera en la que los Estados 
Miembros instrumentalizan las politicas comunitarias en sus encrucijadas políticas domésticas para dotar de una mayor legitimidad sus propios intereses partidistas y ciertas iniciativas politicas y legislativas de envergadura sensible y restrictiva.

La segunda cuestión que emerge en nuestro estudio es a la hora de asociar los cambios legislativos acontecidos a nivel nacional y en los que la UE se presenta como justificación o causa, con los mecanismos previstos en el sistema legal Europeo para garantizar el estado de derecho y los derechos fundamentales en los procesos de Europeanización de las politicas nacionales. En este sentido, el papel llevado a cabo por los tribunales comunitarios y la tradición jurisprudencial consistente en el desarrollo de un conjunto de principios generales del derecho europeo constituyen elementos de especial relevancia. El poder judicial comunitario tiene como uno de sus objetivos primordiales el velar por la legalidad de acciones no solo por parte de la UE y de las instituciones Europeas, sino también por los Estados Miembros a la hora de ejercitar sus competencias en el ámbito Europeo. En particular, los principios generales del derecho Europeo representan herramientas clave en manos de los tribunales comunitarios para la protección e interpretación de derechos y libertades de naturaleza comunitaria, y para su defensa contra cualquier interferencia ilicita o excepción iliberal por parte de las autoridades públicas procedentes de los distintos niveles de autoridad pública en la UE. Los principios generales del derecho Europeo presentan un gran potencial en el campo del derecho de inmigración Europeo.

Uno de los objetivos principales de este libro ha sido el estudio de los procesos por los que la integración de inmigrantes se ha convertido en una norma juridica constitutiva del derecho de inmigración tanto a nivel nacional como Europeo, y las implicaciones que emanan de esa conversión normativa en lo relativo al estatuto juridico de nacionales de terceros paises y a la coherencia misma de la política de inmigración común Europea. Ofrecemos una genealogía de los planteamientos, enfoques y funciones fundamentales que han guiado los propósitos y objetivos del concepto de integración en la UE prestando especial atención a la manera en la que ésta se ha ido alejándose paulatinamente de los significados clásicos que la caracterizaban originariamente en el seno del mercado interior, y como ha ido evolucionando progresivamente hacia una regla de naturaleza vinculante para el acceso de la población inmigrada a derechos, seguridad e inclusión social. Nuestro enfoque se centra en el entendimiento de los efectos múltiples consecuencia de la relación cambiante entre los marcos jurídicos Europeos y nacionales sobre integración, inmigración y nacionalidad/ciudadania.

\section{La Integración en la UE: El Marco Común Europeo de Integración y el Derecho Europeo de Inmigración}

El Capítulo 2 empieza por trazar una genealogia de los distintos significados y enfoques que caracterizan el término de integración desde las primeras respuestas politicas y legislativas a nivel Europeo hasta la entrada en vigor del Tratado de Ámsterdam en Mayo de 1999. Ofrecemos un estudio de las trayectorias principales tomadas por la integración en el discurso adoptado por las politicas comunitarias relativas a nacionales de terceros paises desde principios de los años 1970 hasta la etapa inmediatamente posterior a 1999. Nuestra meta ha sido la identificación desde una perspectiva histórica de la existencia de enfoques predominantes o rasgos consistentes en el discurso y referencias expresas a la integración dentro del derecho y políticas Europeas. La sección primera de esta Capitulo pone de manifiesto como los rasgos perfilando el significado y funciones de la integración durante estas etapas han sido entre otros los siguientes: En primer lugar, la integración ha venido emparejada con la garantia de seguridad de residencia y reunificación familiar de nacionales de terceros países; En segundo lugar, la concesión de derechos se ha entendido como un elemento esencial en todo proceso de integración; Por otro 
lado, la duración de la residencia regular en el pais receptor se ha considerado como uno de los signos más significativos a la hora de indicar el grado de integración del individuo; Además, referencias a la integración han venido tradicionalmente ligadas a los principios de paridad, nomalidad e igualdad de nacionales de terceros paises residiendo en situación administrativa regular, etc.

En base a las competencias juridicas reconocidas por el Tratado de Ámsterdam y el mandato adoptado por el Consejo Europeo en el primer Programa pluri-anual sobre políticas relativas al ALSJ, el Programa de Tampere en Octubre de 1999, la Comisión Europea presentó un paquete de iniciativas legislativas cuyo objetivo principal fue el pistoletazo de salida en la construcción de una politica común Europea sobre inmigración. Sin embargo, el establecimiento de dicha política no ha estado exento de obstáculos dificiles de flanquear, que en su mayoria han sido producto de las reticencias expresadas por los Estados Miembros a la hora de ver su discrecionalidad y competencias afectadas por los procesos de harmonización legislativa Europeos. Los Estados Miembros han adoptado una estrategia de resistencia, guiada en cierta medida por unas lógicas de intergubernamentalidad y de competitividad, a la hora de desarrollar politicas comunes sobre las condiciones de entrada y residencia de nacionales de terceros paises. Estas lógicas se han nutrido de una serie de estrategias politicas que han hecho uso del principio de subsidiariedad como uno de sus emblemas e insignias fundamentales. En efecto, la simple existencia de una base jurídica en los Tratados (Título IV "Visados, Asilo, Inmigración y Otras Políticas Relacionadas con la Libre Circulación de Personas" en el Tratado Constitutivo de la Comunidad Europea, TCE) y el aparente consenso político alcanzado entre las autoridades de los Estados Miembros en el seno del Consejo para el desarrollo de una politica común de inmigración no han ido acompañados de pocas dificultades por parte de la Comisión Europea para traducir ambiciones políticas en realidades jurídicas, sobre todo en al ámbito de la inmigración regular. Por otro lado, a pesar de que el Consejo ha reconocido en varias ocasiones que las politicas de integración constituyen elementos estratégicos de mayor relevancia para le futuro del ALSJ, estas han sido otro ejemplo claro donde las competencias de los Estados Miembros y el principio de subsidiaridad han prevalecido.

Las tensiones producto de la difĩcil relación entre el principio de subsidiaridad y la Europeanización afectando las politicas de immigración e integración han dado lugar a la aparición de un marco regulador dual o bicéfalo en lo que se refiere a la integración de nacionales de terceros paises, y que se encuentra compuesto por el derecho Europeo sobre inmigración y el Programa Marco Europeo sobre Integración. Los Capítulos 3 y 4 del libro se han centrado en el estudio del escenario normativo que ha desencadenado esta dualidad en la UE, i.e. la adopción por la Comisión Europea de dos Comunicaciones sobre una Política Común de Inmigración COM(2000)757 y sobre un Método Abierto de Coordinación para la Política de Inmigración Comunitaria COM(2001) 387. La naturaleza e implicaciones de estos dos campos dentro de la política de inmigración común ha sido objeto de estudio. Nuestro análisis ha continuado prestando especial atención a la evolución y dinámicas experimentadas por el concepto de integración en cada uno de estos ámbitos paralelos, y a la existencia de mutaciones significativas en las funciones y enfoques caracterizando el trato concedido por el derecho y políticas Europeas a la integración de inmigrantes.

El Capitulo 3 presenta un panorama de los origines, mecanismos y estructuras propias del Programa Marco Europeo sobre Integración que ha venido desarrollandose, lenta pero progresivamente, desde el año 2002. El Marco Europeo cuenta ahora con unos Principios Básicos Comunes de Integración (PBCs), un Fondo Europeo para la Integración, un Foro Europeo para la Integración, tres Informes Anuales, el establecimiento de los Puntos Nacionales de Contacto sobre Integración de Inmigrantes, etc. Todo ello ha hecho de él un sistema 
normativo supranacional sui generis caracterizado por un conjunto de instrumentos reguladores de carácter no vinculante (algunos de los cuales caen dentro de la categoría de "soft law"), y de una serie de redes Europeas compuestas por autoridades públicas y de sociedad civil organizada. Este tablero de instrumentos juridicos 'suaves' y redes supranacionales al margen de las instituciones Europeas propiamente dichas, han dado lugar a la aparición de un quasi-Método Abierto de Coordinación en materia de integración a nivel Europeo. El Capítulo 3 ofrece igualmente una evaluación de la técnica de benchmarking en el Marco Europeo de Integración, y una visión de conjunto de algunos de los estudios e informes más relevantes que se han llevado a cabo a nivel Europeo.

Los enfoques tradicionales de la integración en el derecho y politicas comunitarias sobre inmigración han experimentado grandes cambios dentro del Marco Europeo de la Integración. Ello ha sido producto de la preferencia y valor atribuido al intercambio de información y de 'buenas prácticas' entre las autoridades de los Estados Miembros. Las pautas guiando el enfoque Europeo sobre la integración presentan como consecuencia cada vez más referencias a políticas y estrategias de indole nacional que hacen uso de la misma como parte de una politica restrictiva de inmigración y como una norma exigiendo a los nacionales de terceros paises a integrarse en el idioma y los valores, tradiciones y costumbres que se perciben como reinantes en el 'estilo de vida' de los Estados Miembros y la UE, y todo ello para tener acceso a derechos y seguridad. La transformación en el paradigma inspirador de la integración dentro del Marco Europeo sobre Integración es evidente en la mayoria de las medidas que han sido adoptadas o propuestas por la Comisión Europea o el Consejo en el Marco Europeo de Integración, como por ejemplo los PBCs, las referencias a programas de integración, a módulos para la integración de inmigrantes, a cursos de integración, educación cívica, el respeto a los valores nacionales y Europeos, etc.

El Capitulo 4 aborda la relación entre la integración y el derecho Europeo sobre immigración, y estudia los rasgos principales presentados por la integración dentro del sistema legal Europeo sobre inmigración regular. Tras proporcionar una visión de conjunto sobre los instrumentos juridicos más importantes que han sido adoptados al respecto como parte del acquis comunitario en base al Título IV del Tratado Constitutivo de la Comunidad Europea (TCE), nuestro análisis se centra en la Directiva sobre el estatuto de nacionales de terceros paises que son residentes de larga duración 2003/109 y la relativa al derecho de reunificación familiar 2003/86. La forma en la que ambas Directivas utilizan la integración muestra tendencias muy similares a las percibidas en el Programa Marco Europeo sobre Integración. Debido a la influencia de determinados Estados Miembros durante las negociaciones de las propuestas de la Comisión dentro del Consejo, el texto final de ambas Directivas ha incluido referencias a la integración como una 'medida' o una 'condición' para que los nacionales de terceros paises puedan beneficiarse de los derechos y garantías ofrecidos por éstas. Ello ha consolidado la visión y puesta en práctica de la integración como instrumento juridico de control y exclusión en manos de los Estados Miembros para limitar los canales de inmigración regular y el acceso a derechos y libertades por parte de nacionales de terceros países. La Parte II del libro termina con un anejo presentado de forma sintetizada la evolución experimentada por el concepto y funciones atribuidas a la integración en el discurso utilizado por el derecho y políticas Europeas sobre inmigración desde principios de los años 1970 hasta nuestros días.

\section{La Integración a Nivel Nacional: Los Casos de España y Francia}

La Parte IIl del libro se centra en la dimensión nacional, y estudia en particular los casos de España y Francia (Capitulos 5 y 6). La metodología que hemos llevado a cabo a la hora de analizar ambos Estados ha seguido pautas similares. En primer lugar cada capitulo empieza con 
una breve presentación y discusión de las líneas teóricas caracterizando las estrategias, filosofias - 'modelos' públicos tradicionalmente practicados por estos paises en el control y administración de la inmigración y la diversidad. Ello se complementa con una perspectiva histórica enfocada al encuentro de los origines y el estudio de las dinámicas experimentadas en la evolución normativa de la integración en sus respectivos sistemas políticos y legislativos, y el análisis de sus sistemas legales de nacionalidad e inmigración vigentes en la actualidad. Prestamos especial atención al lugar y papel jugado por la integración en los mismos, y a las influencias procedentes de la politica común de immigración de la UE en los significados y funciones dados a esta última.

El Capitulo 5 está dedicado a la integración de inmigrantes en el paisaje legal y político de inmigración y nacionalidad en España. Durante los últimos veinte años España ha experimentado toda una serie de procesos de transformación como consecuencia de una incipiente movilidad humana. España deja de ser un 'país de origen' o de 'emigración', para empezar a ser un destino de inmigración extra-comunitaria. La naturaleza inesperada de este cambio ha supuesto un sentimiento por parte de las autoridades públicas de una cierta falta de experiencia, y de reacción lenta, en las respuestas del Estado a dichos acontecimientos sociales. Desde el establecimiento de la democracia, el sistema juridico espanol ha reconocido las diversidades nacionales en términos de organización política y territorial, algo que tiene una manifestación expresa en el reparto competencial entre el Estado y las Comunidades Autónomas en materias relacionadas con la inmigración y la integración social. El estado central ha sin embargo evitado abrir un debate plural y abierto acerca de la naturaleza y límites de la identidad nacional que se supone que existe en el pais, lo cual ha llevado consigo la carencia de una filosofia pública oficial e identificable en su sistema político y normativo de integración, y el desarrollo de un 'no-modelo de integración' donde la UE tiene el papel protagonista.

Desde 1985 los desarrollos institucionales y las respuestas públicas destinadas al control del fenómeno migratorio han sido numerosos y diversos. A pesar de que el concepto de integración aparece tímidamente en ciertos debates y documentos políticos relativos a la cuestión migratoria durante los 1990s, no fue hasta la tercera fase de construcción de 'la España Inmigrante' (desde 2000 hasta nuestros días) donde ésta pasa a ser objeto de medidas normativas específicas. La integración ha ejercido la función de condición juridica principalmente a la hora de solicitar la adquisición de la nacionalidad española mediante naturalización desde 1990. La adopción en el 2007 del Plan Estratégico de Ciudadanía e Integración constituye el primer ejemplo a destacar de la existencia de un marco general a nivel estatal proponiendo una estrategia pública nacional relativa a la integración de la población inmigrante. El Plan presenta referencias múltiples al marco Europeo sobre la integración y a los Principios Básicos Comunes para la integración de inmigrantes, lo cual representa una prueba fehaciente de la influencia que el 'derecho suave' procedente de la UE en lo relativo al campo de la integración está teniendo en el ámbito nacional español. Tal y como hemos señalado, uno de los elementos criticos consecuencia de dicha influencia ha sido la introducción de ciertos enfoques y planteamientos innovadores de la integración que la conciben como la necesidad por parte de nacionales de terceros países de conocer y respetar "los valores comunes de la UE y de España" así como "el idioma, historia e instituciones de la sociedad de acogida".

Por último, el Capitulo 5 ha estudiado la trasposición llevada a cabo por las autoridades españolas del derecho Europeo sobre inmigración regular y las Directivas 2003/86 y 2003/109. En breve, la Directiva sobre el estatuto de nacionales de terceros países de larga duración 2003/109 no ha sido todavía traspuesta en su ordenamiento jurídico de inmigración. Además, el gobiemo Español ha considerado que la Directiva relativa al derecho de reunificación familiar 2003/86 es en su totalidad compatible con el régimen legal de inmigración doméstico ya 
existente, y por ello no se ha considerado necesario realizar ninguna reforma legislativa al efecto. Es por ello que se puede concluir que el impacto de los procesos de integración Europea en el campo de la immigración regular en España ha sido hasta ahora minimo.

Por su lado el Capítulo 6 aborda la naturaleza y efectos de la articulación entre la integración y el derecho y políticas de inmigración y nacionalidad en Francia. La relación entre la integración/asimilación y el marco politico y legal de nacionalidad e inmigración han sido objeto de varias dinámicas a lo largo de la historia reciente Francesa. Al igual que en el caso de España, comenzamos por trazar unas lineas teóricas sobre el 'paradigma Republicano de integración' practicado por el Estado Francés en la administración y regulación del fenómeno migratorio y la diversidad de identidades. El paradigma republicano Francés de integración ha constituido las bases sobre las cuales se han desarrollado las filosofias públicas y estrategias de control llevadas a cabo por las autoridades estatales sobre la movilidad humana y la diversidad dentro de la nación imaginada. Francia muestra una larga tradición en la propaganda y defensa de la existencia de un 'modelo nacional de integración' basado en una lectura muy particular del Republicanismo. El pensamiento Francés republicano divulga una cierta memoria histórica nacional y aboga por un compromiso con el principio del universalismo el cual niega toda diferencia étnica y cultural en el ámbito público, y que propaga la existencia de ciertos valores, modo de vida y costumbres dificil de compaginar con la diversidad y la heterogeneidad propia de toda sociedad. Uno de los factores constitutivos del Republicanismo Francés es la privatización de las diferencias culturales y la desaparición de identidades y modos de vida que no corresponden con el modelo nacional o de ciudadano perfecto. El principio de igualdad y el reconocimiento de estatuto de miembro son privilegios estrechamente vinculados a la necesidad de asimilación y naturalización del 'anormal' en la ciudadania francesa. La asimilación, o en su versión moderna, la integración, funciona como una norma en manos del Estado para obligar al no-nacional a perder sus identidades y diferencia a favor de la que se dice ostentada por la nación Francesa.

El Capítulo 6 continúa entonces con una perspectiva histórica de los desarrollos políticos y legislativos más significativos afectando la articulación entre la integración, la nacionalidad y la inmigración desde los 1880 s hasta la actualidad. La aparición de la categoría normativa de la integración como un asunto institucional y estructural se ha situado en los 1980s como consecuencia del papel jugado por la extrema derecha francesa ("Front National") y la estrategia de la izquierda consistente en proporcionar una terapia de identidad en tiempos de especial crisis política y como remedio a anoranzas post-coloniales. Desde entonces la integración ha contaminado todo el espectro político francés. La integración Republicana se ha institucionalizado como consecuencia de las intervenciones e informes elaborados por actores nacionales como el ("Haut Conseil à l'Intégration") y expertos tomando parte en comités de estudio de nacionalidad e inmigración. Al igual que en el caso español, la doctrina de integración republicana francesa encuentra sus raices en el derecho de nacionalidad, y más específicamente, como uno de los requisitos para tener acceso a la nacionalidad vía naturalización.

Desde 2003 la integración se ha mudado del derecho de la nacionalidad a las nomas reguladoras de las condiciones de admisión y residencia de nacionales de terceros países. La integración ha pasado así a ser una norma constitutiva del Derecho y políticas de inmigración francesas, lo cual ha supuesto un cambio radical en la manera en la que el sistema juridico francés habia concebido y aplicado la integración. Ello ha supuesto que la condición de integración Republicana no solamente juega funciones de control en manos del Estado para corregir toda anomalia o desviación de la ciudadania 'perfecta' e identidad nacional, sino que ahora también actúa como un criterio subjetivo e indeterminado para que los nacionales de terceros paises tengan acceso a seguridad de residencia y derechos. Los últimos desarrollos legislativos han reforzado este nexo 
normativo entre la integración y la immigración, y han llevado a la emergencia de una doctrina neo-Republicana de integración en el marco del derecho de inmigración. Las Leyes Sarkozy de 2003 y 2006, y la nueva "Loi relative à la maitrise de l'immigration, à l'intégration et à l'asile" de 2007 han fomentado progresivamente el desarrollo de los siguientes procesos afectando en gran manera los enfoques y funciones de la integración: normativización (CAl, "Contrat d'accueil et d'intégration"), expansionismo (CAIF, "Contrat d'accuell et d'intégration pour la famille") y externalización (integración en el extranjero). Todos ellos presentan la integración como una condición vinculante y obligatoria para que los inmigrantes tengan acceso a derechos y protección ligados a las dimensiones politicas de admisión, seguridad de residencia y reunificación familiar.

La normatividad de la integración republicana promulgada por el derecho de immigración francés ha sido justificada por las autoridades francesas como una consecuencia directa de las obligaciones de trasponer en su derecho nacional el derecho Europeo de inmigración regular, y en concreto, las Directivas 2003/109 sobre el estatuto de nacionales de terceros paises de larga duración y 2003/86 sobre el derecho a la reagrupación familiar. La UE ha sido de esta manera instrumentalizada para apoyar el desarrollo y puesta en práctica de unas prioridades y lineas políticas de carácter restrictivo sobre el campo de la inmigración regular. Los efectos de este tipo de 'Europeanismo' y la naturaleza de la trasposición francesa del derecho Europeo plantean dificultades de conciliación con los principios generales del derecho europeo.

\section{La Interacción entre el Derecho Nacional y Europeo de Inmigración: Los Principios Generales del Derecho de la UE}

La Parte IV del libro da un paso más en nuestro análisis y regresa al nivel Europeo para examinar la interacción entre el derecho de inmigración nacional y el Europeo, y los limites previstos por el sistema legal Comunitario al grado de discrección ostentado por los Estados Miembros a la hora de trasponer el derecho de la UE, y a la hora de aplicar la integración como un instrumento juridico de control migratorio condicionando el acceso a derechos y libertades. El potencial ofrecido por los principios generales del derecho de la UE, tal y como han sido desarrollados por los tribunales comunitarios, es de gran relevancia a la hora de limitar el grado de discreción y margen de apreciación de los Estados Miembros. Éstos constituyen una herramienta clave para valorar la legitimidad y legalidad de las excepciones y restricciones aplicadas por los Estados Miembros a derechos de indole europeo concedidos a inmigrantes por el derecho de inmigración de la UE.

El Capítulo 7 empieza desarrollando varias lineas teóricas sobre los principios generales del derecho comunitario y su papel dentro del ordenamiento juridico de la UE, y en concreto el derecho europeo sobre inmigración legal. La Europeanización de las políticas de inmigración no solo conlleva un cierto grado de influencia o instrumentalización de la UE en los sistemas jurídicos nacionales, sino que va también acompañado de una serie de mecanismos supranacionales destinados a delimitar el ámbito de acción de los Estados Miembros en la práctica de excepciones, derogaciones o limitaciones de derechos y libertades concedidos por el derecho comunitario. Los principios de proporcionalidad y derechos fundamentales son especialmente importantes a la hora de proteger nacionales de terceros paises en la aplicación de los Estados Miembros del derecho europeo de inmigración, y a la hora de garantizar la consistencia y coherencia de la política comunitaria de inmigración a lo largo y ancho de la UE.

La manera en la que Francia ha traspuesto las Directivas relativas a la inmigración regular, y el uso que ha realizado de la integración en dicho proceso, proporciona un caso de gran interés al 
ponerlo en relación con los principios generales del derecho Europeo. En particular dos aspectos destacan por su relevancia: En primer lugar, las lógicas de normativización, expansionismo y externalización afectando a la integración en el derecho francés de inmigración constituyen un ejemplo claro de limitación al acceso a derechos y libertades de naturaleza Europea; en segundo lugar, el desarrollo del paradigma neo-republicano de integración se ha basado en la necesidad de trasponer el derecho Europeo, y las Directivas 2003/109 y 2003/86. La combinación entre los principios generales de proporcionalidad y derechos fundamentales constituye dos fundamentos clave para examinar la legalidad de las medidas legislativas francesas y del Europeanismo abogado por el Estado francés. El Capitulo 7 ha finalmente ofrecido un análisis pormenorizado del ámbito de aplicación e interpretación jurisprudencial llevada a cabo por el Tribunal de Justicia de las Comunidades Europeas en relación a estos dos principios generales y su relevancia en las acciones de los Estados Miembros dentro del contexto del derecho Europeo de immigración. La última sección lleva a cabo un ejercicio de evaluación del derecho de inmigración francés, y de la integración republicana, en respecto a derechos fundamentales y al principio de proporcionalidad. Los resultados son reveladores a la hora de estudiar las tensiones existentes entre ciertas trasposiciones del derecho Europeo por parte de los Estados miembros y el respeto del estado de derecho y la libertad en la UE. 


\section{REFERENCES}

Adam Muñoz, M. D. (2005), "El Estatuto Jurídico del Extranjero en el Sistema Español: Una Perspective Histórica", en M. D. Adam Muñoz y I. Blázquez Rodríguez (coord.), Nacionalidad, Extranjeria y Ciudadania de la Union Europea, Editorial Colex: Madrid.

Adam, C. and A. Devillard (2008), Comparative Study of the Laws in the 27 EU Member States for Legal Migration - Including an Assessment of the Conditions and Formalities Imposed by Each Member State for Newcomers, European Parliament Study, Policy Department C: Citizens' Rights and Constitutional Affairs: Brussels.

Ager, A. and A. Strang (2004), Indicators of Integration: Final Report, Home Office Development and Practice Report, Home Office: London.

Aja, E. (2006), "La Evolución de la Nomativa sobre Inmigración", en E. Aja y J. Arango (eds), Veinte Años de Inmigración en España: Perspectivas Juridica y Sociológica [19852004], Fundación CIDOB: Barcelona, Spain, pp. 17-44.

Aja, E. (2006), "La Política Inmigratoria del Estado como Marco de la Actividad de las Comunidades Autónomas", en E. Aja, J. A. Montilla y E. Roig (coords.), Las Comunidades Autónomas y la Immigración, Novedades de Derecho Público 9, Instituto de Dret Public, Tirant lo Blanch: Valencia, pp. 153-184.

Aja, E. y J. Arango (2007), La Immigración en España 2006, Anuario de Inmigración y Politicas de Inmigración, Edición 2007, CIDOB: Barcelona.

Akehurst, M. (1981), 'The Application of General Principles of Law by the Court of Justice of the European Communities', British Yearbook of International Law, 52, pp. 29-51.

Alston, P. (2001), L'Union Européene et les Droits de l'Homme, Académie de Droit Européen Institut Universitaire Européen, Bruylant: Bruxelles.

Alston, P., M. Bustelo and J. Heenan (1999), The EU and Human Rights, Oxford University Press: Oxford.

Alter, K. (2001), Establishing the Supremacy of European Law: The Making of an International Rule of Law in Europe, Oxford University Press: Oxford.

Álvarez Rodríguez, A. (2007), 'Directiva 2003/109 versus Legislación Española Actual: ¿La Transposición exige la modificación de la LO 4/2000?', Revista de Derecho Migratorio y de Extranjeria, No. 15, pp. 9-42.

Álvarez Rodriguez, A. (2006), La Transposición de Directivas de la UE sobre Immigración: Las Directivas de las Reagrupación Familiar y de Residentes de Larga Duración, Documentos CIDOB Número 8, Serie Migraciones: Barcelona.

Álvarez Rodriguez, A. (2005), 'La interpretación de la Dirección General de los Registros y del Notariado en materia de nacionalidad: recensión y comentario de las decisiones dictadas de enero a octubre de 2005', Revista de derecho migratorio y extranjeria, $\mathrm{N}^{\circ} 10,2005$, pp. 213-233.

Álvarez Rodriguez, A. (2000), 'La Nueva Ley de Extranjeria: ¿Ruptura e incumplimiento de Tampere? ¿innovación o seguimiento del modelo italiano?', Revista Migraciones, N7, pp. 92-93.

Alvarez Rodriguez, A. (1990), Nacionalidad y Emigración, La Ley: Madrid. 
Anderson, B. (1991), Imagined Communities, Reflections on the Origin and Spread of Nationalism, Verso: London.

Anderson, M. and J. Apap (2002), Striking a Balance between Freedom, Security and Justice in an Enlarged European Union, Centre for European Policy Studies, CEPS: Brussels.

Apap, J. (2002), Freedom of movement of persons: A practitioner's handbook, Kluwer Law Intemational: The Hague, pp. 19-30.

Apap, J. and S. Carrera (2005), Spain's new regularization procedure: Is this the way forward? CEPS Commentary, Centre for European Policy Studies, CEPS: Brussels, February 2005.

Apap, J and S. Carrera (2004), "Progress and Obstacles in the Area of Justice and Home Affairs in an Enlarging Europe", in J. Apap (ed), Justice and Home Affairs in the EU; Liberty and Security Issues after Enlargement, Edward Elgar: Cheltenham, pp. 1-24.

Apap, J. and S. Carrera (2003), Family Reunification - A case for anmulment before the ECJ?, CEPS Commentary, Centre for European Policy Studies, CEPS: Brussels.

Apap, J. and S. Carrera (2003), Towards a Proactive Immigration Policy for the EU?, CEPS Working Document No. 198, Centre for European Policy Studies: CEPS, Brussels.

Aparicion López, R. (2006), 'Stratégies d'intégration des groupes d'immigrés en Espagne', |érés| Outre-Terre, 2006/4, No17, pp. 167-177.

Aragón, R. (1996), 'Diez Años de Política de Inmigración', Revista Migraciones, № 0.

Arango, J. (2002), La Fisonomia de la Inmigración en España, Red Internacional de Inmigración y Desarrollo, disponible en www.migracionydesarrollo.org

Arango, J. (1999) "Becoming a Country of Immigration at the End of the XXth Century: the Case of Spain", en R. King, G. Lazaridis and C. Tsardanidis, (eds.), Eldorado or Fortress? Migration in Southern Europe, Macmillan Press: London, pp. 253-276.

Arango, J. y R. Sandell (2004), Inmigración: Prioridades para una Nueva Politica Española, Informes Elcano, Real Instituto Elcano: Madrid.

Arango, J. y N. Garcia-Pardo (2000), Push and Pull Factors of International Migration. Moroccan and Senegalese Jmmigrants in Spain, Eurostat Working Papers: La Haya, pp. xxi y 167.

Arnull, A. (1990), The General Principles of EEC Law and the Individual, Leicester University Press: Leicester.

Babiano, J. y A. Femández Asperilla (2003), "Elementos del proceso de la inmigración española de los años sesenta. La voz de un pasado reciente", en Ciudadania y Derechos Sociales y Politicos de los Inmigrantes, Gaceta Sindical: Reflexión y Debate, Confederación Sindical de Comisiones Obreras, Junio 2003, p. 279.

Baganha, M.I. and H. Entzinger (2004), "The Political Economy of Migration in an Integrating Europe: An Introduction", in M. Bommes, K. Hoesch, U. Hunger and H. Kolb (eds), Organisational Recritment and Patterns of Migration, Special Issue 25/2004, Institut für Migrationsforschung und Interkulturelle Studien (IMIS), MIS-Beiträge, University of Osnabrück. 
Balch, A. (2005), "Spain", in J. Niessen and Y. Schibel, Immigration as a Labour Market Strategy - European and North American Perspectives, Migration Policy Group: Brussels.

Balibar, E. (2001), Nous, citoyens d'Europe? Les Frontiers, L'État, le peuple, La D'couvert: Paris.

Balzacq, T. and S. Carrera (2006), "The Hague Programme: The Long Road to Freedom, Security and Justice", in T. Balzacq and S. Carrera (eds.), Security versus Freedom: A Challenge for Europe's Future, Ashgate Publishing: Hampshire, pp. 1-34.

Balzacq, T. and S. Carrera (2005), The EU's Fight against International Terrorism: Security Problems, Insecure Solutions, CEPS Policy Brief, No. 80, Centre for European Policy Studies, CEPS: Brussels.

Balzacq, T. and S. Carrera (2005), Migration, Borders and Asylum: Trends and Vulnerabilities in EU Policy, Centre for European Policy Studies, CEPS: Brussels.

Bauböck, R. (1994), From Aliens to Citizens, Aldershot: Avebury.

Bauböck, R., A. Kraler, M. Martiniello and B. Perchinig (2006), "Migrants' Citizenship: Legal Status, Rights and Political Participation", in R. Penninx, M. Berger and K. Kraal (eds), The Dynamics of International Migration and Settlement in Europe: A State of the Art, IMISCOE Joint Studies, Amsterdam University Press, pp. 65-98.

Bernitz, U. and J. Nergelius (2000), General Principles of European Community Law, European Monographs, Kluwer Law International: The Hague.

Bertossi, C. (2004), "Politics and Policies of French Citizenship, Ethnic Minorities and the European Agenda", in A. Gorny and P. Ruspini (eds), Migration in the New Europe: East-West Revisited, Basingstoke: Palgrave.

Bertossi, C. (2002), Dilemme de la citoyenneté-Intégration / anti-discrimination en Europe: le cas français, Working Paper présenté lors de la Rencontre du CEDEM du 18 avril 2002, ULg, Liège, Belgique.

Bertozzi, S. (2007), Integration: An Ever Closer-Challenge, CEPS Working Document No. 258, Centre for European Policy Studies, CEPS: Brussels.

Besselink, L.F.M. (2006), "Unequal Citizenship: Integration Measures and Equality", in S. Carrera (ed.), The Nexus between Immigration, Integration and Citizenship in the EU, CHALLENGE Collective Conference Volume, Centre for European Policy Studies, CEPS: Brussels, pp. 14-19.

Besselink, L.F.M. (2005), Inburgering, gelijke behandeling en verblijfsrecht van vreemdelingen in Nederland, Staats-en Bestuursrecht, Faculteit Rechtsgeleerdheid, University of Utrecht (retrieved from www.libertysecurity.org).

Bigo, D. (2006), "Liberty, whose Liberty? The Hague Programme and the Conception of Freedom", in T. Balzacq and S. Carrera (eds), Security versus Freedom? A Challenge for Europe's Future, Ashgate Publishing: Hampshire, pp. 35-44.

Bigo D. (2005), "From foreigners to abnormal aliens: How the faces of the enemy have changed following September the 11 th with the process of policing beyond borders", in Van J., Selm E., Guild E. (dir.), International Migration and Security: Immigrants as an Asset or Threat?, Routledge: London. 
Bigo, B. (2002), 'Security and Immigration: Toward a Critique of the Governmentality of Unease', Altematives: Global, Local, Political, Vol. 27, Special Issue, February 2002, pp. 63-92.

Bigo, D. and S. Carrera (2004), From New York to Madrid: Technology as the Ultra-solution to the Permanent Siate of Fear and Emergency in the EU, CEPS Commentary, Centre for European Policy Studies, CEPS: Brussels.

Bigo, D. and E. Guild (2005), "Policing at a Distance: Schengen Visa Policies", in D. Bigo and E. Guild (eds), Controlling Frontiers, Ashgate: Hants/Burlington, pp. 233-263.

Bigo, D. and E. Guild (2003), La Mise à L'Écart des Étrangers: La Logique du Visa Schengen, Cultures \& Conflits, L'Harmattan: Paris.

Bigo, D. and E. Guild (2002), De Tampere à Séville : bilan de la sécurité européenne, Cultures \& Conflits: Sociologie, Politique, International, L'Hamattan: Paris.

Bigo, D., S. Carrera and E. Guild (2008), What Future for the Area of Freedom, Security and Justice? Recommendations on EU Migration and Border Policies in a Globalizing World, CEPS Policy Brief No. 156, March 2008, Centre for European Policy Studies, CEPS: Brussels.

Bigo, D., S. Carrera, E. Guild and R.B.J. Walker (2007), The Changing Landscape of European Liberty and Security: Mid-Term Report on the Results of the CHALLENGE Project, CHALLENGE Research Paper No. 4, February 2007, Centre for European Policy Studies, CEPS: Brussels.

Bigo, D., L. Bonelli, E. P. Guittet, C. Olsson and A. Tsoukala (2006), Illiberal Practices of Liberal Regimes: The (In)Secwrity Game, Collection Cultures \& Conflits, Centre d'Études sur les Conflits, L'Harmattan: Paris.

Birnbaum, P. (1998), La France Imaginée: Déclin des rêves unitaires?, Gallimard: Paris.

Blanc-Chaléard, M.C. (2006), "Old and New Migrants in France: Italians and Algerians", in L. Lucassen, D. Feldman and J. Otmer (eds), Paths of Integration: Migrants in Western Europe (1880-2004), IMISCOE Research, Amsterdam University Press: Amsterdam, pp. 46-62.

Blanco Fernández de Valderrama, C. (2001), 'La Integración de los Inmigrantes. Fundamentos para Abordar una Política Global de Intervención', Revista Migraciones, 10, pp. 207248.

Boelaert-Suominen, S. (2005), 'Non-EU nationals and Council Directive 2003/109/EC on the status of third-country nationals who are long-term residents: Five paces forward and possibly three paces back', Common Market Law Review, Vol. 42, No. 4, August, pp. $1011-1052$.

Boeles, P. (2007), 'Some Thoughts on General Principles of Community Law and Other. Conceivable Impact on European Migration Law', Presentation at the Meeting of the Scientific Research Group "Transposition of and Legal Protection under Future European Migration Law", 5 October 2007, Antwerpen.

Bocles, P. (2006), "What rights have migrating third country nationals?", in J.W. de Zwaan and F. Goudappel (eds), Freedom, Security and Justice in the European Union: Implementation of The Hague Programme, The Hague: T.M.C Asser Press (2006), pp. $151-63$. 
Boeles, P. (2001), 'Directive on Family Reunification: Are the Dilemmas Resolved?', European Journal of Migration and Law, Vol. 3, No., pp. 61-71.

Boeles, P. (2001), "Introduction: Freedom, Security and Justice for All", in E. Guild and C. Harlow (eds), Implementing Amsterdam: Immigration and Asylum Rights in EC Law, Hart Publishing: Antwerpen, pp. 1-12.

Boeles, P. and M. Bruins (2007), 'Case Reports of the European Court of Human Rights and the Human Rights Committee', European Joumal of Migration and Law, Vol. 9, No. 2, pp. 253-276.

Bogusz, B. (2004), "Modes of Governance for an EU Immigration Policy - What Role for the Open Method of Coordination", in B. Bogusz, R. Cholewinski, A. Cygan and E. Szyszczak (eds), Irregular Migration and Human Rights: Theoretical, European and International Perspectives, Martinus Nihjoff: Leiden, p. 224.

Bogusz, B., R. Cholewinski, A. Cygan and E. Szyszczak (2004), Irregular Migration and Human Rights: Theoretical, European and International Perspectives, Martinus Nihjoff: Leiden.

Bonino Covas, C. (2003), "Los Planes de las Comunidades Autónomas para la Integración de las Personas Inmigrantes", en Ciudadania y Derechos Sociales y Politicos de los Inmigrantes, Gaceta Sindical: Reflexión y Debate, Confederación Sindical de Comisiones Obreras, Junio 2003, pp. 179-207.

Bonino Covas, C., J. R. Medina y F. Rocha Sánchez (2003), Los Planes de las CCAA para la Integración Social de las Personas Inmigrantes, CCOO: Madrid.

Borrel, C. (2006), Enquêtes Ammuelles de Recensement 2004 et 2005: Près de 5 million d'immigrés à la mide de 2004, Insee, Cellule Statistiques et études sur immigration, Insee Première $N^{\circ}$ 1098, August 2006.

Boulouis, B. J. (1993), Droit Institutionnel des Communautés Européenes, Fourth Edition, Montcherstein: Paris.

Brinkmann, G. (2001), "Family Reunion, Third Country Nationals and the Community's New Powers", in E. Guild and C. Harlow (eds), Implementing Amsterdam: Immigration and Asylum Rights in EC Law, Hart Publishing: Oxford, pp. 241-266.

Brinkmann, G. (2002), 'Family Reunification of Third-Country Nationals: Access of Family Members to Social Protection Benefits', European Journal of Migration and Lav, Vol. 4, No. 3, pp. 291-308.

Brouwer, E. (2008), Digital Borders and Real Rights: Effective Remedies for Third-Coumtry Nationals in the Schengen Information System, Martinus Nijhoff Publishers: Leiden.

Brubaker, R. (2003), "The Return of Assimilation? Changing Perspectives on Immigration and its Sequels in France, Germany and the United States", in C. Joppke and E. Morawska (eds), Toward Assimilation and Citizenship: Immigrants in Liberal Nation-States, Basingstoke: Palgrave Macmillan, pp. 39-58.

Brubaker, R. (1992), Citizenship and Nationhood in France and Germany, Cambrigde, Mass: Harvar University Press.

Bruno, I. (2007), "Généalogie du Benchmarking. Itinéraire d'une technique de gouvemement", P. Laborier et J. Vogel (dirs.), Les Sciences Camérales. Activités Pratiques et Histoire des Dispositifs Publics, PUF: Paris, pp. 97-107. 
Bruno, I., S. Jacquot and L. Mandin (2006), 'Europeanization through its Instrumentation: Benchmarking, Mainstreaming and the Open Method of Coordination...Toolbox or Pandora's Box', Joumal of European Public Policy, Vol. 13, No. 4, pp. 519-536.

Bunyan, T. (1997), Key Texts on Justice and Home Affairs in the European Union, Volume 1, Statewatch.

Caballero Gea, J. A. (2005), Asilo. Extranjeria. Inmigración. Homologación de títulos extranjeros. Nacionalidad: Sintesis y Ordenación de la Doctrina de los Tribunales, Dykinson: Madrid, pp. 541-543.

Cabellos Espiérrez, M. A. y E. Roig Molés (2006), "El Tratamiento Juridico del Extranjero en Situación Regular", en E. Aja y J. Arango (coord.), Veinte Años de Immigración en España: Perspectivas Juridica y Sociológica (1985 - 2004), Fundació Cidob, Barcelona, Spain, pp. 113-129.

Cachón, L (2007), "El Plan Estratégico de Ciudadania e Integración 2007-2010", en E. Aja y J. Arango (eds), La lmmigración en España en 2006. Anuario de Inmigración y Politicas de Inmigración, CIDOB: Barcelona, pp. 246-266.

Cachón, L. (2007), "Diez Notas sobre la Inmigración en España 2006", en J. Arango (coord.), lmmigrates: El Continente Movil, Vanguardia Dossier, Número 22, Enero/Marzo 2007, pp. 68-74.

Cachón, L. (2006), “Los Inmigrantes en el Mercado de Trabajo en España (1996-2004)”, en E. Aja y J. Arango (coord.), Veinte Años de Immigsación en España: Perspectivas Juridica y Sociológica (1985 - 2004), CIDOB: Barcelona, Spain, pp. 175-201.

Cachón, L. (2003), 'La Inmigración en España: Los Desafios de la Construcción de una Nueva Sociedad', Revista Migraciones, Número 14, pp. 219-304.

Cachón, L. (2002), 'La formación de la 'España Inmigrante': Mercado y Ciudadania', Revista Española de Investigaciones Sociológicas, № 97, enero-marzo, pp. 95-126.

Cachón, L. (1999), Prevenir el Racismo en el Trabajo en España, Ministerio de Trabajo y Asuntos Sociales, Secretaria General de Asuntos Sociales, Instituto de Migraciones y Servicios Sociales, IMSERSO: Madrid.

Cachón, L. (1995), 'Marco Institucional de la Discriminación y Tipos de Inmigrantes en el Mercado de Trabajo en España', Revista Española de Investigaciones Sociológicas, $\mathrm{N}^{\circ}$ 69, Enero-Marzo 1995, pp. 105-124.

Cano Bagaza, E. (2005), "La Ley 36/2002, de 8 de Octubre, de modificación del Código Civil en Materia de Nacionalidad", en M. D. Adam Muñoz y I. Blázquez Rodriguez (coord.), Nacionalidad, Extranjeria y Ciudadania de la Unión Europea, Editorial Colex: Madrid, pp. 11-24.

Caritas Europa (2007), Integration: A Process Involving All, Advocacy Paper on the Integration of Migrants and Refugees, Brussels, August 2007.

Carlier, J.Y. and E. Guild (eds) (2006), The Future of Free Movement of Persons in the EU, Collection du Centre des Droits de L'Homme de la'Université Catholique de Louvain, Bruylant: Brussels. 
Carrascosa, J. (2003), "Sistema Español de Nacionalidad", en F. M. Mariño (dir.), Derecho de Extranjeria, Asilo yefugio, Ministerio de Trabajo y Asuntos Sociales, Secretaría General de Asuntos Sociales, Instituto de Migraciones y Servicios Sociales (IMSERSO): Madrid, pp. 329-414.

Carrera, S. (2008), Benchmaking Integration in the EU: Analyzing the Debate on Integration Indicators and moving it Forward, Bertelsmann Stiftung Foundation Berlin.

Carrera, S. (2007), "FRONTEX and the EU's Integrated Border Management Strategy", in J. Lodge (ed.), Are you who you say you are? The EU and Biomerric Borders, Wolf Legal Publishers: Nijmegen, pp. 67-100.

Carrera, S. (2007), Building a Common Policy on Labou Migration: Towards a Comprehensive and Global Approach in the EU?, CEPS Working Document No. 256, Centre for European Policy Studies, CEPS: Brussels.

Carrera, S. (2006), 'Programas de integración para inmigrantes: una perspectiva comparada en la Unión Europea', Revista Migraciones, N. 20, Universidad Pontificia de Comillas, Madrid, pp. 37-73.

Carrera, S. (2006), "Integration of Immigrants versus Social Inclusion? A Typology of Integration Programmes in the EU", in T. Balzacq and S. Carrera (2006), Security versus Freedom? A Challenge for Europe's Future, Ashgate: Hampshire, pp. 87-112.

Carrera, S. (2006), A Comparison of Integration Programmes in the EU: Trends and Weaknesses, CHALLENGE Research Paper No. 1, Centre for European Policy Studies, CEPS: Brussels.

Carrera, S. (2006), Legal Migration Law and Policy Trends in a Selection of Member States, Briefing Paper prepared for the European Parliament, Policy Unit, Citizens Rights and Constitutional Affairs: Brussels.

Carrera, S. (ed) (2006), The Nexus between Immigration. Integration and Citizenship in the EU, CHALLENGE Collective Conference Volume, Centre for European Policy Studies, CEPS: Brussels.

Carrera, S. (2006), A Typology of Different Integration Programmes in the EU, Briefing Paper, DG Internal Policies, European Parliament: Brussels.

Carrera, S. (2006), “Hacia una Política Común sobre Inmigración Laboral en la EU?”, en F. Valdés Dalré and J. M. Zufiaur Narvaiza (eds), Hacia un Mercado Europeo de Empleo, Ministerio de Trabajo y Asuntos Sociales. Centro de Publicaciones, 2006.

Carrera, S. (2005), "Integration as a process of inclusion for migrants? The case of long-term residents in the EU", in H. Schneider (ed.), Migration, Integration and Citizenship: A Challenge for Europe's Future, Forum Maastricht: Maastricht, pp. 109-138.

Carrera, S. (2005), 'What does free movement mean in theory and practice in an enlarged EU?', European Law Journal, Vol. 11, No. 6, November, pp. 699-721.

Carrera, S. and M. Formisano (2005), An EU Approach to Labour Migration: What is the Added Value and the Way Ahead?, CEPS Working Document No. 232, Centre for European Policy Studies, CEPS: Brussels.

Carrera, S. and E. Guild (2006), "No Constitutional Treaty? Implications for the Area of Freedom, Security and Justice", in T. Balzacq and S. Carrera (eds), Security versus Freedom. A Challenge for Future's Europe, Ashgate: Aldershot, pp. 223-240. 
Carrera, S. and F. Geyer (2007), Terrorism, Borders and Migration: The Commission's 2008 Policy Strategy in the Area of Freedom, Security and Justice, CEPS Policy Brief No. 131, June 2007, Centre for European Policy Studies, CEPS: Brussels.

Carrera, S. and F. Geyer (2007), The Reform Treaty and Justice and Home Affairs: Implications for the common Area of Freedom, Securty and Justice, CEPS Policy Brief No. 141, Centre for European Policy Studies, CEPS: Brussels.

Carrera, S. and F. Geyer (2008), 'El Tratado de Lisboa y un Espacio de Libertad, Seguridad y Justicia: Excepcionalismo y Fragmentación en la Unión Europea', Revista de Derecho Commitario Europeo, $\mathrm{N}^{\circ} 29$, January/April 2008.

Carrera, S. and F. Geyer (2008), "The Reform Treaty and Justice and Home Affairs: Implications for the Common Area of Freedom, Security and Justice", in E. Guild and F. Geyer (eds), Security versus Justice? Police and Judicial Cooperation in the European Union, Ashgate: Hampshire, pp. 289-307.

Carrera, S. and A. Turmann (2004), Towards the Free Movement of Workers in an Enlarged EU?, CEPS Commentary, Centre for European Policy Studies, CEPS: Brussels.

Cassese, A. Clapham and J. Weiler (eds), European Union: The Human Rights Challenge, Nomos: Baden-Baden.

Castles, S. and M. J. Miller (2003), The Age of Migration: International Population Movements in the Modern World, Basingstoke: MacMillan.

Caviedes, A. (2004), 'The Open Method of Coordination in Immigration Policy: A Tool for Prying Open Fortress Europe', Joumal of European Public Policy, 11:2, April 2004, pp. 289-310.

Causa, O. and S. Jean (2007), Integration of Immigrants in OECD Countries: Do Policies Matter?, Economic Department Working Papers No. 564, OECD, retrievable from www.oecd.org/eco

Ceri Jones, H., C. Pineda, F. Pissart and T. Timmermans (2005), Beyond the Common Basic Principles on Integration: The Next Steps, European Policy Centre: Brussels.

Cholewinski, R. (2001), 'The EU acquis on Irregular Migration: Reinforcing Security at the Expense of Rights', European Jownal of Migration and Law, Vol. 2, pp. 361-405.

Cholewinski, R. (2002), 'Family Reunification and Conditions Placed on Family Members: Dismantling a Fundamental Human Right', Etropean Jounal of Migration and Law, Vol. 4, no. 3, pp. 271-290.

Chopin, 1. (2000), 'Possible Harmonization of Anti-Discrimination Legislation in the European Union: European and Non-Governmental Proposals', European Joumal of Migration and Law, Vol. 2, pp. 413-430.

Chopin, I. (1999), 'The Starting Line Group: A Harmonized Approach to Fight Racism and to Promote Equal Treatment', European Journal of Migration and Law 1, pp. 111-129.

Chopin, I. and J. Niessen (1998), Proposals for legislative measures to combat racism and to promote equal rights in the European Union, co-published by the Starting Line Group and the British Commission for Racial Equality.

Cimade (2006), 'Le Contrat d'Accueil et d'Intégration : un marché de dupes?', Causes Communes, numéro 49 - Janvier / Février 2006, available at www.cimade.org 
Cimade (2007), Analyse du Projet de Loir Relatif a l'Immigration, a l'Intégration et a l'Asile, Version du Projet de Loi du 4 Juillet 2007, retriavable from www.cimade.org

Clapham, A. (1991), Human Rights and the European Community: A Critical Overview, Nomos: Baden-Baden.

Colas, D. (2004), Citoyenneté et Nationalité, Folio Histoire, Gallimard: Paris.

Colectivo IOE (1999), "La inmigración extranjera en España, 2000", en VVAA, La immigración extranjera en España. Los retos educativos, Fundación La Caixa: Barcelona, pp. 3-68.

Collet, E. (2006), One Size fits All? Tailored Integration Policies for Migrants in the European Union, EPC Working Paper No. 24, European Policy Centre: Brussels.

Commissioner for Integration and Migration of the Senate of Berlin (ed.) (2007), Encouraging Diversity - Strengthening Cohesion, Integration Policy in Berlin 2007-2011, Der Beauftragte für Integration und Migration: Berlin.

Coppel, J. and A. O'Neill (1992), 'The European Court of Justice: Taking Rights Seriously?', Common Market Law Review, 29, p. 669.

Comelius, W., P.L. Martin and J. Hollifield (eds) (1994), Controlling Immigration: A Global Perspective, Standford: Standford University Press.

Coussey, M. (2000), Framework of Integration Policies, Council of Europe, Directorate General III - Social Cohesion, Directorate of Social Affairs and Health, Council of Europe Publishing: Strasbourg.

Craig, P. (2006), EU Administrative Law, Oxford University Press: Oxford.

Craig, P. and G. de Búrca (2007), EU Law: Text, Cases and Materials, Oxford University Press: Oxford, Sixth Edition.

Crespo Navarro, E. (2004), 'La Directiva 2003/109/CE del Consejo relativo al estatuto de los nacionales de terceros Estados residentes de larga duración y la normativa española en la materia', Revista de Derecho Comunitario Europeo, No. 18 (mayo-agosto 2004), pp. $531-552$.

Daadouch, C. (2004), 'Le droit des étrangers', édition à jour de la loi du 26 novembre 2003, Collection Droit, Mode d'emploi, Editions MB Formation: Paris, p. 32.

Davies, G. (2006), 'Subsidiarity: The Wrong Idea, in the wrong place, at the wrong time', Common Market Law Review, Vol. 43, No. 1, pp. 63-84.

De Bruycker, P. (2003), The Emergence of a European Immigration Policy - L'Émergence d'une Politique Européene D immigration, Bruylant: Brussels.

De Búrca, G. (2000), "Proportionality and Subsidiarity as General Principles of Law", in U. Bernitz and J. Nergelius (eds), General Principles of European Community Law, European Monographs: Kluwer Law International: The Hague, pp. 95-112.

De Búrca, G. (1993), 'The Principle of Proportionality and its Application in EC Law', Yearbook of European Law, Vol. 13, pp. 105-150.

De Cecco, F. (2006), 'Room to Move? Minimum Harmonization and Fundamental Rights', Common Market Law Review, No. 1, Vol. 43, pp. 9-30.

De Groot, G.R. (2007), A Clarification of the Fundamental Rights Implications of Stateless and Erased Persons, Briefing Paper European Parliament, DG Internal Policies: Brussels. 
De Groot, G. R. (2006), "Reflections on Integration and Access to Nationality/Citizenship through Naturalisation: A Comparative Perspective", in S. Carrera (ed.), The Nexus between Immigration, Integration and Citizenship in the EU, Collective Conference Volume, April 2006, pp. 21-27.

De Groot, G.R. (2006), "Nationality Law", in J.M. Smits (ed.), Elgar Encyclopedia of Comparative Law, Cheltenham: Edward Elgar, pp. 476-492.

De Groot, G.R. (2005), "Towards a European Nationality Law", H. Schneider (ed), Migration, Integration and Citizenship: A Challenge for Europe's Future, Volume I, pp. 13-53.

De Groot, G.R. (2004), Towards a European Nationality Law - Vers un droit européen de nationalité, Inaugural lecture delivered on 13 November 2003 on the occasion of the acceptance of the Pierre Harmel chair of professeur invité at the University of Liège, Unigraphic, University of Maastricht: Maastricht.

De Groot, G.R. (2003), "Loss of Nationality. A Critical Inventory", in D. A. Martin and K. Hailbronner (eds), Rights and Duties of Dual Nationals. Evolution and Prospects, Kluwer Law Intemational: The Hague, pp. 201-299.

De Groot, G.R. (1998), "The relationship between the nationality legislation of the Member States of the European Union and European Citizenship", Chapter VI, in La Torre, M. (ed.), European Citizenship: An Institutional Challenge, Kluwer International Law: The Hague.

De la Porte, C. (2002), "Is the Open Method of Coordination Appropriate for Organising Activities at European Level in Sensitive Policy Areas?', European Law Joumal, Vol. 8, No. 1, March 2002, pp. 38-58.

De Lucas, J. (2007), Voces y Ecos de las Elecciones en Francia, Página Abierta $N^{\circ} 183$, Julio 2007, retriavable from "Pensamiento Crítico", www.pensamientocritico.org

De Lucas, J. (2006), "La Integración de los Inmigrantes: La Integración Política, condición del modelo de integración", en J. de Lucas y L. Dízz Bueso (coord.), La Integración de los Inmigrantes, Centro de Estudios Políticos y Constitucionales, Foro para la Inmigración y la Ciudadania: Madrid, pp. 11-43.

De Lucas, J. (2002), 'Política de Inmigración: 30 Propuestas', Claves de Razón Práctica, N 121, Abril 2002, pp. 32-36.

De Lucas, J. (2002), 'La Dimensión Política de la Inmigración: Una Dimensión Pendiente', en VV.AA. (Centro Pignatelli, ed.), La Inmigración, Una Realidad en España, Zaragoza: Centro Pigantelli/Gobiemo de Aragón.

De Lucas, J. (2001), "Una Oportunidad Perdida para la Política de Inmigración: "La contrarreforma" de la Ley $8 / 2000$ en España", en J. de Lucas, S. Peña y A. Solanes (coords.), Inmigrantes: Una Aproximación Juridica a sus Derechos, Germania: Valencia, pp. 33-56.

De Lucas, J. (2001), "Las Propuestas sobre Política de Inmigración en Europa y la Nueva Ley de Extranjeria 4/2000 en España", en VV.AA. (Colomer ed.), Emigrantes y Estabilidad en el Mediterráneo, Nomos/Coma: Valencia.

De Lucas, J. (2001), "Identidad y Constitución Europea ¿Es la identidad cultural Europea la clave del proyecto Europeo?", en J. de Lucas (coord.), Europa: Derechos, Culnmas, Tirant Lo Blanch: Valencia, pp. 123-152. 
De Lucas, J. (2000), 'El Marco Juridico de la Inmigración. Algunas Proposiciones acerca de la Necesidad de Reformar la Ley Orgánica 4/2000', Jueces para la Democracia, 38/2000.

De Lucas, J. (1999), ¿QQué Politicas de Inmigración? Reflexiones al Hilo de la Reforma de la Ley de Extranjería en España', Tiempo de Paz, $\mathrm{N}^{\circ} 55$.

De Lucas, J. (1994), Europa: ¿Convivir en la diferencia? Editorial Tecnos: Madrid.

De Lucas, J. (1994), El Desafio de las Fronteras: Derechos Humanos y Xenofobia frente a una Sociedad Plural, Ediciones Temas de Hoy: Madrid.

De Lucas, J. (1992), Europa: ¿Convivir con la Diferencia? Racismo, Nacionalismo y Derechos de las Minorias, Editorial Tecnos: Madrid.

De Palo, D., R. Faini and A. Venturini (2006), The Social Assimilation of Immigrants, IZA Discussion Papers Series No. 2439, Institute for the Study of Labour, November 2006.

De Schutter, O. (2007), Promoting and Protecting Fundamental Rights in the European Union: The Relations between the European Convention of Human Rights, the European Charter and the Member States' Constitutions, Briefing Paper, European Parliament, DG Internal Policies of the Union: Brussels.

De Schutter, O. (2005), "L'influence de la Cour européenne des droits de l'homme sur la Cour de justice des Communautés européennes", in G. Cohen-Jonathan et J.-Fr. Flauss (dir.), Le rayonnement international de la jurisprudence de la Cour européenne des droits de I'homme, Bruylant-Nemesis: Bruxelles, pp. 189-242.

De Wenden, C. (1998), "Changing Representations of the Other in France: The Mirror of Migration", in R. Bauböck and J. Rundell (eds), Blurred Boundaries: Migration, Ethnicity, Citizenship, Ashgate: Aldershot.

De Witte, B. (2001), "Le Rôle Passé et Futur de la Cour de Justice des Communautés Européenes dans la Protection des Droits de L'homme", dans P. Alston, M. BUstelo et J. Heenan (dir.), L'Union Européenne et les Droit de l'Homme, Académie de Droit Européen, Institut Universitaire Européen, Bruylant: Bruxelles, pp. 895-935.

De Witte, B. (2000), "Institutional Principles: A Special Category of General Principles of EC Law", in U. Bernitz and J. Nergelius (eds), General Principles of Community Law. European Monographs, Kluwer Law International: The Hague, pp. 143-159.

De Witte, B. (1999), "Direct Effect, Supremacy and the Nature of the Legal Order", in P. Craig and G. de Búrca (eds), The Evolution of EU Law, Oxford University Press: Oxford, pp. 177-213.

Del Camino Vidal Fueyo, M. (2007), "Las Politicas Autonómicas en Materia de Inmigración en el Año 2006", en E. Aja y J. Arango (eds), La Inmigración en España en 2006, Anuario de Inmigración y Politicas de Inmigración, CIDOB Publicacions: Barcelona, pp. $112-$ 126.

Debray, R. (1989), Que vive la République, Paris: Odile Jacob.

Dehousse, R. (2004), L'Europe sans Bruxelles? Une analyse de la Methode Owverte de Coordination, L'Harmattan: Paris. 
Den Boer, M. (2005), "The European Convention and its Implications for Justice and Home Affairs Cooperation", in J. Apap (ed.), Justice and Home Affairs in the EU: Liberty and Security Issues after Enlargement, Edward Elgar Publishing: Cheltenham, pp. 121-133.

Diez Bueso, L. (2006), "Los Derechos de los Inmigrantes y sus Garantias (1990-2004)", en E. Aja y J. Arango (coord.), Veinte Años de Inmigración en España: Perspectivas Juridica y Sociológica (1985 - 2004), CIDOB: Barcelona, pp. 205-218.

Díez Bueso, L. (2006), "Veinte Años de Normativa sobre Extranjería en España: ¿Hacia una Politica de Integración?", en J. de Lucas y L. Diez Bueso (coord.), La Integración de los Inmigrantes, Centro de Estudios Politicos y Constitucionales, Foro para la Inmigración y la Ciudadania: Madrid.

Durán Ruiz, J. (2004), "El derecho comunitario y la consecución de la ciudadanía: la Directiva relativa al estatuto de los nacionales de terceros Estados que son residentes de larga duración". Ponencia presentada en el $4^{\circ}$ Congreso sobre la Inmigración en España. Cindadania y Participación. Mesa 4: Ciudadania: Marco Juridico y Politicas en materia de Inmigración, Girona, del 10 al 13 de noviembre de 2004 (www.udg.edu/congres_immigracio/);

Edelman, M. (1988), Constructing the Political Spectacle, The University of Chicago Press: Chicago and London.

Edelman, M. (1964), The Symbolic Uses of Politics, University of Illinois Press, Urbana and Chicago: Illini Books.

Eeckhout P. (2002), 'The EU Charter of Fundamental Rights and the Federal Question', Common Market Law Review, Vol. 39, No. 5, pp. 945-994.

Ellis, E. (1999), The Principle of Proportionality in the Laws of Europe, Hart Publishing: Oxford.

Emiliou, N. (1996), The Principle of Proportionality in European Law: A Comparative Perspective, Kluwer Law International: The Hague.

Entzinger, H. and R. Biezeveld (2003), Benchmarking in Immigration Integration, European Research Centre on Migration and Ethnic Relations, Erasmus University of Rotterdam.

Entzinger, H. and R. Biezeveld (2004), "Benchmarking in Immigrant Integration", in R. Süssmuth and W. Weidenfeld (eds), Managing Integration: The European Union's Responsibilities towards Immigrants, Verlag Bertelsmann Stiftung: Gütersloh, pp. 123136.

Espinar Vicente, J. M. (1994), La Nacionalidad y la Extranjeria en el Sistema Juridico Español: Tratados y Manuales, Civitas: Madrid, pp. 126-129.

Etienne, B. (1989), L'islam en France, Hachette: France.

Fach Gómez, K. (2003), 'Propuesta de Directiva relativa al estatuto de los nacionales de terceros paises residentes de larga duración en la Unión Europea', Revista de Derecho Migratorio y Extranjeria. No. 2, pp. 53-64.

Favell, A. (1998), Philosophies of Integration: Immigration and the Idea of Citizenship in France and Britain, Macmillan: London.

Feldblum, M. (1999), Reconstructing Citizenship: The Politics of Nationality Reform and Immigration in Contemporary France, New York: State Universtiy of New York Press. 
Fermin, A. (2001), The Justification of Mandatory Integration Programmes for New Imnigrants: Summary of the Dutch report "Verplichte inburgering van nieuwkomers", European Research Centre on Migration and Ethnic Relations, University of Utrecht.

Fernández Rozas, J. (1987), Derecho Español de la Nacionalidad, Tecnos, Madrid.

Finkielkraut, A. (1987), La Défait de la Pensée, Paris: Gallimard, p. 143.

Forder, C. (2005), "Family Rights and Immigration Law: A European Perspective", in H. Schneider (ed.), Migration, Integration and Citizenship: A Challenge for Europe's Future, Volume II; Forum Maastricht: Maastricht, pp. 71-108.

Foucault, M. (1999), Les Anormatx, Cours au Collège de France. 1974 - 1975, Hautes Études, Gallimard Le Seuil: Paris.

Foncault, M. (1997), Dits et Écrits 1954 - 1988, II (1976 - 1988), Édition Établie sous la Direction de D. Defert et F. Ewald avec la collaboration de J. Lagrange, Quarto Gallimard: Paris.

Foncault, M. (1997), Sècurité, territoire, population: Cours an Collège de France (1977-1978), Gallimard Seuil: Paris, pp. $111-113$.

Gaspard, F. (1992), 'Assimilation, Insertion, Intégration: Les Mots pour "devenir François", Hommes et Migrations, Mai 1992.

Geddes, A. (2005), "Europe's Border Relationships and Intemational Migration Relations", Jounal of Common Market Studies, Vol. 43, No. 4, pp. 787-806.

Geddes, A. (2003), "Migration and the Welfare State in Europe", in S. Spencer (ed.), The Politics of Migration: Managing Opportnnity, Conflict and Change, Blackwell Publishing: Ames, IA, pp. 25-38.

Geddes, A. (2003), The Politics of Migration and Immigration in Europe, Sage Publications Lid: London.

Geddes, A., J. Niessen, A. Balch, C. Bullen and M.J. Peiro (2005), European Civic Citizenship and Inclusion Index, British Council Brussels, Foreign Policy Centre and Migration Policy Group, British Council: Brussels.

Geisser, V. (2006), "L'Intégration Républicaine: Réflexion sur une Problématique PostColonial", P. Blanchard et N. Bancel (eds), Culture Post-Coloniale 1961-2006: Trace et Memoires Coloniales en France, Editions Autrement: Paris, pp. 145-165.

Gil Araújo, S. (2006), Las Argucias de la Integración: Constnucción Nacional y Gobiemo de lo Social a través de las Politicas de Integración de Inmigrantes: Los Casos de Cataluñay Madrid, Tesis Doctoral, Departamento de Cambio Social, Facultad de Ciencias Politicas y Sociologia, Universidad Complutense de Madrid.

Gisti (2008), Le guide de l'entrée et du séjour des étrangers en France, La Découverte: Paris, pp. 95-105.

Gómez, I. (2006), "Madrid", en E. Aja, J. A. Montilla y E. Roig (coords.), Las Comunidades Autónomas y la Inmigración, Novedades de Derecho Público 9, Instituto de Dret Public, Tirant lo Blanch, Valencia, pp. 373-420.

Groenendijk, K. (2007), "The Long-Term Residents Directive, Denizenship and Integration", in A. Baldaccini, E. Guild and H. Toner (eds), Whose Freedom, Security and Justice? EU Immigration and Asylum Law and Policy, Hart Publishing: Oxford, pp. 429-450. 
Groenendijk, K. (2006), "The Legal Integration of Potential Citizens: Denizens in the EU in the final years before the implementation of the 2003 directive on long-term resident third country nationals", in R. Bauböck, E. Ersboll, K. Groenendijk and H. Waldrauch (eds), Acquisition and Loss of Nationality, Volume I: Comparative Analyses: Policies and Trends in 15 European Countries, Amsterdam University Press: Amsterdam, pp. 385410 .

Groenendjik, K. (2006), "Citizens and Third Country Nationals: Differential Treatment or Discrimination?", in J.Y. Carlier and E. Guild (eds), The Future of Free Movement of Persons in the EU, Collection du Centre des Droits de L'Homme de la'Université Catholique de Louvain, Bruylant. Brussels, pp. 79-101.

Groenendijk, K. (2006), "Integration Policy and Community Law", in S. Carrera (ed.), The Nexus between Immigration. Integration and Citizenship in the EU, Collective Conference Volume, Centre for European Policy Studies, CEPS: Brussels, April 2006, pp. 9-11.

Groenendijk, G. (2006), 'Family Reunification as a Right under Community Law', European Jomnal of Migration and Law, Vol. 8, No. 2, pp. 215-230.

Groenendijk, K. (2005), "Access of Third-Country Nationals to Employment under the New EC Migration Law", in F. Julien-Laferriere, H. Labaye nad O. Edström (eds), The European Immigration and Asylum Policy: Critical Assesment Five Years after the Amsterdam Treaty, Bruylant: Brussels, pp. 141-174.

Groenendijk, K. (2004), 'Legal Concepts of Integration in EU Migration Law', European Jounal of Migration and Law, Vol. 6, No. 2, pp. 111-126.

Groenendijk, K., E. Guild and R. Barzilay (2000), Study on The Legal Status of Third-Country Nationals who are Long-Term Residents in a Member State of the European Union, Centre for Migration Law, Radboud University of Nijmegen, Nijmegen: The Netherlands.

Groenendijk, K., E. Guild and H. Dogan, (1998), Security of Residence of Long-Term Migrants: A Comparative Study of Law and Practice in European Countries, Council of Europe, Strasbourg.

Groenendijk, K., R. Fernhout, D. Van Dam, R. Van Oers and T. Strik (2007), The Family Reunification Directive in EU Member States: The First Year of Implementation, Wolf Legal Publishers: Nijmegen.

Guild, E. (2007), EU Policy on Labour Migration: A First Look at the Commission's Blue Card Initiative, CEPS Policy Brief No. 145, Centre for European Policy Studies: Brussels.

Guild, E. (2006), "Citizenship and Fundamental Rights", in J. Carlier and E. Guild (2006) (eds), The Furure of Free Movement of Persons in the EU-L'avenir de la libre circulation des persomes dans l'U.E., Bruylant: Brussels, pp. 45-63.

Guild, E. (2005), "Cultural and Identity Security: Immigrants and the Legal Expression of National Identity", in E. Guild and J. Van Selm (eds), International Migration and Security: Opportunities and Challenges, Routledge: New York, pp. 101-112.

Guild, E. (2004), The Legal Elements of European Identity: EU Citizenship and Migration Law, Kluwer Law International, European Law Library: The Hague. 
Guild, E. (2004), "Who is an Irregular Immigrant", in B. Bogusz, R. Cholewinski, A. Cygan and E. Szyszczak (eds), Irregular Migration and Human Rights: Theoretical, European and International Perspectives, Leiden: Martinus Nihjoff, pp. 3-28.

Guild, E. (2004), 'The Variable Subject of the EU Constitution, Civil Liberties and Human Rights', European Journal of Migration and Law, Vol. 6, No. 4, pp. 381-394.

Guild, E. (2004), "Citizens, Immigrants, Terrorists and Others", in S. Peers and A. Ward (eds), The EU Charter of Fundamental Rights, Politics, Law and Policy, Hart: Oxford, pp. 231-47.

Guild, E. (2003), "The Border Abroad - Visas and Border Controls", in K. Groenendijk, E. Guild and P. Minderhoud (eds), In Search of Europe's Borders, Kluwer Law International: The Hague, pp. 87-104.

Guild, E. (2003), "Intersecting Worlds? Understanding the Legal Framework of European Labour Migation in Susan Strange's Modern World", in D. Bigo, and E. Guild (eds), Controlling Frontiers: Free Movement into and within Europe, Aldershot: Ashgate.

Guild (2004), "Mechanisms of Exclusion: Labour Migration in the European Union", in J. Apap (ed.), Justice and Home Affairs in the EU - Liberty and Security Issues after Enlargement, Edward Elgar: Cheltenham, pp. 211-55.

Guild, E. (2001), "Primary Immigration: The Great Myths", in E. Guild and C. Harlow (eds.), Implementing Amsterdam: Immigration and Asylum Rights in EC Law, Hart Publishing: Oxford, pp. 65-94.

Guild, E. (2001), Immigration Law in the European Community, Kluwer Law International: The Hague.

Guild, E. (2001), Moving the Borders of Europe, inaugural lecture delivered at the official ceremony of the assumption of the professorship of the CPO Wisselleerstoel at the University of Nijmegen, 30 May.

Guild, E. (1999), 'Discretion, Competence and Migration in the European Union', European Journal of Migration and Law, Vol. 1, No. 1, pp. 61-87.

Guild, E. (1999), The Legal Framework and Social Consequences of Free Movement of Persons in the Ewropean Union, Kluwer Law International: The Hague.

Guild, E. and S. Carrera (2006), The Hague Programme \& the EU's Agenda on "Freedom, Security and Justice": Delivering Results for Europe's Citizens?, CEPS Commentary, Centre for European Policy Studies, CEPS: Brussels.

Guild, E. and C. Harlow (2001), Implementing Amsterdam: Immigration and Asylum Rights in EC Law, Hart Publishing: Oxford.

Guild, E. and G. Lesieur (1997), The European Court of Justice on the European Convention of Human Rights: Who said what when, Kluwer Law Intemational: The Hague.

Guild, E. and J. Niessen (1996), The Emerging Immigration and Asylum Law of the European Union, Kluwer Law International: The Hague.

Guild, E. and P. Minderhoud (eds) (2001), Security of Residence and Expulsion: Protection of Aliens in Europe, Kluwer Law Internationals: The Hague. 
Guild, E. and S. Peers (2006), "Out of the Ghetto? The Personal Scope of EU Law", in S. Peers and N. Rogers (eds), EU lmmigration and Asylum Law: Text and Commentary, Martinus Nijhoff Publishers: Leiden, pp. 81-114.

Guild, E. and S. Peers (2001), "Defence or Defiance? The Court of Justice's Jurisdiction over Immigration and Asylum", in E. Guild and C. Harlow (eds), Implementing Amsterdam: Immigration and Asy/um Rights in EC Law', Hart Publishing: Oxford, pp. 267-289.

Guild, E. and H. Staples (2003), "Labour Migration in the European Union", in P. de Bruycker (ed.), The Emergence of a European Immigration Policy, Bruylant: Brussels, pp. 171247.

Guimezanes, N. (2007), 'Premier Aperçu du Projet de Loi Maitrise de l'immigration', La Semaine Juridique Edition Générale, No 28, 11 Julliet 2007, act. 321.

Guimezanes, N. (2006), 'Loi de 24 juillet 2006 relative à l'immigration et à l'intégration', La Semaine Juridique - Édition Générale, No 36, 6 Septembre 2006, pp. 1623 and 1624.

Guimezanes, N. (2006), 'Le Statu Légal des Migrants', Revue internationale de droit comparé, Études de Droit Contemporain, Contributions françaises au $17^{\circ}$ Congrès international de droit comparé, Utrecht, 16-22 juillet 2006, cinquante-huitième année, $\mathrm{n}^{\circ} 2$, Avril-Juin 2006, pp. 593-620.

Guimezanes, N. (2003), 'La loi n’ 2003-1119 du 26 novembre 2003 relative à la maîtrise de l'immigration, au séjour des étrangers en France et à la nationalité', La Semaine Juridique Edition Générale n 50, 10 Décembre 2003, act. 592.

Guimezanes, N. (1996), 'Les Lois 'Pasqua' el leur mise en application', La Semaine Juridique Edition Générale, № 42, 16 Octobre 1996, I 3967.

Guiraudon, V. (2008), Integration Contracts for Immigrants: Common Trends and Differences in the European Experience, Commentary, Real Instituto Elcano, 7 may 2008,

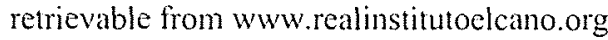

Guzmán Peces, M. (2005), "La Integración en la Adquisición de la Nacionalidad Española por Residencia: Comentario de la Sentencia de 29 de Octubre de 2004 del Tribunal Supremo", en M. D. Adam Muñoz y I. Blázquez Rodríguez (coord.), Nacionalidad. Extranjeriay Ciudadania de la Unión Europea, Editorial Colex: Madrid, pp. 41-50.

Habermas, J. (1998), L'intégration républicaine. Essais de théorie politique, Fayard: Paris.

Habermas, J. (1998), The Inchusion of the Other, Studies in Political Theory, Edited by C. Cronin and P. De Greiff, The Mit Press: Cambridge, pp. 105-127.

Hailbrommer, K. (2000), Immigration and Asylum Policy of the European Union, Kluwer Law International: The Hague.

Hailbronner, K. (1995), "Migration Law and Policy Within the Third Pillar of the Union Treaty", in R. Bieber and J. Monar (eds), Justice and Home Affairs in the European Union: The Development of the Third Pillar, European University Press: Brussels, pp. 95-126.

Halleskov, L. (2005), 'The Long-Term Residents Directive: A Fulfillment of the Tampere Objective of Near Equality', European Jomnal of Migration and Law, Vol. 7, No. 2, 2005, pp. 181-201. 
Handoll, J. (2003), "The Long Term Residents Directive", in J. Carlier and P. de Bruycker (eds), Immigration and Asylum Law of the EU: Current Debates, Bruylant: Brussels, pp. 144160.

Handoll, J. (2003), "The Status of Third-Country Nationals", in P. de Bruycker (ed), The Emergence of A European Immigration Policy, Bruylant: Brussels, pp. 269-362.

Hansen, R. (2003), "Citizenship and Integration in Europe", in C. Joppke and E. Morawska (eds), Toward Assimilation and Citizenship: Immigrants in Liberal Nation-States, Basingstoke: Palgrave Macmillan, pp. 87-109.

Hartley, T. C. (2007), The Foundations of European Community Law: An Introduction to the Constitutional and Administrative Law of the European Community, Oxford University Press: Oxford.

Hatzopoulos, V. (2007), 'Why the Open Method of Coordination is Bad for You: A Letter to the EU', European Law Journal, Vol. 13, Issue 3, May 2003, pp. 309-342.

Hedeman-Robinson, M. (1996), 'Third-Country Nationals, European Citizenship and Free Movement of Persons: A Time for Bridges Rather than Divisions', 16 Yearbook of European Law, 321.

Hollifield, J. (2004), "France Republicanism and the Limits of Immigration Control", in W. Comelius, P.L. Martin and J. Hollifield (eds), Controlling Immigration: A Global Perspective, Standford: Standford University Press, pp. 183-214.

Hollifield, J. (1992), 'L'Etat Français et l'immigration', Revue Française de Science Politique, pp. $943-963$.

House of Lords (2008), The Treaty of Lisbon: An Impact Assessment, European Union Committee, $10^{\text {th }}$ Report of Session 2007-2008, Volume I: Report, House of Lords: London.

Human Rights Watch (2008), The Netherlands: Discrimination in the Name of Integration Migrant's Rights under the Integration Act Abroad, May 2008;

Huysmans, J. (2002), 'Defining Social Constructivism in Security Studies: The Normative Dilemma of Writing Security', Alternatives: Global, Local, Political, Vol. 27, Special Issue, February 2002, pp. 41-62.

Iglesias Fernández, S. (2007), 'El Valor de la Directiva 2003/86/CE sobre Reagrupación Familiar a la Luz de los Derechos Fundamentales y de la Sentencia del TJCE en el Asunto 540/03', Revista de Derecho Commitario Europeo, No. 26, Enero/Abril, pp. 125-153.

Illamola Dausà, M. (2006), 'La Unión Europea y la Politica de Integración de los Inmigrantes', en M. Aparicio Wilhelmi, M. Illamola Dausà, D. Moya Malapeira y S. Rodera Ranz (coord.), Las Fronteras de la Ciudadania en España y en la Unión Europea, Actas del II y III Encuentro de Jóvenes Investigadores en Derecho de Inmigración y Asilo, Documenta Universitaria: Girona, pp. 61-72.

Illamola Dausà, M. (2005), 'Égalité et intégration', F. Julie-Laferriere , H. Labaye et örjan Edstrom (dir.), La Politique Européenne D'Immigration et D'Asile: Bilan Critique Cinq Ans Après le Traité D'Amsterdam, Bruylant: Bruxelles, pp. 175-202. 
International Centre for Migration Policy Development (ICMPD) (2005), Integration Agreements and Voluntary Measures: Compulsory or Voluntary Nature - Comparison of Compulsory Integration Courses, Programmes and Agreements and Voluntary Integration Programmes and Measures in Austria, France, Germany, the Netherlands and Switzerland, ICMPD, Vienna, May.

INTI-Project 13 Indicators on Immigrant Integration (June 2005 - June 2006), Immigrant Integration Indicators: Proposal for Contributions to the Formulation of a System of Common Integration Indicators (2006), Research \& Documentation Centre (WODC), Ministry of Justice, the Netherlands. Retrievable from http://english.wodc.nl/publicaties

Izquierdo Escribano, A. (1996), La Immigración Inesperada: La Poblaciuon Extranjera en España (1991-1995), Trotta: Madrid.

Izquierdo Escribano, A. (1992), La Inmigración en España (1980-1990), Ministerio de Trabajo y Seguridad Social: Madrid.

Jacobs, F. G. (2007), 'Citizenship of the European Union - A Legal Analysis', European Law Joumal, Special Issue on EU Citizenship, Vol. 13, Issue 5, pp. 591-622.

Jans, J.H., R. de Lange, S. Prechal and R.J.G.M. Widdershoven (2007), Europeanisation of Public Law, Europa Law Publishing: Groningen.

Jennings, J. (2000), 'Citizenship, Republicanism and Multiculturalism in Contemporary France', British Journal of Political Science, Vol. 30, No. 4, Oct. 2000, pp. 575-597.

Joppke, C. (2007), 'Beyond National Models: Civic Integration Policies for Immigrants in Western Europe', West European Politics, Vol. 30, No. 1, January 2007, pp. 1-22.

Joppke, C. and E. Marzal (2004), 'Courts, the New Constitutionalism and Immigrant Rights. The Case of the French Conseil Constitutionnel', European Journal of Political Research, 43, pp. 825-846.

Julie-Laferriere, F., H. Labaye et O. Edstrom (2005), La Politique Européenne D'Immigration et D'Asile: Bilan Critique Cinq Ans Après le Traité D'Amsterdam, Bruylant: Bruxelles.

Kadelbach, S. (2003), Union Citizenship, Jean Monnet Working Paper 9/03, Max Planck Institute for Comparative Public Law and Intemational Law, Heidelberg, pp. 24-27.

Kate, M. A. and J. Niessen (2007), Locating Immigrant Integration Policy Measure in the Machinery of the European Commission, Migration Policy Group: Brussels.

Khosrokhavar, F. (1996), "L'universel abstrait, le politique et la construction de l'islamisme comme une forme d'altérité", in M. Wieviorka (ed.), Une société fragmentée: Le multiculturalisme en débat, Paris: La Découverte, pp. 113-51.

Kirisci, K. (2008), "Three Way Approach" to Meeting the Challenges of Migrant Incorporation in the European Union: Reflections from a Turkish Perspective, CARIM Research Reports 2008/03, European University Institute, Robert Schuman Centre for Advanced Studies.

Kok, W. (2004), Facing the Challenge: The Lisbon Strategy for Growth and Employment, Office for Official Publications of the EC: Luxembourg.

Kostakopoulou, D. (2007), 'European Citizenship: Writing the Future', European Law Journal, Special Issue on EU Citizenship, Vol. 13, Issue 5, pp. 623-646. 
Kostakopoulou, T. (2002), 'Integrating Non-EU Migrants in the European Union: Ambivalent Legacies and Mutating Paradigms', The Columbia Journal of European Law, Vol. 8, No. 2, Spring, pp. 181-201.

Kostakopoulou, T. (2002), 'Long-term Resident Third-Country Nationals in the European Union: Normative Expectations and Institutional Openings', Journal of Ethmic and Migration Studies, Vol. 28, No. 3, pp. 443-462.

Kostakopoulou, T. (2001), "Invisible Citizens? Long-Term Resident Third-Country Nationals in the EU and their Struggle for Recognition", in R. Bellamy and A. Warleigh (eds), Citizenship and Governance in the European Union, Continuum Studies in Citizenship, Continuum: London, pp. 180-206.

Kostakopoulou, T. (2001), Citizenship, Identity and Immigration in the European Union: Between Past and Future, Manchester University Press: Manchester.

Labayle, H. (2007), 'Le Droit des Etrangers au Regroupement Familial, Regards Croisés du Droit Interne et du Droit Européen', Revue Française de Droit Administrative, 1, pp. 1 37.

Laborde, C. (2001), 'The Culture(s) of the Republic: Nationalism and Multiculturalism in French Republican Thought', Political Theory, Vol. 29, No. 5, (Oct. 2001), pp. 716-735.

Laborde, C., "Republican Citizenship and the Crisis of Integration in France", in R. Bellamy, D. Castiglione and E. Santoro (eds), Lineages of European Citizenship: Rights, Belonging and Participation in Eleven Member States, Palgrave: Macmillan, pp. 46-72.

Laferrière, F. J. (2005), "La Loi No 2003-1119 du 26 Novembre 2003 relative à la maitrise de l'immigration, au sejour des étrangers en France et à la nationalité", in J.Y. Carlier and P. de Bruycker (eds), Immigration and Asylum Law of the EU: current debates / Actualité du Dioit Européen d l'immigration et de l'asile, Bruylant: Brussels, pp. 530557.

Laferrière, F. J. (2004), 'Une modification d'ampleur de l'ordonnance du 2 novembre 1945', l'Actualité juridique - Droit administratif (A.J.D.A.), n 5/2004, 9 February 2004.

Lagarde, P. (2004), 'Note sur "Loi du 26 novembre 2003"”, Rev. Crit. DIP, 93(2), avril-juin 2004 , p. 495.

Lagarde, P. (1996), "Le Droit Français de la Nationalite", in B. Nascimbene (ed.), Nationality Laws in the European Union. Le Droit de la Nationalité dans l'Union Européenne, Butterworths, Giuffrè Editore, pp. 309-336.

Lagarde, P. (1993), 'La nationalité française rétrécie', Rev. Crit. Dr: Int. Privé, p. 535.

Larios Paterna, M. J. (2006), "Cataluña", en E. Aja, J. A. Montilla y E. Roig (coords.), Las Comunidades Autónomas y la Immigración, Novedades de Derecho Público 9, Instituto de Dret Public, Tirant lo Blanch, Valencia, pp. 285-316.

Laurenzo Copello, P. (2004), 'Ultimas Reformas en el Derecho Penal de los Extranjeros: Un Nuevo Paso en la Política de Exclusión', Jueces para la Democracia, No. 50, pp. 30-35.

Lochak, D. (2006), 'Le Tri des Étrangers: Un Discours Récurrent', in 'Immigration, paroles de trop', Plein Droit n 69, juillet 2006. Retriavable from Gisti, www.gisti.org 
Lochak, D. (2006), "L'intégration comme injonction. Enjeux idéologiques et politiques liés à l'immigration", in Identifier et Surveiller: Les Technologies de Sécurité, Cultures \& Conflits, No 64 Hiver, L'Harmattan: Paris, pp. 131-147.

Lochak, D. (2005), 'L'intégration alibi de la précarisation', Plein Droit 59-60, pp. 3-6.

Long M. (1998), Etre français aujourd'hui et demain: rapport de la Comission de la Nationalité, Pairs: Olivier Orban.

López Pich, P. (2007), 'La Politica de Integración de la Unión Europea', Revista Migraciones, Vol. 22, Diciembre 2007, Universidad Pontificia de Comillas, Madrid, pp. 221-256.

López Sala, M. (2005), Inmigrantes y Estados: La Respuesta Política ante la Cuestión Migratoria, Anthropos Editorial: Barcelona, pp. 171-175.

López Santana, M. (2006), 'Domestic Implications of European Soft-Law: Framing and Transmitting Change in Employment Policy', Journal of European Public Policy, 13:4, June 2006, pp. 481-499.

Marinelli, V. (2005), "The Netherlands", in J. Niessen, Y. Schibel and C. Thompson (eds), Current Immigration Debates in Europe: A Publication of the European Migration Dialogıe, Migration Policy Group: Brussels.

Martin, D. (2007), 'Comments on European Parliament v. Council (Case C-540/03 of 27 June 2006)', European Journal of Migration and Law, Vol. 9, No. 1, pp. 144-153.

Martín D. y Pérez de Nanclares, J. (2002), La Inmigración y el Asilo en la Unión Europea, Editorial Colex: Madrid.

Martiniello, M. (2008), Towards a Coherent Approach to Immigrant Integration Policy(ies) in the European Union, retrievable from www.oecd.org on January 2008.

Martiniello, M. (1994), "Citizenship of the European Union. A Critical View", in R. Bauböck (ed), From Aliens to Citizens: Redefining the Status of Immigrants in Europe, Avebury: Aldershol, pp. 29-48.

Masson, B. (2006), 'L'harmonisation des conditions du regroupement familial: La Cour fait la leçon sur le titre IV CE (CJCE 27 juin 2006, Parlement européen c/ Conseil de l'Union européenne)', Revue Trimestrielle de Droit Européen, Vol. 42, № 4, pp. 673-685.

McAndrew, M. and M. Weinfeld (1996), "The Social integration of immigrants and the response of institutions", in M. Lombardi, Metropolis: First Conference, Fondazione Cariplo: Milan, pp. $51-73$ (retrieved from htıp:/www.international.metropolis.net).

Michalowski, I. (2004), "Integration Programmes for Newcomers - A Dutch model for Europe?", in A. Böcker, B. de Hart and I. Michalowski, Migration and the Regulation of Social Integration, IMIS-Beiträge Special Issue, No. 24, IMIS, Universität Osnabrück.

Michalowski, I. (2004), An Overview on Introduction Programmes for Immigrants in Seven European Member States, Adviescommissie voor Vreemdelingenzaken, The Hague.

Moinet, J. P. (2006), Célébrer la bienvenue dans la République française, Rapport sur les cérémonies célébrant l'acquisition de la nationalité française Rapport à la Ministre déléguée à la Cohésion Sociale et à la Parité, Mme Catherine Vautrin, avril 2006. 
Monar, J. (1995), "Democratic Control of Justice and Home Affairs: The European Parliament and the National Parliaments", in R. Bieber and J. Monar (eds), Justice and Home Affairs in the European Union: The Development of the Third Pillar, European University Press: Brussels, pp. 243-257.

Monar, J. (1994), "The Evolving Role of the Union Institutions in the Framework of the Third Pillar", in J. Monar and R. Morgan (eds), The Third Pillar of the European Union: Cooperation in the Fields of Justice and Home Affairs, European University Press: Brussels, pp. 69-83.

Montilla, J. A. (2006), "Inmigración y Comunidades Autónomas", en E. Aja y J. Arango (eds.), Veinte Años de Inmigración en España: Perspectivas Juridica y Sociológica [19852004], CIDOB: Barcelona.

Montilla, J. A. (2006), "Las Funciones y Competencias de las Comunidades Autónomas en Inmigración", en E. Aja, J. A. Montilla y E. Roig (coords.), Las Comunidades Autónomas y la Inmigración, Novedades de Derecho Público 9, Instituto de Dret Public, Tirant lo Blanch, Valencia, pp. 23-75.

Moreno Fuentes, F. J. (1999), 'La Migration et le Droit de la Nationalité Espagnole', P. Weil et R. Hansen (dir.), Nationalité et Citoyenneté en Europe, La Decouverte: Paris, pp. $117-$ 144.

Müller-Graff, P. (1994), "The Legal Bases of the Third Pillar and its Position in the Framework of the Union Treaty", in J. Monar and R. Morgan (eds), The Third Pillar of the European Union: Cooperation in the Fields of Justice and Home Affairs, European University Press: Brussels, pp. 21-36.

Muñoz Pérez, F. y A. Izquierdo Escribano (1989), 'L'Espagne, pays d'immmigration', Population, 2, INED: Paris.

NATAC Summary (2006), recommendations, available at http://www.imiscoe.org/natac/index.html.

Niessen, J. (2006), "Integration, Citizenship and the Benchmarking of Integration in the EU", in S. Carrera (ed.), The Nexus between Immigration, Integration and Citizenship in the EU, Collective Conference Volume, Centre for European Policy Studies, CEPS: Brussels, pp. 33-37.

Niessen, J. (2002), 'Consultations on Immigration Policies', European Journal of Migration and Law, Vol. 4, no. 1, pp. 79-83.

Niessen, J. (2000), The Management and Managers of Immigration, Migration Policy Group: Brussels.

Niessen, J. and Isabelle Chopin (eds) (2004) The development of legal instruments to combat racism in a diverse Europe, MPG: Brussels.

Niessen, J. and T. Huddleston (2007), (With N. Verbruggen and M. A. Kate), Setting up a System of Benchmarking to Measure the Success of Integration Policies in Europe, Policy Department C, Citizens Rights and Constitutional Affairs, European Parliament: Brussels.

Niessen, J. and M. A. Kate (2007), From Principles to Practice: The Common Basic Principles on Integration and the Handbook Conclusions, Migration Policy Group: Brussels, June 2007. Retrievable from http:/www.migpolgroup.com 
Niessen, J. and Y. Schibel (2004), Handbook on Integration for Policy-makers and Practitioners, DG Justice, Freedom and Security, European Commission, European Communities, November 2004

Niessen, J. and Y. Schibel (2007), Handbook on Integration for Policy Makers and Practitioners, DG Justice, Freedom and Security, European Commission, European Communities, Second Edition, May 2007.

Niessen, J., T. Huddleston and L. Citron (2007) (in cooperation with A. Geddes and D. Jacobs), Migrant Integration Policy Index, British Council and Migration Policy Group.

See www.integrationindex.eu

Niessen, J., M. J. Peiro and Y. Schibel (2005), Civic Citizenship and Immigrant Inchusion -A Guide for the Implementation of Civic Citizenship Policies, Migration Policy Group: Brussels.

Noiriel, G. (2007), Immigration, antisémitisme et racisme en France (XIXe-XXe siècle) : Discours publics, humiliations privées, Fayard: Paris.

Noiriel, G. (2006), Le Creuset Français: Histoire de l'immigration XIV-XX siecle, Editions du Seuil: Paris, Édition Mise Á Jour et Augmentée d'une Préface.

Noiriel, G. (2000), Petite Histoire de l'intégration: la française, Le Monde Diplomatique.

Oliveira, A.C. (2002), 'Workers and other persons: Step-by-step from movement to citizenship Case law 1995-2001', Common Market Law Review, 39, pp. 77-127.

Oosterom-Staples, H. (2007), "The Family Reunification Directive: A Tool Preserving Member State Interest or Conducive to Family Reunification Unity?", in A. Baldaccini, E. Guild and H. Toner (eds). Whose Freedom, Security and Justice? EU Immigration and Asylum Law and Policy, Hart Publishing: Oxford, pp. 451-488.

Ortega Martín, E. (2005), Mamual Práctico de Derecho de Extranjeria, Europa de Derecho, Editorial Juridica: Madrid.

Ovey C. and R. C.A. White (2006), Jacobs \& White: The European Convention on Human Rights, Fourth Edition, Oxford University Press: Oxfors, pp. 514-519.

Pajares, M. (2008), EL Contrato de Integración, Periódico de Cataluña, 9 February 2008, www.elperiodico.com

Pajares, M. (2006), "Las Políticas Locales en el Ámbito de la Inmigración", en E. Aja y J. Arango (coord.), Veinte Años de Inmigración en España: Perspectivas Juridica y Sociológica (1985 - 2004), CIDOB: Barcelona, pp. 369-393.

Pajares, M. (2005), La Integración Ciudadana: Una Perspectiva para la Inmigración, Barcelona: Icaria Antrazyt.

Pajares, M. (2004), Inmigración y politicas de integración social. Fundación Alternativas: Madrid.

Pajares, M. (1999), La inmigración en España. Icaria: Barcelona.

Papadopoulou R.E. (1996), Principes Généraux de Droit et Droit Communautaire, Origines et Concrétisation, Bruylant: Bruxelles. 
Parejo, L. (2003), "El Régimen de Permanencia de los Extranjeros", en F. M. Mariño (dir.), Derecho de Extranjeria, Asilo y Refugio, Ministerio de Trabajo y Asuntos Sociales, Secretaría General de Asuntos Sociales, Instituto de Migraciones y Servicios Sociales (IMSERSO): Madrid, pp. 515-566.

Pastore, F. (2004), "Visas, Borders, Immigration: Formation, Structure and Current Evolution of the EU Entry Control System", in N. Walker (ed.), Europe's Area of Freedom, Security and Justice, Academy of European Law, European University Institute, Oxford: Oxford University Press, pp. 89-142.

Peers, S. (2007), EU Reform Treaty: Analysis 1: Version 3: JHA Provisions, Statewatch Analysis, 22 October 2007, retrievable from www.statewatch.org

Peers, S. (2007), "The Jurisdiction of the Court of Justice over EC Immigration and Asylum Law: Time for a Change?", in A. Baldaccini, E. Guild and H. Toner (eds), Whose Freedom. Security and Justice? EU Immigration and Asylum Law and Policy, Hart Publishing: Oxford, pp. 85-108.

Peers, S. (2006), EU Justice and Home Affairs Law, Second Edition, Oxford EC Law Library: Oxford.

Peers, S. (2006), "The EU Institutions and Title IV", in S. Peers and N. Rogers (eds), EU Immigration and Asylum Law: Text and Commentary, Martinus Nijhoff Publishers: Leiden, pp. 47-79.

Peers, S. (2005), "The UK Opt-Out from EU Immigration and Asylum Law in Practice", in J.-Y. Carlier and P. De Bruycker (eds), Immigration and Asylum Law of the EU: Current Debates, Bruylant: Brussels, pp. 161-165

Peers, S. (2004), "Taking the Rights Away? Derogations and Limitations", in S. Peers and Ward (eds), The EU Charter of Rights: Politics, Law and Policy, Hart Publishing: Oxford, $\mathrm{p}$. 141.

Peers, S. (2004), 'Implementing equality? The Directive on Long-term Resident Third Country Nationals', European Law Review, 29(4), p. 437-440;

Peers, S. (2004), "Family Reunion and Community Law", in N. Walker (ed), Europe's Area of Freedom. Security and Justice, Oxford University Press, pp. 143-197.

Peers, S. (2003), Readmission agreements and EC external migration law, EU: Statewatch analysis No. 17 (retrievable from www.statewatch.org).

Peers, S. (2001), 'Immigration, Asylum and the European Union Charter of Fundamental Rights', European Journal of Migration and Law, Vol. 3, No. 2, pp. 141-169.

Peers, S. (2000), EU Justice and Home Affairs Law, Person Education Limited, Essex.

Peers, S. (2000), "Who is Judging the Watchmen? The Judicial System of the Area of Freedom, Security and Justice', 18 Yearbook of European Law, p. 337.

Peers, S. (1999), "Raising Minimum Standards or Racing for the Bottom: The Commission's Proposed Migration Convention", in E. Guild (ed) (1999), The Legal Framew'ork and Social Consequences of Free Movement of Persons in the European Union, Kluwer Law Intemational: The Hague.

Peers, S. (1998), 'Building Fortress Europe: The Development of EU Migration Law', 35 Common Market Law Review 1235 
Peers, S. (1997), 'Undercutting Integration: Developments in EU Policy on Third-Country Nationals', European Law Review 22, pp. 76-84.

Peers, S. (1997), 'Justice and Home Affairs: Undercutting Integration: Developments in Union Policy on Third-Country Nationals', European Law Review 22, pp. 76-84

Peers, S. and N. Rogers (eds) (2006), EU Immigration and Asylum Law: Text and Commentary, Martinus Nijhoff Publishers: Leiden.

Peña, S. (2001), "La Historia Reciente de la Legislación Española sobre Derechos y Libertades de los Extranjeros y Algunas de las Actuaciones que han Provocado", en J. de Lucas, S. Peña y A. Solanes (coords.), Immigrames: Una Aproximación Juridica a sus Derechos, Germania: Valencia, pp. 17-32.

Penninx, P. (2003), Immigration without Integration: A Recipe for Disaster, Policy Brief, Summary Report of the Athens Capstone Conference, pp.60-64, retrievable from www.migrationpolicy.org/AMPI

Peminx, R. (2004), Integration of Migrants: Economic, Social, Cultural and Political Dimensions, background paper for the UNECE Conference 12-14 January 2004, Geneva.

Penninx, R. (2005), "Integration of Migrants: Economic, Social, Cultural and Political Dimensions", in M. Macura, A.L. MacDonald and W. Haug (eds), The New Demographic Regime. Population Challenges and Policy Responses, New York/Geneva: United Nations, pp. 137-152.

Pemninx, R., M. Berger and K. Kraal (eds) (2006), The Dynamics of International Migration and Sethement in Europe. A State of the Art, Amsterdam: AUP, IMISCOE Joint Studies Series.

Penninx, R., D. Spencer and N. Van Her (2008), Migration and Integration in Europe: the State of Research, ESRC Centre on Migration, Policy and Society (COMPAS), University of Oxford retrievable from www.norface.org

Perchinig, B. (2006), "EU Citizenship and the Status of Third Country Nationals", in R. Bauböck (ed.), Migration and Citizenship: Legal Status, Rights and Political Participation, IMISCOE Reports, Amsterdam University Press: Amsterdam, pp. 67-82.

Pereda, C. y M. A. Prada (cords.) (1987), Los Inmigrantes en España, Monográfico de Documentación Social, 66, Madrid.

Pérez Díaz, V. (1969), Emigración y Sociedad en la Tierra de Campos: Estudio de un Proceso Migratorio y un Proceso de Cambio Social, Escuela Nacional de Administración Pública: Madrid.

Pérez-Díaz, V., B. Álvarez-Miranda y C. González-Enríquez, España ante la Inmigración, Colección de Estudios Sociales, Núm. 8, Fundación La Caixa, 2001.

Pratt, S. (2006), "Immigration, Integration and Citizenship: Latest Developments and the EU's Role", in S. Carrera (ed.), The Nexus between Immigration, Integration and Citizenship in the EU, Collective Conference Volume, April 2006, Centre for European Policy Studies: CEPS, Brussels, pp. 12-15. 
Prechal, S. (2007), "Direct Effect, Indirect Effect, Supremacy and the Evolving Constitution of the European Union", in C. Barnard (ed.), The Fundamentals of EU Law Revisited: Assessing the Impact of the Constitutional Debate, Oxford University Press: Oxford, pp. $109-152$.

Prechal, S. (2005), Directives in EC Law, Second Edition, Oxford University Press: Oxford.

Putman, E. (2006), 'Loi du 24 Juillet 2006: Une Immigration selon les Mérites?', Revue Juridique Personnes \& Famille, 12, pp. 6-8.

Radaelli, C. (2001), "The Domestic Impact of the European Union Public Policy: Notes on Concepts, Methods and the Challenge of Empirical Research', Politique européene, 5, pp. 107-142.

Ray, B. (2003), The Policy Challenges of Intervention in Local and Private Integration Processes, Policy Brief, Summary Repon of the Athens Capstone Conference, pp. 6468 , retrievable from www.migrationpolicy.org/AMPI

Régnard, C. (2006), Rapport Annuel de la Direction de Population et des Migrations, Immigration et Présence Étrangère en France en 2005, Ministère de l'Emploi, de la Cohésion Social et du Logement, pp. 96-112.

Roig, E. (2002), 'Autonomia e Inmigración: Competencias y Participación de las CCAA y los Entes Locales en Materia de Inmigración', Amuario de Derecho Constitucional y' Parlamentario, Vol. 14, page 201.

Roig, E. (2006), "Relaciones Intergubernamentales en Materia de Inmigración: Desarrollo de un Modelo en Construcción", en E. Aja, J. A. Montilla y E. Roig (coords.), Las Comunidades Autónomas y la Inmigración, Novedades de Derecho Público 9, Instituto de Dret Public, Tirant lo Blanch, Valencia, pp. 77-152.

Roman, J. (1995), 'Un multiculturalisme á la française', Esprit, June 1995, pp. 145-60.

Rubio, J. (1974), La Immigración Española a Francia, Ariel: Barcelone.

Rubio Marin, R. (2008), Inmigrantes y Contratos Electoralistas, El País, 29 February 2008, www.elpais.es

Rubio Marin, R. (2006), "Spain", in in R. Bauböck, E. Ersboll, K. Groenendijk and H. Waldrauch (eds), Acquisition and Loss of Nationality, Volume 2: Country Analyses, Policies and Trends in 15 European Countries, IMISCOE Research, Amsterdam University Press: Amsterdam, pp. 477-515.

Rubio Torrano, E. (2004), 'La Buena Conducta Cívica en La Adquisición de la Nacionalidad Española', Aranzadi Civil, Sección Tribuna, Núm. 1/2004, pp. 1-3.

Ryan, B. (2007), "The European Union and Labour Migration: Regulating Admission or Treatment?", in A. Baldaccini, E. Guild and H. Toner (eds), Whose Freedom, Sectwity and Justice? EU Immigration and Asylum Law and Policy, Hart Publishing: Oxford, pp.489-515;

Sagarra Trías, E. "Modificación de la regulación de nacionalidad española en el Código Civil", Real e Ilustre Colegio de Abogados de Zaragoza, retriavable from www.reicaz.es 
Santolaya, P. (2006), "Los inmigrantes en situación irregular: derechos expulsión y regularización", en E. Aja y J. Arango (eds), Veinte Años de Immigración en España: Perspecrivas Juridica y Sociológica [1985 - 2004], CIDOB: Barcelona, Spain, pp. 129 141.

Santolaya, P. (2005), "España", en E. Aja y L. Díez (coord.), La Regulación de la Inmigración en Europa, Colección de Estudios Sociales Núm. 17, Obra Social, Fundación "La Caixa": Barcelona, pp. 242-274.

Sassen, S. (ed) (1999), Guests and Aliens, The New Press.

Schaffrin, D. (2005), "Which Standard for Family Reunification for Third-Country Nationals in the European Union", in J.Y. Carlier and P. de Bruycker (eds), Immigration and Asylum Lav of the EU: Current Debates, Bruylant: Brussels, pp. 90-143.

Schain M. (1999), "Minorities and Immigrant Incorporation in France: The State and the Dynamics of Multiculturalism", in Joppke, C. and S. Lukes (eds), Multicultural Questions, Oxford: Oxford University Press, pp. 199-223.

Schermes, H. G. and D. F. Waelbroeck (2001), Judicial Protection in the European Union, Kluwer Law International: The Hague.

Schibel, Y. (2004), 'Transposing EU Law on Legal Migration', European Joumal of Migration and Law, Vol. 6, no.4, pp. 395-404.

Schieffer, M. (2003), 'Community readmission agreements with third countries - objectives, substance and current state of negotiations', European Journal of Migration and Law, Vol. 3, pp. 343-357. See also below 167 and 172.

Schnapper, D. (2007), Qu'est-ce que l'intégration?, Folio Actuel 125, Gallimard: Paris.

Schnapper, D. (1994), La Communanté des Citoyens: Sur l'idée moderne de nation, Gallimard: Paris.

Schnapper, D. (1992), L'Europe des Immigrés, Essai su' les Politiques d'Immigration, François Bourin: Paris.

Schnapper, D. (1991), La France de L'integration. Sociologie de la nation en 1990, Gallimard: Paris.

Schneider, H. (2005), "Towards a European Migration Policy: From Maastricht to Amsterdam, from Tampere to the Hague", in H. Schneider (ed.), Migration, Inregration and Citizenship: A Challenge for Europe's Future, Volume II, Forum Maastricht: Maastricht, pp. 7-33.

Schneider, H. and A. Wiesbrock (2005), "The Council Directive on Family Reunification: Establishing Proper Rights for Third Country Nationals?", in H. Schneider (ed.), Migration, Integration and Citizenship: A Challenge for Europe's Future, Volume II: The Position of Third Country Nationals in Europe, Forum Maastricht: Maastricht, pp. 35-70.

Scliwarze, J. (2003), 'The Principle of Proportionality and the Principle of Impartiality in European Administrative Law', Rivista Trimestrale di Dirito Pubblico, pp. 53-75.

Schwarze, J. (1992), European Administrative Law, Sweet and Maxwell: London.

Senden, L. (2003), Soft Law in European Community Law: Its Relationship to Legislation, Wolf Legal Publishers: Nijmegen. 
Senden, L. and S. Prechal (2001), "Differentiation in and Through Community Soft-Law", in B. de Witte, D. Hanf and E. Vos (eds), The Many Faces of Differentiation in EU Law, Intersentia: Antwerpen, pp. 181-199.

Simon, D. (1991), 'Y A-T-Il des Principes Généraux du Droit Communautaire?', Droits, Revue Française de Théorie Juridique, 14, pp. 73-86.

Snyder, F. (1994), 'Soft Law and Institutional Practice in the European Community', in S. Martin (ed.), The Construction of Europe, Essays in Honour of Emile Noël, Kluwer: Dordrecht, pp. 197-225.

Solanes, A. (2006), "Valencia", en E. Aja, J. A. Montilla y E. Roig (coords.), Las Commidades Autónomas y la Immigración, Novedades de Derecho Público 9, Instituto de Dret Public, Tirant lo Blanch, Valencia, pp. 317-341.

C. Solé y A. Izquierdo (coords.) (2005), Integraciones Diferenciadas: Migraciones en Cataltũa, Galicia y Andalucia, Anthropos Editorial: Barcelona.

Solé, C. y S. Parella (2001), "La Inserción de los Inmigrantes en el Mercado de Trabajo. El Caso Español", en C. Solé (coord.), El Impacto de la Inmigración en la Economia y en la Sociedad Receptora, Anthropos: Barcelona, pp. 11-50.

Spencer, S. (2003), The Challenges of Integration for the European Union, Policy Brief, Summary Report of the Athens Capstone Conference, pp. 68-72, retrievable from www.migrationpolicy.org/AMPI

Staples, H. (1999), The Legal Status of Third Country Nationals Resident in the European Union, European Monographs 22, Kluwer Law International: The Hague;

Steiner, J., L. Woods and C. Twigg-Flesner (2006), EU Law, $9^{\text {th }}$ Edition, Oxford University Press: Oxford.

Sudre, F. (2006), Droit européén et international des droits de l'homme, Presses Universitaires de France: Paris, pp. 646-649.

Szyszczak, E. (2006), 'Experimental Governance: The Open Method of Coordination', European Law Joumal, 12(4), p. 486.

Tajadura, J. Tejada (2004), 'Constitución y Extranjería: Los Derechos de los Extranjeros no Comunitarios en España', Revista de Derecho Migratorio y de Extranjeria, No. 7, pp. 952.

Tapinos, G. (1992), La France dans deux Générations, Foyard: Paris.

Taylor, C. (1994), Multiculturalism and the Politics of Recognition, Princeton University Press: Princeton, $\mathrm{NJ}$.

The European Foundation for Quality Management (EFQM), Excellence Toolbook for Benchmarking, Brussels: EFQM, 2003. See www.efqm.org

Thiellay, J. P. (2005), "Le Volet "Nationalite" de la loi du 26 novembre 2003: un durcissement en catimini', L'Actualité Juridique de Droit Administrative, 17 Janvier 2005, pp. 67-70.

Todd, E. (1994), Le Destin des Immigrés: Assimilation et Ségrégation dans les Démocraties Occidentales, Seuil: Paris.

Toner, H. (2003), 'Comments on Mary Carpenter v. Secretary of State, 11 July 2002 (Case C60/00)', European Joumal of Migration and Law, Vol. 5, No. 1, pp. 163-172. 
Tóth, J. (2007), Ethnic Citizenship - can it be obtained and tested? Not yet published.

Trimidas, T. (2006), The General Principles of EU Law, Oxford University Press: Oxford, Second Edition.

Trimidas, T. (1996), "The Principle of Proportionality in Community Law: From the Rule of Law to Market Integration', The Irish Jurist, 31, p. 83.

Trubek, D. M. and L. G. Trubek (2005), "The Open Method of Coordination and the Debate over "Hard" and "Soft" Law", in J. Zeitlin and P. Pochet (eds), The Open Method of Coordination Action: The European Employment and Social Inclusion Strategies, P.I.E.Peter Lang: Brussels, pp. 83 103.

Trubek, D.M., P. Cottrell and M. Nance (2005), Soft-Law. Hard-Law and European Integration: Toward a Theory of Hybridity, Jean Monnet Working Paper 02/05, The Jean Monnet Programme, NYU School of Law, New York.

Turpin, D. (2004), 'Les nouvelles lois sur l'immigration et l'asile dans le contexte de l'Europe et la mondialisation', Revue Critique de DIP, 93(2) avril-juin 2004.

Unth, H. (2005), 'Building a Momentum for the Integration of Third-Country Nationals in the European Union', European Journal of Migration and Law, Vol. 7, No. 2, pp. 163-180.

Van der Mei, A.P. (2004), 'Comments on Akrich (Case C-109/01 of 23 September 2003)', European .Jounal of Migration and Law', Vol. 6, No. 3, pp. 277-280.

Van Dijk, P. (2001), "Protection of "Integrated" Aliens against Expulsion under the European Convention of Human Rights", in E. Guild and P. Minderhoud (eds) (2001), Security of Residence and Expulsion: Protection of Aliens in Europe, Kluwer Law Internationals: The Hague, pp. 23-40.

Vandendriessche, X. (2005), 'Le Droit des Érrangers', Connaissance du droit, Éditions Dalloz: Paris, p. 79.

Velluti, S. (2007), 'What European Strategy for Integrating Migrants? The Role of the OMC Soft Mechanisms in the Development of an EU Immigration Policy', European Journal of Migration and Law, Vol. 9, No. 1, pp. 53-82.

Vidal Fueyo, C. (2006), "Luces y Sombras del Vigente Reglamento de Extranjeria", en M. Aparicio, M. Illamola Dausà, D. Moya Malapeira y S. Rodera Ranz (coord.), Las Fronteras de la Ciudadania en España y en la Unión Europea, Actas del Il y III Encuentro de Jóvenes Investigadores en Derecho de Inmigración y Asilo, Documenta Universitaria, Edicions a Perició: Barcelona, pp. 89-100.

Waldrauch, H. (2006), 'Acquisition of Nationality', Chapter 3, NATAC, retrievable from the IMISCOE website at http://www.imiscoe.org/natac/acquisition_bookchapters.html

Weil, P. (2005), La République et sa Diversité: Immigration, Intégration. Discrimination, Editions du Seuil et la République des Idées, avril 2005.

Weil, P. (2004), 'Histoire et Mémoire des Discriminations en matière de nationalité Française', Vingtième Siècle. Revue d'Histoire, 84, octobre-décembre 2004, pp. 7-8.

Weil, P. (2002), Qu'est-ce qu'un Français? Histoire de la nationalité française de la Révolution à nos jotrs, Grasset: Paris. 
Weil, P. (1997), Mission d'étude des législations de la nationalité et de l'immigration : des conditions d'application du principe du droit du sol pour l'attribution de la nationalité française, pour une politique de l'immigration juste et efficace, La Documentation Française: Paris.

Weil, P. (1991), La France et ses Etrangers - L'aventure d'une Politique de l'Immigration, 1938-1991, Calmann-Lévy: Paris.

Weil, P. and A. Spire (2006), "France", in R. Bauböck, E. Ersboll, K. Groenendijk and H. Waldrauch (eds), Acquisition and Loss of Nationality, Volume 2: Country Analyses, Policies and Trends in 15 European Countries, IMISCOE Research, Amsterdam University Press: Amsterdam, pp. 187-211.

Weil, P. and J. Crowley (1994), "Integration in Theory and Practice: A Comparison of France and Britain", in M. Baldwin-Edwards and M. Schain (eds), The Politics of Immigration in Western Europe, Frank Cass: London.

Weiler, J.H.H and N. Lockhart (1995), 'Taking Rights Seriously' Seriously: The European Court and its Fundamental Rights Jurisprudence', Common Market Law Review, 32, pp. $59-82$.

Wieviorka, M. (1998), 'Le multiculturalisme est-il la réponse?', Cahiers Internationaux de Sociologie 105 (1998), pp. 233-68.

Wieviorka, M. (1996), Une société fragmentée? Le multiculuralisme en débat, Paris: La Découverte: Paris.

Wieriorka, M. (1992), La France Raciste, Fayard: Paris.

Wihtol de Wenden, C. (2002), 'Ouverture et Fermeture de la France aux Étrangers: Un Siècle D'Évolution', Vingtième Siècle: Revue d'Histoire, 73, janviers-mars 2002, pp. 27-38.

Wihtol de Wenden, C. (1999), L'Immigration en Europe, La Documentation Française: Paris, pp. 148-152.

Wihtol de Wenden, C. (1994), "Citizenship and Nationality in France", in R. Bauböck (ed), From Aliens to Citizens: Redefining the Status of Immigrants in Europe, Avebury: Aldershot, pp. 85-94.

Williams, A. (2004), EU Human Rights Policies: A Study in Irony, Oxford University Press: Oxford.

Zapata-Barrero, R. (2006), 'Immigration, autonomie politique et gestion de l'identité: le cas de la Catalogne', |érès| Outre - Terre, 2006/4, N 17, pp. 189-209.

Zapata-Barrero, R. (2003), "Cambio Structural y Redes de Actores en las Politicas de Acomodación de los Inmigrantes en España: Una Perspectiva desde el Territorio", en G. Aubarell (dir.), Perspectivas de la Immigración en España: Una aproximación desde el Territorio, Icaria: Antrazyt Editorial, Barcelona, pp. 327-348.

Zapata-Barrero, R. (2002), El Tumo de los Inmigrantes, Esferas de Justicia y Políticas de Acomodación, Imserso: Madrid.

Zapata-Barrero, R. (2002), Una Cultura Poliglota de la Integración, La Vanguardia, 14 Enero. 
Zapata-Barrero, R., C. Adamuz García y I. Martínez Luna (2002), "Estructuras Institucionales y Redes de Actores en las Políticas de Acomodación de los Inmigrantes en España: Cultura de Acomodación y Cambio Estructural", en F. J. Garcia Castaño et al. (eds), La Inmigración en España: Contextos y Alternativas, Actas del III Congreso de Inmigración en España (Ponencias), Granada: Laboratorio de Estudios Interculturales, pp. 83-110.

Zappi, S. (2003), French Government Revives Assimilation Policy, Migration Information Source, Migration Policy Institute, 1 October 2003. Retriavable from: http://www.migrationpolicy.org/

Zeillin, J. and P. Pochet (eds), The Open Method of Coordination Action: The European Employment and Social Inclusion Strategies, P.I.E.-Peter Lang: Brussels.

Zlobina, A., N. Basabe and D. Páez, 'Adaptación de los Inmigrantes Extranjeros en España: Superando el Choque Cultural', Revista Migraciones, 15(2004), pp. 43-84. 


\section{TABLE OF CASES}

European Court of Justice (http://curia.europa.eu)

Case 8/55, Fédération Charbonnière de Belgique y High Authority of the European Coal and Steel Commumity, 16 July 1956, [1956] ECR 00245.

Case 8/56, Alma, 10 December 1957 [1957-1958] ECR 98.

Joined Cases 7/56, 3/57 to 7/57, Dineke Algera, Giacomo Cicconardi. Simone Couturand, Ignazio Gemuardi, Félicie Steichen v Common Assembly of the European Coal and Steel Community, 12 July 1957, [1957] ECR 00039.

Case 19/61, Mannesmam AG / ECSC High Authority, 13 July 1962, [1962], ECR 675.

Case 29/69, Erich Stander v City of Ulm-Sozialamt, 12 November 1969, [1969], ECR 00419.

Case 11/70, Internationale Handelsgesellschaft mbH v Einfish- und Vorratsstelle fiil Getreide und Futtermittel, 17 December 1970, [1970] ECR 01125.

Case 4/73, J. Nold. Kohlen- und Baustoffgroßhandlung $v$ Commission of the European Communities, 14 May 1974, [1974] ECR 00491.

Case 41/74, Yvome van Duyn v Home Office, 4 December 1974, [1974] ECR 1337.

Case 67/74, Carmelo Angelo Bonsignore v. Oberstadtdirektor der Stadt Köln [1975] ECR 00297.

Case 36/75, Roland Rutili v Ministre de l'intérieur, 28 October 1975, [1975] ECR 01219.

Case 30/77, Régina v Pierre Boucherean, [1977] ECR 1999.

Case 44/79, Hawer v Land Rheinland Pfalz, 13 December 1979, [1979] ECR 3727.

Case 155/79, AM\& S/Commission, 18 May 1982, [1982] ECR 1575.

Case 77/81, Zuckerfabrik Franken GmbH v Federal Republic of Germany, 18 February 1982, [1982] ECR 00681.

Case 66/82, Fromançais SA v Fonds d'orientation et de régularisation des marchés agricoles (FORMA), 23 February 1983, [1983] ECR 395.

Case 125/83, OBEA v Corman, l October 1985, [1985] ECR 3039.

Case 294/83, Les Vertes v. Parliament, 23 April 1986, [1986] ECR 01339.

Case 222/84, Johnston v Chief Constable of the Royal Ulster Constabulary, [1986] ECR 1651, paragraph 18.

Joined Cases 201/85 and 202/85, Klensch and Others, 25 November 1986, [1986] ECR 3477, paragraph 10.

Joined Cases C- 281, 283, 284, 285 and 287/85, Germany and Others v. Commission [1987] ECR 3245.

Case 249/86, Commission of the European Communities v Federal Republic of Germany, [1989] ECR 01263.

Case 265/87, Hermam Schräder HS Kraftfutter GmbH \& Co. KG v Hauptzollamt Gronau, 11 July 1989, [1989] ECR 2237. 
Case 5/88, Hubert Wachauf v Bundesamt fïr Ernährung und Forstwirtschaft, 13 July 1989, [1989] ECR 02609.

Case C-331/88, The Queen v Minister of Agriculture, Fisheries and Food and Secretary of State for Health, ex parte: Fedesa and others, 13 November 1990, [1990] ECR I-04023.

Case C-118/89, Firma Oto Lingenfelser v Federal Republic of Germany, 27 June 1990, [1990] ECR I-02637.

Case C-177/90, Kïhn [1992] ECR [-35, paragraph 16.

Case C-369/90, M.V. Micheletti and others v. Delegacion del Gobierno en Cantabria [1992] ECR I-4239, para. 10.

Case C-169/91, Council of the City of Stoke-on-Trent and Nonwich City Council vB \& $Q$ plc, [1992], ECR I-06635.

Joined Cases C-259/91, C-331/91 and C-332/91, Allue and Others, [1993] ECR I-4309.

Case C-11/92, The Queen v Secretary of State for Health, ex parte Gallaher Ltd, Imperial Tobacco Ltd and Rothmans International Tobacco (UK) Ltd., [1993] ECR I-3545.

Case C-19/92, Dieter Kraus v Land Baden-Wirttemberg [1993] ECR I-1663.

Case C-315/92, Verband Sozialer Wettbewerb eV v Clinique Laboratoires SNC et Estée Lauder Cosmetics GmbH, 2 February 1994, [1994] ECR I-00317.

Joined Cases C-133/93, C-300/93 and C-362/93, Antonio Crispoltoni v Fattoria Autonoma Tabacchi and Giuseppe Natale and Antonio Pontillo v Donatab Srl., 5 October 1994, [1994] ECR I-04863.

Case C-280/93, Germany v Council [1 994] ECR I-4973.

Case C-22/94, The Irish Farmers' Association and Others, [1997] ECR I-1809.

Case C-44/94, $R \vee$ Minister of Agriculture, Fisheries and Food, ex parte Fishermen's Organisations and Others, [1995] ECR I-3115.

Case C-55/94, Gebhard v Consiglio dell'Ordine degli Avvocail e Procuratori di Milano, 30 November 1995, [1995] ECR I-4165

Case C-63/94, Groupement National des Négociants en Pommes de Terre de Belgique (Belgapom), 11 August 1995, [1995] ECR 1-0000.

Joined cases C-286/94, C-340/95, C-401/95 and C-47/96, Garage Molenheide BVBA, Peter Schepens, Bureau Rik Decan-Business Research \& Development NV (BRD) and Sanders BVBA v Belgische Staat, 18 December 1997, [1997] ECR I-07281.

Case C-398/95, Syndesmos ton en Elladi Touristikon kai Taxidiotikon Grafeion v Ypourgos Ergasias (SETTG) [1997] ECR I-3091.

Case C-200/96, Metronome Musik GmbH v Music Point Hokamp GmbH., 28 April 1998, [1998] ECR I-01953.

Case C-348/96, Criminal proceedings against Donatella Calfa, 19 January 1999, [1999] ECR I11.

Case C-2/97, Socièà italiana petroli SpA (IP) y Borsana Srl, [1998] ECR I-8597.

Case C-77/97, Österreichische Unilever GmbH v Smithkline Beecham Markenarikel GmbH, 28 January 1999, [1999] ECR I-00431. 
Case C-293/97, Standley and Others [1999] ECR 1-2603.

Case C-357/98, The Queen v Yiadom, [2000] ECR I-9265.

Case C-184/99, Grzelczyk v Centre Public d'Aide Sociale d'Ottignes-Louvain-la-Neuve [2001] ECR I-6193.

Case C-192/99, Manjit Kawr, [2001] ECR [-1237.

Case C-313/99, Gerard Mulligan, Tim O'Sullivan, Tom Power, Hugh Duncan v Minister for Agriculture and Food, 20 June 2002, [2002], ECR I-5719

Case C-413/99, Bambast, Rv Secretary of State for the Home Department, [2002] ECRI-7091.

Joined Cases C-20/00 and C-64/00, Booker Aquaculture Ltd, rading as Marine Harvest Mc Connell, Hydro Seafood GSP Ltd and The Scottish Ministers, 10 July 2003, OJ C 200 23.08.2003.

Case C-60/00, Mary Carpenter v Secretary of State for the Home Department, [2002] ECR I6279.

Case C-112/00 Eugen Schmidberger, Intemationale Transporte und Planzüge v Republik Osterreich, 12 June 2003, [2003] ECR 1-05659.

Joined Cases C-480/00 to $482 / 00$, C-484/00, C-489/00 to C-491/00 and C-497/00 to C-499/00, Azienda Agricola Ettore Ribaldi v Azienda di Stato per gli interventi nel mercato agricolo (AIMA), Ministero del Tesoro, del Bilancio e della Programmazione Economica and Others, 25 March 2004, [2004], ECR I-2943.

Case C-109/01, Secretary of State for the Home Department v Hacene Akrich, [2003] ECR I9607.

Case C-224/01, Gerhard Köbler v Republik Österreich [2003] ECR I-10239.

Joined Cases C-482/01 and C-493/01, Georgios Orfanopoulos, Natascha Orfanopoulos, Melina Orfanopoulos, Sofia Orfanopoulos v Land Baden-Wïrttemberg, and between Raffaele Oliveri v Land Baden-Wïrttemberg, 29 April 2004, [2004] ECR I5257.

Case C-491/01, The Queen and Secretary of State for Health v British American Tobacco (Investments) and Imperial Tobacco, [2002] of 10 December 2002, OJ C 56 of 02.03.2002.

Case C-36/02, Omega Spielhallen- und Automatenaufstellumgs-GmbH v Oberbürgermeisterin der Bundesstadt Bom, 14 October 2004, [2004] ECR I-9609.

Joined Cases C-184/02 and C-223/02, Kingdom of Spain and Republic of Finland v European Parliament and Council of the European Union, 9 September 2004, OJ C 262, 23.10.2004, p. 3.

Case C-200/2002, Kunqian Catherine Zhu, Man Lavette Chen, v Secretary of State for the Home Department, [2004], I-9925.

Case C-327/02, Panayotova and others, [2004] ECR 1-11055, paragraph 27.

Case C-6/03, Deponiezweckverband Eiterköpfe v. Land Rheinland Pfalz, 14 April 2004, [2005] ECR I-02753.

Case C-209/03, the High Court of Justice of England and Wales, Queen's Bench Division (Administrative Court) The Queen (on the application of Dany Bidar) y London Borough 
of Ealing, Secretary of State for Education and Skills, [2005] ECR I-2119, para. 56 and 57

Case C-443/03, Gölz Leffler v Berlin Chemie $A G, 8$ November 2005, [2005] ECR-9611, para. 38.

Case C-451/03, Servizi Ausiliari Dottori Commercialisti v Giuseppe Calafiori. [2006] ECR $1-2941$.

Case C-540/03, European Parliament v. Council, 27 June 2006, [2006] ECR I-5769.

Case C-1/04 Staubitz-Schreiber, 17 January 2006, [2006] 1-701, para. 25 and 26.

Case C-94/04, Federico Cipollav Stefano Macrino, [2006] ECR I-11421.

Case C-145/04, Spain v. United Kingdom, [2006], ECR 1-7917, para. 94.

Case C-300/04, Eman and Sevinger v. Council of the Siate [2006], ECR I-8055, para. 61.

Case C-406/04, Gérald De Cuyper v Office national de l'emploi, [2006] ECR 1-6947, para. 42.

Case C-40/05, Kaj Lyyski v Umeå universitet, 11 January 2007, [2007], ECR I-99.

Case C-341/05, Laval un Partneri Ltd v Svenska Byggnadsarbetareförbundet, Svenska Byggnadsarbetareförbundets avd. I, Byggettan, Svenska Elektrikerförbundet, 18 December 2007, not yet reported.

Cases C-11/06 and C-12/06, Rhiannon Morgan v Bezirksregierung Köln and Iris Bucher v Landrat des Kreises Dïren, 23 October 2007, not yet reported.

Case C-59/07, European Conmission v. Spain, 15 November 2007, not yet reported.

Case C-33/07, Ministerul Administratiei si Intemelor - Directia Generală de Paşapoarte Bucureşti v. Jipa, 10 July 2008, not yet reported.

Case C-127/08, Metock and Others, 25 July 2008, not yet reported.

\section{European Court of Human Rights (http:/www.echr.coe.int)}

Malone $v$. the United Kingdom, judgment of 2 August 1984, Series A no. 82.

$W$ v. The United Kingdom, 8 July 1987, Series A no. 121-A.

Olsson v. Sweden, 24 March 1988, Series A no. 130.

Berrehab v. The Netherlands, no. 10730/84, 21 June 1988, Series A. 126/177.

Moustaquim v. Belginm, 18 February 1991, Series A no. 193.

Gïl v. Switzerland, 19 February 1996, Reports of Judgments and Decisions 1996-I.

Ahmut v. The Netherlands, No. 21702/93, 28 November 1996, Reports 1996-VI.

Mehemi v. France, 26 September 1997, Reports 1997-VI, p. 1971.

Dalia v. France, 19 February 1998, Reports of Judgments and Decisions 1998-I.

Uner $v$. The Netherlands [GC], no. $46410 / 99$.

Slivenko v. Latvia [GC], no. 48321/99, § 99, ECHR 2003-X.

Boultif v. Switzerland, no. 54273/00, 2 November 2001, ECHR 2001-IX. 
Sen v. The Netherlands, no. 31465/96, 21 December 2001.

Al-Nashif v. Bulgaria, no. 50963/99, 20 June 2002.

Tuquabo-Tekle and Others v. The Netherlands, no. 60665/00, 1 December 2005.

Lupsa v. Romania, no. 10337/04, 8 June 2006, ECHR 2006.

Üner v. The Netherlands [GC], no. 46410/99, 18 October 2006.

Liu and Liu v. Russia, no. 42086/05, 6 December 2007, not yet reported.

Spanish Case Law (http:/www.poderjudicial.es/jurisprudencia)

Audiencia Nacional

Sala de lo Contencioso-Administrativo, 4 Enero 1999, RAJC, 1999, núm. 3421.

Sala de lo Contencioso-Administrativo, 19 Enero 2000 (inédita).

Sala de lo Contencioso-Administrativo, 31 Octubre de 2000, 2000/312497.

Sala de lo Contencioso-Administrativo, 22 Noviembre 2000 (inédita).

Sala de lo Contencioso-Administrativo, 25 Octubre 2001, 2002/10008.

Sala de lo Contencioso-Administrativo, 15 Enero 2002, 2003/58266.

Sala de lo Contencioso-Administrativo, 19 Noviembre 2002. Recurso 264/2001, 2003/25888.

Sala de lo Contencioso-Administrativo, 19 Noviembre 2002. Recurso 414/2001, 2003/25891.

Sala de lo Contencioso-Administrativo, 23 Diciembre 2002, 2003/26371.

Sala de lo Contencioso-Administrativo, 28 Octubre 2003, 2004/131624

Sala de lo Contecioso-Administrativo, 6 April 2004, 2004/248095.

Sala de lo Contencioso Administrativo, 27 Diciembre 2006, Recurso 7957/2003.

Sala de lo Contencioso Administrativo, 20 Abril 2007, Recurso 9481/2003.

\section{Tribunal Supremo}

Sala Tercera, Sección 6, 28 Mayo 2004, Recurso de Casación: 1230/2000.

Sala Tercera, Sección 6, 29 Octubre 2004, Recurso de Casación: 7900/2000.

Sala Tercera, Sección 6, 9 April 2007, Recurso de Casación: 279/2003.

Sala Tercera, Sección 6, 19 Junio 2008, Recurso de Casación; 6358/2002.

French Case Law (http://www.conseil-etat.fr/ce/home/index.shtml and http://www.conseilconstitutionnel.fr)

Conseil d'Etat, Ministre des affaires sociales et de l'emploi c. Diagne, 11 mars 1988.

Conseil d'Etat, Majid Karshenas Najaf Abadi, 2/6 SSR, N¹16144, 23 mars 1994.

Conseil d'Etat, M. Webina Orombia, Mme Webina Orombia, M. Kanou té, Leb. 11 février 1994.

Conseil d'Etat, A. Faiza, N²86798, 27 juin 2008. 
TABLE OF CASES

Conseil Constitutionnel, Decision No 2006-539 DC, 25 juillet 2006.

Conseil Constitutionnel, Décision $N^{\circ}$ 2007-557 DC, 15 novembre 2007. 


\section{LEGISLATIVE \& POLICY ACTS}

This Amnex does not attempt to provide an exhaustive list of legislative and policy documents dealing with the themes addressed in this book. It offers a compilation of those legal and policy acts at EU and national levels (Spain and France) which have been expressly reffered to across the different Chapters.

\section{EU LEVEL}

\section{ADOPTED LEGAL MEASURES}

Decision 2007/435/EC establishing the European Fund for the Integration of Third-Country Nationals for the Period 2007 to 2013 as part of the General Programme "Solidarity and Management of Migration Flows", 27 June 2007, OJ L 168/18, 28.6.2007.

Decision 2004/927/EC providing for certain areas covered by Title IV of Part Three of the Treaty establishing the European Community to be governed by the procedure set out in Article 251 of that Treaty, 22 December 2004, OJ L 396/45.

Decision setting up a Prior Communication and Consultation Procedure on Migration Policies in relation to Non-member countries, 8 July 1985, OJ L 217, 19.8.1985.

Directive 2005/71/EC on a Specific Procedure for Admitting Third-country Nationals for the purposes of Scientific Research, 12 October 2005, OJ L 289/15, 3.11.2005.

Directive 2004/38/EC on the Right of Citizens of the Union and their Family Members to Move and Reside Freely within the Territory of the Member States amending Regulation (EEC) No. 1612/68 and repealing Directives 64/221/EEC, 68/360/EEC, 72/194/EEC, 73/148/EEC, 75/34/EEC, 75/35/EEC, 90/364/EEC, 90/365/EEC and 93/96/EEC, 29 April 2004, OJ L 158/77, 30.4.2004.

Directive 2004/114/EC on the Conditions of Admission of Third-country Nationals for the Purposes of Studies, Pupil Exchange, Unremunerated Training or Voluntary Service, 13 December 2004, OJ L 375, 23.12.2004.

Directive 2003/86/EC on the Right to Family Reunification, 22 September 2003, OJ L 251/12, 3.10 .2003 .

Directive 2003/109/EC concerning the Status of Third-country Nationals who are Long-term Residents, 25 November 2003, OJ L 16/44, 23.1.2004.

Directive 2000/43/EC implementing the Principle of Equal Treatment between Persons Irrespective of Racial or Ethnic Origin, 19 June 2000, OJ L 180, 19.7.2000.

Directive 2000/78/EC establishing a General Framework for Equal Treatment in Employment and Occupation, 27 November 2000, OJ L 303, 2.12.2000.

Recommendation 2005/762/EC to facilitate the Admission of Third-country Nationals to carry out Scientific Research in the European Community, 12 October 2005, OJ L 289/26, 3.11 .2005 .

Regulation No. 862/2007 on Community Statistics on Migration and International Protection and repealing Council Regulation (EEC) No. $311 / 76$ on the Compilation of Statistics on Foreign Workers, 11 July 2007, OJ L 199, 31.07.2007. 


\section{INITIATIVES}

Proposal for a Council Directive on the Conditions of Entry and Residence of Third-country Nationals for the Purposes of Highly Qualified Employment, COM(2007) 637 final, Brussels, 23.10.2007.

Proposal for a Council Directive on a Single Application Procedure for a Single Permit for Third-country Nationals to Reside and Work in the Territory of a Member State and on a Common Set of Rights for Third-country Workers Legally Residing in a Member State, $\operatorname{COM(2007)} 638$ final, Brussels, 23.10.2007.

Proposal for a Council Directive on the Conditions of Entry and Residence for the Purpose of Paid Employment and Self-employment Activities, COM(2001) 0386 final, Brussels, 11.7 .2001 .

Proposal for a Council Act establishing the Convention on Rules for the Admission of ThirdCountry Nationals to the Member States, COM(1997)387, Brussels, 30.7.1997.

Proposal for a Convention on Member States' Migration Policies, COM(1997) 387, 30.7.1997, Brussels, OJ 1997, C 337/9.

Proposal for a Council Act establishing the Convention on Rules for the Admission of Thirdcountry Nationals to the Member States, COM(1997)387, 97/0227 (CNS), Brussels, 30.7.1997.

Proposal for a Council Directive on the Right of Third-country Nationals to travel in the Community, COM(1995) 346 final, Brussels, 12.7.1995

\section{NON-LEGALLY BINDING MEASURES}

\subsection{European Commission}

Commission Communication, A Common Immigration Policy for Europe: Prínciples, Actions and Tools, COM(2008) 359 final, 17.6.2008.

Commission Communication, Towards a Common Immigration Policy, COM(2007)780 final, SEC(2007) 1632, 5.12.2007.

Commission Staff Working Document, Accompanying Document to the Proposal for a Council Directive on the Conditions of Entry and Residence of Third-country Nationals for the Purpose of Highly Qualified Employment, SEC(2007) 1403, 23.10.2007.

Commission Staff Working Document, Accompanying document to the Proposal for a Council Directive on a Single Application Procedure for a Single Permit for Third-country Nationals to Reside and Work in the Territory of a Member State and a Common Set of Rights for Third-country Workers legally residing in a Member State, Impact Assessment, SEC(2007) 1408, 23.10.2007.

Commission Communication, Third Annual Report on Migration and Integration, $\operatorname{COM}(2007) 512,11.9 .2007$.

Commission Communication on Circular Migration and Mobility Partnerships between the European Union and Third Countries, COM(2007) 248 final, 16.5.2007.

Commission Communication, The Global Approach to Migration one year on: Towards a Comprehensive European Migration Policy, COM(2006) 735 final, 30.11.2006. 
Commission Staff Working Document, Second Annual Report on Migration and Integration, SEC(2006) 892, 30.6.2006.

Commission Staff Working Document, Evaluation of the Open Method of Coordination for Social Protection and Social Inclusion, SEC(2006) 345, 8.3.2006.

Commission Communication, Working together, Working Better: A New Framework for the Open Coordination of Social Protection and Inclusion Policies in the European Union, $\operatorname{COM}(2005) 706,22.12 .2005$

Commission Communication concerning Terrorist Recruitment: Addressing the Factors contributing to Violent Radicalization, $\operatorname{COM}(2005) 313$ final, 21 9.2005.

Commission Communication, A Common Agenda for Integration - Framework for the Integration of Third Country Nationals in the European Union, COM(2005) 389, 1.9.2005.

Commission, Impact Assessment Guidelines, SEC (2005) 791, 15.6.2005.

Commission of the European Communities, Communication from the Commission to the Council and the European Parliament: The Hague Programme: Ten Priorities for the Next Five Years, COM(2005) 184, 10.5.2005.

Commission Communication, First Annual Report on Migration and Integration, $\operatorname{COM}(2004) 508,16.7 .2004$.

Commission Communication, Study on the Links between Legal and Illegal Migration, $\operatorname{COM}(2004) 412,4.6 .2004$.

Green Paper on an EU Approach to Managing Economic Migration, COM(2004) 811 final, II.1.2004.

Commission Communication on Immigration, Integration and Employment, COM(2003) 336, 3.6.2003.

Commission Staff Working Paper on Extended Impact Assessment on the Communication on Immigration, Integration and Employment, SEC(2003) 694, 3.6.2003.

European Commission, European Governance: A White Paper, COM(2001) 428 final, 25.7.2001.

Commission Communication, on a Open Method of Coordination for the Community Immigration Policy, COM(2001)387, 11.7.2001.

Commission Communication, on a Community Immigration Policy COM (2000) 757, 22.11.2000.

Commission Communication, Towards an Area of Freedom, Security and Justice, COM(1998) 459 final, 14.7.1998.

Commission Communication on Immigration and Asylum Policies, COM(1994) 23 final, 23.2.1994.

Commission Communication on Immigration, SEC(1991)1855 final, 23.10.1991.

Commission of the European Communities, Policies on Immigration and the Social Integration of Migrants in the European Community, SEC(1990) 1813 fmal, 28.9.1990.

Commission Communication, Guidelines for a Community Policy on Migration, COM(1985) 48 final, Bulleting of the European Communities, Supplement 9/85, 7.3.1985. 
European Commission, Action Programme in favour of Migrant Workers and their Families, COM(74) 2250, Brussels, 14.12.1974.

\subsection{Council of the EU}

Council Resolution of 14 October 1996 laying down the Priorities for Cooperation in the Field of Justice and Home Affairs for the Period from 1 July 1996 to 30 June 1998, Official Joumal C $319,26 / 10 / 1996$, p. $0001-0006$.

Council Resolution of 4 March 1996 on the Status of Third-country Nationals residing on a Long-term Basis in the Territory of the Member States, Official Joumal C 080 , 18/03/1996, p. 0002 - 0004. A sixth Resolution was adopted related to marriages of convenience in December 1997, OJ 1997 C 382/1.

Council Resolution of 30 November 1994 relating to the Limitations on the Admission of Thirdcountry Nationals to the Territory of the Member States for the Purpose of pursuing Activities as Self-employed persons, Official Journal C 274 , 19/09/1996, p. $0007-$ 0009.

Council Resolution of 30 November 1994 on the Admission of Third-country Nationals to the Territory of the Member States for Study Purposes, Official Journal C 274, 19/09/1996, p. $0010-0012$

Council Resolution of 20 June 1994 on Limitations on Admission of Third-country Nationals to the Territory of the Member States for Employment, Official Journal C 274/3, 19/09/1996, p. $0003-0006$.

Council Resolution of 27 June 1980 on Guidelines for a Community Labour Market Policy, OJ C 168, 8.7.1980.

Council Resolution of 16 July 1985 on Guidelines for a Community Policy on Migration, OJ C $186,26.7 .1985$

Council Resolution on an Action Programme for Migrant Workers and Members of their Families, Bulleting of the European Communities, B.E.C. Supplement 3/76, 9 February 1976.

\subsection{Council/Presidency Conclusions}

Council of the EU, Justice and Home Affairs $2887^{\text {th }}$ Council meeting, Brussels, 11653/08, 24-25 July 2008.

Council of the EU, Justice and Home Affairs Council Meeting 2807 $7^{\text {th }}$, Press Release, 10267/07, Luxembourg, 12-13 June 2007.

Council of the EU, Brussels European Council, Presidency Conclusions, 21-22 June 2007, $11177 / 1 / 07,20$ July 2007.

Council of the EU, Justice and Home Affairs Council Meeting 261 $8^{\text {th }}$, Brussels. Common Basic Principles on Immigrants Integration', 14615/04, 19 November 2004.

Council of the EU, Justice and Home Affairs and Civil Protection, $2455^{\text {th }}$ Council meeting, 12894/02, Luxembourg, 14-15 October 2002. 
European Council, Presidency Conclusions of the Brussels European Council of 15-16

December 2005, SN 15914/01/05, 30.12.2005.

European Council, Note from the Presidency on a Global Approach to Migration: Priority Actions focusing on Africa and the Mediterranean, 15744/05, Brussels, 13.12.2005.

European Council, The Hague Programme: Strengthening Freedom, Security and Justice in the European Union, 2005/C53/01, OJ C53/1, 3.3.2005.

European Council, Brussels Presidency Conclusions, 4-5 November 2004, 14292/1/04, Brussels,

8 December 2004, Annex 1, "The Hague Programme: Strengthening Freedom, Security and Justice in the European Union".

European Council, 19-20 June 2003, Thessaloniki Presidency Conclusions, 11638/03, Brussels, 1 October.

European Council, Lisbon Presidency Conclusions, 23-24 March 2000, Brussels.

European Council, Tampere Presidency Conclusions, SN 200/99, 15-16 October 1999.

European Council, Conclusions of the Presidency, Edinburgh, 11 and 12 December 1992, Annex 1: Decision of the Heads of State and Government conceming certain problems raised by Denmark on the Treaty on European Union, Section A: Citizenship.

European Council, Fontainebleau, Bull; EC 6-1984, 25-26 June 1984.

\subsection{European Parliament}

Report on the Treaty of Lisbon, 2007/2286(INI), A6/0013/2008, 29 January 2008.

Report on Strategies and Means for the Integration of Immigrants in the European Union, 2006/2056/INI, A6-0190/2006, 17.5.2006, Committee on Civil Liberties, Justice and Home Affairs.

Report on the Links between Legal and Illegal Migration and Integration of Migrants, 2004/2137(INI), A6/0136/2005, 3 May 2005.

Report on the Communication from the Commission on Immigration, Integration and Employment, 2003/2147(INI), A5-0445/2003, 1 December 2003.

Report on the Commission Communication on an open method of coordination for the Community immigration policy, C5-0337/2002 - 2002/2181(COS), A5-0224/2003, 16 June 2003.

Resolution on the Treaty of Lisbon, 2007/2286(NI), 20 February 2008.

Resolution on the Communication from the Commission on Immigration and Asylum Policies C3-0107-94, A4-0169/1995, 21 September 1995.

Resolution on European Immigration Policy, 15 July 1993, OJ C255, 20.9.1993, p. 184.

Resolution on European Immigration Policy, 18 November 1992, OJ C337, 21.12.1992, p. 94. 


\subsection{EESC}

EESC (2007), Immigration: The Role of Civil Society in Integration, Foreword by Franco Frattini, Office for the Official Publications of the European Communities: Luxembourg.

Opinion on the Proposal for a Council Directive on a single application procedure for a single permit for third-country nationals to reside and work in the territory of a Member State and on a common set of rights for third-country workers legally residing in a Member State, SOC(307), 9 July 2008, Brussels.

Opinion on the Proposal for a Council Directive on the conditions of entry and residence of third country nationals for the purposes of highly qualified employment, SOC/300, Brussels, 9 July 2008.

Opinion, Elements for the Structure, Organization and Functioning of a Platform for the Greater involvement of Civil Saciety in the EU-level promotion of policies for the integration of third country nationals, SOC/281, Brussels, 9 July 2008.

Opinion on Immigration in the EU and integration policies: cooperation between regional and local governments and civil society organizations, SOC/219, Brussels, 13 September 2006.

Opinion on the Communication from the Commission to the Council and the European Parliament: The Hague Programme: Ten priorities for the next five years - The Partnership for European renewal in the field of Freedom, Security and Justice COM(2005) 184 final, SOC 209, Brussels, 15 December 2005.

Opinion on the Commission Communication on Immigration, Integration and Employment, 1613/2003, SOC/138, 10 December 2003. Rapporteur: Mr. Pariza Castaños;

Opinion on Immigration, Integration and the Role of Civil Society, SOC/075, CES 365/2002, 21 March 2002, Brussels, rapporteur: Mr. Pariza Castaños.

Opinion on the Commission Communication on an Immigration and Asylum Policies, 94/393/13, OJ No. 393/69, 31.12.1994. See in particular point 8 on "integration policy".

\section{PRESS RELEASES AND OTHER RELEVANT DOCUMENTS}

European Commission, Press Release, Imtegration of Third Coumry Nationals, MEMO/05/290, Brussels, I September 2005.

European Commission, Press Release, Integrating Third Country Nationals: The Commission launches the 2007 Call for Proposals under the New Community Actions of the European Fund for the Integration of Third Country Nationals, IP/07/1882, Brussels, 10 December 2007.

European Commission, Press Release, Global Approach to Migration, Brussels, 5 December 2007, MEMO/07/549.

European Commission, Press Release, A Comprehensive Immigration Policy, MEMO/07/188, Brussels, 14 May 2007.

European Commission, Press Release, Integration of Third Country Nationals, MEMO/05/290, Brussels, I September 2005.

The Federal Government of Germany, Europe - succeeding together; Presidency Programme, 1 January to 30 June 2007 , page 18. 
Background paper for the Informal Meeting of Justice and Home Affairs Ministers, "Initiative concerning the European migration policy", held in Dresden on 14-16 January 2007 (both documents are retrievable from http://www.eu2007.de/en on January 2007).

The Federal Government of Germany, German Presidency of the Council of the EU, Informal Meeting EU Integration Ministers, Postdam, 10/11 May 2007', Information from the Presidency, retrievable from http://www.eu2007.de/en on January 2007.

F. Frattini (2006), 'A Common Approach for European Policy on the Integration of Migrants European Debate', Speech/07/295, Informal Meeting of EU Integration Ministers, Postdam, 10 May, 2006, Retrievable from http://ec.europa.

eu/commission_barroso/frattini/webroot/welcome/default_en.htm or http:/europa.eu/rapid/searchAction.do 


\section{NATIONAL LEVEL}

\section{SPAIN}

\section{Legislation and other Policy Measures}

Decreto por el que se aprueba el Reglamento de la Ley de Registro Civil, 14 Noviembre 1958 , BOE N $N^{\circ} 296,11$ Diciembre 1958.

Dirección General de Migraciones del Ministerio de Asuntos Sociales Aprobación del Plan para La Integración Social de los Inmigrantes (P.I.S.I.). Consejo de Ministros del 2 Diciembre 1994.

Ley 36/2002 de modificación del Código Civil en materia de nacionalidad, $\mathrm{BOE} \mathrm{N}^{\circ} 242,9$ Octubre 2002.

Ley 18/1990, sobre reforma del Código Civil en materia de nacionalidad. Boletín Oficial del Estado, núm. 302, 18 December 1990.

Ley Orgánica 14/2003, de 20 de Noviembre, de Reforma de la Ley orgánica 4/2000, de 11 de Enero, sobre derechos y libertades de los extranjeros en España y su integración social, modificada por la Ley Orgánica 8/2000, de 22 de Diciembre.

Ley Orgánica 11/2003, de 29 de Septiembre, de medidas concretas en materia de seguridad ciudadana, violencia doméstica e integración social de los extranjeros, BOE $\mathrm{N}^{\circ} 234,30$ Septiembre 2003.

Ley Orgánica 8/2000, de 22 de Diciembre, de reforma de la Ley Orgánica 4/2000, de 11 de Enero, sobre derechos y libertades de los extranjeros en España y su integración social, BOE N 307,23 Diciembre 2000.

Ley Orgánica 4/2000, de 11 de Enero, sobre derechos y libertades de los extranjeros en España y su integración social, BOE N $N^{\circ}$ 10, 12 Enero 2000.

Ley Orgánica $7 / 1985$ sobre Derechos y Libertades de los Extranjeros en España, LOE, I Julio 1985.

Plan Estratégico de Ciudadanía e Integración, Secretaria de Estado de Inmigración y Emigración, DG de Integración de Inmigrantes, Junio 2006.

Proposición no de Ley, La Situación de los Extranjeros en España. Líneas Básicas de la Política Española de Extranjeria, 9 Abril 1999.

Real Decreto 1129/2008 por el que se desarrolla la estructura orgánica básica del Ministerio de Trabajo e Inmigración y se modifica el Real Decreto 438/2008 del 14 abril, por el que se aprueba la estructura básica de los departamentos ministeriales, 4 Julio 2008, BOE Núm. 165, pp. 29969-29979.

Real Decreto 3/2006, de 16 de Enero, por el que se regula la composición, competencias y régimen de funcionamiento del Foro para la integración social de los inmigrantes, BOE $N^{\circ} 14,17$ Enero 2006.

Real Decreto 2393/2004, de 30 de Diciembre del 2004, por el que se aprueba el Reglamento de ejecución de la Ley Orgánica 4/2000, sobre derechos y libertades de los extranjeros en España y su integración social, BOE, 7 Enero 2005. 
Real Decreto 864/2001, de 20 de Julio, por el que se aprueba el Reglamento de ejecución de la Ley Orgánica 4/2000, de 11 de Enero, sobre derechos y libertades de los extranjeros en España y su integración social, reformada por Ley Orgánica 8/2000, de 22 de Diciembre, BOE N $N^{\circ} 174,21$ Julio 2001.

Real Decreto 2816/1998, de 23 de Diciembre, por el que se modifica el Real Decreto 490/1995, de 7 de Abril, de creación del Foro para la Integración Social de los Inmigrantes, BOE No 13, 15 Enero 1999.

Real Decreto 155/1996, de 2 de Febrero, por el que se aprueba el Reglamento de ejecución de la Ley Orgánica 7/1985, BOE N"47, 23 Febrero 1996.

Resolución de 17 de Abril de 2001, de la Delegación del Gobiemo para la Extranjería y la Inmigración, por la que se dispone la publicación del Acuerdo del Consejo de Ministros del día 30 de Marzo de 2001, por el que se aprueba el Programa Global de Regulación y Coordinación de la Extranjería y la Inmigración, BOE N 101, 27 April 2001.

\section{AACC}

Plan Valenciano de Inmigración 2007, Gobierno de Valencia, retriavable from: www.bsocial.gva.es

Plan de Integración 2006-2008, Comunidad de Madrid, retriavable from: www.madrid.org

Pla de Ciutadania i Immigració, 2005-08, Generalitat de Catalunya, Departament de Benestar i Familia, Secretaria per a la Immigració, Generalitat de Catalunya, 28 Juny 2005.

Pla Interdepartamental d'Immigració 1993-2000, Comisión Interdepartamental de Immigración, Generalitat de Catalunya.

\section{Other Relevant Documents}

Anuario Estadístico de Inmigración 2007, Ministerio de Trabajo y Asuntos Sociales, Secretaria de Estado de Immigration y Emigración, Madrid, retriavable from http://extranjeros.mtas.es

Foro para la Integración Social de los Inmigrantes (2007), Informe sobre la Situación de la Integración Social de los Inmigrantes y Refugiados en 2007, Aprobado en Pleno Ordinario el 8 Noviembre 2007.

Gobierno de España, Ministerio de Trabajo e Inmigración, Comparecencia del Ministro de Trabajo e Inmigración, Sr. Celestino Corbacho Chaves, I Parte, La Politica de Inmigración del Gobierno, Comisión de Trabajo e Inmigración, Congreso de los Diputados, 22 Julio 2008, Madrid.

Ministerio de Justicia, Oficina de Prensa, Nota de Prensa, Concedida la Nacionalidad Española a 30 miembros de la Comunidad de Judios Sefardies, 6 Julio 2007.

Ministerio de Trabajo y Asuntos Sociales (2007), El Gobierno concedió 7.427 autorizaciones de residencia temporal por arraigo, Nota de Prensa, Gabinete de Comunicación, 13 Febrero 2007.

Ministerio de Trabajo y Asuntos Sociales (2007), Secretaria de Estado de Inmigración y Emigración, Dirección General de Integración de Inmigrantes (2007), Memoria 2006: Foro para la Integración Social de los Inmigrantes, Madrid. 
Ministerio de Trabajo y Asuntos Sociales (2006), Secretaria de Estado de Immigración y

Emigración, Observatorio Permanente de la Inmigración, Anuario Estadístico de

Inmigración, Madrid. Retrievable from

http://extranjeros.mtas.es/es/general/Datos_Estadisticos_index.html

Ministerio de Trabajo y Asuntos Sociales e ilustre Colegio de Abogados de Madrid (2004), 'Tribunal Supremo: Concesión de la Nacionalidad Española a Súbdita de Marruecos que mantiene las Costumbres y Tradiciones Musulmanas", 28 Mayo 2004.

PSOE, Programa Electoral, Elecciones Generales 2008, Motivos para Crecer.

\section{DGRN}

Instrucción DGRN sobre certificado de nacionalidad española, IDGRN de 14 de abril 1999 , BOE del 30 Abril 1999.

Instrucción DGRN sobre competencia de los registros municipales en materia de adquisición de nacionalidad española y adopciones internacionales, 28 Febrero 2006, BOE $\mathrm{N}^{\circ} 71,24$ Marzo 2006.

Instrucción DGRN, 20 Marzo 1991, BOE, n. 73, 26 Marzo 1991.

Instrucción DGRN, sobre tramitación de las solicitudes de adquisición de la nacionalidad española por residencia, 26 Julio 2007, BOE N 189, 8 Agosto 2007.

\section{Journal Articles}

ABC, Europea dificulta el acceso a la nacionalidad a los inmigrantes, 7 Octubre 2007.

El Pais, Cambio de Rumbo en la Politica de Inmigración - El Gobierno ofrecerá incentivos para repatriar a un millón de inmigrantes, 15 June 2008.

El País, Trabajo endurecerá la Reagnupamiento Familiar: Corbacho quiere frenar la llegada de padres y'suegros, 15 June 2008.

El País, El Gobierno de Camps copia el contrato para inmigrantes de Rajoy, 28 April 2008.

El País, 'Hay que revisar la contratación de immigrantes en el extranjero', Entrevista a Celestino Corbacho, Ministro de Trabajo e Inmigración, 20 April 2008.

El Pais, El 56\% apoya obligar al inmigrante a 'respetar las costumbres españolas', 10 February 2008.

El Pais, Mariano Rajoy quiere obligar a los inmigrantes a firmar un 'contrato de integración': El PP incluye la higiene entre las obligaciones para los extranjeros, 7 February 2008.

El Pais, Los Partidos Antiinmigración alcanzan el Pode: Las Secuelas Politicas del 27-M, 3 de Junio de 2007.

El Pais, Los que sí quieren ser Españoles: Centenares de Inmigrantes juran diariamente la Constitución para mejorar su vida, 7 October 2007.

La Vanguardia, CIU propone exigir Catalán y Castellano para obtener la residencia permanente en Cataluña, 16 January 2008. 


\section{FRANCE}

\section{Legislation and other Key Policy Measures}

Arrêté du 30 janvier 2008 relatif à la commission sur le cadre constitutionnel de la nouvelle politique d'immigration, JORF n0032 du 7 février 2008, page 2321, texte $n^{\circ} 22$.

Arrêté du 19 janvier 2007 relatif aux formations prescrites aux étrangers signataires du contrat d'accueil et d'intégration et à l'appréciation du niveau de connaissances en français prévues aux articles R. 311-22 à R. 311-25 du décret no 2006-1791 du 23 décembre 2006 relatif au contrat d'accueil et d'intégration et au contrôle des connaissances en français d'un étranger souhaitant s'installer durablement en France et modifiant le code de l'entrée et du séjour et du droit d'asile (partie réglementaire) NOR: SOCN0710178A, J.O du 30 janvier 2007, Texte 13 sur 103.

Arrêté du 22 février 2005 relatif au compte rendu de l'entretien individuel prévu à l'article 15 du décret no 93-1362 du 30 décembre 1993 relatif aux déclarations de nationalité, aux décisions de naturalisation, de réintégration, de perte, de déchéance et de retrait de la nationalité française.

Circulaire interministérielle DPM/N3 no 2007-63 du 9 février 2007 aux cérémonies d'accueil dans la citoyenneté française.

Circulaire interministérielle DPM/N3/DLPAJ/DAPAF no 2006-446 du 10 octobre 2006 sur la mise en ouvre des dispositions de la loi no $2006-911$ du 24 juillet 2006 relative à l'immigration et à l'intégration concernant la procédure de naturalisation.

Circulaire DPM n 2000-254 du 12 mai 2000 relative aux naturalisations, réintégrations dans la nationalité française et perte de la nationalité française, ministère de l'emploi, et de la solidarité Direction de la population et des migrations ministère de l'intérieur Direction des libertés publiques et des affaires juridiques.

Circulaire du 5 juillet 1974 du secrétaire d'Etat auprès du ministre du travail, et de la circulaire susvisée du ministre d'Etat, ministre de l'intérieur, du 26 novembre 1974, ayant eu pour objet de suspendre provisoirement l'immigration de travailleurs étrangers.

Circulaires n 11-74 du 9 juillet 1974, n 17-74 du 9 août 1974 et n²2-74 du 27 décembre 1974 du secrétaire d'Etat auprès du ministre du travail, suspendant provisoirement l'introduction en France des familles des travailleurs étrangers.

Décret $n^{\circ} 2007-999$ du 31 mai 2007 relatif aux attributions du ministre de l'Immigration, de l'Intégration, d l'Identité nationale et du Codéveloppement, J.O n 125, 1 juin 2007, page 9964 , texte $n^{\circ} 11$.

Décret $n^{\circ}$ 2006-1791 du 23 décembre 2006 relatif au contrat d'accueil et d'intégration et au contrôle des connaissances en français d'un étranger souhaitant durablement s'installer en France et modifiant le code de l'entrée et du séjour des étrangers et du droit d'asile (partie réglementaire), NOR: SOCN0612582D, J.O n 303 du 31 décembre 2006 page 20346, texte $n^{\circ} 39$.

Décret $n^{\circ} 2003-84$ du 30 janvier 2003 modifiant le décret $n^{\circ} 89-881$ du 6 décembre 1989 portant création du comité interministériel à l'intégration.

Décret $n^{\circ} 93-1362$ du 30 décembre 1993 relatif à la manifestation de volonté, aux déclarations de nationalité, aux décisions de naturalisation, de réintégration, de perte, de déchéance et de retrait de la nationalité française, J.O. n 303 du 31 décembre 1993. 
Décret $n^{\circ} 89-881$ du 6 décembre 1989, Décret portant création du comité interministériel à l'intégration, JORF du 9 décembre 1989.

Loi constitutionnelle $n^{\circ} 2008-724$ du 23 juillet 2008 de modemisation des institutions de la Ve République, JORF n0171 du 24 juillet 2008 page 11890.

Loi $\mathrm{n}^{\circ}$ 2007-1631 relatif à la mâtrise de l'immigration, à l'intégration et à l'asile, version consolidée 21 novembre 2007.

Loi $n^{\circ}$ 2006-911 relative à l'immigration et à l'intégration of 24 July 2006, JORF, No. 170, 25 July 2006, page 11047.

Loi $n^{\circ} 2005-32$ of 18 January 2005 de programmation pour la cohésion sociale.

Loi $n^{\circ} 2003-1119$, relative à la maîtrise de l'immigration, au séjour des étrangers en France et à la nationalité, 26 November 2003, JORF 27 novembre 2003.

Loi $n^{\circ}$ 98-170 du 16 mars 1998 art. 2 Joumal Officiel du 17 mars 1998 en vigueur le ler septembre 1998.

Ordonnance $n^{\circ} 45-2658$ relative aux conditions d'entrée et de séjour des étrangers en France of 2 November 1945 .

\section{Other Relevant Documents}

Borrel, C. (2006), Enquêtes Amnuelles de Recensement 2004 et 2005: Près de 5 million d'immigrés à la mide de 2004, Insee, Cellule Statistiques et études sur immigration, Insee Première $N^{\circ} 1098$.

Chirac, J. (2002), Discours de monsieur Jacques Chirac Président de la République, Troyes Aube, lundi 14 octobre 2002, available at www.elysee.fr

Commission de la nationalité, 'Etre Français aujourd'hui et demain', Rapport remis au Premier ministre par Marceau Long, Président de la Commission de la Nationalité, Revue critique du droit international privé, 77(1) janv. - mars 1988, p. 122 et ss.

Commission sur le cadre constitutionnel de la nouvelle politique de l'immigration (2008), Pour Une Politique des Migrations Transparente, Simple et Solidaire, July 2008, available at www.immigration.gouv. $\mathrm{fr}$

Fillon, F. (2003), Audition Publique de Monsieur François Fillon, Ministre des affaires sociales, du travail et de la solidarité, Haut Conseil à l'Intégration, 8 décembre 2003.

Guide du formateur de la Journée d'information (rvivre en France» (2006), Ministère de l'emploi, de la cohésion sociale et du logement, Direction de la population et des migrations, janvier 2006.

Haut Conseil à l'intégration (2006), Le Bilan de la Politique d'Intégration 2002-2005, available at http://www.hci.gouv.fr/

Haut Conseil à l'intégration (2003), Le contrat et l'intégration, Rapport à Monsieur le Premier Ministre, retraivable from http://www.hci.gouv.fr/rubrique.php3?id_rubrique $=16$

Haut Conseil à l'intégration (2002), Les parcours d'intégration, La Documentation française, coll. «Rapports officiels», available at http://www.hci.gouv.fr/.

Haut Conseil à l'intégration, (1991) Pour un modèle d'intégration, La documentation française: Paris. 
Hortefeux, B. (2007), Allocution de Brice Hortefeux lors de la remise de décrets de naturalisation, retriavable from the web page of the Ministry of Immigration, Integration, National Identity and Codevelopment, Salle de Presse, Discourses at www.premierministre.gouv. fr

L'accueil des étrangers en France: Le contrat d'accueil et d'intégration (2003), Direction de la population et des migrations Bureau de l'action sociale, culturelle et territoriale, L'expérimentation de mise en place du contrat d'accueil et d'intégration, 31 July 2003, retrievable from: http://www.social.gouv.fr/htm/pointsur/accueil/som_cai.htm

Moinet, J. P. (2006), Célébrer la bienvemue dans la République française, Rapport sur les cérémonies célébrant l'acquisition de la nationalité française Rapport à la Ministre déléguée à la Cohésion Sociale et à la Parité, Mme Catherine Vautrin, avril 2006, p. 8.

Note DPM/ACI I No 78 relative aux modalités de mise en oeuvre de l'expérimentation du contrat d'accueil et d'inegration, 23 avril 2003.

Protocole d'accord DPM/OMI/FASILD relatif à la mise en oeuvre du service public de l'accueil et du contrat d'accueil et d'intégration du 16 mars 2005.

Rapport Annuel de la sous-direction des naturalisations (2007), Acquisitions et pertes de la nationalité française; Francisation des Noms et Prénoms, Données Chiffrées et Commentaires, Année 2006, Ministère de l'Emploi, de la Cohésion Sociale et du Logement. Retraivable from www.travail-solidarite.gouv.fr

Rapport Annuel de la sous-direction des naturalisations (2006). Acquisitions et pertes de la nationalité française; Francisation des Noms et Prénoms, Données Chiffrées et Commentaires, Année 2005, Ministère de l'Emploi, de la Cohésion Sociale et du Logement.

Sarkozy, N. (2008), Conférence de Presse du Président de la République, M. Nicolas Sarkozy, Mardi 8 janvier 2008, Palais de l'Elysée, retraivable from http:/www.elysee.fr/accueil

Sarkozy, N. (2007), Mon Projet. Ensemble tout devient possible, retriavable from www.sarkozy.fr

Secrétariat général du comité interministériel de contrôle de l'immigration (2007), Rapport au Parlement, Les orientations de la politique de l'immigration, quatrième rapport établi en application de l'article L. $111-10$ du Code de l'entrée et du séjour des étrangers et du droit d'asile, December 2007, La Documentation Française, Retriavable from http://www.ladocumentationfrancaise. $\mathrm{fr}$

Weil, P. (1997), Mission d'étude des législations de la nationalité et de l'immigration, Paris: La Documentation Française.

Zappi, S. (2003), French Government Revives Assimilation Policy, Migration Information Source, Migration Policy Institute, 1 October 2003. Retriavable from: http://www.migrationpolicy.org/

\section{Journal Articles}

Le Monde, Regroupement familial, mythes et réalités, 19 septembre 2007.

Le Monde, L'évaluation du niveau de français au caur du texte de loi, 19 septembre 2007. 
Le Monde, Associations et partis de gauche critiquent le projet de loi sur l'immigration, 18 septembre 2007.

Le Monde, Tests ADN pour certains candidats à l'immigration, 14 septembre 2007.

Liberation, Sarkozy veut un ministère de l'immigration et l'identité nationale, 9 mars 2007, retriavable from www.liberation. fr

Liberation, Ma Vision de l'Identité Nationale, Brice Hortefeux contribue au débat organisé par Liberation toute la semaine dernière, 27 Juillet 2007.

Liberation, Un PS bien discret sur le projet Sarkozy, 1 avril 2006.

Actualités, Vers une refondation du modèle français d'intégration, Actualités, 10 April 2004, available at : http://www.premier-ministre.gouv.fr/ 


\section{BIOGRAPHY}

Sergio Carrera Nuñez was born the 6 September 1976 in Ponferrada (León), Spain. He studied law at the Faculty of Law of the University of Salamanca (Spain) and the University of Maastricht (The Netherlands). He obtained an LL.M. on European, International and Comparative Law (MIC Programme) at the University of Maastricht in 2002. Carrera Nuñez is Head of Section and Research Fellow at the Justice and Home Affairs Section of the Centre for European Policy Studies (CEPS) in Brussels. He is involved in the coordination and research of the CHALLENGE project (The Changing Landscape of European Liberty and Security), funded by the Sixth Framework Programme of DG Research of the European Commission. During the last years he has also collaborated in various trans-European projects and has published widely as regards fields related to the Area of Freedom, Security and Justice in the EU, with particular attention to immigration, inclusion and borders. He is extemal expert on these very issues for the European Economic and Social Committee and the European Parliament. 


\section{INDEX}

A

A Common Agenda for Integration, 61, 69, 207

Aclive Participation, 74, 170

Amsterdam Treaty, 1, 3, 6, 23, 32, 33, 35, 41, $42,101,115,122,140,148,274,321,368$

ANAEM, 256, 257, 258, 303

Annual Report on Migration and Integration, $51,60,66,67,73,167,170,339$

Area of Freedom, Security and Justice, 4, 5 , $25,32,34,75,77,80,81,111,115,159$, $164,284,290,339,358,361,362,377$

Assimilation, 105, 223, 224, 225, 227, 235, $236,237,243,245,246,252,264,335$, $359,365,367,371,381,384,403$

Autonomous Communities, 7, 174, 176, 177, $206,210,211$

Aznar, 181, 187, 192

\section{B}

Benchmarking, 9, 88, 89, 93, 94, 95, 97, 98, $99,101,104,105,359,360,361,366$, 375,381

Blue Card, 150, 151, 152, 153, 154, 155, 159,368

\section{C}

CAI, 146, 221, 228, 249, 252, 253, 254, 255, $256,257,258,265,299,301,302,303$, $304,306,309,313,314,317,328,344$

CAIF, 263, 265, 299, 300, 301, 313, 314, $315,317,328,344$

Catalunya, 212, 214, 216, 218, 376, 399

CBPs, 45, 56, 58, 59, 60, 61, 63, 66, 68, 69, $71,72,76,80,83,84,85,87,88,98,167$, $169,170,206,207,209,214,215,219$, $320,323,326,342$

Centre for Migration Law, 99, 127, 130, 368

Charter of Fundamental Rights, 38, 57, 58, $82,120,125,160,167,284,285,287$, $289,297,298,309,311,315,366,369$, 377
Child, 116, 298

Chirac, 235, 236, 238, 239, 252, 402

Cities, 46, 87

CIU, 216, 400

Civic Citizenship, 90, 91, 96, 165, 367, 376

Civic Courses, 168

Civic orientation, 169

Civil Registry, 178, 196, 198, 199, 200, 201, 202

Civil Society, 39, 47, 69, 86, 165, 208, 396

Code Civil, 230, 239, 243

Committee of Regions, $41,81,86,128,132$, 160

Common Basic Principles for Immigrant Integration Policy, 55, 56, 57, 206

Common Framework of Rights, 155

Common Immigration Policy, 37, 76, 77, 171, 392

Community method of cooperation, $1,11,33$, $37,42,45,107,109,319,338$

Constitution, 27, 36, 177, 178, 182, 192, 196, $203,207,210,211,223,242,248,255$, $272,284,325,369,379$

Council of the EU, 11, 73, 79, 85, 128, 338, 394,397

\section{D}

DG JFS, 46, 47, 52, 73, 85, 89, 93, 339

Double Nationality, 197

\section{E}

EC status of long-term resident, 129, 141 , $147,152,156,299,328$

ECHR, 286, 287, 289, 290, 291, 292, 293 , $294,295,296,297,298,303,308,309$, $310,311,312,313,314,316,330,388$, 389

Education, 14, 17, 31, 32, 57, 158, 257, 377, 388

EESC, 28, 39, 41, 47, 50, 69, 70, 86, 117 , $118,126,128,132,143,155,159,163$, $165,180,186,208,215,396$

EIF, 70, 71, 72, 76, 83, 85, 303, 307, 341 
EMMI, 68, 74, 75, 106, 170, 171, 323, 342 Employment, 28, 39, 40, 47, 48, 50, 57, 60, $82,84,85,122,138,140,148,165,166$, $167,195,197,206,252,261,322,339$, $368,372,374,382,384,395,396$

$\mathrm{EP}, 29,49,50,61,63,64,81,82,85,86,94$, $97,99,100,101,103,111,114,117,119$, $125,132,143,160,164,165,166,168$, $169,293,294,296,302,308,309,310$, 316

EP v. Council, 293, 294, 302, 308, 309, 310 , 316

Equal Treatment, 92, 144, 301, 362

EU Framework on Integration, 1, 2, 4, 5, 6, 7, $11,13,18,23,42,45,46,51,56,59,60$, $61,63,67,68,76,78,79,81,82,83,84$, $85,86,87,88,98,100,101,106,107$, $109,160,161,173,179,180,207,209$, $214,215,216,219,319,321,322,323$, $324,325,326,332,337,339,340,342$

Eurocities, 87

European Citizenship, 25, 26, 30, 364, 371, 372,373

European Commission, 1, 3, 5, 6, 9, 11, 14, $19,21,26,29,31,32,35,36,37,38,39$, $40,41,42,46,47,50,51,52,56,61,62$, $63,65,66,67,68,70,71,72,73,75,76$, $77,78,79,81,82,83,85,86,87,88,89$, $93,99,100,104,106,107,109,110,111$, $112,113,114,115,116,117,118,121$, $123,125,128,130,131,132,133,134$, $137,139,142,144,148,149,150,151$, $154,155,156,157,162,163,164,165$, $167,169,170,171,180,186,208,214$, $217,276,311,321,322,323,339,372$, $376,388,392,396$

European Convention on Human Rights, 116 , $125,159,287,312,376$

European Economic and Social Committee, $28,47,56$

European identity, 26, 179, 337

European Integration Forum, 45, 68, 69, 87, 341

European Integration Fund, 4, 36, 45, 69, 70, 303
European Modules for Migrant Integration, $68,74,323$

European Pact on Immigration and Asylum, 77,79

European Parliament, 4, 5, 25, 29, 35, 41, 47, $49,50,56,60,63,66,70,81,82,86,94$, $101,110,117,118,119,122,128,133$, $143,148,195,207,271,284,285,286$, $289,293,294,295,312,331,355,361$, $363,365,374,375,387,388,395,396$

European Parliament v. Council, 4, 119, 122, $294,295,320,331,374,388$

Europeanisation, 1, 2, 4, 5, 7, 9, 10, 13, 33, $36,54,99,106,110,136,137,161,173$, $180,221,267,272,274,275,279,315$, $320,321,323,324,325,329,332,337$, 338,372

Europeanism, 173, 179, 180, 181, 186, 190, $209,215,219,221,229,250,265,268$, $298,316,326,329,331,343$

Expulsion, 128, 131, 132, 133, 135, 290, 301, 369,382

\section{F}

Family Reunification, 115, 117, 119, 120, $122,127,147,261,293,298,301,307$, $311,356,359,362,368,376,380$

First Pillar, 25, 33, 109, 274, 280

FN, 233, 234, 239, 264

France, $6,7,8,9,10,20,46,66,68,101$, $126,127,128,132,133,136,143,145$, $146,147,161,174,179,221,222,223$, $224,225,226,227,228,229,230,231$, $232,233,234,235,236,237,238,239$, $240,241,242,243,244,245,247,248$, $249,250,251,252,253,254,255,256$, $257,258,259,260,261,262,263,265$, $267,268,291,298,299,300,301,302$, $306,307,308,309,312,313,314,320$, $321,325,327,328,331,332,333,334$, $336,343,344,358,359,365,366,367$, $370,371,372,373,376,379,380,381$, $383,388,391,401,402,403$

Frattini, 69, 73, 74, 75, 86, 87, 396, 397 
Free Movement of Persons, 9, 14, 25, 26, 30, $110,274,280,281,360,368,369,371$, 377

French Citizenship, 238, 357

French Presidency of the EU, 131, 160

French Revolution, 222, 224

Front National, 223, 233

FRONTEX, 181, 361

Fundamental Rights, 25, 82, 101, 182, 267, $272,275,283,285,287,288,298,304$, $308,312,313,363,365,368,383$

\section{G}

General Directorate of the Registries and the Notary, 199

General Principles of EU Law, 268, 270, 285, $329,344,382$

German Presidency of the EU, 73

Global Approach to Migration, 171, 395, 396

González, 174, 177, 181, 187, 378

Green Paper, 148, 149

Guigou Law, 239

\section{H}

Hague Programme, 4, 34, 36, 55, 149, 167 , $180,209,274,284,357,358,369,395$, 396

Handbook on Integration, 4, 52, 61, 64, 70, $73,74,99,106,134,167,169,376$

Haut Conseil à l'Intégration, 236, 254, 402

$\mathrm{HCl}, 236,253,264$

Health, 95, 145, 277, 281, 289, 305, 363, 386,387

Highly Qualified Employment, 150

Holistic Approach, 165, 167

Hortefeux, 241

\section{I}

Indicators, $88,90,94,97,98,100,102,103$, $104,171,355,361,372$

Insertion, 235, 367

Integration Abroad, 134, 301, 307, 308

Integration Measures, 17, 67, 134, 259, 357

Integration Website, 4, 45, 68
Intercultural Dialogue, 76, 171

INT1, 93, 103, 104, 372

Introduction Programmes, 66, 168, 374

Ireland, 20,46, 70, 101, 112,119, 137

liregular Immigration, 181

$\mathbf{J}$

Justice and Home Affairs, 4, 5, 14, 25, 27 , $28,29,30,31,32,34,45,56,58,63,65$, $73,74,80,81,86,88,111,112,148,149$, $159,167,171,206,340,356,360,362$, $366,369,370,375,377,378,394,395$, 397

L

Lambrinidis, 63,86

Language, 76, 162,166, 168

Le Pen, 233, 237, 239, 240

LODYLE, 176, 182, 188, 189, 190, 194, 203, 204, 325

Long-Term Residents Status, 129

\section{M}

Maastricht Treaty, 25

Madrid, 64, 75, 127, 174, 176, 177, 178, 180, $182,183,184,185,191,193,194,195$, $196,197,198,199,202,203,204,205$, $206,207,210,211,212,213,215,217$, $355,356,358,359,360,361,364,365$, $366,367,370,372,374,376,377,378$, $383,399,400$

Mainstreaming, 58, 63, 99, 167, 169, 170, 171,360

Mandatory Integration Programmes, 66, 367

Migrant Integration Policy Index, 74, 93, 376

Migration Policy Group, 40, 52, 66, 67, 71, $74,90,93,94,167,169,195,357,367$, $372,374,375,376$

MIPEX, 74, 93, 94, 95, 97, 102, 106

MPG, 52, 64, 66, 70, 74, 86, 91, 92, 107 , 375,376

N

National Action Plans, $40,52,83$ 
National Contact Points on Integration, 4, 46, $52,64,68$

National Identity, 241, 247, 335, 368, 403

National Parliaments, 25, 81, 375

Nationality, 1, 8, 25, 26, 92, 129, 173, 179, $196,221,230,238,243,244,332,343$, $364,366,368,373,379,382,383$

Naturalisation, 196, 243, 364

NCPI , 46, 52, 53, 63, 64, 66, 69, 75, 76, 83, $86,87,89,99,107,169,170,320$

Newcomers, 67, 127, 134, 166, 355, 374

Non-discrimination, 96

Normality, 162

\section{o}

Open Method of Coordination, 4, 5, 39, 40, $42,45,82,85,98,99,112,322,359,360$, $362,364,371,381,382,384$

P.I.S.I., 185, 186, 398

Pariza Castaños, 11, 39, 47, 69, 208, 396

Partido Popular, 181, 193

Partido Socialista Obrero Español, 181

Policy Plan, 149, 206

Political Participation, 26, 39, 357, 378

Postdam, 73, 397

Proportionality, 81, 267, 272, 275, 276, 277, $278,280,282,298,304,308,309,313$, $363,366,380,382$

\section{$\mathbf{R}$}

Radicalisation, 171

Rajoy, 216, 218, 400

Regular Immigration, $110,148,196$

Republic, 20, 68, 137, 149, 222, 223, 225, $229,231,236,238,241,248,253,254$, $256,258,261,263,277,279,288,289$, $303,307,310,328,373,385,386,387$

Republicanism, 222, 223, 224, 225, 226, 228 , $230,231,233,237,240,251,264,327$, 371,372
$\mathbf{S}$

Sarkozy, 228, 229, 239, 240, 241, 242, 249, $255,259,260,265,403,404$

Schengen, 33, 183, 229, 337, 358

SCIFA, 133, 135, 136

Sephardic Jews, 197

Seville, $118,133,181$

Social Integration, $21,46,47,67,127,162$, $165,173,176,181,182,185,186,187$, $188,196,203,205,206,209,210,211$, $212,219,325,326,374$

Social Partners, 28

Spain, 6, 7, 27, 46, 68, 84, 101, 133, 143, $147,161,170,173,174,175,177,178$, $179,180,181,182,183,184,185,186$, $187,189,191,192,193,194,195,196$, $197,198,200,201,203,204,205,207$, $208,209,213,215,216,217,218,219$, $232,263,289,298,320,323,325,326$, $327,332,342,355,356,357,360,366$, $379,380,387,388,391$

Spanish Immigration Policy, 183

Strategic Plan of Citizenship and Integration, 203, 205, 209, 214, 219

Superior Tribunal, 198, 200, 201, 202, 203, 204

\section{$\mathrm{T}$}

Tampere Programme, 3, 5, 6, 13, 34, 35, 36, $38,41,42,95,112,116,148,156,164$, $190,302,321,322,339,342$

Terrorism, 75, 336, 362

The Netherlands, 13, 20, 66, 67, 68, 87, 99, $127,130,134,136,273,292,293,303$, $310,314,368,370,371,374,388,389$

Thessaloniki, 48, 49, 51, 56, 83, 118, 166, 395

Third Pillar, 25, 27, 29, 31, 33, 370, 375

Treaty of Lisbon, 4, 9, 36, 80, 82, 111, 159, $160,284,312,321,338,340,371,395$

Two-way Process, 60

UMP, 239, 240, 252 
Unanimity, 35

United Kingdom, 27, 46, 112, 291, 388

Universalism, 223

$\mathrm{V}$

Valencia, 176, 180,183, 188, 190, 192, 210, $211,212,213,215,216,218,326,355$, $364,367,373,375,378,379,381,399$

Values, 82,168

Visa, $229,337,358$

\section{W}

Watson, 117

Working Party on Migration and Expulsion, $126,128,132,140,142$

\section{$\mathrm{Z}$}

Zapatero, 181, 194, 195, 218 